

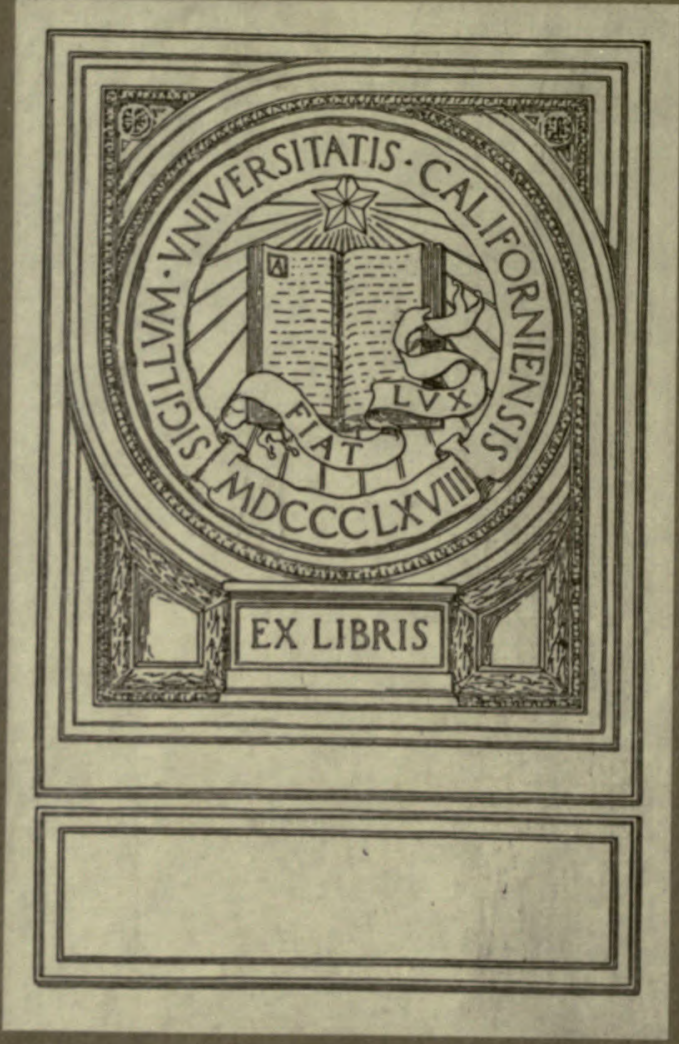







\section{SMITHSONIAN CONTRIBUTIONS TO KNOWLEDGE.}

\section{O B S ER VA T I O N S}

ON

\section{TE R R E S TR I A L II A G N ETIS II}

AND ON THE

\section{DEVIATIONS OF THE COMPASSES}

OF THE UNITED STATES IRON CLAD MONADNOCK DURING HER CRUISE FROM PIIILADELPHIA TO SAN FRANCISC0, IN 1865 AND 1866.

BY

WM. HARKNESS, M.D., PROFESSOR OF MATHEMATICS, UNITED STATES NAVY. 


\section{INTRODUCTORY NOTE.}

THIs paper was originally an official report presented to the Navy Department by Professor Harkness; but, as that department made no use of it, the National Academy of Sciences, in August, 1867, passed a resolution asking for the manuscript. This request was complied with; and, an abstract of the paper having been read to the Academy in April, 1869, it was referred to a commission consisting of the President of the Academy, Professors J. H. C. Coffin, and F. Rogers, in accordance with whose recommendation it is now published by the Smithsonian Institution.

\section{Joseph HenRy,}

Secretary S. I. 


\section{TABLE OF CONTENTS.}

\section{SECTION I.}

INTRODUCTION.

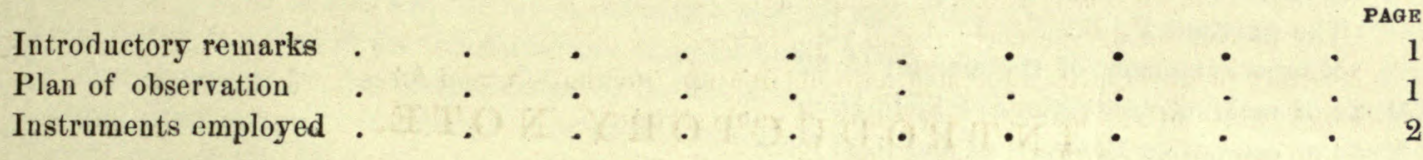

\section{SECTION II.}

DESCRIPTIONS OF STATIONS.

Philadelphia

Gosport

St. Thomas

Isle Royal

Ceara

Pernambueo

Bahia

Rio Janeiro

Monte Video

Sandy Point

Valparaiso

Callao

Payta .

Panama.

Acapulco

Magdalena Bay.

San Francisco

\section{SECTION III.}

ASTRONOMICAL OBSERVATIONS.

General remarks

Observations of the sun for latitude

Observations of the sun for time

Mode of determining true bearings

Observations of the sun for the determination of true bearing

Triangulation at Ceara .

Table of observed latitudes

Errors of pocket chronometer, Fletcher, No. 906

Chronometer comparisons

True bearings of objects used as azimuth marks 


\section{SECTION IV.}

OBSERVATIONS ON TERRESTRIAL MAGNETISM.

Description of the portable declinometer, D. 22

Description of the transit theodolite

General remarks on the methods of using the instruments

Mode of determining absolute declinations

Mode of making observations of vibrations

Mode of making observations of deflections

Mode of calculating horizontal force

Determination of constants peculiar to the portable declinometer, D. 22

Temperature coefficients of magnets

Value of magnet scales

Moment of inertia of the magnet, C. 32 .

The constant $P$.

Magnetic moment of the magnet C. 32 .

Mode of making observations of inclination

Mode of computing the vertical and total force.

Abstract of observations for magnetic declination, inclination, and force Final values of the magnetic elements at each station .

Observations of magnetic declination .

Observations of magnetic inclination

Horizontal intensity. Observations of vibrations

Horizontal intensity. Observations of deflections

\section{SECTION $V$.}

OBSERVATIONS ON THE MAGNETISM OF THE SHIP.

Description of the Monadnock .

Positions of the compasses

Mode of swinging the ship.

Corrections peculiar to the After Binnacle and After Ritchie Compasses $\quad$. . . 121

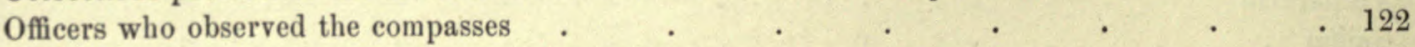

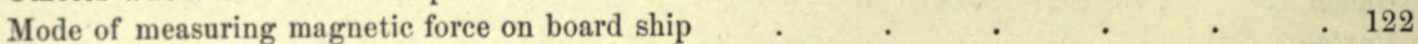

Mathematical theory of the deviations of the compass . $\quad . \quad \ldots \quad . \quad . \quad . \quad . \quad 123$

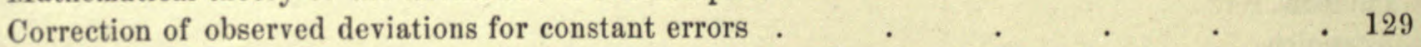

Observations for determining the deviations of the Admiralty Standard Compass ․ $\quad$. 133

Observations for determining the deviations of the After Binnacle Compass . $\quad . \quad 140$

Observations for determining the deviations of the After Ritchie Compass . . . 147

Observations for determining the deviations of the After Azimuth Compass . . . 154

Observations for determining the deviations of the Forward Alidade Compass $\quad . \quad$. 160

Observations for determining the deviations of the Forward Binnacle Compass _ . 167

Observations for determining the deviations of the Forward Ritchie Compass . $\quad$. $\quad 174$

Mode of computing the coefficients $A_{1}, B_{1}, C_{1}, D_{1}, E_{1}$. . . . . . . 181

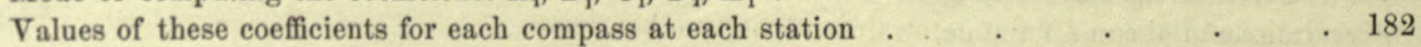

Probable errors of the values of the coefficients $A_{1}, B_{1}, C_{1}, D_{1}, E_{1}$. . . 184

Computation of the constants $A_{1}, \frac{c}{\lambda}, \frac{P}{\lambda}, \frac{\Delta P}{\lambda}, \frac{f}{\lambda}, \frac{Q}{\lambda}$, and $\frac{\Delta Q}{\lambda}$, for each compass . $\quad 185$

Values of the coefficients $\mathfrak{A}, \mathfrak{B}, \mathfrak{C}, \mathfrak{D}, \mathfrak{E}$, for each compass at each station $\quad . \quad$. 191

Table showing the values of the constants $A_{1}=\mathfrak{A}, \frac{c}{\lambda}, \frac{P}{\lambda}, \frac{\Delta P}{\lambda}, \frac{f}{\lambda}, \frac{Q}{\lambda}, \frac{\Delta Q}{\lambda}, \mathfrak{D}$, and $\mathfrak{E}$,

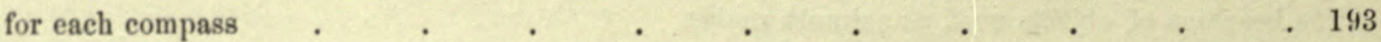


Computation of the coeffieients $\mathfrak{P}, \mathfrak{B}, \mathfrak{C}, \mathfrak{I}, \mathfrak{C}$, for cach eompass at each station, from the constants, $A_{1}, \frac{c}{\lambda}, \frac{P}{\lambda}, \frac{\Delta P}{\lambda}, \frac{f}{\lambda}, \frac{Q}{\lambda}, \frac{\Delta Q}{\lambda}, \mathfrak{D}$, and $\mathbb{E}$.

PAGE

Comparison of the coeffieients thus computed with those found directly from the observations at caeh station

Resulting probable errols

Does the theory accurately represent the scmi-cireular deviation?

Tables showing the most important features of the deviations of each compass during the cruise .'

Hard and soft íron forees

Nagnetic moment of magnets used for measuring horizontal force on board ship

Ober 202

Observations for absolute force at the Admiralty Standard Compass . . . . 205

Observations for absolute force at the After Azimuth Compass . . . . 206

Values of $\lambda \quad . \quad . \quad . \quad . \quad . \quad . \quad . \quad . \quad 207$

Values of $g, h, k, R$ and $\Delta R$, for the Admiralty Standard and After Azimuth Compasses . 207

Values of $a, b, e$, and $d$, for the Admiralty Standard and After Azimuth Compasses . . 209

General equations for the determination of the deviations of the Admiralty Standard Compass 210

General equations for the determination of the deviations of the After $\Lambda$ zimuth Compass $\quad 211$

Variations of the hard iron foree, during the eruise, at the Admiralty Standard and After Azimuth Compasses . . . . . . . . . 211

Computation of the coeffieients $A_{1}, B_{1}, C_{1}, D_{1}, E_{1}$, for each compass, at places where the deviations were observed on less than thirty-two points . . . . . . 211

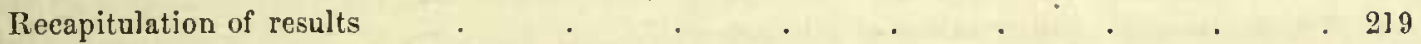

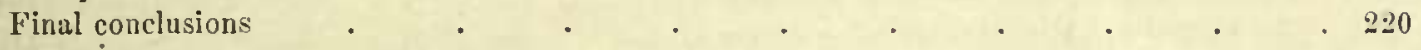





\title{
REPORT ON MAGNETIC OBSERVATIONS.
}

\author{
SECTI $0 \mathrm{~N}$ I. \\ I N T ROD U C T I O N.
}

ON the fifth of October, 1865, I was ordered to the U. S. Tron-clad Monadnock $^{1}$ for the purpose of making observations on the action of her compasses during the cruise which she was about to undertake from Pliiladelphia to San Francisco, by way of the Straits of Magellan. She was then fitting out at the Philadelphia Navy Yard, and the work on her was so far advanced that it was expected she would sail in about two weeks. As the department had not previously intimated its intention of assigning me to this duty, and as everything relating to the number and kind of observations to be made, and the instruments required, was left entirely to my own discretion, it will be seen that the time available for making plans and collecting the necessary apparatus was very limited.

The plan of observation ultimately adopted was that at every port in which we remained for more thall twenty-four hours the following operations should be gone through with. 1st. The ship should be swung, and as her head pointed successively to each of the thirty-two true magnetic points, the reading of every compass on board should be recorded for each point. 2d. That at such of the compasses as were so situated as to render it possible, the horizontal force and inclination should be determined. $3 \mathrm{~d}$. The position of the dividing line between tlie north and south polarity should be traced on each turret. 4th. The magnctic declination, inclination, and horizontal force should be determined on shore. While at sea it was intended to observe the declination-and consequently the deviation - and horizontal force daily, by means of the standard compass; but this turned out to be impracticable, because the only place in the ship where it was possible to mount that instrument was on top of the after pilot-house; a situation

1 The Monadnock is a double-turreted ressel of the monitor type. During the cruise in question, Lieutenant Commander Francis M. Bunce, U.S.N., was her captain, and she was attached to the squadron commanded by Commodore (now Rear- $\Lambda$ dmiral) Jolın Rogers, U.S. N., at whose special request I was detailed by the Nary Department to make the observations which are the subject of this paper.

1 December, 1871. 
where no binnacle could be put, and where the compass was nearly on a level with the top of the smoke-stack. 'Thus, while at sea, the position occupied by it was almost constantly enveloped in smoke and gas, rendering it absolutely necessary, whenever we left port, to dismount the instrument in order to preserve it from injury.

Owing to the very short time at my disposal previous to sailing, there was great difficulty in providing proper instruments, but I succeeded in obtaining all that were absolutely necessary. The following is a list of them:

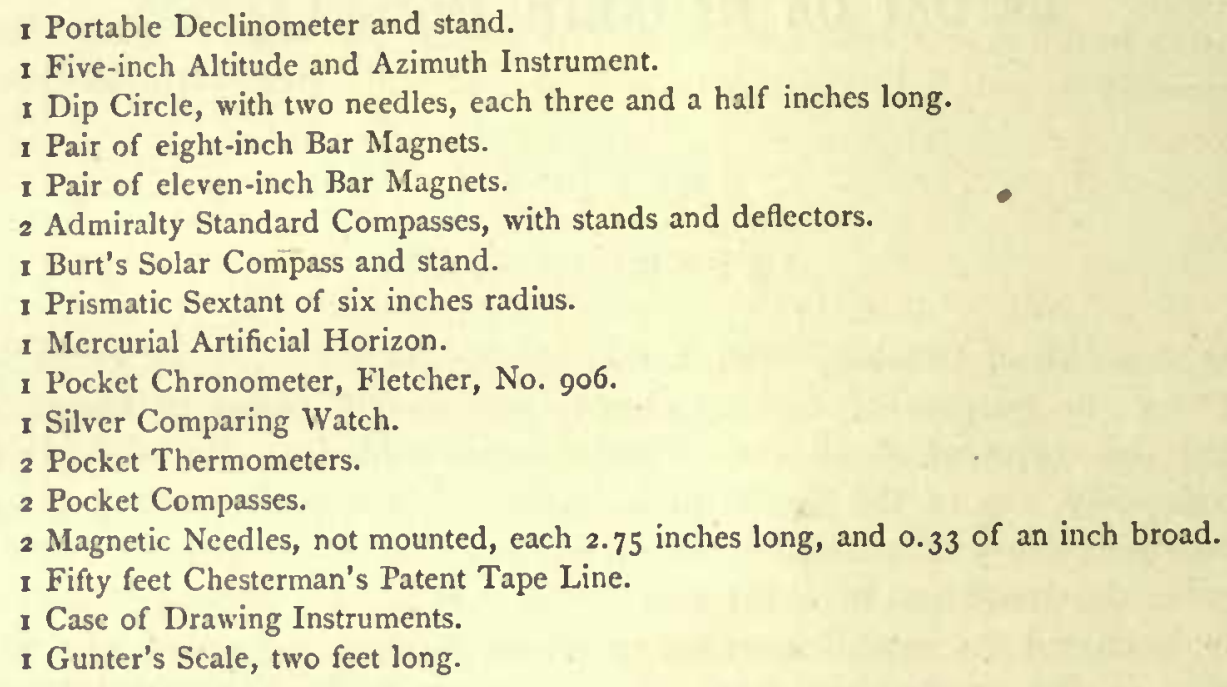

'The portable declinometer belonged to the U.S. Coast Survey, and was kindly lent by Prof. J. E. Hilgard.

'Ihe small unmounted magnetic needles were intended to be used for measuring the relative liorizontal force on shore and at each of the compasses on board ship. For this purpose it was proposed to vibrate one of them on shore, and then taking it on board ship to the compass at which it was desired to measure the rclative horizontal force, to remove the compass card from the centre-point, and putting the small needle in its place, vibrate it again. Unfortunately the small needles were not finished till just before we left Philadelphia, and there was no opportunity of trying them till after we were at sea, when, to my great regret, it was found that the jewels were so small that they would not fit on the centre-point of any compass on board, thus rendering them entirely useless. Under the circumstances, for lorizontal force on board ship it was necessary to rely entirely upon measures made with the deflectors belonging to the Admiralty standard compasses-a method certainly not so convenient, and, owing to the constant swinging of the ship when at anchor, probably not so accurate as counting the vibrations of a small needle.

The observations on terrestrial magnetism, and for latitude, time, and true bearings, were all made by myself and recorded by Mr. Corrin F. Smith, who was captain's clerk on the Monadnock, and acted as my assistant when I was observing. My best thanks are due to him for the efficient manner in which he performed his duties, sometimes under circumstances of very considerable plysical cliscomfort. 
The reductions and discussions in this report have been made by me, so that I am personally responsible, not only for the general plan of the work, but for every figure contained in it. All the results have been very carefully checked, and it is hoped no material error will be found in them; still, absolute accuracy is scarcely to be expected in any work involving so many figures, the more especially as much of it has been done during moments snatched from other and more pressing professional duties.

The observations naturally divide themselves into three classes: 1st. Those relating to astronomy. $2 \mathrm{~d}$. Those relating to terrestrial magnetism. $3 \mathrm{~d}$. Those relating to the magnetism of the ship. As that is the order in which they must necessarily be reduced, they will be so treated of in the subsequent sections of this report. 


\section{S E C TI 0 N II. \\ DESCRIPTIONS OF ST TIONS.}

UNLESS otherwise stated, the assumed positions of light-houses, forts, etc., have been taken from the English Admiralty Charts, or from the English Admiralty List of Lights, the latest editions obtainable in 1865 being employed. 'The longitudes are counted from the meridian of Greenwich.

The method used in testing a station for local attraction by means of fore and back sights with a compass, was as follows: The compass was set up at the station, and the bearing of a point distant one hundred yards, or more, was observed. 'Then the compass was transferred to that point, and the bearing of the station was observed. These two bearings should evidently differ from each other by $180^{\circ}$; if they did not, it was certain that local attraction existed at one or both of the points, and a new station was sought for. This process is almost certain to detect any strictly local magnetic attraction, but it will not suffice to demonstrate the existence of an abnormal state of the magnetic elements extending over a large territory.

Pinladelpita, Pa. The magnetic observations were made at a spot on the east bank of the Delaware river, about twenty feet from the water's edge. It is nearly southeast from the U.S. Navy Yard, from which it is distant about three-quarters of a mile. The soil is a dark-nearly black-earth, which appears to have been deposited by the river. The approximate position of the station was

$$
\begin{aligned}
& \text { Lat. } 39^{\circ} 55^{\prime} \mathrm{N} \text {. } \\
& \text { Long. } \quad 5^{\mathrm{h}} \quad 0^{\mathrm{m}} \quad 32^{\mathrm{s}} \mathrm{W} \text {. }
\end{aligned}
$$

Gosport, $V a$. The magnetic observations were made on a white sandy beach, on the west bank of the Elizabeth river, about thirty feet from the water's edge. From the place where the instruments stood, the flagstaff in the U.S. Navy Yard bore due north by compass, and was distant about half a mile.

Assuming the position of the flagstaff to be lat. $36^{\circ} 49^{\prime} 32^{\prime \prime} \mathrm{N}$., long. $5^{\mathrm{h}} 5^{\mathrm{m}} 9^{\mathrm{s}} .8 \mathrm{~W}$., as stated by the authorities at the Navy Yard, the position of the spot occupied by the instruments is approximately

$$
\begin{aligned}
& \text { Lat. } 36^{\circ} \quad 49^{\prime} \quad 0^{\prime \prime} \mathrm{N} \text {. } \\
& \text { Long. } 5^{\mathrm{h}} \quad 5^{\mathrm{m}} 9^{\mathrm{s}} .8 \mathrm{~W} \text {. }
\end{aligned}
$$

The ship was swung at the compass station in Hampton Roads, on November 1st, 1865 , in the usual manner. Her position at the time was lat. $36^{\circ} 58^{\prime} \mathrm{N}$., long. $76^{\circ} 20^{\prime} \mathrm{W}$. Joint XII on the after turret was 14.4 inches to port. 
ST. 'Thomas, West Indies. The ship was swung in this harbor, on November 18th, 1865, in the usual manner. Her position at the time was lat. $18^{\circ} 19^{\prime} \mathrm{N}$., long. $64^{\circ} 56^{\prime} \mathrm{W}$. Joint XII on the after turret was 14.4 inches to port.

The obscrvations on shore were made in Long Bay, at a spot about thirty feet from the water's edge, on a gravelly beach, to the eastward of the town. From the place where the instruments stood the true bearing of Fort Cowell, at the entrance to the harbor, is $\mathrm{S} .34^{\circ} 50^{\prime} \mathrm{W}$., and it is distant about one mile.

Assuming the position of Fort Christian to be lat. $18^{\circ} 20^{\prime} 27^{\prime \prime}$ N., long. $4^{\mathrm{h}} 19^{\mathrm{m}}$ $42.7 \mathrm{~W}$., then, according to the English Admiralty Chart, the position of the spot where the instruments were set up is

$$
\begin{array}{lccc}
\text { Lat. } \quad 18^{\circ} & 20^{\prime} & 22^{\prime \prime} \mathrm{N} . \\
\text { Long. } & 4^{\mathrm{n}} & 19^{\mathrm{m}} & 40^{\prime} .6 \mathrm{~W} .
\end{array}
$$

IsLE Royal, Salute Islands. An attempt was made to swing the ship here, on November 30 th, 1865, in the usual manner, but it failed on account of the continual rain which shut off the view of the distant azimuth mark. The position of the ship at the time was lat. $5^{\circ} 17^{\prime} \mathrm{N}$., long. $52^{\circ} 33^{\prime} \mathrm{W}$. Joint XII on the after turret was 0.6 of an inch to starboard.

The magnetic and astronomical observations on shore were made on the southwest side of the island, at.a spot from which the corner made by the southeast and southwest faces of the government coal sheds bears N. $64^{\circ} \mathrm{W}$. (true), and is distant one hundred and thirty-two feet. The place was examined carefully for local attraction by taking fore and back sights with a compass, but none could be detected. The position occupied by the instruments is in

$$
\begin{array}{llll}
\text { Lat. } \quad 5^{\circ} & 17^{\prime} & 29^{\prime \prime} \mathrm{N} . \\
\text { Long. } & 3^{\mathrm{h}} & 30^{\mathrm{m}} & 11^{\mathrm{s}} .4 \mathrm{~W} .
\end{array}
$$

The latitude was determined from a single set of circummeridian altitudes of the sun observed by me, and the longitude was taken from the French chart.

Ceara, Brazil. An attempt was made to swing the ship here, on December 19 th, 1865, in the usual manner, but although a very favorable opportunity was chosen, she could only be made to turn through ten points. Her position at the time was lat. $3^{\circ} 44^{\prime} \mathrm{S}$., long. $38^{\circ} 34^{\prime} \mathrm{W}$. Joint XII on the after turret was 0.6 of an inch to starboard. The wind, current, and sea are so strong here that vessels at anchor in the roads always ride with their heads nearly in the same direction, never swinging more than about three points.

At this place there is no harbor whatever, merely an open roadstead. A heavy surf is constantly running on the beach, and as there are almost no facilities for landing in small boats, getting the instruments on shore involved a good deal of trouble and some risk. However, I succeeded in landing them safely, and obtained a very good set of observations on the white sand beach at a spot about one hundred and fifty feet from the water's edge, and from which the true bearing of the southeast corner of the custom-house on the wharf is N. $53^{\circ} 19^{\prime} \mathrm{W}$., and its distance two hundred feet. From the same spot the true bearing of 
Point Macoripe Light-house is N. $75^{\circ} 38^{\prime} \mathrm{E}$. The position occupicd by the instruments is in

$$
\begin{array}{llll}
\text { Lat. } & 3^{\circ} & 43^{\prime} & 59^{\prime \prime} \mathrm{S} . \\
\text { Long. } & 2^{\mathrm{h}} & 34^{\mathrm{m}} & 6^{\mathrm{s}} \mathrm{W} .
\end{array}
$$

The latitude was deduced from my own observations, and the longitude was taken from the list of geographical positions given in Raper's Navigation.

Pernasibuco, Brazil. The ship was not swung in this port because there was not room to do it in the position where she took her coal, and as she only remained in the harbor twenty-four hours, there was not time to take up another position in order to swing.

The magnetic and astronomical observations on shore were made on the white sand beach, at a spot from which the true bearing of the salient angle of the southeast bastion of Fort Brum is N. $15^{\circ} 46^{\prime} \mathrm{W}$, and its distance four hundred and thirty fect.

Assuming the position of the light-house, near to Fort Picao, to be lat. $8^{\circ} 3^{\prime} 42^{\prime \prime}$ S., long. $2^{\mathrm{h}} 19^{\mathrm{m}} 26^{\mathrm{s}} .8 \mathrm{~W}$., as it is given in the English Admiralty List of Lights, edition of 1866, then, according to the English Admiralty Chart, the position occupied by the instruments is in

$$
\begin{array}{lccc}
\text { Lat. } & 8^{\circ} & 3^{\prime} & 37^{\prime \prime} \mathrm{S} . \\
\text { Long. } & 2^{\text {h }} & 19^{\mathrm{m}} & 28^{\mathrm{s}} .2 \mathrm{~W} .
\end{array}
$$

BuHi , Brazil. The ship was swung in this harbor, on December 30th, 1865, in the usual manner. Her position at the time was lat. $12^{\circ} 59^{\prime} \mathrm{S}$., long. $38^{\circ} 31^{\prime} \mathrm{W}$. Joint XII on the after turret was 0.6 of an inch to starboard.

The magnetic and astronomical observations of December 27 th were made at a spot, one hundred and fifty feet from the water's edge, situated in a cocoanut grove on the beach about half-way between Monserat Point and Fort Victoria. The soil is a coarse white sand. It was not possible to get any bearings which would define the exact position, but the above directions are sufficient to enable any one to find the place very nearly.

Assuming the position of Fort St. Antonio Light to be lat. $13^{\circ} 0^{\prime} 55^{\prime \prime} \mathrm{S}$., long. $2^{\mathrm{h}} 34^{\mathrm{m}} 6^{\mathrm{s}} .9 \mathrm{~W}$., then, according to the English Admiralty Chart, the position occupied by the instruments is in

$$
\begin{array}{llll}
\text { Lat. } \quad 12^{\circ} & 56^{\prime} & 55^{\prime \prime} \mathrm{S} . \\
\text { Long. } \quad 2^{\mathrm{h}} & 34^{\mathrm{m}} & 0^{\mathrm{s}} .5 \mathrm{~W} .
\end{array}
$$

Rio JANeiro, Brazil. The ship was swung in this harbor, on January 10th, 1866, in the usual manner; but, owing to a strong wind which was blowing at the time, it was not possible to get her through more than seventeen points. Her position was lat. $22^{\circ} 54^{\prime} \mathrm{S}$., long. $43^{\circ} 9^{\prime} \mathrm{W}$. Joint XII on the after turret was 0.8 of an inch to port.

During the whole week we were at Rio there was not one clear day. Consequently it was extremely difficult to make astronomical observations, and it was only by patiently watching for the sun and seizing the opportunities when it was 
momentarily visible through breaks in the clouds, that the few sights necessary in order to complete the magnetic observations were obtained.

With a single exception, all the magnetic and astronomical observations were made at a spot from whicl the true bearing of the entrance on the north face of Fort Caraguata (erroneously spelled Gravata on the English charts) is S. $70^{\circ} \mathrm{W}$., and its distance fifty-five fect. There were no guns in the fort at the time. The surrounding country is very hilly, the bare, coarse, granite rocks cropping out everywhere from the hill-sides, but in the more level places they are thinly covered with earth. Assuming the position of Fort. Villegagnon to be lat. $22^{\circ} 54^{\prime} 42^{\prime \prime}$ S., long. $2^{\mathrm{h}} 52^{\mathrm{m}} 36^{\mathrm{s}} .0 \mathrm{~W}$., then, according to the English Admiralty Chart, the position occupied by the instruments is in

\section{Lat. $22^{\circ} 54^{\prime} 5^{\prime \prime} \mathrm{S}$. \\ Long. $2^{\mathrm{h}} \quad 52^{\mathrm{m}} 30^{\mathrm{s}} .7 \mathrm{~W}$.}

The exception referred to above is some observations of the sun for time, made on January 9 th. They were got on Rat Island, the spot where naval officers usually go to rate their chronometers when lying in this harbor. Assuming the position of Fort Villegagnon as above, then, according to the Englisl Admiralty Chart, the position of Rat Island is

$$
\begin{array}{lccc}
\text { Lat. } \quad 22^{\circ} & 53^{\prime} & 45^{\prime \prime} & \mathrm{S} . \\
\text { Long. } & 2^{\mathrm{h}} & 52^{\mathrm{m}} & 37^{\mathrm{s}} .9 \mathrm{~W} .
\end{array}
$$

Monte Video, Uruguay. The ship was swung in this harbor, on January 24th, 1866, in the usual manner. We first attempted to get her around about 1 P.M., but owing to the force of the wind and tide we only obtained ten points, viz., those from E. by S. to S.S. W. Just at sunset we tried it again, and succeeded in getting the remainder of the circle. It was nearly dark when we finished, but as the distant object used for an azimuth mark shone plainly against the sky, there was sufficient light to see pretty distinctly when it was in range with the sights of the compass.

The readings of part of the circle on the After Ritchie compass were lost, owing to the failure of daylight and delay in procuring a lantern. The officer who usually read the After Azimuth compass was on shore at the time, and the duty of making the observations at that instrument was assigned to another, but it turned out that he did not understand how to read an azimuth compass, and his observations were worthless.

While we were lying at Monte Video the tide was very irregular. Most of the time the ship only swung to it about $90^{\circ}$, but two or three times she swung $180^{\circ}$. At the time we swung her to obtain the deviation of the compasses her position was lat. $34^{\circ} 55^{\prime} \mathrm{S}$., long. $56^{\circ} 13^{\prime} \mathrm{W}$., and joint XII on the after turret was 4.5 inches to port.

The greater part of the magnetic observations on shore were made on January 18th, at a station on the ground occupied by 'Tomkinson's slaughtering establishment. 'The instruments were set up at a spot where there are four large umbu trees standing in a line. The exact position may be recovered by means of the following true bearings. 'The corner made by the south and west sides of the dwelling-house 
bears N. $39^{\circ} \mathrm{E}$, and is distant about one hundred feet. The light-house on the Mount, on the west side of the harbor, bears N. $59^{\circ} 0^{\prime} \mathrm{W}$. 'The water's edge is distant from the station about four hundred feet. 'The soil is a thin stratum of very poor earth, covering a greenish-colored slaty rock, which crops ont in many places. Assuming the position of the light-house on the Mount to be lat. $34^{\circ} 53^{\prime} 15^{\prime \prime}$ S., long. $3^{\mathrm{h}} 44^{\mathrm{m}} 59^{\mathrm{s}} .0 \mathrm{~W}$., then, according to the English Admiralty Charts, the position occupied by the instruments is in

$$
\begin{array}{lrll}
\text { Lat. } & 34^{\circ} & 53^{\mathrm{n}} & 39^{\prime \prime} \mathrm{S} . \\
\text { Long. } & 3^{\mathrm{h}} & 44^{\mathrm{m}} & 55^{\mathrm{s}} .8 \mathrm{~W} .
\end{array}
$$

As a clieck, some magnetic observations were made, on January 19th, at a station from which the true bearing of the light-house on the Monnt is N. $89^{\circ} 41^{\prime} \mathrm{W}$., and the true bearing of the light on the Cathedral is S. $17^{\circ} 42^{\prime} \mathrm{W}$. Assuming the position of the light-house to be as stated above, and the light on the cathedral to be in lat. $34^{\circ} 54^{\prime} 20^{\prime \prime} \mathrm{S}$., long. $3^{\mathrm{h}} 44^{\mathrm{m}} 50^{\mathrm{s}} .0 \mathrm{~W}$., as given in the English Admiralty List of Lights in South America, edition of 1865, the geographical position of this station was

$$
\begin{array}{lrll}
\text { Lat. } & 34^{\circ} & 53^{\prime} & 16^{\prime \prime} \mathrm{S} . \\
\text { Long. } & 3^{\mathrm{h}} & 44^{\mathrm{m}} & 48^{\mathrm{s}} .3 \mathrm{~W} .
\end{array}
$$

It will be observed that the difference of longitude between the lights on the Mount and on the cathedral, as deduced from the Admiralty List cited above, cannot be made to agree with the positions given on the English Aduniralty Chart.

On January 24th some observations for time were made on Rat Island. Assum. ing the position of the light-house on the Mount to be as stated above, then, according to the Linglish Admiralty Chart, the position of the station on Rat Island was

$$
\begin{array}{llll}
\text { Lat. } \quad 34^{\circ} & 53^{\prime} & 18^{\prime \prime} \mathrm{S} . \\
\text { Long. } & 3^{\text {h }} & 44^{\mathrm{n}} & 52^{3} .9 \mathrm{~W} .
\end{array}
$$

Sandr Point, Straits of Magellan. The ship was swung in this harbor, on Febriary 10th, 1866, in the usual manner. Her position at the time was lat. $53^{\circ}$ $11^{\prime} \mathrm{S}$., long. $70^{\circ} 55^{\prime} \mathrm{W}$. Joint XII on the after turret was 4.5 inches to port. While we were lying here the ship was perfectly free to swing to the tide, but she generally turned through an arc of only about ninety degrees, namely, from W.N.W. to N.N.E.

'The observations on shore were made in the meadow, between the settlement' and the beach, at a spot from which the true bearing of the flagstaff was N. $47^{\circ} 8^{\prime}$ W., and its distance about eight hundred feet. The soil is sandy, and there is no rock anywhere near. The place was examined for local attraction by taking fore and back sights with a compass, but nothing of the kind conld be detected.

Assuming the position of the flagstrff to be lat. $53^{\circ} 10^{\prime} 15^{\prime \prime}$ S., long. $4^{\mathrm{h}} 43^{\mathrm{m}} 36^{\mathrm{a}} .0$ W., as given on the English Admiralty Chart, cdition of 1861 , the position occupied by the instruments is in

$$
\begin{array}{lrrl}
\text { Lat. } & 53^{\circ} & 10^{\prime} & 20^{\prime \prime} \mathrm{S} . \\
\text { Long. } & 4^{\mathrm{h}} & 43^{\mathrm{m}} & 35^{\mathrm{s}} .3 \mathrm{~W} .
\end{array}
$$


VALPARAiso, Chile. The ship was swung in this harbor, on April 4th, 1866, in the usual manner. Her position at the time was lat. $33^{\circ} 2^{\prime} \mathrm{S}$., long. $71^{\circ} 38^{\prime} \mathrm{W}$. Joint XII on the after turret was 4.25 inches to port. While we were lying at Valparaiso the ship was perfectly free to swing to the tide, and she turned in all directions.

The observations taken on shore March $2 \mathrm{~d}$ were made on the south end of the white sand beach at the Estero de Quilpue, at a spot about two hundred and fifty feet from the rocks. Assuming the position of Fort San Antonio to be lat. $33^{\circ} 1^{\prime}$ $53^{\prime \prime}$ S., long. $4^{\text {h }} 46^{\mathrm{m}} 46^{\mathrm{s}} .0 \mathrm{~W}$., then, according to the English Admiralty Chart, the position of this station was approximately

$$
\begin{array}{lll}
\text { Lat. } \quad 33^{\circ} & 1^{\prime} .4 \mathrm{~S} . \\
\text { Long. } \quad 4^{\mathrm{h}} & 46^{\mathrm{m}} & 31^{\mathrm{s}} \mathrm{W} .
\end{array}
$$

'The observations of March 19 th, and all taken subsequently to that date, were made at a spot distant about six hundred and fifty feet, nearly true north, from the most northern of the custom-houses. The instruments were set up, near to the watcr's edge, on the public road which here runs along under a high bank of rock. 'The true bearing of the flagstaff at Fort San Antonio, on the top of the hill, was S. $31^{\circ} 45^{\prime} \mathrm{W}$., and its estimated distance was seven hundred feet. Assuming the position of the fort to be as stated above, the position occupied by the instruments is in

$$
\begin{array}{lccc}
\text { Lat. } & 33^{\circ} & 1^{\prime} & 47^{\prime \prime} \mathrm{S} . \\
\text { Long. } & 4^{\mathrm{h}} & 46^{\mathrm{m}} & 45^{\mathrm{s}} .7 \mathrm{~W} .
\end{array}
$$

Both this station and that of March $2 \mathrm{~d}$ were carefully tested for local attraction by taking fore and back sights with a compass, but none could be detected.

In adopting $4^{\mathrm{h}} 46^{\mathrm{m}} 46^{\mathrm{s}} .0$ as the longitude of Fort San Antonio, I have followed Raper, but this value is doubtless too large. Capt. Jas. M. Gilliss, U. S. N., from a series of occultations and moon culminations, observed during the years 1850-51-52, determined the longitude of the Observatory on the hill of Santa Lucia, in Santiago, to be $4^{\mathrm{h}} 42^{\mathrm{m}} 33^{\mathrm{s}} .8$. Dr. Moesta, from subsequent observations up to the year 1862, corrected this value to $4^{\mathrm{h}} 42^{\mathrm{m}} 33^{\mathrm{s}} .0$. Capt. Gilliss, by means of the electric telegraph, found the difference of lougitude between the Observatory at Santiago and Mr. Mouatt's Observatory at Valparaiso to be $3^{\mathrm{m}} 56^{\mathrm{s}} .5$. Hence, adopting Dr. Moesta's value of the longitude of Santiago, we have

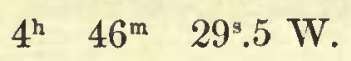

as the longitude of Mr. Mouatt's Observatory; but I have been unable to find any description of its position, and consequently cannot refer this longitude to Fort San Antonio.

Findlay, in his "Directory to the South Pacific Ocean," edition of 1863, gives for the longitude of Fort San Antonio $4^{\mathrm{h}} 46^{\mathrm{m}} 28^{\mathrm{s}} .8$, and quotes Dr. Moesta as the authority. The Connaissance des 'Temps, for the year 1868, on the same authoritygives $4^{\mathrm{h}} 46^{\mathrm{m}} 27^{\mathrm{s}} .5$ for the same position. Which of the two values is nearest correct $I$ am unable to say.

Callao, Peru. The ship was swung in this harbor, on April 29th, 1866, in the usual manner. Her position at the time was lat. $12^{\circ} 3^{\prime}$ S., long. $77^{\circ} 14^{\prime} \mathrm{W}$. Joint 2 December, 1871. 
XII on the after turret was 5.5 inches to port. While we were lying at Callao the ship was perfectly free to swing to the tide, but the wind and current were so strong that she did not do so, but always lay with her head pointing in a southerly direction.

The observations taken on shore, April 26th, were made on the northeast side of San Lorenzo Island, about two and a half miles southenst of the light-house. The island is a mass of hills, rising to an elevation of more than a thousand fect, composed of loose friable rock which seems to be of voleanic origin, and which is constantly disintegrating into a fine yellow sand. 'The place selected for making the observations is at the foot of a gorge where there is a beach, about a quarter of a mile long, of the yellow sand mentioned above. On the beach stand a number of fishermen's huts, and a few steps back, at the foot of the gorge, stands a large, square, two-story house. 'The spot where the instruments stood is on the southeast end of the beach, a little beyond the fishermen's huts, and just above high-water mark. Assuming the position of the light-house to be lat. $12^{\circ} 4^{\prime \prime} 0^{\prime \prime}$ S., long. $5^{\text {h }}$ $9^{\mathrm{m}} 18^{\circ} .0 \mathrm{~W}$, the position occupied by the instruments is in

$$
\begin{array}{lrll}
\text { Lat. } \quad 12^{\circ} & 5^{\prime} & 14^{\prime \prime} \mathrm{S} . \\
\text { Long. } & 5^{\mathrm{h}} & 9^{\mathrm{m}} & 9^{2} .1 \mathrm{~W} .
\end{array}
$$

The place was carefully tested for local attraction by taking fore and back sights with a compass, but none could be detected.

Parta, Peru. We remained in this port only from $2^{\mathrm{h}} 30^{\mathrm{m}}$ P. M. of May 6th, 1866 , till $6^{\text {h }}$ P. M. of May 7th, and there was neither time nor opportunity to swing the ship. However, a complete set of magnetic observations were made on shore at a station on the beach four-tenths of a mile northwest of the large iron building which stands just back from the mole, and is used by the government as a customhouse, etc. As nearly as conld be deternined from angles carefully mensured, and plotted on the English Admiralty Chart, this station is identical with the one occupied by the officers of H. B. M. surveying vessel "Beagle," in the year 1836 , when making their observations for determining the position of Payta. According to their determinations it is in

$$
\begin{array}{lccl}
\text { Lat. } \quad 5^{\circ} & 5^{\prime} & 36^{\prime \prime} \mathrm{S} . \\
\text { Long. } & 5^{\mathrm{h}} & 24^{\mathrm{m}} & 22^{\mathrm{s}} .0 \mathrm{~W} .
\end{array}
$$

the longitude depending upon the position of the northeast bastion at Panama, New Granada, which is taken to be $5^{\mathrm{h}} 18^{\mathrm{m}} 4^{\mathrm{s}} .6 \mathrm{~W}$.

The instruments were set up, just above high-water mark, on the gray sand beach, about fifty feet back from which the land rises into bluffs, two hundred feet high, composed of a hard yellow earth, alternating with sedimentary rocks. The station was carefully examined for local attraction, by taking fore and back sights with a compass, but none could be detected.

Paxama, Neno Granada. The ship was swung in this roadstead, on May 20th, 1866 , in the usual manner. Her position at the time was lat. $8^{\circ} 55^{\prime} \mathrm{N}$., long. $79^{\circ}$ $30^{\prime} \mathrm{W}$. Joint XII on the after turret was 5.5 inches to port. While we were lying here the ship was swinging freely in all directions to the wind and tide. 
'The observations taken on shore, May 14th, were made on the northern side of Flanenco Island, to the westward of a small cocoanut grove, and northeast of the Naval Cemetery. 'The instruments were set up about ten feet north of the most western of the ruins which are to be found therc. 'The island is rocky, but at this station the rocks are covered with earth. The spot was carefully tested for local attraction by taking forc and back sights with a compass, but none could bc detected.

If we assume the position of the northeast bastion at Panama to be lat. $8^{\circ} 56^{\prime}$ $56^{\prime \prime}$ N., long. $5^{\mathrm{h}} 18^{\mathrm{m}} 4^{\mathrm{s}} .6 \mathrm{~W}$., as given by Capt. H. Kellet, R. N., then, according to the English Admiralty Chart, the position occupied by the instruments is in

$$
\begin{aligned}
& \text { Lat. } 8^{\circ} 54^{\prime} 31^{\prime \prime} \mathrm{N} \text {. } \\
& \text { Long. } 5^{\mathrm{h}} \quad 18^{\mathrm{m}} \quad 1^{\mathrm{s}} .8 \mathrm{~W} \text {. }
\end{aligned}
$$

Acapulco,. Arexico. 'The ship was swung in this harbor, on June 1st, 1866, in the usual manner. Her position at the time was lat. $16^{\circ} 50^{\prime} \mathrm{N}$., long. $99^{\circ} 52^{\prime} \mathrm{VV}$. Joint X1I on the after turret was 5.5 inches to port. During the three days we were lying at Acapulco the ship was swinging freely to the wind and tide.

At the extreme south end of St. Lucia Bay, in this harbor, are two cocoanut groves, the most western of the two containing the graves of a number of our naval officers. The western end of the eastcrn grove is the place where the, observations taken on shore, on May 30 th, were made. The trees come almost close down to high-watcr mark, and the soil is a gray sand. The instruments were set up about forty fect from high-wvater mark, at a spot from which the true bearing of the gate of Fort St. Dicgo is N. $6^{\circ} 22^{\prime} \mathrm{E}$.

If we assume the position of this gate to be lat. $16^{\circ} 50^{\prime} 56^{\prime \prime} \mathrm{N}$., long. $6^{\mathrm{h}} 39^{\mathrm{m}} 29^{\mathrm{g}} .0$ W., as given on the English Admiralty Chart, then, according to that chart, the position occupied by the instruments is in

$\begin{array}{llll}\text { Lat. } \quad 16^{\circ} 50^{\prime} & 3^{\prime \prime} & \mathrm{N} \\ \end{array}$

Magdalena Bat, Lonver California. An attempt was made to swing the ship in this bay, on June 9 th, 1 S66, in the usual manner, but owing to a very stiff breeze which was blowing at the time, she could only bc turned through fourtcen points. Her position was lat. $24^{\circ} 38^{\circ} \mathrm{N}$., long. $112^{\circ} 6^{\prime} \mathrm{W}$. Joint XII on the after turret was 5.5 inches to port. During the threc days that we lay in this bay the wind was so strong that the ship did not swing to the tide, but rode with her head constantly to the west.

As it is difficult to describe the land-marks here, the most convenient way of giving positions will be to refer them to the English Admiralty Chart, the position formerly occupied by Capt. Sir Edw. Belcher's observatory being taken to be lat. $24^{\circ} 38^{\prime} 18^{\prime \prime} \mathrm{N}$., long. $7^{\mathrm{h}} 28^{\mathrm{m}} 25^{\mathrm{s}} .4 \mathrm{~W}$, as given on the chart.

On Junc 8th a landing was effected at a spot on the beach, about a mile south of the position of Capt. Bclcher's observatory, for the purpose of making a set of magnetic observations; but, after getting a time sight, it was found that there was a great deal of local attraction, nearly all the stones on the beach being magnetic, and consequently it was useless to attempt anything there. The approximate position of this spot is 


\section{Lat. $24^{\circ} \quad 38^{\prime} \mathrm{N}$. \\ Long. $7^{\mathrm{h}} 28^{\mathrm{m}} 24^{\mathrm{s}} \mathrm{W}$.}

On June 9th, after going to the extreme northern end of the bay, and pulling a short distance up a creek, a place was found which, upon careful cxamination by taking fore and back sights with a compass, scemed to be entirely free from all local attraction. The land there is composed of fine white-sand hillocks, which. are constantly being shifted by the wind, and are so loose that a man will sink halfway to his knees in walking over them. The only place where the surface was sufficiently solid to admit of the instruments being set up was below bigh-ivater mark, where the sand was wet. A complete set of magnetic observations were made there, which, however, were not as satisfactory as could liave been wished, owing to the magnets being disturbed by a stiff breeze which shook the instruments, and from which there was no shelter. The position of this station was

$$
\begin{array}{llll}
\text { Lat. } \quad 24^{\circ} & 39^{\prime} & 36^{\prime \prime} & \mathrm{N} . \\
\text { Long. } \quad 7^{\mathrm{h}} & 28^{\mathrm{m}} & 26^{\mathrm{s}} .2 \mathrm{~W} .
\end{array}
$$

It was on the east side of the creek (on its left-hand bank), at a place where there is a sharp bend in its course, and can easily be found by plotting the position, given above, on the chart.

San Dirgo Bar, California. We were only in this harbor from 11 A.M. of June 15 th, 1866 , till 11 A.M. of June 16 th, and there was no time to swing the ship. However, during the afternoon of the 15 th a complete and very satisfactory set of magnetic observations were made on shore at a spot on the beach near the extreme southern end of the slightly rising ground at La Playa. 'The instruments were set up just above high-water mark, and nearly due cast of the U.S. Coast Survey Astronomical Station. 'The true bearing of the light-house on Point Loma was $\mathrm{S} .3^{\circ} 56^{\prime} \mathrm{W}$., and its distance exactly two statute miles in a direct line. The spot was tested for local attraction by taking fore and back sights with a compass, but none could be detected.

'The position of the station, according to the U.S. Coast Survey Chart, was

$$
\begin{array}{lccl}
\text { Lat. } & 32^{\circ} & 41^{\prime} & 58^{\prime \prime} \mathrm{N} . \\
\text { Long. } & 7^{\mathrm{h}} & 48^{\mathrm{m}} & 52^{\mathrm{s}} .6 \mathrm{~W} .
\end{array}
$$

Sar Francisco, California. The ship was swung in this harbor, on June 23d, 1866 , in the usual manner. Her position at the time was lat. $37^{\circ} 48^{\prime} \mathrm{N}$., long. $122^{\circ} 22^{\prime} \mathrm{WV}$. Joint XII on the after turret was 5.3 inches to port. While we were lying lere the ship was swinging freely to the wind and tide.

The observations taken on shore June 26th were made on the sand beach in a cove on the east side of Yerba Bnena Island, the instruments being set up just at ligh-water mark, and about one hundred and fifty feet north of a long pier which runs out over a mud flat. 'The place was tested for local attraction by taking fore and back sights with a compass, but none could be detected.

According to the U.S. Coast Survey Chart the position of this station was

$$
\begin{array}{llll}
\text { Lat. } \quad 37^{\circ} & 48^{\prime} & 46^{\prime \prime} \mathrm{N} . \\
\text { Long. } & 8^{\mathrm{t}} & 9^{\mathrm{m}} & 22^{3} .6 \mathrm{~W} .
\end{array}
$$




\section{SECTION III.}

ASTRONOMICAL OBSERVATIONS.

THE observations contained in this section were all made on the sun, and are for the determination of latitude, local time, and true bearings. The instruments used were a prismatic sextant of six inches radius, by Pistor and Martins; a mereurial artificial horizon; and a pocket mean time chronometer, by Fletcher, marked number 906.

The index correction of the sextant was usually obtained by measuring the diameter of the sun, both on and off the arc. For determining the density of the atmosphere thermometers with Fahrenheit scales, and a mercurial barometer graduated to English inches, were employed.

'The refractions have been computed by means of BesseL's tables, as given in I,00Mis' "Practical Astronomy;" from which book the tabular parts of the reductions to the meridian have also been taken. The necessary fundamental data have been obtained from the American Nautical Almanac.

Observations of circummeridian altitudes of the sun for latitude were made in sets of twelve, so arranged as to eliminate both the sun's semi-diameter, and all errors depending on the roof of the artificial horizon.

Circummeridian Altitudes of the Sun for Latitude, observed at the south front of Fort Christian, St. Thomas, November I 7 th, 1865.

$\begin{array}{rrr}10^{\mathrm{h}} & 55^{\mathrm{m}} & 0^{\mathrm{s}} \\ & 55 & 48 \\ & 56 & 14 \\ 10 & 57 & 3 \\ \text { I } & 0 & 3 \mathrm{I} \\ & 1 & 5 \\ & \text { I } & 33 \\ & 2 & 9 \\ 2 & 46 \\ & 3 & 28 \\ 3 & 59 \\ & 4 & 29\end{array}$

$\left.\begin{array}{ccc}105^{\circ} & 14^{\prime} & 20^{\prime \prime} \\ 15 & 20 \\ 16 & 50 \\ 18 & 0 \\ 21 & 40 \\ 22 & 20 \\ 104 & 18 & 10 \\ 18 & 20 \\ 18 & 25 \\ 18 & 50 \\ 18 & 55 \\ 18 & 40\end{array}\right\} 2 \bigodot$

\begin{tabular}{|c|c|c|c|c|c|}
\hline \multirow{4}{*}{$359^{\circ}$} & \multicolumn{4}{|c|}{ Index correction. } & \multirow{4}{*}{$\begin{array}{l}50^{\prime \prime} \\
10 \\
20\end{array}$} \\
\hline & I I $I^{\prime}$ & $10^{\prime \prime}$ & $0^{\circ}$ & 15 & \\
\hline & I I & 10 & & 16 & \\
\hline & I I & 40 & & I 6 & \\
\hline \multirow[t]{4}{*}{35} & I I & 20.0 & $\circ$ & 56 & 6.7 \\
\hline & \multicolumn{3}{|c|}{ Correction $=+1 \sigma^{\prime}$} & $\mathrm{I} \mathrm{\sigma}^{\prime \prime}$. & \\
\hline & Ex & ther. & $83^{\circ}$ & & \\
\hline & $\begin{array}{l}\text { At. } \\
\text { Ba }\end{array}$ & ther. & $\begin{array}{l}86 \\
30.16\end{array}$ & & \\
\hline
\end{tabular}

Mean of chronometer times

Chronometer slow of local mean time

Equation of time

Local apparent time

Mean of observed double altitudes

Index correction.

Apparent altitude of sun's centre

Refraction.

\begin{tabular}{|c|c|c|}
\hline - $\quad \mathbf{I}^{\mathrm{h}}$ & $0^{m}$ & $2^{8} .0$ \\
\hline 0 & 40 & 47.3 \\
\hline.+ & 14 & 47.1 \\
\hline - I I & 55 & 36.4 \\
\hline $.104^{\circ}$ & $48^{\prime}$ & $19^{\prime \prime} \cdot 2$ \\
\hline.+ & I 6 & 16.7 \\
\hline - $\quad 5^{2}$ & $3^{2}$ & I 8.0 \\
\hline . - & o & 42.1 \\
\hline
\end{tabular}




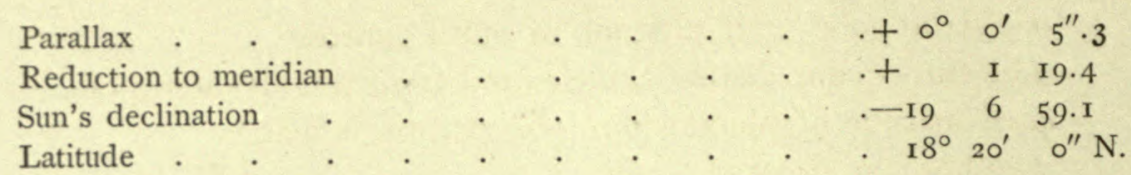

Circummeridian Altitudes of the Sun for Latitude, observed at Isle Royal, Salute Islands, November 28 th, 1865 .

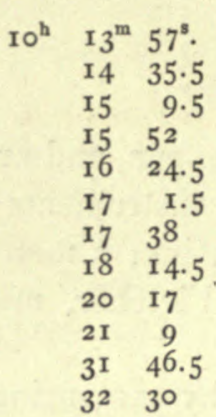

\begin{tabular}{|c|c|c|}
\hline $125^{\circ}$ & $50^{\prime}$ & $30^{\prime \prime}$ \\
\hline & 49 & 30 \\
\hline & 49 & $3^{\circ}$ \\
\hline & $\begin{array}{l}49 \\
48\end{array}$ & $\begin{array}{l}20 \\
50\end{array}$ \\
\hline & 48 & 40 \\
\hline 126 & $5^{2}$ & Io \\
\hline & $5^{1}$ & I0 \\
\hline & 48 & 20 \\
\hline & 46 & Io \\
\hline & $3^{\circ}$ & 0 \\
\hline & 26 & 50 \\
\hline
\end{tabular}

Mean of chronometer times

Chronometer slow of local mean time

Equation of time

Local apparent time.

Mean of observed double altitudes

Index correction

Apparent altitude of sun's centre

Refraction .

Parallax

Reduction to meridian

Sun's declination

Latitude

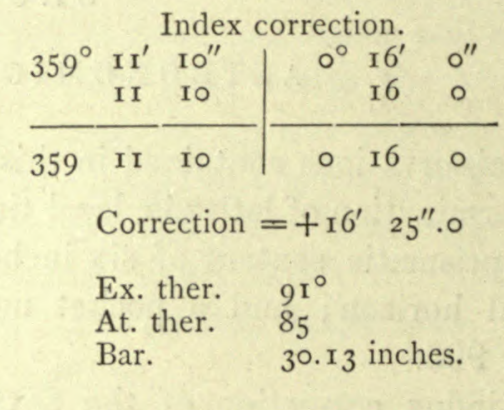

Observations for time were usually made in such a manner as to eliminate both the sun's semi-diameter and all errors which might be produced by the roof of the artificial horizon. For full details of the method see page 33 of the "Reports on Observations of the Total Eclipse of the Sun, August 7, 1869," published by the U.S. Naval Observatory, Washington.

The reduction of the observations for time has been effected by means of the following formulæ:

$$
\begin{gathered}
a=\frac{A+\omega}{2}-r+p \\
S=\frac{a+d+\phi}{2} \\
\sin \frac{1}{2} t=\sqrt{ } \sin (S-a) \cos S \sec \phi \operatorname{cosec} d \\
d t=t+\tau-T
\end{gathered}
$$

$T=$ mean of observed chronometer times.

$A=$ mean of observed double altitudes.

$\omega=$ index correction.

$r=$ refraction.

$p=$ parallax. 
$a=$ true geocentric altitude of sun's centre.

$d=$ sun's polar distance, measured from the elevated pole.

$\phi=$ latitude of place where observation is made.

$t=$ hour angle at the pole.

$\tau=$ equation of time.

$d t=$ correction of chronometer to reduce the reading of its face to local mean time.

Double Altitudes of the Sun, for Time, observed at the flagstaff in the Navy-yard at Portsmouth, Va., Octoher 29 th, 1865 .

$\begin{array}{lll}8^{\mathrm{h}} & 5^{\mathrm{m}} & 7^{\mathrm{s}} \\ 5 \mathrm{I} & 42 \\ 52 & 22 \\ 53 & 23 \\ 53 & 56.5 \\ 54 & 47 \\ 55 & 50 \\ 56 & 25 \\ 56 & 57 \cdot 5 \\ 57 & 59 \cdot 5 \\ 5^{8} & 32.5 \\ 59 & \mathrm{I} 3.5\end{array}$

$\left.\begin{array}{rrr}49^{\circ} & 27^{\prime} & 50^{\prime \prime} \\ & 38 & 20 \\ 50 & 49 & 30 \\ 50 & 70 \\ & 17 & 50 \\ 50 & 32 & 20 \\ 49 & 47 & 0 \\ & 57 & 20 \\ 50 & 6 & 20 \\ & 24 & 50 \\ 34 & 30 \\ 45 & 50\end{array}\right\} 2$

Index correction,

$$
=+15^{\prime} 42^{\prime \prime}
$$

Ex. ther. $50^{\circ}$.

Refraction $=-125^{\prime \prime}$

At. ther. $92^{\circ}$.

Bar. 30.40 inches.

Parallax $=+8$ Latitude $+3^{6} 493^{2}$

Mean of observed double altitudes . . . . . $50^{\circ} 7^{\prime} 27^{\prime \prime}$

Local apparent time . . . . . . . . $9^{\mathrm{h}} 6^{\mathrm{m}} 40^{\mathrm{s}} .8$

Equation of time . . . . . . . . . . 1610.6

Local mean time . . . . . . . . 85030.2

Mean of chronometer times . . . . . . 855 II.3

Chronometer fast of local mean time . . . . . 04 4I.I

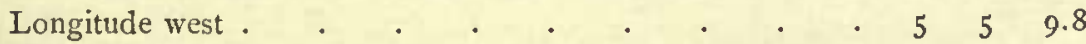

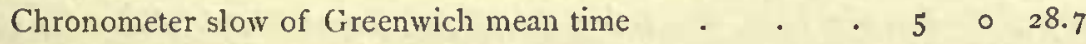

Double Altitudes of the Sun for Time, observed at the flagstaff in the Nazy-yard at Portsmouth, Va., October 29 th, 1865 .

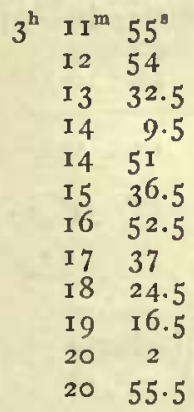

\begin{tabular}{|c|c|c|c|}
\hline $40^{\circ}$ & IO' & $10^{\prime \prime}$ & \\
\hline 39 & 51 & 20 & \\
\hline & $3^{8}$ & 30 & \\
\hline 40 & 30 & $3^{\circ}$ & \\
\hline & I 7 & 0 & \\
\hline & 2 & 20 & \\
\hline 39 & 37 & 30 & \\
\hline & 23 & IO & \\
\hline & 8 & 30 & \\
\hline 7 & 46 & 0 & \\
\hline & $3 I$ & 30 & \\
\hline & 20 & IO & \\
\hline
\end{tabular}

Index correction,

Ex. ther. $55^{\circ}$

At. ther. $79 \quad$ Bar. $30.3^{6}$ inches.

Refraction $=-170^{\prime \prime} .1$

Sun's declination $-\mathrm{I}^{\circ} 4 \mathrm{O}^{\prime} 42^{\prime \prime} .0$

Parallax $=+8.0$

Latitude $\quad+3^{6} 493^{2}$.

Mean of observed double altitudes . . , . . $39^{\circ} 16^{\prime} 23^{\prime \prime} \cdot 3$

Local apparent time . . . . . . . . $3^{\mathrm{h}} 27^{\mathrm{m}} 55^{\mathrm{I}} \cdot 9$ 
Equation of time . . . . . . . . - . $0^{\mathrm{h}} \mathrm{I}^{\mathrm{m}} \mathrm{II}^{8} \cdot 6$

Local mean time . . . . . . . . . . 3 II 40.3

Mean of chronometer times . . . . . . $\begin{array}{lllll}3 & 16 & 20.4\end{array}$

Chronometer fast of local mean time. . . . . $\quad 0 \quad 4$ 40.I

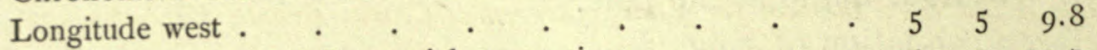

Chronometer slow of Greenwich mean time . $\quad \begin{array}{llll} & 5 & 0 & 29.7\end{array}$

Double Altitudes of the Sun for Time, observed at Fort Christian, St. Thomas, West Indies, November $13^{\text {th }}, \mathbf{1} 865$.

$\begin{array}{ccc}9^{\mathrm{h}} & \mathrm{O}^{\mathrm{m}} & 42^{8} \cdot 5 \\ \mathrm{I} & 21 \cdot 5 \\ 2 & 2 \\ 3 & 2.5 \\ 3 & 4 \\ 4 & 54 \\ 6 & 0.5 \\ 6 & 4 \mathrm{I} \\ 7 & 10 \\ 7 & 54.5 \\ 8 & 21.5 \\ 8 & 48.5\end{array}$

Ex. ther. $84^{\circ}$

Refraction $=-57^{\prime \prime} \cdot 7$

Parallax $=+6.2$

$\left.\begin{array}{rrr}84^{\circ} & 32^{\prime} & 50^{\prime \prime} \\ & 46 & 20 \\ & 57 & 30 \\ 85 & 16 & 50 \\ & 35 & 10 \\ 85 & 51 & 0 \\ 87 & 15 & 20 \\ & 28 & 30 \\ & 37 & 0 \\ & 50 & 20 \\ & 59 & 20 \\ 88 & 7 & 0\end{array}\right\}=$

At. ther. $86^{\circ}$

Index correction.

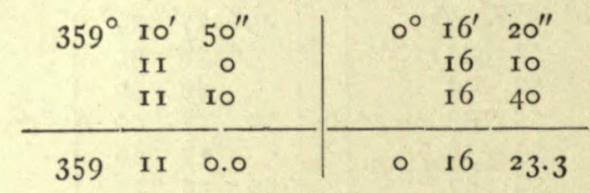

Correction $=+\mathrm{I} 6^{\prime} \quad \mathrm{I} 8^{\prime \prime} \cdot 4$

Mean of observed double altitudes . . . . . $86^{\circ} 26^{\prime} 25^{\prime \prime} .8$

Local apparent time . . . . . . . . . $10^{\mathrm{h}} \mathrm{I}^{\mathrm{m}} 20^{\mathrm{s}} .0$

Equation of time : . . . . . . . . . $\quad$ I5 3 I.2

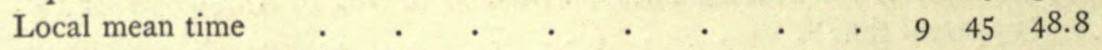

Mean of chronometer times _. . . . . . $\quad \begin{array}{lllll} & & 9 & 5 & 5.2\end{array}$

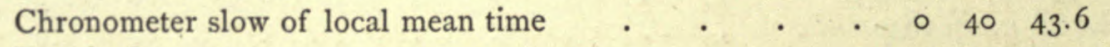

$\begin{array}{lllllllllll}\text { Longitude west . } & . & . & & & 4 & 19 & 42.7\end{array}$

Chronometer slow of Greenwich mean time $\quad \begin{array}{llll}\text {. } & 5 & 5 & 26.3\end{array}$

Double Altitudes of the Sun for Time, observed at Isle Royal, Salute Islands, November 28th, 1865.

$\begin{array}{lll}8^{\mathrm{h}} & 47^{\mathrm{m}} & 5^{8} \\ 48 & 35 \\ 49 & 8 \\ 49 & 5^{8} \\ 5 \circ & 31 \\ 50 & 56 \cdot 5 \\ 51 & 44 \cdot 5 \\ 5^{2} & 39 \cdot 5 \\ 53 & 13 \cdot 5 \\ 53 & 47 \\ 54 & 19 \\ 54 & 53 \cdot 5\end{array}$

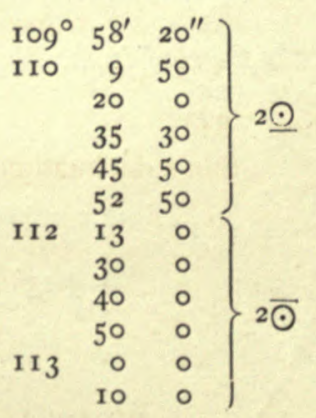
Index correction.

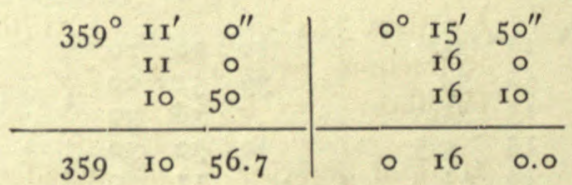

Ex. ther. $93^{\circ}$

Refraction $=-36^{\prime \prime} \cdot 3$

At. ther. $85^{\circ}$

Bar. 30.13 inches.

Parallax $=+4.9$

Sun's declination $-21^{\circ} \quad 23^{\prime} \quad 30^{\prime \prime} \cdot 3$

Latitude $\quad+51729$.

Mean of observed double altitudes . . . . . $\mathrm{III}^{\circ} 35^{\prime} 26^{\prime \prime} .6$

Local apparent time . . . . . . . . $10^{\mathrm{h}} 33^{\mathrm{m}} 3 \mathrm{I}^{\mathrm{s}} .8$

Equation of time . . . . . . . . . II 43.8

Local mean time . . . . . . . . . . 102148.0

Mean of chronometer times . . . . . . . $85^{1} \quad 28.6$ 
Chronometer slow of local mean time.

Longitude west .

Double Altitudes of the Sun for Time, observed at Ceara, Brazil, December $13^{\text {th, }}$, 865 .

$\begin{array}{lll}I^{8} & 15^{\mathrm{m}} & 13^{8} \cdot 5 \\ 15 & 58 \cdot 5 \\ 16 & 41 \\ 17 & 3 \cdot 5 \\ 17 & 26 \\ 18 & 43 \\ 19 & 5 \\ 19 & 26.5 \\ 19 & 50 \\ 20 & 11 \cdot 5\end{array}$

$\left.\begin{array}{rrr}63^{\circ} & 0^{\prime} & 0^{\prime \prime} \\ 62 & 40 & 0 \\ & 20 & 0 \\ & 10 & 0 \\ 62 & 0 & 0 \\ 62 & 30 & 0 \\ & 20 & 0 \\ & 10 & 0 \\ 62 & 0 & 0 \\ 61 & 50 & 0\end{array}\right\} 2 \odot$

Index correction.

Ex. ther. $84^{\circ}$

Refraction $=-89^{\prime \prime} \cdot 5$

At. ther. $82^{\circ}$

\begin{tabular}{|c|c|c|}
\hline $359^{\circ}$ & $\begin{array}{lc}\text { I I' } & 0^{\prime \prime} \\
\text { 10 } & 50 \\
\text { I0 } & 40\end{array}$ & $\begin{array}{ccc}0^{\circ} \text { I } 6^{\prime} & 0^{\prime \prime} \\
& 10 \\
& 0\end{array}$ \\
\hline 359 & 50.0 & $\begin{array}{lll}\circ & 16 & 3.3\end{array}$ \\
\hline
\end{tabular}

Parallax $=+7 \cdot 4$

Bar. 30.05 inches.

Sun's declination $-23^{\circ}$ I $2^{\prime} 4^{\prime \prime} .0$

Mean of observed double altitudes . . . . . $62^{\circ} 18^{\prime} \circ^{\prime \prime} . \circ$

Mean of chronometer times . . . . . . $\mathbf{I}^{\mathrm{h}} \mathbf{1} 7^{\mathrm{m}} 57^{\mathrm{6}} .8$

Equation of time * . . . . . . . . 520.9

Reducing this observation with latitude $=-3^{\circ} 43^{\prime} 15^{\prime \prime}$, we find the chronometer $2^{\mathrm{h}} 26^{\mathrm{m}} 29^{\mathrm{s}} .6$ slow of local mean time. Reducing it with latitude $=-3^{\circ} 44^{\prime} 15^{\prime \prime}$, we find the chronometer $2^{\mathrm{h}} 26^{\mathrm{m}} 32^{\mathrm{s}} .0$ slow of local mean time.

Double Altitudes of the Sun for Time, observed at Ceara, Brazil, December 14 th, 1865 .

$\begin{array}{lll}7^{\mathrm{h}} & 2^{\mathrm{m}} & 0^{\mathrm{s}} \cdot 5 \\ 2 & 24.5 \\ 2 & 49 \\ 3 & 12.5 \\ 3 & 36 \\ 6 & 9 \\ 6 & 3^{2.5} \\ 6 & 57.5 \\ 7 & 21.5 \\ 7 & 45.5\end{array}$

$\left.\begin{array}{rrr}99^{\circ} & 30^{\prime} & 0^{\prime \prime} \\ & 40 & 0 \\ 100 & 50 & 0 \\ 100 & 0 \\ 100 & 10 & 0 \\ & 10 & 0 \\ & 20 & 0 \\ 30 & 0 \\ 40 & 0 \\ 100 & 50 & 0\end{array}\right\} 2 \odot$

Index correction.

Ex. ther. $81^{\circ}$

Refraction $=-45^{\prime \prime} \cdot 9$

At. ther. $82^{\circ} \quad$ Bar. 30.12 inches.

Parallax $=+5.6$

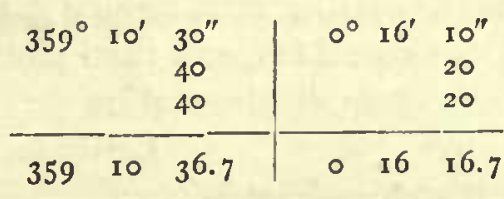

Correction $=+16^{\prime} 33^{\prime \prime} \cdot 3$

Mean of observed double altitudes . . . . . $100^{\circ} 10^{\prime} 0^{\prime \prime} .0$

Mean of chronometer times . . . . . . $7^{\mathrm{h}} 4^{\mathrm{m}} 5^{2^{\mathrm{b}} .8}$

Equation of time . . . . . . . . 459.5

Reducing this observation with latitude $=-3^{\circ} 43^{\prime} 15^{\prime \prime}$, we find the chronometer $2^{\mathrm{h}} 26^{\mathrm{m}} 33^{\mathrm{s}} .7$ slow of local mean time. Reducing it with latitude $=-3^{\circ} 44^{\prime} 15^{\prime \prime}$, we find the chronometer $2^{\mathrm{h}} 26^{\mathrm{m}} 30^{\mathrm{s}} .9$ slow of local mean time. 
Double Altitudes of the Sun for Time, observed at Ceara, Brazil, December $14^{t h}$, 1865.

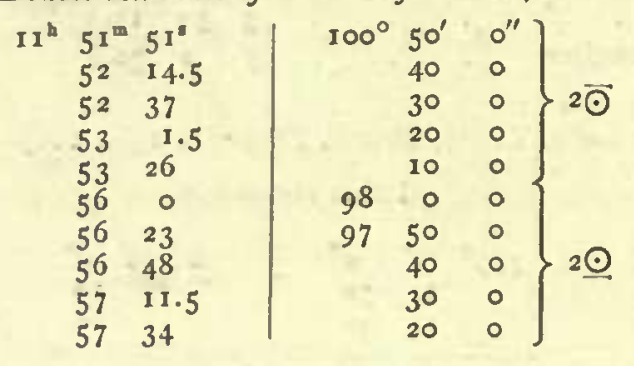

Ex. ther. $86^{\circ}$

Refraction $=-45^{\prime \prime} .6$

Parallax $=+5.6$
At. ther. $83^{\circ}$

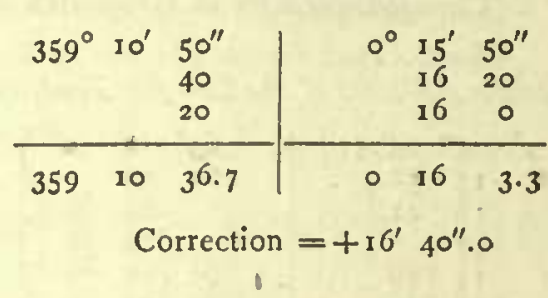

Bar. 30.00 inches.

Sun's declination $-23^{\circ} 15^{\prime} 27^{\prime \prime} .4$
Mean of observed double altitudes
$99^{\circ} \quad 5^{\prime} \quad 0^{\prime \prime} .0$
Mean of chronometer times
Equation of time
- $11^{\mathrm{h}} 54^{\mathrm{m}} 42^{\mathrm{s}} .6$
$\begin{array}{lll}4 & 53.7\end{array}$

Reducing this observation with latitude $=-3^{\circ} 43^{\prime} 15^{\prime \prime}$, we find the clronometer $2^{\mathrm{h}} 26^{\mathrm{m}} 30^{\mathrm{s}} .7$ slow of local mean time. Reducing it with latitude $=-3^{\circ} 44^{\prime} 15^{\prime \prime}$, we find the chronometer $2^{\mathrm{h}} 26^{\mathrm{m}} 33^{\mathrm{s}} .1$ slow of local mean time.

In order to determine both the latitude of Ceara and the error of the chronometer from the three observations which have just been given, we proceed as follows:

Comparing the error obtained on the afternoon of December 13th, with that obtained on the afternoon of December 14th, we find that the chronometer was losing 1.17 seconds per day; and this rate is independent of any small change in the adopted value of the latitude.

By means of this rate, reducing all the observed chronometer errors to $2^{\mathrm{h}} 26^{\mathrm{m}}$ P. M. December 14th, and then plotting them according to Sumner's method, we get for the place of observation

ind for the chronometer,

$$
\text { Latitude } 3^{\circ} \quad 43^{\prime} \quad 59^{\prime \prime} \mathrm{S} \text {. }
$$

Chronometer slow of local mean time.

Longitude west .

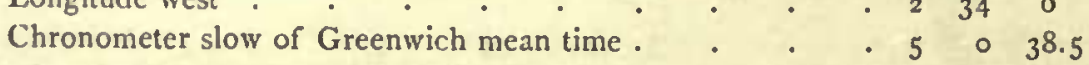

Double Altitudes of the Sun for Time, observed at Pcrnambuco, Brazil, December $23^{d}, 1865$.

$\begin{array}{lll}7^{b} & 30^{m} & 15^{\prime} \\ 30 & 39 \cdot 5 \\ 3^{1} & 3 \\ 3^{2} & 52.5 \\ 33 & 15 \\ 33 & 40\end{array}$

Ex. ther. $83^{\circ}$

Refraction $=-32^{\prime \prime} .1$

Parallax $=+4.5$

Mean of obscrved double altitudes

Local apparent time.

Equation of time

Iocal mean time

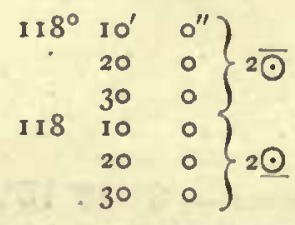

At. ther.
Index correction.

\begin{tabular}{|c|c|c|}
\hline $359^{\circ}$ & $\begin{array}{ll}10^{\prime} & 50^{\prime \prime} \\
50^{\circ}\end{array}$ & $\begin{array}{ccc}0^{\circ} & 16^{\prime} & 0^{\prime \prime} \\
16 & 10\end{array}$ \\
\hline 359 & $\begin{array}{l}10 \\
\text { Correcti }\end{array}$ & $\begin{array}{lll}0 & 16 \\
=+I 6^{\prime} & 5 \cdot 0\end{array}$ \\
\hline
\end{tabular}

Bar.

Sun's declination $-23^{\circ} 26^{\prime} \quad 31^{\prime \prime}$

Latitude $\quad-8337$

. $118^{\circ} 20^{\prime} 0^{\prime \prime} .0$

- $10^{\mathrm{h}} 9^{\mathrm{m}} 3^{\mathrm{c}} \cdot 5$

- $\quad 3^{1.2}$

- $10 \quad 832.3$ 
Mean of chronometer times . . . . . . $7^{\mathrm{h}} 31^{\mathrm{m}} 57^{\mathrm{s}} \cdot 5$

Chronometer slow of local mean time . . . . $\quad 2 \quad 3^{6} 34.8$

Longitude west . $\quad . \quad . \quad . \quad . \quad . \quad 2 \quad$ i 28.2

Chronometer slow of Greenwich mean time . . . $\quad \begin{array}{lll}4 & 5^{6} & 3.0\end{array}$

Double Altitudes of the Sun for Time, observed at Bahia, Brazil, December 27 th, 1865 .

$6^{\mathrm{h}} 5^{2^{\mathrm{m}}} 10^{\mathrm{s}}$

$\begin{array}{ll}5^{2} & 31.5\end{array}$

$\begin{array}{ll}52 & 54.5\end{array}$

$54 \quad 32$

$54 \quad 53 \cdot 5$

$55 \quad 16.5$

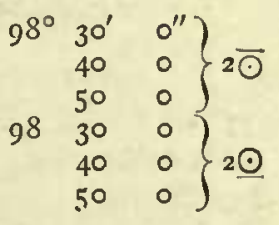

At. ther

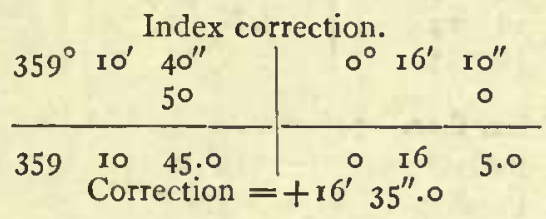

Bar.

Ex. ther. $88^{\circ}$

Refraction $=-45^{\prime \prime} \cdot 9$

Parallax $=+5.7$

Sun's declination $-23^{\circ}$ I $9^{\prime} 33^{\prime \prime} .8$

Latitude $\quad-\mathrm{r}_{2} \quad 5^{6} \quad 55$.

Mean of observed double altitudes

Local apparent time .

Equation of time

Local mean tim

Mean of chronometer times

Chronometer slow of local mean time

Longitude west .

Chronometer slow of Greenwich mean time . . $\quad \begin{array}{lllll} & 4 & 5^{6} & 7 \cdot 3\end{array}$

Double Altitudes of the Sun for Time, observed at the Light-house in Fort St. Antonio, Bahia, Brazil, December 29 th, $\mathbf{1} 865$.

$\begin{array}{lll}8^{\mathrm{h}} & \text { I } 4^{\mathrm{m}} & 46^{\mathrm{a}} \cdot 5 \\ & \text { 15 } & 10 \\ \text { I5 } & 3 \mathrm{I} \\ \text { I5 } & 5^{6} \\ \text { I6 } & 19 \cdot 5 \\ \text { I7 } & 17 \cdot 5 \\ \text { I7 } & 44 \\ \text { I8 } & 7 \\ \text { 18 } & 3^{\mathrm{I}} \cdot 5 \\ \text { I8 } & 54\end{array}$

$\left.\begin{array}{rrr}\mathrm{I} 34^{\circ} & 50^{\prime} & 0^{\prime \prime} \\ \mathrm{I} 35 & 0 & 0 \\ 10 & 0 \\ 20 & 0 \\ 30 & 0 \\ 134 & 50 & 0 \\ \mathrm{I} 35 & 0 & 0 \\ 10 & 0 \\ 20 & 0 \\ 30 & 0\end{array}\right\}=2 \odot$

Index correction.

Ex. ther. $84^{\circ}$

At. ther.

\begin{tabular}{|c|c|c|}
\hline $359^{\circ} \quad \mathrm{ro}^{\prime}$ & $\begin{array}{l}50^{\prime \prime} \\
50 \\
40\end{array}$ & $0^{\circ} \times 6^{\prime}$ \\
\hline ro & 46.7 & - 16 \\
\hline
\end{tabular}

Correction $=+16^{\prime} 33^{\prime \prime} \cdot 3$

Refraction $=-22^{\prime \prime} . \mathrm{I}$

Parallax $=+3.3$

At. ther.

Bar.

Mean of observed double altitudes

$$
\begin{array}{llll}
\text { Sun's declination } & -23^{\circ} & \text { I } 3^{\prime} & 3^{\prime \prime} .1 \\
\text { Latitude } & -13 & 0 & 55 .
\end{array}
$$

Local apparent time :

Equation of time

Local mean time

Mean of chronometer times

Chronometer slow of local mean time

$$
\begin{aligned}
& \text { - } 135^{\circ} \text { I } 0^{\prime} 0^{\prime \prime} .0 \\
& \text { - } 10^{\mathrm{h}} 3^{6^{\mathrm{m}}} 25^{\mathrm{s}} \cdot 7 \\
& \text {. } 227.6 \\
& \text { - } 103^{\circ} 53.3 \\
& \text { - } 81649.7 \\
& \text { Longitude west . . . . . . . . . } 234 \text {. } 24.9
\end{aligned}
$$$$
\text { Chronometer slow of Greenwich mean time . . . } 45^{6} 10.5
$$ 
Double Altitudes of the Sun for Time, observed at Rio Janeiro, Brazil, January 9th, 1866.

$\begin{array}{ccc}5^{\mathrm{h}} & 13^{\mathrm{m}} & 17^{\mathrm{s}} \\ 13 & 39 \\ 14 & 3 \cdot 5 \\ 14 & 26.5 \\ 15 & 43 \\ 15 & 8 \\ 16 & 8 \\ 16 & 29 \\ 16 & 53\end{array}$

$\left.\begin{array}{crr}47^{\circ} & 40^{\prime} & 0^{\prime \prime} \\ & 50 & 0 \\ 48 & 0 & 0 \\ & 10 & 0 \\ 47 & 40 & 0 \\ 48 & 50 & 0 \\ 48 & 0 & 0 \\ & 10 & 0\end{array}\right\} 2 \underline{ }$

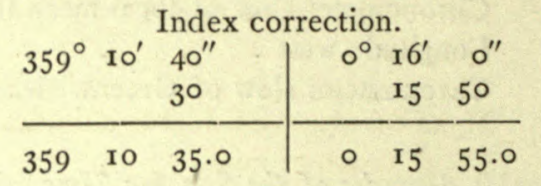

Correction $=+16^{\prime} 45^{\prime \prime} \cdot 0$
Ex. ther. $74^{\circ}$

Refraction $=-123^{\prime \prime} \cdot 2$.

Parallax $=+7.9$
At. ther. $77^{\circ}$.

Bar. 29.94 inches.

Sun's declination $-22^{\circ} 6^{\prime} \quad 24^{\prime \prime} .6$

Latitude $\quad-22 \quad 54 \quad 5$.

Mean of observed double altitudes . . . . . . $47^{\circ} 55^{\prime} 0^{\prime \prime} .0$

Local apparent time . . . . . . . . $7^{\mathrm{h}} 11^{\mathrm{m}} 19^{8} \cdot 5$

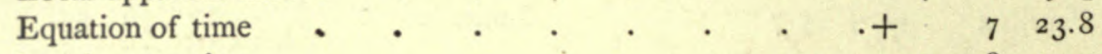

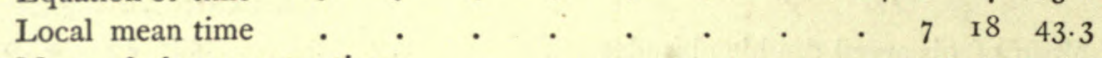

$\begin{array}{lllllllllll}\text { Mean of chronometer times } & . & . & . & & 5 & 15 & 4.9\end{array}$

Chronometer slow of local mean time . . . . $\quad \begin{array}{llll}2 & 3 & 38.4\end{array}$

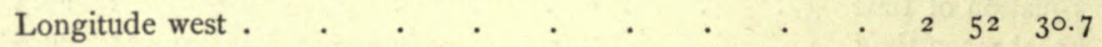

Chronometer slow of Greenwich mean time . . $\quad 4^{4} \quad \begin{array}{cc}5^{6} & 9 \cdot 1\end{array}$

Double Altitudes of the Sun for Time, observed at Rat Island, harbor of Rio Janeiro, January 9 th, 1866.

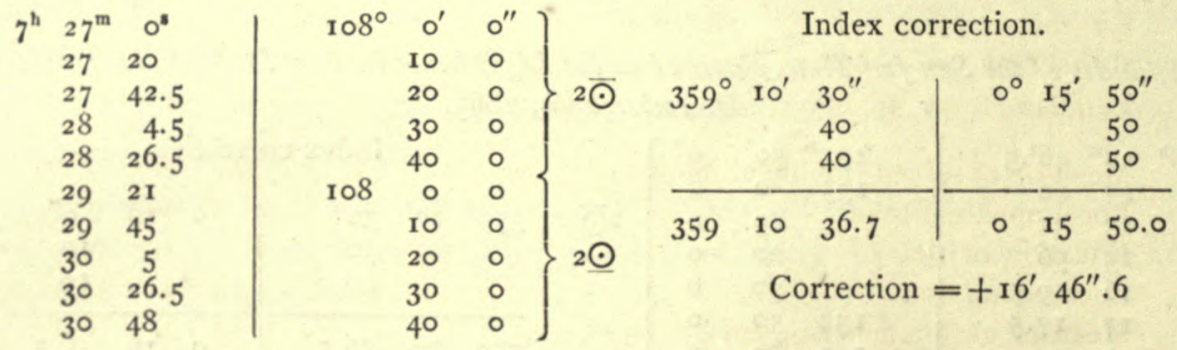

Ex. ther. $75^{\circ}$

Refraction $=-39^{\prime \prime} .8$

Parallax $=+5.1$
At. ther. $77^{\circ}$

Sun's declination $-22^{\circ} 5^{\prime} 37^{\prime \prime} \cdot 3$

Latitude

Mean of observed double altitudes

Local apparent time .

$+726.0$

Local mean time . . . . . . . . . $9 \begin{array}{lll}9 & 32 & 26.7\end{array}$

$\begin{array}{lllllllllll}\text { Mean of chronometer times } & \text {. } & 2 & 28 & 53.9\end{array}$

Chronometer slow of local mean time $\quad$. $\quad . \quad \begin{array}{llllll}2 & 2 & 3 & 32.8\end{array}$

Longitude west . $\quad . \quad 2 \quad . \quad . \quad . \quad 2 \quad 5237.9$

Chronometer slow of Greenwich mean time . . . $\quad \begin{array}{llll}4 & 4 & 5^{6} & 10.7\end{array}$

Double Altitudes of the Sun for Time, observed at Monte Video, Uruguay, January 18 th, 1866.

$\begin{array}{lll}4^{\mathrm{k}} & \mathrm{O}^{\mathrm{m}} & 26^{\circ} \cdot 5 \\ \circ & 51 \cdot 5 \\ \mathrm{I} & 17 \\ 2 & 3 \cdot 5 \\ 3 & 5 \cdot 5 \\ 3 & 30 \\ 3 & 56 \cdot 5 \\ 4 & 46\end{array}$
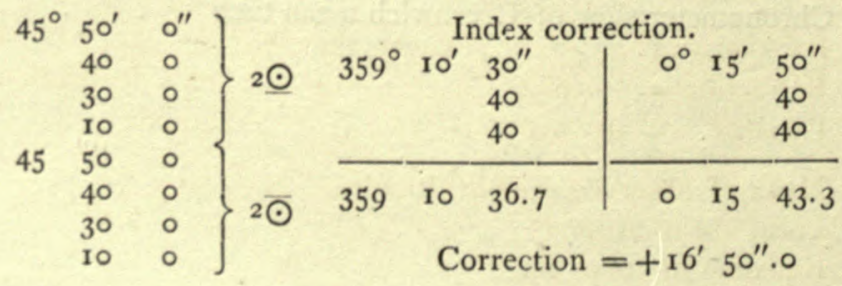
Ex. ther. $76^{\circ}$

Refraction $=-x_{30} 0^{\prime \prime} 2$

Parallax $=+8.0$
At. ther. $79^{\circ}$ Sun's declination $-20^{\circ} 26^{\prime} \quad 55^{\prime \prime} .2$ Latitude
Bar. 30.02 inches.

$-34 \quad 53 \quad 39$

Mean of observed double altitudes . . . . . $45^{\circ} 32^{\prime} 30^{\prime \prime} .0$

Local apparent time . . . . . . . . $5^{\mathrm{h}} 3^{\mathrm{m}} 5^{\mathrm{h}} \cdot 2$

Equation of time . $\quad . \quad$. . . . . . . . ro 5 r.4

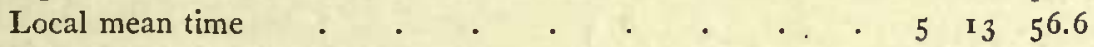

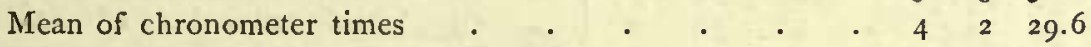

Chronometer slow of local mean time . . . . I II 27.0

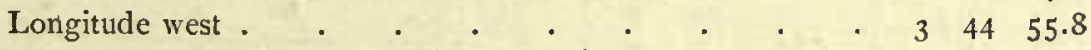

Chronometer slow of Greenwich mean time . . $\quad \begin{array}{llll}4 & 56 & 22.8\end{array}$

Double Altitudes of the Sun for Time, observed on Rat Island, harbor of Monte Video, Uruguay, January 24 th, 1866.

\begin{tabular}{|c|c|c|c|c|c|c|c|c|c|c|c|}
\hline $2^{\mathrm{b}} 29^{\mathrm{m}}$ & $x^{8} \cdot 5$ & - $82^{\circ}$ & $30^{\prime}$ & $0^{\prime \prime}$ & & & & Index & ctior & & \\
\hline $\begin{array}{l}29 \\
20\end{array}$ & $\begin{array}{r}25.5 \\
50.5\end{array}$ & & 20 & 0 & $2 ?$ & $250^{\circ}$ & Io' & I" & $0^{\circ}$ & $15^{\prime}$ & $40^{\prime \prime}$ \\
\hline 30 & $\begin{array}{r}50.5 \\
13.5\end{array}$ & 82 & 0 & 0 & 22 & & 10 & 10 & & & 40 \\
\hline $3^{\circ}$ & $3^{8.5}$ & $8 I$ & 50 & $\circ$ & & & 10 & 10 & & & 20 \\
\hline $\begin{array}{l}3^{1} \\
3^{2}\end{array}$ & $\begin{array}{c}3^{8 \cdot} \cdot 5 \\
3\end{array}$ & 82 & $\begin{array}{l}30 \\
20\end{array}$ & 0 & & 359 & 10 & 10.0 & 0 & I 5 & $33 \cdot 3$ \\
\hline $\begin{array}{l}32 \\
32\end{array}$ & $\begin{array}{l}26 \\
51\end{array}$ & 82 & $\begin{array}{r}10 \\
0\end{array}$ & $\begin{array}{l}0 \\
0\end{array}$ & $2 \bar{\odot}$ & & Corr & ection & $I z^{\prime}$ & $8^{\prime \prime}$ & .3 \\
\hline 33 & 16 & $8 I$ & 50 & 0 & & & & & & & \\
\hline
\end{tabular}

Ex. ther. $74^{\circ}$

At. ther.

Bar.

Refraction $=-62^{\prime \prime} \cdot 7$

Parallax $=+6.5$

Sun's declination $-19^{\circ} 6^{\prime} \quad 33^{\prime \prime} .8$

Latitude

$-34 \quad 53 \quad 18$

Mean of observed double altitudes . . . . . $82^{\circ} 10^{\prime} \mathrm{o}^{\prime \prime} .0$

Local apparent time . . . . . . . $3^{\mathrm{h}} 30^{\mathrm{m}} 5^{\mathrm{s}} \cdot 7$

Equation of time . . . . . . . . . $\quad$ r 29.2

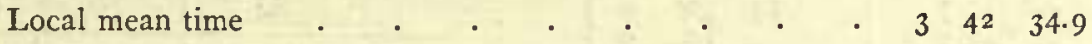

Mean of chronometer times . . . . . . . $23^{2} \quad 8.4$

Chronometer slow of local mean time $\quad$. . . . I II 26.5

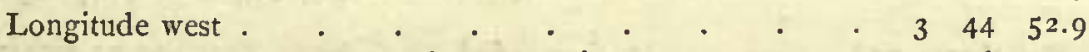

Chronometer slow of Greenwich mean time . . . $\begin{array}{llll}3 & 46 & 19.4\end{array}$

Double Altitudes of the Sun, for Time, observed at Sandy Point, in the Straits of Magellan,

$\begin{array}{lll}9^{\mathrm{h}} & 59^{\mathrm{m}} & 24^{\mathrm{s}} \cdot 5 \\ \text { 10 } & 0 & 11 \\ 1 & 1 \\ 1 & 49 \cdot 5 \\ 2 & 37 \cdot 5 \\ 4 & 39 \cdot 5 \\ 5 & 27 \cdot 5 \\ 6 & 18.5 \\ 7 & 9 \\ 7 & 58 \cdot 5\end{array}$

\section{Feliruary 7 th, 1866.}
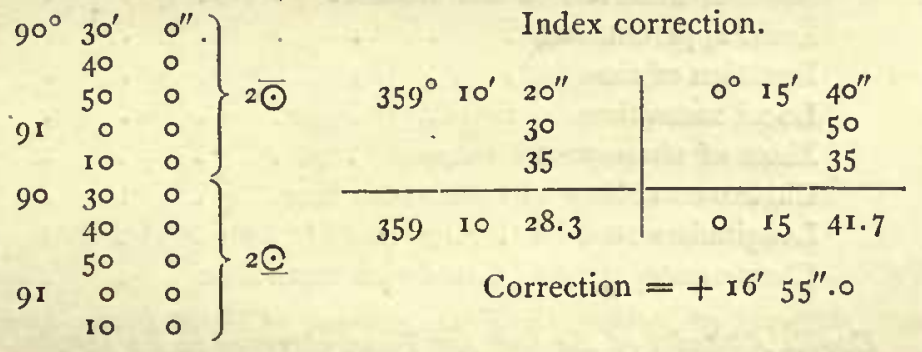

Correction $=+16^{\prime} 55^{\prime \prime} \cdot 0$
Ex. ther. $5^{\circ}$

Refraction $=-56^{\prime \prime} .9$

Parallax $=+6.1$

Mean of observed double altitudes

Local apparent time.

Equation of time
At. ther. $70^{\circ} \quad$ Bar. 30.04 inches.

Sun's declination - I $5^{\circ}$ I $4^{\prime}$ I $5^{\prime \prime} .6$

Latitude $\quad-53$ 10 20

- $90^{\circ} 50^{\prime} 0^{\prime \prime}$

- $10^{\mathrm{h}} \quad 2^{\mathrm{m}} \quad 2^{8} \cdot 2$

. $14 \quad 25 \cdot 5$ 
Local mean time . . . . . . . . . . $10^{\mathrm{h}} 16^{\mathrm{m}} 27^{\mathrm{s}} \cdot 7$

Mean of chronometer times . . . . . . . . 10339.6

Chronometer slow of local mean time . . . . $\quad 0 \quad$ I2 48.1

Longitude west . . . . . . . . . . 44435

Chronometer slow of Greenwich mean time $\begin{array}{lllll}4 & 4 & 2 & 23.4\end{array}$

Double Altitudes of the Sun for Time, observed near Valparaiso, Chile, March 2d, 1866.

$\begin{array}{lll}3^{\mathrm{h}} & 5^{\mathrm{m}} & 15^{\mathrm{s}} \cdot 5 \\ 50 & 39 \cdot 5 \\ 5^{\mathrm{I}} & 3 \\ 5^{\mathrm{I}} & 5^{1} \cdot 5 \\ 5^{2} & 5^{2} \\ 53 & 15 \cdot 5 \\ 53 & 39 \cdot 5 \\ 54 & 30\end{array}$

Ex. ther. $67^{\circ}$

Refraction $=-92^{\prime \prime} .4$

Parallax $=+7.4$

Mean of observed double altitudes

Local apparent time .

Equation of time

Local mean time . . .

Mean of chronometer times . .

Chronometer slow of local mean time

Longitude west

Chronometer slow of Greenwich mean time
Index correction.

\begin{tabular}{|c|c|c|c|c|c|}
\hline $359^{\circ}$ & $10^{\prime}$ & $\begin{array}{l}40^{\prime \prime} \\
45 \\
40\end{array}$ & $0^{\circ}$ & $15^{\prime}$ & $\begin{array}{l}0^{\prime \prime} \\
5 \\
10\end{array}$ \\
\hline 359 & Io & $4 \mathrm{I} \cdot 7$ & 0 & 15 & 5.0 \\
\hline
\end{tabular}

Bar.

Sun's declination - $7^{\circ} \quad \mathrm{x}^{\prime} \quad 53^{\prime \prime}$

Latitude $\quad-33 \quad$ I. 4

Double Altitudes of the Sun for Time, observed in Valparaiso, Chile, March 29th, 1866.

\begin{tabular}{|c|c|}
\hline $2^{\mathrm{h}} \quad 3^{6^{\mathrm{m}}}$ & $55^{8}$ \\
\hline 37 & 40 \\
\hline $3^{8}$ & 23 \\
\hline 40 & I. 5 \\
\hline 40 & $45 \cdot 5$ \\
\hline $4 \mathrm{I}$ & 28.5 \\
\hline
\end{tabular}

Ex. ther. $71^{\circ}$

Refraction $=-75^{\prime \prime} . \mathrm{I}$

Parallax $=+6.9$

Mean of observed double altitudes

Local apparent time.

Equation of time

Local mean time

Mean of chronometer times

Chronometer slow of local mean time.

Longitude west

Chronometer slow of Greenwich mean time

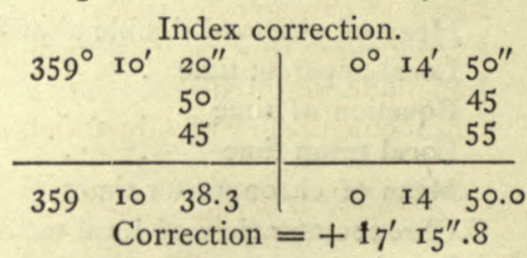

Bar. 30.23 inches.

Sun's declination $+3^{\circ} 3^{\prime} 3^{\prime \prime}$

$\begin{array}{llll}\text { Latitude } & -33 & \text { I } & 47\end{array}$

Double Altitudes of the Sun for Time, observed in Valparaiso, Chile, April 7 th, 1866.

$\left.\begin{array}{ccc|rrr}9^{\mathrm{h}} & 3^{6^{\mathrm{m}}} & 26^{\mathrm{s}} \cdot 5 & 77^{\circ} & 30^{\prime} & 0^{\prime \prime} \\ 37 & 16.5 & & 45 & 0 \\ 38 & 9 & 78 & 0 & 0 \\ 40 & 1.5 & 77 & 30 & 0 \\ 40 & 53 & & 45 & 0 \\ 4 \mathrm{I} & 44.5 & 78 & 0 & 0\end{array}\right\} 2$

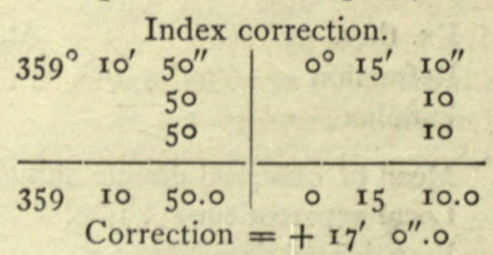


Ex. ther. $67^{\circ}$

Refraction $=-69^{\prime \prime} .8$

Parallax $=+6.7$
At. ther. $65^{\circ}$

Bar. 30.17 inches.

Sun's declination $+6^{\circ} 53^{\prime} 28^{\prime \prime} .6$

Latitude $\quad-33 \quad$ I 47

Mean of observed double altitudes . . . . . $77^{\circ} 45^{\prime} \mathrm{o}^{\prime \prime} . \circ$

Local apparent time . . . . . . . . $9^{\mathrm{h}} 46^{\mathrm{m}} 19^{8} .6$

Equation of time . . . . . . . . . . . . $\begin{array}{lllll} & 2 & 8.9\end{array}$

Local mean time . . . . . . . . 948 . 98.5

Mean of chronometer times . . . . . $\quad \begin{array}{lllll} & 9 & 39 & & 5.2\end{array}$

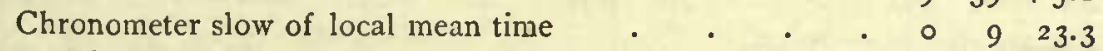

Longitude west . . . . . . . . . 44645

Chronometer slow of Greenwich mean time . . $\quad \begin{array}{lll}4 & 46 & 9\end{array}$

Double Altitudes of the Sun for Time, observed in Valparaiso, Chile, April jth, 1866.

$\begin{array}{ccc}9^{\mathrm{h}} & 43^{\mathrm{m}} & \mathrm{I} 5^{\mathrm{s}} \cdot 5 \\ 44 & 6.5 \\ 45 & 0.5 \\ 46 & 57 \\ 47 & 49.5 \\ 48 & 44.5\end{array}$

$\left.\begin{array}{rrr}79^{\circ} & 30^{\prime} & 0^{\prime \prime} \\ & 45 & 0 \\ 80 & 0 & 0 \\ 79 & 3 \circ & 0 \\ & 45 & 0 \\ 80 & 0 & 0\end{array}\right\} 2 \odot$

At. ther. $65^{\circ}$

Sun's declination $-6^{\circ} 53^{\prime} 35^{\prime \prime} .4$

Latitude
Index correction

$$
=+17^{\prime} \circ^{\prime \prime} . \circ
$$

Bar. 30.17 inches.

Ex. ther. $67^{\circ}$

Refraction $=-67^{\prime \prime} \cdot 3$

Parallax $=+6.6$

Mean of observed double altitudes

-33 I 47

Local apparent time .

Equation of time

Local mean time

$\cdot \begin{array}{lllllll}\cdot & \cdot & \cdot & 0 & 5522.8\end{array}$

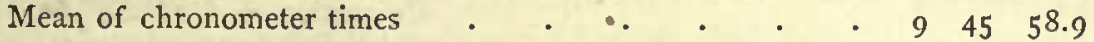

Chronometer slow of local mean time . . . . $\quad 0 \quad 923.9$

Longitude west . . $\quad . \quad$. . . . . 44645

Chronometer slow of Greenwich mean time . . $\quad \begin{array}{llll}4 & 4 & 46\end{array}$

Double Altitudes of the Sun for Time, observed in Valparaiso, Chile, April 14th, 1866.

$\begin{array}{ccc}3^{\mathrm{h}} & 50^{\mathrm{m}} & 20^{\mathrm{g}} \cdot 5 \\ 5 \mathrm{I} & \mathrm{I} \cdot 5 \\ 51 & 39 \\ 53 & 7 \\ 53 & 46 \\ 54 & 24 \cdot 5\end{array}$

Ex. ther. $65^{\circ}$

Refraction $=-170^{\prime \prime} \cdot 3$

Parallax $=+8.1$

$$
\left.\begin{array}{rrr}
3^{6^{\circ}} & 30^{\prime} & 0^{\prime \prime} \\
& 15 & 0 \\
3 & 0 & 0 \\
36 & 30 & 0 \\
& 15 & 0 \\
& 0 & 0
\end{array}\right\} 2 \odot
$$

Mean of observed double altitudes

At. ther. $66^{\circ} \quad$ Bar. 30.13 inches.

Sun's declination $+9^{\circ} 33^{\prime} 33^{\prime \prime} .6$

Latitude

-33 I 47

Local apparent time .

Equation of time

Local mean time

Mean of chronometer times . . . . . . $352^{23.1}$

Chronometer slow of local mean time . . . . O $\quad$ II 1.7

Longitude west . . . . . . . . . 44645

Chronometer slow of Greenwich mean time . $\quad$. $\quad 4 \quad 57 \quad 47.4$ 
Double Altitudes of the Sun for Time, observed on the Island of San Lorenzo, near Callao, Peru, April 26 th, 1866.

$\begin{array}{rrr}11^{\mathrm{h}} & 17^{\mathrm{mm}} & 45^{\mathrm{g}} \\ 18 & 5^{2} \\ 20 & 3 \\ 22 & 46 \\ 24 & 2 \\ 25 & 18\end{array}$

Ex. ther. $80^{\circ}$

Refraction $=-29^{\prime \prime} .2$.

Parallax $=+4.0$

Mean of observed double altitudes

Local apparent time.

Equation of time

Local mean time

Mean of chronometer times

Chronometer fast of local mean time .

Longitude west .

Chronometer slow of Greenwich mean time
Index correction.

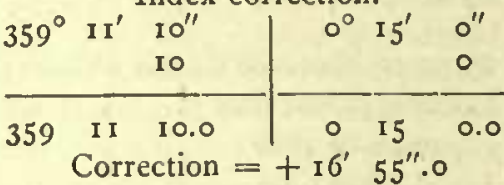

Bar.

Sun's declination $+13^{\circ} 35^{\prime} 18^{\prime \prime}$

Latitude

- I 25 I 4

Double Altitudes of the Sun for Time, observed at Payta, Peru, May 7 th, 1866.

$8^{\mathrm{h}} \quad 40^{\mathrm{m}} \quad 44^{\mathrm{m}} \cdot 5$

417.5

4 I 5 I

$\begin{array}{ll}43 & 1.5\end{array}$

$43 \quad 34.5$

$44 \quad 7 \cdot 5$

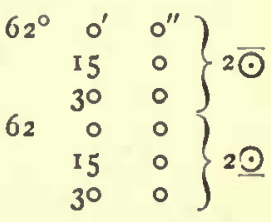

Index correction.

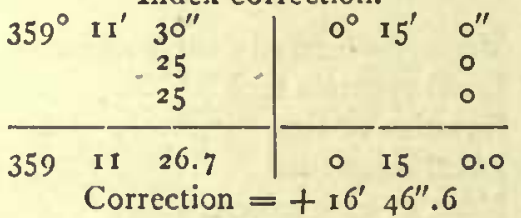

Ex. ther. $78^{\circ}$

Refraction $=-90^{\prime \prime} .7$

Parallax $=+7 \cdot 3$
At. ther. $80^{\circ}$

Sun's declination $+16^{\circ} 50^{\prime} 46^{\prime \prime}$

Latitude

$$
\text { - } 553^{6}
$$

Mean of observed double altitudes . . . . . $62^{\circ} 15^{\prime} 0^{\prime \prime} .0$

Local apparent time . . . . . . . . $8^{\mathrm{h}} 19^{\mathrm{m}} 22^{\mathrm{s}} \cdot 3$

Equation of time . . . . . . . . . $33^{8.1}$

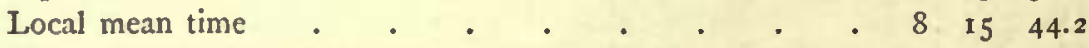

Mean of chronometer times . . . . . 842 26.I

Chronometer fast of local mean time. . . . . $\quad$. 264 I.9

Longitude west . . . . . . . . . 52422.0

Chronometer slow of Greenwich mcan time $\quad . \quad . \quad 4 \quad 5740.1$

Dubble Altitudes of the Sun for Time, observed on Flamenco Island, Panama Bay, May 14th, 1866.

$\begin{array}{cll}9^{\text {h }} & 24^{\mathrm{m}} & 59^{\circ} \\ 25 & 31 \\ 26 & 3 \cdot 5 \\ 27 & 12 \\ 27 & 43 \cdot 5 \\ 28 & 15\end{array}$

Ex. ther. $85^{\circ}$

Refraction $=-49^{\prime \prime} \cdot 5$

Parallax $=\dashv-5.7$
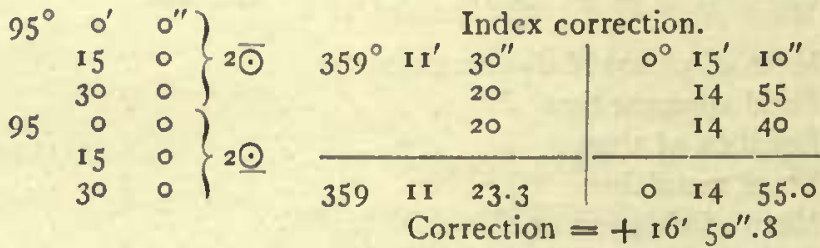

At. tner. $85^{n}$

Bar. 30.10 inches.

Sun's declination + $18^{\circ} 39^{\prime} 49^{\prime \prime}$

Latitude

$+85431$ 
Miean of observed double altitudes

Local apparent time .

Equation of time

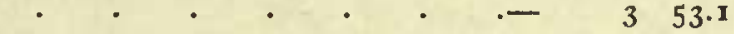

$\cdot \cdot \cdot \cdot \cdot 9620.4$

Mean of chronometer times . . . . . . 92637.3

Chronometer fast of local mean time . . . . . . $020 \begin{array}{lll} & 20 & 16.9\end{array}$

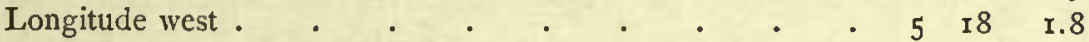

Chronometer slow of Greenwich mean time • . $\quad \begin{array}{llll} & 4 & 57 & 44.9\end{array}$

Double Altitudes of the Sun for Time, observed at Acapulco, Mexico, May 30 th, r 866.

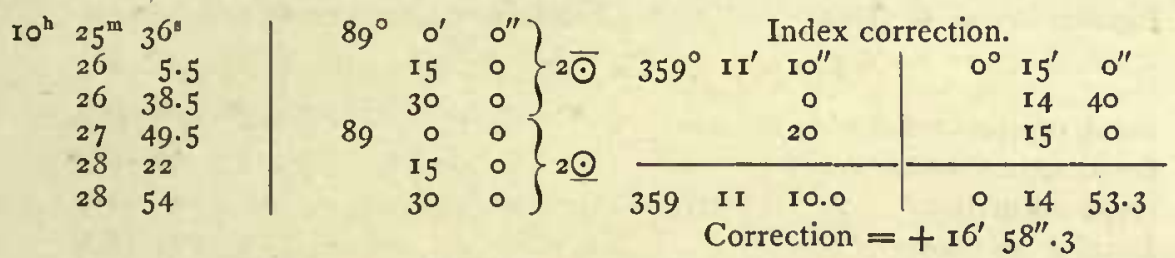

Ex. ther. $89^{\circ}$

Refraction $=-54^{\prime \prime} \cdot 5$

Parallax $=+6.0$
At. ther. $85^{\circ}$

Bar. 30. ro inches.

Mean of observed double altitudes

Sun's declination $+2 \mathrm{r}^{\circ} 48^{\prime} 7^{\prime \prime}$

Local apparent time.

Latitude

$+\mathrm{r} 6503$

Equation of time

Local mean time

Mean of chronometer times

Chronometer fast of local mean time.

Longitude west .

Chronometer slow of Greenwich mean time

$$
\begin{aligned}
& \text { - } 89^{\circ} 15^{\prime} 0^{\prime \prime} .0 \\
& \text { - } \quad 8^{\mathrm{h}} 48^{\mathrm{m}} 3^{8 \mathrm{~s}} \cdot 4 \\
& \text {. } \quad 246.4 \\
& \text { - } 84552.0 \\
& \text { - } 10 \quad 27 \quad 14.2 \\
& \text { - } I \text { II } 22.2 \\
& \text { - } 63929.4 \\
& \text { - } 45^{8} 7.2
\end{aligned}
$$

Double Altitudes of the Sun for Time, observed in Magdalena Bay, Lower California, June 8 th, 1866 .

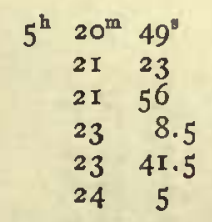

Ex. ther. $69^{\circ}$

Refraction $=-46^{\prime \prime} .4$

Parallax $=+5.4$

Mean of observed double altitudes

Local apparent time .

Equation of time

Lucal mean time

Mean of chronometer times

Chronometer fast of local mean time

Longitude west .

Chronometer slow of Greenwich mean time
Index correction.

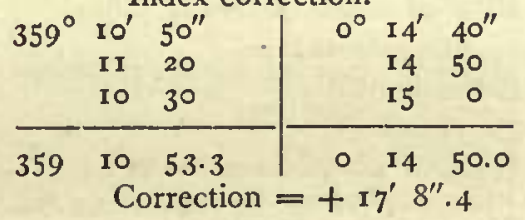

At. ther. $70^{\circ}$

Bar. 30.02 inches.

Sun's declination $+22^{\circ} 53^{\prime} 42^{\prime \prime}$

Latitude

$+243^{8}$ 
Double Altitudes of the Sun for Time, observed at La Playa, San Diego Bay, California, June $15^{\text {th }}, \mathbf{1} 866$.

$\begin{array}{lll}5^{\mathrm{h}} & 16^{\mathrm{m}} & 41^{\mathrm{s}} . \\ 17 & 16 \\ 17 & 5^{1} \cdot 5 \\ 19 & 10 \\ 19 & 46 \\ & \\ 20 & 21.5\end{array}$

Ex. ther. $71^{\circ}$

Refraction $=-37^{\prime \prime} \cdot 4$

Parallax $=+4.7$

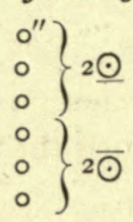

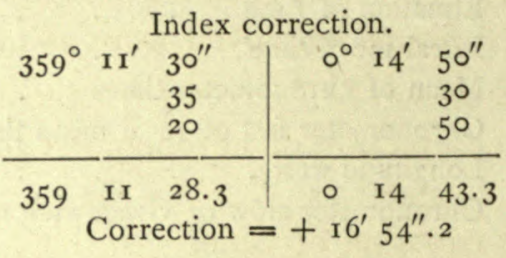

At. ther. $72^{\circ}$ Bar. 30.12 inches.
Sun's declination $+23^{\circ} 20^{\prime} \mathbf{2 2 ^ { \prime \prime }}$

Latitude $+3^{2} 4^{1} 5^{8}$

Mean of observed double altitudes . . . . . II $2^{\circ} 15^{\prime} 0^{\prime \prime} .0$

Local apparent time . . . . . . . . $2^{\mathrm{h}} 27^{\mathrm{m}} 47^{\mathrm{s}} \cdot 3$

Equation of time . . . . . . . . . . . . 0 II.3

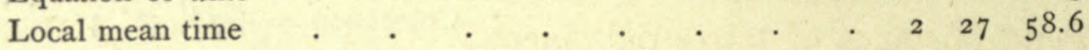

Mean of chronometer times . . . . . . . 5 I8 3 I.I

Chronometer fast of local mean time . . . . . $\quad 2 \quad 50 \quad 32.5$

Longitude west . . . . . . . . . . 74852

Chronometer slow of Greenwich mean time . . . $45^{8} 20 . \mathrm{I}$

Double Altitudes of the Sun for Time, observed on Yerba Buena Island, San Francisco Bay, California, June 26 th, 1866 .

$\begin{array}{lll}4^{\text {h }} & \text { 16m } & 40^{8} \cdot 5 \\ & \text { 17 } & 18 \\ 17 & 55 \cdot 5 \\ 19 & 18 \cdot 5 \\ 19 & 54 \cdot 5 \\ & 20 & 30\end{array}$

Ex. ther. $67^{\circ}$

Refraction $=-72^{\prime \prime} \cdot 5$

Parallax $=+6.6$

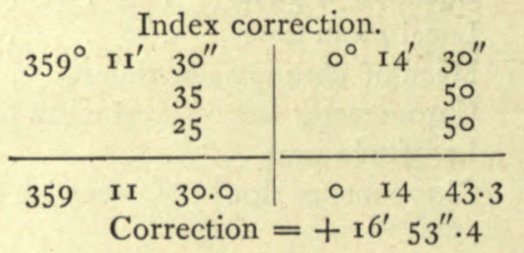

Bar.

At. ther.

Sun's declination $+23^{\circ} 22^{\prime \prime} 7^{\prime \prime}$

Latitude $\quad+374846$

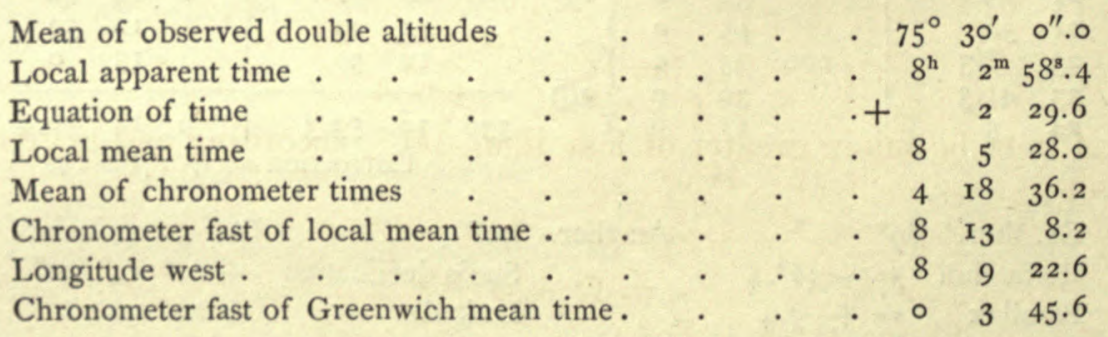

The chronometer used in making this observation was T. S. and J. D. Negus' No. I287.

True bearings were determined by measuring with a sextant the angle between the sun's limb and some well-defined terrestrial object, the time being noted at the instant the angle was observed. If the terrestrial object was much elevated above the horizon its angular altitude was also measured. Knowing the latitude of the place of observation, the local time, and the sun's declination, the sun's zenith distance and true bearing were calculated. Then, having the zenith distance of the sun, the zenith distance of the terrestrial object, and the measured angle between the sun and the terrestrial object, the horizontal angle between them 
was computed, and applying it to the sun's true bearing the true bearing of the terrestrial object at once became known.

The formulæ employed were as follows. Let

$T=$ mean of observed chronometer times.

$d t=$ correction of chronometer to reduce the reading of its face to local mean time.

$\tau=$ equation of time.

$t=$ sun's hour angle, or the apparent time.

$\Omega=$ mean of observed angular distances between the sun's limb and the terrestrial object.

$\omega=$ index correction of sextant.

$s=$ sun's semi-diameter.

$a=$ apparent zenith distance of sun's centre.

$b=$ zenith distance of terrestrial object.

$c=$ true angular distance between the sun's centre and the terrestrial object.

$C=$ horizontal angle included between the sun's centre and the terrestrial object.

$\phi=$ latitude of the place of observation.

$A=$ azimuth, or true bearing, of sun's centre.

$\zeta=$ true zenith distance of sun's centre.

$\delta=$ sun's declination.

$r=$ refraction due to apparent altitude of sun's limb.

$B=$ true bearing of terrestrial object.

Then we have

$$
\begin{aligned}
& t=T+d t+\tau \\
& \tan M=\frac{\tan \delta}{\cos t} \\
& \tan A=\frac{\tan t \cos M}{\sin (\phi-M)} \\
& \tan \zeta=\frac{\tan (\phi-M)}{\cos A}
\end{aligned}
$$

where $A$ is to be taken greater or less than $180^{\circ}$, according as $t$ is greater or less than $180^{\circ}$.

$$
\begin{aligned}
& a=\zeta-r \\
& c=\Omega+\omega+8
\end{aligned}
$$

If $b$ is exactly $90^{\circ}$, we have

$$
\cos C=\frac{\cos c}{\sin a}
$$

But if $b$ is either greater or less than $90^{\circ}$, we have

Finally

$$
\begin{gathered}
S=\frac{a+b+c}{2} \\
\tan \frac{1}{2} C=\sqrt{\frac{\sin (S-a) \sin (S-b)}{\sin S \sin (S-c)}}
\end{gathered}
$$

$$
B=A \pm C
$$


In a few instances true bearings were obtained by observing the sun when its apparent elevation above the horizon was equal to its diameter. In that case

and then

$$
\begin{gathered}
\zeta=90^{\circ} \\
\cos A=\frac{\sin \delta}{\cos \phi}
\end{gathered}
$$

in which the azimuth will be north or south of the prime vertical according as the sun's declination is north or south.

Observations of the Sun, made October $3^{1} 1 \mathrm{st}, 1865$, to determine the true bearing of the object used as an azimuth mark in swinging the ship at Hampton Roads, Va.

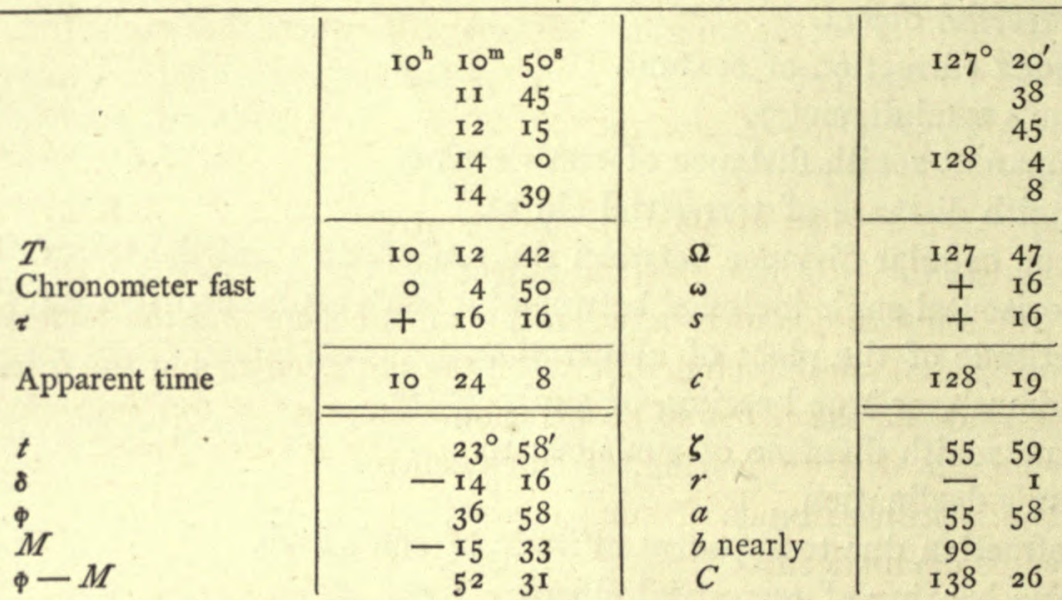

True bearing of sun .

S. $28^{\circ} 2 \mathrm{I}^{\prime} \mathrm{E}$.

$\angle$ Seminary to sun .

$\angle$ Seminary to Rip Raps.

$\angle$ Rip Raps to tree.

. . $\mathrm{r}_{3} 826$

$$
\cdot \dot{0} \cdot \dot{0}
$$

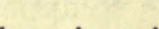

. . . . .6244

..$\quad \cdot \quad 11437$

True bearing of tree . . . . . . S. $1034 \mathrm{~W}$.

Observations of the Sun, made November 18 th, 1865 , to determine the true bearing of the object used as an azimuth mark in swinging the ship at St. Thomas, West Indies.

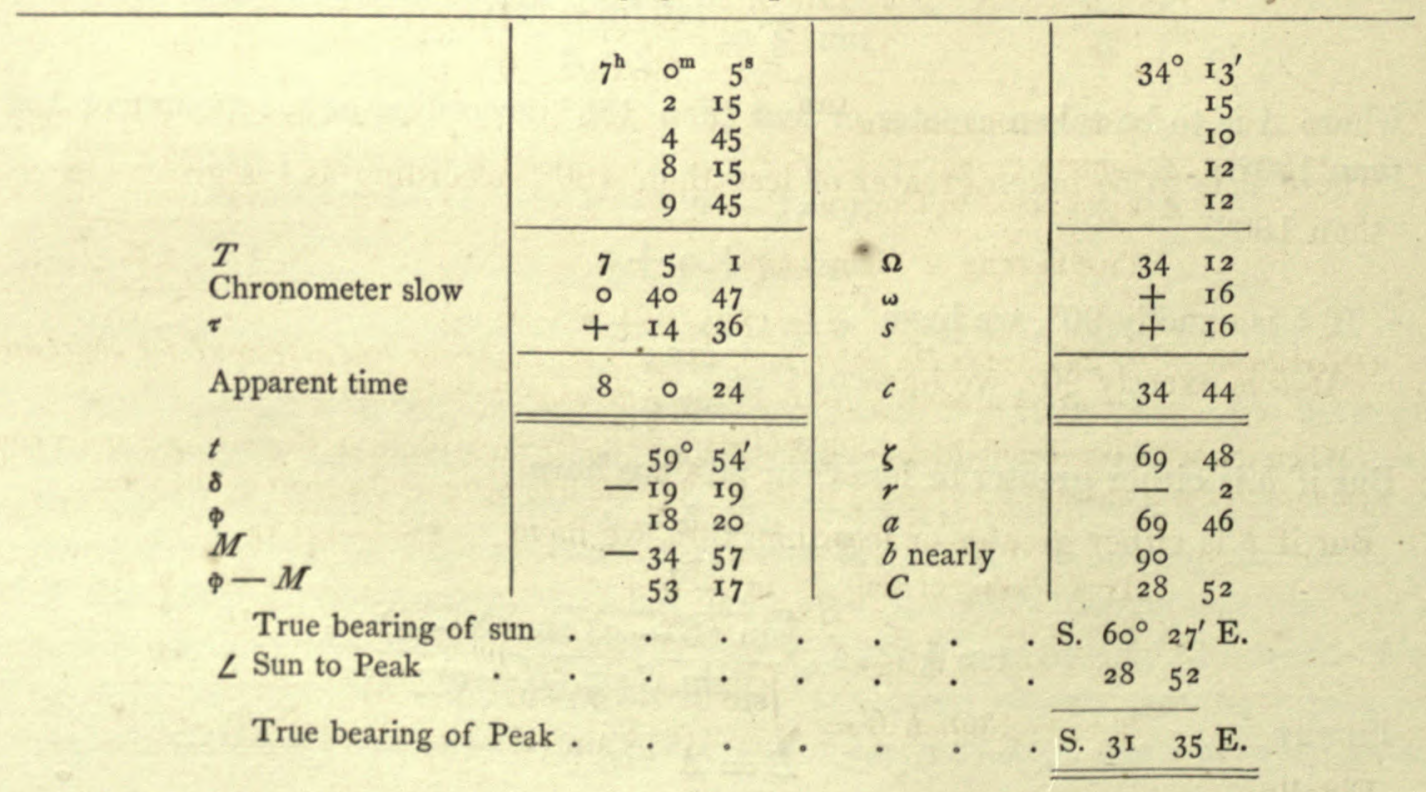


Observations of the Sun, made Novem. er 28 th, 1865, to determine the true bearing of the object used as an azimuth mark in swinging the ship at Isle Royal, Salute Islands.

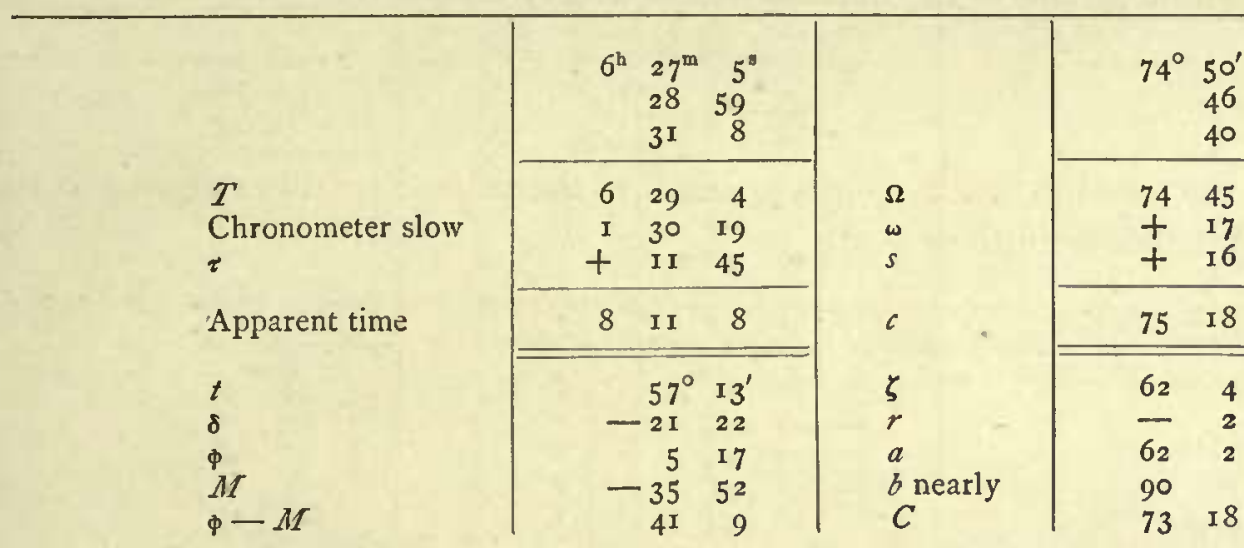

True bearing of sun . . . . . . S. $62^{\circ} 24^{\prime} \mathrm{E}$.

$\angle$ Sun to Nob

True bearing of Nob

- $73 \quad 18$

. S. $1054 \mathrm{~W}$.

Observations of the Sun, made December I 2 th, I865, to determine the true bearing of the object used as an azimuth mark in swinging the ship at Ceara; Brazil.

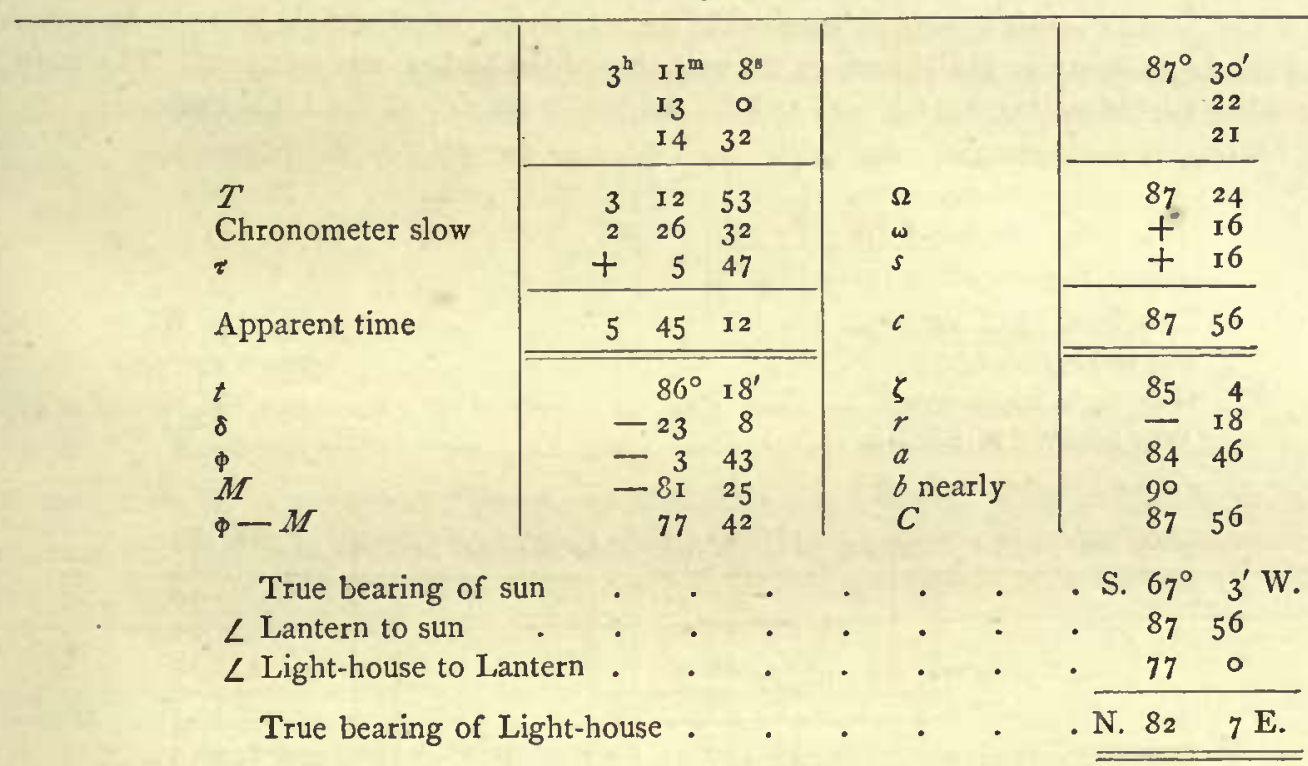

Observations of the Sun, made December 29th, 1865 ; to determine the true bearing of the object used as an azimuth mark in szoinging the ship at Bahia, Brazil.

When the sun's true zenith distance was about $90^{\circ}$, the angle between its nearest limb and a conspicuous tree was measured and found to be $31^{\circ} 38^{\prime}$, the tree being to the right of the sun.

$$
\phi=-12^{\circ} 59^{\prime} \quad \delta=-23^{\circ} \mathrm{I}^{\prime}
$$

True bearing of sun S. $66^{\circ} 9^{\prime} \mathrm{W}$.

$\angle$ Sun to tree . . . . . . . . . $313^{8}$

Sun's semi-diameter . . . . . . . . 016

True bearing of tree . . . . . N. $8157 \mathrm{~W}$. 
Observations of the Sun, made Jamuary 7 th, 1866 , to determine the true bearing of the object used as an azimuth mark in swinging the ship at Rio Janeiro, Brazil.

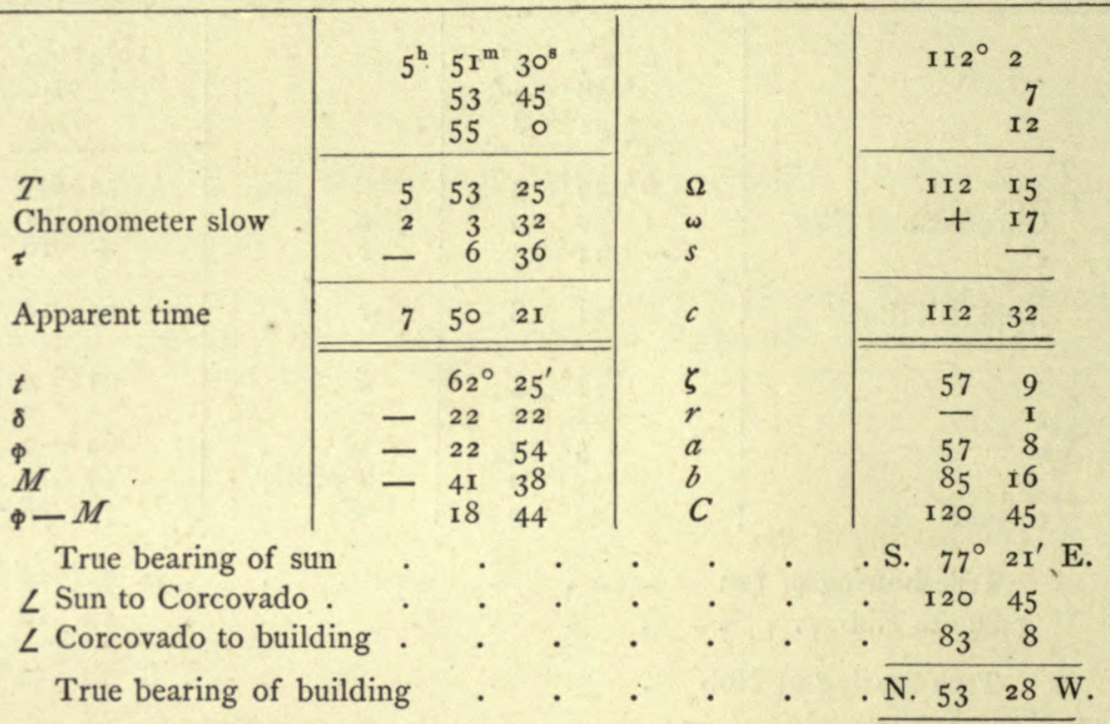

Observations of the Sun, made January $23 d$, 1866 , to determine the true bearing of the object used as an azimuth mark in swinging the ship at Monte Video, Uruguay.

Near sunset, when the true zenith distance of the sun was about $90^{\circ}$, the angle between its nearest limb and the Light-house on the Mount, on the west side of the harbor, was measured. The uncorrected reading of the sextant was $69^{\circ} 40^{\prime}$, and the sun was to the left of the Light-house.

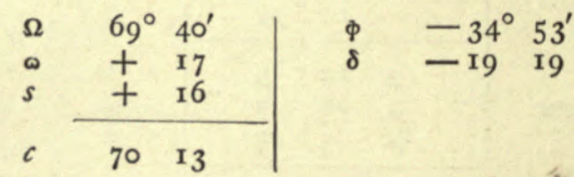

True bearing of sun . . . . . . S. $66^{\circ} 13^{\prime} \mathrm{W}$.

$\angle$ Sun to Light-house. $\quad . \quad+\quad . \quad . \quad . \quad . \quad . \quad 7013$

$\angle$ Hillock to Light-house . $\quad . \quad . \quad . \quad . \quad . \quad 348$

True bearing of hillock. . . . . . N. $77 \quad 5_{2}^{2} \mathrm{~W}$.

Observations of the Sun, made February 9 th, 1866, to determine the true bearing of the object used as an azimuth mark in swinging the ship at Sandy Point, in the Straits of Magellan.

\begin{tabular}{|c|c|c|c|}
\hline$\stackrel{7}{\text { Chronometer slow }}$ & $\begin{array}{l}9 \\
0\end{array}$ & $\begin{array}{l}15 \\
12\end{array}$ & $\begin{array}{l}19 \\
48\end{array}$ \\
\hline$\tau$ & - & 14 & $3 \circ$ \\
\hline Apparent time & 9 & ${ }^{1} 3$ & 37 \\
\hline$t$ & - & $4 \mathrm{I}^{\circ}$ & $36^{\prime}$ \\
\hline $\begin{array}{l}\delta \\
\phi\end{array}$ & - & 14 & 37 \\
\hline$M^{*}$ & $\overline{-}$ & $\begin{array}{l}53 \\
19\end{array}$ & $\begin{array}{l}\text { II } \\
\text { I4 }\end{array}$ \\
\hline$\phi-M$ & & 33 & 57 \\
\hline
\end{tabular}

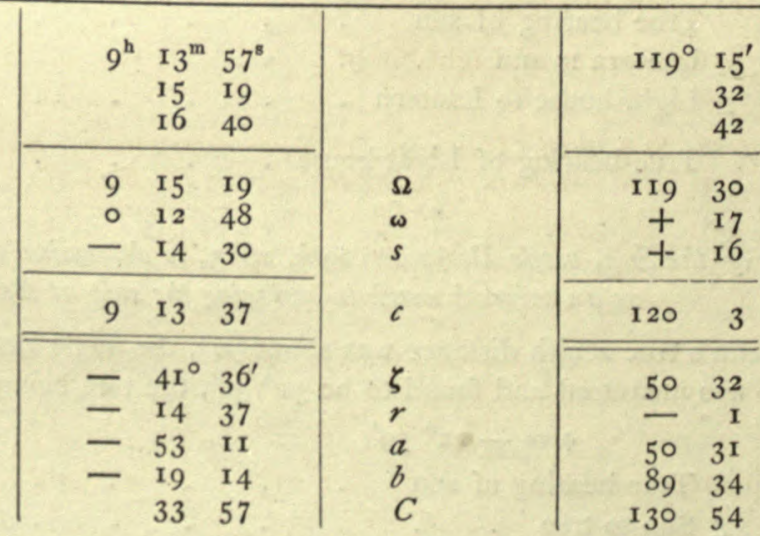

True bearing of sun

. N. $5^{6^{\circ}} 20^{\prime} \mathrm{E}$.

$\angle$ Mount St. Felipe to sun.

. $\frac{{ }^{1} 3054}{\text { S. } 7 \mathrm{I}_{4} \mathrm{~W}}$ 
Observations of the Sun, made April 2d, 1866, to determine the true bearing of the object used as an azimuth mark in swinging the ship at Valparaiso, Chile.

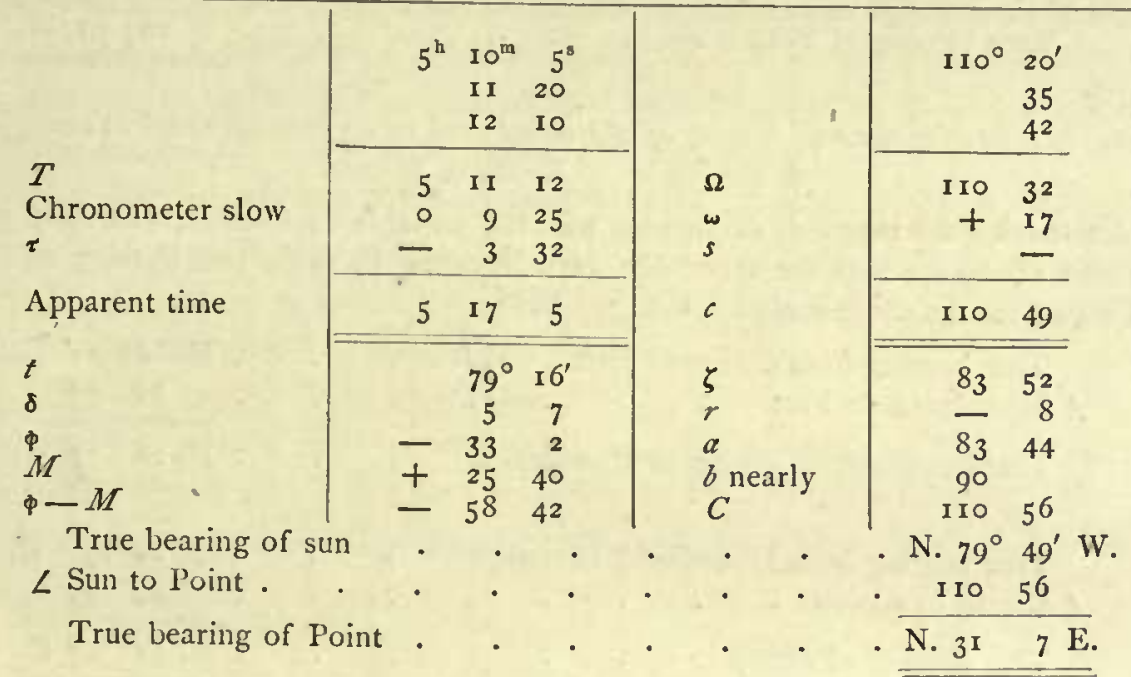

Observations of the Sun, made April 27th, 1866, to determine the true bearing of the object used as an azimuth mark in swinging the ship at Callao, Peru.

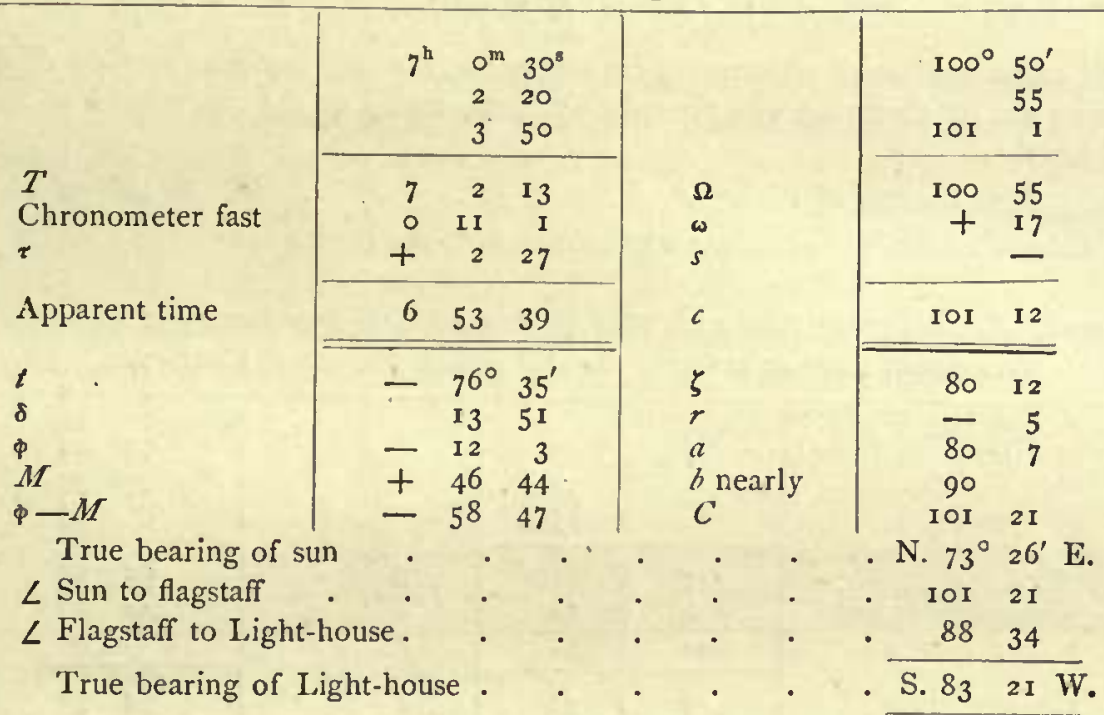

Observations of the Sun, made May I $3^{\text {th }}, \mathrm{I} 866$, to determine the true bearing of the object used as an azimuth mark in swinging the ship in Panama Bay, Nez' Granada.

\begin{tabular}{|c|c|c|c|c|c|c|}
\hline & & $\begin{array}{l}\text { I } 7^{\mathrm{m}} \\
\text { I } 8\end{array}$ & $\begin{array}{c}3^{8} \\
15\end{array}$ & & & $\begin{array}{l}5^{6^{\prime}} \\
5^{8}\end{array}$ \\
\hline $\begin{array}{l}T \\
\text { Chronometer fast } \\
\tau\end{array}$ & $\begin{array}{r}6 \\
0 \\
+\end{array}$ & $\begin{array}{r}17 \\
20 \\
3 \\
\end{array}$ & $\begin{array}{l}39 \\
17 \\
53 \\
\end{array}$ & $\begin{array}{l}\Omega \\
\omega \\
s\end{array}$ & $\begin{array}{l}86 \\
+ \\
\end{array}$ & $\begin{array}{l}57 \\
17 \\
-\end{array}$ \\
\hline Apparent time(P.M.) & 6 & I & 15 & $c$ & 87 & I 4 \\
\hline $\begin{array}{l}t \\
8 \\
\phi \\
M \\
\phi-M\end{array}$ & - & $\begin{array}{c}90^{\circ} \\
18 \\
8 \\
89 \\
80\end{array}$ & $\begin{array}{r}19^{\prime} \\
3 \mathbf{I} \\
55 \\
3 \\
8\end{array}$ & $\begin{array}{l}\zeta \\
r \\
a \\
b \text { nearly } \\
c\end{array}$ & $\begin{array}{l}\frac{86}{86} \\
90 \\
86\end{array}$ & $\begin{array}{l}54 \\
14 \\
40\end{array}$ \\
\hline
\end{tabular}




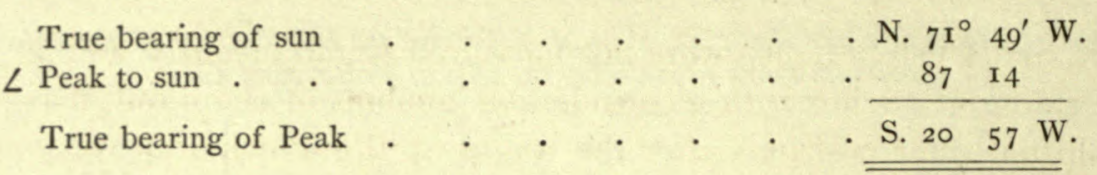

Observations to determine the true bearing of the object used as an azimuth mark in swinging the ship in the harbor of Acapulco, Mexico.

When determining the magnetic declination with the portable declinometer, on May 3 oth, I866, an observation of the sun with the theodolite gave N. $6^{\circ} 22^{\prime} \mathrm{E}$. as the true bearing of the gate of Fort St. Diego from the shore station. We then have

True bearing from station to Fort - . . . N. $6^{\circ} 22^{\prime} \mathrm{E}$.

$\angle$ Monadnock to Fort . . . . . . . $26 \quad 54$

True bearing from station to Monadnock . . N. $20 \quad 32 \mathrm{~W}$.

True bearing from Monadnock to station . . S. $20^{\circ} 32^{\prime} \mathrm{E}$.

$\angle$ Clump to station . . . . . . . . 8745

True bearing of clump . . . . . . N. $71 \quad 43$ E.

Observations of the Sun, made June 9 th, 1866, to determine the true bearing of the object used as an azimuth mark in swinging the ship in Magdalena Bay, Lower California.

Owing to a combination of unfortunate circumstances, the only available method of determining a true bearing was by observing with the solar compass, set up on the quarterdeck of the ship. In that way I found

True bearing of Peak . . . . . . S. $46^{\circ} 30^{\prime} \mathrm{E}$.

which can only be considered as a near approximation to the truth.

Observations of the Sun, made June ${ }_{2} 3^{d}$, 1866 , to determine the true bearing of the object used as an azimuth mark in swinging the ship at San Francisco, California.

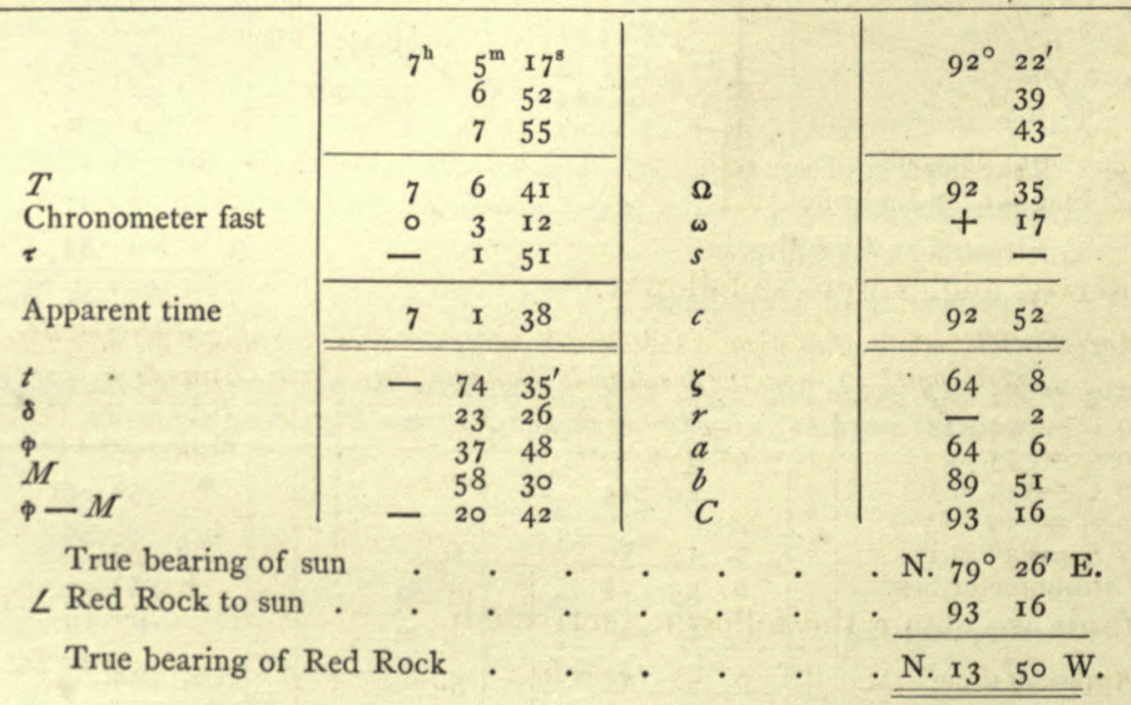

The following triangulation was made for the purpose of determining the geographical position of some points in and about Ceara, Brazil. The angles were observed on December 14th, 15th, and 16th, 1865. Those between the Powhattan, 
Monadnock, and Custom-house were not measured simultaneously, and as the two ships were riding at anchor with a considerable amount of chain out, it is probable that they shifted their positions after the angle at the Powhattan was measured, and before the angles at the Monadnock and Custom-house were taken. This will account for the excess of the sum of the three angles over $180^{\circ}$.

In the accompanying sketch the different points are designated as follows:

$A=$ Point Macoripie Light-house.

$B=$ Northeast corner of Custom-house on the wharf.

$C=\dot{U}$. S. Iron-clad Monadnock.

$D=\mathrm{U}$. S. Sloop of War Powhattan.

$E=$ most southern of the two steeples on the Church of the Conception.

$F=$ most southern of the two steeples on St. Joseph's Chureh.

$M=$ Magnetic and Astronomical Station of December 13th and 14th.

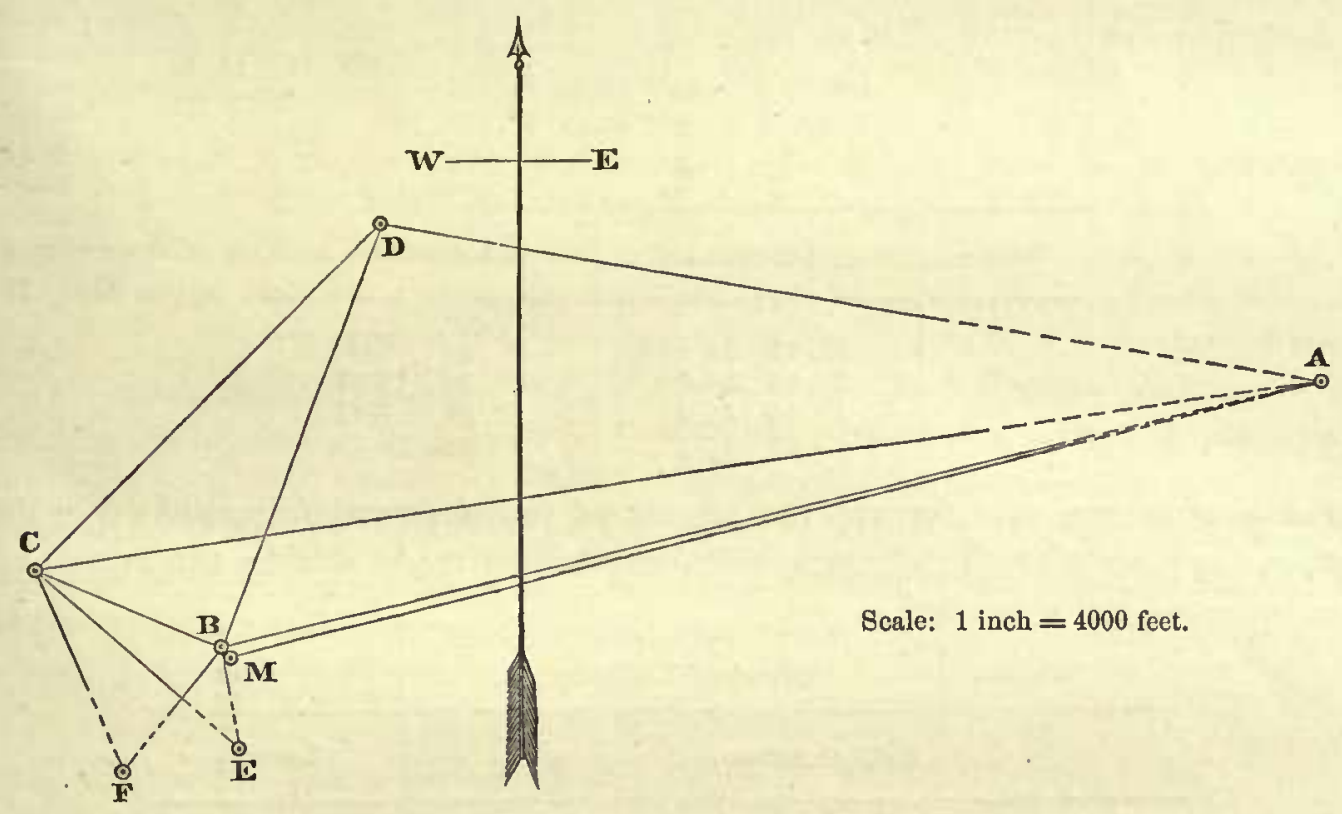

The observed angles were as follows:

\begin{tabular}{|c|c|c|c|}
\hline Angles at $B$. & & Angles at $C$. & Angles at $D$. \\
\hline$D$ to $A=55^{\circ}$ & $12^{\prime}$ & $D$ to $A=3^{6^{\circ}}$ & $A$ to $B=10 \mathrm{I}^{\circ}$ \\
\hline$D$ to $C=84$ & I 7 & $D$ to $B=71$ & $B$ to $C=25$ \\
\hline$F$ to $C=73$ & I 2 & $B$ to $F=42$ & $A$ to $C=126$ \\
\hline$E$ to $C=125$ & 6 & $B$ to $E=15$ & 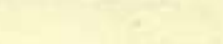 \\
\hline $\begin{array}{l}E \text { to } F=52 \\
A \text { to } E=95\end{array}$ & $\begin{array}{r}15 \\
6\end{array}$ & & \\
\hline
\end{tabular}

From these we obtain the following eorrected

Angles at $B$.

$A$ to $E=95^{\circ} \quad \mathrm{II}^{\prime}$

$E$ to $F=52 \quad 9$

$F$ to $C=73 \quad 14$

$C$ to $D=84 \quad 5$

$D$ to $A=55 \quad 2$ I

B March, 1872.
Angles at $C$.

$D$ to $B=70^{\circ} \quad 5^{8}$

$D$ to $A=3^{6} \quad 14$

$A$ to $B=34 \quad 44$

$B$ to $E=15 \quad 40$

Li to $F=26 \quad 48$
Angles at $D$.

$A$ tc $B=$ IOI $^{\circ} 3^{6}$

$B$ to $C=24 \quad 57$ 
The Powhattan fired a salute, and, from the mean of seven observations, the interval between the flash and report, noted at $B$, was 6.55 seconds. External thermometer $86^{\circ}$. Hence the distance from $B$ to $D$ was 7526 feet.

Distance from $B$ to $M=200$ feet.

Azimuth from $M$ to $A=\mathrm{N}$. $75^{\circ} 38^{\prime} \mathrm{E}$.

Angle $A M B=128^{\circ} 57^{\prime}$.

From these data we find the distances between the several points as follows:

\begin{tabular}{l|l|l}
$A D=15814$ feet. & $C E=4355$ feet. & $B E=1443$ feet. \\
$A C=21491$ " & $B C=3358$ " & $C D=7919$ " \\
$A B=18826$ " & $B F=2516 "$ & $C F=3568$ "
\end{tabular}

Angle $B A M=0^{\circ}{ }_{2} 8^{\prime} \quad \mid$ Angle $A M B={ }_{12} 8^{\circ} 57^{\prime} \quad$ | Angle $A B M=50^{\circ} 35^{\prime}$

Azimuth from $M$ to $A=\mathrm{N} .75^{\circ} 38^{\prime} \mathrm{E}$.

" " $B$ to $A=\mathrm{N} .76$ E. " 6 " $B$ to $F=\mathrm{S} .4326 \mathrm{~W}$.

Assuming the position of $M$ to be

we get finally

Lat. $3^{\circ} 43^{\prime} 59^{\prime \prime} . \circ \mathrm{S}$.

Long. $2^{\text {h }} \quad 34^{\mathrm{m}} 6^{\mathrm{s}} .00 \mathrm{~W}$.

\begin{tabular}{|c|c|c|c|c|c|c|}
\hline Station. & \multicolumn{3}{|c|}{ Latitude. } & \multicolumn{3}{|c|}{ Longitude. } \\
\hline$B$ & $3^{\circ}$ & $43^{\prime}$ & $57^{\prime \prime} .8 \mathrm{~S}$. & $2^{\mathrm{h}}$ & $34^{\mathrm{m}}$ & $6^{8} .11 \mathrm{~W}$. \\
\hline$E$ & 3 & 44 & 12.0 & 2 & 34 & 5.97 \\
\hline$F$ & 3 & 44 & I5.9 & 2 & 34 & 7.25 \\
\hline$A$ & 3 & 43 & 13.3 & 2 & 33 & 54.10 \\
\hline
\end{tabular}

For convenience of reference the results of the observations contained in this section, together with the chronometer comparisons made during the cruise, are here collected and appended.

Observed Latitudes.

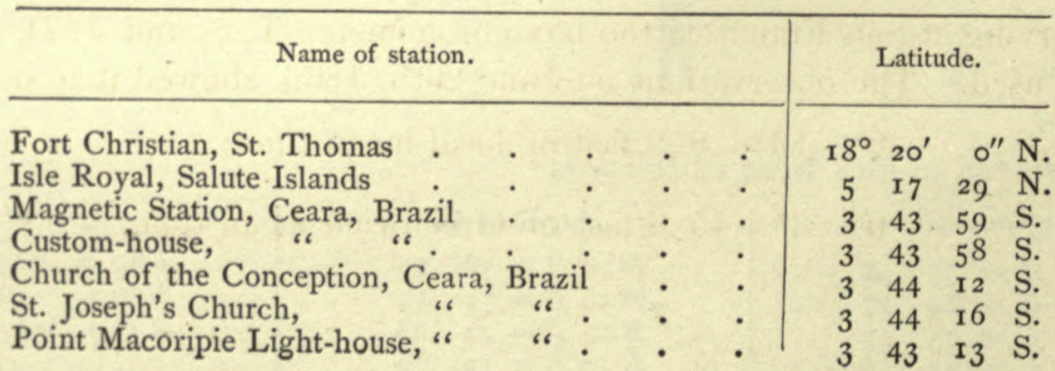


Errors of Pocket Chronometer, Fletcher, No. 906.

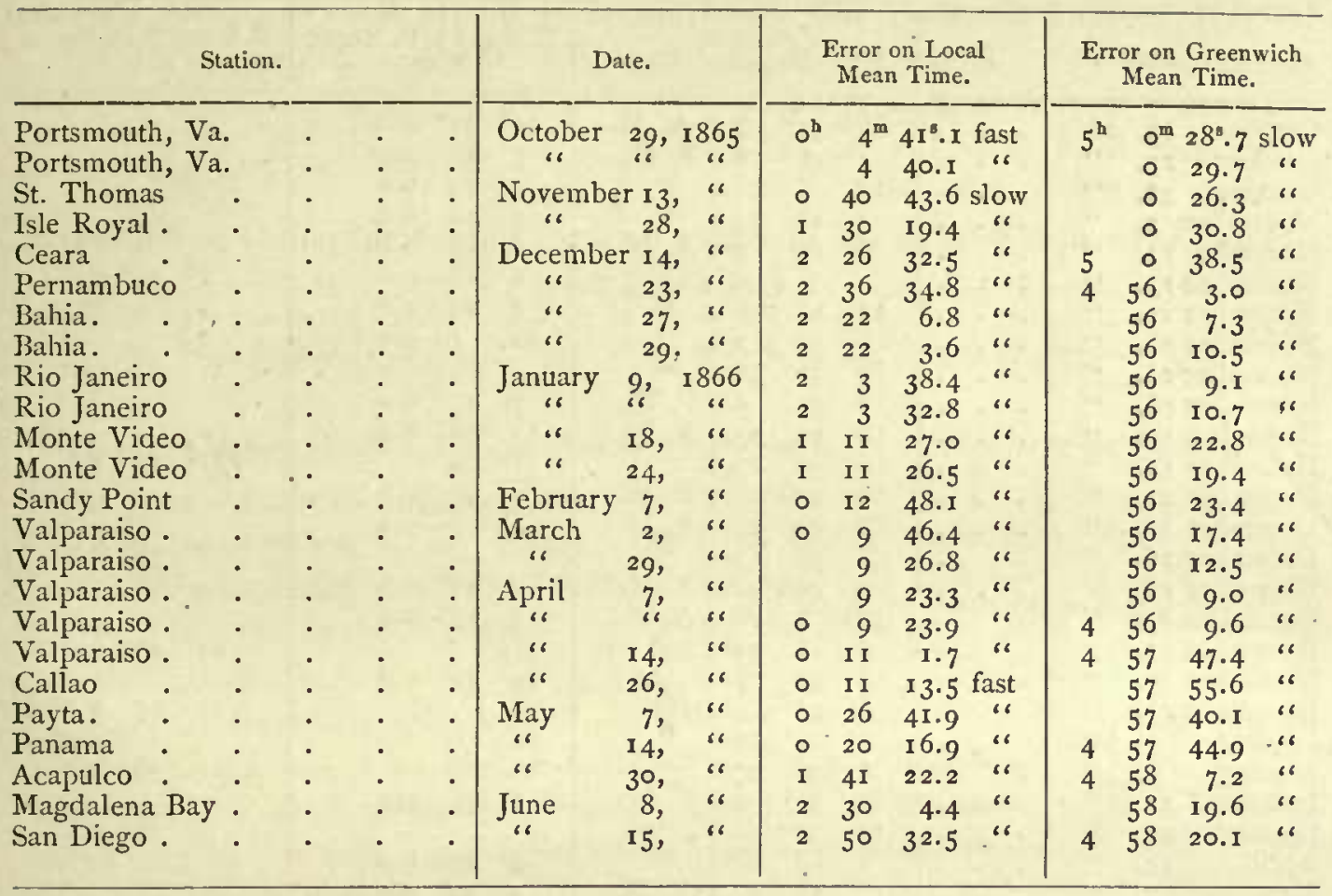

This chronometer (Fletcher, 906) was habitually carried in my pocket. It was aceidentally allowed to run down on the night of December 17th and 18th, 1865, and after remaining stopped twelve hours was wound and compared. Some time between $5^{\text {h }}$ P. M. of April 13th and $3^{\text {h }}$ P. M. of April 14th, 1866, it stopped for about $1^{\mathrm{m}} 37^{\mathrm{s}}$, but started again of itself. On June 20 th, 1866 , when its face showed $6^{\mathrm{h}} 45^{\mathrm{m}} \mathrm{P}$. M. it stopped without any apparent eause, and, as it would not xum again, it became useless.

In observing at San Francisco the box chronometer T. S. and J. D. Negus, No. 1287 was used. The observations on June 26 th, 1866 , showed it to be

and

$$
8^{\mathrm{h}} \cdot 13^{\mathrm{m}} \quad 8^{\mathrm{s}} .2 \text { fast of local mean time; }
$$

$0^{4} \quad 3^{\mathrm{m}} \quad 45^{\mathrm{s}} \cdot 6$ fist of Greenwich mean time. 
Chronometer Comparisons.

\begin{tabular}{|c|c|c|c|c|c|c|c|c|c|c|c|c|c|c|}
\hline \multicolumn{6}{|c|}{ Date. } & \multicolumn{3}{|c|}{$\begin{array}{l}\text { Fletcher, } \\
906 .\end{array}$} & \multicolumn{3}{|c|}{$\begin{array}{l}\text { T. S. and J. D. Negus, } \\
\text { I } 317 .\end{array}$} & \multicolumn{3}{|c|}{$\begin{array}{l}\text { T. S. and J. D. Negus, } \\
1287 \text {. }\end{array}$} \\
\hline October & 29 , & I 865 & . & . & . & $7^{\mathrm{h}}$ & $39^{\mathrm{m}}$ & $5^{6^{8} .8}$ A. M. & $12^{\mathrm{b}}$ & $44^{\mathrm{m}}$ & $0^{8} .0$ & & & \\
\hline October & 29 , & "6 & . & . & . & 2 & 28 & 56.० P. M. & 7 & 33 & 0.0 & 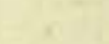 & & \\
\hline October & $3 \pi$ & "6 & . & . & . & I 2 & 8 & 48.2 6 & 5 & I3 & 0.0 & & & \\
\hline November & 3 & "6 & . & . & . & 4 & 17 & $33.0 \%$ & 9 & 22 & 0.0 & & & \\
\hline November & I 3 & " & . & . & . & 8 & $2 \mathrm{I}$ & 4.8 A. M. & I & 26 & 0.0 & & & \\
\hline November & I3, & 6 & . & . & . & & . & ... & I & 28 & 0.0 & $I^{b}$ & $16^{\mathrm{m}}$ & $23^{3} \cdot 5$ \\
\hline November & I 7 , & "6 & - & . & . & I 2 & 18 & $46.0 " 6$ & 5 & 24 & 0.0 & & & \\
\hline November & 28 & 66 & . & . & & 6 & 55 & 10.8 & 12 & I & 0.0 & & & \\
\hline November & 28 & $" 6$ & - & . & . & 6 & 56 & 56.8 & - & . & & I I & 50 & 0.0 \\
\hline November & 28 & "6 & . & . & . & 2 & 39 & 9.8 P. M. & 7 & 45 & 0.0 & & & \\
\hline December & 14 , & “ & . & . & . & 6 & 29 & $23.0 \mathrm{~A} . \mathrm{M}$. & I I & $3^{6}$ & 0.0 & & & \\
\hline December & I 4 & “" & . & . & . & 6 & 30 & 19.8 & . & $\therefore$ & & I I & 25 & 0.0 \\
\hline December & I 4 , & $66^{\circ}$ & . & . & . & 12 & 43 & 22.5 P. M. & 5 & 50 & 0.0 & & & \\
\hline December & 16 , & $" 6$ & . & . & . & 8 & 54 & $16.0 \mathrm{~A} . \mathrm{M}$. & 2 & I & 0.0 & & & \\
\hline December & 16 & 66 & . & . & . & 8 & $5^{6}$ & I $5.2 \%$ & . . & . . & & $\mathbf{I}$ & $5 I$ & 0.0 \\
\hline December & I 8 & 18 & - & . & . & 9 & 44 & 42.8 P. M. & 2 & 47 & 0.0 & & & \\
\hline December & 23 & 66 & - & . & & 8 & 7 & $28.0 \mathrm{~A} . \mathrm{M}$. & $\mathbf{I}$ & 10 & 0.0 & & & \\
\hline December & 23 & " & . & . & & 8 & 8 & 32.5 & . . & . . & & I 2 & 59 & 0.0 \\
\hline December & 29, & 66 & - & . & . & 6 & 22 & 59.2 & I I & 26 & 0.0 & & & \\
\hline December & 29 & " & . & . & . & 6 & 24 & 9.06 & . & . & & I I & 15 & 0.0 \\
\hline January & 9 , & 1866 & . & . & . & 6 & 46 & 21.8 & I I & 50 & 0.0 & & -3 & \\
\hline January & 9 , & 16 & . & . & . & 6 & 46 & $43.2 "$ & . &. & & I I & $3^{8}$ & 0.0 \\
\hline January & 24, & 6 & . & . & 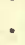 & 12 & $4 I$ & 4.0 P. M. & 5 & 46 & 0.0 & & & \\
\hline January & 24, & $" r$ & - & - & . & 12 & $4 I$ & 50.8 & $\cdot \cdot$ & $\therefore$ & & 5 & 34 & 0.0 \\
\hline April & 14, & $\because$ & . & . & • & 4 & I 6 & 24.4 & 9 & 29 & 0.0 & & & \\
\hline May & 7 & $" 6$ & . & - & & I I & 34 & 26.4 A. M. & 4 & 49 & 0.0 & & & \\
\hline May & I 4 , & "6 & • & - & & 12 & 2 & 49.6 P. M. & 5 & I 8 & 0.0 & & & \\
\hline May & 30 , & 66 & • & - & . & I I & 55 & I3.2 A. M. & 5 & 12 & 0.0 & & & \\
\hline June & 8 , & $"$ & • & . & & 6 & 28 & 24.8 P. M. & I I & 46 & 0.0 & & & \\
\hline June & I5, & $" 6$ & & - & 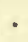 & I 2 & 0 & 46.8 A. M. & 5 & I9 & 0.0 & & & \\
\hline June & 26 , & " & . & . & . & & . . & •. . & 6 & 34 & 0.0 P.M. & 6 & I 7 & 0.2 \\
\hline
\end{tabular}

Table showing the True Bearings of the various objects used as azimuth marks in stoinging the U.S. Iron-clad Monadnock during her cruise from Philadelphia to San Francisco in 1865 and 1866.

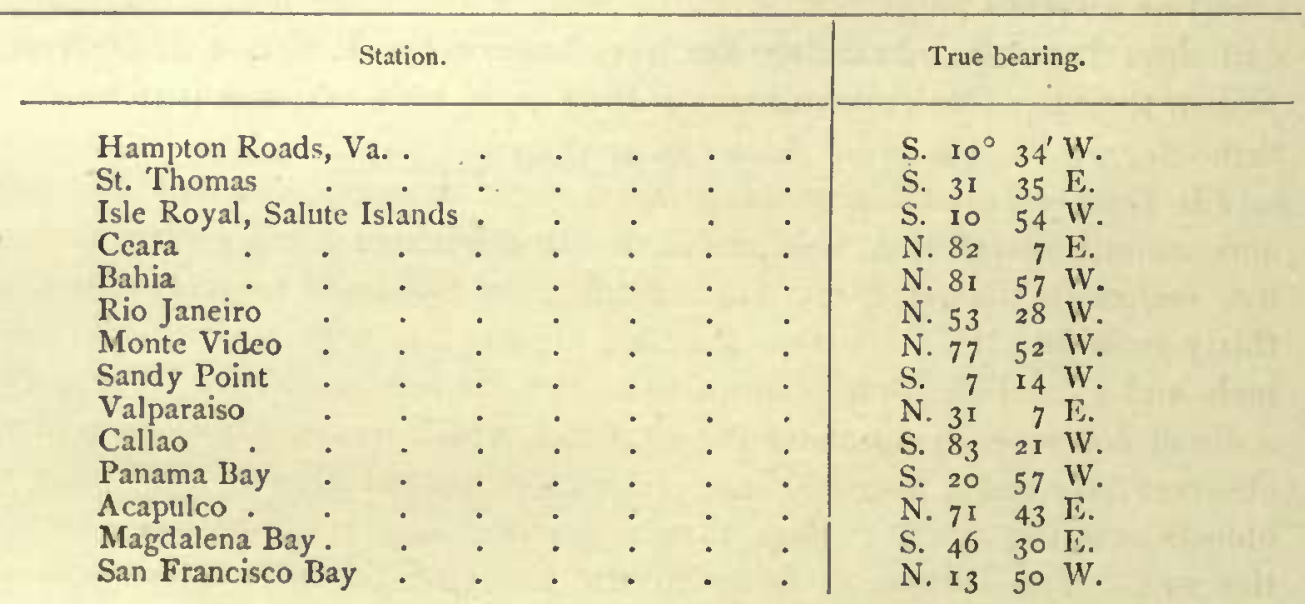




\section{SECTION IV.}

OBSERVATIONS ON TERRESTRIAL MAGNETISM.

THE observations of magnetic declination and force were made by means of the same instruments-a portable declinometer, and a transit theodolite.

The Declinometer, kindly lent by the U.S. Coast Survey, and marked D. 22, was originally constructed by Jones, of London, but had been altered in many particulars so as to make it more convenient for field use. It was provided with two collinator magnets which were hollow cylinders of steel, each 0.70 of an inch in external diameter, and 0.58 of an inch in internal diameter. One of them, marked C. 32 , was 3.92 inches long; while the other, marked S. 8, was 3.25 inches long. Each of these magnets carried in its south end a lens; and in its north end, at the solar focus of the lens just mentioned, a piece of plane glass on which was cut a scale of equal parts containing one hundred and seventy divisions, each division being equal to 0.00255 of an inch. Both magnets were provided witl light sliding brass rings which were intended to be used for keeping them horizontal under great changes of magnetic declination, but the slight play which the magnets had in the stirrup was found quite sufficient for that purpose, and the rings were never employed. The same suspension was used during the whole of the observations. It consisted originally of six parallel fibres of unspun silk, each about nine inches long; but at Callao one of the fibres was accidentally broken, and after that the remaining five were used. The torsion circle, which formed part of the suspension apparatus, was 0.88 of an inch in diameter, divided to every three degrees, and read by means of a vernier to single degrees.

The Transit Theodolite, which perhaps might be more correctly called an altitude and azimuth instrument, was provided with a horizontal and a vertical circle, each five inches in diameter, and each reading by means of two opposite verniers to thirty seconds. The telescope had an object-glass with a clear aperture of one inch, and a focal length of about nine inches. It was provided with two eye-pieces; a direct one magnifying about twenty times, which was employed in almost all the observations; and a diagonal one of lower power, which was sometimes used for objects near the zenith. Both these eye-pieces had colored glasses for observing the sun. The system of wires in the focus of the object-glass was a simple rectangular cross, one wire being vertical, the other horizontal.

For the sake of convenience in setting up the instruments, and also for the perfect security which it affords against changes in the angular value of the divisions of the magnet scales depending upon changes in the distance between them and 
the telescope, a special table was provided, which was mounted upon a tripod stand, and which carried both the declinometer and theodolite in a fixed and invariable position relatively to each other-the object-glass of the telescope being about three inches from the south end of the magnet.

Pocket Chronometer, Fletcher, No. 906, was always used to note time. Its errors have been already given in detail in Section III.

General remarlis on the method of using the instruments. When observations were to be made the tripod stand was set up, and the table, having been placed upon it, was approximately levelled by the eye, and set, by means of a pocket compass, so that its longest side was nearly in the magnetic meridian, the end destined to carry the declinometer being to the north. In packing the declinometer for travelling, the glass suspension tube was never unscrewed from the magnet-box, but when the collimator magnet was lifted from the stirrup a cylinder of wood of the same size was at once substituted, and two pieces of wood, provided for the purpose, were slipped in, one from each side of the magnet-box. 'These pieces of wood completely filled up the box, and at the same time held the wooden cylinder securely between them in such a manner that it could neither break the suspension fibres, nor allow them to twist in the slightest. With this packing, after the suspension fibres were once thorouglily freed from torsion, they remained so, and it was not necessary to examine them whenever the instrument was used, but only at considerable intervals, thus saving much time in the field. The brass carriers for the deflecting magnet having been screwed, one on each end of the wooden bar, and the bar in its turn having been screwed to the bottom of the inagnet-box, the declinometer was placed upon the table in such a position that its three levelling screws fitted into the cavities provided for their reception. 'Then the packing blocks were taken out of the magnet-box, and the wooden cylinder laving been removed from the stirrup, the collimator magnet was put in its place, and left free to assume its proper direction. 'The magnet-box was next levelled. For that purpose the suspension fibres were used as a plumb line, and the box was assumed to be level when they were seen to hang in the axis of the suspension tube throughout its whole length. Finally, the magnet was made to hang nearly level by moving it a little endwise in its stirrup; its scale was placed horizontal, with the figures erect; it was shaded from the direct rays of the sun by covering the glass top of the box; the mirror was screwed to the back of the box and adjusted so as to illuminate the magnet seale properly; and a thermometer was placed inside the magnet-box. The theodolite was next placed in its proper position on the other end of the table and levelled; particular care being taken that the horizontal axis of the telescope was truly level-especially if the altitude of the sun was considerable. The telescope having been turned towards the magnet and adjusted so as to obtain distinct vision of its scale, the hori\%ontal circle was firmly clamped in such a position that the vertical wire in the ficld of the telescope cut the magnet scale as nearly as possible at the magnetic axis. By means of the vertical circle the optical axis of the telescope was then placed truly level, and the final adjustment of the magnet for horizontality was 
made by shifting it endwise in its stirrup till the scale was seen in the field of the telescope parallel to, and just in contact with, the horizontal wire.

When making my first observations considerable difficulty was experienced in getting a proper illumination of the magnet scale, but after some practice the following perfectly satisfactory plan was adopted. In cloudy weather the light of a white cloud was reflected into the magnet by means of the concave mirror. In clear weather the light of the blue sky, reflected from the mirror, was not sufficient, and it would not do to throw in the direct rays of the sun because of their heating power, which would certainly have led to the use of a wrong value of the magnetic moment; because the magnet would have been at a higher temperature than that shown by the thermometer in the box.' Under these circumstances, in place of the mirror a piece of perfectly white paper was substituted, and the direct rays of the sun being allowed to fall upon it, it afforded a beautiful illumination of the magnet scale.

'The copper damper, provided to slip into the magnet-box for the purpose of quieting the vibrations of the magnet, was never used. As the observations were all made in the open air, and as there was frequently wind enongh to canse the instruments to vibrate perceptibly, the magnets seldom or never came to a state of absolute rest. Hence, the plan adopted to secure accurate readings of the scales was as follows. A screw-driver was slightly magnetized, and by approaching its south pole for an instant towards the south pole of the vibrating magnet, at a time when the magnet was moving towards the sclew-driver, the arc of vibration was readily made quite small. Then, placing my eye to the telescope, I read off, and called out to my assistant, the scale reading at the instant the magnet attained the limit of its excursion in the eastern direction, and again when it attained the limit in a western direction-in other words, the greatest and least readings of the scale were noted. Five complete vibrations were generally observed, thus giving three eastern and three western readings, and the mean of the six was assumed to be the reading which would have been obtained if the magnet had been in a state of perfect rest.

In order to preserve the magnetism of the collimator magnets, they were always packed in a vertical position, with that pole downwards which would be lowest in a dipping needle.

Absolute Declinations were observed as follows: The instruments having been set up and adjusted in the manner already explained, the long magnet, C. 32, was suspended in the magnet-box, the telescope pointed nearly to its magnetic axis, and the horizontal circle of the theodolite firmly clamped. Then, $1^{\circ}$. The horizontal limb of the theodolite was read. $2^{\circ}$. The magnet scale being erect-that is, the figures upon it being right side up-the point upon it cut by the vertical wire of the telescope was observed. $3^{\circ}$. The telescope remaining as before, the magnet scale was inverted-that is, the magnet was turned on its axis through $180^{\circ}$, so that the figures upon its scale were seen inverted-and the point upon it cut by the vertical wire was again noted. $4^{\circ}$. The horizontal circle-was unclamped, a colored glass placed upon the eye-piece, and the telescope pointed so that its vertical wire was just in advance of the first limb of the sun. Then the horizontal circle 
was clamped, the time of transit of the sun's first limb over the vertical wire noted, and the horizontal circle read. $5^{\circ}$. If the observation was made at a time of day when the sun's azimuth was changing tolerably rapidly, the telescope was not mored in azimuth at all, but, the reading of the horizontal circle remaining precisely as before, the sun was followed by moving the telescope in altitude, and the transit of its second limb was waited for and noted. If, however, the sun was changing its altitude much more rapidly than its azimuth then, in order to save time, the horizontal circle was unclamped, the telescope moved till its vertical wire was just in advance of the sun's second limb, the horizontal circle clamped, the time of transit of the sun's second limb over the vertical wire noted, and the horizontal circle read. $6^{\circ}$. 'The telescope of the theodolite was reversed in its Y's. $7^{\circ}$. 'The transit of the sun's first limb orer the vertical wire was observed, and the horizontal circle read. $8^{\circ}$. 'The transit of the sun's second limb over the vertical wire was observed, and the horizontal circle read. $9^{\circ}$. 'The colored glass was removed from the eyc-piece of the telescope, and a reading of the magnet scale (which was still inverted) was taken. $10^{\circ}$. The magnet was revolved on its axis through $180^{\circ}$, so as to place the scale erect, and another reading of the scale wis taken. $11^{\circ}$. 'The horizontal cirele was read.

Immediately before, and immediately after, going through with the operations just described, the telescope should be pointed to some well-defined distant object, and the reading of the horizontal circle noted. By so doing a check is afforded against any accidental shift of the horizontal circle; and if the same station is occupied at another time, absolute declinations may be determined without again referring to the sun, thus rendering it possible to observe during cloudy weather.

In the instruments under consideration the reading of the horizontal circle of the theodolite increases from left to right; and in both the magnets, C. 32 and S. 8 , when the scale is erect an increase of scale reading indicates a motion of the north end of the magnet towards the cast.

Let

$\rho=$ reading of magnet, scale erect.

$\rho^{\prime}=$ reading of magnet, seale inverted.

$R^{\prime}=$ reading of horizontal circle of theodolite at the time the readings $\rho$ and $\rho^{\prime}$. were observed.

$d=$ value, in minutes of arc, of one division of the magnet scale.

$R^{\prime \prime}=$ reading of horizontal circle of the theodolite at the time of transit of sun's first limb over the vertical wire.

$R^{\prime \prime}=$ reading of horizontal circle of the theodolite at the time of transit of sun's second limb orer the vertical wire.

$a=$ observed chronometer time of transit of sun's first limb over the vertical wire.

$a^{\prime}=$ observed chronometer time of transit of sun's second limb orer the vertical wire.

$\imath=$ correction of chronometer to reduce the reading of its face to local mean time.

$\tau=$ equation of time. 
$t=$ the sun's hour angle at the pole.

$\phi=$ latitude of the place of observation; positive when north of the equator.

$A=$ azimuth of sun's centre at the time of its transit over the vertical wire: the azimuth being counted from the south around by the west.

$\delta=$ sun's declination; positive when north.

Then we have

$$
\begin{aligned}
& t=\frac{\alpha+\alpha^{\prime}}{2}+d t+\tau \\
& \tan M=\frac{\tan \delta}{\cos t} \\
& \tan A=\frac{\tan t \cos M}{\sin (\phi-M)}
\end{aligned}
$$

where $A$ is to be taken greater or less than $180^{\circ}$ according as $t$ is greater or less than $180^{\circ}$.

$$
\text { Magnetie declination }=R^{\prime}+\frac{d}{2}\left(\rho-\rho^{\prime}\right)+A-180^{\circ}-\frac{R^{\prime \prime}+R^{\prime \prime}}{2}
$$

in which the declination is east if its sign is positive; west if its sign is negative.

The reading of the magnetic axis of the magnet is

$$
\frac{1}{2}\left(\rho+\rho^{\prime}\right)
$$

which we will designate by $c$. It should be constant. Then, if at any station the magnet has only been observed with its scale erect, if $c$ is known the observation may be reduced by the formula

$$
\text { Magnetic declination }=R^{\prime}+d(\rho-c)+A-180^{\circ}-\frac{R^{\prime \prime}+R^{\prime \prime}}{2}
$$

\begin{tabular}{|c|c|c|c|c|c|}
\hline & \multicolumn{3}{|c|}{ Circle readings. } & \multicolumn{2}{|c|}{ Reading of magnet. } \\
\hline \multirow{5}{*}{ 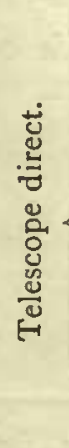 } & \multirow{3}{*}{\multicolumn{2}{|c|}{ Vernier }} & \multirow[t]{3}{*}{$12^{\circ} 23^{\prime} 30^{\prime \prime}$} & \multirow{2}{*}{$\begin{array}{l}\text { (I) Scale erect } \\
\text { (2) Scale inverted } \\
\text { (1) }-(2)=\Delta\end{array}$} & $\begin{array}{l}78^{d} . \circ \\
80.3\end{array}$ \\
\hline & & & & & -2.3 \\
\hline & & & & \multicolumn{2}{|c|}{ Transit of sun's } \\
\hline & $\begin{array}{l}\text { Vernier } \\
\text { Vernier }\end{array}$ & : $:$ & $\begin{array}{lll}75^{\circ} & 25^{\prime} & 3^{\prime \prime \prime} \\
74 & 55 & 3^{\circ}\end{array}$ & \multirow{2}{*}{$\begin{array}{l}\text { Ist } \operatorname{limb} \\
\text { 2d } \operatorname{limb} b \\
\text { Mean }\end{array}$} & $\begin{array}{lll}8^{\mathrm{h}} & 14^{\mathrm{m}} & 28^{\mathrm{s}} \\
& 15 & 28 \\
& 28\end{array}$ \\
\hline & Mean . & . . & 75 I0 30 & & $\begin{array}{lll}8 & 14 & 58.0\end{array}$ \\
\hline
\end{tabular}

The following example shows fully the form employed in recording and reducing the observations.

\section{Magnetic Declination.}

Station, Acapulco, Mexico. Date, May 30, 1866. Portable Declinometer, D. 22. Magnet C. 32. Observer, WM. HARKNESS.

6 March, 1872. 


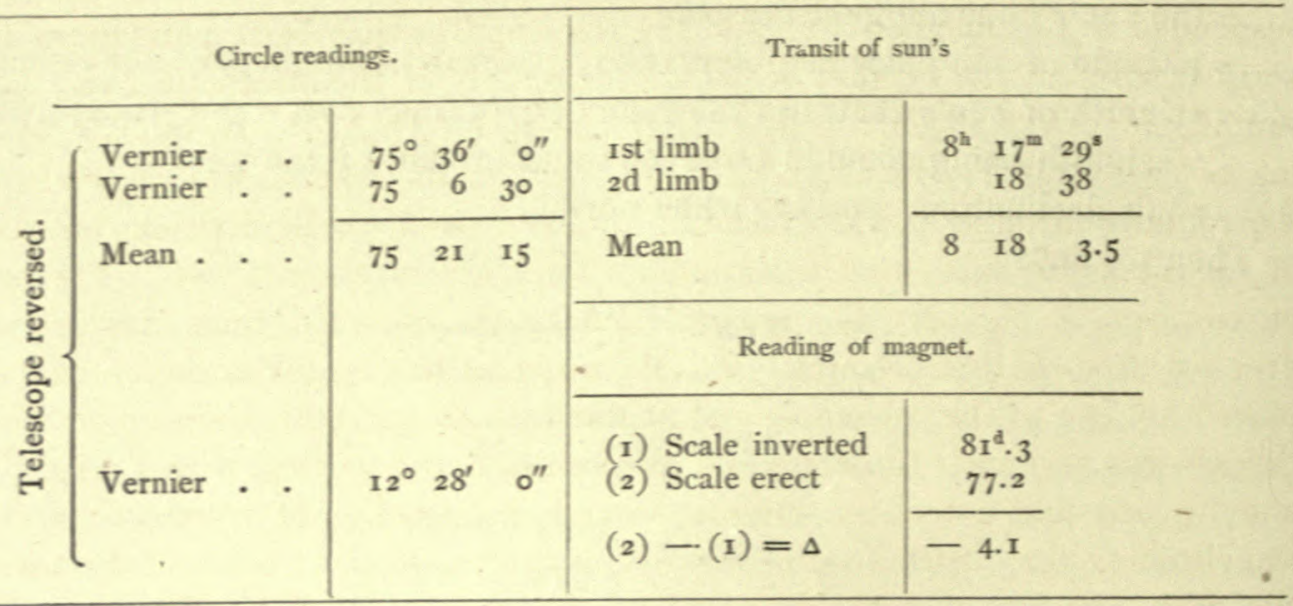

Value of one division of magnet scale $=\mathscr{Z} .349$.

The telescope is direct when the vertical circle is on the left-hand side.

These observations were made before noon, and time was noted by chronometer Fletcher, 906, which was $1^{\text {h }} 41^{\mathrm{m}} 22^{\mathrm{s}} .2$ fast of local mean time.

At the time the azimuth was observed, the reading of the horizontal circle, telescope direct, to distant referring mark was $10^{\circ} 23^{\prime} 30^{\prime \prime}$.

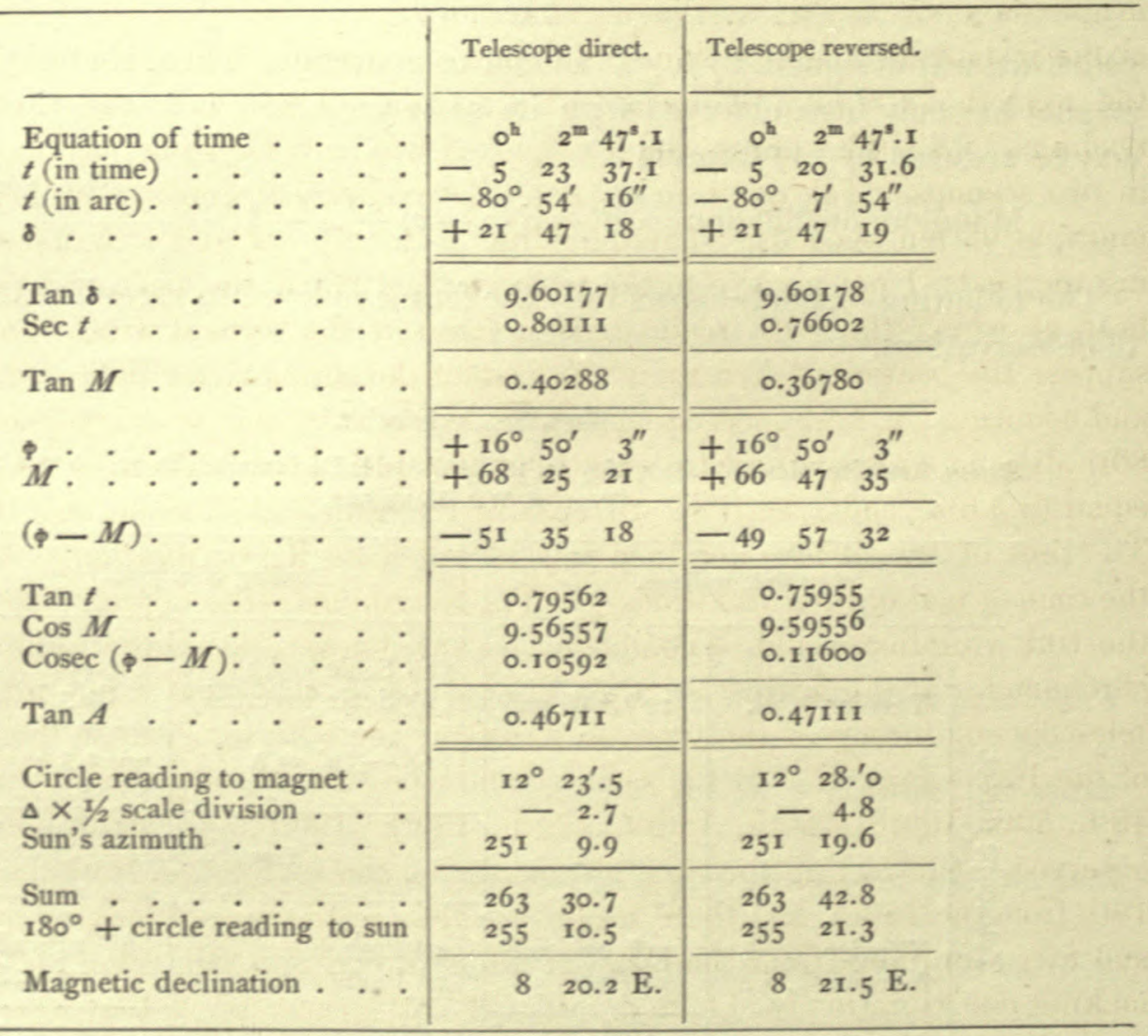

Observations of Vibrations were made as follows: The instrument having been set up and adjusted in the manner already explained, the long magnet, C. 32, was 
suspended in the magnet-box; and the telescope having been pointed so that its vertical wire cut the magnet scalc approximately at the magnetic axis, the horizontal limb of the theodolite was firmly clamped. 'Then, $1^{\circ}$. By quickly approaching and withdrawing the magnetised screw-driver the magnet was caused to vibrate horizontally through an arc extending to about twenty scale divisions on each side of the magnetic axis - that is, through a total arc of about $1^{\circ} 34^{\prime}$. The semi-arc of vibration being only 47 , no correction to the observed time of vibration was erer required on that account. $2^{\circ}$. My assistant having taken the chronometer, I placed my eye to the telescope, and at the instant the 80 th division of the scale (which was very near the magnetic axis) crossed the vertical wire I cried " time," and my assistant noted the minute, second, and fraction of a second indicated by the chronometcr. Still keeping my eye at the telescope, I counted the transits of the 80 th division orer the wire, calling the one at which time was noted 0 , the next 1 , the next 2 , and so on up to the 10 th, when I again cried "time," and my" assistant once more noted the minute, second, and fraction of a second indicated by the chronometer. 'The difference of these two chronometer times gave a value for the time of ten vibrations of the magnet which was correct within about half a second. However, to guard against mistakes, the process was always repeated a second or third time. $3^{\circ}$. The tempcrature indicated by the thermometer in the magnet-box was noted; and then putting my eye to the telescope, I read the scale at the instant the magnet attained the eastern extremity, and again when it attained the western extremity, of its arc of vibration. These were the "extreme scale readings." $4^{\circ}$. The chronometer employed was a pocket onc, beating five times in two seconds. Taking it in my hand, I commenced counting its beats at some multiple of ten seconds. Then, holding it to my ear and still mentally counting the beats, I put my eye to the telescope and noted the beat, and fraction of a beat, at which the 80 th scale division crossed the vertical wirc. For example, suppose the beat was taken up at the instant the chronometer indicated $10^{\mathrm{h}} 2^{\mathrm{m}} 10^{\mathrm{s}}$, and counting the first succeeding beat 1 , the next 2 , and so on, suppose that the 80 th division crossed the wire exactly at the 14 th beat. Then, as 14.0 beats are equal to 5.6 scconds, the time of transit of the 80 th scale division was $10^{\mathrm{h}} 2^{\mathrm{m}} 15^{\mathrm{s}} .6$. The time of transit thus obtained was recorded as the 0 vibration. Adding to it the time of making ten vibrations-before determined-the approximate time when the 10 th vibration would be completed became known. 'Taking up the beat of the chronometer at the nearest eren ten seconds before that time, I put my eye to the telescope and observed the time of transit of the 80th division at the completion of the 10th vibration. In the same manner the time of completing the $20 \mathrm{th}, 30$ th, 40 th, 50 th, 100 th, 150 th, 160 th, 170 th, 180 th, 190 th, and 200 th vibration was observed. Subtracting the time of completing the 0 vibration from the 150 th, the 10 th from the 160 th, \&c., there result six values of the time of making one hundred and fifty vibrations, from the mean of which a rery accurate valuc of the time of making one vibration is obtained. It will not escape notice that when observing in the manner just described there is no risk of making a mistake of one vibration, because the magnet. must, at all subsequent transits, be moving in the same direction as at the first transit, while in order to make a mistake of one ribration it 
would be necessary that it shonld be moving in the opposite direction. $5^{\circ}$. The extreme scale readings attained by the magnet at the eastern and western extremities of its are of vibration were again observed; and then the thermometer in the magnet-box was read. $6^{\circ}$. The necessary observations for determining the coefficient of torsion of the suspension fibres were made. When the instrument was properly adjusted for observation the torsion circle always read $300^{\circ}$. With it remaining at that reading the arc of vibration of the magnet was reduced to four or five scale divisions (by means of the magnetized screw-driver) and then the scale was read. Next the torsion circle was turned bacliward one-quarter of a revolution, so as to make it indicate $210^{\circ}$, and the seale was again read. After that, the torsion circle was turned forward half a revolution (passing through the point $300^{\circ}$ ), so as to make it indicate $30^{\circ}$, and the scale was read. Finally, the torsion circle was turned backuard one-quarter of a revolution, so as to make it indicate $300^{\circ}$, and the scale was once more read. Subtracting the second scale reading from the first, the second from the third, and the fourth from the third, gave three differences, which were added together and divided by four. 'The result was the number of scale divisions through which the magnet was deflected by a twist of ninety degrees in the suspension fibres.

Observations of Deflections were made as follows: 'The instruments liaving been set up and adjusted in the manner already explained, the short magnet, S. 8, was suspended in the magnet-box, and the telescope laving been pointed so that its vertical wire cut the magnet scale approximately at its central division (not necessarily the magnetic axis) the horizontal limb of the theodolite was clamped firmly. 'Then, $1^{\circ}$. The time was noted. $2^{\circ}$. 'The thermometer inside the magnet-box was read. $3^{\circ}$. The long magnet C. 32 (which we will now call the deflecting magnet) was placed on the deflecting bar support, with its axis east and west, its centre on a level with and at a distance of two feet to the west of the suspended magnet, and its north end west; the vibrations of the suspended magnet were reduced to four or five scale divisions, by means of the magnetised screw-driver, and then its scale was read. $4^{\circ}$. The deflecting magnet (remaining in the same place on the deflecting bar support as before) was reversed end for end, so as to bring its north end east, and the scale of the suspended magnet was read. $5^{\circ}$. The reversals were repeated twice more, so as to give in all two scale readings with the north end of the deflecting magnet to the west, and two scale readings with it to the east. 'The mean of the two scale readings obtained with the north end of the deflecting magnet west, were subtracted from the mean of the two scale readings obtained with its north end east. 'The difference was twice the value of the angle of deflection, as resulting from observations made with the deflecting magnet west of the suspended magnet. $6^{\circ}$. The deflecting magnet was lifter from the deflecting bar support to the west, and placed on that to the east, of the suspencled magnet; its distance from the suspended magnet being still two feet, and its north end being to the east, the scale of the suspended magnet. was read. $7^{\circ}$. 'The deflecting magnet (remaining in the same place on the eastern deflecting bar support) was reversed end for end, so as to bring its north end west, and the scale of the suspended magnet was read, $8^{\circ}$. 'l'he reversals were repeated twice more, so to give in all two 
scale readings with the north end of the deflecting magnet to the east, and two scale readings with it to the west. Krom the mean of the two scale readings obtained with the north end of the deflecting magnet east, the mean of the two scale readings obtained with its north end west were subtracted. 'The difference was twice the value of the angle of deflection, as resulting from observations made with the deflecting magnet east of the suspended magnet. 'The mean between this result and that obtained from tlie observations with the deflecting magnet west of the suspended magnet, was adopted as the true value of twice the angle of deflection, with the deflecting magnet at a distance of two feet from the suspended magnet. $9^{\circ}$. 'The thermometer inside the magnet-box was read. $10^{\circ}$. The time was noted. $11^{\circ}$. All the observations just described were repeated with the deflecting magnet at a distance of two and a half feet from the suspended magnet. 12。. The torsion of the suspension fibres was determined, precisely as described under the head of "observations of vibrations."

Horizontal Force was calculated from the observations of vibrations and deflectious by the following formulx:

$T_{0}=$ observed time of one vibration of the magnet.

$T^{\prime \prime}=$ time of vibration, corrected for rate of chronometer and are of vibration.

$T=$ time of vibration, corrected for rate of chronometer, arc of vibration, torsion force of the suspending thread, temperature, and induction.

$s=$ daily rate of chronometer, + when gaining, - when losing.

$\alpha, \alpha^{i}=$ semiarc of vibration, at the beginning and end of the observation, expressed in parts of radius.

$\frac{H}{F}=$ ratio of the force of torsion of the suspending thread to the magnetic directive force.

$q=$ coefficient of the decrease of the magnetic moment of the magnet produced by an increase of temperature of $1^{\circ}$ Fall. (This is not constant for all temperatures, and the correction is more exactly expressed by a formula of the form - correction to $t^{\prime}=q\left(t^{\prime}-t\right)+q^{\prime}\left(t^{\prime}-t\right)^{2}$, where $t^{\prime}$ is the observed temperature, and $t$ an adopted standard temperature.)

$\boldsymbol{K}=$ moment of inertia of the magnet, including its suspending stirmp and other appendages. (This is constant for the same magnet and suspension, but varies slightly with the temperature, owing to the expansion of the materials.)

$\pi=$ batio of the circumference of a circle to its diameter $=3.14159$.

$\mu=$ coefficient of increase in the magnetic moment of the magnet produced by the inducing action of a magnetic force equal to unity of the English system of absolute measurement.

$r_{0}=$ apparent distance between the centres of the deflecting and suspended magnets in the observations of deflections.

$r=$ the same distance corrected for error of graduation and temperature. $\left(r=r_{0}\left[1+0.00001\left(t^{\prime}-62^{\circ}\right)\right]+\right.$ correction for scale error. $)$

$d=$ value, in minutes of arc, of one rlivision of the magnet scale.

$u_{0}=$ observed angle of deflection, in scale divisions. 
$u=$ angle of deflection, corrected for torsion force of the suspending thread. $P=$ a constant depending upon the distribution of magnetism in the deflecting and suspended magnets.

$m=$ magnetic moment of the deflecting or vibrating magnet.

$X=$ horizontal component of the earth's magnetic force.

$\frac{m^{\prime}}{X^{\prime}}=$ value of $\frac{m}{X}$ before the application of the correction $\left(1-\frac{P}{r^{2}}\right)$

$$
\left(1+\frac{H}{F}\right)=\frac{5400+v}{5400}
$$

where $v=$ the angle, expressed in minutes of arc, through which the suspended magnet is deflected by a twist of $90^{\circ}$ in the suspension thread.

$$
\begin{aligned}
T^{\prime} & =T_{0}\left(1-\frac{s}{86400}\right)\left(1-\frac{\alpha \alpha^{\prime}}{16}\right) \\
T^{2} & =T^{\prime 2}\left\{1+\frac{H}{F}\right\}\left\{1-\left(t^{\prime}-t\right) q\right\}\left\{1+\mu \frac{X^{\prime}}{m^{\prime}}\right\} \\
m X & =\frac{\pi^{2} K}{T^{2}} \\
u & =d u_{0}\left(1+\frac{H}{F}\right) \\
m^{\prime} & =\frac{1}{2} r^{3} \tan u \\
X^{\prime} & \frac{m^{\prime}}{m^{\prime}}=\frac{P}{X^{\prime}}\left(1-\frac{P}{r^{2}}\right) \\
m & =\sqrt{m X} \frac{m}{X} \\
X & =\frac{m X}{m}
\end{aligned}
$$

In order to facilitate the finding of $\log$. $\tan u$, in the reduction of observations of deflection, the following table has been prepared. With the argument log. $u$ ( $u$ being expressed in minutes of arc) it gives the quantity (log. $\tan u-\log . u$ ), or, in other words, the quantity which it is necessary to add to log. $u$ in order to obtain $\log . \tan u$. The arrangement of the table is such that the quantity (log. $\tan u-\log . u$ ) is to be added to the log. $u$ on the same line with it, or to any other log. $u$ less than the one on the line next below. For example, if it were required to find log. $\tan u$ corresponding to any $\log$. $u$ from 8.0000 to 1.4340 , it would only be necessary to add 6.46373 to the given log. $u$. 


\begin{tabular}{l|l||l|l}
\hline Log. $u$. & Log. $\tan u-\log . u$. & Log. $u$. & Log. $\tan u-\log u$. \\
\hline & & & \\
\hline 8.0000 & 6.46373 & 2.1159 & 6.46394 \\
1.4341 & 6.46374 & 2.1261 & 6.46395 \\
1.5957 & 6.46375 & 2.1358 & 6.46396 \\
1.6874 & 6.46376 & 2.1452 & 6.46397 \\
1.7517 & 6.46377 & 2.1541 & 6.46398 \\
1.8014 & 6.46378 & 2.1626 & 6.46399 \\
1.8414 & 6.46379 & 2.1708 & 6.46400 \\
1.8756 & 6.46380 & 2.1787 & 6.46401 \\
1.9047 & 6.46381 & 2.1864 & 6.46402 \\
1.9310 & 6.46382 & 2.1937 & 6.46403 \\
1.9538 & 6.46383 & 2.2008 & 6.46404 \\
1.9750 & 6.46384 & 2.2079 & 6.46405 \\
1.9934 & 6.46385 & 2.2146 & 6.46406 \\
2.0111 & 646386 & 2.2209 & 6.46407 \\
2.0274 & 6.46387 & 2.2271 & 6.46408 \\
2.0426 & 6.46388 & 2.2332 & 6.46409 \\
2.0565 & 6.46389 & 2.2393 & 6.46410 \\
2.0700 & 6.46390 & 2.2453 & 6.46411 \\
2.0824 & 6.46391 & 2.2509 & 6.46412 \\
2.0941 & 6.46392 & 2.2565 & 6.46413 \\
2.1055 & 6.46393 & & \\
& & &
\end{tabular}

The following are specimens of the forms employed in recording and reducing the observations of vibrations and deflections.

HORIZONTAL INTENSITY.

Observations of Vibrations.

Station, Acapulco, Mexico. Date, May 3oth, 1866. Magnet C. 32. Inertia ring No.

Chron. Fletcher 906 , rate, $I^{8} \cdot 38$ losing on mean time.

\begin{tabular}{|c|c|c|c|c|c|c|c|}
\hline $\begin{array}{l}\text { Number } \\
\text { of } \\
\text { vibrations. }\end{array}$ & \multicolumn{3}{|c|}{ Time. } & Temp. & \multicolumn{2}{|c|}{$\begin{array}{l}\text { Extreme scale } \\
\text { readings. }\end{array}$} & $\begin{array}{c}\text { Time of } \\
\text { I } 50 \text { vibrations. }\end{array}$ \\
\hline 0 & $8^{h}$ & $3^{2^{\mathrm{m}}}$ & $3^{8} \cdot 8$ & $87^{\circ}$ & $57^{d} \cdot 8$ & $102^{d} \cdot 2$ & \\
\hline 10 & 8 & 32 & 57.0 & & & & \\
\hline 20 & 8 & 33 & 50.6 & & & & \\
\hline $3^{\circ}$ & 8 & 34 & 43.9 & & & & \\
\hline 40 & 8 & 35 & 37.0 & & & & \\
\hline 50 & 8 & $3^{6}$ & 30.6 & & & & \\
\hline 100 & 8 & 40 & 57.2 & & 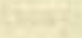 & & \\
\hline 150 & 8 & 45 & 23.4 & & & & $13^{\mathrm{m}} 19^{\mathrm{s}} \cdot 6$ \\
\hline 160 & 8 & 46 & 17.2 & & & & 1320.2 \\
\hline 170 & 8 & 47 & 10.2 & & ' & & 19.6 \\
\hline 180 & 8 & 48 & $3 \cdot 7$ & & & & 19.8 \\
\hline 190 & 8 & 48 & 57.0 & & & & 20.0 \\
\hline 200 & 8 & 49 & 50.5 & $9 \mathrm{I}$ & 65.2 & 95.0 & $\begin{array}{ll}13 & 19.9\end{array}$ \\
\hline & & & eans, & 89.0 & & & 19.85 \\
\hline
\end{tabular}

Coefficient of torsion. Value of one scale div. $=2^{\prime} \cdot 349$

\begin{tabular}{|c|c|c|}
\hline Tor. cir. & Scale. & Diff's. \\
\cline { 1 - 2 } $300^{\circ}$ & $80^{\mathrm{d}} . \mathrm{I}$ & \\
30 & 83.5 & 3.4 \\
210 & 76.7 & 6.8 \\
300 & $80 . \mathrm{I}$ & 3.4 \\
\hline \multicolumn{3}{|c|}{ Mean $=\mathrm{v}=3.40$} \\
\hline
\end{tabular}

$$
\begin{aligned}
& v=\quad 8^{\prime} .0 \\
& 5400^{\prime}+v^{\prime} \\
& 5400 \text { (ar. co.) } \\
& \quad 1+\frac{H}{F}
\end{aligned}
$$

Log's.

$3 \cdot 73304$ 6.26761

0.00065 
Horizontal InTEnsity. Calculation.

$$
T^{2}=T^{\prime 2}\left(r+\frac{H}{F}\right)\left(r-\left(t^{\prime}-t\right) q\right)
$$

Observed time of 150 vibrations $=799^{8} .85$

Time of one vibration

Correction for rate

$=5.33^{2}$

$$
\mathrm{T}^{\prime}=\frac{.000}{5.33^{2}}
$$

\begin{tabular}{|c|c|c|c|}
\hline & & & Log's. \\
\hline$q$ & & $\mathrm{~T}^{\prime}$ & 0.72689 \\
\hline$t^{\prime}-t$ & $+4 \cdot 3$ & $\mathrm{~T}^{\prime 2}$ & I. 45378 \\
\hline$r-\left(t^{\prime}-t\right) q$ & & $I-\left(t^{\prime}-t\right) q$ & $9 \cdot 999^{62}$ \\
\hline \multirow{3}{*}{\multicolumn{2}{|c|}{$\mathrm{mX}=\frac{\pi^{2} \mathrm{~K}}{\mathrm{~T}^{2}}$}} & $\begin{array}{l}\mathrm{T}^{2} \\
\pi^{2} \mathrm{~K}\end{array}$ & $\begin{array}{l}\text { I. } 45405 \\
\text { 2.1 } 7768\end{array}$ \\
\hline & & $\begin{array}{l}\mathrm{mX} \\
\mathrm{m}\end{array}$ & $\begin{array}{l}0.723^{63} \\
9.83487\end{array}$ \\
\hline & & $7.740=x$ & 0.88876 \\
\hline
\end{tabular}

* Ob's of defl'n. Date. May 3 oth, 1866.

$$
\begin{array}{c|c|c}
\hline *_{\mathrm{m}} & 8.94854 \\
\mathrm{t}=84^{\circ} \cdot 7 & \mathrm{X} & 0.72363 \\
\hline \mathrm{mX} & \mathrm{m}^{2} & 9.67217 \\
\mathrm{~m} & 9.83608 \\
\hline
\end{array}
$$

The chronometer used in this observation was $I^{\mathrm{h}} 4 \mathrm{I}^{\mathrm{m}} 22^{\mathrm{s}} .2$ fast of local mean time.

HoRizontal InTENSITY.

Observations of Deflections.

\begin{tabular}{|c|c|c|c|c|c|c|c|c|}
\hline 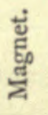 & $\begin{array}{l}5 \\
\text { है } \\
\text { 乙े }\end{array}$ & & & Temp. & $\begin{array}{c}\text { Scale } \\
\text { Readings. }\end{array}$ & $\begin{array}{l}\text { Alternate } \\
\text { Means. }\end{array}$ & Diff's. & Dist. \\
\hline$\dot{0}$ & $\begin{array}{l}\text { W. } \\
\text { E. } \\
\text { W. } \\
\text { E. }\end{array}$ & 7 & 22 & $86^{\circ}$ & $\begin{array}{r}53^{\mathrm{d}} \cdot 9 \\
107.0 \\
53.9 \\
107.0\end{array}$ & $\begin{array}{r}53^{\mathrm{d}} \cdot 9 \\
107 \cdot 0\end{array}$ & $53^{d} \cdot 1$ & 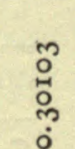 \\
\hline 苞 & $\begin{array}{l}\text { E. } \\
\text { W. } \\
\text { E. } \\
\text { W. }\end{array}$ & 7 & $3^{2}$ & 84 & $\begin{array}{r}107.5 \\
53.5 \\
107.7 \\
53.8\end{array}$ & $\begin{array}{r}107.6 \\
53.6\end{array}$ & 54.0 & 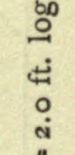 \\
\hline \multicolumn{2}{|c|}{ Means, } & & & 85.0 & & $2 u^{d}$ & 53.53 & \\
\hline
\end{tabular}

Station, Acapulco, Mexico. Date, May 3 oth, 1866. Mag. C. 32 deflecting. Mag. S. 8 suspended. Observer, WM. HaRkNeSS. 


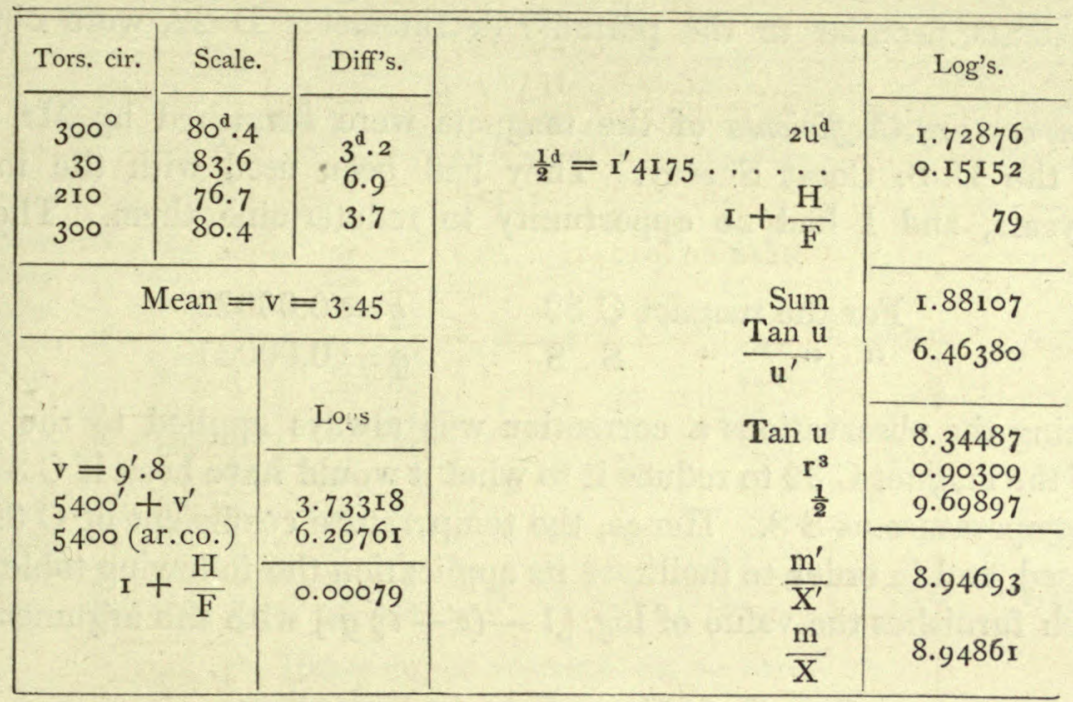

HoRizontal InTENSity.

Observations of Deflections.

Station, Acapulco, Mexico. Date, May zoth, r866. Mag. C. 32 deflecting. Mag. S. 8 suspended. Observer, WM. HaRkness.

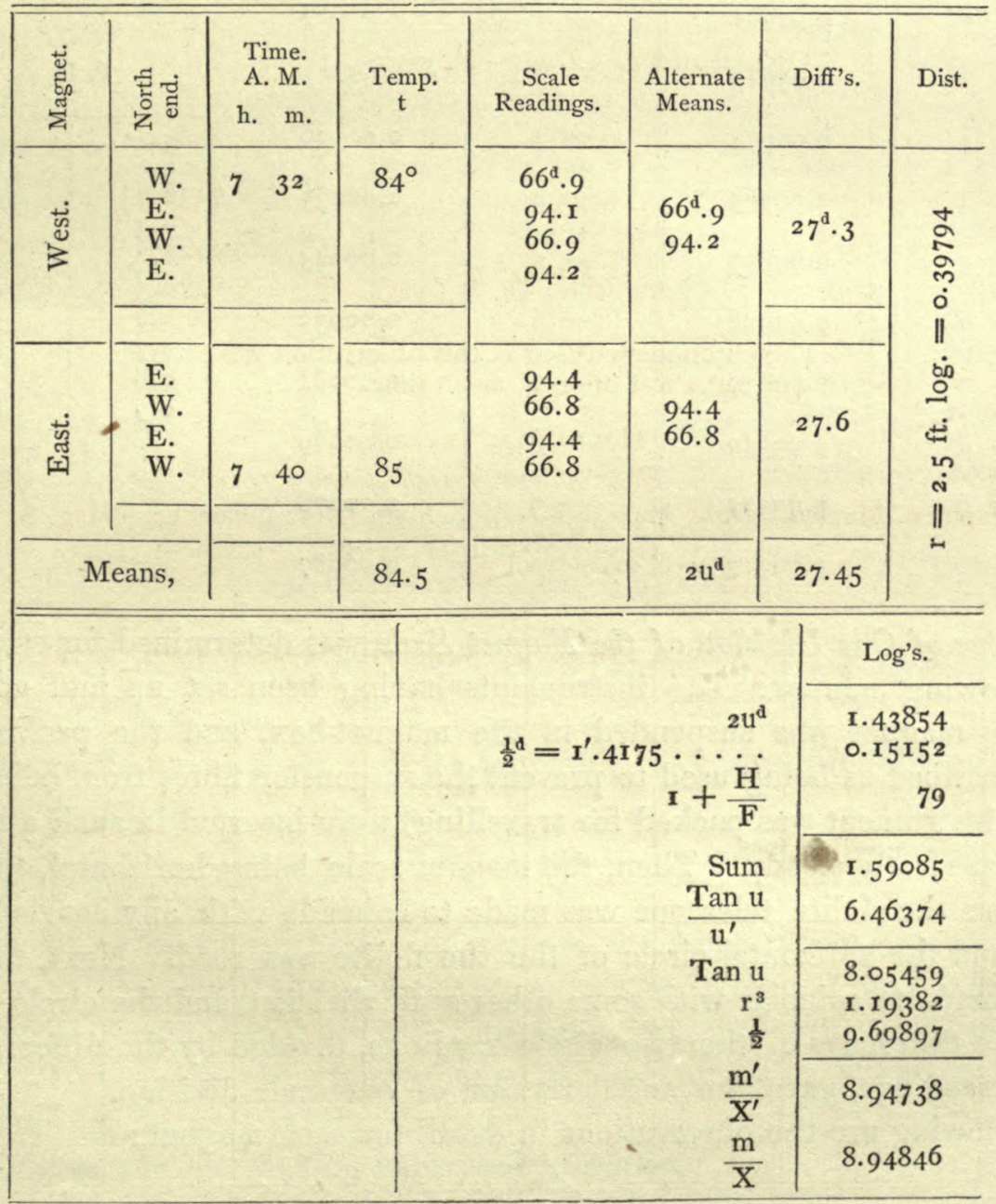


'The constants, peculiar to the portable declinometer 1 22, were obtained as follows :

The Temperature Coefficients of the magnets were furnished by Mr. Chas. A. Schott, of the U.S. Coast Survey. 'They liad been used with the instrument for some years, and I had no opportunity to redetermine them. 'They are as follows :

$$
\begin{array}{cccc}
\text { For the magnet C } 32 & q=0.00020 \\
\text { " " " } & \text { S } 8 & q=0.00027
\end{array}
$$

In reducing the observations a correction was always applied to the magnetic moment of the magnet $\mathrm{C} 32$ to reduce it to what it would have been if $\mathrm{C} 32$ had had tlie same temperature as $\mathrm{S} 8$. Hence, the temperature coefficient of $\mathrm{C} 32$ was the only one used, and in order to facilitate its application the following table was computed which furnishes the value of $\log .\left[1-\left(t^{\prime}-t\right) q\right]$ with the argument $\left(t^{\prime}-t\right)$.

Correction of Magnet C. 32 for Temperature

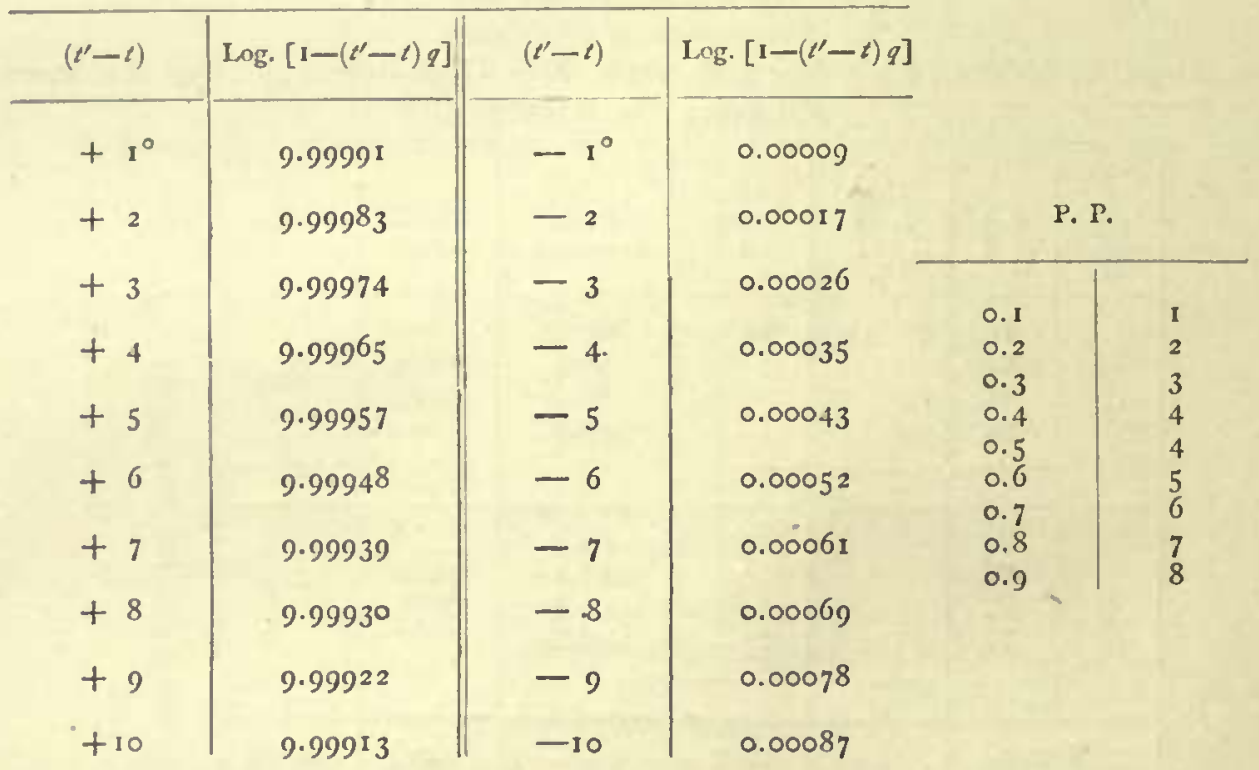

The Value of One Division of the Magnet Scale was determined for ench magnet in the following inauner: 'The instruments having been set up and adjusted as usual, the magnet was suspended in the magnet-box, and the packing blocks (before described as being used to prevent the suspension fibres from being twisted when the instrument was packed for travelling) were inserted in such a manner as to hold it perfectly steady. 'Then, the magnet scale being horizontal, the vertical wire of the theodolite telescope was made to coincide witl any convenient scale division, and the horizontal circle of the theodolite was read. Next, the vertical wire was made to coincide witl some other scale division, and the circle was again read. The difference of the two circle readings, clivided by the difference of the two scale readings, gave the angular value of one scale division.

I'le following are the observations in detail for each magnet: 
Magnet C. 32 .

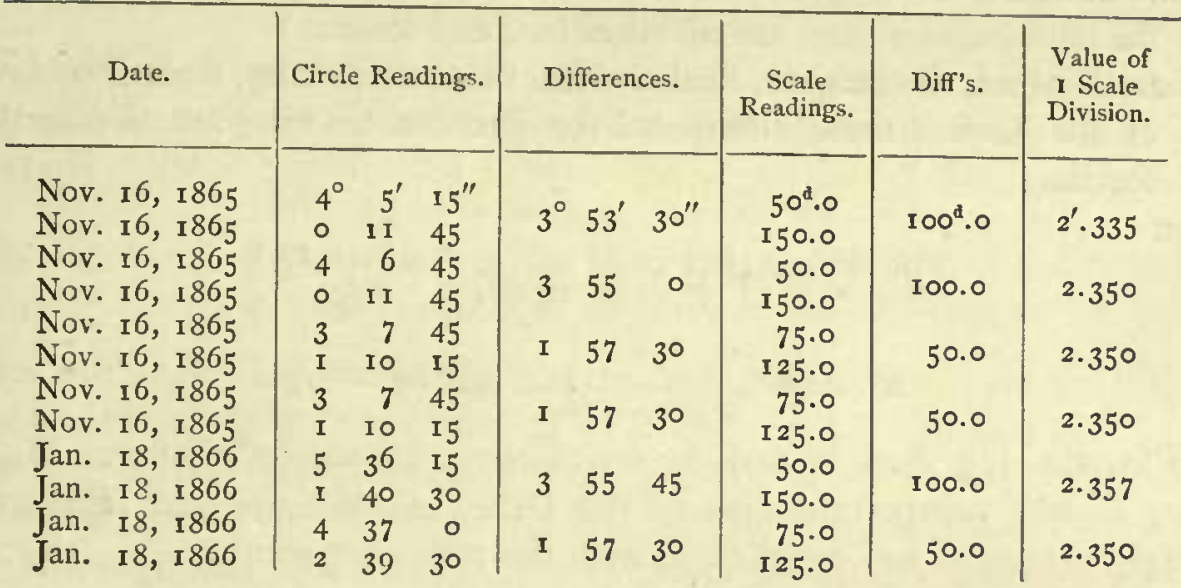

Hence for the magnet $\mathrm{C}_{32}$, we have I scale division $=2^{\prime} \cdot 349 \pm 0^{\prime} .0020$.

Magnet S. 8.

\begin{tabular}{|c|c|c|c|c|c|c|c|c|c|}
\hline Date. & \multicolumn{3}{|c|}{ Circle Readings. } & \multicolumn{3}{|c|}{ Differences. } & $\begin{array}{c}\text { Scale } \\
\text { Readings. }\end{array}$ & Diff's. & $\begin{array}{l}\text { Value of } \\
\text { I Scale } \\
\text { Division. }\end{array}$ \\
\hline $\begin{array}{l}\text { Nov. } 16, \text { I } 865 \\
\text { Nov. } 16, \text { I } 865\end{array}$ & $\begin{array}{r}4^{\circ} \\
359^{\circ}\end{array}$ & $\begin{array}{r}9^{\prime} \\
26\end{array}$ & $\begin{array}{l}45^{\prime \prime} \\
30\end{array}$ & $4^{\circ}$ & $43^{\prime}$ & $15^{\prime}$ & $\begin{array}{l}50^{d} .0 \\
150.0\end{array}$ & $100^{d} .0$ & $2^{\prime} .833$ \\
\hline $\begin{array}{l}\text { Nov. I6, I } 865 \\
\text { Nov. I } 6,1865\end{array}$ & $\begin{array}{r}4 \\
359\end{array}$ & $\begin{array}{r}9 \\
26\end{array}$ & 45 & 4 & 43 & I 5 & 50.0 & 100.0 & 2.832 \\
\hline Nov. I6, I 865 & $\begin{array}{r}359 \\
2\end{array}$ & $5^{8}$ & 45 & & $2 \mathrm{I}$ & & $\begin{array}{r}50.0 \\
75.0\end{array}$ & & \\
\hline $\begin{array}{l}\text { Nov. } 16,1865 \\
\text { Nov. } 16,1865\end{array}$ & $\begin{array}{l}0 \\
2\end{array}$ & 37 & $\circ$ & & & 45 & 125.0 & 50.0 & 2.835 \\
\hline $\begin{array}{l}\text { Nov. I6, I } 865 \\
\text { Nov. 16, } 866_{5}\end{array}$ & $\begin{array}{l}2 \\
0\end{array}$ & $\begin{array}{l}59 \\
37\end{array}$ & $3^{\circ}$ & & 21 & $3^{\circ}$ & $\begin{array}{r}75.0 \\
125.0\end{array}$ & 50.0 & 2.830 \\
\hline $\begin{array}{l}\text { Jan. } 18,1866 \\
\text { Tan. } 8,1866\end{array}$ & $\begin{array}{l}5 \\
0\end{array}$ & 36 & 30 & & 44 & I 5 & 50.0 & 100.0 & 2.842 \\
\hline Jan. I 8, I 866 & 4 & $\begin{array}{l}52 \\
25\end{array}$ & 30 & & & & 75.0 & 50.0 & 2.840 \\
\hline Jan. I8, I 866 & & 3 & 30 & & 22 & 0 & 125.0 & 50.0 & \\
\hline
\end{tabular}

Hence, for the magnet S 8, we have I scale division $=2^{\prime} .835 \pm 0^{\prime} .0013$.

The Moment of Inertia, and its Temperature Coefficient, of the Magnet $C$ 32, was detcrmined as follows: Let,

$K_{\tau}=$ moment of inertia of the magnet, including its suspending stirrup and other appendages, at the temperature $\tau$.

$\Delta K=$ change in the value of $K$ corresponding to a change of temperature of $1^{\circ}$ Fah. in the magnet.

$K^{\prime}{ }_{r}=$ moment of inertia of the inertia ring, at the temperature $\tau$.

$d_{i}=$ internal diameter of the incrtia ring, expressed in feet, at the temperaturc $\tau_{0}$.

$d_{e}=$ external diameter of the inertia ring, expressed in feet, at the temperature $\tau_{0}$.

$\varepsilon=$ cocfficient of expansion for a change of temperature of $1^{\circ} \mathrm{Fah}$. in the metal composing the inertia ring.

$W=$ weight of the inertia ring expressed in grains. 
$t=$ time in which the magnet makes one vibration at the temperature $\tau_{0}$ (corrected for chronometer rate, arc of vibration, and torsion.)

$t^{\prime}=$ time in which the maguet, loaded with the inertia ring, makes one vibration at the temperature $\tau_{0}$ (corrected for chronometer rate, are of vibration, and torsion)

Then

$$
\begin{gathered}
K_{\tau}^{\prime}=W\left[1+2 \varepsilon\left(\tau-\tau_{0}\right)\right]\left\{\frac{d_{i}^{2}+d_{e}^{2}}{8}\right\} \\
K_{\tau}=K_{\tau_{0}}^{\prime}\left(\frac{t^{2}}{t^{\prime 2}-t^{2}}\right)+\Delta K\left(\tau-\tau_{0}\right)
\end{gathered}
$$

The incrtia ring used in making my observations was of bronze. Mr. Josepll Saxton, Assistant Superintendent of the Office of Weights and Measures, very obligingly measured and weighed it, with the following result:

Internal diameter $=2.385$ inches $=0.19875$ foot

External diameter $=2.947$ inches $=0.24558$ foot

Weight $=798.72$ grains

the temperature of the ring being $74^{\circ} \mathrm{Fah}$.

Hence, assuming the coefficient of expansion for an increase of temperature of $1^{\circ}$ liah. in the metal of this ring to be 0.0000105 , we find by the formula given above

or

$$
K_{\tau}^{\prime}=9.9601+\left(\tau-50^{\circ}\right) 0.000209
$$

$$
\text { Log. } K^{\prime}{ }_{\tau}=0.99827+\left(\tau-50^{\circ}\right) 0.0000091
$$

The following table contains all the times of vibration which werc observed for the purpose of determining the moment of inertia of the magnet, together with the computation of the corresponding values of $\log . K$ from them. 'The value of $t^{\prime}$ was always obscrved eitlier immediately before, or immediately after, the corresponding value of $t$ which was to be used with it. 'This was done in order to have the temperature in both cases as nearly as possible the same, so that the correction neces-

\begin{tabular}{|c|c|c|c|c|c|c|c|c|c|}
\hline \multicolumn{3}{|c|}{ Date. } & $\tau$ & Log. $t^{\prime 2}$ & $\log \cdot t^{2}$ & $\log \cdot\left(t^{\prime 8}-t^{8}\right)$ & $\log \cdot\left(\frac{t^{2}}{t^{2}-t^{2}}\right)$ & $\log \cdot K^{\prime \prime}$ & $\log \cdot K_{\tau}^{-}$ \\
\hline Oct. & 28 & 1865 & 73.0 & 1.88210 & 1.66424 & I. 4781 I & $0.186 \mathrm{I}_{3}$ & 0.99849 & I. I 8462 \\
\hline Nov. & I 6 & 1865 & 87.7 & 1.72767 & I. 50891 & 1.32504 & 0.18385 & 0.99862 & 1. 18247 \\
\hline Nov. & 28 & 1865 & 90.0 & 1.72835 & 1.51108 & I. 32345 & 0.18763 & 0.99864 & I. I 8627 \\
\hline Dec. & I3, & 1865 & $89 \cdot 5$ & I. 74459 & 1.52673 & 1.34060 & 0.186 I 3 & 0.99864 & 1.1 8477 \\
\hline Dec. & 27, & 1865 & 98.0 & I. $7668 \mathrm{I}$ & 1. 54810 & 1.36412 & 0.1 8398 & 0.99872 & 1.18270 \\
\hline Jan. & 18 & 1866 & 87.2 & I. 77770 & I. $559^{2}$ I & 1.37467 & 0. I $845^{8}$ & 0.99861 & I. I 83 I 5 \\
\hline March & 19 & 1866 & 76.2 & I. $75^{849}$ & I. 54 IOI & I. 35391 & 0.18710 & $0.99^{85} 1$ & I. $1856 \mathrm{I}$ \\
\hline April & II, & 1866 & 74.0 & 1.75824 & I. 54019 & I. 35454 & 0.18565 & $0.99^{85}$ & 1. 18415 \\
\hline May & 30 & I 866 & $84 \cdot 7$ & 1.67351 & I. 45405 & 1.27196 & 0.18200 & 0.99859 & I. 18068 \\
\hline Nov. & 2 , & I 866 & 70.0 & I. 90424 & 1.68479 & 1.50268 & 0. I 82 I I & 0.99846 & I. I 8057 \\
\hline Nov. & 2 & I 866 & 70.0 & 1.90391 & 1.68450 & 1.50229 & $0.1822 \mathrm{I}$ & 0.99846 & 1. 18067 \\
\hline Nov. & 2 , & I 866 & 53.5 & I. 92843 & 1.70989 & 1.52548 & o. I 844 I & $0.99^{8} 30$ & I. I 827 I \\
\hline & & & $79 \cdot 5$ & & & & & & I. 18320 \\
\hline
\end{tabular}
sary to reduce $t^{\prime}$ to the same temperature as $t$ was always very small. Then having a sufficient number of values of $K$, obtained from observations made at widely different temperatures, the value of $\Delta K$ was easily found. 
Let $K_{0}$ represent the mean of all the logarithms of $K$ in the above table; then

$$
K_{0}=1.18320
$$

at a temperature of $79^{\circ} .5$. Now, assuming

we have

$$
\text { Log. } K_{\tau}=K_{0}+\left(\tau-79^{\circ} .5\right) \Delta K
$$

$$
0=K_{0}-\log . K_{\tau}+\left(\tau-79^{\circ} .5\right) \Delta K
$$

and each value of $\log$. $K_{\tau}$, given in the table above, will furnish one equation of condition for the determination of $\Delta K$, as follows : the absolute terms being in units of the fifth place of decimals.

$$
\begin{array}{l|l}
0=-142-6.5 \Delta K & 0=-241-3.3 \Delta K \\
0=+73+8.2 \Delta K & 0=-95-5.5 \Delta K \\
0=-307+10.5 \Delta K & 0=+252+5.2 \Delta K \\
0=-157+10.0 \Delta K & 0=+263-9.5 \Delta K \\
0=+50+18.5 \Delta K & 0=+253-9.5 \Delta K \\
0=+5+7.7 \Delta K & 0=+49-26.0 \Delta K
\end{array}
$$

From these equations of condition we obtain, by the method of least squares, the normal equation

whence

\begin{tabular}{|c|c|c|c|}
\hline r & $\log \cdot \pi^{2} K_{\tau}^{-}$ & \multicolumn{2}{|c|}{$P . P$. } \\
\hline $50^{\circ}$ & 2.17645 & & 4 \\
\hline 60 & 2.17681 & $\begin{array}{l}3 \\
4\end{array}$ & $\begin{array}{l}\text { II } \\
14\end{array}$ \\
\hline 70 & 2.17716 & $\begin{array}{l}5 \\
6\end{array}$ & $\begin{array}{l}\text { I } 8 \\
2 I\end{array}$ \\
\hline 80 & 2. $1775^{2}$ & $\begin{array}{l}7 \\
8\end{array}$ & $\begin{array}{l}25 \\
28\end{array}$ \\
\hline 90 & 2.17787 & 9 & $3^{2}$ \\
\hline 100 & 2.17823 & & \\
\hline
\end{tabular}

$$
0=-5856.2+1646.0 \Delta K
$$

$$
\text { Log. } \Delta K=0.55119
$$

$$
\Delta K=+3.56
$$

and finally

$$
\text { Log. } K_{\tau}=1.18320+\left(\tau-79^{\circ} .5\right) 0.0000356 \pm 0.000368
$$

or

Hence we have

$$
K_{\tau}=15.248+\left(\tau-79^{\circ} .5\right) 0.00125 \pm 0.0129
$$

$$
\pi^{2} K_{\tau}=150.49+\left(\tau-79^{\circ} .5\right) 0.01234
$$

or

$$
\text { Log. } \pi^{2} K_{\tau}=2.17750+\left(\tau-79^{\circ} .5\right) 0.0000356
$$

In order to facilitate the reduction of the observations of vibrations, the following table has been computed from the formula last given. It furnishes the value of $\log . \pi^{2} K_{\tau}$ to the argument $\tau$.

.The Constant $P$, depending upon the distribution of the magnetism in the magnets $\mathrm{C} 32$ and $\mathrm{S} 8$, was determined by means of the formula

$$
P=\frac{A-A^{\prime}}{\frac{A}{r^{2}}-\frac{A^{\prime}}{r^{\prime 2}}}
$$


where

$A=$ value of $\frac{m^{\prime}}{X^{\prime}}$ determined from an observation of deflection with the deflecting magnet at the distance $r$ from the suspended magnet.

$A^{\prime}=$ value of $\frac{m}{X^{\prime}}$ determined from an observation of deflection with the deflecting magnet at the distance $r^{\prime}$ from the suspended magnet.

The following table contains all the observed values of $A$ and $A^{\prime}$, together with the computation of the corresponding values of $P$. The values of $A$ were obtained from deflections at a distance of 2.0 feet: those of $A^{\prime}$ from deflections at a distance of 2.5 fect.

\begin{tabular}{|c|c|c|c|c|c|c|c|c|c|c|}
\hline \multicolumn{3}{|c|}{ Date. } & $\log . A$ & Log. $A^{\prime}$ & $\begin{array}{c}\text { Log. } \\
\left(A-A^{\prime}\right)\end{array}$ & $\log \cdot \frac{A}{y^{2}}$ & $\log \cdot \frac{A^{\prime}}{r^{\prime 8}}$ & $\left(\frac{A^{\log .}}{r^{-8}}-\frac{A^{\prime}}{r^{\prime}}\right)$ & $\log \cdot P$ & $P$ \\
\hline & $3 \circ$ & 1865 & 9.1660 & 9.1669 & $6.4829 n$ & $8.5^{6} 40$ & 8.37 II & 8.1187 & $8 \cdot 3^{6} 43^{n}$ & $-0.023 I$ \\
\hline November & 13 & 1865 & & 9.0094 & $6.3^{8}$ & 8.4063 & 8.2135 & $7 \cdot 9608$ & $274 n$ & 0.0268 \\
\hline November & 16 & 1865 & 9.0 & 9.0088 & $5.1491 n$ & 8.4067 & 8.2129 & 7.9629 & $863 n$ & 0.0015 \\
\hline November & 28 & 1865 & 9.0068 & 9.0078 & $6.3989 n$ & 8.4047 & 8.2100 & 7.9591 & $398 n$ & -0.0275 \\
\hline December & 13 & I 865 & 9.0234 & 9.0175 & 7.1527 & 8.4213 & 8.2216 & 7.9879 & & +0.1462 \\
\hline December & 23, & 1865 & 9.0 & 9.0317 & 6.7 & 8.4274 & $8.235^{8}$ & 7.9798 & $8.7534^{n}$ & -0.0567 \\
\hline December & 27 & 1865 & $9.042 \mathrm{I}$ & 9.0413 & $6.3^{2}$ & 8.4400 & 8.2454 & 7.9978 & $8 \cdot 3^{2}$ & +0.0211 \\
\hline January & 6 & 1866 & 9.0628 & 9.0633 & $6.0587 n$ & 8.4608 & 8.2674 & $8.016_{3}$ & $8.0424 n$ & -0.0110 \\
\hline January & I8, & 1866 & 9.0531 & $9.053^{6}$ & $6.1399 n$ & 8.45 II & 8.2578 & 8.0064 & 8. I $335 n$ & $0.013^{6}$ \\
\hline February & 7 & 1866 & 9.0 & 9.0495 & 6.3 & 8.4465 & $8.253^{6}$ & 8.0012 & $9 n$ & 0.0237 \\
\hline March & 2 & 1866 & 9.0 & 9.0339 & 6.4 & 8.4308 & 8.2380 & 7.9852 & $98 n$ & -0.0275 \\
\hline Ma & I9, & 1866 & 9.0 & 9.0342 & 6.3 & $8.433^{\circ}$ & $8.23^{8} 3$ & 7.9907 & & +0.0209 \\
\hline March & 29, & 1866 & $9 . c$ & 90347 & 4.8 & $8.43^{26}$ & 8.2388 & 7.9890 & 6. & +0.0008 \\
\hline April & 7 & 1866 & 9.0 & 9.0373 & 6.1 & 8.4346 & 8.2414 & 899 & 8.1 & -0.0146 \\
\hline April & I1, & 1866 & 56 & 9.0360 & $5 \cdot 9$ & $8.433^{6}$ & 8.2401 & $7 \cdot 9$ & 7.9 & 0.0087 \\
\hline April & 13 & 1866 & 43 & 368 & $52 n$ & & 8.2409 & 7.9842 & Ion & $-0.063^{2}$ \\
\hline Apr & 26 , & 1866 & 8.990 & 8.9896 & 6.1 & 882 & 8.1937 & 7.9456 & 59 & +0.0161 \\
\hline Ma & 7 & 1866 & 8.9680 & 8.9704 & 6.7 & 8.3659 & 8.1745 & 7.9178 & or 0 n & $-0.063^{2}$ \\
\hline Ma & 14 , & 1866 & 8.9468 & 8.9544 & & 8.3447 & $8.15^{85}$ & 7.8872 & & 0.2022 \\
\hline Ma & 30 , & 1866 & 8.9 & 8.9472 & & 8.3448 & 8.1513 & 7.9004 & $386 n$ & 0.0097 \\
\hline Jun & 9 , & 1866 & & 8.9817 & $6.9669 n$ & 8.3754 & 8.1858 & 7.9241 & $27 n$ & -0.1103 \\
\hline Jun & 15 & I 866 & 9.0376 & 9.0346 & 6.8666 & & 8.2387 & 7.9970 & 8.8697 & +0.0741 \\
\hline June & 26 & 1866 & 9.0810 & 9.0826 & $6.6509 n$ & & 8.2868 & 8.0324 & $8.6185 n$ & -0.0415 \\
\hline November & I, & I 866 & 9.1991 & 9.1972 & 6.8414 & 8.5971 & 8.4014 & 8.1 1568 & 8.6847 & +0.0484 \\
\hline
\end{tabular}

The indiscriminate mean of all the observations gives

$$
P=-0.0166 \pm 0.0088
$$

But Peirce's criterion for the rejection of doubtful observations throws ont those of December 13 and May 14. Accordingly, excluding tlien, and taking the mean of all the others, there results

$$
P=-0.0155 \pm 0.0057
$$

and that value $I$ have adopted. Hence, for $r=2.0$ feet, we have

and for $r=2.5$ feet

$$
\text { Log. }\left(1-\frac{P}{r^{2}}\right)=0.00168
$$

$$
\log \cdot\left(1-\frac{P}{r^{2}}\right)=0.00108
$$


The Magnetic Moment of the Magnet $C 32$ was computed as follows: Observations of deflection were always taken at two different distances, viz., at 2.0 feet and at 2.5 ficet. In general, the two values of $\frac{m}{X}$ thus obtained differed slightly from each other, and the mean of the two was assumed to be correct. This mean was combined with the value of $m X$, obtained from a set of vibrations observed on the same $d a y$, and thus $m$ was determined. In no case was more than one set of observations of deflections taken on any single day, but in a few instances several sets of observations of vibrations were made. Under such circumstances, the mean of all the observed values of $m X$ was combined with the mean of the two values of $\frac{m}{X}$, and thus a single value of $m$ was deduced.

Let

$m_{\tau}=$ observed value of the magnetic moment at the temperature $\tau$.

$m=$ value of $m_{\tau}$ after being multiplied by $\left[1+\left(\tau-75^{\circ} .8\right) q\right]$, or, in other words, after being reduced to the temperature $75^{\circ} .8$ Fah.

$m_{0}=$ mean of all the observed values of $m$.

$\alpha=$ daily decrease in the value of $\log . m$, expressed in units of the fifth decimal place.

$d=$ time in days at which $m$ is taken; $d$ being counted from March 7 th, 1866 .

'The following table contains all the observed values of log. $m_{\tau}$, together with the computation from them of the final values of the same quantity. The column headed "days" gives the time in days counted from October 24 th, 1865.

\begin{tabular}{|c|c|c|c|c|c|c|c|c|}
\hline \multicolumn{2}{|l|}{ Date. } & $\tau$ & Log. $m_{r}$ & $\stackrel{\text { Log. }}{\left[1+\left(\tau-75^{\circ} .8\right) q\right]}$ & Log. $m$ & Days. & $\begin{array}{l}\text { Concluded } \\
\text { Log. } m\end{array}$ & $\begin{array}{l}\text { Concluded } \\
\text { Log. } m_{\tau}\end{array}$ \\
\hline October & $24, \quad 1865$ & $57 \cdot 5$ & 9.84148 & 9.99841 & 9.83989 & $\circ$ & 9.83990 & 9.84149 \\
\hline October 3 & $30, \quad 1865$ & 58.7 & 9.84139 & $9.9985 \mathrm{I}$ & 9.83990 & 6 & 9.83979 & $9.84 \mathrm{r} 28$ \\
\hline November I & 13,1865 & $85 \cdot 5$ & 9.83908 & 0.00082 & 9.83990 & 20 & 9.8395 I & 9.83869 \\
\hline November $\mathbf{I}$ & 16,1865 & $87 \cdot 7$ & $9.8395 \mathrm{I}$ & 0.00104 & 9.84055 & 23 & 9.83945 & 9.83841 \\
\hline November 2 & 28,1865 & 90.0 & 9.83773 & $0.0012 \mathrm{I}$ & 9.83894 & 35 & 9.83922 & $9.8380 \mathrm{I}$ \\
\hline December I & 13,1865 & 89.5 & 9.83645 & 0.00117 & 9.83762 & 50 & 9.83893 & $9.8377^{6}$ \\
\hline December 2 & 23,1865 & 87.2 & 9.83768 & 0.00100 & 9.83868 & 60 & 9.83873 & 9.83773 \\
\hline December 2 & 27,1865 & 98.0 & $9.83^{6} 55$ & 0.00191 & $9.83^{846}$ & 64 & 9.83865 & 9.83674 \\
\hline January & $6, \quad$ r 866 & 74.2 & 9.83915 & 9.99986 & 9.83901 & 74 & 9.83846 & 9.83860 \\
\hline January & x $8, x 866$ & 87.2 & 9.83666 & 0.00100 & 9.83766 & 86 & $9.83^{823}$ & $9.837^{2} 3$ \\
\hline February & $7, \mathbf{1 8 6 6}$ & $69 \cdot 5$ & 9.83783 & 9.99945 & 9.83728 & 106 & 9.83784 & 9.83839 \\
\hline March & 2,1866 & $69 \cdot 7$ & 9.83831 & 9.99947 & 9.83778 & 129 & 9.83739 & $9.8379^{2}$ \\
\hline March & $19, x 866$ & 76.2 & 9.83618 & 0.00004 & 9.83622 & 146 & 9.83706 & 9.83702 \\
\hline March & $29, \times 866$ & 68.2 & 9.83780 & 9.99934 & 9.83714 & $x_{5} 6$ & 9.83686 & 9.83752 \\
\hline April & $7, \times 866$ & 67.0 & 9.83861 & 9.99923 & 9.83784 & 165 & 9.83669 & 9.83746 \\
\hline April & I I , I 866 & 74.0 & 9.837 I 6 & 9.99984 & 9.83700 & 169 & $9.8366 \mathrm{I}$ & 9.83677 \\
\hline April & I 3,1866 & 65.7 & 9.837 I I & 9.99912 & $9.83^{623}$ & 171 & 9.83657 & 9.83745 \\
\hline April & 26, r 866 & 79.2 & 9.83626 & 0.00030 & 9.83656 & $\mathrm{r} 84$ & $9.83^{6} 3^{2}$ & 9.83602 \\
\hline May & 7, I 866 & 77.0 & $9.83^{6} 70$ & 0.00009 & $9.83^{6} 79$ & 195 & 9.83610 & $9.8360 \mathrm{r}$ \\
\hline May & 14,1866 & 82.2 & 9.83448 & $0.0005^{6}$ & 9.83504 & 202 & 9.83596 & 9.83540 \\
\hline May & $30, \quad$ I 866 & 84.7 & 9.83602 & 0.00078 & 9.83680 & 218 & $9.835^{6} 5$ & 9.83487 \\
\hline Jun & $9, \times 866$ & 65.0 & 9.83662 & 9.99906 & 9.83568 & 228 & 9.83546 & 9.83640 \\
\hline June & 15,1866 & 71.0 & 9.83493 & 9.99958 & $9.8345 \mathrm{I}$ & 234 & 9.83534 & 9.85576 \\
\hline June & 26,1866 & $6_{3.0}$ & 9.83548 & 9.99889 & 9.83437 & 245 & $9.835 \mathrm{I} 3$ & $9.83^{624}$ \\
\hline November & $\mathrm{x}, \mathrm{I} 866$ & 66.2 & 9.83326 & $9 \cdot 99916$ & 9.83242 & 373 & $9.83^{26} 3$ & 9.83347 \\
\hline & Means & 75.8 & & & 9.83729 & I54 & & \\
\hline
\end{tabular}


The mean of the quantities in the column lieaded $\tau$ is $75^{\circ} .8$. Accordingly, adding log. $\left[1+\left(\tau-75^{\circ} .8\right) q\right]$ to each $\log . m \iota_{\tau}$, we obtain the values of log. $m$ given in the table. 'Taking the mean of these values, and also the mean of the numbers in the column "days," we find that at 134 days, which corresponds to March 7 th, 1866 , the value of $\log . m$ was $9.83729=\log . m_{0}$. Then, assuming

we have

$$
\text { Log. } m=\log . m_{0}-a d
$$

$$
0=9.83729-\log . m-\alpha d
$$

and exch value of $\log$. $m$ furnishes an equation of condition for the determination of $\alpha$, as follows.

$$
\begin{aligned}
& 0=-260+134 a \\
& 0=-261+128 a \\
& 0=-261+114 a \\
& 0=-326+111 a \\
& 0=-165+99 a \\
& 0=-33+84 a \\
& 0=-139+74 a \\
& 0=-117+70 a \\
& 0=-172+60 a \\
& 0=-37748 a \\
& 0=+1+28 a \\
& 0=-49+5 a \\
& 0=+107-12 a
\end{aligned}
$$

$0=+15-22 a$
$0=-55-31 a$
$0=+29-35 a$
$0=+106-37 a$
$0=+73-50 a$
$0=+50-61 a$
$0=+225-68 a$
$0=+49-84 a$
$0=+161-94 a$
$0=+278-100 a$
$0=+292-111 a$
$0=+487-239 a$

By the method of least squares we obtain the normal equation

Solving, we get

$$
0=-397497+203965 \alpha
$$

Hence

$$
\alpha=+1.9488
$$

or

$$
\text { Log. } m=9.83729-0.0000195 d \pm 0.000090
$$

$$
m=0.68753-0.0000310 d \pm 0.000144
$$

From the first of these expressions the quantities in the column "concluded log. $m$ " were computed.

If, in the expression for log. $m$, given above, we introduce the correction for temperature, we obtain

$$
\text { Log. } m_{\tau}=9.83729-0.0000195 d-0.000087\left(\tau-75^{\circ} .8\right)
$$

by means of which the quantities in the column "concluded log. $m_{\tau}$ " were computed.

The probable error of a single observed value of log. $m$ is \pm 0.000452 , and of a single observed value of $m$ it is \pm 0.000719 .

Observations of Inclination were all made with a dip circle by Henry Barrow $\&$ Co., of London. It was provided with two needles, marked A 1 and A 2, each 3.5 inches long, and having axles 0.016 of an inch in diameter. 'The distance between the agate planes on which they rested was 0.74 of an inch. By means of two microscopes, one opposite each end of the needle-each of which, assuming distinct vision to be obtained at a distance of ten inches, magnified 18 diametersthe inclination of the needle was referred to, and read off upon a vertical circle six inches in diameter, divided to half degrees, and reading by means of two verniers to single ininutes. 'The pointing of the microscopes to the ends of the needle was 
effected by means of a clamp and tangent screw. The horizontal circle of the instrument was four inches in diameter, divided to half degrees, and reading by means of onc vernier to single minutes. It was provided with a clamp, but no tangent screw.

Readings of the position of the dipping needle were made as follows: In the field of view of each microscope was a plate of glass upon which was engraved three finc parallel lines, the middle one being intended to represent one of the two extremities of a diameter passing through a vertical circle described about the prolongation of the axle of the needle. The north microscope having been turned till the centre line in its field of view coincided with the north end of the needle, the vernier belonging to that microscope was read off, and recorded as the reading of the north end of the needle. Then the south microscope was turned till the centre line in its ficld of view coincided with the south end of the needle, and the vernier bclonging to that microscope was read off, and recorded as the reading of the south end of the necdle. In order to distinguish between the two microscopes the letter $\mathrm{N}$ was scratched upon one of them, and that one was always, in all positions of the instrument, used to read the north end of the needle.

The instrument having been set up and levelled, before beginning to observe it was neccssary to place the plane of the vertical circle in the magnetic meridian. At a few of the earlier stations this was accomplished as follows: The needle was placed on the agate planes, with the side on which the letters were marked facing the microscopes. Then $1^{\circ}$. The microscopes having been turned till they were nearly in a vertical line, the vernier of the lower one was set to $90^{\circ} 0^{\prime}$, and the vertical circle was moved in azimuth - so that its face (by which is meant the side on which the microscopes were) was south-till the lower end of the needle was bisected by the middle line in the lower microscope; the Y's were raiscd and lowered gently, and if the bisection of the necdle was altered, it was corrected by turning the circle in azimuth. Then the horizontal circle was clamped and read off; and this reading was callcd $A .2^{\circ}$. The vernier of the upper microscope was set to $90^{\circ} 0^{\prime}$, and the horizontal circle having been unclamped, the vertical circle was moved in azimuth-its face still remaining south-till the upper end of the needle was bisected by the middle line in the upper microscope; the Y's were raised and lowered gently, and if the biscction of the necdle was altered, it was corrected by turning the circle in azimuth. Then the horizontal circle was clamped and read off, and this reading was called $B$. $3^{\circ}$. The horizontal circle was unclamped, and turned in azimuth $180^{\circ}$, so as to bring the face of the instrument to the north, and then the $1^{\circ}$ and $2^{\circ}$ processes just described were repeated; thus giving two more readings of the horizontal circle, which were called $\mathrm{C}$ and $\mathrm{D}$. Then

$$
\frac{A+B+C+D}{4}=E
$$

where $E$ is the division of the horizontal circle at which it was necessary to set the vernier in order that the plane of the vertical circle might be at right angles to 8 April, 1872. 
the magnetic meridian. Therefore the vernier was set at $90^{\circ}+E$, and the plane of the vertical circle coincided with the magnetic meridian. However, it soon beeame evident that this process consumed too much time, and the following, which is quite as accurate and much more expeditious, was adopted: A fine line was marked permanently upon the top of the instrument parallel to the plane of the vertical circle; then, after the instrument had been levelled, but before the dipping needle had been placed upon the agrate planes, a pocket eompass, with a needle about one and a half inches long, was placed with its centre upon the fine line, and the vertical circle was turned in azimuth till the compass needle and line were parallel to each other. 'That being the case, the plane of the vertical circle was known to be in the magnetic meridian, and the horizontal circle was clamped and read off.

The following is the method which was adopted in making observations of dip: $1^{\circ}$. 'The agate planes, and those parts of the axle of the needle which would rest upon them, were carefully wiped with a piece of chamois leather (I have since seen reason to believe that a piece of cork would have answered the purpose better), and then the instrument was set up, levelled, and the plane of the vertical eircle placed in the magnetic meridian by the process before described. $2^{\circ}$. The needle was secured upon a block, provided for the purpose, and magnetised by means of a pair of eight-incl bar magnets, in such a manner that its marked end acquired north polarity. It was considered to be saturated with magnetism when the bar magnets had been drawn from its centre to its extremities six times, the process being performed upon both of its sides, and then it was removed from the block and placed in position upon the agate planes, with its face (by which is meant that side upon which the letters were marked) towards the east. $3^{\circ}$. The plane of the vertical cirele being in the magnetic mericlian, with the face of the instrument towards the east, and the needle in position upon the agate planes, with its face also towards the east, the north and south ends of the needle were read. Let these readings be designated respectively as $\phi^{\prime}$ and $\phi^{\prime \prime}$. $4^{\circ}$. The needle was reversed upon the agate planes, so as to bring its face towards the west, and its north and south ends were read. Let these readings be designated respectively $\phi^{\prime \prime \prime}$ and $\phi^{\prime T}$. $5^{\circ}$. 'The horizontal circle was unclamped, the vertieal circle turned in azimuth $180^{\circ}$, so as to bring its face towards the west, and the horizontal circle again clamped. 'The face of the needle now being towards the east, its north and soutl ends were read. Let these readings be designated respectively as $\phi^{\nabla}$ and $\phi^{\nabla \gamma}$. $6^{\vee}$. The needle was reversed upon the agate planes, so as to bring its face towards the west, and its north and south ends were read. Let these readings be designated respectively as $\phi^{r \prime \prime}$ and $\phi^{r H}$. $7^{\circ}$. The time was noted, and then the needle, having been removed from the agate planes, was placed upon the block provided for the purpose, and remagnetised in such a manner that its marked end acquired south polarity; after which it was again placed in position upon the agate planes, with its face towards the west, and its north and south ends were read. Let these readings be designaterl respectively as $\psi^{\prime}$ and $\psi^{\prime \prime} .8^{\circ}$. 'The needle was reversed upon the agate planes, so as to bring its face towards the east, and its north and south ends were read. Let these readings be designated respectively as $\psi^{m}$ and $\psi^{\prime v}$. $9^{\circ}$. The horizontal circle was unelamped, the vertical circle turned in azimuth $180^{\circ}$, 
so as to bring its face to the east, and the horizontal circle again clamped. The face of the needle now being towards the west, its north and south ends were read. Let these readings be designated respectively as $\psi^{\nabla}$ and $\psi^{\nabla 1}$. $10^{\circ}$. The needle was reversed upon the agate planes, so as to bring its face towards the east, and its north and south ends were read. Let these readings be designated respectively as $\psi^{\nabla I I}$ and $\psi^{\nabla I I T}$.

At the first few stations each of the readings $\phi^{\prime}, \phi^{\prime \prime}, \phi^{\prime \prime \prime} \ldots \phi^{V I I I}, \psi^{\prime}, \psi^{\prime \prime}, \psi^{\prime \prime \prime} \ldots \psi^{v I I}$, was repeated three times, the $Y^{\prime}$ 's being raised and lowered again between each repetition; but after some experience I became convinced that the increase of accuracy obtained by three repetitions, over that obtained by a single careful reading, was not sufficient to warrant the greatly increased expenditure of time, and accordingly the repetitions were abandoned.

'The needle A 2 proved to be well balanced, and the observations made with it were therefore reduced by the usual formula, namely

$$
\begin{gathered}
\frac{\phi^{\prime}+\phi^{\prime \prime}+\phi^{\prime \prime \prime}+\phi^{I V}+\phi^{V}+\phi^{V I}+\phi^{V I I}+\phi^{V I I I}}{8}=\alpha \\
\frac{\psi^{\prime}+\psi^{\prime \prime}+\psi^{\prime \prime \prime}+\psi^{I V}+\psi^{\nu}+\psi^{V I}+\psi^{I I I}+\psi^{V I I}}{8}=\beta \\
\theta=\frac{\alpha+\beta}{2}
\end{gathered}
$$

where $\theta$ is the magnetic inclination or dip.

'The needle A 1 proved not to be well balanced, which was shown by the great difference between the values of $\alpha$ and $\beta$ obtained with it in low magnetic latitudes; although they agreed well enough at places where the dip was large. An examination of all the observations showed that in every case

and

$$
\frac{\phi^{\prime}+\phi^{\prime \prime}+\phi^{\nabla}+\phi^{\nabla I}}{4}=\frac{\phi^{\prime \prime \prime}+\phi^{I T}+\phi^{\nabla I I}+\phi^{\nabla I I I}}{4}
$$

$$
\frac{\psi^{\prime}+\psi^{\prime \prime}+\psi^{\nabla}+\psi^{\nabla r}}{4}=\frac{\psi^{\prime \prime \prime}+\psi^{I T}+\psi^{\nabla I I}+\psi^{\nabla r I I}}{4}
$$

at least within about one degree. It therefore followed that, although the centre of gravity of the needle did not lie in its axle, it did lie somewhere in the line joining the two extremities of the necdle and passing through its axle. In such cases we have

$$
\tan \theta=\frac{\tan \alpha+\tan \beta}{2}
$$

and by that formula all the observations made with this needle were reduced.

At St. Thomas some observations of dip were made with the plane of the vertical circle out of the magnetic meridian. They were reduced by the formula

$$
\tan \theta=\tan \theta^{\prime} \cos \alpha
$$

where $\theta$ is the true dip, and $\theta^{\prime}$ the dip observed with the vertical circle in a plane whose azimuth, measured from the magnetic meridian, was $\alpha$. 
The values of the Vertical and Total Force have been computed from the horizontal force and inclination by the formulie

$$
\begin{aligned}
& Z=X \tan \theta \\
& R=X \sec \theta
\end{aligned}
$$

where

$X=$ horizontal component of the earth's magnetic force.

$Z=$ vertical component of the earth's magnetic force.

$R=$ total magnetic intensity.

$\theta=$ magnetic inclination.

All values of foree are expressed in English units; namely, in terms of grains, feet, and seconds. If it is desired to have them in metric units, expressed in terms of milligrams, millimeters, and seconds, they must be multiplied by 0.46108 .

The observations of magnetic declination, inclination, and force are given in full at the end of this section, but for convenience of reference the following

\begin{tabular}{|c|c|c|c|c|c|c|c|c|}
\hline \multirow{2}{*}{ Station. } & \multirow[b]{2}{*}{ Date. } & \multirow{2}{*}{ Declination. } & \multicolumn{2}{|c|}{ Inclination. } & \multirow{2}{*}{$\log \cdot \frac{m}{X}$} & \multirow{2}{*}{$\log \cdot m X$} & \multirow{2}{*}{ Temp. } & \multirow{2}{*}{$\begin{array}{l}X= \\
\text { Hor. Force }\end{array}$} \\
\hline & & & Needle A.I. & Needle A.2. & & & & \\
\hline $\begin{array}{l}\text { Philadelphia, Pa. } \\
\text { Gosport, Va. } \\
\text { Gosport, Va. } \\
\text { st. Thomas, } \\
\text { st. Thomas, }\end{array}$ & $\begin{array}{lll}\text { Oct. } & 24, & 1865 \\
\text { Oct. } & 28, & 1865 \\
\text { Oct. } & 30, & 1865 \\
\text { Nov. } & 13, & 1865 \\
\text { Nov. } & 16, & 1865\end{array}$ & 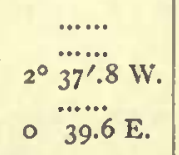 & $\begin{array}{r}\ldots \ldots \\
+\ldots \ldots \\
+69^{\circ} \\
+493 \\
+4936\end{array}$ & $\begin{array}{r}\ldots . . \\
\ldots \ldots{ }^{\circ} \\
+64^{\prime} \\
+4932 \\
+4944\end{array}$ & $\begin{array}{c}9.22363 \\
\ldots \ldots \\
9.16787 \\
9.01026 \\
9.01014\end{array}$ & & $\begin{array}{l}57.5 \\
73.0 \\
58.7 \\
85.5 \\
87.7\end{array}$ & $\begin{array}{l}4.148 \\
4.709 \\
4.717 \\
6.749 \\
6.768\end{array}$ \\
\hline $\begin{array}{l}\text { Salute Islands, } \\
\text { Ceara, } \\
\text { Pernambuco, } \\
\text { Bahia, } \\
\text { Rio Janeiro, }\end{array}$ & $\begin{array}{lrr}\text { Nov. } & 28, & 1865 \\
\text { Dec. } & 13,1865 \\
\text { Dec. } & 23, & 1865 \\
\text { Dec. } & 27, & 1865 \\
\text { Jan. } & 6, & 1866\end{array}$ & $\begin{array}{rr}0 & 3.8 \mathrm{~W} . \\
8 & 28.8 \mathrm{~W} . \\
10 & 59.6 \mathrm{~W} \\
7 & 56.6 \mathrm{~W} . \\
& \ldots \ldots .\end{array}$ & $\begin{array}{rr}+34 & 27 \\
+21 & 26 \\
+12 & 6 \\
+\quad 431 \\
+11 & 48\end{array}$ & $\begin{array}{rl}+34 & 42 \\
+21 & 20 \\
+12 & 10 \\
+\quad 417 \\
-11 & 46\end{array}$ & $\begin{array}{l}9.00868 \\
9.02178 \\
9.03195 \\
9.04305 \\
9.06444\end{array}$ & & $\begin{array}{l}90.0 \\
89.5 \\
87.2 \\
98.0 \\
74.2\end{array}$ & \\
\hline $\begin{array}{l}\text { Rio Janeiro, } \\
\text { Monte Video, } \\
\text { Monte Video, } \\
\text { Monte Video, } \\
\text { Sandy Point, }\end{array}$ & $\begin{array}{lrr}\text { Jan. } & 9, & 1866 \\
\text { Jan. } & 18, & 18666 \\
\text { Jan. } & 18, & 18666 \\
\text { Jan. } & \mathbf{1 9}, & 18666 \\
\text { Feb. } & \mathbf{7}, & \mathbf{1} 866\end{array}$ & $\begin{array}{rc}2 & 41.8 \mathrm{~W} . \\
9 & 16.6 \mathrm{E} . \\
& \ldots \ldots . . \\
9 & 25.0 \mathrm{E} . \\
2 \mathrm{I} & 52.0 \mathrm{E} .\end{array}$ & 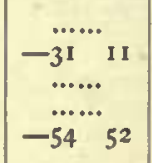 & $\begin{array}{c}\ldots \ldots \\
-30 \\
-318 \\
\ldots \ldots \ldots \\
-55 \quad 2\end{array}$ & $\begin{array}{c}\ldots \ldots . . \\
9.05476 \\
\ldots \ldots . . \\
9.05044\end{array}$ & $\begin{array}{l}0.61205 \\
0.61892 \\
0.61822 \\
0.61754 \\
0.62523\end{array}$ & $\begin{array}{l}80.5 \\
87.2 \\
87.2 \\
89.5 \\
69.5\end{array}$ & \\
\hline & $\begin{array}{rr}\text { March 2, } 1866 \\
\text { March 19, } 1866 \\
\text { March 29, } 1866 \\
\text { Marcl 29, } 1866 \\
\text { April } 7,1866\end{array}$ & 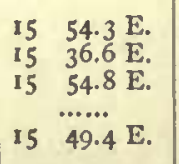 & $\begin{array}{rr}-34 & 50 \\
-35 & 28 \\
-35 & 34 \\
\ldots \ldots & \\
-35 & 26\end{array}$ & $\begin{array}{lr}-35 & 7 \\
-35 & 28 \\
-35 & 27 \\
\ldots \ldots & \\
-35 & 23\end{array}$ & $\begin{array}{c}9.03474 \\
9.03599 \\
\ldots \ldots \ldots \\
9.03607 \\
9.03837\end{array}$ & $\begin{array}{l}0.64188 \\
0.63637 \\
0.64126 \\
0.63782 \\
0.63885\end{array}$ & $\begin{array}{l}69.7 \\
76.2 \\
68.2 \\
68.2 \\
67.0\end{array}$ & \\
\hline $\begin{array}{l}\text { Valparaiso, } \\
\text { Valparaiso, } \\
\text { Callao, } \\
\text { Payta, }\end{array}$ & $\begin{array}{lrr}\text { April } & \text { I1, } & 1866 \\
\text { April } & 11, & 1866 \\
\text { April } & 13, & 1866 \\
\text { April } & 26,1866 \\
\text { May } & 7, & 1866\end{array}$ & $\begin{array}{ll}15 & 57.6 \mathrm{E} . \\
& \ldots \ldots . . \\
15 & 53.9 \mathrm{E} \\
10 & 29.6 \mathrm{E} \\
8 & 53.0 \mathrm{E}\end{array}$ & $\begin{array}{l}-3529 \\
\ldots . . . \\
-3540 \\
-628 \\
+59\end{array}$ & $\begin{array}{r}-3536 \\
\ldots \ldots \\
-35 \quad 12 \\
-6 \quad 29 \\
+4 \quad 47\end{array}$ & $\begin{array}{l}\ldots . . . \\
9.03720 \\
9.03692 \\
8.99132 \\
8.97055\end{array}$ & & $\begin{array}{l}74.0 \\
74.0 \\
65.7 \\
79.2 \\
77.0\end{array}$ & \\
\hline $\begin{array}{l}\text { Panama Bay, } \\
\text { Acapulco, } \\
\text { Acapulco, } \\
\text { Magdalena Bay, } \\
\text { Magdalena Bay, }\end{array}$ & $\begin{array}{lrr}\text { May } & 14, & 1866 \\
\text { May } & 30, & 1866 \\
\text { May } & 30, & 1866 \\
\text { June } & 9, & 1866 \\
\text { June } & 9, & 1866\end{array}$ & $\begin{array}{rc}5 & 55.8 \mathrm{E} . \\
8 & 20.8 \mathrm{E} . \\
8 & 23.6 \mathrm{E} . \\
10 & 40.5 \mathrm{E} . \\
& \ldots . . .\end{array}$ & $\begin{array}{r}+325 \\
+3949 \\
+{ }_{43}{ }^{3}\end{array}$ & $\begin{array}{c}+3147 \\
+3958 \\
\ldots \ldots \ldots \\
+4822 \\
\ldots \ldots\end{array}$ & $\begin{array}{c}8.95196 \\
8.94841 \\
\ldots \ldots . . \\
\ldots .9 . \ldots \\
8.9098\end{array}$ & $\begin{array}{c}0.71700 \\
0.72363 \\
\ldots \ldots .7 \\
0.69240 \\
0.69211\end{array}$ & $\begin{array}{l}82.2 \\
84.7 \\
\ldots \ldots . . \\
65.0 \\
65.0\end{array}$ & $\begin{array}{l}7.614 \\
7.740 \\
\ldots \ldots . . \\
7.178 \\
7.173\end{array}$ \\
\hline $\begin{array}{l}\text { San Diego Bay, } \\
\text { San Francisco I3ay, } \\
\text { Washington, D. C. } \\
\text { Washington, D. C. }\end{array}$ & $\begin{array}{lr}\text { June } & 15,1866 \\
\text { June } & 26,1866 \\
\text { Nov. } & 1,1866 \\
\text { May } & 6,1867\end{array}$ & $\begin{array}{rrr}13 & 9.4 & \mathrm{E} . \\
16 & 25.5 & \mathrm{E} \\
2 & 44.2 & \mathrm{~W} . \\
& \ldots . .\end{array}$ & $\begin{array}{r}+5751 \\
+6213 \\
+71 \\
+71 \\
+71\end{array}$ & $\begin{array}{r}+5756 \\
+6231 \\
+7213 \\
+725\end{array}$ & $\begin{array}{c}9.03746 \\
9.08320 \\
9.19956 \\
\ldots \ldots\end{array}$ & $\begin{array}{c}0.63241 \\
0.5^{8} 777 \\
0.46695 \\
\ldots \ldots\end{array}$ & $\begin{array}{l}71.0 \\
63.0 \\
66.2 \\
\ldots \ldots . .\end{array}$ & $\begin{array}{l}6.261 \\
5.643 \\
4.300 \\
\cdots \cdots\end{array}$ \\
\hline
\end{tabular}
abstract of them is inserted here. 
Taking the means we obtain the final values of the magnetic elements at each station, as follows:

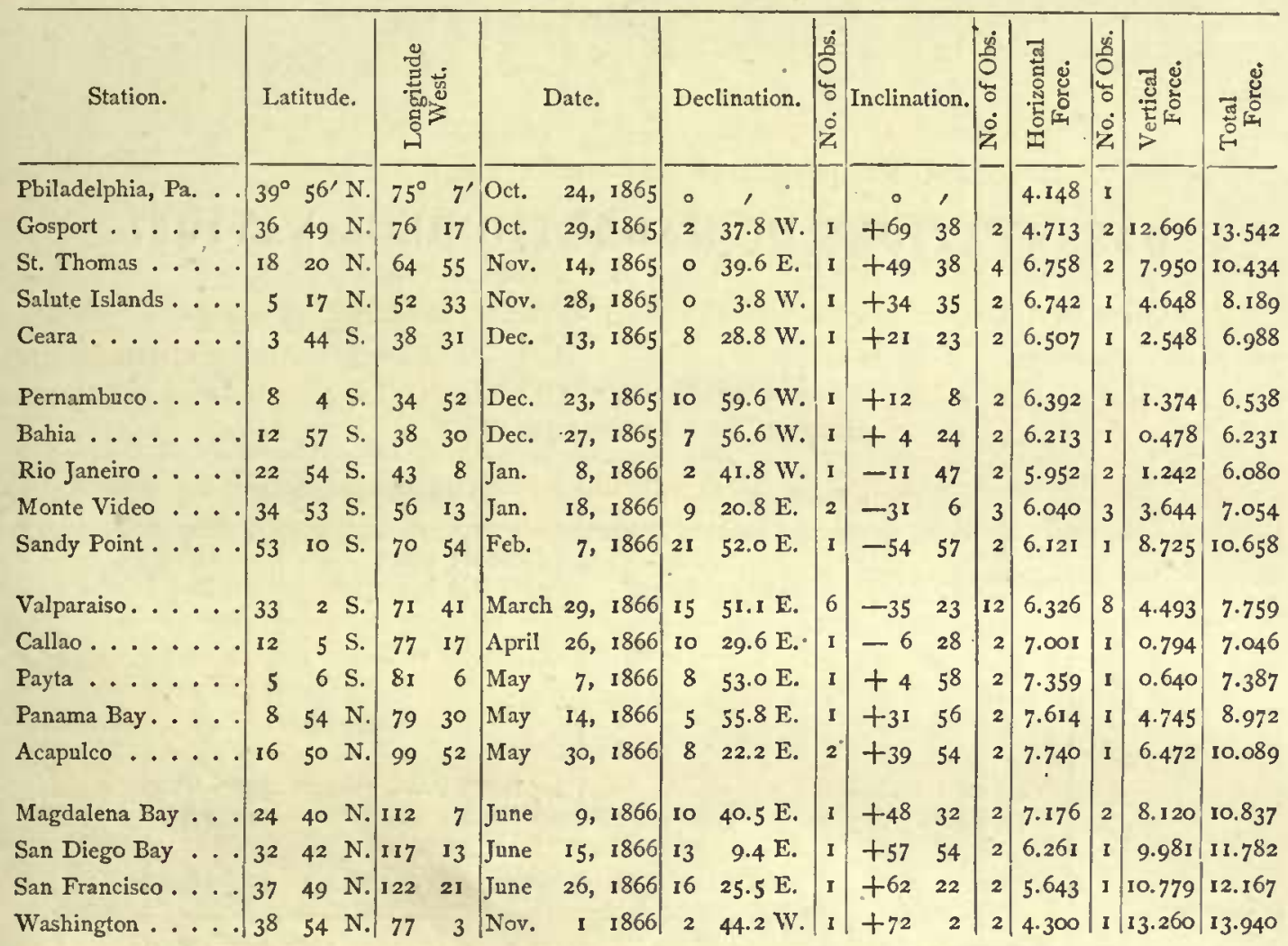




\section{OBSERVATIONS OF MAGNETIC DECLINATION.}

Magnetic Declination.

Gosport, Va. October 30, 1865 .

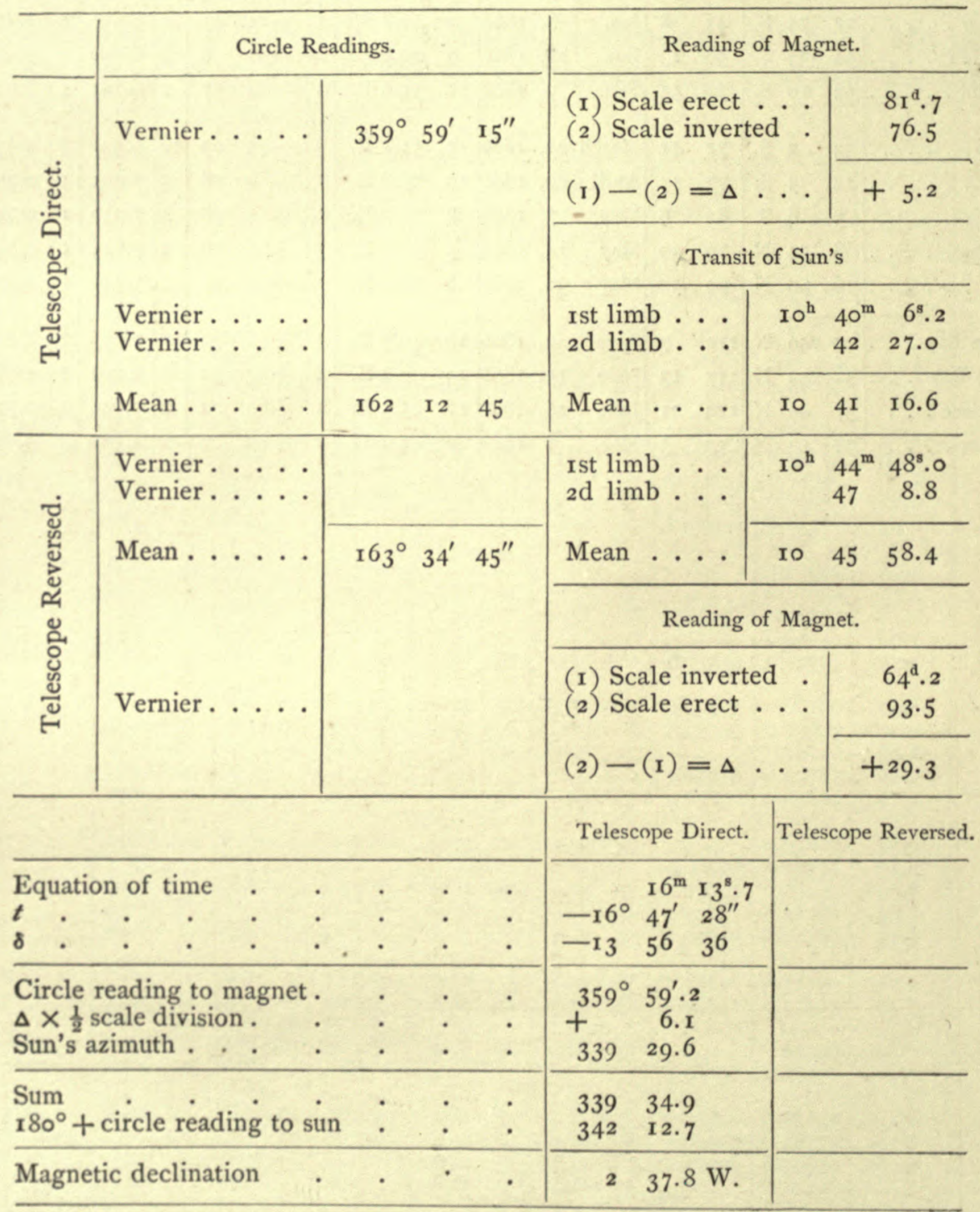

These observations were made before noon.

Chronometer $0^{\text {h }} 4^{\mathrm{m}} 40^{\mathrm{s}} \cdot 2$ fast of local mean time. 


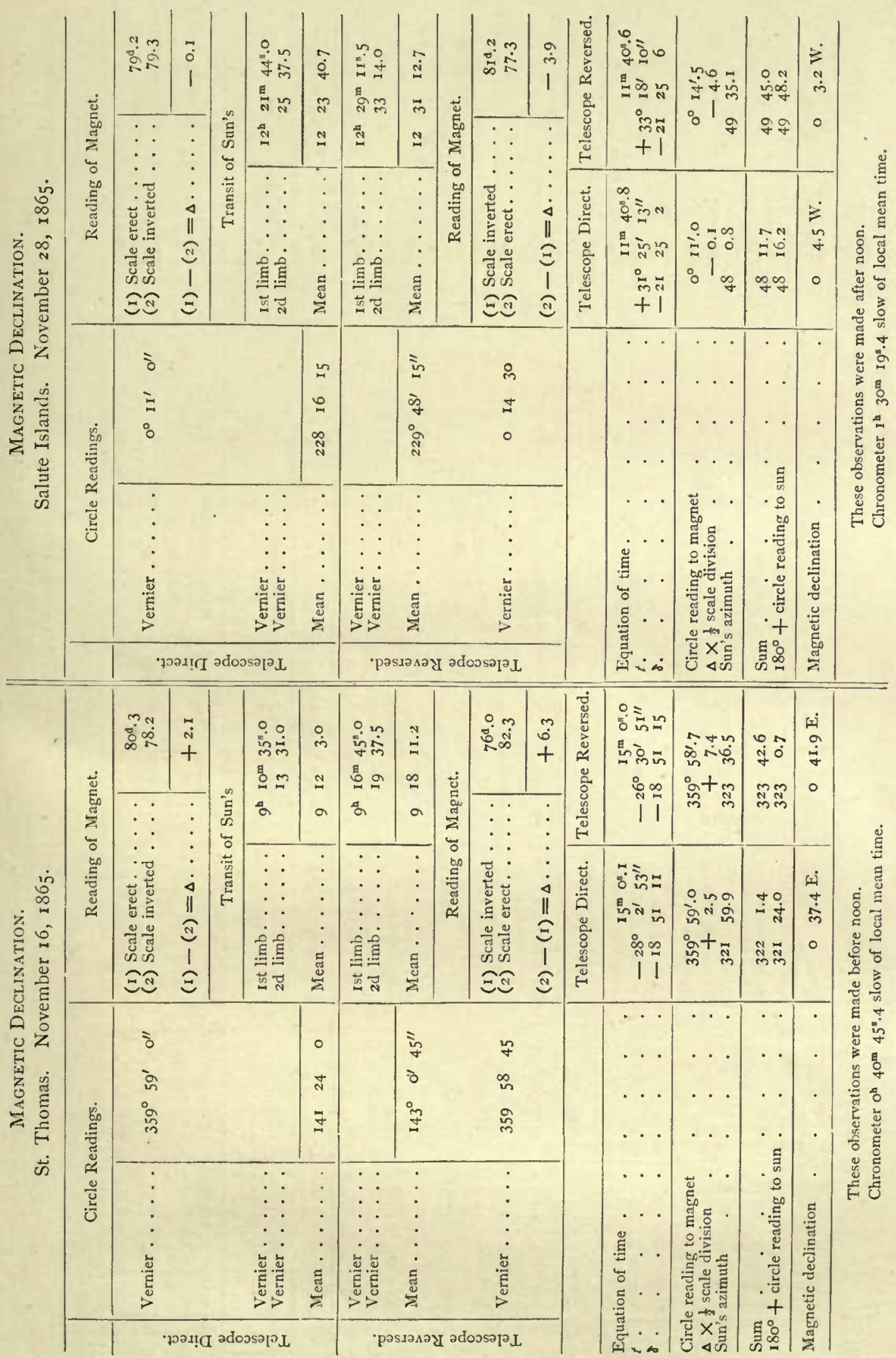




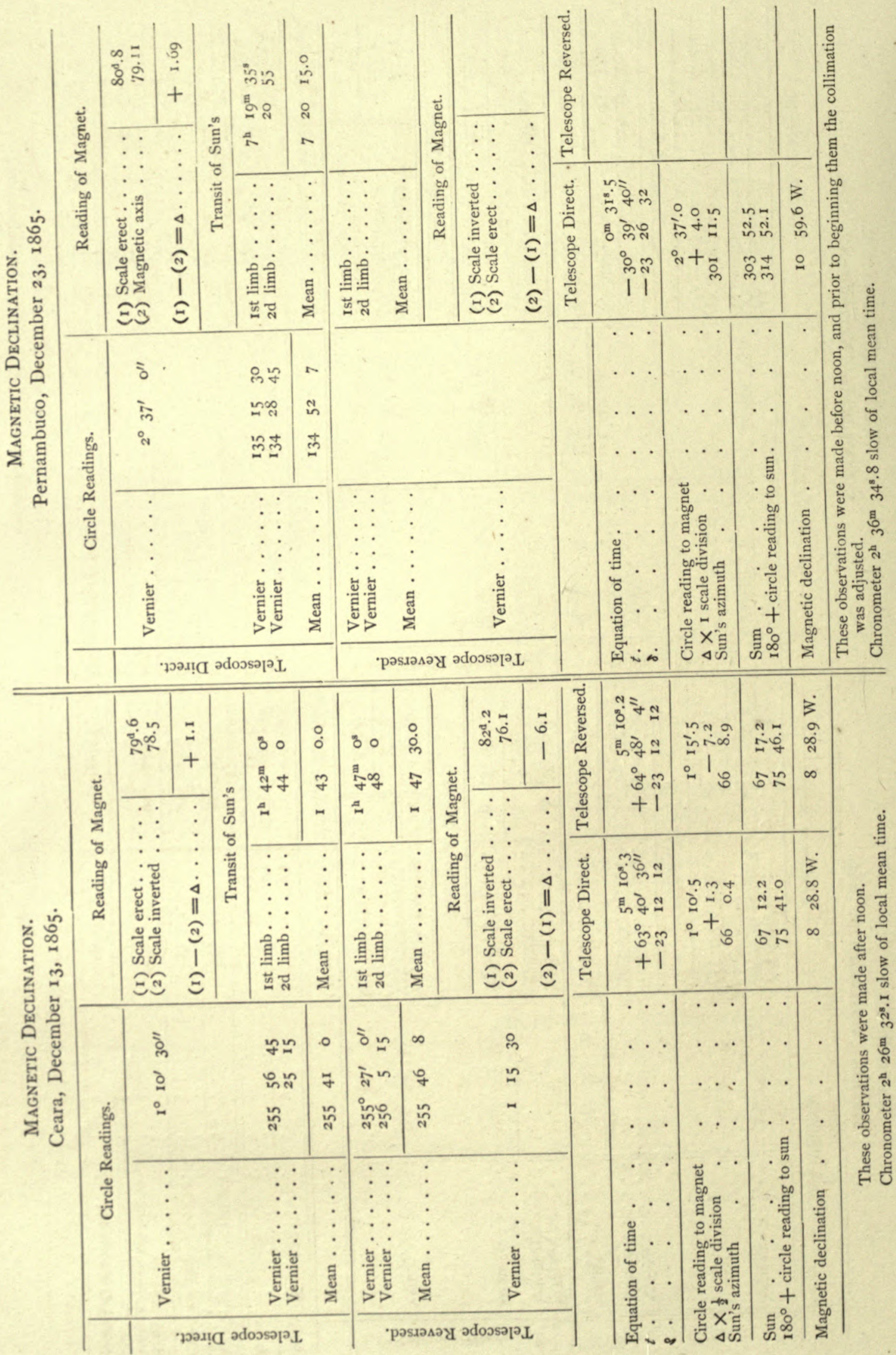


II G N TIC OBSERVATIONS.
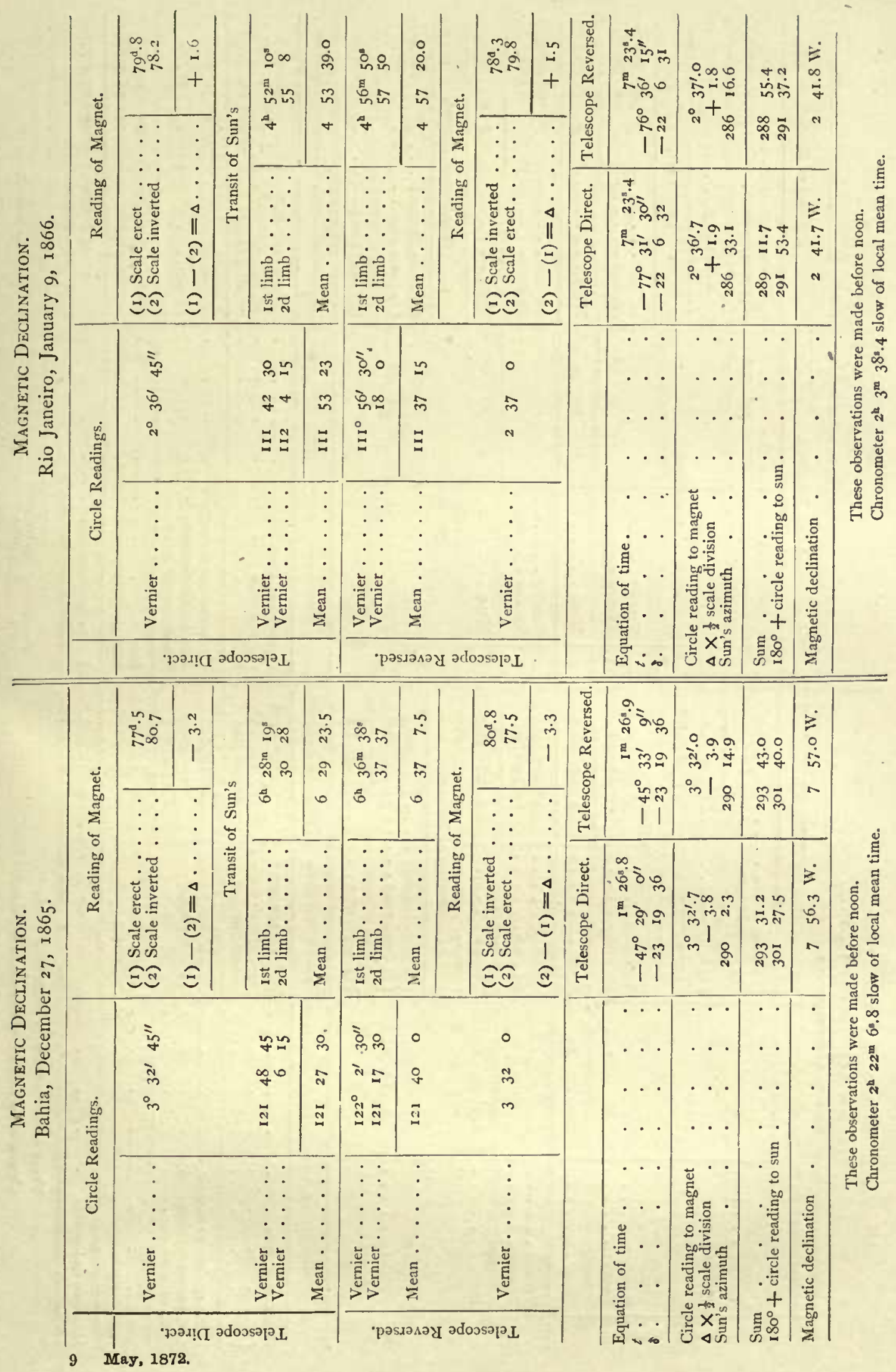


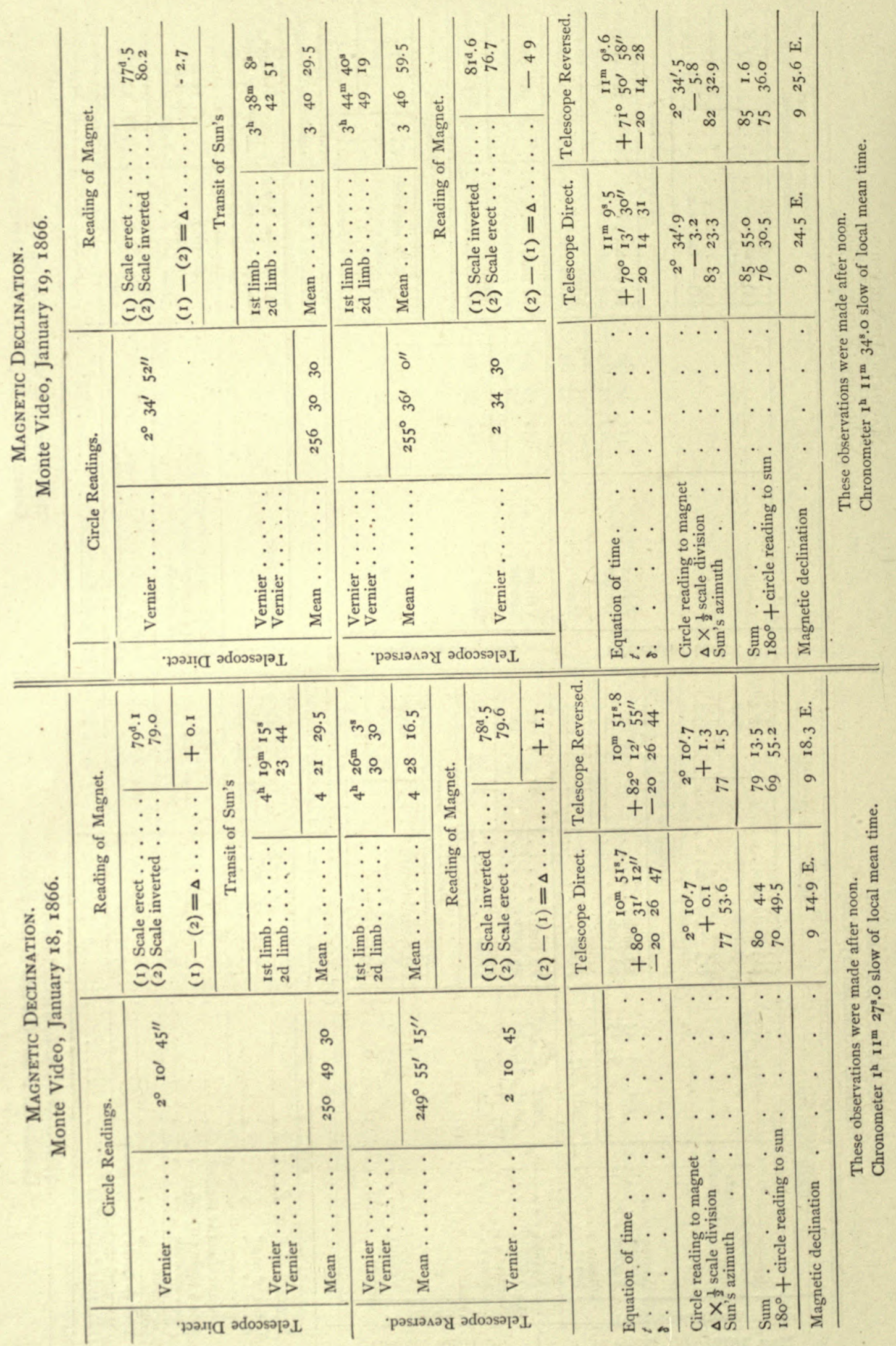




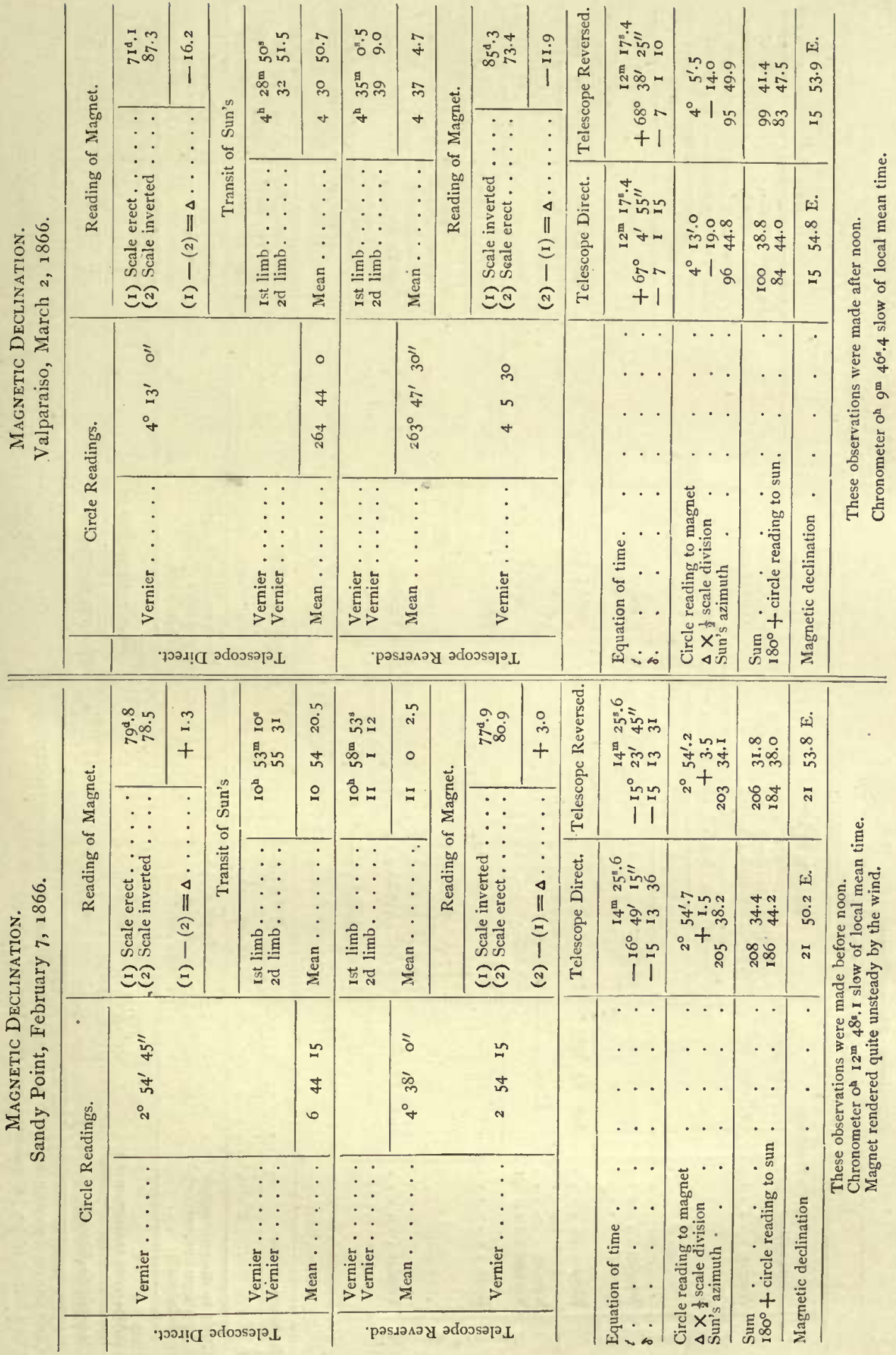




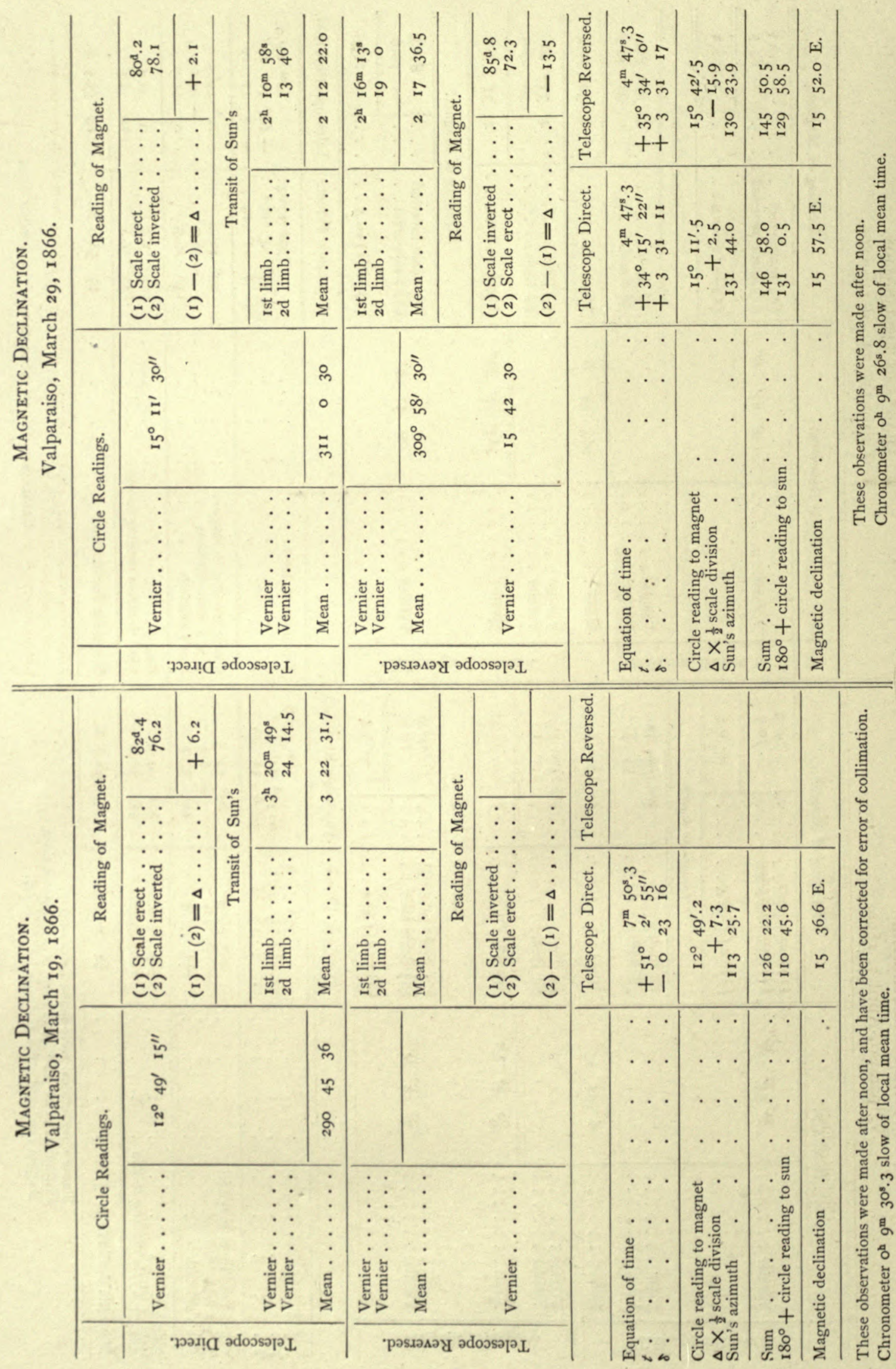




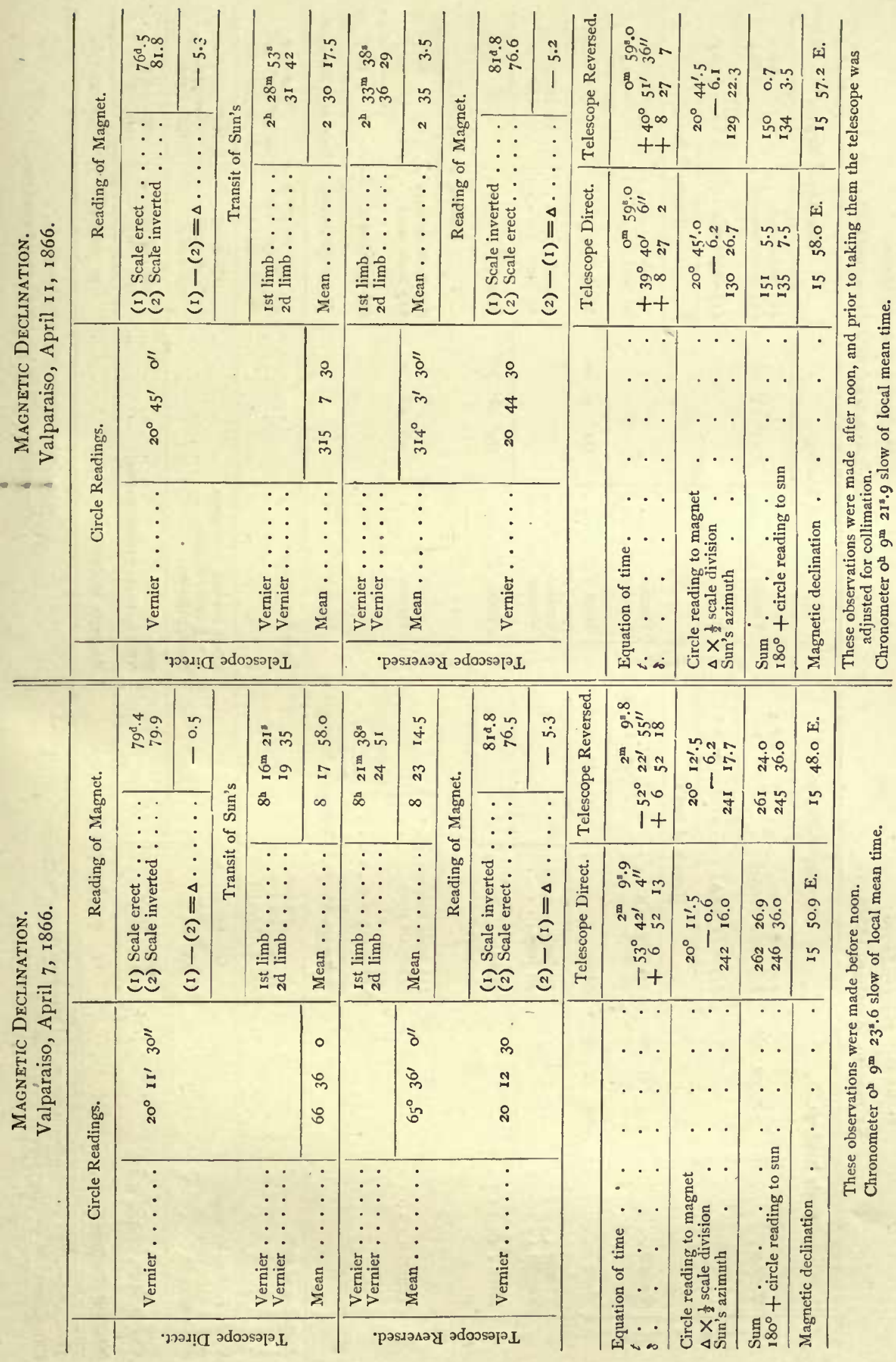



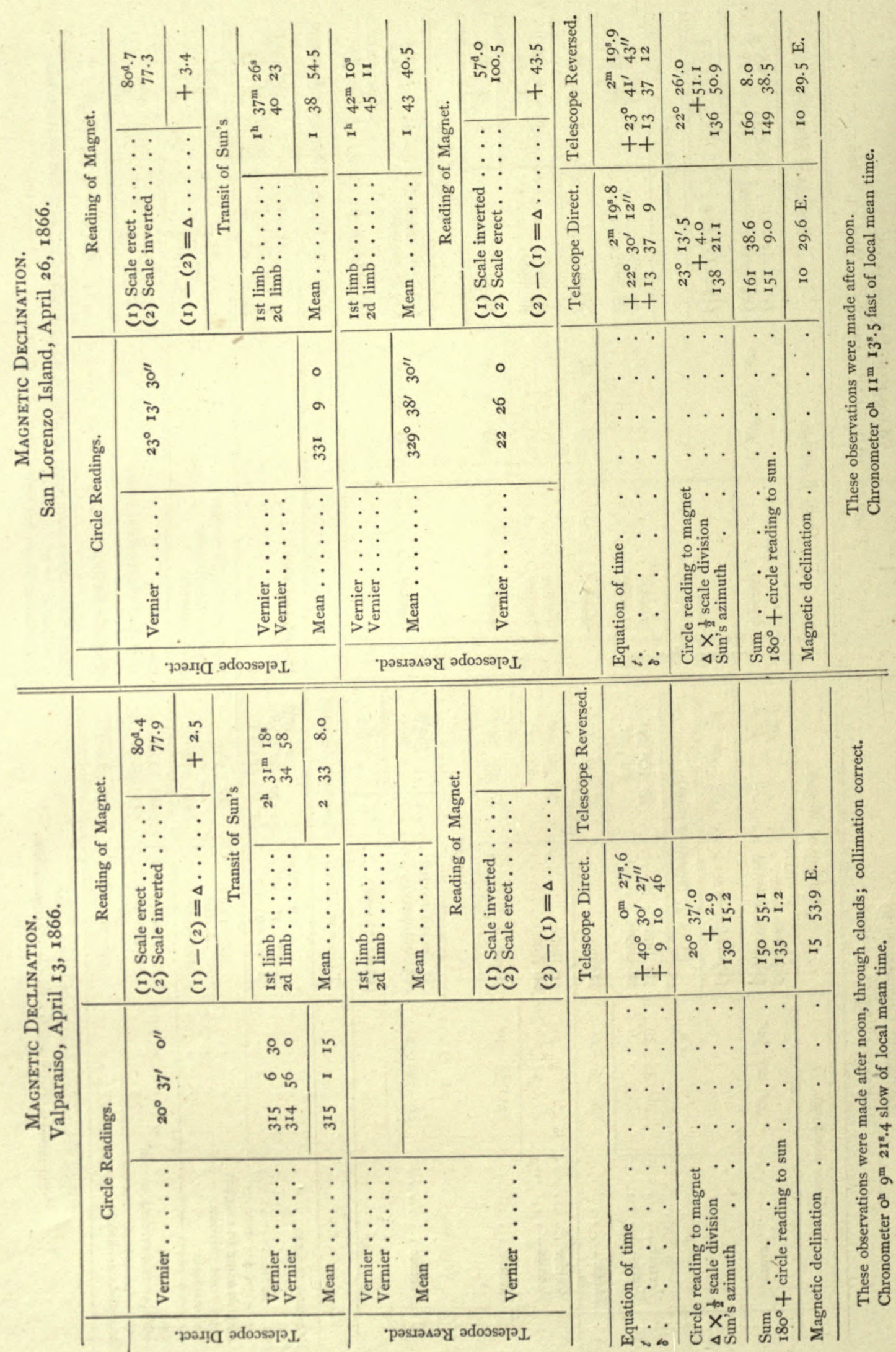


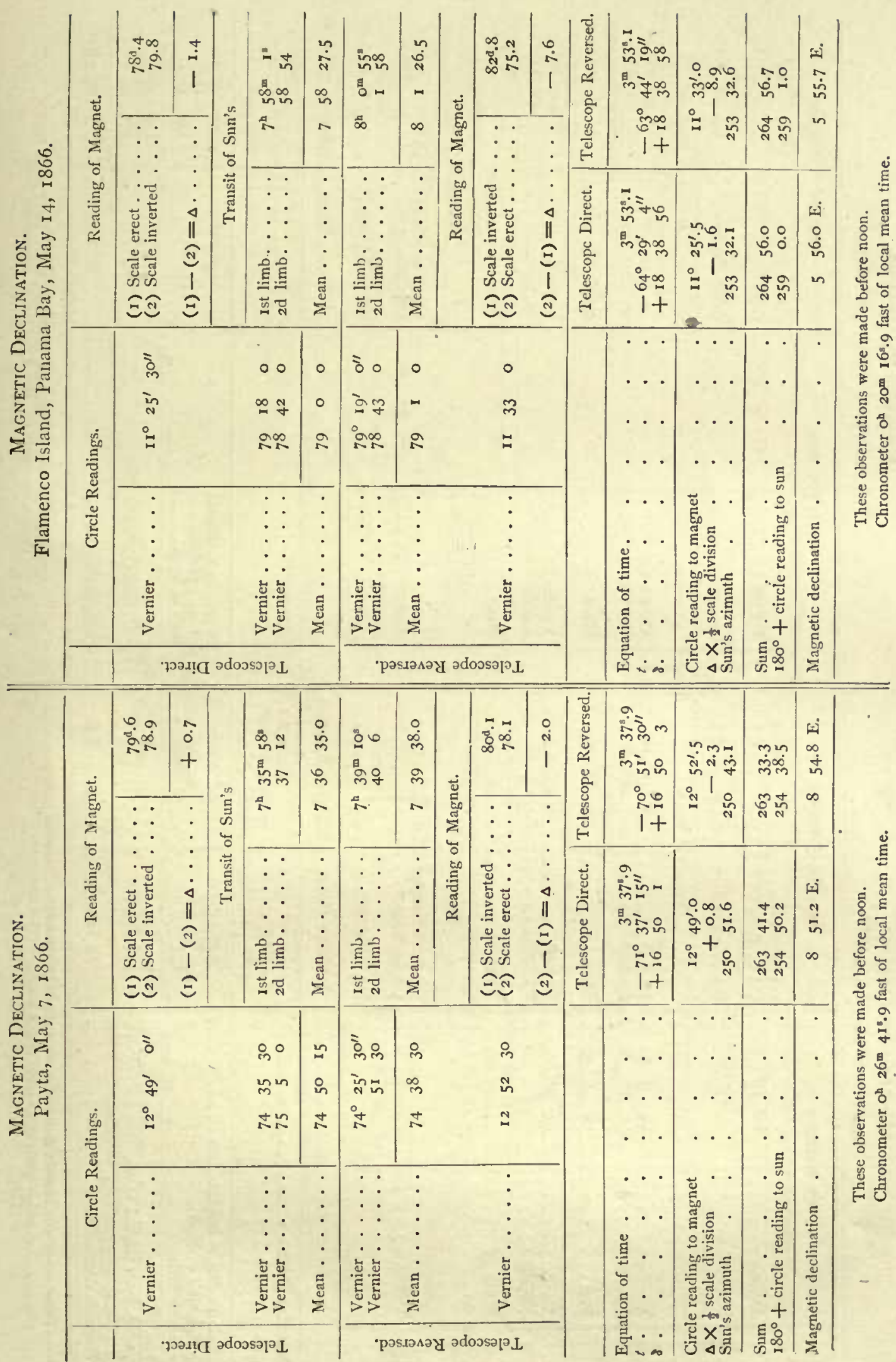




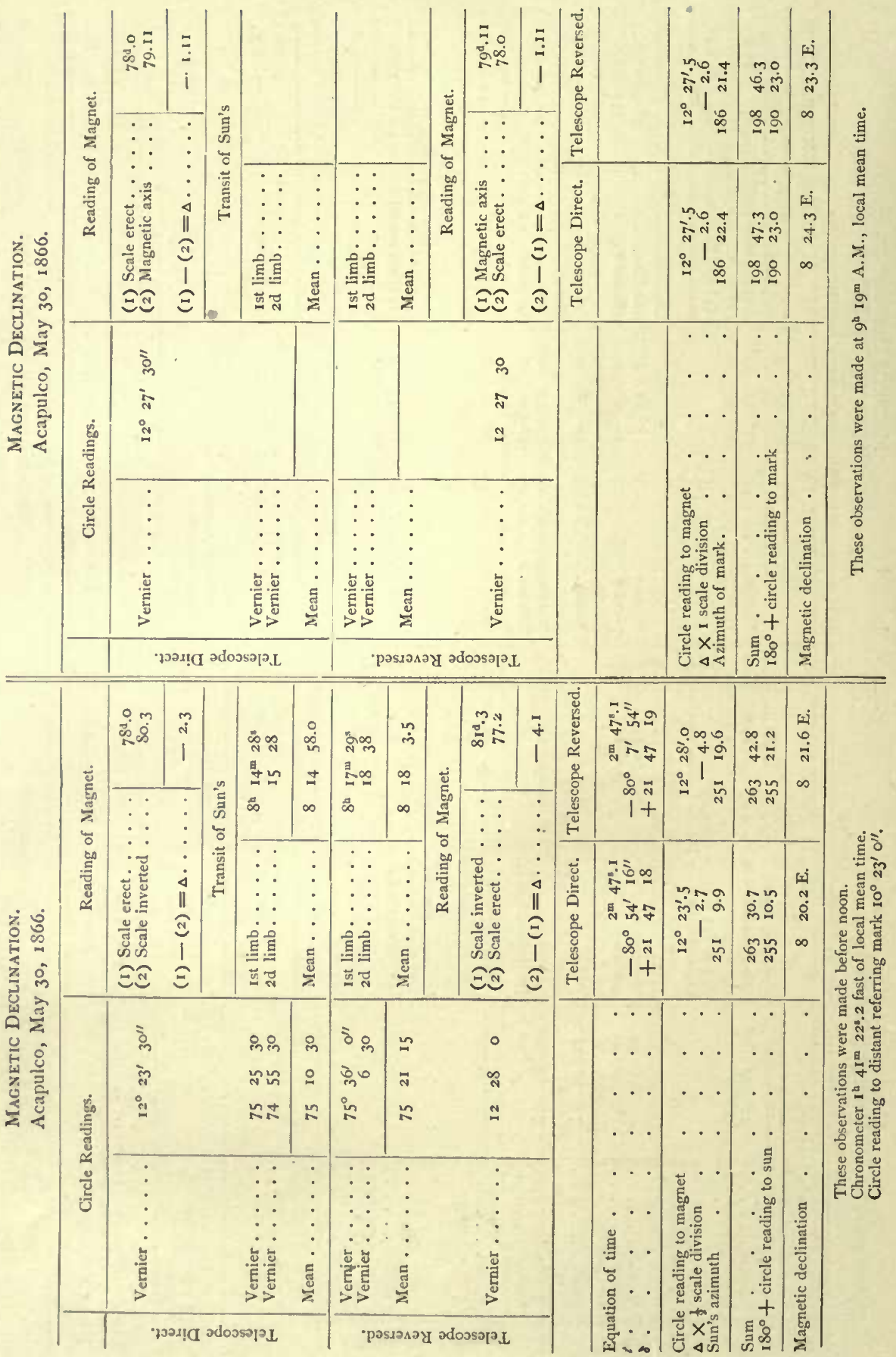


MAGNETIC OBSERVATIONS.

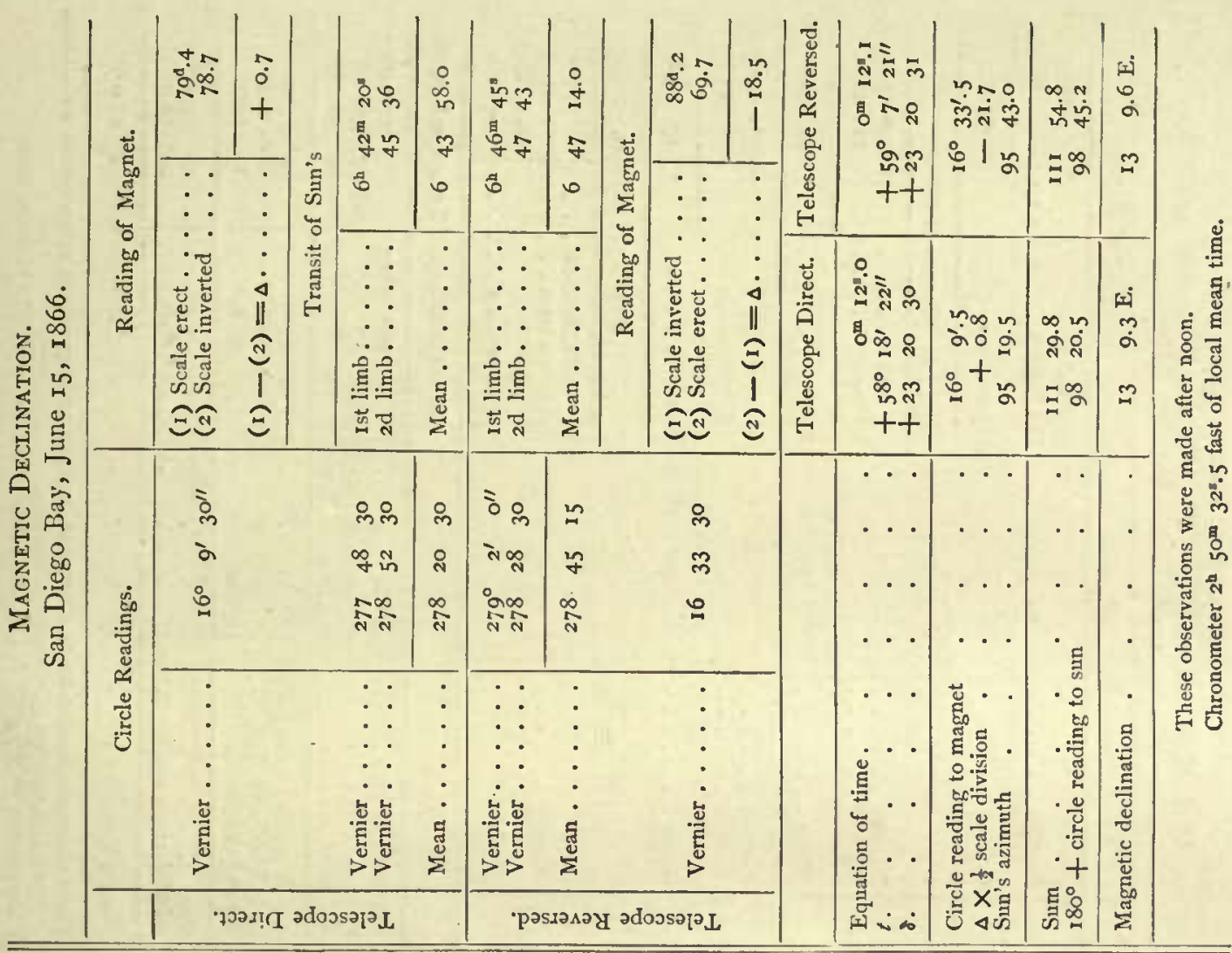

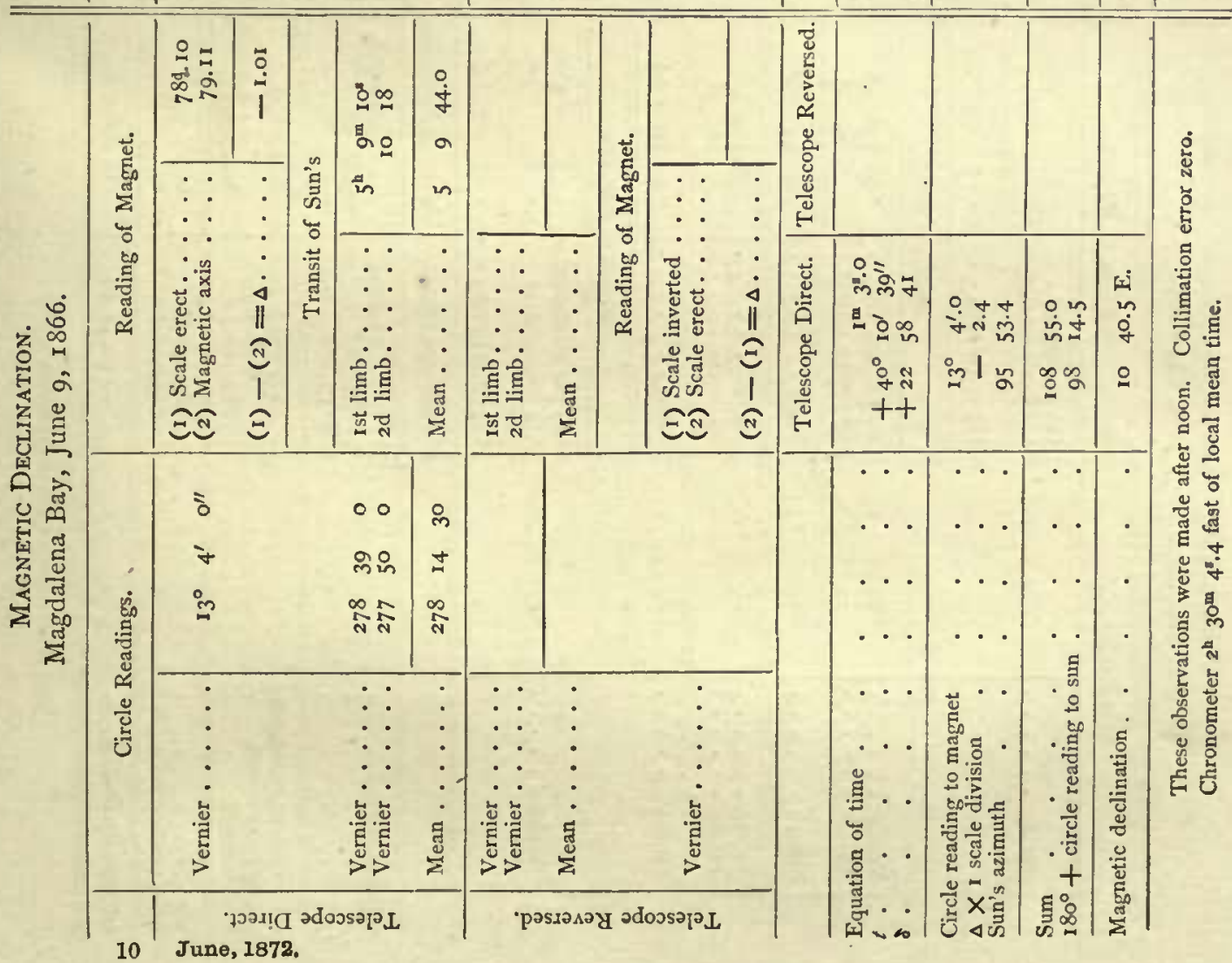




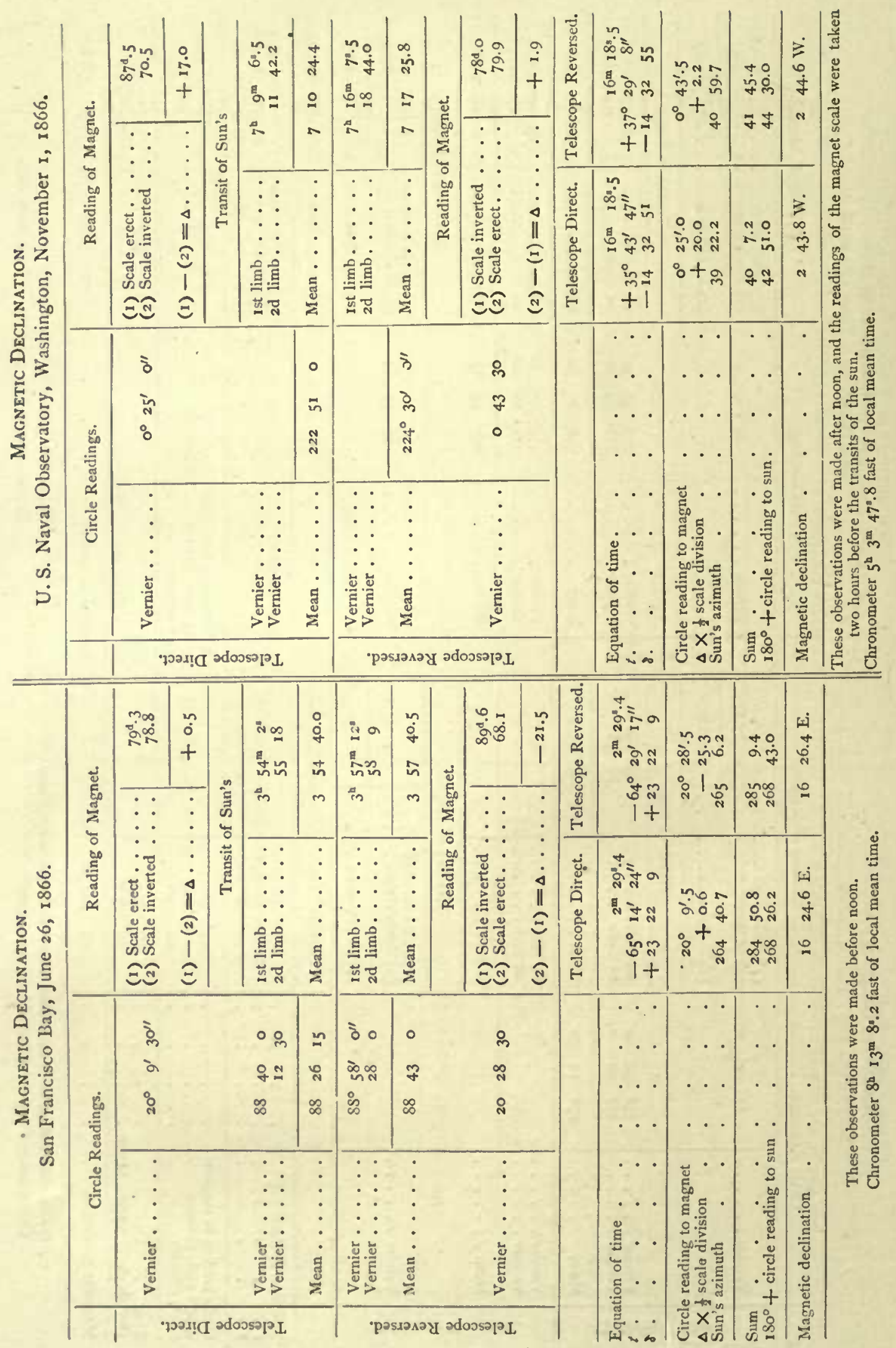




\section{OBSERVATIONS OF MAGNETIC INCLINATION.}

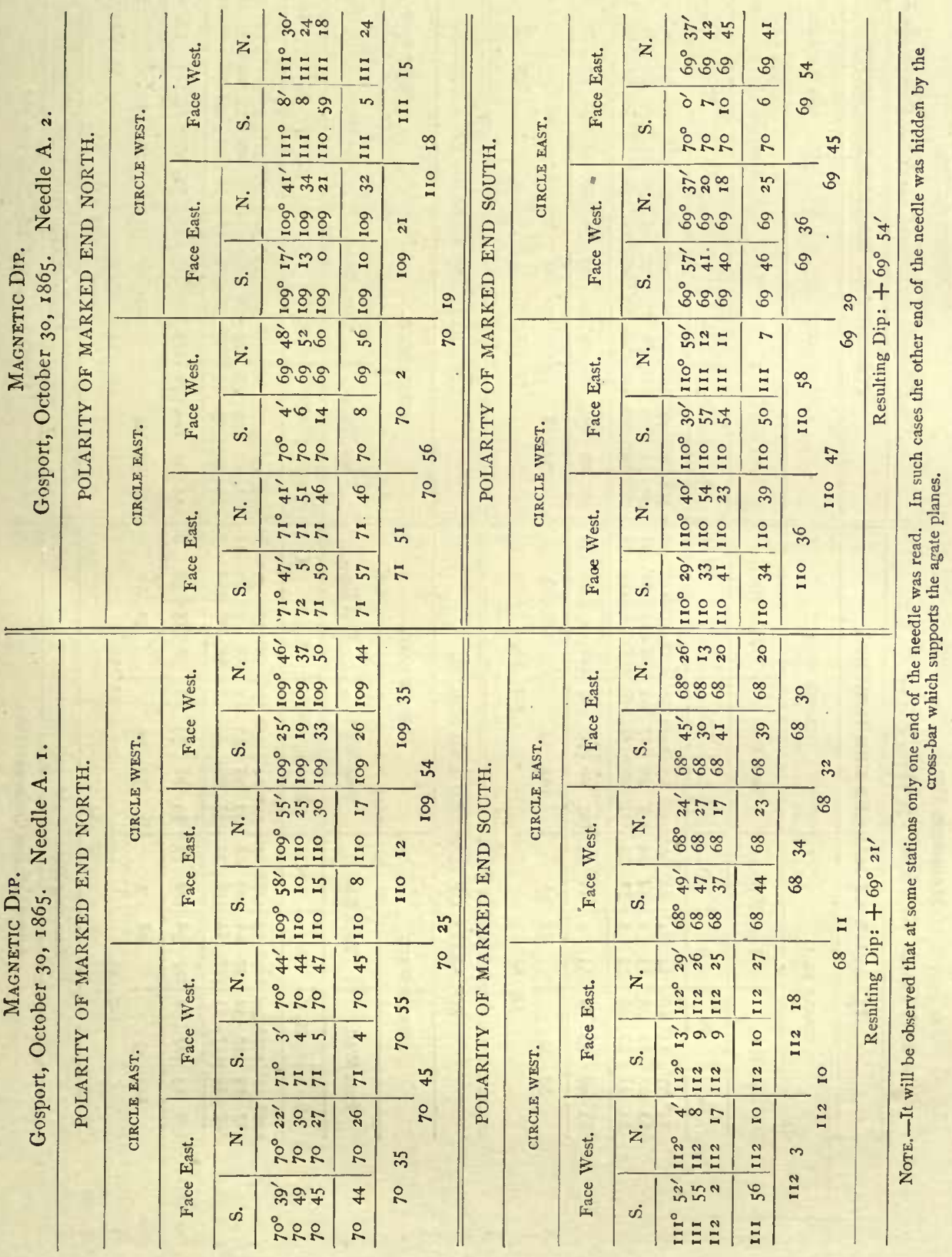




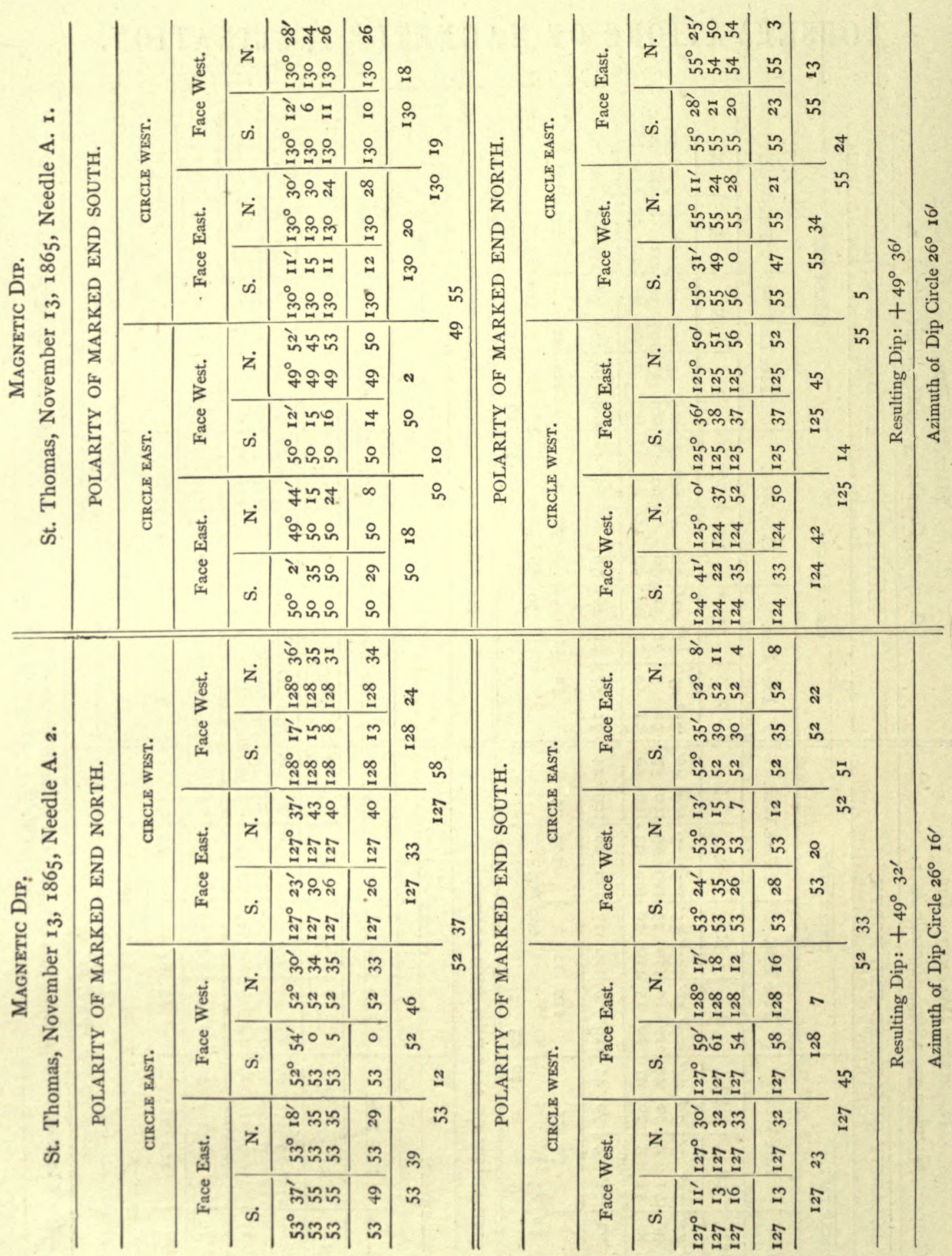




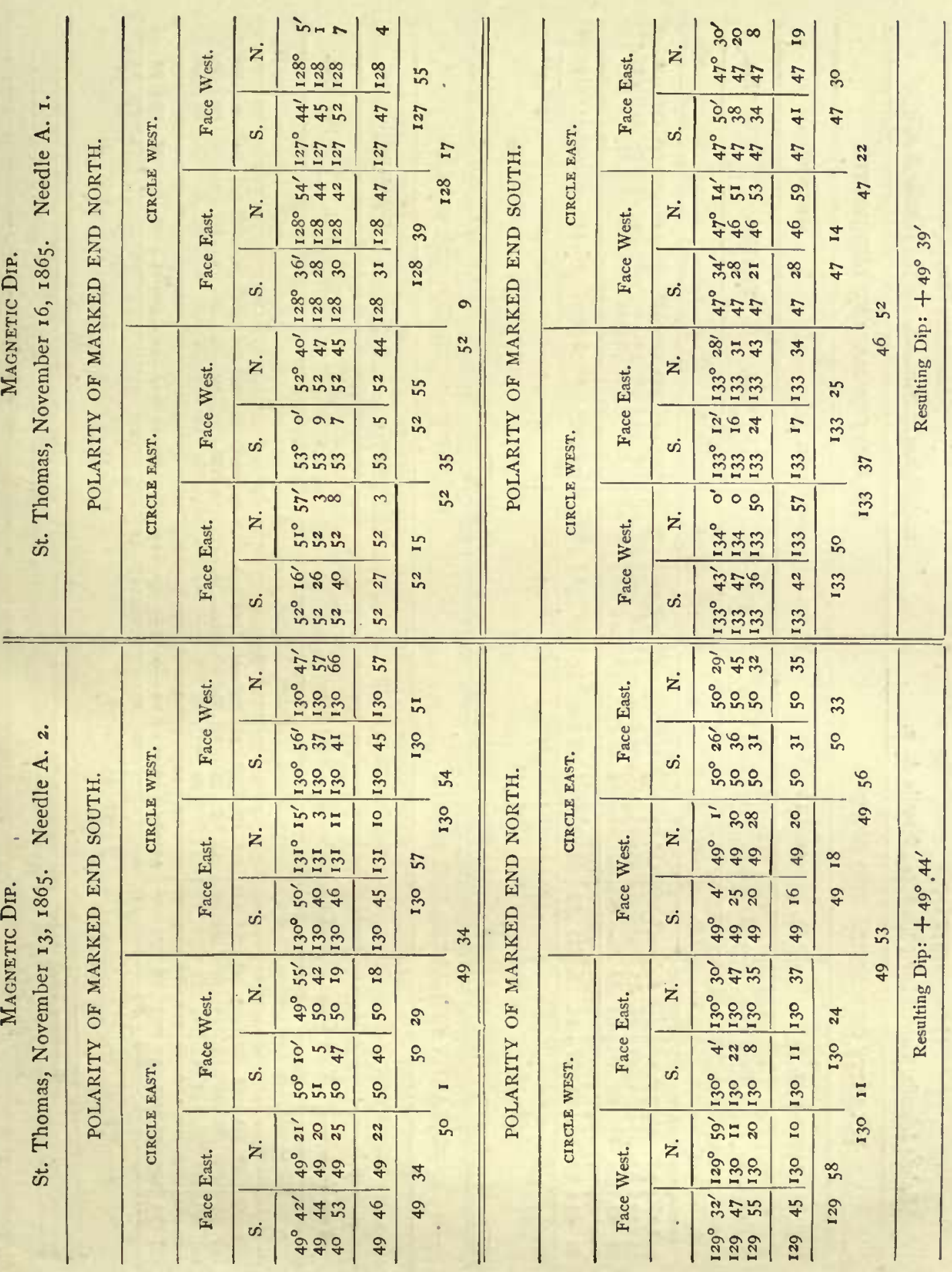




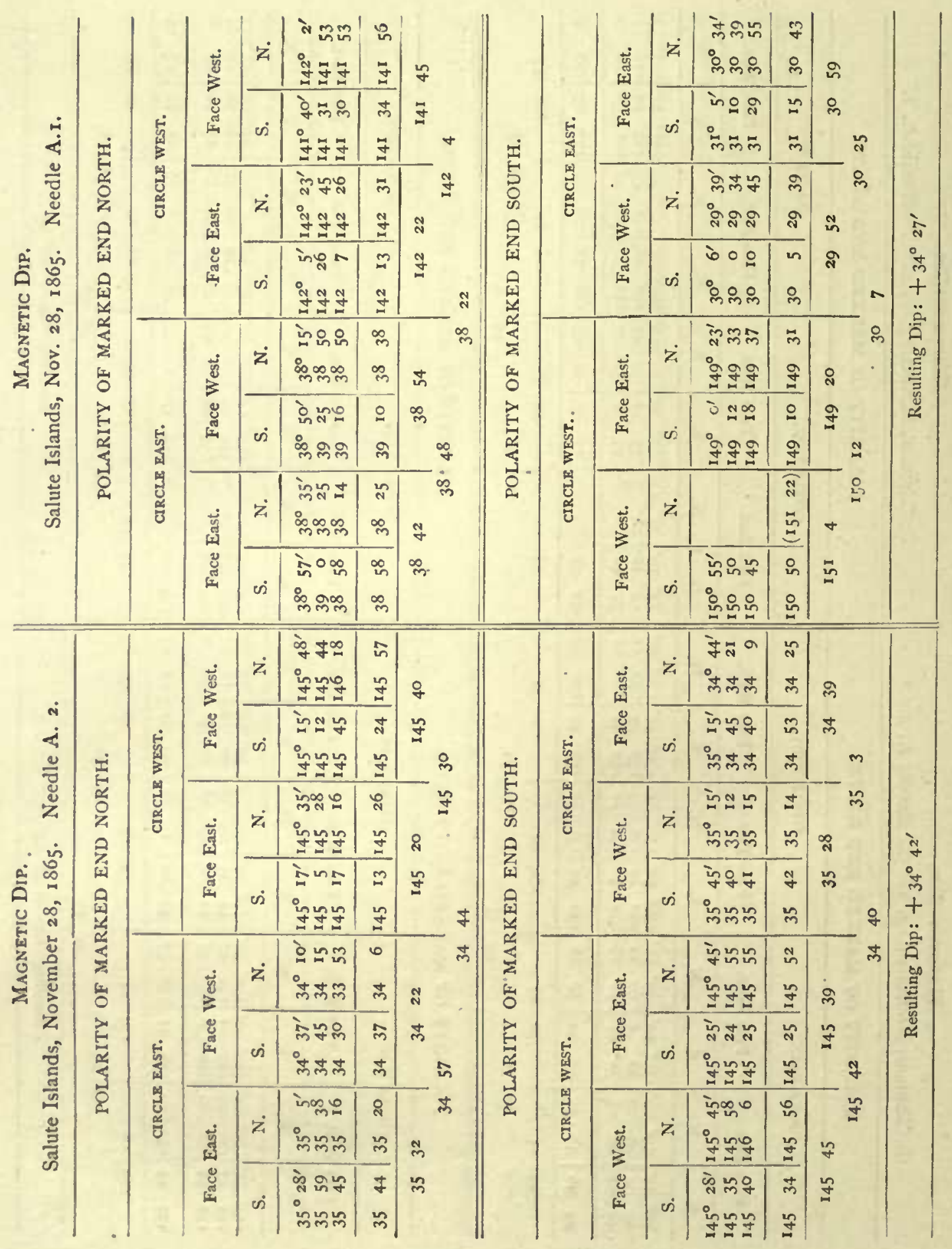








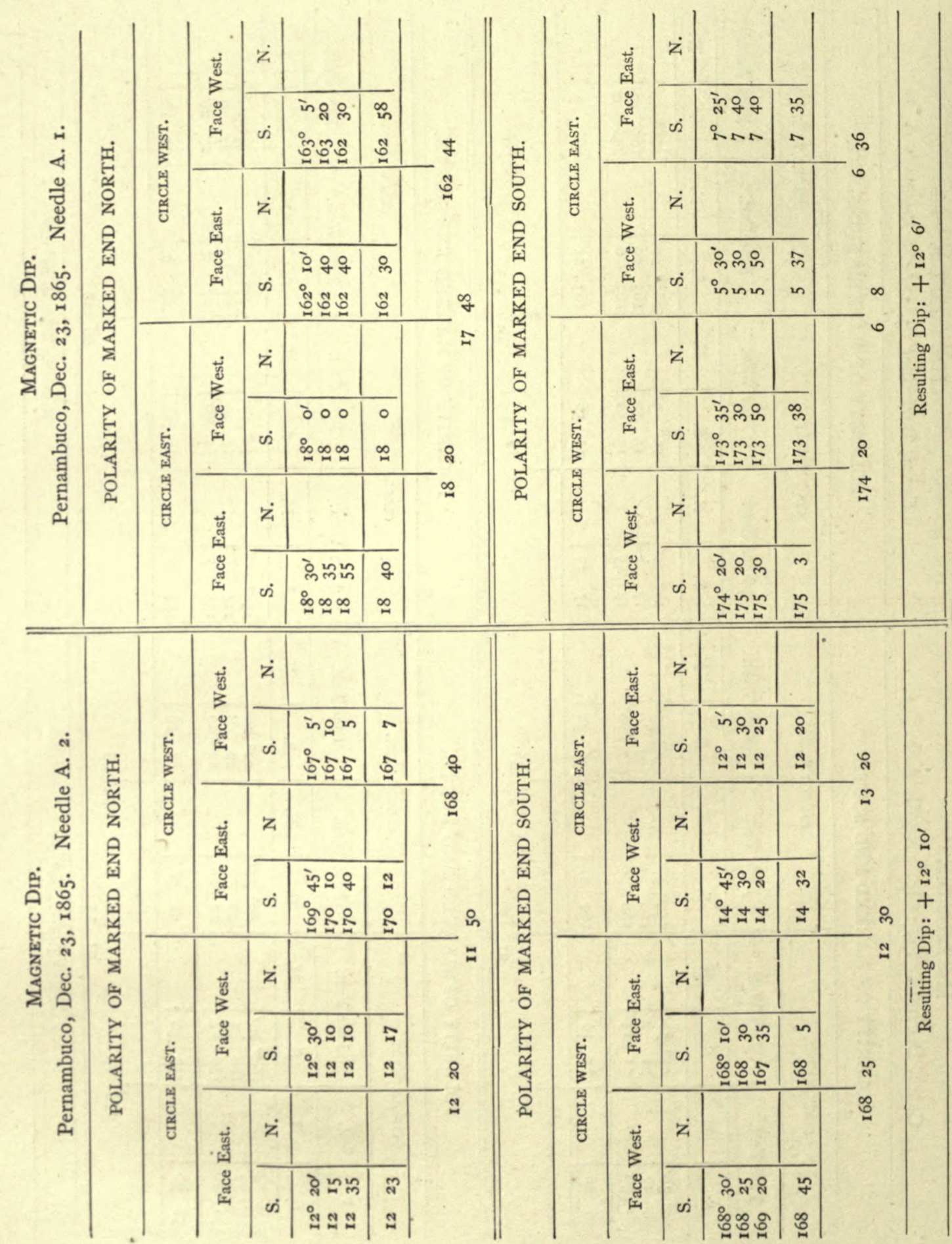


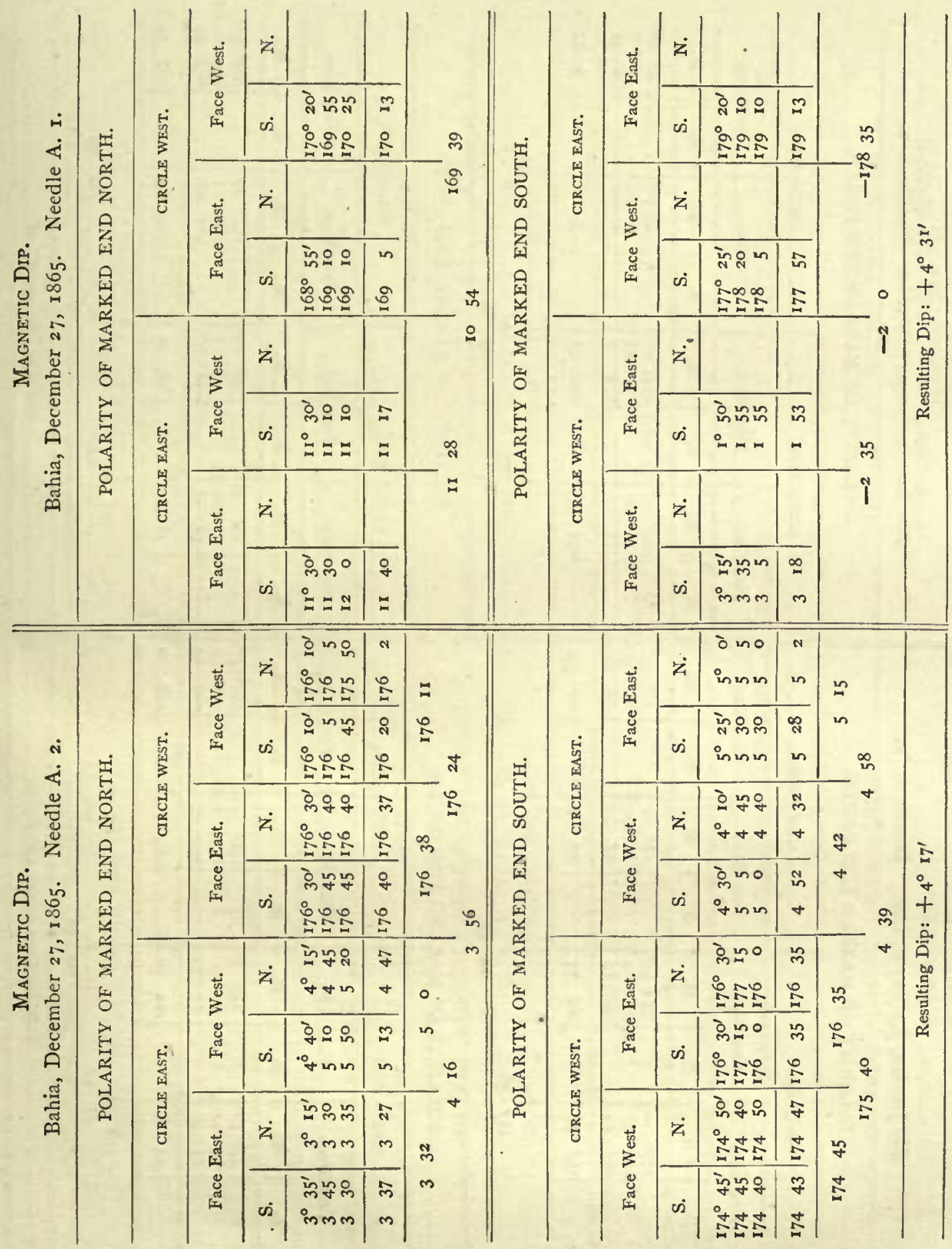




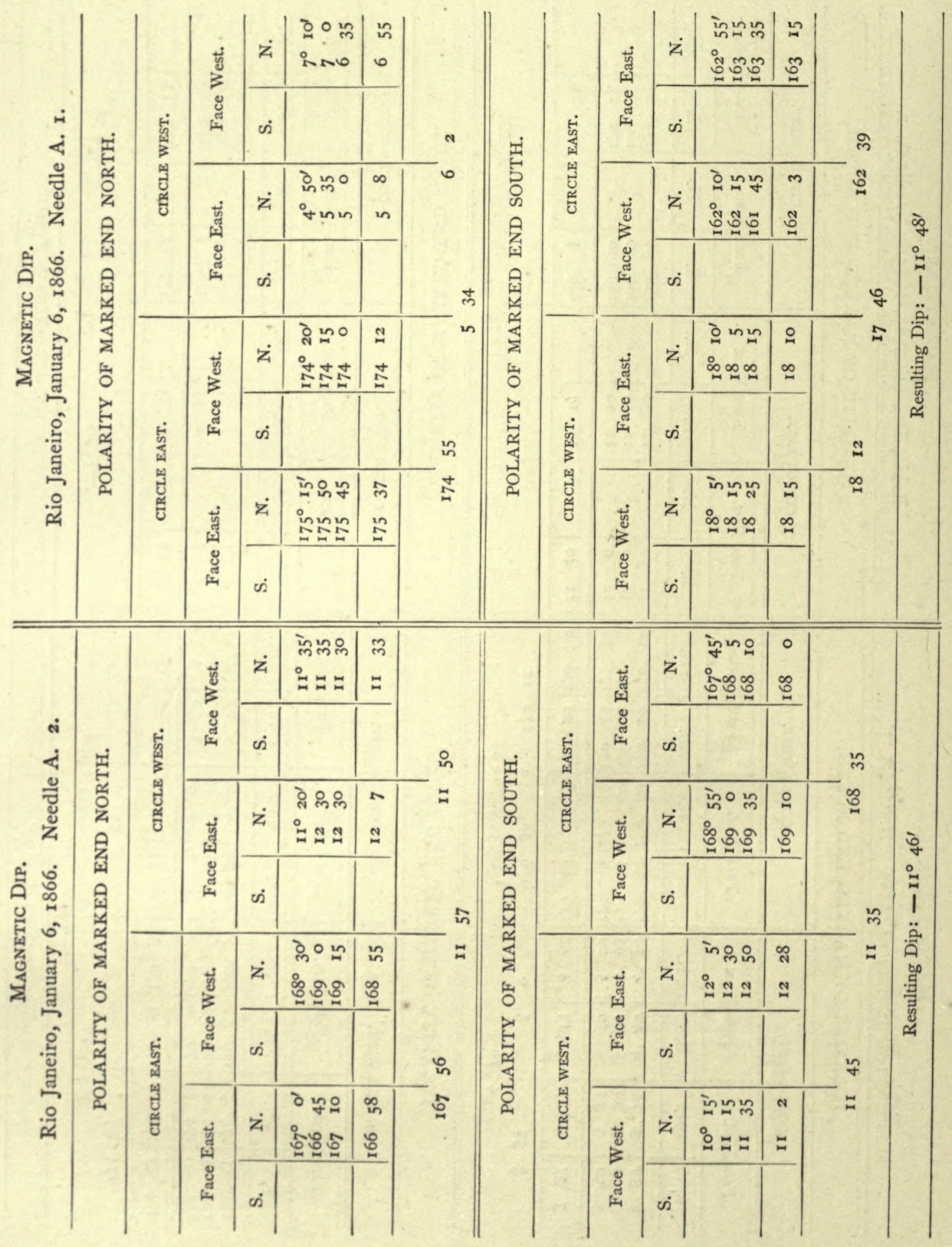




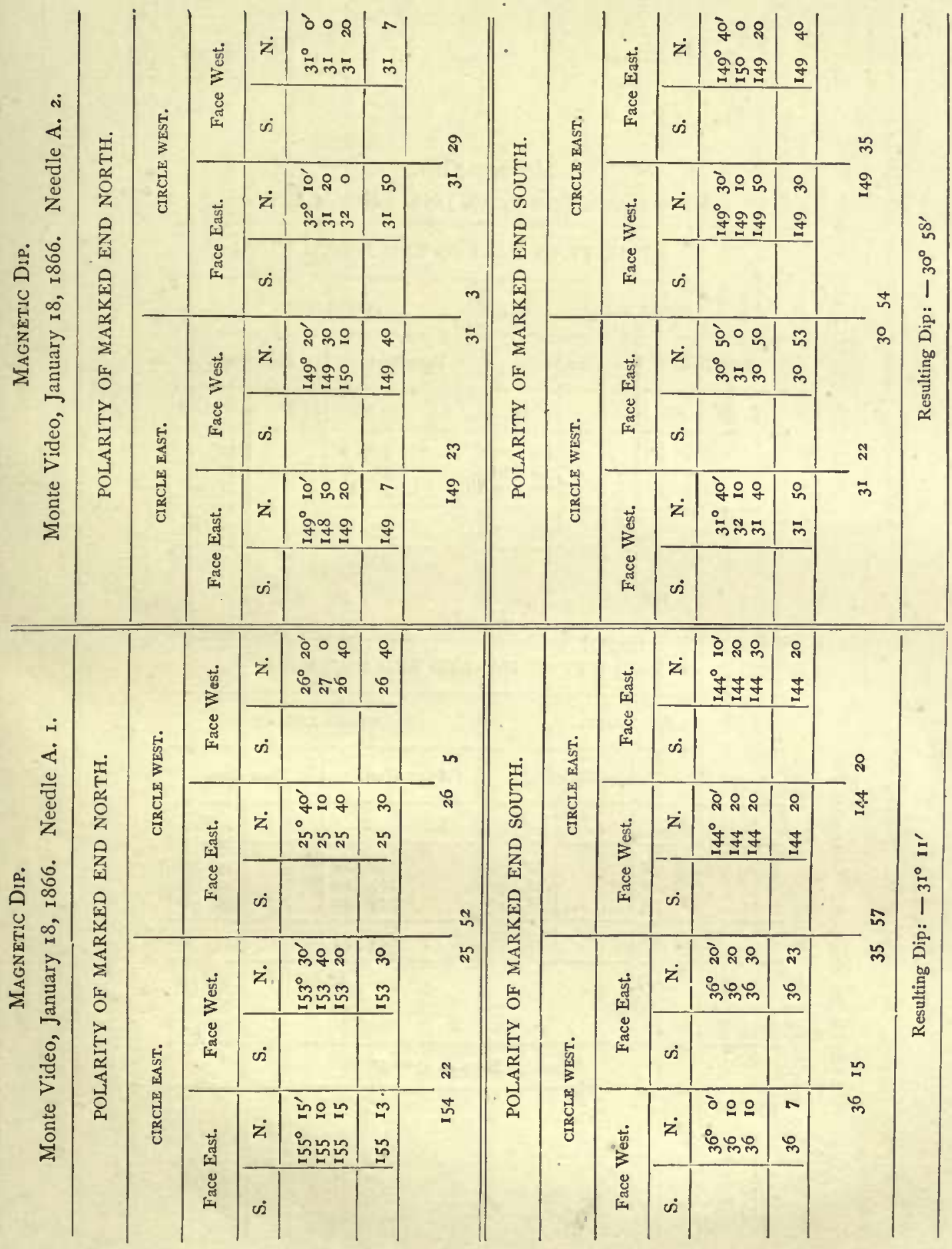


Magnetic Dip.

Monte Video, January 18, 1866. Needle A. 2.

POLARITY OF MARKED END NORTH.

\begin{tabular}{|c|c|c|c|c|c|c|c|}
\hline \multicolumn{4}{|c|}{ CIRCLE EAST. } & \multicolumn{4}{|c|}{ CIRCLE WEST. } \\
\hline \multicolumn{2}{|c|}{ Face East. } & \multicolumn{2}{|c|}{ Face West. } & \multicolumn{2}{|c|}{ Face East. } & \multicolumn{2}{|c|}{ Face West. } \\
\hline S. & N. & S. & N. & S. & N. & S. & N. \\
\hline & $\begin{array}{rr}148^{\circ} & 50^{\prime} \\
149 & 0 \\
149 & 30\end{array}$ & & $\begin{array}{ll}149^{\circ} & 20^{\prime} \\
148 & 50 \\
149 & 0\end{array}$ & A & $\begin{array}{ll}3 \mathrm{I}^{\circ} & \mathrm{O}^{\prime} \\
3 \mathrm{I} & 10 \\
3 \mathrm{I} & 20\end{array}$ & & $\begin{array}{ll}31^{\circ} & 0 \\
31 & 40 \\
31 & 40\end{array}$ \\
\hline & 1497 & & $149 \quad 3$ & & $31 \quad 10$ & & $\begin{array}{ll}31 & 27\end{array}$ \\
\hline - & - 149 & 5 & 31 & 7 & $3 I$ & I9 & \\
\hline
\end{tabular}

POLARITY OF MARKED END SOUTH.

\begin{tabular}{|c|c|c|c|c|c|c|c|}
\hline & \multicolumn{2}{|c|}{ CIRCLE WEST } & . & \multicolumn{4}{|c|}{ CIRCLE EAST. } \\
\hline \multicolumn{2}{|c|}{ Face West. } & \multicolumn{2}{|c|}{ Face East. } & \multicolumn{2}{|c|}{ Face West. } & \multicolumn{2}{|c|}{ Face East. } \\
\hline S. & N. & $\mathrm{S}$. & N. & S. & N. & S. & N. \\
\hline & $\begin{array}{lr}32^{\circ} & 0^{\prime} \\
32 & 0 \\
3^{1} & 50 \\
\end{array}$ & & $\begin{array}{lr}3 \mathbf{I}^{\circ} & 0^{\prime} \\
31 & 20 \\
3 \mathbf{I} & 40\end{array}$ & & $\begin{array}{ll}149^{\circ} & 1^{\prime} \\
149 & 10 \\
149 & 20\end{array}$ & & $\begin{array}{ll}149^{\circ} & 10^{\prime} \\
149 & 3^{\circ} \\
\text { I49 } & 5^{\circ}\end{array}$ \\
\hline & $31 \quad 57$ & & $31 \quad 20$ & & $149 \quad 13$ & & $149 \quad 30$ \\
\hline & $3 \mathbf{I}$ & 39 & $3^{\mathrm{I}}$ & 8 & I49 & 22 & \\
\hline & & & ulting $\mathrm{Di}_{\mathbf{I}}$ & $-3^{\mathrm{I}^{\circ}}$ & $8^{\prime}$ & & \\
\hline
\end{tabular}




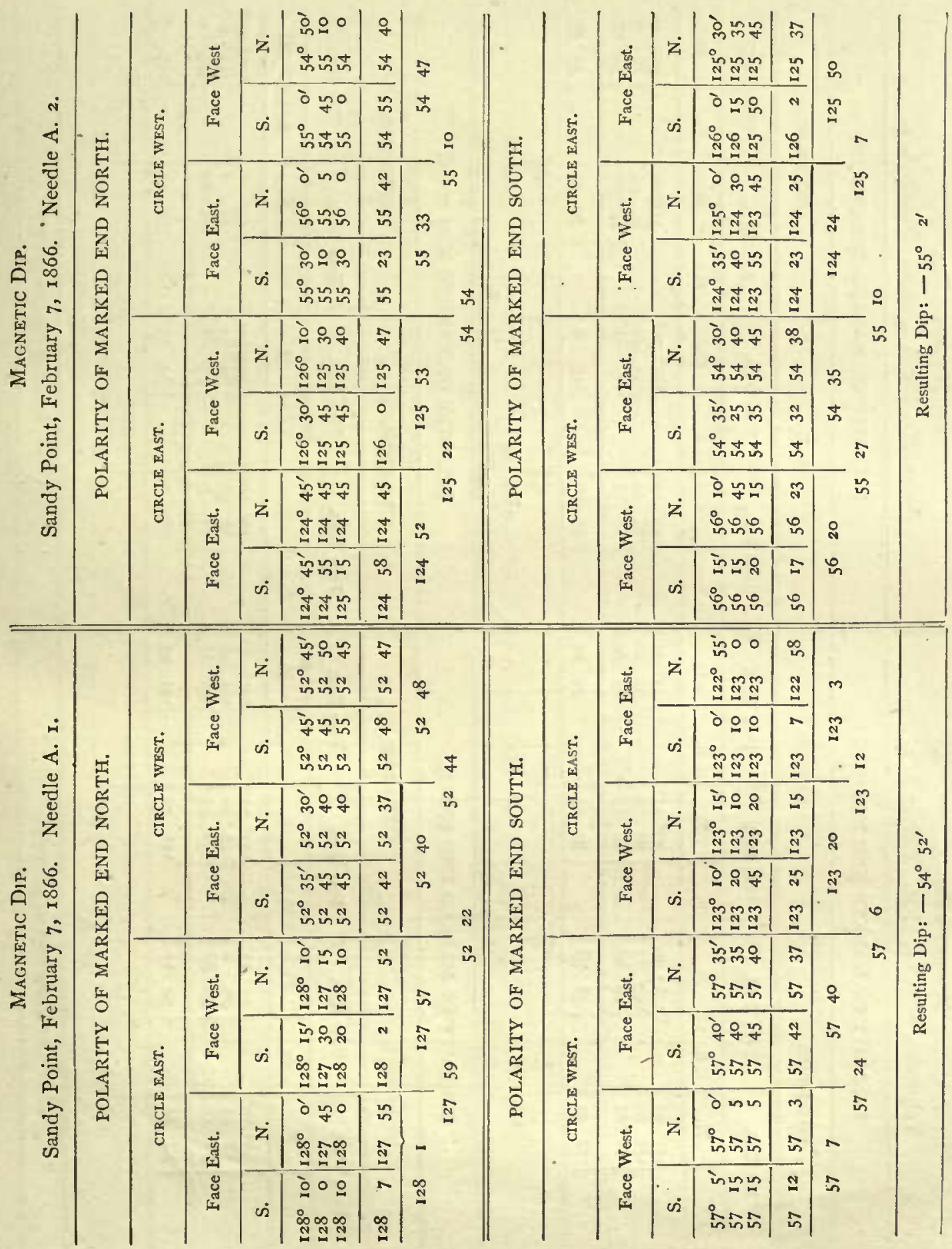



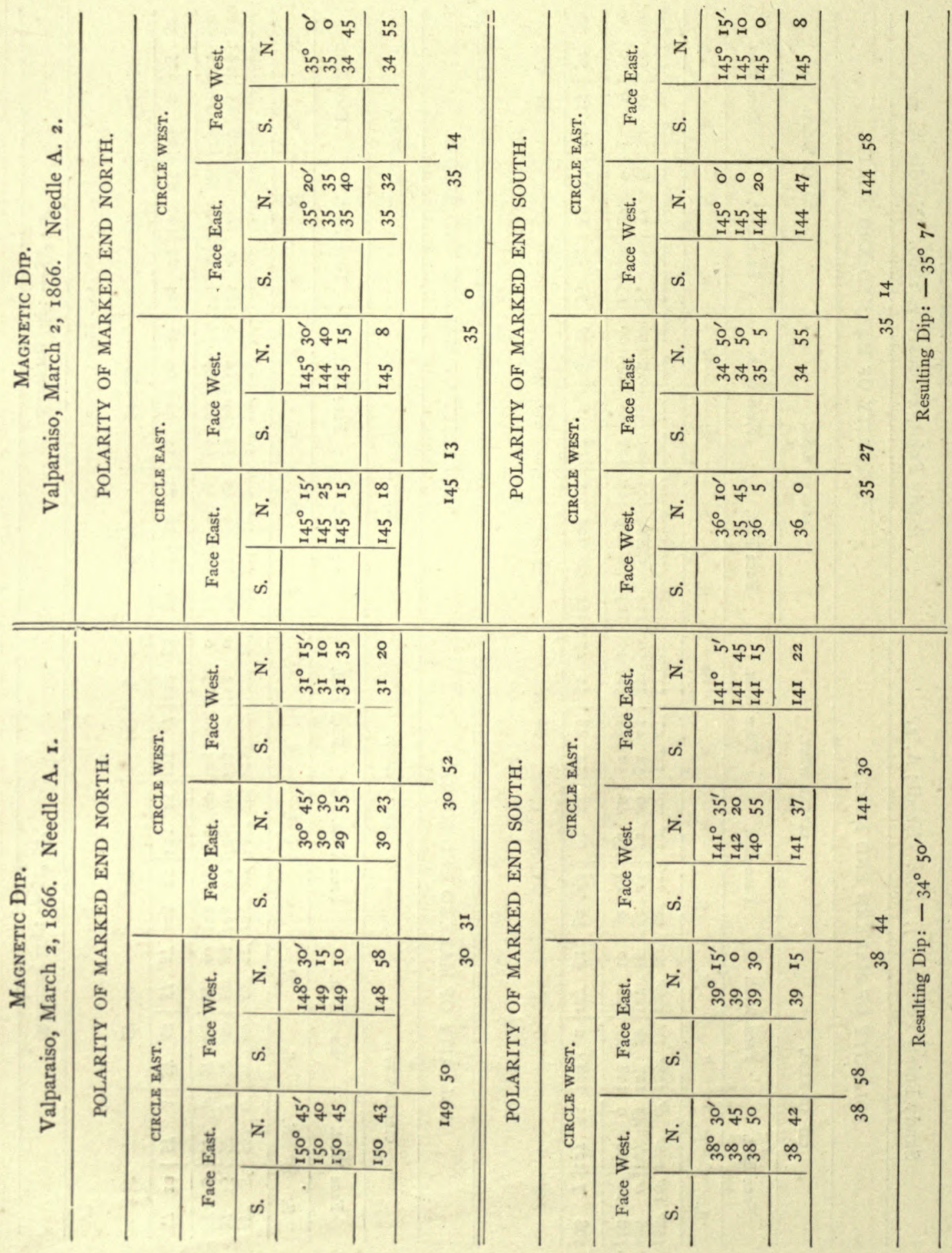


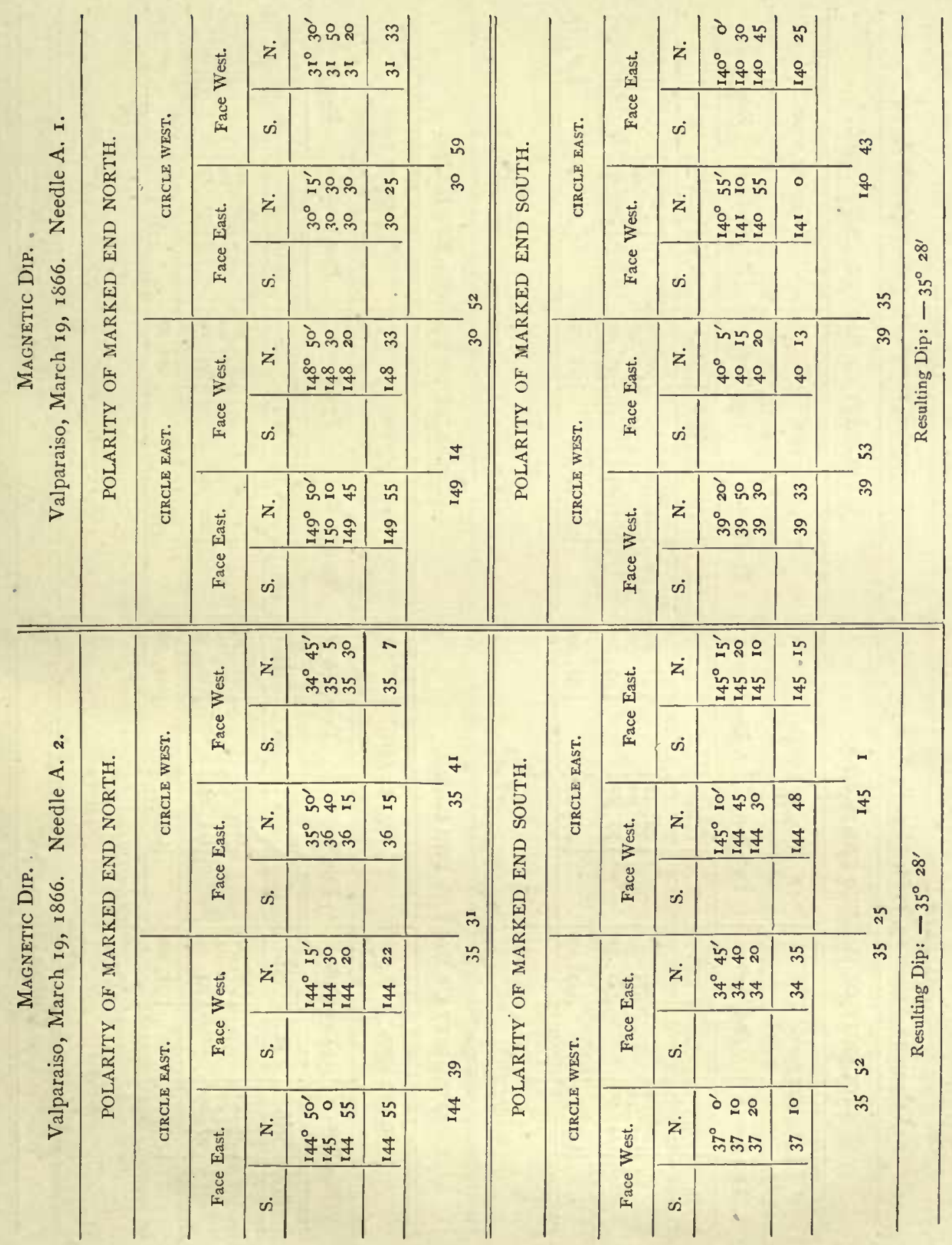



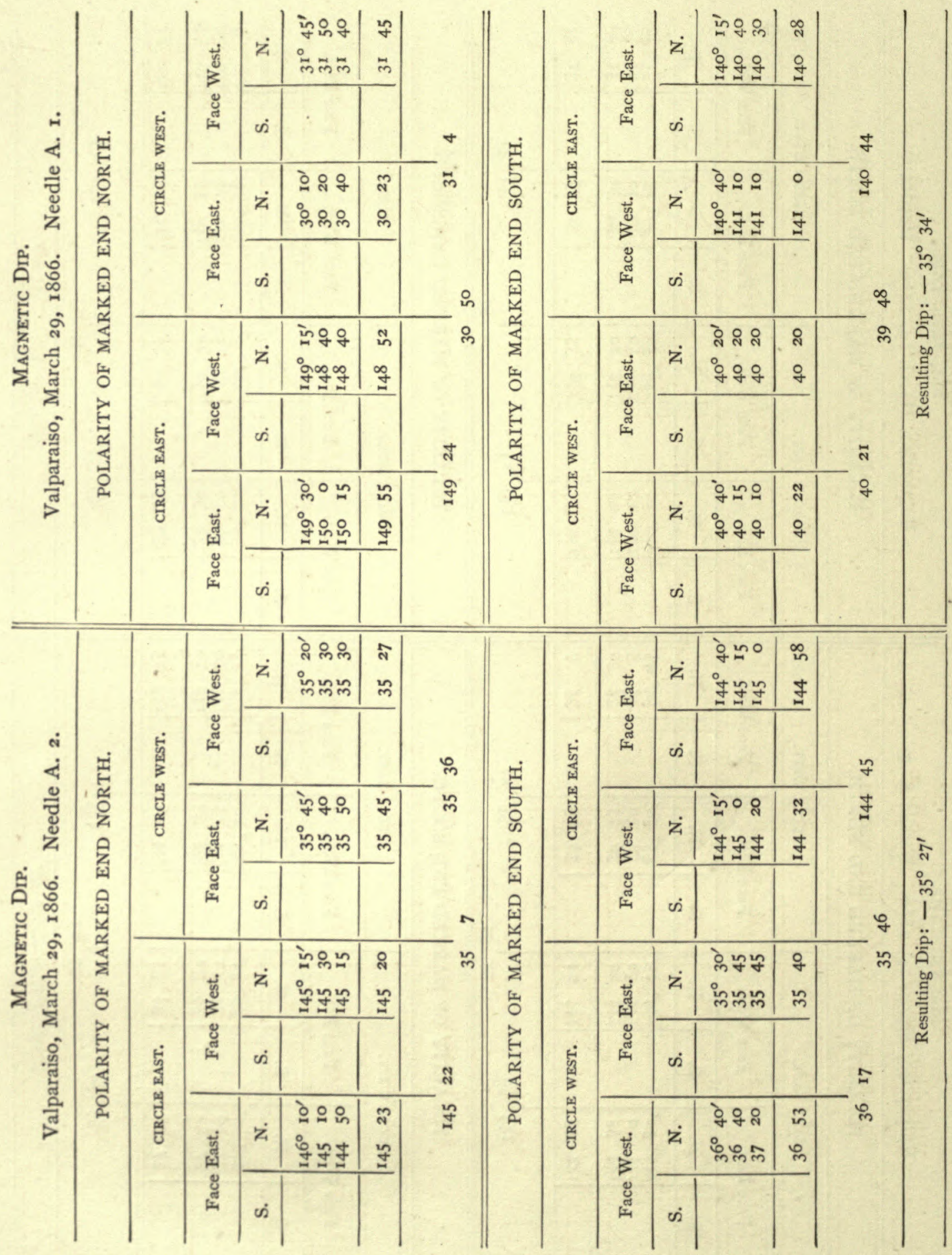

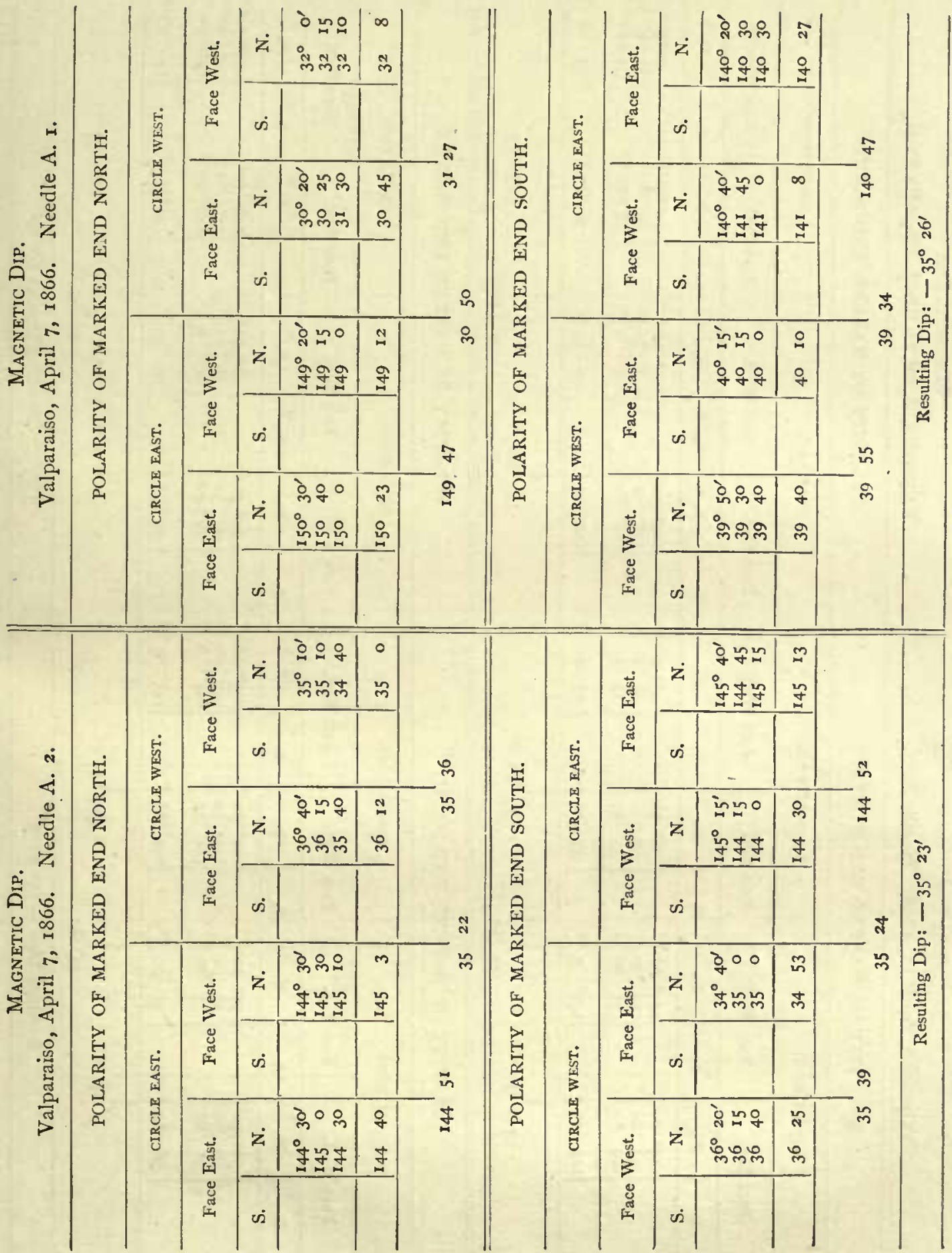

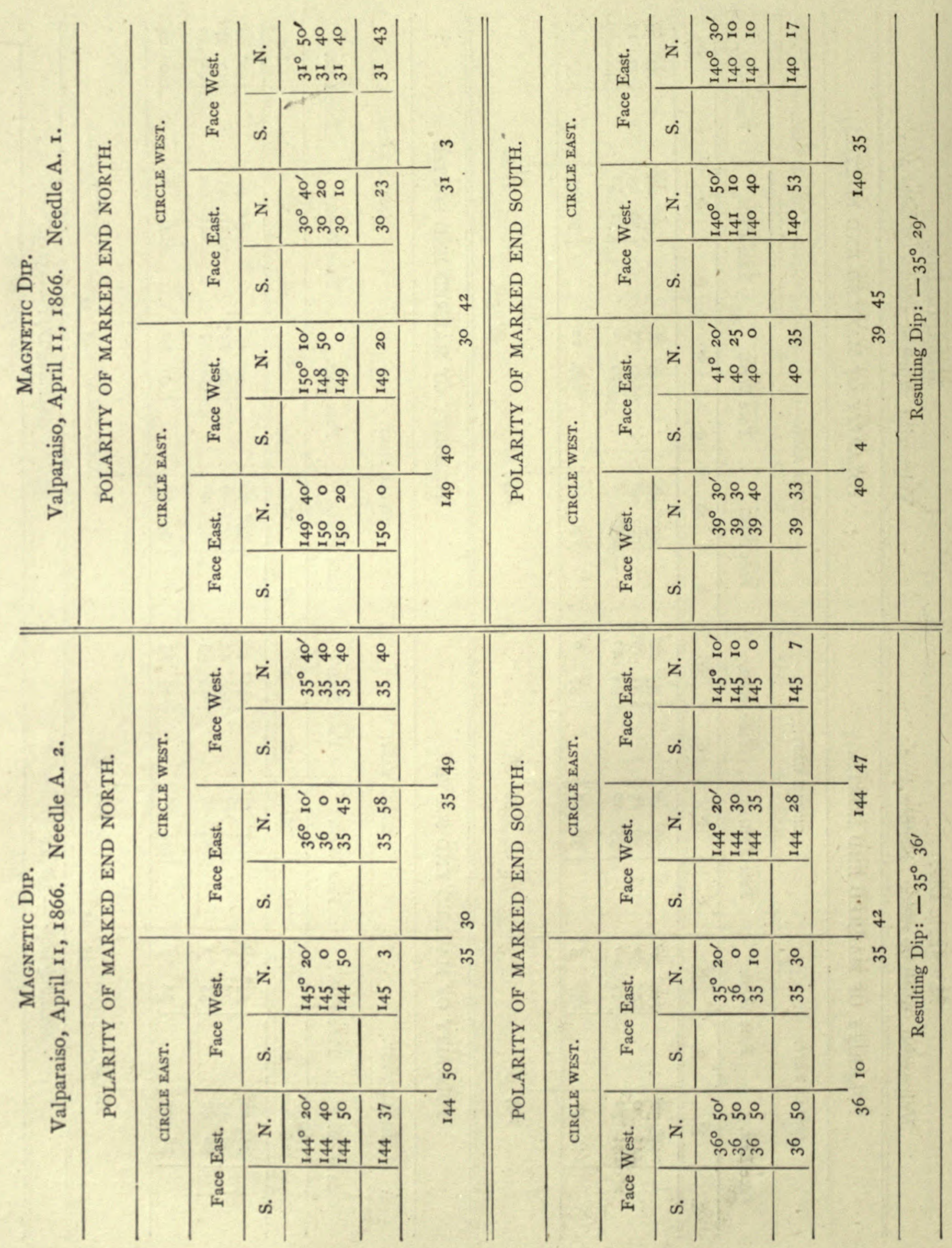

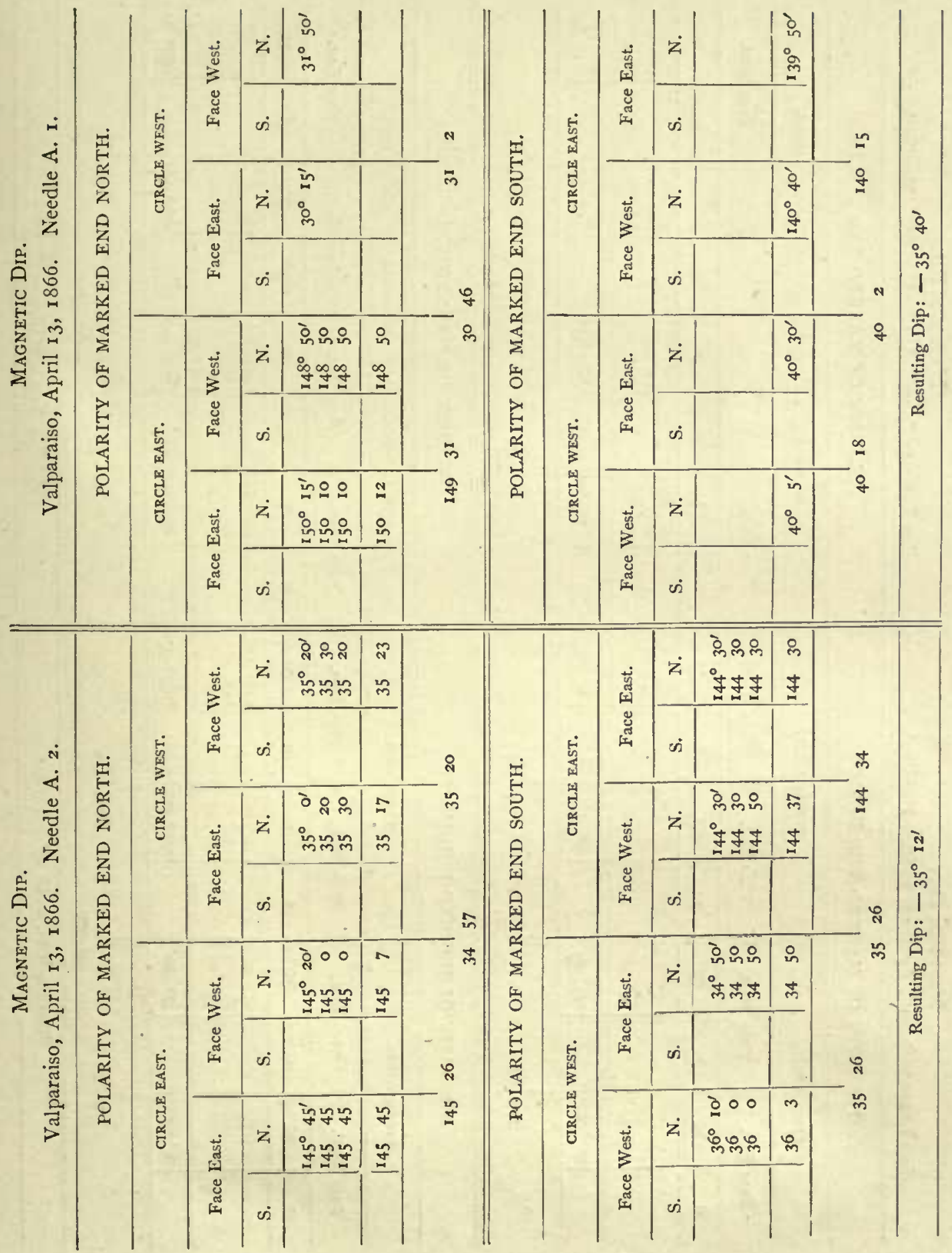


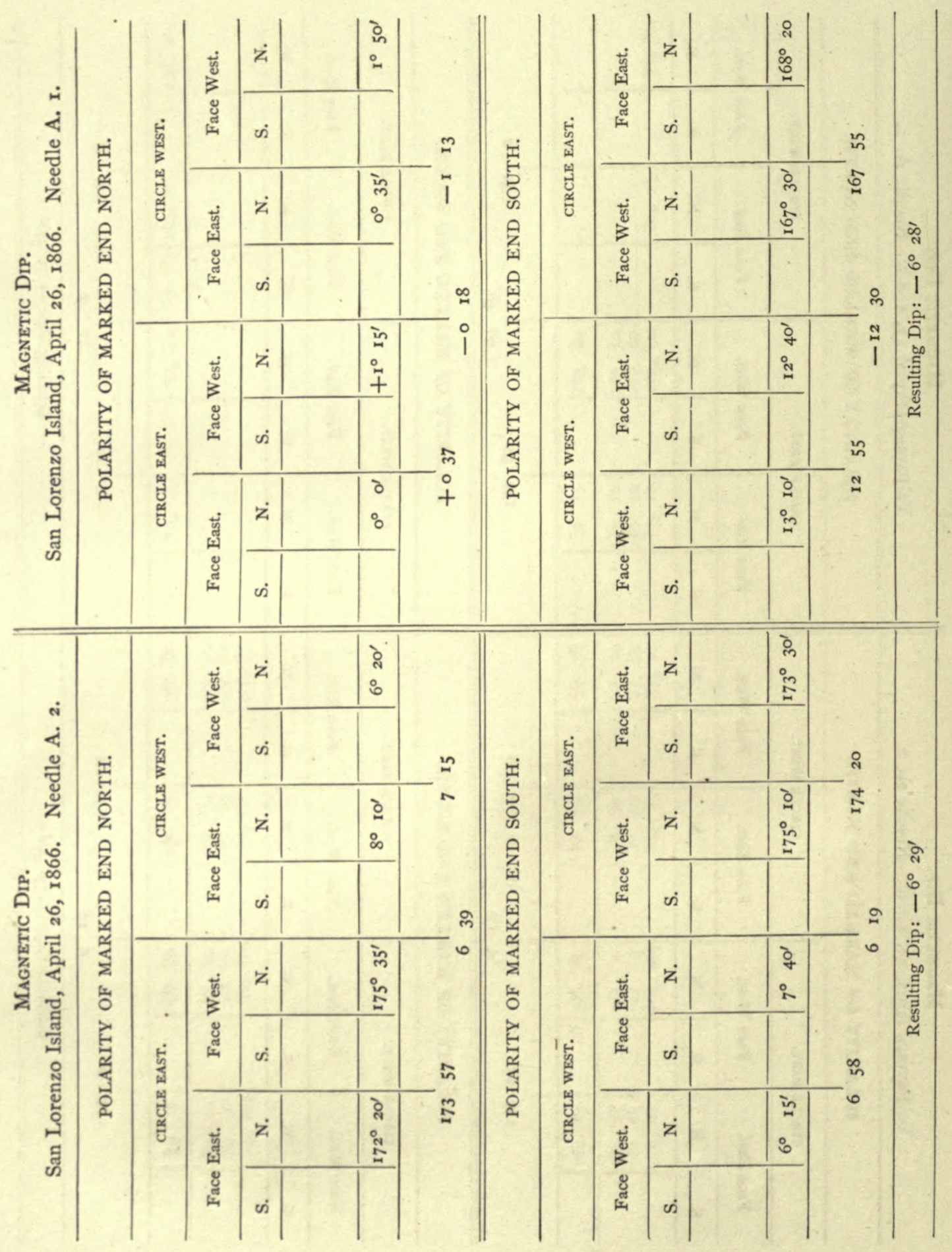




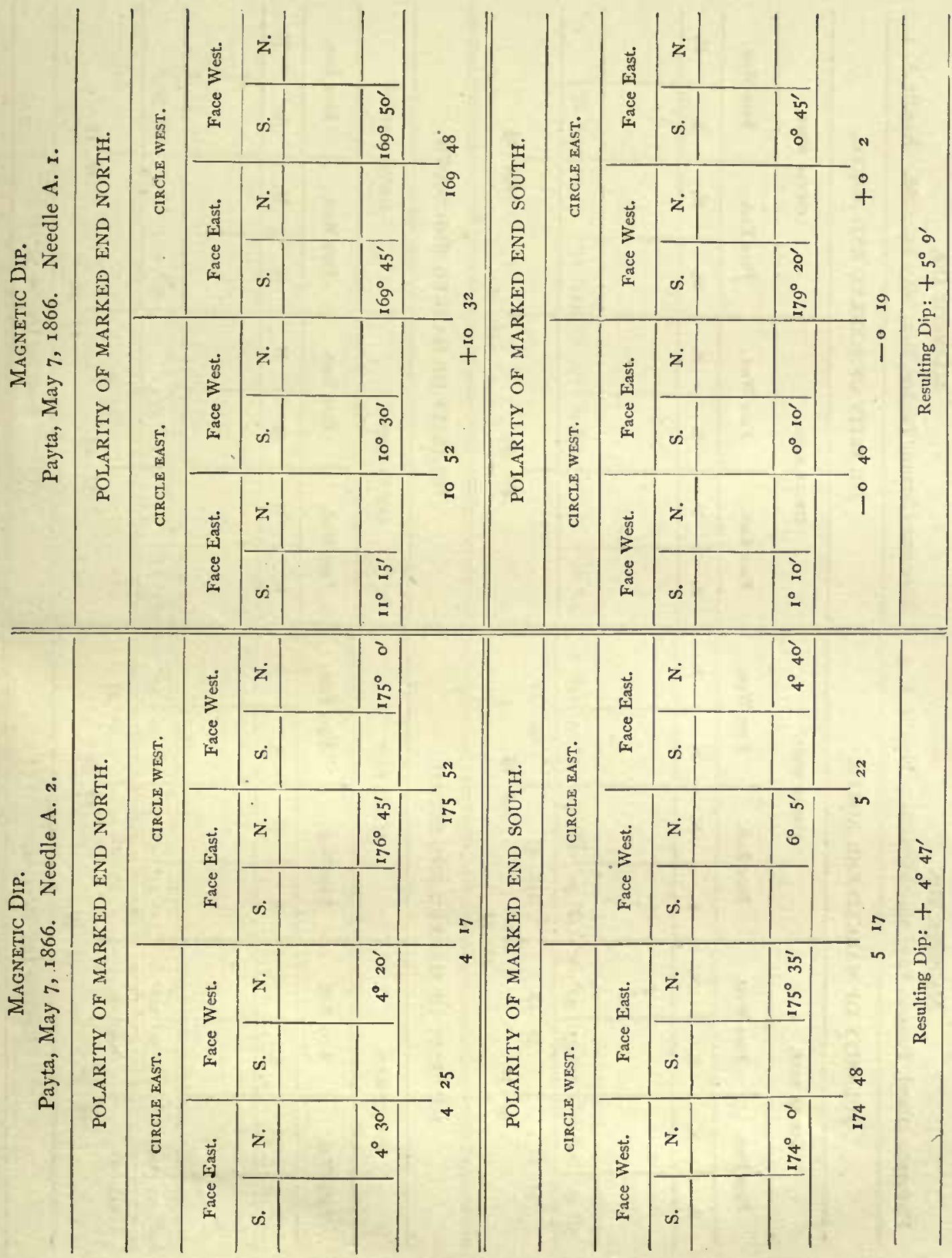




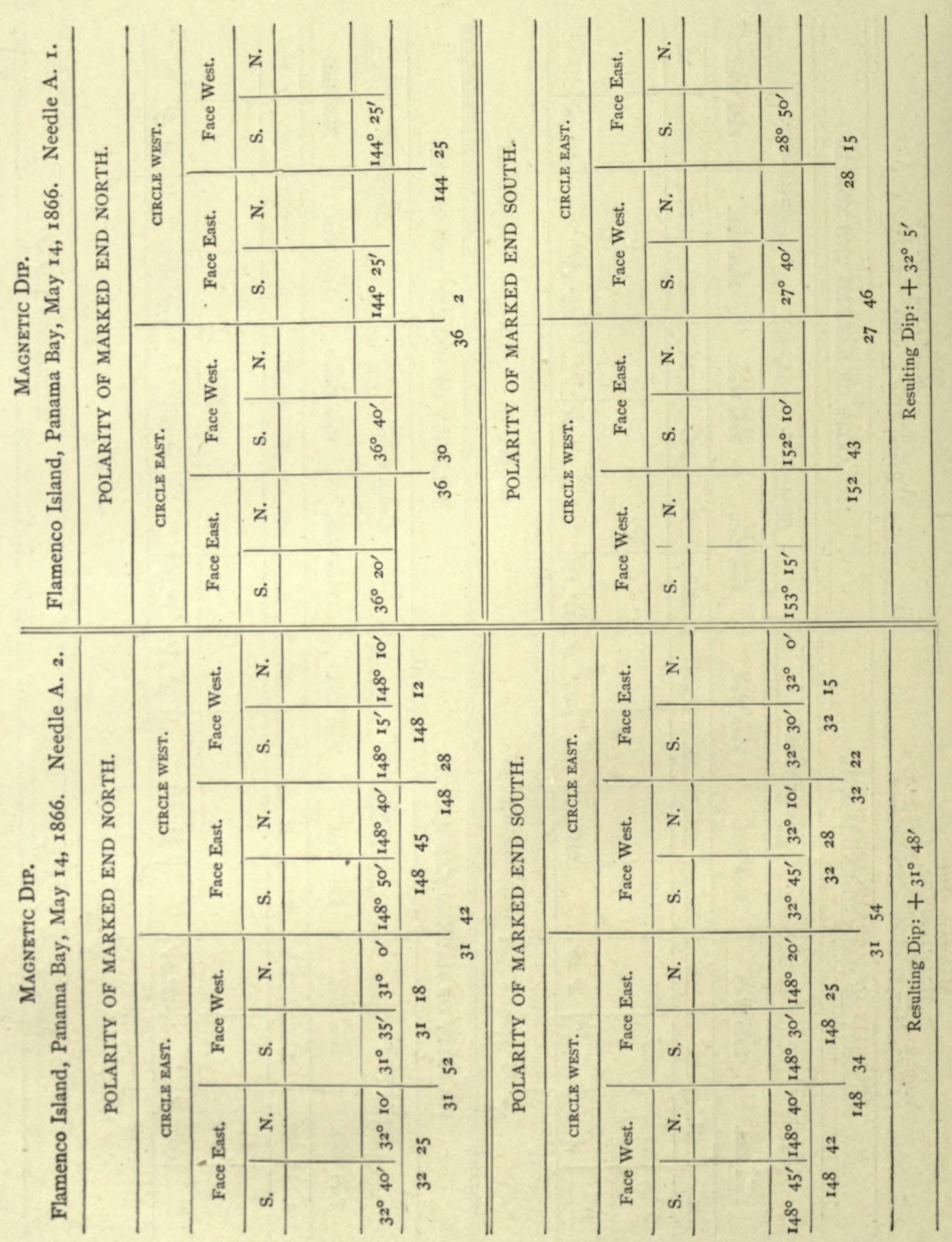




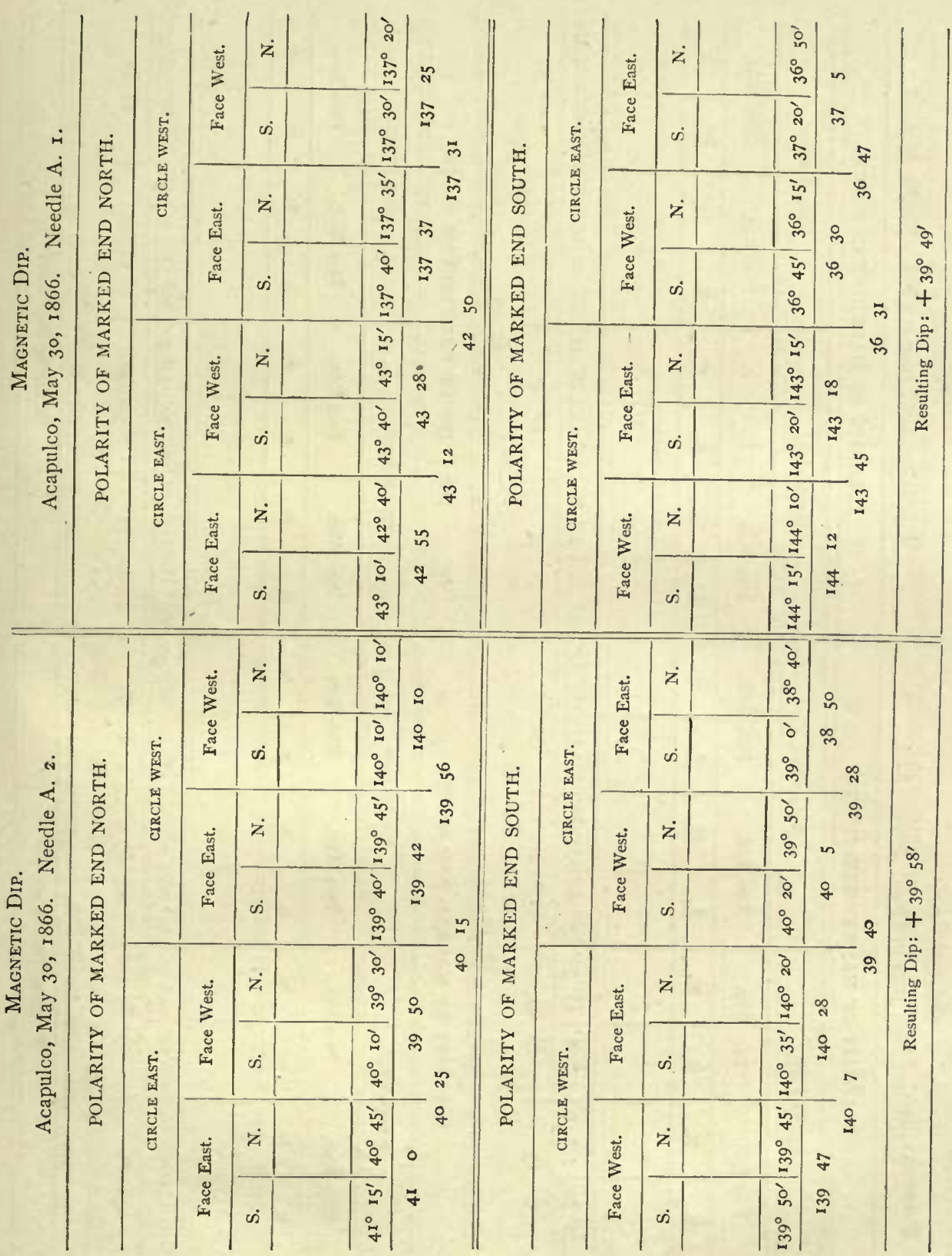




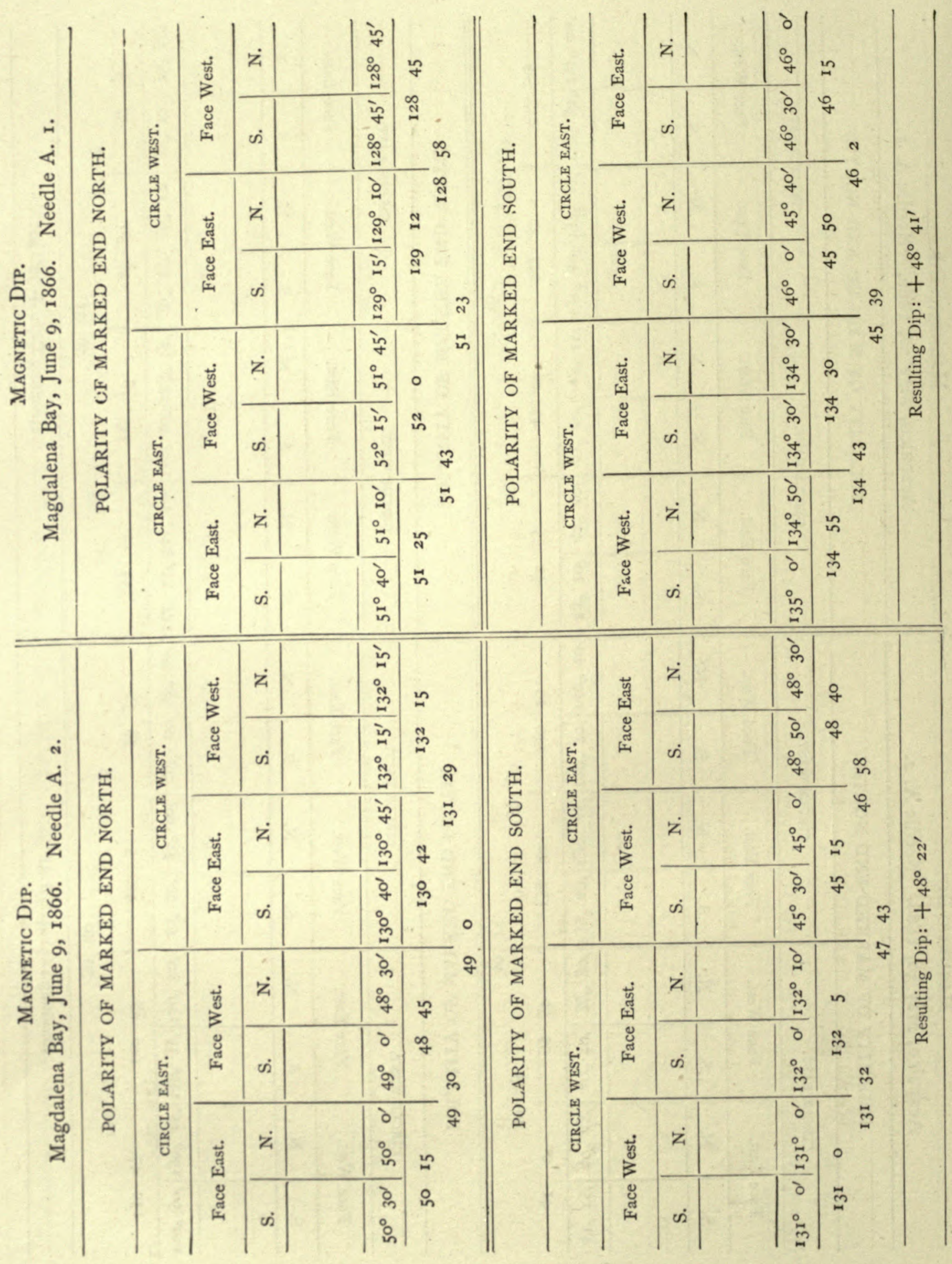




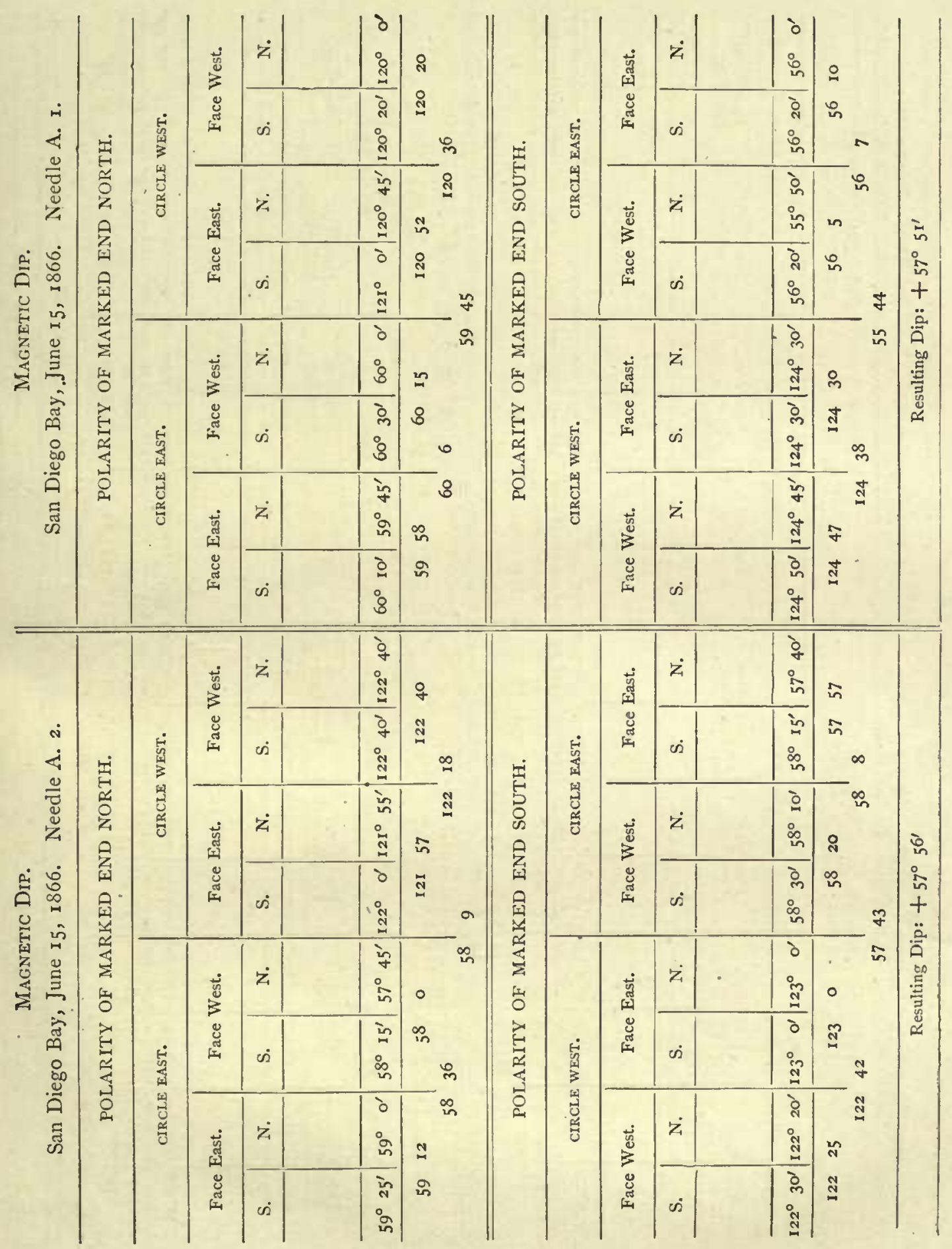




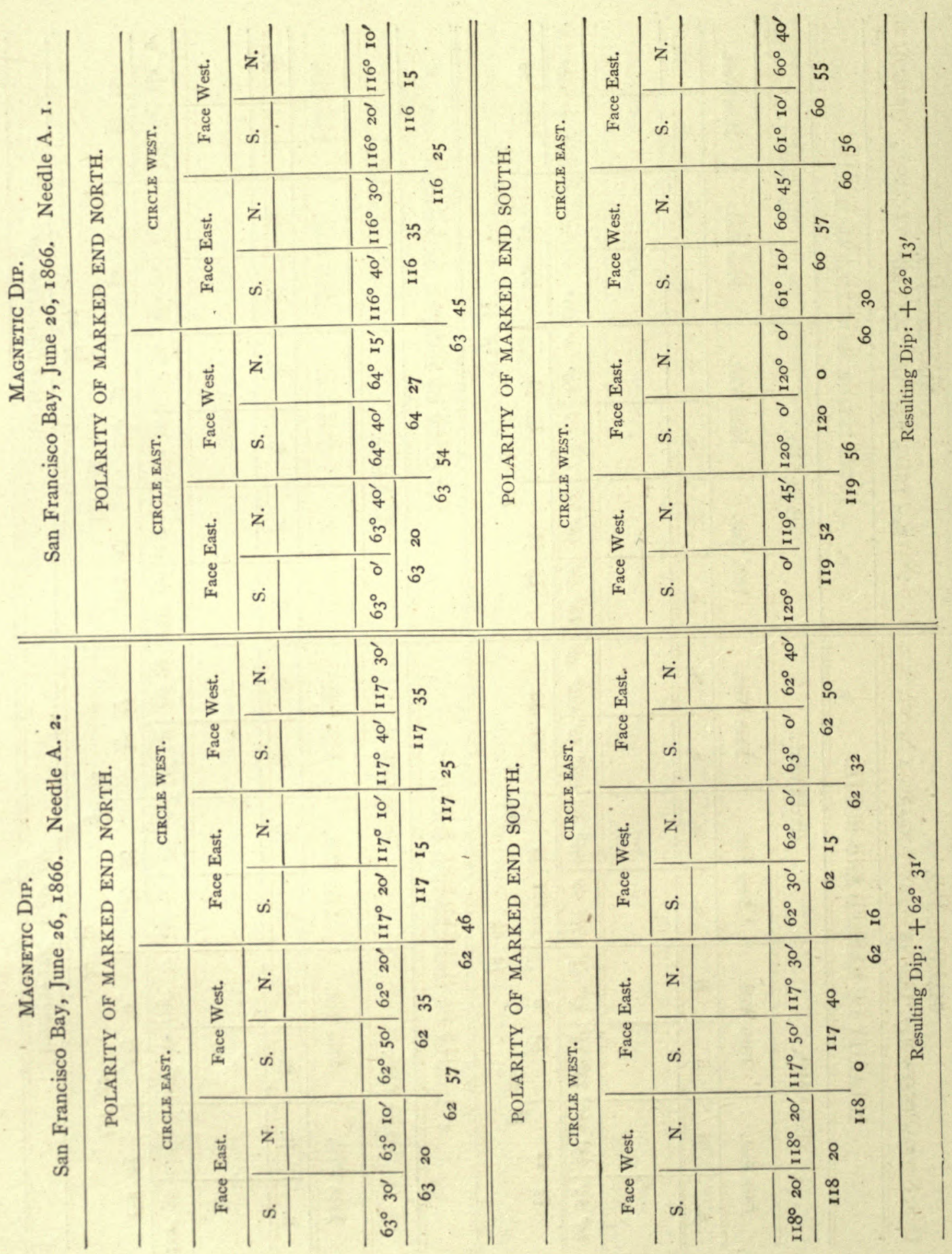




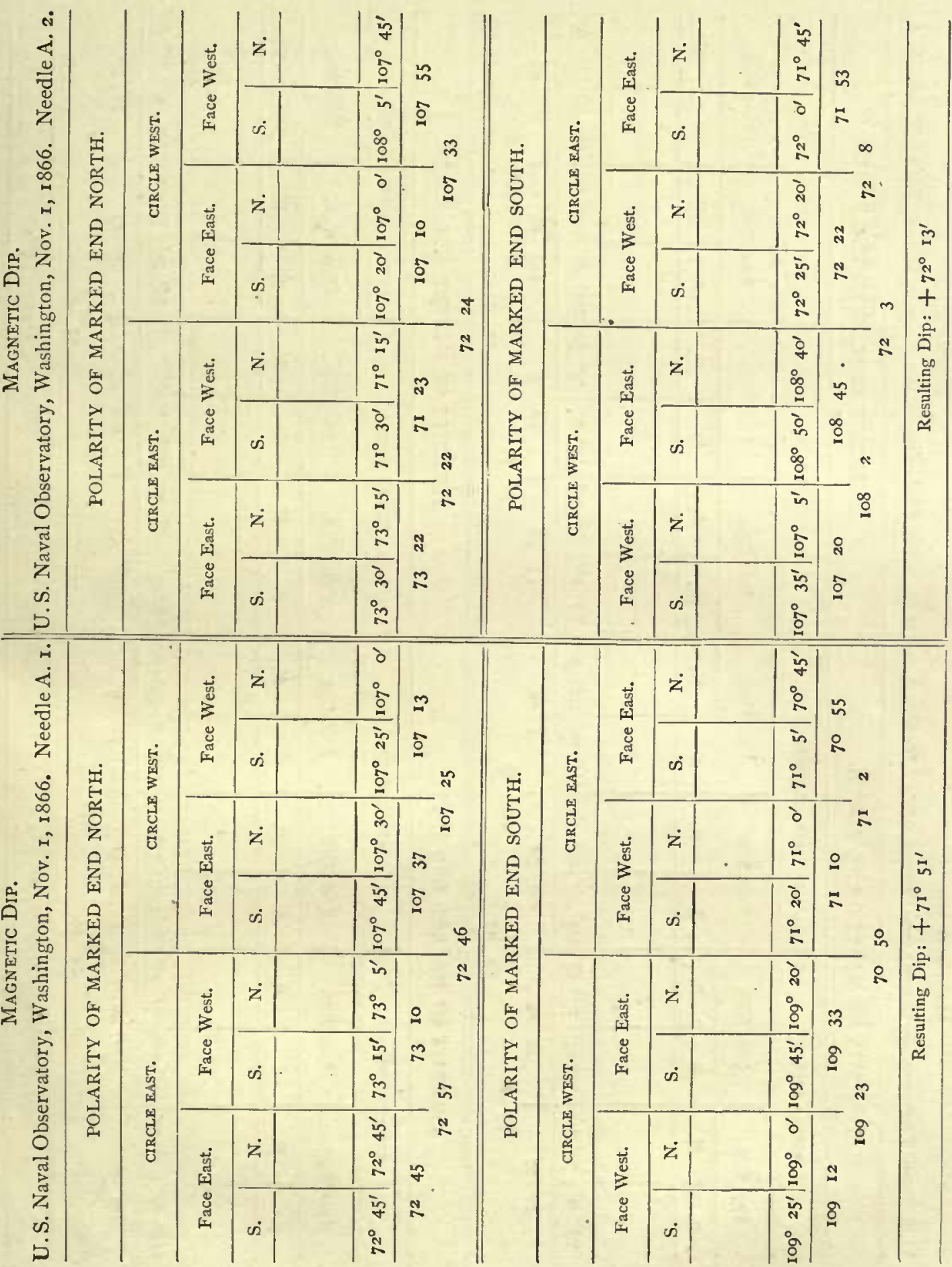




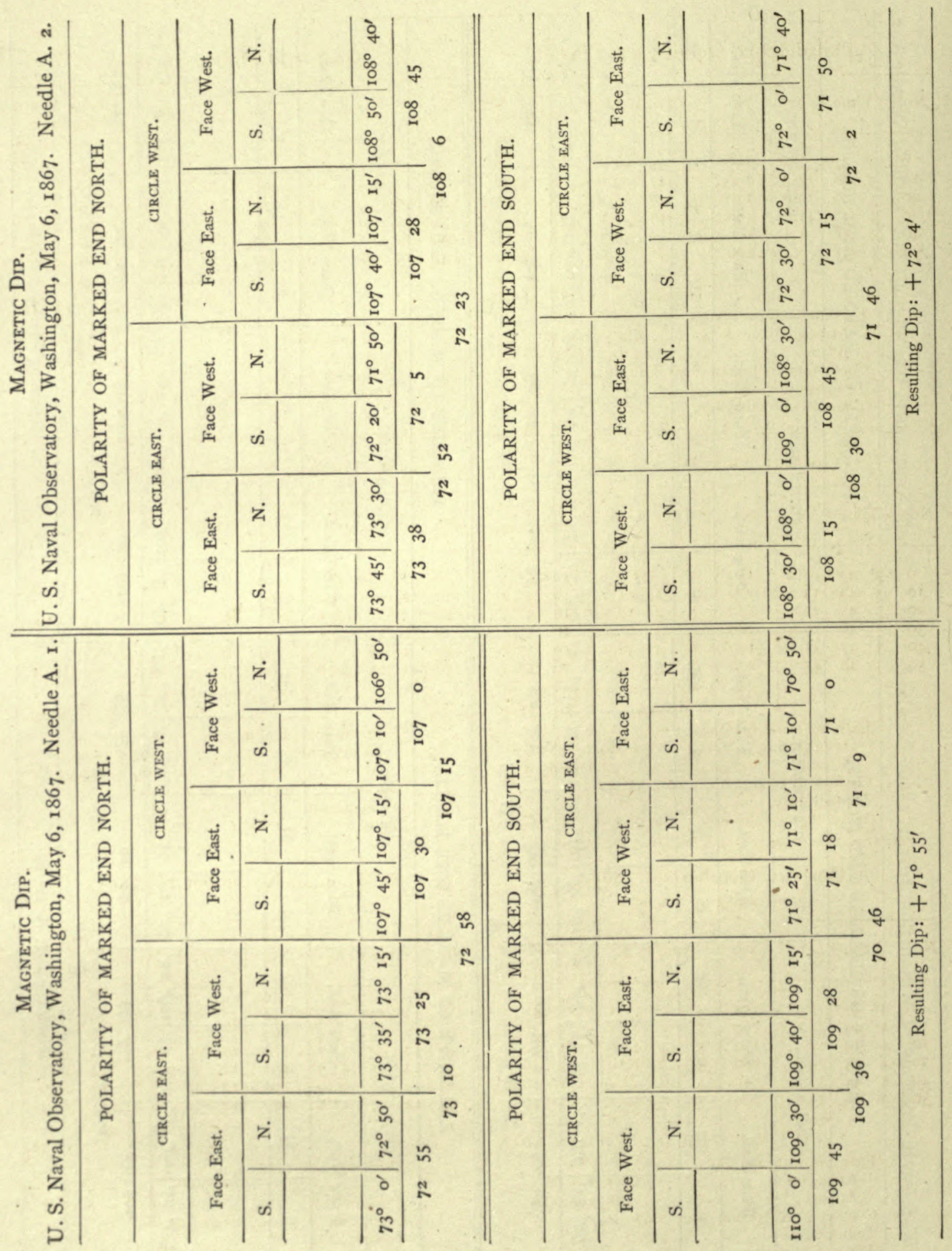




\section{HORIZONTAL INTENSITY. OBSERVATIONS OF VIBRATIONS.}

Philadelphia, October 24, I 865 .

\begin{tabular}{|c|c|c|c|c|c|}
\hline No. & Time P. M. & No. & Time P. M. & \multicolumn{2}{|c|}{$\begin{array}{l}\text { Time of } 156 \\
\text { vibrations. }\end{array}$} \\
\hline 0 & $3^{\mathrm{h}} \quad 27^{\mathrm{m}} \quad 5^{\mathrm{s}} .6$ & I 56 & $3^{\mathrm{h}} 45^{\mathrm{m}} 50^{\mathrm{s}} .8$ & $18^{\mathrm{m}}$ & $45^{3} .2$ \\
\hline Io & $\begin{array}{lll}3 & 28 & 17,2\end{array}$ & 166 & $\begin{array}{lll}3 & 47 & 2.0\end{array}$ & 18 & 44.8 \\
\hline 20 & 29.6 & 176 & $48 \quad 15.2$ & 18 & 45.6 \\
\hline 30 & 42.0 & 186 & $\begin{array}{ll}49 & 27.2\end{array}$ & 18 & 45.2 \\
\hline 40 & $3 \quad 31$ & 196 & $50 \quad 39.2$ & 18 & 44.8 \\
\hline \multirow[t]{3}{*}{50} & 333 & 206 & $\begin{array}{lll}3 & 51 & 51.6\end{array}$ & 18 & 45.2 \\
\hline & & & Mean ... & 18 & 45.13 \\
\hline & \multicolumn{5}{|c|}{$\begin{array}{l}\text { Extreme scale readings, } \\
\text { At beginning } \cdot: \cdot 5.0-150.0 \\
\text { At end } \cdot 23.0-86.0 \\
\text { Coefficient of torsion } v=8.12 \text { div. } \\
\text { Temperature } \\
\text { Time of one vibration }: 60^{\circ} .7 \\
\cdot 7^{1} .212\end{array}$} \\
\hline
\end{tabular}

Gosport, October 28, 1865 .

\begin{tabular}{|c|c|c|c|c|c|c|c|}
\hline No. & \multicolumn{2}{|c|}{ Time P. M. } & No. & \multicolumn{3}{|c|}{ Tinne P. M. } & $\begin{array}{l}\text { Time of I } 50 \\
\text { vibrations. }\end{array}$ \\
\hline 0 & $3^{h} 43^{m}$ & 6.4 & 150 & $4^{h}$ & $\mathrm{O}^{\mathrm{m}}$ & $3^{8} .6$ & $16^{\mathrm{m}} 57^{\mathrm{m}} \cdot 2$ \\
\hline 10 & $3 \quad 44$ & 14.4 & 160 & 4 & I & 11.6 & $16 \quad 57.2$ \\
\hline 20 & 345 & 22.0 & 170 & 4 & 2 & 19.5 & $57 \cdot 5$ \\
\hline 30 & 346 & 29.6 & 180 & 4 & 3 & 27.2 & 57.6 \\
\hline 40 & & 37.2 & 190 & 4 & 4 & 34.9 & $57 \cdot 7$ \\
\hline \multirow[t]{2}{*}{50} & \multirow{2}{*}{348} & \multirow[t]{2}{*}{45.6} & \multirow[t]{2}{*}{200} & 4 & 5 & 42.8 & $16 \quad 57.2$ \\
\hline & & & & & & & $16 \quad 57.40$ \\
\hline
\end{tabular}

Extreme scale readings,

At beginning . . 69.2-88.8

At end . . . . . $72.1-85.2$

Coefficient of torsion, $v=7.35$ div.

Temperature . . $73^{\circ} .0$

Time of one vibration $\quad .65 .783$

Gosport, October 28, 1865. Inertia ring on magnet.

\begin{tabular}{|c|c|c|c|c|c|c|c|}
\hline No. & \multicolumn{2}{|c|}{ Time P. M. } & No. & \multicolumn{3}{|c|}{ Time P. M. } & $\begin{array}{l}\text { Time of } \times 50 \\
\text { vibrations. }\end{array}$ \\
\hline o & $4^{\mathrm{n}} 39^{\mathrm{m}}$ & $7^{5} \cdot 9$ & 150 & $5^{h}$ & $\mathrm{o}^{\mathrm{m}}$ & $55^{9} .0$ & $2 \mathrm{I}^{\mathrm{m}} 47^{\mathrm{s}} \cdot \mathrm{I}$ \\
\hline 10 & 440 & 35.1 & 160 & 5 & 2 & 21.7 & $21 \quad 46.6$ \\
\hline 20 & $4^{2}$ & 2.3 & 170 & 5 & 3 & 48.8 & 46.5 \\
\hline 30 & 43 & 29.3 & 180 & 5 & 5 & 16.0 & 46.7 \\
\hline 40 & $4 \quad 44$ & 56.4 & $190^{\circ}$ & 5 & 6 & 43.2 & 46.8 \\
\hline \multirow[t]{2}{*}{50} & \multirow{2}{*}{$4 \quad 40$} & \multirow[t]{2}{*}{23.7} & \multirow[t]{2}{*}{200} & 5 & 8 & 10.1 & $21 \quad 46.4$ \\
\hline & & & & & & & $21 \quad 46.68$ \\
\hline
\end{tabular}

Extreme scale readings,

$\Lambda$ beginning . . . . . 91.0-66.5

At end. . . . . $88.0-69.0$

Coefficient of torsion, $v=8.97$ div.

Temperature . . $70^{\circ} .0$

Time of one vibration $.80 .71 \mathrm{I}$
Gosport, October 30, $186_{5}$.

\begin{tabular}{|c|c|c|c|c|c|c|c|}
\hline No. & \multicolumn{3}{|c|}{ Time. } & No. & \multicolumn{2}{|r|}{ Time. } & $\begin{array}{l}\text { Time of } 150 \\
\text { vibrations. }\end{array}$ \\
\hline 0 & $12^{\mathrm{h}}$ & $17^{\mathrm{m}}$ & $5^{i} \cdot 1$ & 150 & $12^{\mathrm{h}}$ & $33^{\mathrm{m}} 5^{8 \mathrm{x}} .8$ & I $6 \mathrm{~m} 53^{\mathrm{m}} .7$ \\
\hline 10 & 12 & 18 & 12.8 & 160 & 12 & $\begin{array}{ll}35 & 7.8\end{array}$ & 1655.0 \\
\hline 20 & 12 & 19 & 20.7 & 170 & 12 & 16.4 & 55.7 \\
\hline 30 & 12 & 20 & 28.5 & 180 & 12 & 24.0 & 55.5 \\
\hline 40 & 12 & $2 \mathrm{I}^{-}$ & 36.1 & 190 & 12 & 29.6 & $53 \cdot 5$ \\
\hline \multirow[t]{2}{*}{50} & 12 & 22 & 44.0 & 200 & 12 & 39.2 & 1655.2 \\
\hline & & & & & & an & $16 \quad 54.77$ \\
\hline
\end{tabular}

Extreme scale readings,

At beginning . . . . 70.0-88.3

At end . : : : $77.0-82.0$

Temperature . . $60^{\circ} .0$

Time of one vibration . 6.765

St. Thomas, November I3, 1865 .

\begin{tabular}{|c|c|c|c|c|c|c|c|c|c|}
\hline No. & \multicolumn{3}{|c|}{ Tine P. M. } & No. & \multicolumn{3}{|c|}{ Time P. M. } & \multicolumn{2}{|c|}{$\begin{array}{l}\text { Time of I } 50 \\
\text { vibrations. }\end{array}$} \\
\hline 0 & $2^{h}$ & & $6^{8} .2$ & 150 & $2^{\mathrm{h}}$ & $37^{\mathrm{m}}$ & 185.6 & $14^{\mathrm{m}}$ & $12^{n} \cdot 4$ \\
\hline 10 & 2 & 24 & 3.2 & 160 & 2 & 38 & 15.4 & 14 & 12.2 \\
\hline 20 & 2 & 24 & 59.8 & 170 & 2 & 39 & 12.2 & 14 & I 2.4 \\
\hline 30 & 2 & 25 & 56.9 & 180 & 2 & 40 & 8.4 & 14 & 11. 5 \\
\hline 40 & 2 & 26 & & 190 & 2 & $4 \mathrm{I}$ & 5.7 & 14 & \\
\hline \multirow[t]{2}{*}{50} & 2 & 27 & 49.0 & 200 & 2 & 42 & 2.8 & 14 & 13.8 \\
\hline & & & & & & & & 14 & 12.46 \\
\hline
\end{tabular}

Extreme scale readings,

At beginning . . . . $62.2-98.0$

At end . . . . . $69.8-90.2$

Coefficient of torsion, $v=4$-10 div.

Temperature . . . $87^{\circ} .0$

Time of one vibration $\cdot 5^{3} .683$

St. Thomas, November 16 , 1865 .

\begin{tabular}{|c|c|c|c|c|c|c|c|c|}
\hline No. & \multicolumn{2}{|c|}{ Time P. M. } & No. & \multicolumn{3}{|c|}{ Time P. M. } & \multicolumn{2}{|c|}{$\begin{array}{l}\text { Time of I50 } \\
\text { vibrations. }\end{array}$} \\
\hline 0 & & $3^{2} \cdot 4$ & 150 & $12^{\text {h }}$ & & $15^{3.1}$ & $14^{\mathrm{m}}$ & $11^{3} .7$ \\
\hline 10 & 1214 & 0.4 & 160 & 12 & 28 & 12.0 & 14 & II. 6 \\
\hline 20 & $12 \quad 14$ & 57.2 & 170 & 12 & 29 & 8.5 & 14 & II. 3 \\
\hline $3^{\circ}$ & 15 & 54.3 & 180 & 12 & $3^{\circ}$ & 5.4 & I4 & 11.1 \\
\hline 40 & 16 & 50.6 & 190 & I 2 & 31 & 2.2 & 14 & 11.6 \\
\hline \multirow[t]{2}{*}{50} & 12 & 47.8 & 200 & 12 & 31 & 59.0 & 14 & $1 \mathrm{I} .2$ \\
\hline & & & & & & & 14 & II. 42 \\
\hline
\end{tabular}

Extreme scale readings,

At beginning . . . . $59.8-98.8$

At end . : : : $67.2-89.5$

Coefficient of torsion, $\dot{v}=4.25$ div.

Temperature . . $87^{\circ} \cdot 5$

Time of one vibration $.5^{4}, 676$ 
Horizontal Intensity. Observations of Vibrations.

St. Thomas, November I6, 1865 .

Inertia ring on magnet.

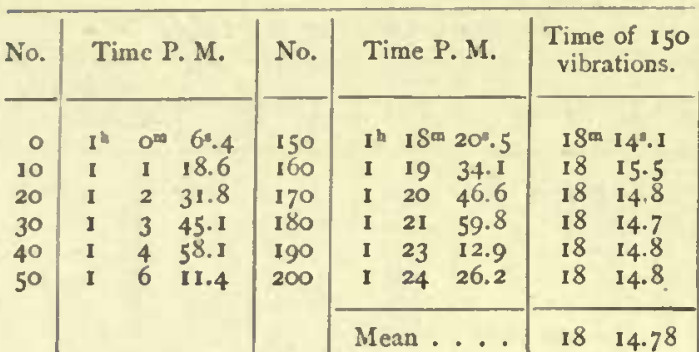

Extreme scale readings,

At beginning . . . . 61.8-98.0

At end . . . . 63.5-96.2

Coefficient of torsion . $v=5.22$ div.

Temperature . . . $86^{\circ} .0$

Time of one vibration . . $\boldsymbol{7}^{\mathbf{4}} .299$

Salute Islands, November 28, 1865 .

\begin{tabular}{|c|c|c|c|c|c|c|c|c|}
\hline No. & Time & 1. M. & No. & & ne $A$ & M. & $\begin{array}{l}\text { Time } \\
\text { vibr }\end{array}$ & $\begin{array}{l}\text { of } 150 \\
\text { ations. }\end{array}$ \\
\hline o & $9^{\text {h }} 43^{m}$ & $3^{4} .6$ & 150 & $9^{h}$ & $57^{\mathrm{m}}$ & $17^{\prime} \cdot 7$ & $14^{\mathrm{m}}$ & $14^{\prime} .1$ \\
\hline 10 & 944 & 0.4 & 160 & 9 & 58 & 14.2 & 14 & 13.8 \\
\hline 20 & 44 & 57.4 & 170 & 9 & 59 & 11.4 & 14 & 14.0 \\
\hline 30 & 45 & 54.2 & 180 & 10 & 0 & 8.6 & 14 & 14.4 \\
\hline 40 & 46 & $5^{1.3}$ & 190 & 10 & I & 5.6 & 14 & 14.3 \\
\hline \multirow[t]{2}{*}{50} & \multirow[t]{2}{*}{9} & \multirow[t]{2}{*}{48.3} & \multirow[t]{2}{*}{200} & 10 & 2 & 2.5 & 14 & 14.2 \\
\hline & & & & & & & 14 & 14.13 \\
\hline
\end{tabular}

Extreme scale readings,

At beginning . . . 57.5-99.8

At end . . . . . 71.4-86.0

Coefficient of torsion . $v=3.72$ div.

Temperature : . . $95^{\circ} \cdot 5$

Time of one vibration . . $5^{3.694}$

Salute Islands, November 28, 1865.

Inertia ring on magnet.

\begin{tabular}{|c|c|c|c|c|c|c|c|c|}
\hline No. & \multicolumn{3}{|c|}{ Time P. M. } & No. & \multicolumn{3}{|c|}{ Time P. M. } & $\begin{array}{l}\text { Time of I } 50 \\
\text { vibrations. }\end{array}$ \\
\hline o & $11^{*}$ & $31=$ & $9^{4} .5$ & 150 & $11^{\mathrm{b}}$ & $49^{\mathrm{m}}$ & $25^{\prime \prime} \cdot 1$ & $18^{m} 15^{*} .6$ \\
\hline 10 & 11 & 32 & 22.5 & 160 & II & 5o & $3^{8.6}$ & $18 \quad 16.1$ \\
\hline 20 & II & 33 & 35.6 & 170 & II & 51 & 51.6 & 16.0 \\
\hline 30 & II & 34 & 48.7 & 180 & II & 53 & 4.7 & 16.0 \\
\hline 40 & II & 36 & 1.4 & 190 & II & & 17.8 & 16.4 \\
\hline \multirow[t]{2}{*}{ 50 } & 11 & 37 & 14.8 & 200 & II & 55 & 30.3 & $18 \quad 15.5$ \\
\hline & & & & & & & & $\begin{array}{ll}18 & 15.93\end{array}$ \\
\hline
\end{tabular}

Extreme scale readings,

At beginning . . . 54.8-105.3

At end . : . 65.4-94.0

Cofficient of torsion . $v=5.65$ div.

Temperature . . . $91^{\circ} .0$

Time of one vibration . . $7^{\prime} \cdot 306$
Ceara, December I3, r 865 .

\begin{tabular}{|c|c|c|c|c|c|c|c|}
\hline No. & \multicolumn{2}{|c|}{ Time P. M. } & No. & \multicolumn{3}{|c|}{ Time P. M. } & $\begin{array}{l}\text { Time of } 150 \\
\text { vibrations. }\end{array}$ \\
\hline$\circ$ & II $35^{\mathrm{m}}$ & $8 * 3$ & 150 & $\mathrm{I}^{\mathrm{h}}$ & $49^{n}$ & $3^{64} .0$ & $14^{\mathrm{m}} 27^{\mathrm{s}} \cdot 7$ \\
\hline I0 & $11 \quad 36$ & 6.2 & 160 & II & 50 & 34.2 & 1428.0 \\
\hline 20 & 37 & 4.2 & 170 & II & 51 & 33.4 & $14 \quad 29.2$ \\
\hline 30 & $3^{8}$ & 1.o & 180 & I I & 52 & 31.2 & 30.2 \\
\hline 40 & 38 & 59.1 & 190 & II & 53 & 28.2 & 29.1 \\
\hline \multirow[t]{2}{*}{50} & 39 & 57.0 & 200 & II & & 25.6 & 1428.6 \\
\hline & & & & & & & 1428.80 \\
\hline
\end{tabular}

Extreme scale readings,

At beginning . . . 59.0-101.0

At end . . . . 45.5- 115.0

Coefficient of torsion $\cdot v=5.40$ div.

Temperature . . . . $89^{\circ} .0$

Time of one vibration . . $5^{n} .792$

A strong breeze blowing, which made the vibrations somewhat unsteady.

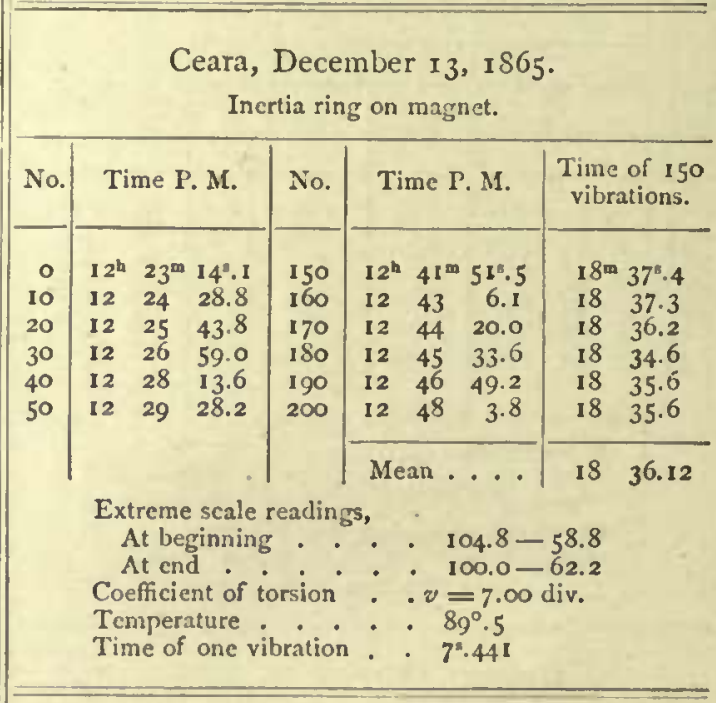

Pernambuco, December 23, 1865 .

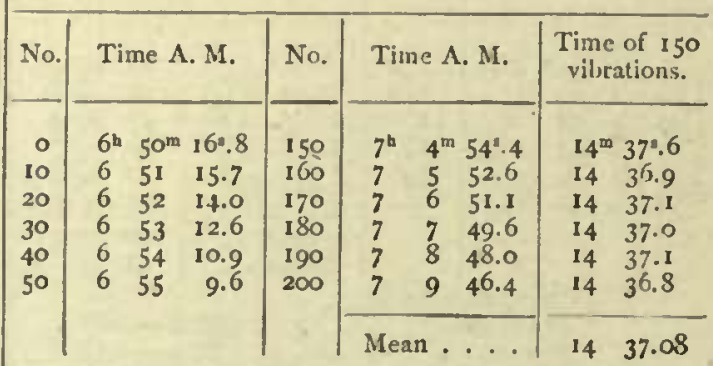

Extreme scale readings,

At beginning . . . . 46.0- I 15.0

At end . . . 62.0-99.0

Coefficient of torsion $: v=4.27$ div.

Temperature . . . $90^{\circ} .5$

Tinc of one vilsration : $5^{2.87}$ 
Horizontal Intensity. Observations of Vibrations.

Bahia, December 27,1865 .

\begin{tabular}{|c|c|c|c|c|c|c|c|c|}
\hline No. & \multicolumn{3}{|c|}{ Time A. M. } & No. & \multicolumn{3}{|c|}{ Time A. M. } & $\begin{array}{l}\text { Time of I } 50 \\
\text { vibrations. }\end{array}$ \\
\hline 0 & $7^{\text {h }}$ & $14^{\mathrm{m}}$ & $5^{3} \cdot 6$ & 150 & $7^{\mathrm{h}}$ & $28 \mathrm{~m}$ & $55^{2} \cdot 6$ & $14^{m} 5^{\circ} .0$ \\
\hline 10 & 7 & 15 & 4.9 & 160 & 7 & 29 & 55.0 & 1450.1 \\
\hline 20 & 7 & I 6 & 4. I & 170 & 7 & 30 & 54.4 & 50.3 \\
\hline $3^{\circ}$ & 7 & 17 & 3.6 & 180 & 7 & & 53.6 & 50.0 \\
\hline 40 & 7 & 18 & 2.9 & I 90 & 7 & $3^{2}$ & 53.0 & 50.1 \\
\hline 50 & 7 & I9 & 2.2 & 200 & 7 & 33 & 52.2 & 50.0 \\
\hline & & & & & & & & 14 \\
\hline
\end{tabular}

Extreme scale readings,

At beginning . . . 92.8-63.I

At end . . . . $86.8-68.3$

Coefficient of torsion . . $v=4.85$ div.

Temperature . . . . $92^{\circ} \cdot 5$

Time of one vibration . $5^{3} \cdot 934$

Bahia, December 27, 1865 .

Inertia ring on magnet.

\begin{tabular}{|c|c|c|c|c|c|c|c|c|c|}
\hline No. & \multicolumn{3}{|c|}{ Time A. M. } & No. & \multicolumn{3}{|c|}{ 'Time A. M. } & \multicolumn{2}{|c|}{$\begin{array}{l}\text { Time of } 150 \\
\text { vibrations. }\end{array}$} \\
\hline 0 & $8^{\text {h }}$ & $3^{m}$ & $4^{3} \cdot 2$ & 150 & $8^{b}$ & $22^{\mathrm{m}}$ & $9^{8} .4$ & $19^{\mathrm{m}}$ & $5^{10.2}$ \\
\hline 10 & 8 & 4 & 20.8 & 160 & 8 & 23 & 25.8 & 19 & 5.0 \\
\hline 20 & 8 & 5 & 37.0 & 170 & 8 & 24 & 42.2 & 19 & 5.2 \\
\hline 30 & 8 & 6 & 53.4 & 180 & 8 & 25 & 58.6 & 19 & 5.2 \\
\hline 40 & 8 & 8 & 9.8 & 190 & 8 & 27 & 14.8 & 19 & 5.0 \\
\hline \multirow[t]{2}{*}{50} & 8 & 9 & 26.0 & 200 & 8 & 28 & 30.8 & 19 & 4.8 \\
\hline & & & & & & & & 19 & 5.07 \\
\hline
\end{tabular}

Extreme scale readings,

At beginning . . . 57.9- 100.4

At end . . . . . 67.9-89.2

Coefficient of torsion . . $v=6.70$ div.

Temperature . . . . $97^{\circ} .5$

Time of one vibration . . $7^{3} .634$

Rio Janeiro, January 6, 1866.

\begin{tabular}{|c|c|c|c|c|c|c|c|c|c|}
\hline No. & \multicolumn{3}{|c|}{ Time P. M. } & No. & \multicolumn{3}{|c|}{ Time P. M. } & \multicolumn{2}{|c|}{$\begin{array}{l}\text { Time of } 150 \\
\text { vibrations. }\end{array}$} \\
\hline 0 & $3^{h}$ & $2 I^{m}$ & 65.8 & 150 & $3^{h}$ & $3^{6^{\mathrm{m}}}$ & $12^{8} .5$ & $15^{\mathrm{m}}$ & $5^{\mathrm{a}} \cdot 7$ \\
\hline Io & 3 & 22 & 5.8 & 160 & 3 & 37 & 12.5 & 15 & 6.7 \\
\hline 20 & 3 & 23 & .6 .6 & 170 & 3 & 38 & 13.3 & 15 & 6.7 \\
\hline 30 & 3 & 24 & 70 & 180 & 3 & 39 & 13.6 & 15 & 6.6 \\
\hline 4 & 3 & 25 & 7.7 & 190 & 3 & 40 & I 4.5 & 15 & 6.8 \\
\hline \multirow{2}{*}{50} & 3 & 26 & 8.1 & 200 & 3 & $4 \mathrm{I}$ & 15.0 & 15 & 6.9 \\
\hline & & & & & & & & 15 & 6.57 \\
\hline
\end{tabular}

Extreme scale readings,

At beginning . . . $62.1-96.3$

At end . . . . . 70.0-89.2

Cuefficient of torsion $\cdot . v=5$. Io div.

Tcmperature . . . $76^{\circ} .0$

Time of one vibration . . $6^{\mathrm{s}} .044$
Rio Janeiro, January 9, 1866.

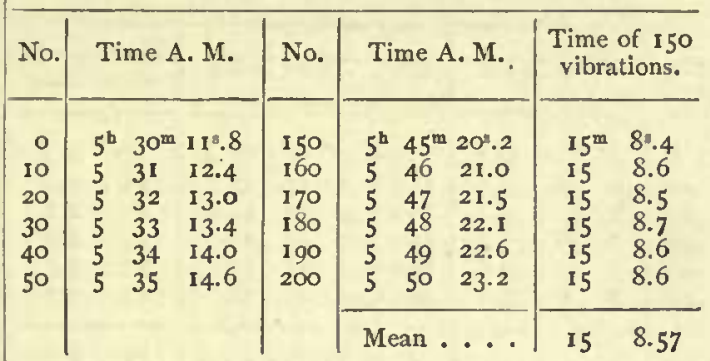

Extreme scale readings,

At beginning . . . 62.2-98.1

At end . : $: 69.2-91.2$

Temperature . . . . $80^{\circ} .5$

Time of one vibration . $6^{8} .057 \mathrm{i}$

Monte Video, January I8, I866.

\begin{tabular}{|c|c|c|c|c|c|c|c|c|}
\hline No. & \multicolumn{3}{|c|}{ Time P. M. } & No. & \multicolumn{2}{|c|}{ Time P. M. } & \multicolumn{2}{|c|}{$\begin{array}{l}\text { Time of } 150 \\
\text { vibrations. }\end{array}$} \\
\hline 0 & $I^{\text {h }}$ & $27^{\mathrm{m}}$ & 8.2 & 150 & $1^{h} 42^{m}$ & $9^{8} \cdot 4$ & $15^{m}$ & I". 2 \\
\hline IO & I & 28 & 8.2 & 160 & I 43 & 9.5 & I 5 & 1.3 \\
\hline 20 & I & 29 & 8.3 & 170 & 44 & 9.7 & 15 & 1.4 \\
\hline 30 & I & 30 & 8.2 & 180 & 45 & 9.7 & 15 & 1.5 \\
\hline 40 & I & 31 & 8.5 & 190 & 46 & 9.7 & 15 & 1.2 \\
\hline \multirow{2}{*}{50} & I & 32 & 8.5 & 200 & I 47 & 9.9 & 15 & 1.4 \\
\hline & & & & & Mean & & 15 & 1.33 \\
\hline
\end{tabular}

Extreme scale readings,

At beginning . . . $58.4-98.3$

At end . . 66.8-90.2

Coefficient of torsion $. v=5.10$ div.

Temperature . . . . $84^{\circ} .0$

Time of one vibration . 6 6.009

Monte Video, January I8, 1866.

Inertia ring on magnet.

\begin{tabular}{|c|c|c|c|c|c|c|c|c|}
\hline No. & \multicolumn{3}{|c|}{ Time P. M. } & No. & \multicolumn{3}{|c|}{ Time P. M. } & $\begin{array}{l}\text { Time of I50 } \\
\text { vibrations. }\end{array}$ \\
\hline 0 & $2^{\mathrm{h}}$ & $10^{\mathrm{m}}$ & $3^{2} .2$ & 150 & $2^{h}$ & $29^{m}$ & $22^{8} .9$ & $19^{m} 19^{m} .7$ \\
\hline 10 & 2 & II & 20.5 & 160 & 2 & 30 & $40 . \hat{I}$ & I9 19.6 \\
\hline 20 & 2 & 12 & 37.8 & 170 & 2 & $3^{I}$ & 57.3 & 19.5 \\
\hline 30 & 2 & I3 & 55.1 & 180 & 2 & 33 & 14.6 & 19.5 \\
\hline 40 & 2 & 15 & 12.4 & 190 & 2 & 34 & 31.8 & 19.4 \\
\hline \multirow[t]{2}{*}{50} & 2 & 16 & 29.8 & 200 & & 35 & $49 \cdot 3$ & 19.5 \\
\hline & & & & & $\mathrm{Me}$ & & & I9 19.53 \\
\hline
\end{tabular}

Extreme scale readings,

At beginning . . . 56.9- I0r.0

At end . : : $: 65.9-91.4$

Coefficient of torsion : $v=6.25$ div.

Temperature . . . . $84^{\circ} \cdot 5$

Time of one vibration $\cdot 7^{\circ} .73^{\circ}$ 
Horizontal Intensity. Observations of Vibrations.

Monte Video, January I8, I 866.

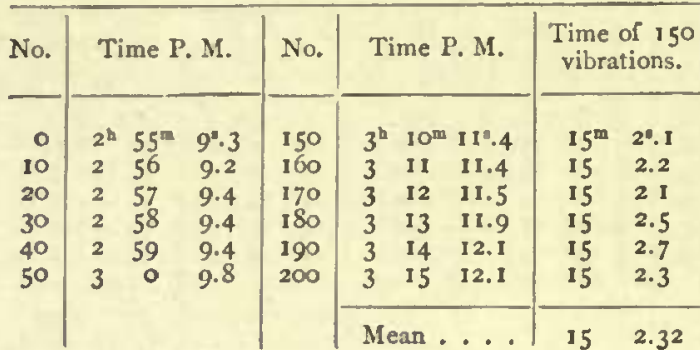

Extreme scale readings,

At beginning $: . \quad 58.0-100.2$

$\Lambda t$ end . . . . . 65.8-9r.6

Temperature . . $86^{\circ} .0$

Time of one vibration . . 60.015

Monte Video, January 19, I866.

\begin{tabular}{|c|c|c|c|c|c|c|c|c|c|}
\hline No. & \multicolumn{3}{|c|}{ Time P. M. } & No. & \multicolumn{3}{|c|}{ Time P. M. } & \multicolumn{2}{|c|}{$\begin{array}{l}\text { Time of } 150 \\
\text { vibrations. }\end{array}$} \\
\hline 0 & $3^{n}$ & $3^{m}$ & $8^{8.8}$ & 150 & $3^{\text {t }}$ & $18^{\mathrm{m}}$ & $11^{\circ} .8$ & $15^{\mathrm{m}}$ & $3: 0$ \\
\hline 10 & 3 & 4 & 8.9 & 160 & 3 & 19 & 12.2 & 15 & 3.3 \\
\hline 20 & 3 & 5 & 9.3 & 170 & 3 & 20 & 12.6 & 15 & $3 \cdot 3$ \\
\hline 30 & 3 & 6 & 9.4 & ISO & 3 & 21 & 12.6 & I5 & 3.2 \\
\hline 40 & 3 & 7 & 9.7 & 190 & 3 & 22 & 13.0 & 15 & $3 \cdot 3$ \\
\hline \multirow[t]{2}{*}{50} & 3 & 8 & 10.1 & 200 & & 23 & $13 \cdot 3$ & 15 & 3.2 \\
\hline & & & & & & & $\cdots$ & 15 & 3.22 \\
\hline
\end{tabular}

Extreme scale readings,

At beginning . . . . 56.0-102.0

At end. . . . . 66.6-91.5

Temperature . . . $89^{\circ} .5$

Time of one vibration . . 65.021

Sandy Point, February 7, 1866.

\begin{tabular}{|c|c|c|c|c|c|}
\hline No. & \multicolumn{2}{|c|}{ Time A. M. } & No. & Time A. M. & $\begin{array}{l}\text { Time of } 150 \\
\text { vibrations. }\end{array}$ \\
\hline 0 & $11^{\text {th }} 37^{\text {II }}$ & $4^{2} \cdot 5$ & 150 & $11^{\text {th }} 5^{1^{\mathrm{m}}} 5^{80} \cdot 4$ & $14^{m} 53^{\prime} .9$ \\
\hline Io & I1 $3^{8}$ & 4.5 & 160 & $\begin{array}{lll}11 & 52 & 58.4\end{array}$ & $14 \quad 53.9$ \\
\hline 20 & 39 & 3.7 & 170 & 58.2 & 54.5 \\
\hline 30 & 40 & 4.1 & 180 & 58.0 & 53.9 \\
\hline 45 & $4 I$ & $3 \cdot 3$ & 190 & 57.8 & 54.5 \\
\hline $5^{\circ}$ & 42 & 2.5 & 200 & $\begin{array}{lll}\text { II } & 56 & 57.8\end{array}$ & 55.3 \\
\hline & & & & Mean. & 145 \\
\hline
\end{tabular}

Extreme scale readings,

Al beginning . . . 61.0 -100.0

At end . . . . 60.5-97.5

Coefficient of torsion : $v=6.85$ div.

Temperature . . . $71^{\circ} .5$

Time of one vibration . $5^{n} .962$

Magnet rendered quite unsteady by the high wind.
Valparaiso, March 2, 1866.

\begin{tabular}{|c|c|c|c|c|c|c|c|c|}
\hline No. & \multicolumn{3}{|c|}{ Time P. M. } & No. & \multicolumn{3}{|c|}{ Time P. M. } & $\begin{array}{l}\text { Time of } 150 \\
\text { vibrations. }\end{array}$ \\
\hline o & $5^{\mathrm{b}}$ & $\mathrm{o}^{\mathrm{m}}$ & $3^{3} \cdot 4$ & 150 & $5^{\mathrm{h}}$ & $14^{m}$ & $41^{3} \cdot 0$ & $14^{\mathrm{m}} 37^{\mathrm{1}} \cdot 6$ \\
\hline ro & 5 & I & 2.2 & 160 & 5 & 15 & $39 \cdot 3$ & 1437.1 \\
\hline 20 & 5 & 2 & 0.6 & 170 & 5 & 16 & 37.8 & 37.2 \\
\hline 30 & 5 & 2 & 59.4 & iso & 5 & 17 & 36.6 & 37.2 \\
\hline 40 & 5 & 3 & $57 \cdot 4$ & 190 & 5 & 18 & 35.1 & 37.7 \\
\hline \multirow[t]{2}{*}{50} & 5 & 4 & 55.7 & 200 & 5 & 19 & 33.7 & 1438.0 \\
\hline & & & & & & & & $14 \quad 37.47$ \\
\hline
\end{tabular}

Extreme scale readings,

At beginning . . . $99.8-56.8$

At end . . . . 9 97.8- 57.8

Coefficient of torsion . $v=6.17$ div.

Temperature . . $.72^{\circ} .5$

Time of one vibration . . $\quad 5^{3} .850$

Valparaiso, March 19, 1866.

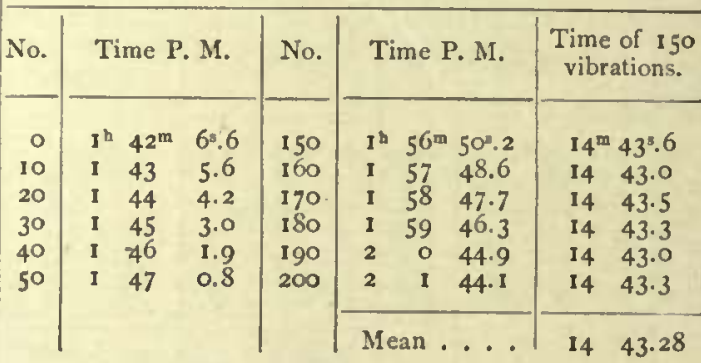

Extreme scale readings,

At beginning . . . 65.0-95.8

At end . . . . 61.2-96.8

Coefficient of torsion . . $v=4.75 \mathrm{div}$

Temperature . . . $76^{\circ} .0$

Time of one vibration . . $5^{5} .889$

Valparaiso, March 19, 1866.

Inertia ring on magnet.

\begin{tabular}{|c|c|c|c|c|c|c|c|c|}
\hline No. & \multicolumn{3}{|c|}{ Time P. M. } & No. & \multicolumn{3}{|c|}{ Time P. M. } & $\begin{array}{l}\text { Time of } 150 \\
\text { vibrations. }\end{array}$ \\
\hline 0 & $2^{\mathrm{h}}$ & $3^{2^{m}}$ & $5^{\circ} \cdot 4$ & 150 & $2^{\mathrm{h}}$ & $51^{\mathrm{m}}$ & 0.4 & $18 \mathrm{~m} 55^{\circ} .0$ \\
\hline I0 & 2 & 33 & 21.2 & 160 & 2 & 52 & 15.8 & $18 \quad 54.6$ \\
\hline 20 & 2 & 34 & 36.8 & 170 & 2 & 53 & 30.8 & 54.0 \\
\hline 30 & 2 & 35 & 52.5 & 180 & 2 & 54 & 47.2 & 54.7 \\
\hline 40 & 2 & 37 & 8.2 & 190 & 2 & 56 & 1.2 & 53.0 \\
\hline \multirow[t]{2}{*}{50} & 2 & $3^{8}$ & 23.9 & 200 & & 57 & 15.8 & $18 \quad 51.9$ \\
\hline & & & & & & & & $\begin{array}{ll}18 & 53.87\end{array}$ \\
\hline
\end{tabular}

Extreme scale readings,

At beginning . . . . 61.6-98.9

$\Lambda t$ end . . . . 73.3-84.0

Coeficient of torsion : $v=6.82 \mathrm{div}$

Temperature . . $73^{\circ} .0$

Timc of one vibration . 7.559 
HoRizontal Intensity. OBservations of Vibrations.

Valparaiso, March 29, r 860.

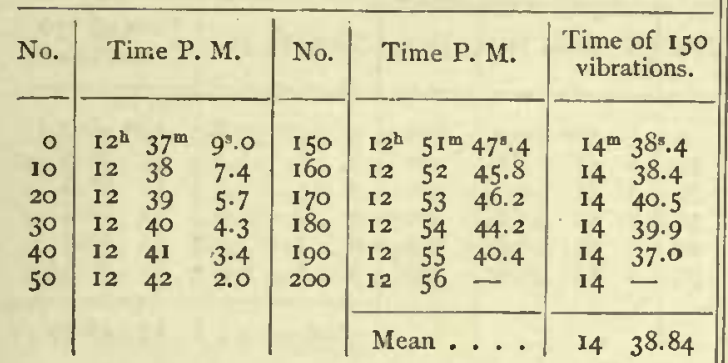

Extreme scale readings,

At beginning . . . 61.3-97.2

Tcmperature : : $76^{\circ} .0$

Time of one vibration . . $5^{*} .859$

Magnet brought to rest by the vibrations of the instrument caused by the wind.

Valparaiso, March $29,1866$.

Valparaiso, March 29, 1866.

\begin{tabular}{|c|c|c|c|c|c|c|c|c|c|}
\hline No. & \multicolumn{3}{|c|}{ Time P. M. } & No. & \multicolumn{3}{|c|}{ Time P. M. } & \multicolumn{2}{|c|}{$\begin{array}{l}\text { Time of I } 50 \\
\text { vibrations. }\end{array}$} \\
\hline 0 & $I^{b}$ & $28 \mathrm{~m}$ & $7^{5} \cdot 2$ & 150 & $\mathrm{I}^{\mathrm{h}}$ & $42^{m}$ & $49^{3} \cdot 0$ & $14^{\mathrm{m}}$ & $4 I^{\circ} .8$ \\
\hline 10 & I & 29 & 5.2 & 160 & I & 43 & 48.0 & 14 & 42.8 \\
\hline 20 & I & $3^{\circ}$ & 6.8 & 170 & I & 44 & 46.9 & I4 & 40. I \\
\hline 30 & I & $3 I$ & 2.4 & I 80 & I & 45 & 45.2 & I4 & 42.8 \\
\hline 40 & I & $3^{2}$ & 0.6 & I go & I & $4^{6}$ & 43.8 & 14 & 43.2 \\
\hline 50 & I & $3^{2}$ & 58.6 & 200 & I & 47 & 43.0 & 14 & 44.4 \\
\hline & & & & & & & & I4 & 42.52 \\
\hline
\end{tabular}

Extreme scale readings,

At beginning . . $63.0-98.8$

At end . . . . $65.5-96.0$

Coefficient of torsion : $v=3.80$ div.

Temperature . . $75^{\circ} .5$

Time of one vibration . . 5.883

Vibrations irregular on acconnt of the wind, which, at onc time, almost bronght the magnet to rest.

Valparaiso, April 7, I 866.

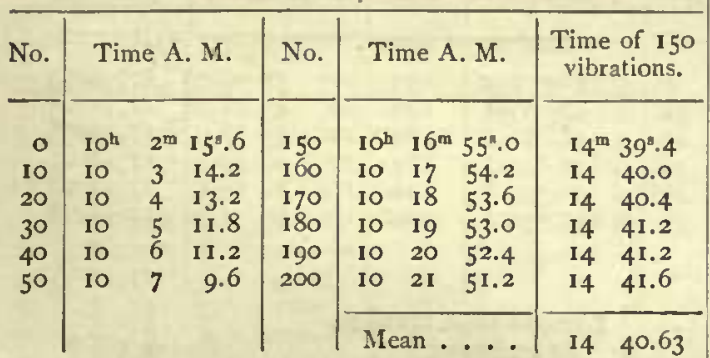

Extreme scale readings,

At beginning . . . $59.8-102.8$

At end . . . . 56.5-106.5

Eoefficient of torsion $: y=3.92$ div.

Temperature . . . $66^{\circ} .5$

Time of one vibration . $5^{3.871}$
Valparaiso, April II, I 866.

\begin{tabular}{|c|c|c|c|c|c|c|c|c|}
\hline No. & \multicolumn{3}{|c|}{ Time P. M. } & No. & \multicolumn{3}{|c|}{ Time P. M. } & $\begin{array}{l}\text { Time of } 150 \\
\text { vibrations. }\end{array}$ \\
\hline 0 & $12^{\mathrm{b}}$ & $15^{\mathrm{m}}$ & $14^{3} .0$ & 150 & $12^{\mathrm{h}}$ & & $5^{63.6}$ & $14^{\mathrm{m}} 42^{\mathrm{s}} \cdot 6$ \\
\hline 10 & 12 & 16 & I 3.0 & 160 & I 2 & $3^{\circ}$ & 55.4 & I4 42.4 \\
\hline 20 & 12 & 17 & 11. 8 & 170 & 12 & $3^{I}$ & 54.2 & $14 \quad 42.4$ \\
\hline 30 & 12 & 18 & 10.4 & 180 & 12 & 32 & 53.2 & $14 \quad 42.8$ \\
\hline 40 & I 2 & I9 & 9.0 & 190 & 12 & 33 & 52.0 & $14 \quad 43.0$ \\
\hline 50 & 12 & 20 & 7.8 & 200 & 12 & 34 & 51.0 & $14 \quad 43.2$ \\
\hline & & & & & & & . & $14 \quad 42.73$ \\
\hline
\end{tabular}

Extreme scale readings,

At beginning . . . 56.0 - 103.0

At end . . . . 64.5-91.0

Temperature . . . $74^{\circ} .5$

Time of one vibration . $5^{\circ} .885$

Valparaiso, April 11, I 866.

\begin{tabular}{|c|c|c|c|c|c|c|c|c|}
\hline No. & \multicolumn{3}{|c|}{ Time P. M. } & No. & \multicolumn{3}{|c|}{ Time P. M. } & $\begin{array}{l}\text { Time of I } 50 \\
\text { vibrations. }\end{array}$ \\
\hline 0 & $12^{\mathrm{h}}$ & $37^{n}$ & I $2^{3} .2$ & 150 & $12^{\mathrm{h}}$ & $5 \mathrm{I}^{\mathrm{m}}$ & $55^{5} .0$ & $14^{\mathrm{m}} 42^{\mathrm{s}} .8$ \\
\hline 10 & 12 & 38 & II.O & 160 & 12 & $5^{2}$ & 54.0 & $14 \quad 43.0$ \\
\hline 20 & 12 & 39 & 9.8 & 170 & 12 & 53 & 52.8 & 43.0 \\
\hline 30 & 12 & 40 & 8.6 & 180 & 12 & 54 & 51.8 & 43.2 \\
\hline 40 & 12 & $4 \mathrm{I}$ & $7 \cdot 4$ & I 90 & 12 & 55 & 50.6 & 43.2 \\
\hline \multirow[t]{2}{*}{50} & 12 & $4^{2}$ & 6.4 & 200 & I 2 & $5^{6}$ & 49.4 & $14 \quad 43.0$ \\
\hline & & & & & & & & $14 \quad 43.03$ \\
\hline
\end{tabular}

Extreme scale readings,

At beginning . . . 64.5-91.0

At end . . . . 7 70.0-85.0

Temperature :. $: 81^{\circ} .0$

Time of one vibration . $5^{3.887}$

Valparaiso, April I r, 1866.

Inertia ring on magnet.

\begin{tabular}{|c|c|c|c|c|c|c|c|c|}
\hline No. & \multicolumn{3}{|c|}{ Time P. M. } & No. & \multicolumn{3}{|c|}{ Time P. M. } & $\begin{array}{l}\text { Time of I } 50 \\
\text { vibrations. }\end{array}$ \\
\hline 0 & $\mathbf{I}^{\mathbf{h}}$ & $8^{m}$ & 6.6 & 150 & $\mathrm{I}^{\mathrm{b}}$ & $27^{\mathrm{m}}$ & $2^{3} \cdot 4$ & $18^{m} 55^{m} .8$ \\
\hline IO & I & 9 & 22.2 & 160 & 1 & 28 & 18.1 & $18 \quad 55.9$ \\
\hline 20 & I & 10 & 37.8 & 170 & I & 29 & 33.8 & 1856.0 \\
\hline 30 & I & II & $53 \cdot 7$ & 180 & I & 30 & 49.4 & 55.7 \\
\hline 40 & I & 13 & 9.4 & I90 & I & 32 & 5.2 & 55.8 \\
\hline \multirow[t]{2}{*}{50} & I & 14 & 25.0 & 200 & 1 & 33 & 21.0 & 1856.0 \\
\hline & & & & & & & & $\begin{array}{ll}\text { IS } & 55 . S_{7}\end{array}$ \\
\hline
\end{tabular}

Extreme scale readings,

At beginning . . . 58.8 - I0I.6

At end . . . . 67.0-93.2

Coefficient of torsion : $v=5.50$ div.

Temperature . . . . $88^{\circ} .0$

Time of onc vibration $\cdot 7^{3} .57^{2}$ 


\section{Horizontal Intensity. Observations of Vibrations.}

Valparaiso, April 13, I866.

\begin{tabular}{|c|c|c|c|c|c|c|c|c|c|}
\hline No. & \multicolumn{3}{|c|}{ Time P.M. } & No. & \multicolumn{3}{|c|}{ Time P. M. } & \multicolumn{2}{|c|}{$\begin{array}{l}\text { Time of } 15^{\circ} \\
\text { vibrations. }\end{array}$} \\
\hline 0 & $2^{b}$ & $45^{\circ}$ & $23^{2} \cdot 6$ & 150 & $3^{\text {h }}$ & $\mathrm{O}^{\mathrm{m}}$ & 6.2 & $14^{\mathrm{m}}$ & $42^{2} \cdot 6$ \\
\hline 10 & 2 & 46 & 21.8 & 160 & 3 & I & 4.6 & 14 & 42.8 \\
\hline 20 & 2 & 47 & 21.2 & 170 & 3 & 2 & 3.6 & 14 & 42.4 \\
\hline 30 & 2 & 48 & 19.6 & 180 & 3 & 3 & 2.4 & 14 & 42.8 \\
\hline 40 & 2 & 49 & 19.0 & 190 & 3 & 4 & 0.6 & 14 & 41.6 \\
\hline 50 & 2 & 50 & 17.8 & 200 & 3 & 4 & 58.6 & 14 & 40.8 \\
\hline & & & & & & & • & 14 & 42.17 \\
\hline
\end{tabular}

Extreme scale readings,

At beginning . . $57.8-101.5$

At end . . . . 74.2-85.2

Temperature . . . $66^{\circ} .5$

Time of one vibration $5^{3} .88_{1}$

San Lorenzo Island, April 26, 1866.

\begin{tabular}{|c|c|c|c|c|c|c|c|c|c|}
\hline No. & \multicolumn{3}{|c|}{ Time P. M. } & No. & \multicolumn{3}{|c|}{ Time P. M. } & \multicolumn{2}{|c|}{$\begin{array}{l}\text { Time of } 150 \\
\text { vibrations. }\end{array}$} \\
\hline 0 & $12^{b}$ & $40^{\text {m }}$ & 60.9 & 150 & $12^{\mathrm{b}}$ & $54^{\mathrm{m}}$ & $7^{2} \cdot 4$ & $14^{\mathrm{m}}$ & $0^{*} .5$ \\
\hline 10 & 12 & 41 & 3.0 & 160 & 12 & 55 & 3.0 & 14 & 0.0 \\
\hline 20 & 12 & 41 & 59.0 & 170 & 12 & 55 & 59.2 & 14 & 0.2 \\
\hline 30 & 12 & 42 & 55.0 & 180 & 12 & 56 & 54.9 & 13 & 59.9 \\
\hline 40 & 12 & 43 & 51.0 & 190 & 12 & 57 & 50.8 & 13 & 59.8 \\
\hline \multirow[t]{2}{*}{50} & 12 & 44 & 47.1 & 200 & 12 & $5^{8}$ & 47.4 & 14 & 0.3 \\
\hline & & & & & & & & 14 & 0.08 \\
\hline
\end{tabular}

Extreme scale readings,

At beginning . . . $61.2-101.1$

At end. . : : $71.0-89.0$

Coefficient of torsion . v $v=3.10 \mathrm{div}$.

Temperature. . . . $89^{\circ} .0$

Time of one viluration . . $5^{5} .60$ !

Payta, May 7, 1866.

\begin{tabular}{|c|c|c|c|c|c|c|c|c|}
\hline No. & \multicolumn{3}{|c|}{ Time A. M. } & No. & \multicolumn{3}{|c|}{ Time A. M. } & $\begin{array}{l}\text { Time of } 150 \\
\text { vibrations. }\end{array}$ \\
\hline 0 & $9^{b}$ & $21^{\mathrm{m}}$ & 92.8 & 150 & $9^{\mathrm{b}}$ & & $49^{n .4}$ & $13^{\operatorname{man}} 39^{\circ} .6$ \\
\hline 10 & 9 & 22 & 4.4 & 160 & 9 & 35 & 44.0 & 1339.6 \\
\hline 20 & 9 & 22 & 59.2 & 170 & 9 & $3^{6}$ & $3^{8.6}$ & $13 \quad 39.4$ \\
\hline 30 & 9 & 23 & 53.6 & 180 & 9 & 37 & 33.2 & 39.6 \\
\hline 40 & 9 & 24 & 48.2 & 190 & 9 & $3^{8}$ & 27.6 & 39.4 \\
\hline \multirow[t]{2}{*}{50} & 9 & 25 & 42.8 & 200 & & 39 & 22.3 & 1339.5 \\
\hline & & & & & & & & $13 \quad 39.52$ \\
\hline
\end{tabular}

Extreme seale readings,

At heginuing . . . 58.2-101.8

At end...: $67.8-92.2$

Coefficient of torsion : : $v=3.20 \mathrm{div}$.

Temperature . : $87^{\circ} .5$

Time of one vibration . . $5^{1} \cdot 46_{3}$
Flanenco Island, Panama Bay, May 14, I866.

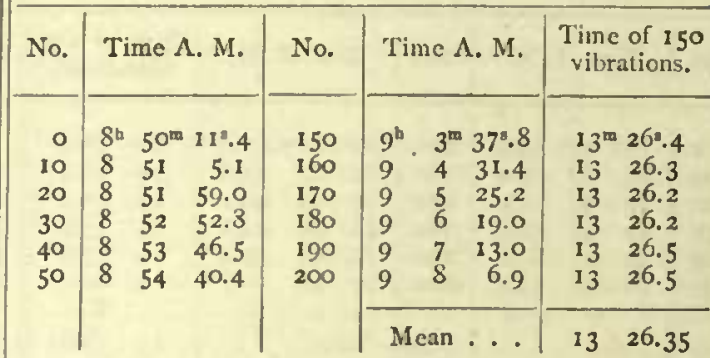

Extreme scale readings,

At beginning . . . . 58.2-101.0

At end . . . 66.6- 02.9

Coefficient of torsion . . $v=2.78$ div.

Temperature. . . . $92^{\circ} .0$

Time of one vibration. . . $5^{5.376}$

Acapulco, May 30, I866.

\begin{tabular}{|c|c|c|c|c|c|c|c|}
\hline No. & \multicolumn{2}{|c|}{ Time A. M. } & No. & \multicolumn{3}{|c|}{ Time A. M. } & $\begin{array}{l}\text { Time of } 150 \\
\text { vibrations. }\end{array}$ \\
\hline 0 & $8^{\mathrm{h}} \quad 32^{\mathrm{m}}$ & 36.8 & 150 & $8^{b}$ & $45^{m}$ & $23^{\prime} \cdot 4$ & $13^{m} 19^{s} .6$ \\
\hline 10 & $8 \quad 32$ & 57.0 & 160 & 8 & 46 & 17.2 & 1320.2 \\
\hline 20 & 33 & 50.6 & 170 & 8 & 47 & 10.2 & 19.6 \\
\hline 30 & 34 & 43.9 & 180 & 8 & 48 & 3.7 & 19.8 \\
\hline 40 & 35 & 37.0 & 190 & 8 & $4^{8}$ & 57.0 & 20.0 \\
\hline \multirow[t]{2}{*}{50} & $3^{6}$ & 30.6 & 200 & 8 & 49 & 50.5 & $13 \quad 19.9$ \\
\hline & & & & & & & $13 \quad 19.85$ \\
\hline
\end{tabular}

Extreme scale readings,

At beginning. . . . 57.8-102.2

At end. : : : $: 65.2=95.0$

Coefficient of torsion . . $v=3.40$ div.

Temperature. . . . . . $89^{\circ} .0$

Time of one vilbration. . . $5^{4} \cdot 33^{2}$

Acapulco, May 30, 1866.

Inertia ring on magnet.

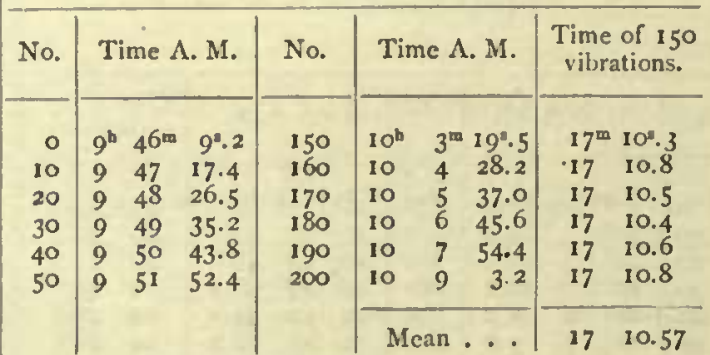

Extreme scale rearlings,

At beginning . . . . 56.2 - 103.7

At end. : : $65.1-94.8$

Coefficient of torsion : : $v=4.55$ div.

Temperature . . . $99^{\circ} .5$

Time of one vibration . 68.870 
Horizontal Intensity. Observations of Vibrations.

Magdalena Bay, June 9, I866.

\begin{tabular}{|c|c|c|c|c|c|c|c|c|}
\hline No. & \multicolumn{3}{|c|}{ Time A. M. } & No. & \multicolumn{3}{|c|}{ Time A. M. } & $\begin{array}{l}\text { Time of I } 50 \\
\text { vibrations. }\end{array}$ \\
\hline 0 & $I^{h}$ & $8^{m}$ & $5^{2} \cdot 4$ & 150 & $\mathbf{I}^{\mathrm{t}}$ & $2 I^{\mathrm{m}}$ & $52^{3} .8$ & \\
\hline 10 & I & 8 & 59.4 & 160 & I & 22 & 49.0 & \\
\hline 20 & I & 9 & 54.5 & 170 & I & 23 & 44.4 & \\
\hline 30 & I & 10 & 49.0 & 180 & I & 24 & 40.2 & \\
\hline 40 & I & II & 44.4 & Igo & I & 25 & 36.0 &. \\
\hline 50 & I & 12 & 39.8 & 200 & I & 26 & 30.8 & \\
\hline 100 & I & 17 & I 6.4 & & & & & \\
\hline & $\begin{array}{l}\text { Ex } \\
\text { Te } \\
\text { Tir }\end{array}$ & $\begin{array}{l}\text { trem } \\
\text { At be } \\
\text { inper } \\
\text { ne of }\end{array}$ & $\begin{array}{l}\text { e scale } \\
\text { ginni } \\
\text { id ... } \\
\text { one }\end{array}$ & $\begin{array}{c}\text { readir } \\
\dot{-} \\
\text { bratio }\end{array}$ & : & $\begin{array}{r}\cdot 5 \\
\cdot \quad 6 \\
\cdot \quad 7 \\
\cdot \quad 5\end{array}$ & $\begin{array}{l}55.0- \\
69.0- \\
79 \circ .0 \\
5.527\end{array}$ & $\begin{array}{l}\text { IOI.O } \\
85.0\end{array}$ \\
\hline
\end{tabular}

In this and the following observation the vibrations of the magnet were very irregular on account of a high wind which shook the instrument.

Magdalena Bay, June 9, I866.

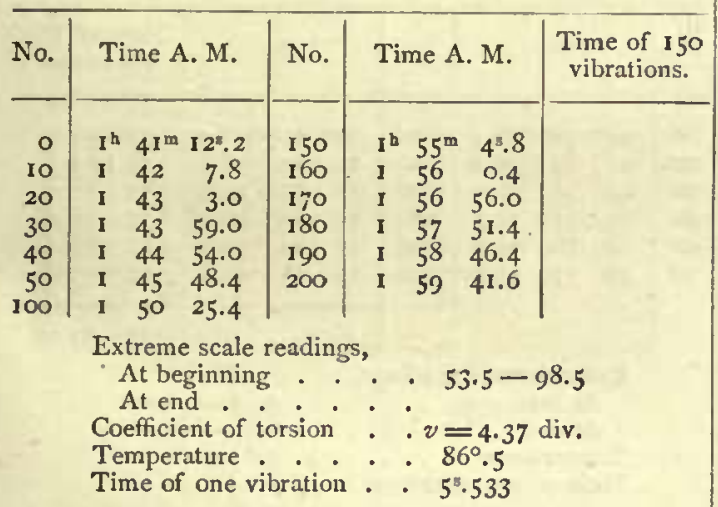

San Diego Bay, June I5, I866.

\begin{tabular}{|c|c|c|c|c|c|c|c|}
\hline No. & \multicolumn{3}{|c|}{ Time P. M. } & No. & \multicolumn{2}{|c|}{ Time P. M. } & $\begin{array}{l}\text { Time of } 150 \\
\text { vibrations. }\end{array}$ \\
\hline o & $6^{\text {h }}$ & I I $\mathrm{m}$ & $9^{9} .2$ & 150 & $6^{h}$ & $25^{\mathrm{m}} 5^{8 \mathrm{~s}} .2$ & $14^{\mathrm{m}} 49^{\mathrm{s}} .0$ \\
\hline 10 & 6 & 12 & 8.3 & 160 & 6 & 2656.6 & $14 \quad 48.3$ \\
\hline 20 & & I3 & 7.4 & 170 & 6 & $27 \quad 55.8$ & 48.4 \\
\hline 30 & 6 & 14 & 7.0 & I so & 6 & 55.4 & 48.4 \\
\hline 40 & 6 & I 5 & 6.2 & Igo & 6 & 53.8 & 47.6 \\
\hline \multirow[t]{2}{*}{50} & 6 & I6 & 5.4 & 200 & & $30 \quad 53.0$ & I4 47.6 \\
\hline & & & & & & $n \ldots$ & $14.4^{8.22}$ \\
\hline
\end{tabular}

Extreme scale readings,

At beginning . . . 94.9-108.9

At end $: 700-88.0$

Coefficient of torsion : $v=3.60 \mathrm{div}$.

Temperature . . . . $79^{\circ} .0$

Time of one vibration . $\quad 5^{1} .921$
San Francisco Bay, June 26, 1866.

\begin{tabular}{|c|c|c|c|c|c|c|c|c|}
\hline No. & \multicolumn{3}{|c|}{ Time A. M. } & No. & \multicolumn{3}{|c|}{ Time A. M. } & $\begin{array}{l}\text { Time of I } 5^{\circ} \\
\text { vibrations. }\end{array}$ \\
\hline o & $3^{b}$ & & $22^{4} .7$ & I 50 & $3^{\mathrm{h}}$ & & $57^{3} \cdot 7$ & $15^{\mathrm{m}} 35^{\mathrm{a}} \cdot \mathrm{o}$ \\
\hline Io & 3 & 22 & 24.7 & 160 & 3 & 38 & 0.0 & 1535.3 \\
\hline 20 & 3 & 23 & 27.2 & 170 & 3 & 39 & 2.5 & $35 \cdot 3$ \\
\hline 30 & 3 & 24 & 30.2 & 180 & 3 & 40 & 4.7 & 34.5 \\
\hline 40 & 3 & 25 & 32.0 & 190 & 3 & $4 I$ & 7.2 & 35.2 \\
\hline \multirow[t]{2}{*}{50} & 3 & 26 & 34.7 & 200 & & 42 & 10.0 & I5 35.3 \\
\hline & & & & & & & $\cdot$ & I5 35.10 \\
\hline
\end{tabular}

Extreme scale readings,

At beginning . . . 57.0- 102.0

At end . : : $68.0-90.5$

Coefficient of torsion,$v=4.35 \mathrm{div}$.

Temperature . . . $77^{\circ} .0$

Time of one vibration . $6^{8} .234$

U. S. N. Observatory, Washington, Noy. I, I866.

\begin{tabular}{|c|c|c|c|c|c|c|c|c|}
\hline No. & \multicolumn{3}{|c|}{ Time P. M. } & No. & \multicolumn{3}{|c|}{ Time P. M. } & $\begin{array}{l}\text { Time of } 150 \\
\text { vibrations. }\end{array}$ \\
\hline o & $5^{b}$ & & $52^{4} \cdot 7$ & 150 & $5^{\mathrm{h}}$ & $37^{\mathrm{n}}$ & $46^{3} .5$ & $17^{\mathrm{m}} 53^{\mathrm{s} .8}$ \\
\hline 10 & 5 & $2 I$ & 5.0 & 160 & 5 & $3^{8}$ & 58.0 & 1753.0 \\
\hline 20 & 5 & 22 & 16.0 & 170 & 5 & 40 & 9.2 & 53.2 \\
\hline 30 & 5 & 23 & 27.5 & 180 & 5 & $4 I$ & 20.7 & 53.2 \\
\hline 40 & 5 & 24 & 39.0 & I 90 & 5 & 42 & 31.8 & 52.8 \\
\hline \multirow[t]{2}{*}{50} & 5 & 25 & 50.7 & 200 & & 43 & 43.0 & I7 52.3 \\
\hline & & & & & & & & $17 \quad 53.05$ \\
\hline
\end{tabular}

Extreme scale readings,

At beginning . . . 52.5-106.0

At end . . . . 66.6-95.2

Coefficient of torsion . . $v=5.80 \mathrm{div}$

Temperature . . . . $67^{\circ} .5$

Time of one vibration : $7^{2} .154$

The following sets of observations of vibrations were made in the basement of the Observatory, where there is much iron, and are to be used only to determine the moment of inertia of the magnet.

Set I. November 2, I 866 .

\begin{tabular}{|c|c|c|c|c|c|c|c|}
\hline No. & & Time & & No. & & Time. & $\begin{array}{l}\text { Time of } 150 \\
\text { vibrations. }\end{array}$ \\
\hline o & $5^{\mathrm{h}}$ & $37^{\mathrm{m}}$ & $3^{I^{2} \cdot 7}$ & I 50 & $5^{\mathrm{b}}$ & $54^{\mathrm{m}} 53^{\mathrm{s}} .8$ & $17^{\mathrm{m}} 22^{\mathrm{B}} \cdot \mathrm{I}$ \\
\hline Io & 5 & $3^{8}$ & 41.2 & 160 & 5 & $5^{6} \quad 3.2$ & 1722.0 \\
\hline 20 & 5 & 39 & 50.7 & 170 & 5 & I 2.7 & 22.0 \\
\hline 30 & 5 & & 0.2 & 180 & 5 & 21.5 & 21.3 \\
\hline $4^{\circ}$ & 5 & $4^{2}$ & 9.7 & Igo & 5 & $3^{1.2}$ & 21.5 \\
\hline \multirow[t]{2}{*}{50} & 5 & 43 & 19.2 & 200 & 6 & 040.7 & $17 \quad 21.5$ \\
\hline & & & & & & . & 21.73 \\
\hline
\end{tabular}

Extreme scale readings,

At beginning . . . 59.I - 99.8

At end . . . . 66.9-92.2

Temperature :. . $65^{\circ} .5$

Time of one vibration . . 6.945 
Horizontal Intensity. Observations of Vibrations.

Set No. 2. November 2, т 866.

Inertia ring on magnet.

\begin{tabular}{|c|c|c|c|c|c|c|c|}
\hline No. & \multicolumn{3}{|c|}{ Time. } & No. & \multicolumn{2}{|r|}{ Time. } & $\begin{array}{l}\text { Time of } 150 \\
\text { vibrations. }\end{array}$ \\
\hline 0 & $6^{h}$ & $17^{m}$ & $25^{\circ} \cdot 3$ & 150 & $6^{h}$ & $39^{m} 4^{6} .8$ & $22^{\mathrm{m}} 2 I^{\mathrm{B}} \cdot 5$ \\
\hline 10 & 6 & 18 & 55.2 & 160 & 6 & $41 \quad 16.2$ & $22 \quad 21.0$ \\
\hline 20 & 6 & 20 & 24.2 & 170 & 6 & 45.7 & 21.5 \\
\hline 30 & 6 & $2 I$ & 54.0 & 180 & 6 & 14.8 & 20.8 \\
\hline 40 & 6 & 23 & 23.7 & 190 & 6 & 44.2 & 20.5 \\
\hline 50 & 6 & & 53.0 & 200 & 6 & $\begin{array}{ll}47 & 13.7\end{array}$ & 20.7 \\
\hline & & & & & & an . & 21.00 \\
\hline
\end{tabular}

Extreme scale readings,

At beginning . . 58.9- I00.8

At end . . . . 68.3-95.5

Coefficient of torsion : : $v=7.58$ div.

Temperature . . : $68^{\circ} .5$

Time of one vibration . . 8.940

Set No. 3. November 2, 1866.

\begin{tabular}{|c|c|c|c|c|c|c|c|c|}
\hline No. & \multicolumn{2}{|r|}{ Time. } & No. & \multicolumn{3}{|c|}{ 'Time. } & \multicolumn{2}{|c|}{$\begin{array}{l}\text { Time of } 150 \\
\text { vibrations. }\end{array}$} \\
\hline 0 & $6^{n}$ & $57^{\mathrm{m}} 41^{\mathrm{s}} \cdot 3$ & 150 & $7^{\text {h }}$ & $15^{\mathrm{m}}$ & $3^{6} .2$ & $17^{\mathrm{m}}$ & $21 \cdot 9$ \\
\hline IO & 6 & $\begin{array}{ll}58 & 50.8\end{array}$ & 160 & 7 & 16 & 12.8 & 17 & 22.0 \\
\hline 20 & 7 & 0.2 & 170 & 7 & 17 & 22.3 & 17 & 22.1 \\
\hline 30 & 7 & 9.8 & 180 & 7 & 18 & 31.5 & 17 & 21.7 \\
\hline 40 & 7 & 219.0 & 190 & 7 & 19 & 41.0 & 17 & 22.0 \\
\hline \multirow[t]{2}{*}{50} & 7 & $\begin{array}{ll}3 & 28.8\end{array}$ & 200 & 7 & 20 & 50.5 & 17 & 21.7 \\
\hline & & & & $\mathrm{Me}$ & & & 17 & 21.90 \\
\hline
\end{tabular}

Extreme scale readings,

At beginning . . . 5 54.2 - 104.5

At end . . . . $63.2-94.9$

Temperature . . . $69^{\circ} .0$

Time of one vibration . . 69.946

Set No. 4. November 2, 1866.

Inertia ring on magnet.

\begin{tabular}{|c|c|c|c|c|c|c|c|}
\hline No. & \multicolumn{3}{|c|}{ Time. } & No. & \multicolumn{2}{|r|}{ Time. } & $\begin{array}{l}\text { Time of } 150 \\
\text { vibrations. }\end{array}$ \\
\hline 0 & $7^{\mathrm{h}}$ & $26 \mathrm{~m}$ & $18 \% .3$ & 150 & $7^{\mathrm{h}}$ & $4^{8 \mathrm{~m}} 39^{\circ} .0$ & $22^{\mathrm{m}} 20^{\mathrm{N}} .7$ \\
\hline 10 & 7 & 27 & 47.7 & 160 & 7 & 50 8.5 & $22 \quad 20.8$ \\
\hline 20 & 7 & 29 & 17.2 & 170 & 7 & 37.9 & $22 \quad 20.7$ \\
\hline 30 & 7 & 30 & 46.7 & 180 & 7 & $7 \cdot 3$ & $22 \quad 20,6$ \\
\hline 40 & 7 & 32 & 16.0 & 190 & 7 & $3^{6.7}$ & $22 \quad 20.7$ \\
\hline \multirow[t]{2}{*}{50} & 7 & 33 & 45.5 & 200 & 7 & 5.8 & $22 \cdot 20.3$ \\
\hline & & & & & & & $22 \quad 20.63$ \\
\hline
\end{tabular}

Extreme scale readings,

At beginning . . . 56.5-103.6

At end . . : . 65.1 - 96.3

Temperature
Time of one vibration : $\quad 8^{2} .938$
Set No. 5. November 2, I 866.

\begin{tabular}{|c|c|c|c|c|c|c|c|c|c|}
\hline No & \multicolumn{3}{|c|}{ Time. } & No. & \multicolumn{3}{|c|}{ Time. } & \multicolumn{2}{|c|}{$\begin{array}{l}\text { Time of } 150 \\
\text { vibrations. }\end{array}$} \\
\hline o & $8^{h}$ & & $22^{\circ} .7$ & 150 & $8^{b}$ & & $44^{\prime} .2$ & \multicolumn{2}{|c|}{$17^{m} 21^{4} \cdot 5$} \\
\hline Io & 8 & 8 & $3^{2.2}$ & 160 & 8 & 25 & 53.7 & 17 & 21.5 \\
\hline 20 & 8 & 9 & 41.7 & 170 & 8 & 27 & 3.2 & 17 & 21.5 \\
\hline 30 & 8 & 10 & 51.2 & 180 & 8 & 28 & 12.7 & 17 & 21.5 \\
\hline 40 & 8 & 12 & 0.7 & 190 & 8 & 29 & 22.0 & 17 & 21.3 \\
\hline \multirow[t]{2}{*}{50} & \multirow[t]{2}{*}{8} & \multirow[t]{2}{*}{13} & \multirow[t]{2}{*}{10.2} & \multirow[t]{2}{*}{200} & 8 & $3^{\circ}$ & 31.7 & 17 & 21.5 \\
\hline & & & & & & & & 17 & 21.47 \\
\hline
\end{tabular}

Extreme scale readings,

At beginning . . . $58.7-99.3$

At end . . : $66.5-91.2$

Coefficient of torsion : $v=6.05$ div.

Temperature . . . $69^{\circ} .5$

Time of one vibration . 6.943

Set No. 6. November 2, 1866.

\begin{tabular}{|c|c|c|c|c|c|c|c|c|}
\hline No. & \multicolumn{3}{|c|}{ Time. } & No. & \multicolumn{3}{|c|}{ Time. } & $\begin{array}{l}\text { Time of } 150 \\
\text { vibrations. }\end{array}$ \\
\hline o & $12^{h}$ & $31^{\mathrm{m}}$ & $5^{83.2}$ & 150 & $12^{\mathrm{h}}$ & $49^{n}$ & $5^{1^{8} .2}$ & $17^{\mathrm{m}} 53^{4} .0$ \\
\hline 10 & 12 & 33 & 9.2 & 160 & 12 & 51 & 2.5 & 1753.3 \\
\hline 20 & 12 & 34 & 21.0 & 170 & 12 & $5^{2}$ & 14.2 & 53.2 \\
\hline 30 & 12 & 35 & 32.7 & 180 & 12 & 53 & 25.7 & 53.0 \\
\hline 40 & 12 & 36 & 44.0 & 190 & 12 & 54 & 37.2 & 53.2 \\
\hline \multirow[t]{2}{*}{50} & \multirow[t]{2}{*}{12} & \multirow[t]{2}{*}{37} & \multirow[t]{2}{*}{55.7} & \multirow[t]{2}{*}{200} & 12 & 55 & 48.7 & 1753.0 \\
\hline & & & & & & & & $17 \quad 53.12$ \\
\hline
\end{tabular}

Extreme seale readings,

At beginning . . . 59.5-99.0

At end . . . . 65.5-92.0

Temperature ... . $56^{\circ} .0$

Time of one vibration . . $7^{7} .154$

Set No. 7. November 2, 1866.

Inertia ring on magnet.

\begin{tabular}{|c|c|c|c|c|c|c|c|c|}
\hline No. & \multicolumn{3}{|c|}{ Time. } & No. & \multicolumn{3}{|c|}{ Time. - } & $\begin{array}{l}\text { Time of } 150 \\
\text { vibrations. }\end{array}$ \\
\hline 0 & $I^{\mathrm{h}}$ & & $23 \cdot 5$ & 150 & $I^{\text {h }}$ & $26^{m}$ & $22^{3} \cdot 7$ & $22^{\mathrm{m}} 59^{\mathrm{s}} .2$ \\
\hline 10 & 1 & 4 & 55.2 & 160 & 1 & 27 & 54.2 & 2259.0 \\
\hline 20 & I & 6 & 27.5 & 170 & I & 29 & 26.7 & $22 \quad 59.2$ \\
\hline 30 & 1 & 7 & 59.2 & 180 & I & $3^{\circ}$ & 58.5 & $59 \cdot .3$ \\
\hline 40 & I & 9 & 31.3 & 190 & I & 32 & 30.2 & 58.9 \\
\hline 50 & 1 & II & 3.2 & 200 & 1 & 34 & 2.5 & $22 \quad 59.3$ \\
\hline & & & & & & & & $22 \quad 59.15$ \\
\hline
\end{tabular}

Extreme scale readings,

At beginning . . . 58.2 - 101.0

$\Lambda t$ end . . . . $68.0-97.2$

Temperature : : $53^{\circ} .5$

Time of one vibration 
MAGNETIC OBSERVATIONS.

Horizontal Intensity. Observations of Vibrations.

Set No. 8. November 2, 1866.

\begin{tabular}{|c|c|c|c|c|c|c|c|c|}
\hline No. & \multicolumn{3}{|c|}{ Time. } & No. & \multicolumn{3}{|c|}{ Time. } & $\begin{array}{l}\text { Time of } 150 \\
\text { vibrations. }\end{array}$ \\
\hline 0 & $I^{\text {b }}$ & $40^{m}$ & $19^{8} .2$ & I 50 & $I^{\text {h }}$ & $5^{8 n}$ & $11^{8} .5$ & $17^{m} 5^{2^{s}} \cdot 3$ \\
\hline 10 & I & 41 & 30.7 & 160 & I & 59 & 23.0 & $17 \quad 52.3$ \\
\hline 20 & I & 42 & 42.2 & 170 & 2 & & 34.5 & 52.3 \\
\hline 30 & I & 43 & 53.7 & 180 & 2 & & 46.0 & 52.3 \\
\hline 40 & I & 45 & 5.2 & 190 & 2 & 2 & 57.5 & 52.3 \\
\hline \multirow[t]{2}{*}{50} & I & 46 & I6.7 & 200 & 2 & & 9.0 & 52.3 \\
\hline & & & & & & & & I7 52 \\
\hline
\end{tabular}

Extreme scale readings,

At beginning . . . 60.0-101.0

At end . . . . $68.0-92.8$

Temperature :. . $52^{\circ} .5$

Time of one vibration: $7^{8} .149$ 
HORIZONTAL INTENSITY. OBSERVATIONS OF DEFLECTIONS.

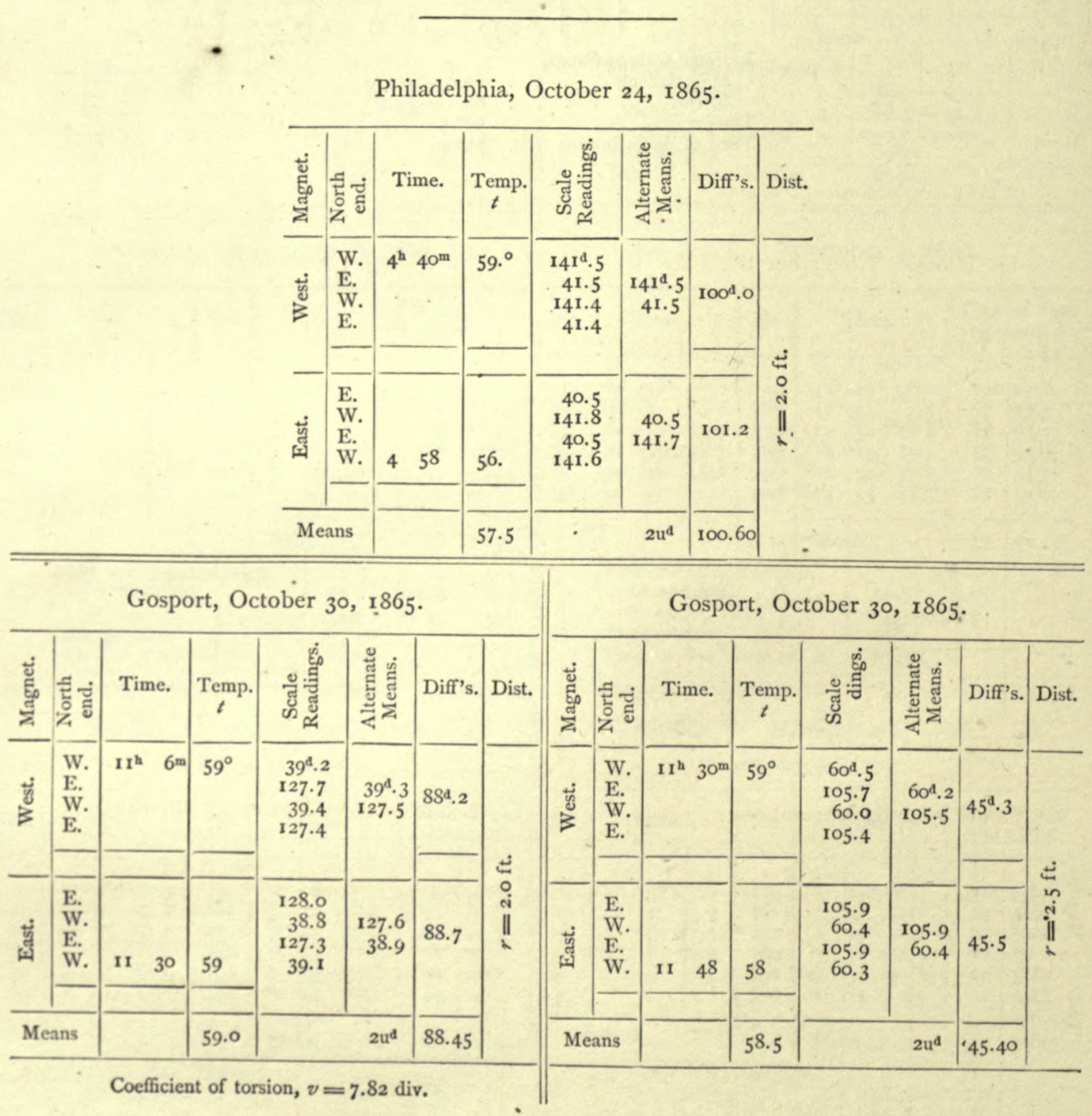


Horizontal Intensity. Observations of Deflections.

St. Thomas, November ${ }_{13},{ }^{2} 865$.

St. Thomas, November I 3, I 865 .

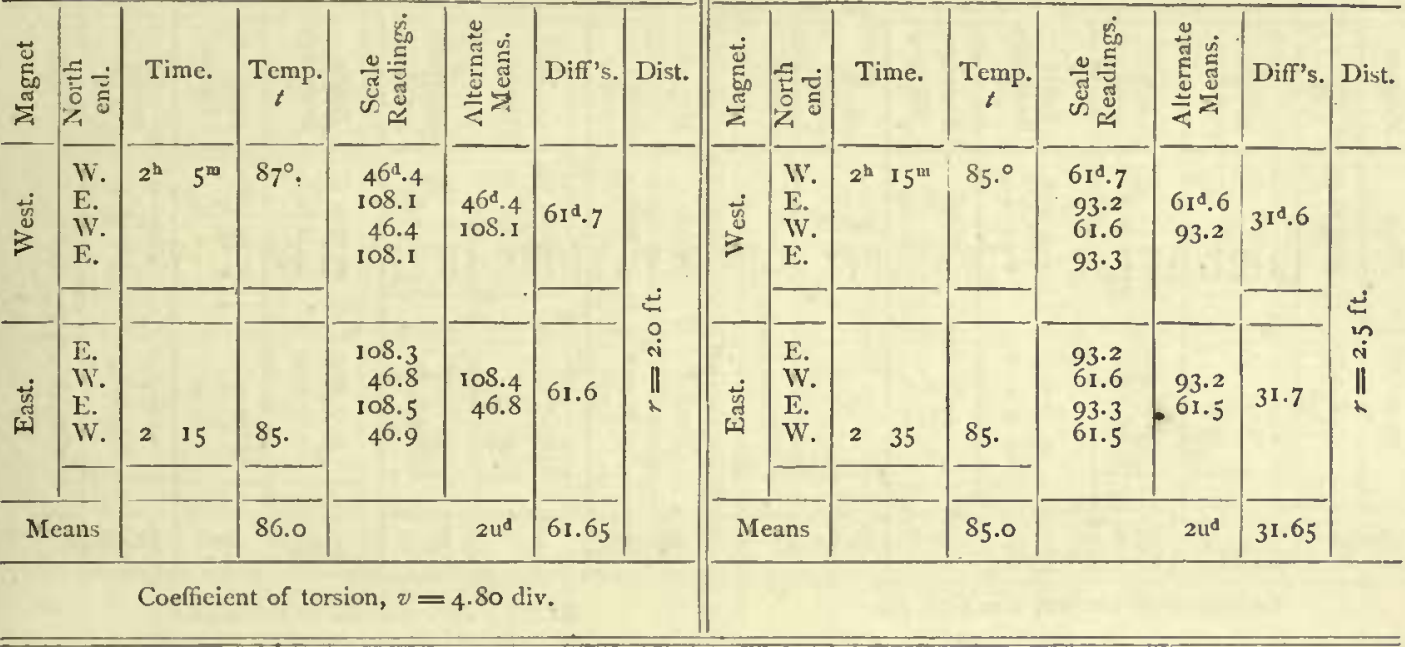

St. Thomas, November I6, I $86_{5}$.

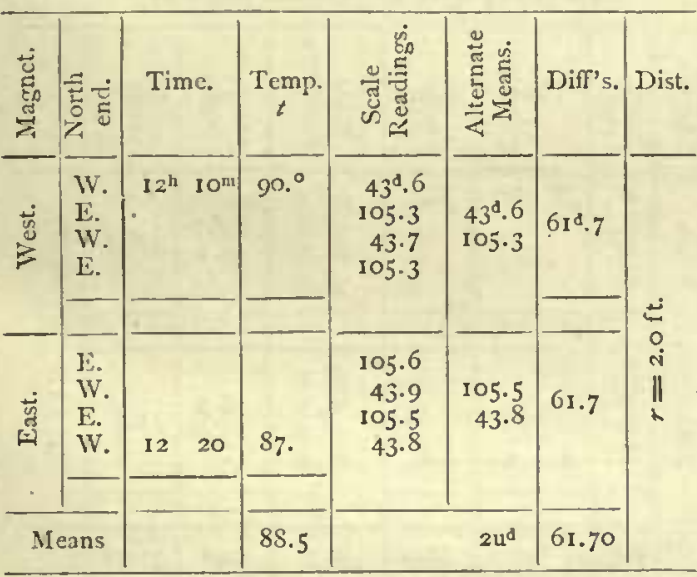

Coefficient of torsion, $v=4.55$ div.
St. Thomas, November I6, 1865 .

\begin{tabular}{|c|c|c|c|c|c|c|c|}
\hline 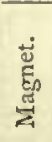 & 范 & Time. & Temp. & 窇密 & 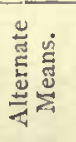 & Diff's. & Dist. \\
\hline 它 & $\begin{array}{l}\text { W. } \\
\text { E. } \\
\text { W. } \\
\text { E. }\end{array}$ & I $2^{\mathrm{h}} 2 \mathrm{O}^{\mathrm{m}}$ & $87^{\circ}$ & $\begin{array}{l}5^{8} .7 \\
90.4 \\
58.6 \\
90.4\end{array}$ & $\begin{array}{l}5^{8^{d} .6} \\
9^{0.4}\end{array}$ & $31^{4} .8$ & \\
\hline 苞 & $\begin{array}{l}\text { E. } \\
\text { W. } \\
\text { E. } \\
\text { W. }\end{array}$ & 1230 & 87. & $\begin{array}{r}90.4 \\
\cdot 59.1 \\
90.5 \\
58.9\end{array}$ & $\begin{array}{l}90.4 \\
59.0\end{array}$ & 31.4 & $\stackrel{\substack{n \\
i}}{i}$ \\
\hline \multicolumn{2}{|c|}{ Means } & & 87.0 & & $2 u^{d}$ & 31.60 & \\
\hline
\end{tabular}

Salute Islands, November 28, 1865.

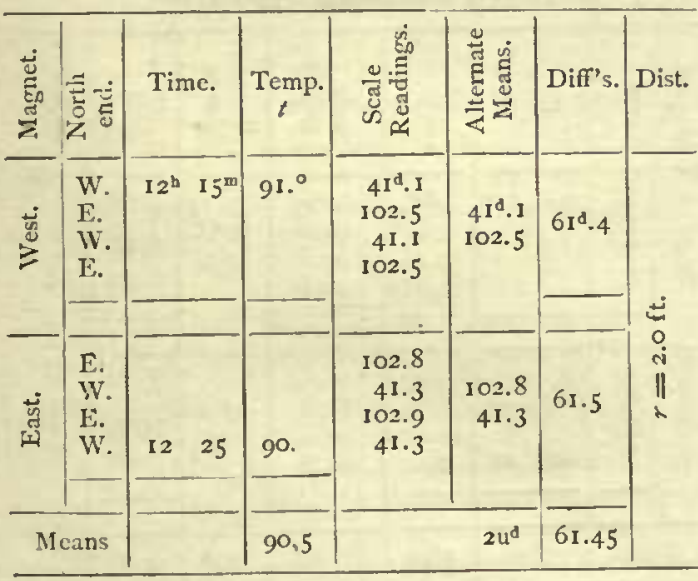

Salute Islands, November 28, 3865.

\begin{tabular}{|c|c|c|c|c|c|c|c|}
\hline 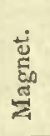 & च. & Time. & Temp. & 窎苛 & 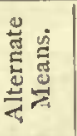 & Diff's. & Dist. \\
\hline $\begin{array}{l}\dot{\dot{u}} \\
\vec{y}\end{array}$ & $\begin{array}{l}\text { W. } \\
\text { E. } \\
\text { W. } \\
\text { E. }\end{array}$ & $12^{\mathrm{h}} 25^{\mathrm{m}}$ & $90 .^{\circ}$ & $\begin{array}{l}56^{\mathrm{d}} \cdot 3 \\
87.8 \\
56.3 \\
87.8\end{array}$ & $\begin{array}{l}56^{\mathrm{d}} \cdot 3 \\
87.8\end{array}$ & $3^{\mathrm{r}^{\mathrm{d}} \cdot 5}$ & \\
\hline $\begin{array}{l}\dot{y} \\
\text { 哥 }\end{array}$ & $\begin{array}{l}\text { E } \\
\text { W. } \\
\text { E. } \\
\text { W. }\end{array}$ & $12 \quad 35$ & 89. & $\begin{array}{l}88.0 \\
56.4 \\
88.0 \\
56.4\end{array}$ & $\begin{array}{l}88.0 \\
56.4\end{array}$ & 31.6 & $\prod_{i}^{n}$ \\
\hline \multicolumn{2}{|c|}{ Means } & & 89.5 & & $2 u^{d}$ & 31.55 & \\
\hline
\end{tabular}


Horizontal Intensity. Observations of Deflections.

Ceara, December 13, I865.

Ceara, December I3, 1865 .

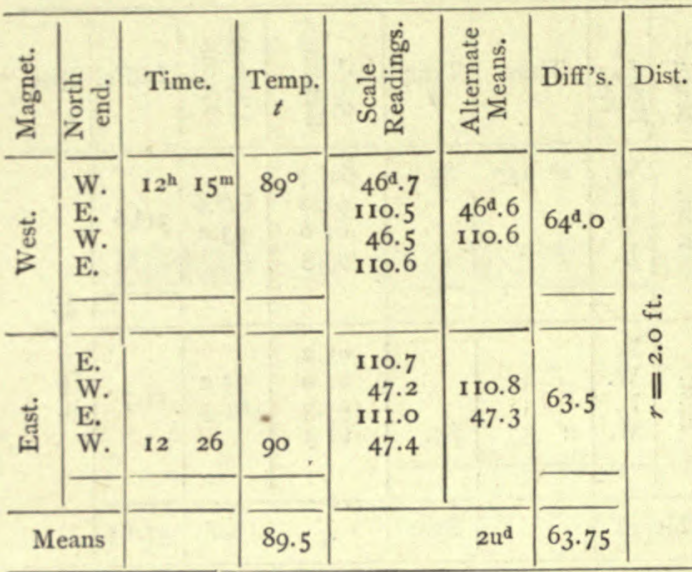

\begin{tabular}{|c|c|c|c|c|c|c|c|}
\hline 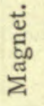 & خृ & Time. & $\underset{t}{\text { Temp. }}$ & 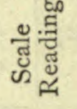 & 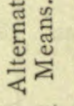 & Diff's. & Dist. \\
\hline$\frac{\dot{v}}{\dot{v}}$ & $\begin{array}{l}\text { W. } \\
\text { E. } \\
\text { W. } \\
\text { E. }\end{array}$ & $12^{h} 26^{\mathrm{m}}$ & $90^{\circ}$ & $\begin{array}{l}62^{d} \cdot 7 \\
95 \cdot 6 \\
62.8 \\
95.2\end{array}$ & $\begin{array}{l}62^{\mathrm{d}} \cdot 8 \\
95 \cdot 4\end{array}$ & $3^{2^{d} \cdot 6}$ & \\
\hline & & . & & & & & \pm \\
\hline $\begin{array}{l}\dot{y} \\
\text { ज्ञ }\end{array}$ & $\begin{array}{l}\text { E. } \\
\text { W. } \\
\text { E. } \\
\text { W. }\end{array}$ & 1240 & 89 & $\begin{array}{l}95.3 \\
63.4 \\
95.7 \\
64.1\end{array}$ & $\begin{array}{l}95 \cdot 5 \\
63.7\end{array}$ & 31.8 & $\|_{2}$ \\
\hline & & & 89.5 & & $2 u^{d}$ & 32.20 & \\
\hline
\end{tabular}

Coefficient of torsion, $v=6.72$ div.

Pernambuco, December 23, 1865 .

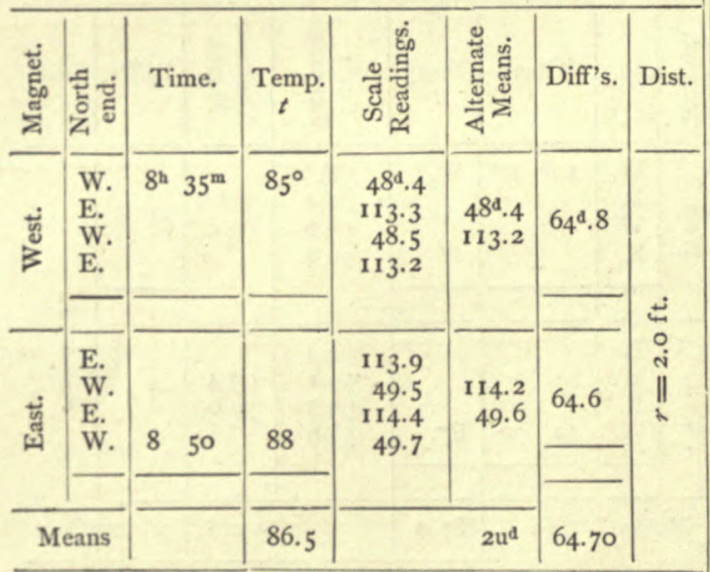

Coefficient of torsion, $v=5.10$ div.

Bahia, December 27, 1865 .

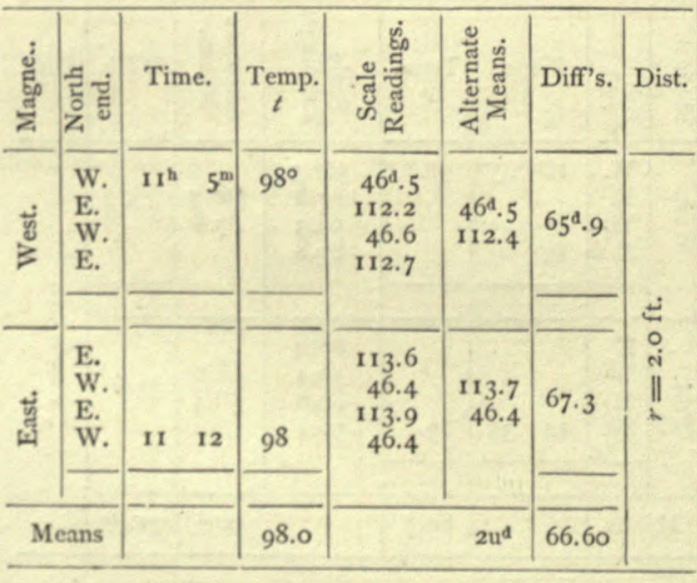

Coefficient of torsion, $v=5.27$ div.
Pernambuco, December 23, 1865 .

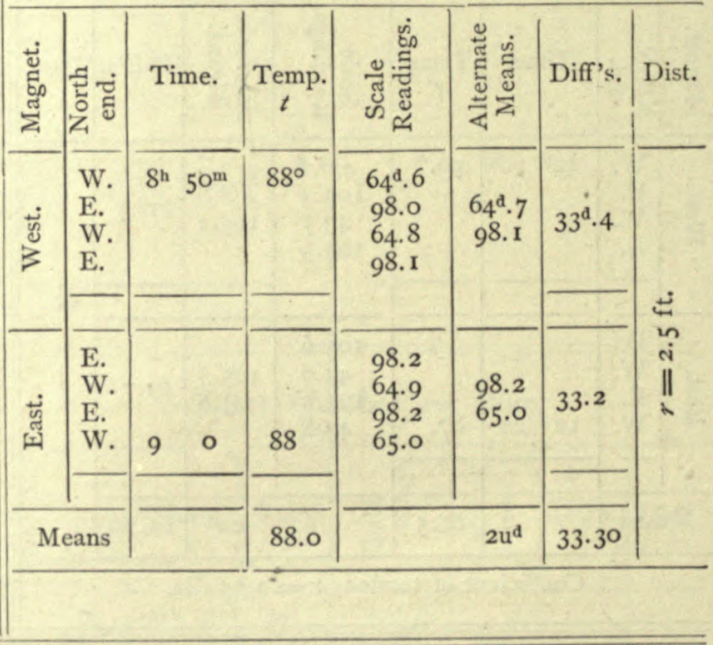

Bahia, December 27, 1865 .

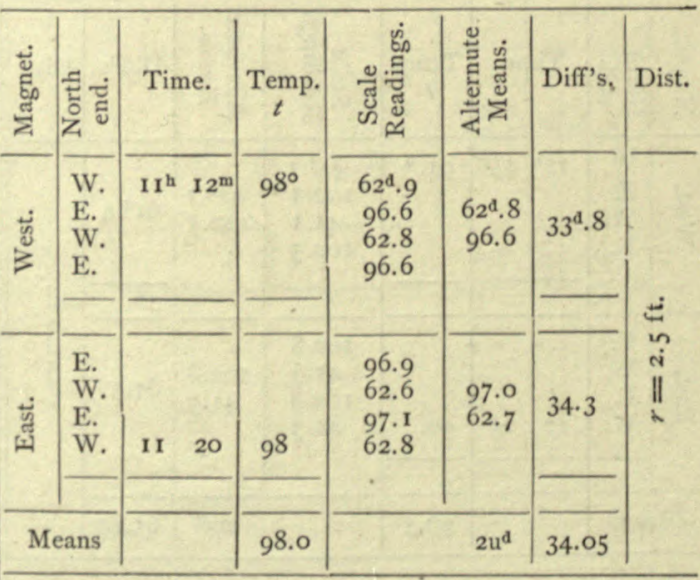


Horizontal Intensity. Observations of Deflections.

Rio Janeiro, January 6, I 866.

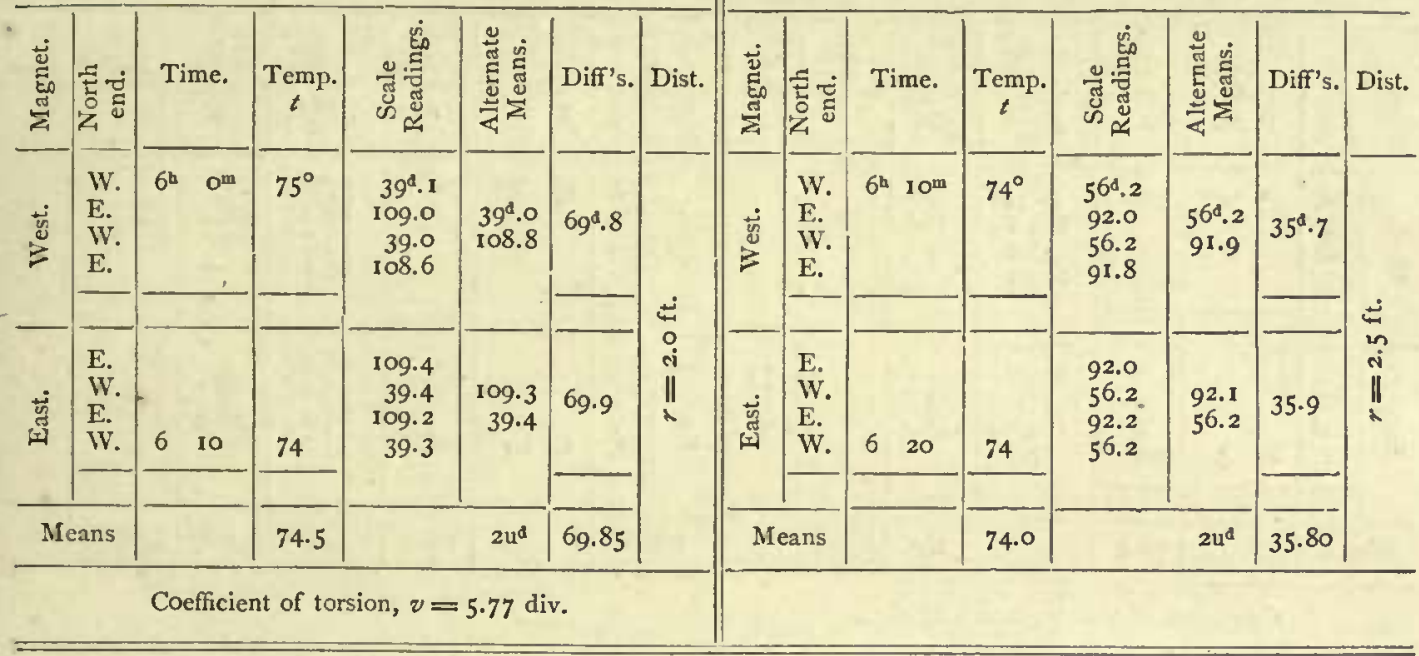

Monte Video, January 18, r866.

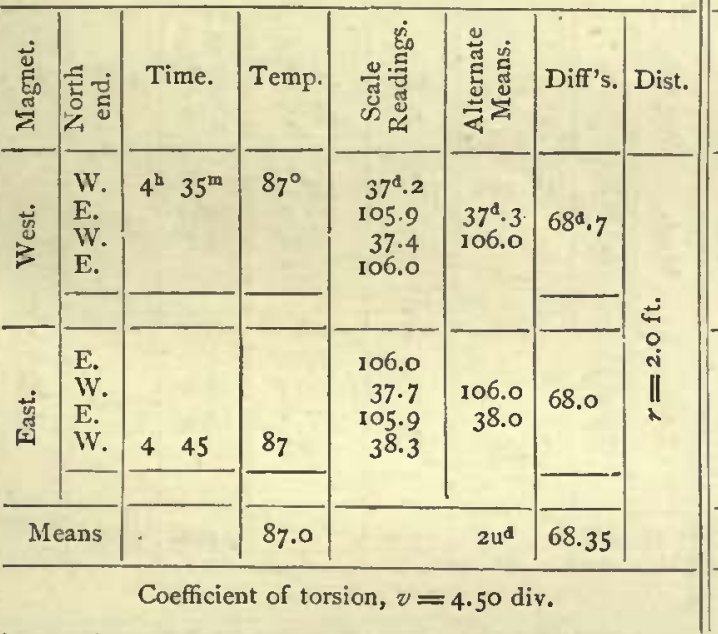

Sandy Point, February $7,1866$.

\begin{tabular}{|c|c|c|c|c|c|c|c|}
\hline 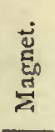 & हีं छं & Time. & Temp. & 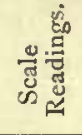 & 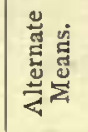 & Diff's. & Dist. \\
\hline$\stackrel{\vec{y}}{\vec{z}}$ & $\begin{array}{l}\text { W. } \\
\text { E. } \\
\text { W. } \\
\text { E. }\end{array}$ & $12^{\text {h }} 45^{m}$ & $72^{\circ}$ & $\begin{array}{r}43^{\mathrm{d} .0} \\
110.2 \\
44.0 \\
110.3\end{array}$ & $\begin{array}{l}43^{4} .5 \\
110.3\end{array}$ & $66^{4} .8$ & \\
\hline & & & & & & 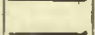 & $\dot{ت}$ \\
\hline 密 & $\begin{array}{l}\mathrm{E} \\
\mathrm{W} \\
\mathrm{E} . \\
\mathrm{W} .\end{array}$ & 8 & 69 & $\begin{array}{r}110.7 \\
42.6 \\
110.9 \\
42.5\end{array}$ & $\begin{array}{r}110.8 \\
42.6\end{array}$ & 68.2 & II \\
\hline \multicolumn{2}{|c|}{ Means } & 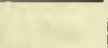 & 70.5 & & $2 u^{d}$ & 67.50 & \\
\hline
\end{tabular}

Rio Janeiro, January 6, r866.

Monte Video, January 18, 1866.

\begin{tabular}{|c|c|c|c|c|c|c|c|}
\hline 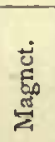 & 矛它 & Time. & Temp. & 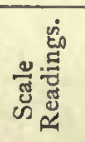 & 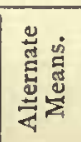 & Diff's. & Dist. \\
\hline & $\begin{array}{l}\text { W. } \\
\text { E. } \\
\text { W. } \\
\text { E. }\end{array}$ & $4^{\mathrm{b}} 45^{\mathrm{m}}$ & $87^{\circ}$ & $\begin{array}{l}54^{d} .4 \\
89.5 \\
54.4 \\
89.5\end{array}$ & $\begin{array}{l}54^{d} .4 \\
89.5\end{array}$ & $35^{d} \cdot 1$ & \\
\hline & $\begin{array}{l}\text { E. } \\
\text { W. } \\
\text { E. } \\
\text { W. }\end{array}$ & $\begin{array}{l}4 \quad 55 \\
\end{array}$ & 88 & $\begin{array}{l}89.7 \\
54.7 \\
89.6 \\
54.6\end{array}$ & $\begin{array}{r}89.6 \\
54.6 \\
\end{array}$ & 35.0 & \\
\hline & eans & & 87.5 & & $2 u^{d}$ & 35.05 & \\
\hline
\end{tabular}

Sandy Point, February $7, \mathbf{x} 866$.

\begin{tabular}{|c|c|c|c|c|c|c|c|}
\hline 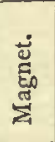 & 평 & Time. & $\underset{t}{\text { Temp }}$ & 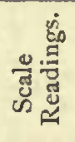 & 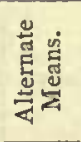 & Diff's. & Dist. \\
\hline & $\begin{array}{l}\text { W. } \\
\text { E. } \\
\text { W. } \\
\text { E. }\end{array}$ & $\mathrm{I}^{\mathrm{b}} \quad \mathrm{g}^{\mathrm{m}}$ & $69^{\circ}$ & $\begin{array}{r}58.8 \\
93.2 \\
58.3 \\
93.2\end{array}$ & $\begin{array}{c}58^{4.6} \\
93.2\end{array}$ & $34^{d} .6$ & \\
\hline & $\begin{array}{l}\text { E. } \\
\text { W. } \\
\text { E. } \\
\text { W. }\end{array}$ & $1 \quad 23$ & 68 & $\begin{array}{l}93.4 \\
58.9 \\
94.0 \\
59.1\end{array}$ & $\begin{array}{l}93.7 \\
59.0\end{array}$ & 34.7 & II \\
\hline & ans & & 68.5 & & $2 u^{d}$ & 34.65 & \\
\hline
\end{tabular}


Horizontal Intensity. Observations of Deflections.

Valparaiso, March 2, r 866.

Valparaiso, March 2, 1866.

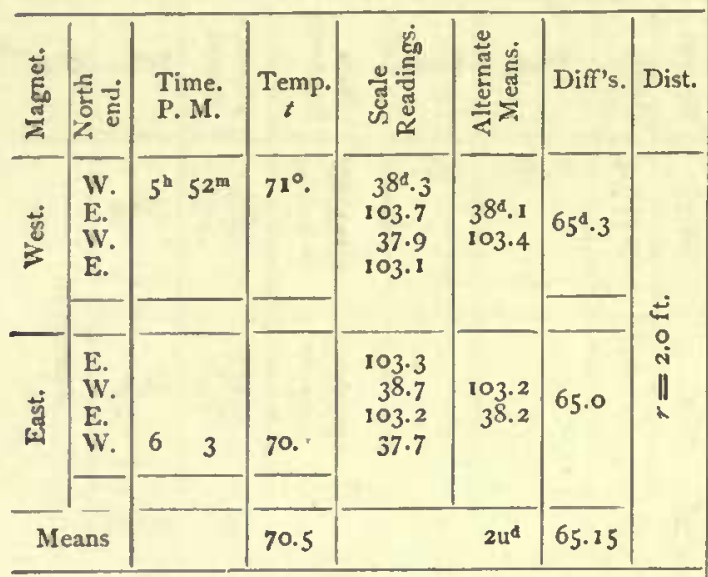

\begin{tabular}{|c|c|c|c|c|c|c|c|}
\hline & 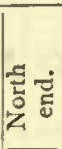 & $\begin{array}{l}\text { Time. } \\
\text { P. M. }\end{array}$ & Temp. & 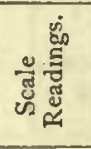 & 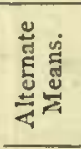 & Diff's. & Dist. \\
\hline & $\begin{array}{l}\text { W. } \\
\text { E. } \\
\text { W. } \\
\text { E. }\end{array}$ & $6^{\mathrm{h}} \quad 3^{\mathrm{m}}$ & $700^{\circ}$ & $\begin{array}{l}53^{4.8} \\
87.1 \\
53.7 \\
87.1\end{array}$ & $\begin{array}{l}53^{\mathrm{d} .7} \\
87.1\end{array}$ & $33^{d} \cdot 4$ & \\
\hline & $\begin{array}{l}\text { E. } \\
\text { W. } \\
\text { E. } \\
\text { W. }\end{array}$ & $\begin{array}{ll}6 & \mathrm{I}\end{array}$ & 68. & $\begin{array}{l}87.2 \\
53.6 \\
87.1 \\
53.6\end{array}$ & $\begin{array}{l}87.1 \\
53.6\end{array}$ & 33.5 & ! \\
\hline \multicolumn{2}{|c|}{ Means } & & 69.0 & & $\mathbf{2} \mathbf{u}^{d}$ & 33.45 & \\
\hline
\end{tabular}

Coefficient of torsion, $v=6.87$ div.

Valparaiso, March 19, 1866.

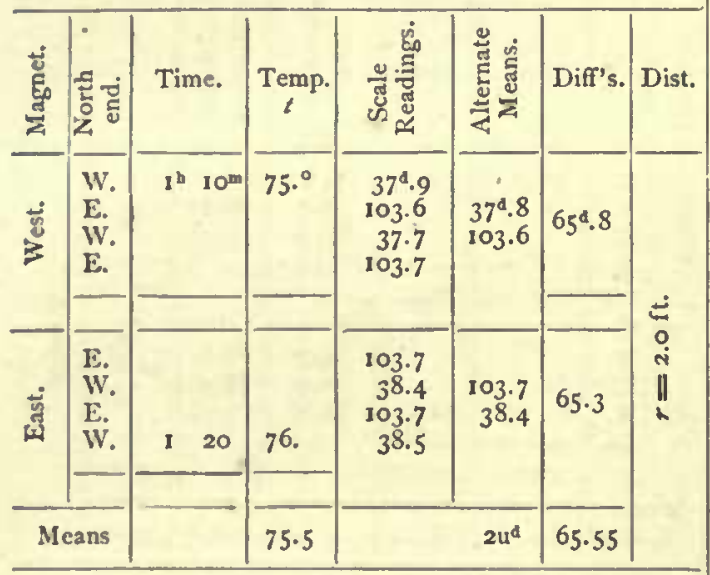

Valparaiso, March I9, I866.

\begin{tabular}{|c|c|c|c|c|c|c|c|}
\hline 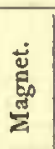 & 莟它 & Time. & Temp. & 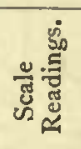 & 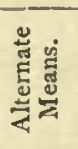 & Diff's: & Dist. \\
\hline 范 & $\begin{array}{l}\text { W. } \\
\text { E. } \\
\text { W. } \\
\text { E. }\end{array}$ & $1^{\text {h }} 20^{\mathrm{m}}$ & $76 .^{\circ}$ & $\begin{array}{l}54^{4.2}= \\
87.7 \\
54.0 \\
87.7\end{array}$ & $\begin{array}{l}54^{d .1} \\
87.7\end{array}$ & $33^{4} .6$ & \\
\hline $\bar{y}$ & $\begin{array}{l}\text { E. } \\
\text { W. } \\
\text { E. } \\
\text { W. }\end{array}$ & I 35 & 78. & $\begin{array}{l}87.8 \\
54.3 \\
87.8 \\
54.5\end{array}$ & $\begin{array}{l}87.8 \\
54.4\end{array}$ & 33.4 & \\
\hline \multicolumn{2}{|c|}{ Means } & & 77.0 & & $2 u^{d}$ & $33.5^{\circ}$ & \\
\hline
\end{tabular}

Coefficient of torsion, $v=4.80$ div.

Valparaiso, March 29, 1866.

\begin{tabular}{|c|c|c|c|c|c|c|c|}
\hline $\begin{array}{l}\frac{\vec{E}}{2} \\
\frac{g}{2}\end{array}$ & है & Time. & $\underset{t}{T}$ & 莺 & 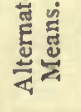 & Iiff's. & \\
\hline \multirow[t]{2}{*}{$\stackrel{\overrightarrow{0}}{\vec{z}}$} & $\begin{array}{l}\text { W. } \\
\text { E. } \\
\text { w. } \\
\text { E. }\end{array}$ & $12^{\mathrm{b}}$ on & $69 .^{\circ}$ & $\begin{array}{r}368.9 \\
102.1 \\
36.9 \\
102.6\end{array}$ & $\begin{array}{r}3^{64} .9 \\
102.4\end{array}$ & $65^{d} \cdot 5$ & \\
\hline & $\begin{array}{l}\text { E. } \\
\text { W. } \\
\text { E. } \\
\text { w. }\end{array}$ & $12 \quad 13$ & 68. & $\begin{array}{r}102.8 \\
37.2 \\
102.8 \\
37.3\end{array}$ & $\begin{array}{r}102.8 \\
37.3\end{array}$ & 65.5 & \\
\hline \multicolumn{2}{|c|}{ Means } & & 68.5 & & $2 u^{d}$ & 65.50 & \\
\hline
\end{tabular}

Valparaiso, March 29, r 866.

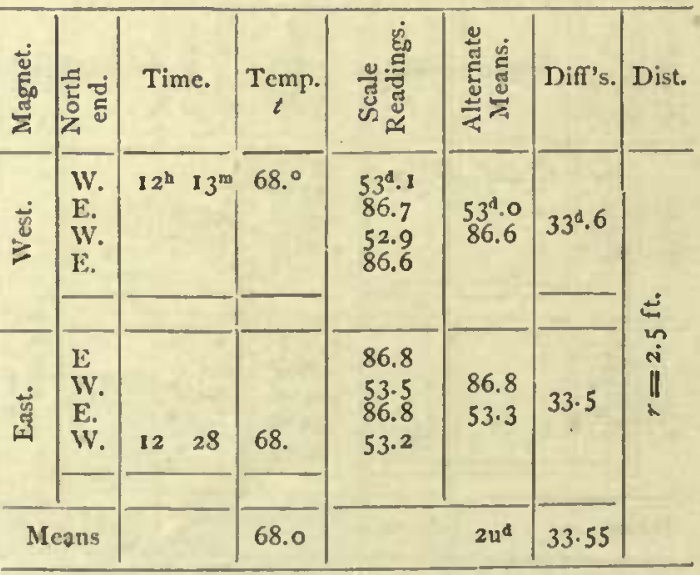

Coefficient of torsion, $v=4.62 \mathrm{div}$. 
Horizontal Intensity. Observations of Deflections.

Valparaiso April 7, 1866.

Valparaiso, April 7, x $\$ 66$.

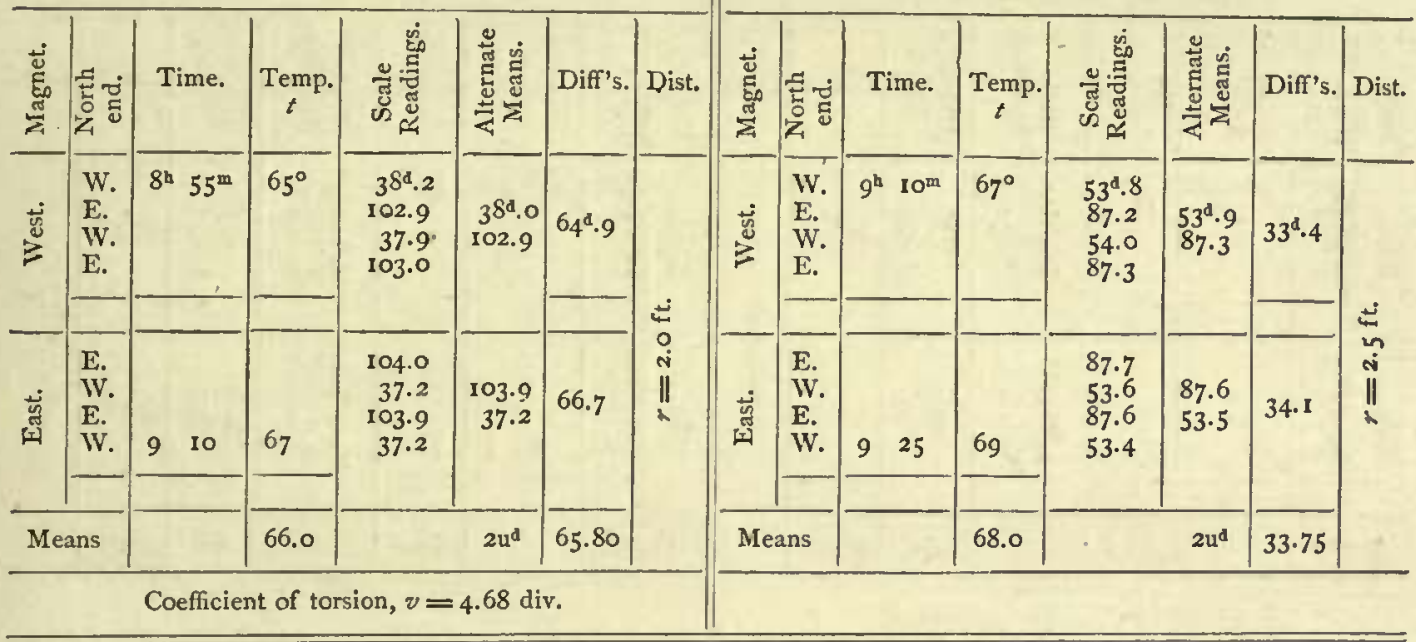

Valparaiso, April Ir, r 866.

Valparaiso, April II, I866.

\begin{tabular}{|c|c|c|c|c|c|c|c|}
\hline & 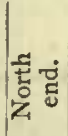 & Time. & Temp & 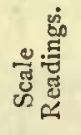 & 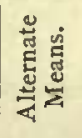 & Diff's. & \\
\hline & $\begin{array}{l}\text { W. } \\
\text { E. } \\
\text { W. } \\
\text { E. }\end{array}$ & $\mathrm{I}^{\mathrm{b}} \quad \mathrm{O}^{\mathrm{mm}}$ & $74^{\circ}$ & $\begin{array}{r}39^{\mathrm{d} .2} \\
\text { OO4.3 } \\
39.3 \\
194.4\end{array}$ & $\begin{array}{c}39^{\mathrm{d}} .2 \\
104.3\end{array}$ & $65^{d} \cdot 1$ & \\
\hline 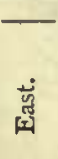 & $\begin{array}{l}\text { E. } \\
\text { W. } \\
\text { E. } \\
\text { W. }\end{array}$ & I II & 74. & $\begin{array}{r}105.2 \\
38.9 \\
105.3 \\
39.2\end{array}$ & $\begin{array}{r}105.2 \\
39.0\end{array}$ & 66.2 & \\
\hline & ans & & 74.0 & & $2 u^{d}$ & 65.65 & \\
\hline
\end{tabular}

\begin{tabular}{|c|c|c|c|c|c|c|c|}
\hline 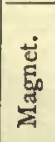 & हี & Time. & $\underset{t}{\text { Temp. }}$ & 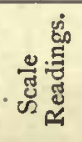 & 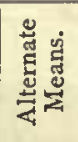 & Diff's. & Dist. \\
\hline 葛 & $\begin{array}{l}\text { W. } \\
\text { E. } \\
\text { W. } \\
\text { E. }\end{array}$ & $I^{\text {h }}$ II $I^{\mathrm{nL}}$ & $74^{\circ}$ & $\begin{array}{l}55^{\mathrm{d} .2} .2 \\
88.4 \\
55.2 \\
88.6\end{array}$ & $\begin{array}{l}55^{\mathrm{d} .2} \\
88.5\end{array}$ & $33^{d} \cdot 3$ & \\
\hline & $\begin{array}{l}\text { E. } \\
\text { w. } \\
\text { E. } \\
\text { w. }\end{array}$ & 123 & 74 & $\begin{array}{l}88.9 \\
54.9 \\
88.9 \\
54.8\end{array}$ & $\begin{array}{l}88.9 \\
54.9\end{array}$ & 34.0 & \\
\hline & eans & & 74.0 & & $2 \mathbf{u}^{\mathbf{d}}$ & 33.65 & \\
\hline
\end{tabular}

Valparaiso, April r3, 1866.

Valparaiso, April I3, I866.

\begin{tabular}{|c|c|c|c|c|c|c|c|}
\hline 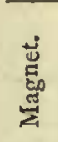 & हैँ & Time. & Temp. & 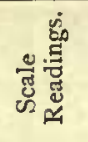 & 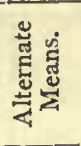 & Diff's. & Dist. \\
\hline$\sum^{\overrightarrow{0}}$ & $\begin{array}{l}\text { W. } \\
\text { E. } \\
\text { W. } \\
\text { E. }\end{array}$ & $I^{\mathrm{h}} 55^{\mathrm{m}}$ & $7 \mathrm{1}^{\circ}$. & $\begin{array}{c}37^{\mathrm{d} .2} \\
102.0 \\
36.9 \\
101.6\end{array}$ & $\begin{array}{l}37^{\mathrm{d}} .0 \\
101.8\end{array}$ & $64^{d} .8$ & \\
\hline 苞 & $\begin{array}{l}\text { E. } \\
\text { W. } \\
\text { E. } \\
\text { W. }\end{array}$ & 7 & 65. & $\begin{array}{r}102.2 \\
36.0 \\
101.7 \\
35.6\end{array}$ & $\begin{array}{r}\text { ror.9 } \\
35.8\end{array}$ & 66.1 & $\begin{array}{l}\text { o } \\
\text { ì } \\
11\end{array}$ \\
\hline & & & 68.0 & & $2 u^{d}$ & 65.45 & \\
\hline
\end{tabular}

\begin{tabular}{|c|c|c|c|c|c|c|c|}
\hline 㥑 & हٓ & Time. & $\underset{t}{\text { Temp. }}$ & 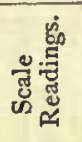 & 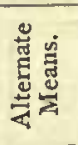 & Diff's. & Dist. \\
\hline 蘂 & $\begin{array}{l}\text { W. } \\
\text { E. } \\
\text { W. } \\
\text { E. }\end{array}$ & $2^{\mathrm{b}} \quad 7^{\mathrm{m}}$ & $65^{\circ}$. & $\begin{array}{l}5 \mathrm{I}^{\mathrm{d}} .9 \\
84.9 \\
51.9 \\
84.9\end{array}$ & $\begin{array}{r}5 \mathrm{I}^{\mathrm{d}} .7 \\
84.9\end{array}$ & $33^{\mathrm{d}} \cdot 2$ & \\
\hline 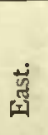 & $\begin{array}{l}\text { E. } \\
\text { W. } \\
\text { E. } \\
\text { W. }\end{array}$ & 220 & 62. & $\begin{array}{l}85.4 \\
51.0 \\
35.0 \\
50.9\end{array}$ & $\begin{array}{l}85.2 \\
51.0\end{array}$ & 34.2 & $\begin{array}{l}n \\
i \\
l \\
!\end{array}$ \\
\hline & eans & & 63.5 & & $2 u^{d}$ & 33.70 & \\
\hline
\end{tabular}


Horizontal Intensity. Observations of Deflections.

San Lorenzo Island, April 26, 1866.

San Lorenzo Island, April 26, 1866.
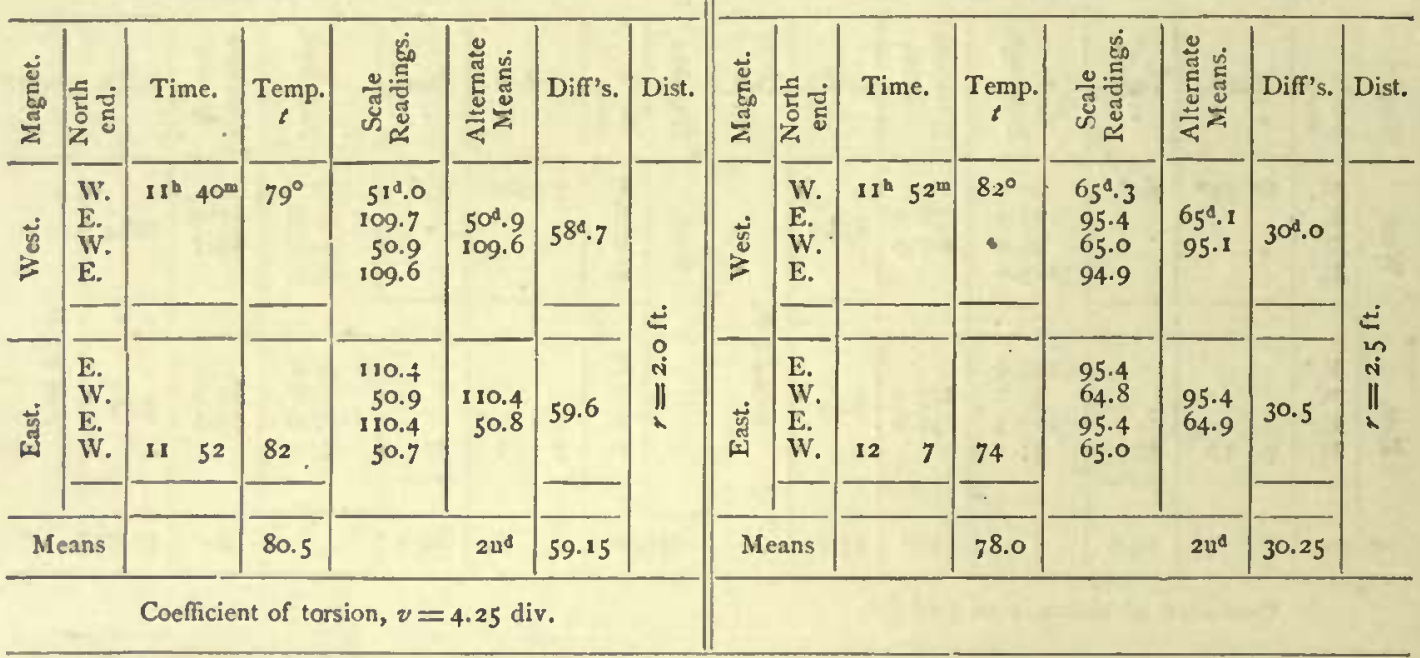

Payta, May 7, 1866.

\begin{tabular}{|c|c|c|c|c|c|c|c|}
\hline 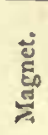 & : & Time. & Temp. & 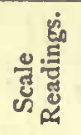 & 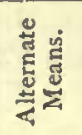 & Diff's. & \\
\hline 乡ัّ & $\begin{array}{l}\text { W. } \\
\text { E. } \\
\text { W. } \\
\text { E. }\end{array}$ & $7^{\mathrm{b}} 33^{\mathrm{m}}$ & $77^{\circ}$ & $\begin{array}{r}52^{\mathrm{d} .2} \\
107.7 \\
52.0 \\
107.8\end{array}$ & $\begin{array}{l}52^{\mathrm{d} .1} \\
107.7\end{array}$ & $55^{d} .6$ & \\
\hline & $\begin{array}{l}\text { E. } \\
\text { W. } \\
\text { E. } \\
\text { W. }\end{array}$ & 746 & 77 & $\begin{array}{r}108.4 \\
51.6 \\
108.3 \\
51.6\end{array}$ & $\begin{array}{r}108.4 \\
51.6\end{array}$ & 56.8 & \\
\hline \multicolumn{2}{|c|}{ Means } & & 77.0 & & $2 u^{d}$ & 56,20 & \\
\hline
\end{tabular}

Payta, May 7, 1866.

Coefficient of torsion, $y=\mathbf{3 . 6 2}$ div.

Flamenco Island, Panama Bay, May 14, 1866.

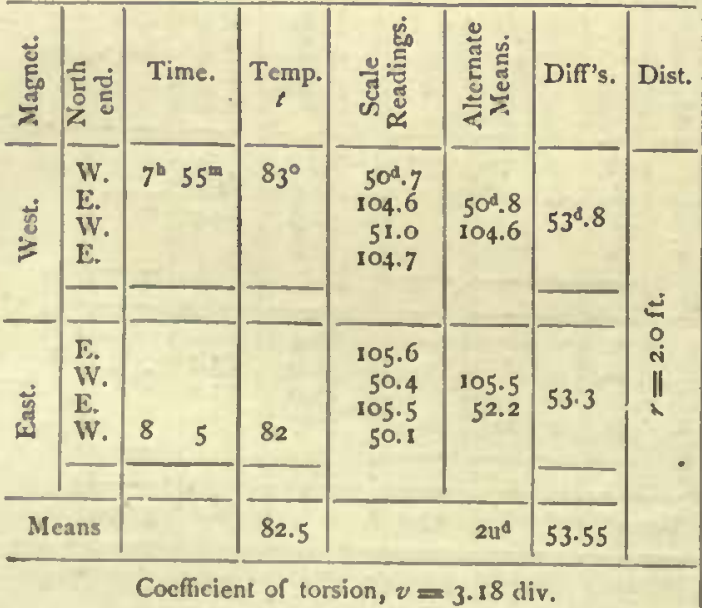

Flamenco Island, Panama Bay, May I 4, 1866.

\begin{tabular}{|c|c|c|c|c|c|c|c|}
\hline 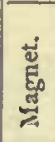 & 远 & Time. & $\underset{t}{T e m p}$ & 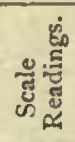 & 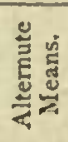 & Diff's. & Dist. \\
\hline 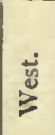 & $\begin{array}{l}\text { W. } \\
\text { E. } \\
\text { W. } \\
\text { E. }\end{array}$ & $8^{\mathrm{h}} \quad 5^{\mathrm{m}}$ & $82^{\circ}$ & $\begin{array}{l}64^{4} .0 \\
91.7 \\
64.0 \\
91.6\end{array}$ & $\begin{array}{r}64^{d} .0 \\
91.6\end{array}$ & $27^{4} .6$ & \\
\hline 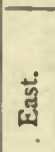 & $\begin{array}{l}\mathbf{E} \\
\text { W. } \\
\text { E. } \\
\text { W. }\end{array}$ & 815 & 82 & $\begin{array}{l}92.0 \\
63.8 \\
92.0 \\
63.8\end{array}$ & $\begin{array}{r}92.0 \\
63.8\end{array}$ & 28.2 & î \\
\hline \multicolumn{2}{|c|}{ Means } & & 82.0 & & $2 u^{a}$ & 27.90 & \\
\hline
\end{tabular}


Horizontal Intensity. Observations of Deflections.

Acapulco, May 3о, 1866.

Acapulco, May 30, 1866.

\begin{tabular}{|c|c|c|c|c|c|c|c|}
\hline 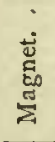 & 苛 & Time. & Temp. & 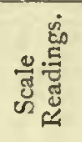 & 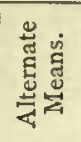 & Diff's. & Dist. \\
\hline$\stackrel{\dot{\mathrm{g}}}{\stackrel{\overrightarrow{\mathrm{s}}}{\rightleftarrows}}$ & $\begin{array}{l}\text { W. } \\
\text { E. } \\
\text { W. } \\
\text { E. }\end{array}$ & $7^{\text {h }} 22^{\mathrm{mm}}$ & $86^{\circ}$ & $\begin{array}{r}53^{\mathrm{d}} .9 \\
107.0 \\
53.9 \\
107.0\end{array}$ & $\begin{array}{l}53^{\mathrm{d}} \cdot 9 \\
107.0\end{array}$ & $53^{\mathrm{d}}: \mathrm{I}$ & \\
\hline & & 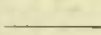 & & & & & $\dot{\Delta}$ \\
\hline 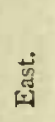 & $\begin{array}{l}\text { E. } \\
\text { W. } \\
\text { E. } \\
\text { W. }\end{array}$ & $\begin{array}{l}7 \quad 32 \\
\end{array}$ & 84 & $\begin{array}{r}107.5 \\
53.5 \\
107.7 \\
53.8\end{array}$ & $\begin{array}{r}107.6 \\
53.6\end{array}$ & 54.0 & ii \\
\hline \multicolumn{2}{|r|}{ eans } & & 85.0 & & $2 u^{d}$ & 53.55 & \\
\hline
\end{tabular}

\begin{tabular}{|c|c|c|c|c|c|c|c|}
\hline हू & 泀 & Time. & Temp. & 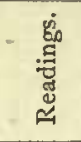 & 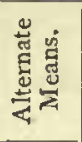 & Diff's. & Dist. \\
\hline & $\begin{array}{l}\text { W. } \\
\mathrm{E} . \\
\text { W. } \\
\mathrm{E} .\end{array}$ & $7^{h} 32^{m}$ & $84^{\circ}$ & $\begin{array}{l}66^{d} .9 \\
94 . \mathrm{I} \\
66.9 \\
94.2\end{array}$ & $\begin{array}{l}66^{\mathrm{d}} \cdot 9 \\
94 \cdot 2\end{array}$ & $27^{\mathrm{d}} \cdot 3$ & \\
\hline 5 & $\begin{array}{l}\text { E. } \\
\text { W. } \\
\text { E. } \\
\text { W. }\end{array}$ & 740 & 85 & $\begin{array}{l}94.4 \\
66.8 \\
94.4 \\
66.8\end{array}$ & $\begin{array}{l}94.4 \\
66.8\end{array}$ & 27.6 & \\
\hline & eans & & 84.5 & & $2 u^{d}$ & 27.45 & \\
\hline
\end{tabular}

Coefficient of torsion, $v=3.45$ div.

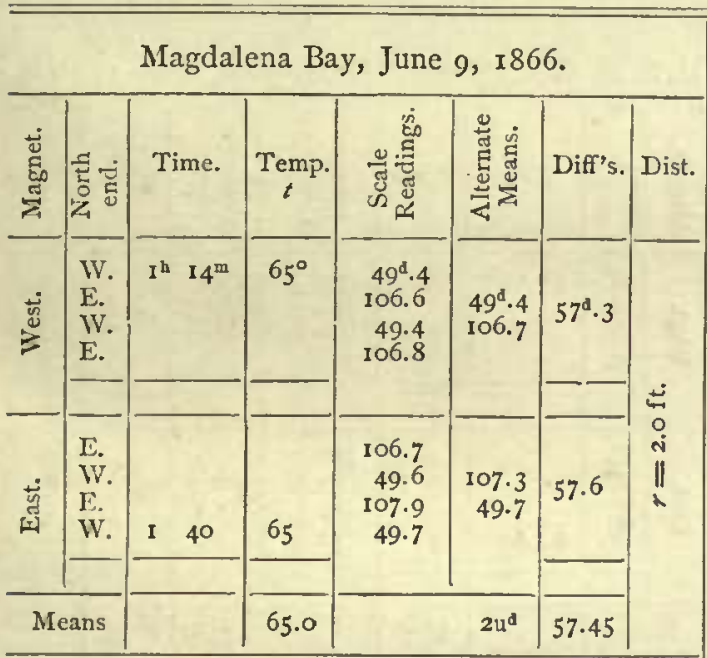

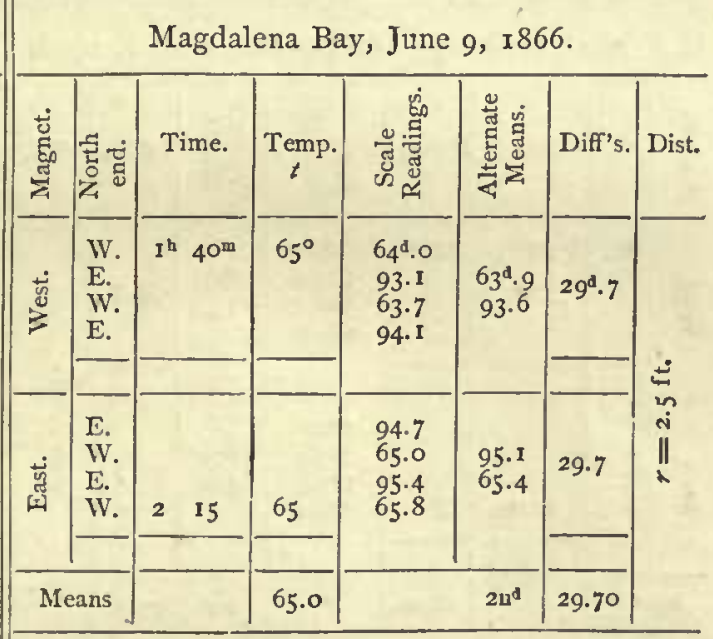

Assumed caefficient of torsion, $v=3.87$ div.

Magnet very unsteady, and its readings uncertain on account of a stiff breeze which shook the instrument.
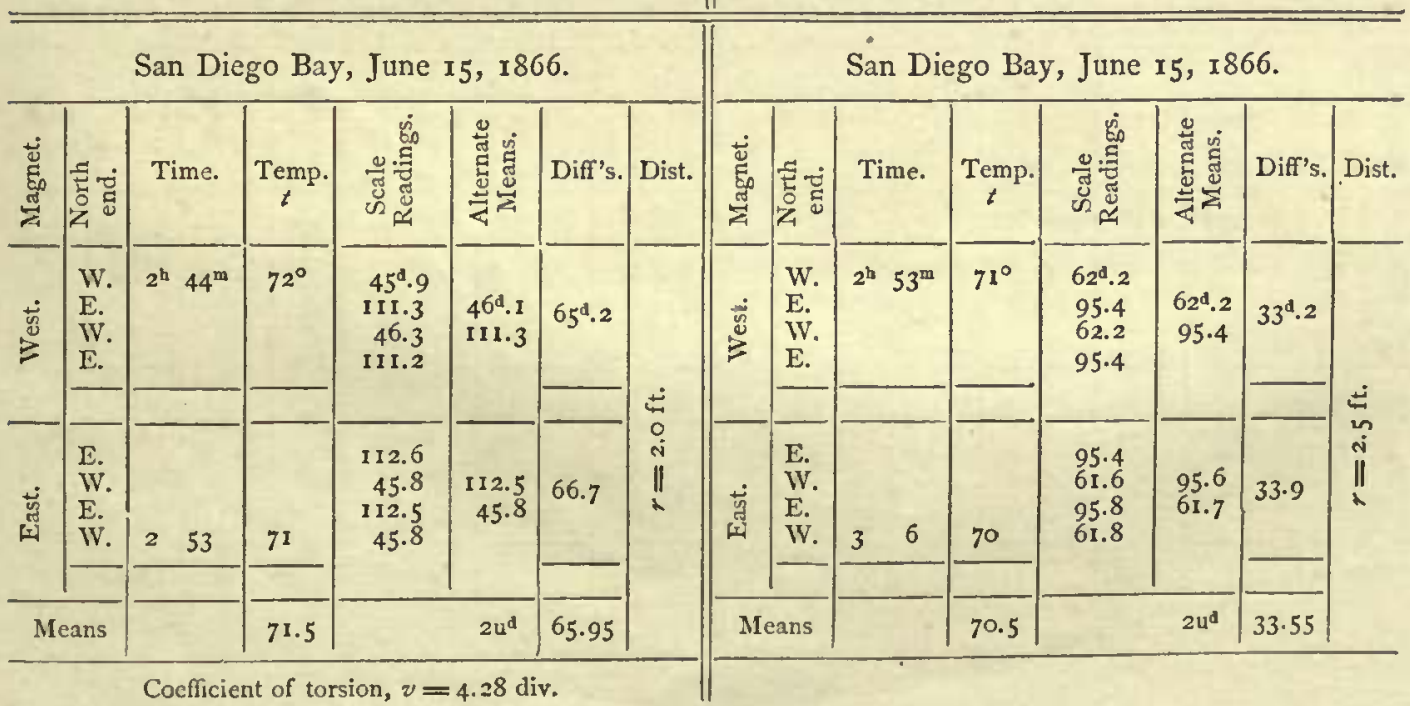
Horizontal Intensity. Observations of Deflections.

San Francisco Bay, June 26, 1866.

San Francisco Bay, June 26, 1866.

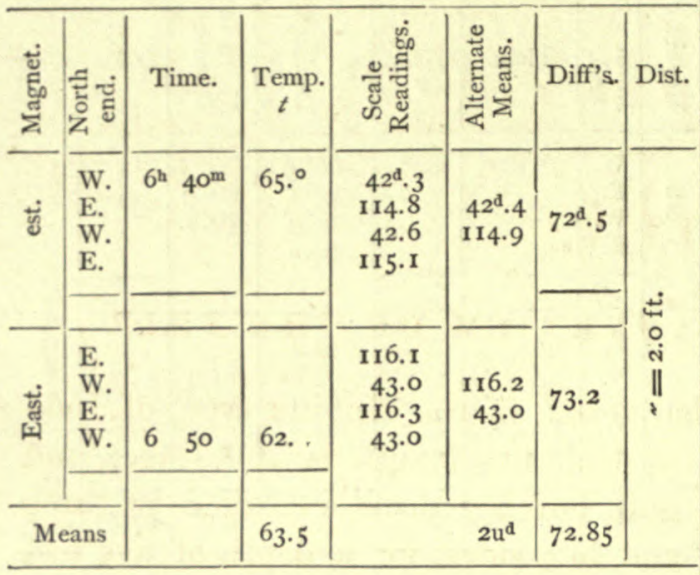

\begin{tabular}{|c|c|c|c|c|c|c|c|}
\hline $\begin{array}{l}\text { 苂 } \\
\text { हूँ }\end{array}$ & हैं & Time. & $\underset{t}{\text { Temp. }}$ & 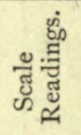 & 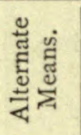 & Diff's. & Dist. \\
\hline$\dot{y}$ & $\begin{array}{l}\text { W. } \\
\text { E. } \\
\text { W. } \\
\text { E. }\end{array}$ & $6^{\mathrm{h}} 5^{\mathrm{o}^{\mathrm{m}}}$ & $62 .^{\circ}$ & $\begin{array}{l}60^{d} .8 \\
98.0 \\
60.7 \\
98.4\end{array}$ & $\begin{array}{c}6 \mathrm{o}^{\mathrm{d}} .8 \\
98.2\end{array}$ & $37^{d} \cdot 4$ & \\
\hline & $\begin{array}{l}\text { E. } \\
\text { W. } \\
\text { E. } \\
\text { W. }\end{array}$ & $\begin{array}{ll}6 & 59\end{array}$ & 63. & $\begin{array}{l}98.4 \\
61.0 \\
98.4 \\
60.9\end{array}$ & $\begin{array}{l}98.4 \\
60.9\end{array}$ & 37.5 & 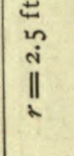 \\
\hline \multicolumn{2}{|c|}{ Means } & & 62.5 & & $2 u^{d}$ & 37.45 & \\
\hline
\end{tabular}

Coefficient of torsion, $v=5.30 \mathrm{div}$.

U.S. N. Observatory, Washington, Nov. I, 1866.

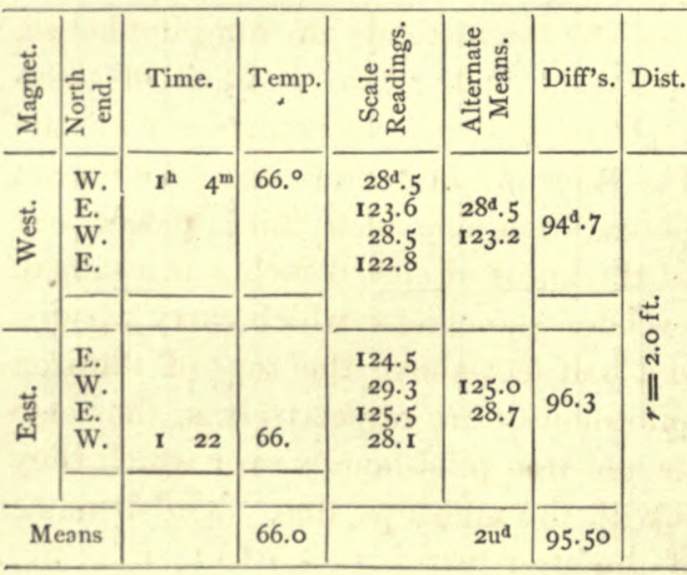

U. S. N. Observatory, Washington, Nov. I, 1866 .

Coefficient of torsion, $v=7.05$ div.

\begin{tabular}{|c|c|c|c|c|c|c|c|}
\hline 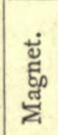 & تีّ & Time. & Temp. & 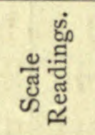 & 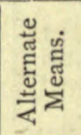 & Diff's. & Dist. \\
\hline $\begin{array}{l}\dot{3} \\
\xi\end{array}$ & $\begin{array}{l}\text { W. } \\
\text { E. } \\
\text { W. } \\
\text { E. }\end{array}$ & $\mathrm{I}^{\mathrm{h}} 22^{\mathrm{m}}$ & $66^{\circ}$ & $\begin{array}{r}52^{\mathrm{d} .5} \\
100.9 \\
52.0 \\
100.5\end{array}$ & $\begin{array}{l}52^{\mathrm{d}} .5 \\
100.7\end{array}$ & $4^{8} \cdot 2$ & \\
\hline 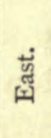 & $\begin{array}{l}\text { E. } \\
\text { W. } \\
\text { E. } \\
\text { W. }\end{array}$ & I 44 & 67. & $\begin{array}{r}\text { I02.0 } \\
52.6 \\
\text { 101.4 } \\
52.3\end{array}$ & $\begin{array}{c}\text { Ior. } 7 \\
52.5\end{array}$ & 49.2 & II \\
\hline \multicolumn{2}{|c|}{ Means } & & 66.5 & & $2 u^{d}$ & 48.70 & \\
\hline
\end{tabular}




\section{SECTION V.}

\section{OBSERVATIONS ON THE MAGNETISM OF THE SHIP.}

Tne Monadnock is a second rate iron-clad vessel, of the Monitor type, of 1564 tons old or 1091 tons new measurement. On deck her length is 260.5 feet, and her breadth 52.0 feet. She has a wooden hull, but her deck is covered by three layers of iron plates, each one inch thick; and her sides, for a depth of five feet from the deck, are covered by six layers of iron plates, each one inch thick. Thus the deck is protected by three, and the sides by six inches of iron. She is provided with two iron turrets, cylindrical in form, each 22.8 feet in outside diameter, 9.0 feet high, and 11 inches thick. On top of each of them stands an iron pilot-house, 7.7 feet in outside diameter, 6.4 feet high, and 11 inches thick. Each of these pilot-houses is cylindrical in form, and so placed that its axis coincides with the axis of the turret upon which it stands. The sides of the turrets and pilot-houses are not solid, but are composed of iron plates, each one inch thick, placed one upon the other and bolted together till a total thickness of eleven inches is attained. To each of the iron pilot-liouses are bolted wooden stanchions, which carry wooden pilot-houses whose floors are about nine and a half feet above the tops of the iron pilot-houses. The centres of the wooden pilot-houses are respectively in the same vertical lines with the centres of the turrets and iron pilot-houses over which they stand. The centres of the turrets coincide with the midships line. The distance from the stern of the vessel to the centre of the after turret is 84.5 feet; from the centre of the after turret to the centre of the forward turret, 99.1 ; and from the centre of the forward turret to the cut-water, 76.9 feet. Passing forward from the after turret, we come first to the ventilator, which is 6.5 feet in diameter, and 22.8 feet high above the deck; and then to the smoke-stack, which is 9.9 feet in diameter, and 31.0 feet high above the deck, both it and the ventilator being of iron. The distance from the centre of the after turret to the centre of the ventilator is 31.3 feet; from the centre of the ventilator to the centre of the smoke-stack, 16.5 feet; and from the centre of the smoke-stack to the centre of the forward turret, 51.3 feet.

At St. Thomas, before the magnetic observations on board ship were made at that place, a wooden mast 77.7 feet high was placed on the ship in order to enable her to carry some sail. Its centre is 22 feet forward of the centre of the forward turret, and what little iron was used in its construction is so placed that it is not at all probable that it affected the deviation of the compasses in its neighborhood in the slightest. 
The following are the designations and positions of the compasses which were used during the cruise:--

The Forward Alidade was a Sands Alidade Compass, and was on top of the forward wooden pilot-house, 33.5 feet above the iron deck.

The Forward Binnacle was a Ritchie Liquid Compass, and was in the binnacle of the forward wooden pilot-house, 27.2 feet above the iron deck.

The Forvard Ritchie was a Ritchie Monitor Compass, and was 6.7 feet above the top of the iron pilot-house on the forward turret. It was 22.1 fect above the iron deck.

Of these three compasses, the Forward Alidade and Forward Ritche were placed exactly in the vertical line passing through the centre of the forward turret, and the Forward Binnacle was placed about two feet further forward, but nearly in the same vertical plane.

The Admiralty Standard Compass was on top of the after wooden pilot-house, 37.0 feet above the iron deck.

The After Binnacle was a Ritchie Liquid Compass, and was in the binnacle of the after wooden pilot-honse, 27.2 feet above the iron deck.

The After Ritchie was a Ritchic Monitor Compass, and was 6.7 feet above the top of the iron pilot-house on the after turret. It was 22.1 feet above the iron deck.

Of these three compasses, the Admiralty Standard and After Ritchie were placed exactly in the vertical line passing through the centre of the after turret, and the After Binnacle was placed about two feet futher forward, but nearly in the same vertical plane.

The After Azimuth was a common Azimuth Compass which was set up temporarily on the quarter deck every time the ship was swung; small cavities having been cut in the iron surface of the deck for the reception of the feet of the tripod, so as to make sure that the instrument always occupied precisely the same position. It stood 47.5 feet abaft the centre of the after turret, and there were two vertical iron stanchions, each two inches in diameter, 10.3 feet high above the deck, and 12.1 feet distant from the compass, one of them being directly forward and the other directly aft of it. This compass was elevated 4.6 feet above the iron deck; but when observations of magnetic force were made, it was necessary to remove it and substitute an Admiralty Standard Compass, which occupied precisely the same position, except that it was 4.8 feet above the deck. When the dip circle was used it also stood 4.8 feet above the deck.

It will be observed that all the compasses stood in the midships line, no matter what their elevation above the deck might be.

All the observations for determining the deviations of the compasses were made by swinging the ship in the following manner: 'The true azimuth of a well defined distant. object was determined by a solar bearing, as explained in Section III, page 26 , and the declination of the magnetic needle having been applied to it, its true magnetic azimuth became known; then, supposing the sight vanes of the Admiralty Standard Compass to be kept pointed steadily to that object while the ship was swung, the reading which they would indicate on the azimuth circle attaclied to 
the cover of the compass, as the ship's head pointed successively to each of the true magnetic points, was computed by means of the formula

where

$$
R=180^{\circ}+A-\zeta
$$

$R=$ reading of sight vanes on the azimuth circle attached to the cover of the compass.

$A=$ true magnetic azimuth of the distant object; the azimuth being counted from the south around by the west.

$\zeta=$ azimuth of the slip's head, counted from the correct magnetic north around by the east.

This having been done, on a tolerably calm day steam was got up in the boilers, and, the vessel riding at a single anchor, slack water was waited for. As soon as the tide ceased to run, the executive officer took the deck; an officer was stationed at eaeh of the compasses; I'went to the Admiralty Standard ; and a quartermaster was stationed at the ship's bell. Then the helm was put hard-a-starboard, or harda-port, depending on the direction in which it was desired to lave her head swing, and the engines having been started, one forward and the other backward (the Monadnock was provided with twin screws which were entirely independent of each other), the vessel at once began to turn, witlout bringing any considerable strain on her cable. Her motion was perfectly under control, and could be made fast or slow at pleasure by merely varying the speed of the engines. I then set the sight vanes of the Admiralty Standard Compass to the reading (on the azimuth circle) of the point at which the ship's head would first arrive, and placing my eye to them I watched for the instant when they pointed to the distant object chosen as an azimuth mark. As the thread of the sight vane approached the object I cautioned the quartermaster to be ready, and at the instant it covered the object I made a signal, by dropping my outstretched arm, and the quartermaster struck a single stroke on the bell. Upon hearing this, every officer at once read off and recorded the heading of the ship, as indicated by the compass at which he was statioued. Then, the engincs not laving been stopped, I turned the sight vanes forward to the reading of the next point, and the same process was repeated; and so on, till the readings of all the compasses had been observed at each of the thirty-two points, which was generally accomplished in about an hour, or an hour and a half. The difference between any observed reading and the true point to which the vessel's head was rirected at the time that reading was made, was of course the deviation of the compass on that point.

The forward iron and woqden pilot-houscs were fixed and did not revolve with the turret, so that the lubber lines of the compasses in them always remained in the same position. But with the after iron and wooden pilot-houses the case was different. They were attached to the turret and revolved with it, and by so doing caused the lubber lines of the compasses in them also to revolve. As the turrets were frequently turned, it became necessary to establish marks by which the position of the after one could always be referred to some fixed position, so that a correction could be applied to the readings of the compasses in its pilot-houses to 16 August, 1872. 
reduce them to what they would have been if their lubber lines had not moved For this purpose, whenever the ship was swung, a fixed line on the under side of the hurricane deck was produced till it touched the after turret, and then tho distance from its point of contact with the turret to a joint (marked number XII) on the ontside of the turret was measured. 'This distance, having been converted into degrees and minutes by means of the known diameter of the turret, was the correction to be applied to the position of the lubber lines. The following table gives the measured distance, and its angnlar equivalent, at every station where the ship was swung; but it must be noticed that these corrections apply only to the After. Binnaele and After Ritehie Compasses. The lubber line of the Admiralty Standard Compass was always properly adjusted before beginning to observe.

\begin{tabular}{|c|c|c|c|c|c|c|c|c|c|c|c|}
\hline \multicolumn{8}{|c|}{ Station. } & Joint XIII. & \multicolumn{3}{|c|}{ Lubber Line. } \\
\hline Hampton $\mathrm{F}$ & Roar & & & & & & & $14^{\text {in }} \cdot 4$ port & & sume & d correct. \\
\hline St. Thomas & & & & . & . & . & . & 14.4 & & " & "4 \\
\hline Salute Islan & $\mathrm{dds}$ & & & • & . & . & . & 0.6 starboard & $6^{\circ}$ & I $8^{\prime} \mathrm{e}$ & east. \\
\hline Ceara. & . & & & . & . & . & . & $0.6 \mathrm{st}$ & & 18 & " \\
\hline Bahia . & & & & • & . & . & i & 0.6 & & I 8 & 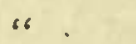 \\
\hline Rio Janeiro & & & & • & . & . & . & 0.8 port & & 43 & $\because$ \\
\hline Monte Vid & & & & • & $\dot{.}$ & . & 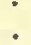 & 4.5 is & $\begin{array}{l}5 \\
4\end{array}$ & $\begin{array}{r}43 \\
0\end{array}$ & “ \\
\hline Sandy Poin & & & & . & . & . & • & $4 \cdot 5 \quad 36$ & 4 & 9 & “ \\
\hline Valparaiso & . & & & • & . & : & . & $\begin{array}{l}4.3 \\
4.2\end{array}$ & $\begin{array}{l}4 \\
4\end{array}$ & $\begin{array}{r}9 \\
17\end{array}$ & “ \\
\hline Cailao . & . & & & • & - & . & . & $5 \cdot 5$ & 3 & 44 & "6 \\
\hline Panama. & - & & & • & . & . & . & $5 \cdot 5$ & 3 & 44 & $“$ \\
\hline Acapulco & & & & . & . & . & - & $5 \cdot 5$ & 3 & 44 & "6 \\
\hline Magdalena & Bay & & & • & . & - & - & $5 \cdot 5$ & 3 & 44 & $"$ \\
\hline San Francis & & & & - & - & . & & $5 \cdot 366$ & & 49 & $" 6$ \\
\hline
\end{tabular}

When the ship was being swung, I always read the Admiralty Standard Compass myself. Each of the other compasses was usually read by the officer whose name is set opposite to it in the following table.

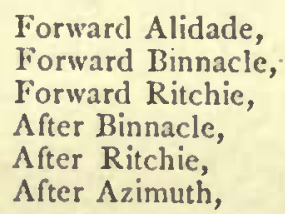

Forward Alidade, Forward Binnacle, Forward Ritchic, After Ritchie, After Azimuth,

\author{
Lieutenant M. Miller. \\ Lieut. Miller, assisted by a Quartermaster. \\ Lieutenant Geo. Smith. \\ Ensign F. Wildes. \\ Master Wm. Barrymore. \\ Mate Jno. Ponte.
}

My instruments for the measurement of magnetic force restricted me to the method of deflections, and the only compasses on board at which that method could be applied were the Admiralty Standard and the After Azimuth. As the ship was always riding at anchor, and of course swinging a little, when such obscrvations were made, in order to render them as accurate as possible the following plan was adopted.

The deflecting bar was screwed to the movable circle which carried the sight vanes of the Admiralty Standard Compass in such a position as to be at right angles to them. That is, when the sight vanes pointed north and south the deflecting bar pointed east and west. 'Then, $1^{\circ}$. The sights being directed exactly 
north and south, as indicated by the compass card, the point, which we will designate by $I$, cut by them on the northern or southern horizon, as might be most convenient, was noted. $2^{\circ}$. The deflecting magnets were placed in the carriers, one to the east and the other to the west of the compass card, both being at the same distance from the centre of the card, and with their similar poles pointing in the same direction. Then, keeping the sight vanes pointed steadily to the object $H$, as soon as the compass card ceased to vibrate it was read off by means of the prism attached to the sight vane. Let this reading be designated as $A .3^{\circ}$. Each deflecting magnet was reversed, end for end, in its own carrier, and, the sight vanes being still kept directed to the object $H$, the card was again read. Let this reading be designated as $B$. Then the observed angle of deflection is $\frac{A-B}{2}$.

The dip was obtained by removing the Admiralty Standard Compass with which the deflections had been observed, and putting in its place a dip circle; the axle of the dipping needle occupying precisely the same position that had previously been occupied by the pivot of the compass card.

The observations of the deviations of the compasses made during the cruise have been compared with the following theory, which is taken from the English Admiralty Manual of the Deviations of the Compass, edition of 1863 .

\section{Let}

$X, Y, Z$, represent the force of the earth's magnetism drawing the north point of the compass needle to the ship's head, to the starboard side and vertically downwaids.

$X^{\prime}, Y^{\prime}, Z^{\prime}$, represent the combined force of the magnetism of the earth and ship in the same directions.

$a, b, c, d, e, f, g, h, k$, represent constant coefficients depending on the amount and arrangement of the soft iron of the ship.

$P, Q, R$, represent constant coefficients depending on the amnunt, arrangement, and independent magnetism of the hard iron of the ship.

$I I=$ the horizontal force of the earth.

$H^{\prime}=$ the horizontal force of the earth and ship.

$\theta=$ the dip.

$\zeta=$ azimuth of the ship's head measured eastward from the correct magnetic north.

$\zeta^{\prime}=$ azimuth of the ship's head measured from the direction of the disturbed needle.

$\delta=\zeta-\zeta^{\prime}=$ the deviation of the compass.

'I'hen the whole mathematical theory of the deviations of the compass is comprised in the three following equations:

$$
\begin{aligned}
& \mathbf{X}^{\prime}=\mathbf{X}+a \mathbf{X}+b Y+c Z+P \\
& Y^{\prime}=Y+d \mathbf{X}+e Y+f Z+Q \\
& Z^{\prime}=Z+g \mathbf{X}+h Y+z Z+R
\end{aligned}
$$


We have also

$$
\begin{array}{ll}
X=H \cos \zeta & Y=-H \sin \zeta \\
X^{\prime}=H^{\prime} \cos \zeta^{\prime} & Y^{\prime}=-H \sin \zeta^{\prime}
\end{array} \quad Z=H \tan \theta
$$

Substituting these values in equations (1), (2), and (3), and dividing by $H$, we have

$$
\begin{aligned}
\frac{H^{\prime}}{H} \cos \zeta^{\prime} & =(1+a) \cos \zeta-b \sin \zeta+c \tan \theta+\frac{P}{H} \\
-\frac{H}{H} \sin \zeta^{\prime} & =d \cos \zeta-(1+e) \sin \zeta+f \tan \theta+\frac{Q}{H} \\
\frac{Z^{\prime}}{H} & =g \cos \zeta-\hbar \sin \zeta+(1+k) \tan \theta+\frac{R}{H}
\end{aligned}
$$

Equation (6) may be written

$$
0=1-\frac{Z^{\prime}}{Z}+g \frac{\cos \zeta}{\tan \theta}-h \frac{\sin \zeta}{\tan \theta}+k+\frac{R}{Z}
$$

From equations (4) and (5) we obtain the following:

(4) $\cos \zeta-(5) \sin \zeta$ gives after some reductions

$$
\begin{gathered}
H^{\prime} \cos \delta=1+\frac{a+e}{2}+\left(c \tan \theta+\frac{P}{H}\right) \cos \zeta-\left(f \tan \theta+\frac{Q}{H}\right) \sin \zeta \\
+\frac{a-e}{2} \cos 2 \zeta-\frac{d+b}{2} \sin 2 \zeta
\end{gathered}
$$

(4) $\sin \zeta+(5) \cos \zeta$ gives after some reductions

$$
\begin{gathered}
\frac{H^{\prime}}{H} \sin \delta=\frac{d-b}{2}+\left(c \tan \theta+\frac{P}{H}\right) \sin \zeta+\left(f \tan \theta+\frac{Q}{H}\right) \cos \zeta \\
+\frac{a-e}{2} \sin 2 \zeta+\frac{d+b}{2} \cos 2 \zeta
\end{gathered}
$$

Now let

$$
\begin{array}{rlrl}
1+\frac{a+e}{2} & =\lambda & \frac{d-b}{2} & =\lambda \mathfrak{A} \\
\frac{a-e}{2} & =\lambda \mathfrak{D} & \frac{d+b}{2} & =\lambda \mathfrak{E} \\
e \tan \theta+\frac{P}{H} & =\lambda \mathfrak{B} & f \tan \theta+\frac{Q}{H} & =\lambda \mathfrak{E}
\end{array}
$$

Then from equations ( 7 ) and (8) we get the following:

$$
\begin{aligned}
& \frac{H}{\lambda H} \cos \delta=1+\mathfrak{B} \cos \zeta-\mathfrak{C} \sin \zeta+\mathfrak{D} \cos 2 \zeta-\mathfrak{E} \sin 2 \zeta \\
& \frac{H^{\prime}}{\lambda H} \sin \delta=\mathfrak{A}+\mathfrak{B} \sin \zeta+\mathfrak{C} \cos \zeta+\mathfrak{D} \sin 2 \zeta+\mathfrak{E} \cos 2 \zeta
\end{aligned}
$$

Dividing (10) by (9),

$$
\tan \delta=\frac{\mathfrak{A}+\mathfrak{B} \sin \zeta+\mathfrak{C} \cos \zeta+\mathfrak{D} \sin 2 \zeta+\mathfrak{E} \cos 2 \zeta}{1+\mathfrak{B} \cos \zeta-\mathfrak{C} \sin \zeta+\mathfrak{D} \cos 2 \zeta-\mathfrak{E} \sin 2 \zeta}
$$


From (11) we easily get

$$
\begin{aligned}
\sin \delta & =\mathfrak{A} \cos \delta+\mathfrak{B} \sin \zeta^{\prime}+\mathfrak{C} \cos \zeta^{\prime}+\mathfrak{D} \sin \left(\zeta+\zeta^{\prime}\right)+\mathfrak{E} \cos \left(\zeta+\zeta^{\prime}\right) \\
& =\mathfrak{A} \cos \delta+\mathfrak{B} \sin \zeta^{\prime}+\mathfrak{C} \cos \zeta^{\prime}+\mathfrak{D} \sin \left(2 \zeta^{\prime}+\delta\right)+\mathfrak{E} \cos \left(2 \zeta^{\prime}+\delta\right)
\end{aligned}
$$

Of the last three equations (11) is used when the deviations are given on the correct magnetic points, (12) when the deviations are given on the compass points affected by deviation.

Equation (12) may be put under the following form, which is sometimes convenient, and which is very nearly exact, viz.:

$\sin \delta=\frac{1}{1-\mathfrak{D} \cos 2 \zeta^{\prime}}\left\{\mathfrak{A}+\mathfrak{B} \sin \zeta^{\prime}+\mathfrak{C} \cos \zeta^{\prime}+\mathfrak{D} \sin 2 \zeta^{\prime}+\mathfrak{C} \cos 2 \zeta^{\prime}\right\}$

By means of the cxpressions for $\sin \delta$ we may calculate the values of the coefficients $\mathfrak{A}, \mathfrak{B}, \mathfrak{C}, \mathfrak{D}, \mathfrak{C}$, if we know the deviations on five points. If we have the deviations on more than five points, we may determine the most probable valnes of the coefficients by the method of least squares; but the calculation will in general be long and difficult.

If, however, the compass points on which the deviations are given divide the circumference into equal parts, we may determine the exact coefficients $\mathfrak{N}, \mathfrak{B}, \mathfrak{C}, \mathfrak{D}, \mathfrak{F}$, with great case, and a sufficient degree of approximation, by determining first the approximate coefficients $A, B, C, D, E$, and then deducing from them the values of the exact coefficients. For that purpose we proceed as follows:

If the coefficients are less than $20^{\circ}$ their squares and products may be neglected, and equation (12) may be put under the form

$$
\delta=A+B \sin \zeta^{\prime}+C \cos \zeta^{\prime}+D \sin 2 \zeta^{\prime}+E \cos 2 \zeta^{\prime}
$$

Let $\delta_{0} \delta_{1} \delta_{2} \ldots \delta_{31}$ be the deviations observed on the 32 points, by compass, $S_{1} S_{2} S_{3}$ $\ldots S_{7}$ the natural sines of the rhumbs or of the angles $11^{\circ} 15^{\prime}, 22^{\circ} 30^{\prime} \ldots 78^{\circ} 45^{\prime}$ respectively, then if the observations have been made on the 32 points we have the following 32 equations from which to determine $A, B, C, D, E$. 


\begin{tabular}{|c|c|c|c|c|c|c|}
\hline Compass Courses. & Deviation. & $A$ & $+B \sin \zeta^{\prime}$ & $+C \cos \zeta^{\prime}$ & $+D$ and $2 \zeta$ & $+E \cos 2 \zeta^{\prime}$ \\
\hline $\begin{array}{l}\text { North } \\
\text { N. by E. } \\
\text { N. N. E. } \\
\text { N. E. by N. } \\
\text { N. E. } \\
\text { N. E. by E. } \\
\text { E. N. E. } \\
\text { E. by N. } \\
\text { East } \\
\text { E. by S. } \\
\text { E. S. E. } \\
\text { S. E. by E. } \\
\text { S. E. } \\
\text { S. E. by S. } \\
\text { S. S. E. } \\
\text { S. by E. } \\
\text { South } \\
\text { S. by W. } \\
\text { S. S. W. } \\
\text { S. W. by S. } \\
\text { S. W. } \\
\text { S. W. by W. } \\
\text { W. S. W } \\
\text { W. by S. } \\
\text { West } \\
\text { W. by N. } \\
\text { W. N. W. } \\
\text { N. W. by W. } \\
\text { N. W. } \\
\text { N. W. by N. } \\
\text { N. N. W. } \\
\text { N. by W. }\end{array}$ & $\begin{array}{l}\delta_{0} \\
\delta_{1} \\
\delta_{2} \\
\delta_{3} \\
\delta_{4} \\
\delta_{5} \\
\delta_{6} \\
\delta_{7} \\
\delta_{8} \\
\delta_{9} \\
\delta_{10} \\
\delta_{11} \\
\delta_{12} \\
\delta_{13} \\
\delta_{14} \\
\delta_{15} \\
\delta_{16} \\
\delta_{17} \\
\delta_{18} \\
\delta_{19} \\
\delta_{20} \\
\delta_{21} \\
\delta_{22} \\
\delta_{23} \\
\delta_{24} \\
\delta_{25} \\
\delta_{26} \\
\delta_{27} \\
\delta_{23} \\
\delta_{29} \\
\delta_{30} \\
\delta_{31}\end{array}$ & $\begin{array}{l}\text { A } \\
\text { A } \\
\text { A } \\
\text { A } \\
\text { A } \\
\text { A } \\
\text { A } \\
\text { A } \\
\text { A } \\
\text { A } \\
\text { A } \\
\text { A } \\
\text { A } \\
\text { A } \\
\text { A } \\
\text { A } \\
\text { A } \\
\text { A } \\
\text { A } \\
\text { A } \\
\text { A } \\
\text { A } \\
\text { A } \\
\text { A } \\
\text { A } \\
\text { A } \\
\text { A } \\
\text { A } \\
\text { A } \\
\text { A } \\
\text { A } \\
\text { A }\end{array}$ & $\begin{array}{l}+\mathrm{BS}_{1} \\
+\mathrm{BS}_{2} \\
+\mathrm{BS}_{3} \\
+\mathrm{BS}_{4} \\
+\mathrm{BS}_{5} \\
+\mathrm{BS}_{6} \\
+\mathrm{BS}_{7} \\
+\mathrm{B}_{7} \\
+\mathrm{BS}_{7} \\
+\mathrm{BS}_{6} \\
+\mathrm{BS}_{5} \\
+\mathrm{BS}_{4} \\
+\mathrm{BS}_{3} \\
+\mathrm{BS}_{2} \\
+\mathrm{BS}_{1} \\
-\mathrm{BS}_{1} \\
-\mathrm{BS}_{2} \\
-\mathrm{BS}_{3} \\
-\mathrm{BS}_{4} \\
-\mathrm{BS}_{5} \\
-\mathrm{BS}_{6} \\
-\mathrm{BS}_{7} \\
-\mathrm{B} \\
-\mathrm{BS}_{7} \\
-\mathrm{BS}_{6} \\
-\mathrm{BS}_{5} \\
-\mathrm{BS}_{4} \\
-\mathrm{BS}_{3} \\
-\mathrm{BS}_{2} \\
-\mathrm{BS}_{1}\end{array}$ & $\begin{array}{l}+\mathrm{C} \\
+\mathrm{CS}_{7} \\
+\mathrm{CS}_{6} \\
+\mathrm{CS}_{5} \\
+\mathrm{CS}_{4} \\
+\mathrm{CS}_{3} \\
+\mathrm{CS}_{2} \\
+\mathrm{CS}_{1} \\
-\mathrm{CS}_{1} \\
-\mathrm{CS}_{2} \\
-\mathrm{CS}_{3} \\
-\mathrm{CS}_{4} \\
-\mathrm{CS}_{5} \\
-\mathrm{CS}_{6} \\
-\mathrm{CS}_{7} \\
-\mathrm{C}^{-} \\
-\mathrm{CS}_{7} \\
-\mathrm{CS}_{6} \\
-\mathrm{CS}_{5} \\
-\mathrm{CS}_{4} \\
-\mathrm{CS}_{3} \\
-\mathrm{CS}_{2} \\
-\mathrm{CS}_{1} \\
+\mathrm{CS}_{1} \\
+\mathrm{CS}_{2} \\
+\mathrm{CS}_{3} \\
+\mathrm{CS}_{4} \\
+\mathrm{CS}_{5} \\
+\mathrm{CS}_{6} \\
+\mathrm{CS}_{7}\end{array}$ & $\begin{array}{l}+\mathrm{DS}_{2} \\
+\mathrm{DS}_{4} \\
+\mathrm{DS}_{6} \\
+\mathrm{D} \\
+\mathrm{DS}_{6} \\
+\mathrm{DS}_{4} \\
+\mathrm{DS}_{2} \\
-\mathrm{DS}_{2} \\
-\mathrm{DS}_{4} \\
-\mathrm{DS}_{6} \\
-\mathrm{D} \\
-\mathrm{DS}_{6} \\
-\mathrm{DS}_{4} \\
-\mathrm{DS}_{2} \\
+\mathrm{DS}_{2} \\
+\mathrm{DS}_{4} \\
+\mathrm{DS}_{6} \\
+\mathrm{D} \\
+\mathrm{DS}_{6} \\
+\mathrm{DS}_{4} \\
+\mathrm{DS}_{2} \\
-\mathrm{DS}_{9} \\
-\mathrm{DS}_{4} \\
-\mathrm{DS}_{6} \\
-\mathrm{D} \\
-\mathrm{DS}_{6} \\
-\mathrm{DS}_{4} \\
-\mathrm{DS}_{2}\end{array}$ & 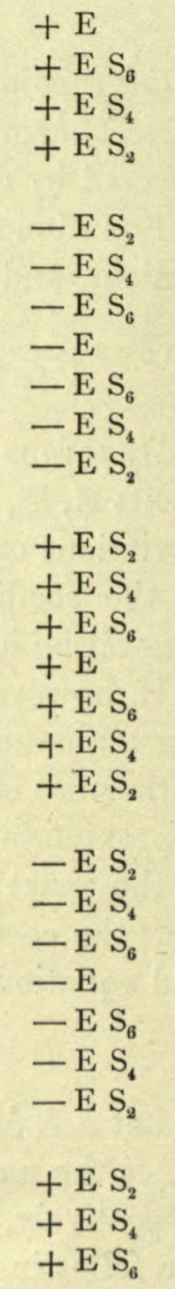 \\
\hline
\end{tabular}

By the method of least squares we obtain, from these 32 equations of condition, the five normal equations

$$
\begin{aligned}
& \delta_{0}+\delta_{1}+\delta_{2} \ldots \ldots \ldots \ldots \ldots \ldots+\delta_{31}=32 A . \\
& \delta_{1} S_{1}+\delta_{2} S_{2}+\delta_{3} S_{3}+\& c \ldots \ldots \ldots \ldots=16 B . \\
& \delta_{1}+\delta_{1} S_{7}+\delta_{2} S_{6}+\& c . \ldots \ldots \ldots \ldots=16 C . \\
& \delta_{1} S_{2}+\delta_{2} S_{4}+\delta_{3} S_{6}+\& c . \ldots \ldots \ldots \ldots=16 D . \\
& \delta_{0}+\delta_{1} S_{6}+\delta_{2} S_{4}+\& c . \ldots \ldots \ldots \ldots=16 E .
\end{aligned}
$$

For convenience of computation these equations have been put under the form

$$
\begin{aligned}
8 A= & \frac{1}{2}\left(\frac{\delta_{0}+\delta_{16}}{2}+\frac{\delta_{8}+\delta_{24}}{2}\right) \\
& +\frac{1}{2}\left(\frac{\delta_{1}+\delta_{17}}{2}+\frac{\delta_{9}+\delta_{25}}{2}\right) \\
& +\frac{1}{2}\left(\frac{\delta_{2}+\delta_{18}}{2}+\frac{\delta_{10}+\delta_{26}}{2}\right)
\end{aligned}
$$




$$
\begin{aligned}
& +\frac{1}{2}\left(\frac{\delta_{3}+\delta_{19}}{2}+\frac{\delta_{11}+\delta_{27}}{2}\right) \\
& +\frac{1}{2}\left(\frac{\delta_{4}+\delta_{20} !}{2} \perp \frac{\delta_{12}+\delta_{28}}{2}\right) \\
& +\frac{1}{2}\left(\frac{\delta_{5}+\delta_{21}}{2}+\frac{\delta_{13}+\delta_{29}}{2}\right) \\
& +\frac{1}{2}\left(\frac{\delta_{6}+\delta_{22}}{2}+\frac{\delta_{14}+\delta_{30}}{2}\right) \\
& +\frac{1}{2}\left(\frac{\delta_{7}+\delta_{23}}{2}+\frac{\delta_{15}+\delta_{31}}{2}\right) \\
& 8 B= \\
& \frac{\delta_{8}+\delta_{24}}{2} \\
& +\frac{\delta_{1}-\delta_{17}}{2} S_{1}+\frac{\delta_{9}-\delta_{25}}{2} S_{7} \\
& +\frac{\delta_{2}-\delta_{18}}{2} S_{2}+\frac{\delta_{10}-i_{26}}{2} S_{6} \\
& +\frac{\delta_{3}-\delta_{19}}{2} S_{3}+\frac{\delta_{11}-\delta_{27}}{2} S_{5} \\
& +\frac{\delta_{4}-\delta_{20}}{2} S_{4}+\frac{\delta_{12}-\delta_{28}}{2} S_{4} \\
& +\frac{\delta_{5}-\delta_{21}}{2} S_{5}+\frac{\delta_{13}-\delta_{29}}{2} S_{3} \\
& +\frac{\delta_{6}-\delta_{22}}{2} S_{6}+\frac{\delta_{14}-\delta_{30}}{2} S_{2} \\
& +\frac{\delta_{7}-\delta_{23}}{2} S_{7}+\frac{\delta_{15}-\delta_{31}}{2} S_{1} \\
& 8 C=\frac{\delta_{0}-\delta_{16}}{2} \\
& +\frac{\delta_{1}-\delta_{17}}{2} S_{7}-\frac{\delta_{9}-\delta_{25}}{2} S_{1} \\
& +\frac{\delta_{2}-\delta_{18}}{2} S_{6}-\frac{\delta_{10}-\delta_{26}}{2} S_{2} \\
& +\frac{\delta_{3}-\delta_{19}}{2} S_{5}-\frac{\delta_{11}-\delta_{27}}{2} S_{3} \\
& +\frac{\delta_{4}-\delta_{20}}{2} S_{4}-\frac{\delta_{12}-\delta_{28}}{2} S_{4} \\
& +\frac{\delta_{5}-\delta_{21}}{2} S_{3}-\frac{\delta_{13}-\delta_{29}}{2} S_{5} \\
& +\frac{\delta_{6}-\delta_{22}}{2} S_{2}-\frac{\delta_{14}-\delta_{30}}{2} S_{\text {. }} \\
& +\frac{\delta_{7}-\delta_{23}}{2} S-\frac{\delta_{15}-\delta_{31}}{2} S_{7}
\end{aligned}
$$




$$
\begin{aligned}
4 D= & +\frac{1}{2}\left(\frac{\delta_{4}+\delta_{20}}{2}-\frac{\delta_{12}+\delta_{28}}{2}\right) \\
& +\frac{1}{2}\left(\frac{\delta_{1}+\delta_{17}}{2}-\frac{\delta_{9}+\delta_{25}}{2}\right) S_{2}+\frac{1}{2}\left(\frac{\delta_{5}+\delta_{21}}{2}-\frac{\delta_{13}+\delta_{29}}{2}\right) S_{5} \\
& +\frac{1}{2}\left(\frac{\delta_{2}+\delta_{18}}{2}-\frac{\delta_{10}+\delta_{26}}{2}\right) S_{4}+\frac{1}{2}\left(\frac{\delta_{6}+\delta_{22}}{2}-\frac{\delta_{14}+\delta_{30}}{2}\right) S_{4} \\
& +\frac{1}{2}\left(\frac{\delta_{3}+\delta_{19}}{2}-\frac{\delta_{11}+\delta_{27}}{2}\right) S_{6}+\frac{1}{2}\left(\frac{\delta_{7}+\delta_{23}}{2}-\frac{\delta_{15}+\delta_{31}}{2}\right) S_{2} \\
4 E= & \frac{1}{2}\left(\frac{\delta_{0}+\delta_{16}}{2}-\frac{\delta_{8}+\delta_{24}}{2}\right) \\
& +\frac{1}{2}\left(\frac{\delta_{1}+\delta_{17}}{2}-\frac{\delta_{9}+\delta_{25}}{2}\right) S_{6}-\frac{1}{2}\left(\frac{\delta_{5}+\delta_{21}}{2}-\frac{\delta_{13}+\delta_{29}}{2}\right) S_{2} \\
& +\frac{1}{2}\left(\frac{\delta_{2}+\delta_{18}}{2}-\frac{\delta_{10}+\delta_{26}}{2}\right) S_{4}-\frac{1}{2}\left(\frac{\delta_{6}+\delta_{22}}{2}-\frac{\delta_{14}+\delta_{30}}{2}\right) S_{4} \\
& +\frac{1}{2}\left(\frac{\delta_{3}+\delta_{19}}{2}-\frac{\delta_{11}+\delta_{27}}{2}\right) S_{2}-\frac{1}{2}\left(\frac{\delta_{7}+\delta_{23}}{2}-\frac{\delta_{15}+\delta_{31}}{2}\right) S_{6}
\end{aligned}
$$

But the deviations about to be discussed were all observed, not on the compass points, but on the correct magnetic points. Treating them in the manner which has just been described, we obtain the approximate coefficients $A_{1}, B_{1}, C_{1}, D_{1}, E_{1}$, which belong to the correct magnetic points. Then, from equation (11) we get, going to terms of the third order inclusive,

$$
\delta=\mathfrak{A}
$$

$$
\begin{aligned}
& +(\mathfrak{B}+\mathfrak{A} \mathfrak{C}) \sin \zeta+(\mathfrak{C}-\mathfrak{A} \mathfrak{B} \cos \zeta \\
& +\left\{\mathfrak{D}-\frac{\mathfrak{B}^{2}-\mathfrak{C}^{2}}{2}\right\} \sin 2 \zeta+\{\mathfrak{C}-\mathfrak{B} \mathfrak{C}-\mathfrak{A} D\} \cos 2 \zeta
\end{aligned}
$$$$
+\left\{-\mathfrak{B D}+\mathfrak{C E}+\frac{\mathfrak{B}^{3}}{3}-\mathfrak{B} \mathfrak{C}^{2}\right\} \sin 3 \zeta
$$$$
+\left\{-\mathfrak{B} \mathfrak{E}-\mathfrak{C D}-\frac{\mathfrak{C}^{3}}{3}+\mathfrak{B}^{2} \mathfrak{C}\right\} \cos 3 \zeta
$$$$
+\left\{-\frac{D^{2}}{2}+\left(\mathfrak{B}^{2}-\mathbb{C}^{2}\right) \mathfrak{D}\right\} \sin 4 \zeta+\{-\mathfrak{D} \mathbb{E}+2 \mathfrak{B} \mathfrak{C} \mathfrak{D}\} \cos 4 \zeta
$$

$+\mathfrak{B} \mathfrak{D}^{2} \sin 5 \zeta+\mathfrak{C} \mathfrak{D}^{2} \cos 5 \zeta$

$+\frac{1}{3} D^{3} \sin 6 \zeta$

where $\delta$ is expressed in terms of the arc which is equal to radius. If we suppose the complete expression for $\delta$ to be

$$
\begin{aligned}
\delta=A_{1} & +B_{1} \sin \zeta+C_{1} \cos \zeta+D_{1} \sin 2 \zeta+E_{1} \cos 2 \zeta \\
& +F_{1} \sin 3 \zeta+G_{1} \cos 3 \zeta+H_{1} \sin 4 \zeta+K_{1} \cos 4 \zeta \\
& +L_{1} \sin 5 \zeta+M_{1} \cos 5 \zeta+N_{1} \sin 6 \zeta
\end{aligned}
$$


Thes, comparing equation (14) with equation (15), we find, to terms of the third order inclusive,

$$
\begin{aligned}
& \mathfrak{A}=A_{1} \\
& \mathfrak{B}=B_{1}-A_{1} C_{1} \\
& \mathfrak{C}=C_{1}+A_{1} B_{1} \\
& \mathfrak{D}=D_{1}+\frac{B_{1}{ }^{2}-C_{1}{ }^{2}}{2} \\
& \mathfrak{E}=E_{1}+B_{1} C_{1}+A_{1} D_{1} \\
& F_{1}=-B_{1} D_{1}+C_{1} E_{1}-\frac{B_{1}^{3}}{6}-\frac{B_{1} C_{1}{ }^{2}}{2} \\
& G_{1}=-C_{1} D_{1}+B_{1} E_{1} \frac{C_{1}^{3}}{6}+\frac{C_{1} B_{1}{ }^{2}}{2} \\
& H_{1}=-\frac{D_{1}{ }^{2}}{2}+\frac{D_{1} B_{1}{ }^{2}}{2}-\frac{D_{1} C_{1}{ }^{2}}{2} \\
& K_{1}=-D_{1} E_{1}+2 B_{1} C_{1} D_{1} \\
& L_{1}=B_{1} D_{1}^{2} \\
& M_{1}=C_{1} D_{1}^{2} \\
& N_{1}=\frac{1}{3} D_{1}^{3}
\end{aligned}
$$

"When the deviation of the compass is small, the several parts of which it is composed are simply added together; these parts are,

1. $A$, the constant deviation.

2. $B \sin \zeta^{\prime}+C \cos \zeta^{\prime}$, the semicircular deviation.

3. $D \sin 2 \zeta^{\prime}+E \cos 2 \zeta^{\prime}$, the quadrantal deviation.

"When the deviation is large, $\mathfrak{A}, \mathfrak{B}, \mathfrak{C}, \mathfrak{D}, \mathfrak{E}$, or the angles of which these quantities are the natural sines, may still be considered as the constant and as the several parts of the semicircular and the quadrantal deviation, each of these angles being in fact the maximum deviation which would exist if all the other coefficients were zero ; but their effects are no longer combined by simple addition."

Before submitting the observed deviations to comparison with the theory, it is necessary to free them from constant errors. These errors originated in two ways.

$1^{\circ}$. When the ship was swung, the variation of the needle at the port where she was lying was seldom accurately known. Hence, in order to obtain the true magnetic azimuth of the object used as an azimuth mark, it was necessary to adopt, for the time being, the best value of the variation which happened to be accessible. In order to facilitate the setting of the sight vanes of the Admiralty Standard Compass while the ship was being swung, the value thus adopted was always so taken that, when the ship's head pointed successively to each of the true - magnetic points, the reading of the sight vanes on the azimuth circle attached to the cover of that compass was always either some whole degree or some quarter of a degree. When the declinometer observations were reduced, the true value of the variation of the compass at each port became known, and then it was discovered 
that in some cases the adopted value was in error by more than three degrees. But an crror in the adopted value of the variation produced an error of the same amount in the magnetic azimuth of the distant object used as an azimuth mark, and, therefore, in the pointing of the ship's head to each of the true magnetic points. Bearing in mind that the observed deviations were obtained by simply taking the difference between the heading of the ship and the reading of the compass, it will be apparent that if we apply to each observed deviation the difference between the true and adopted variation of the compass, with its proper sign, we shall obtain the true deviations for the directions in which the ship's head actually pointed at the time the readings of the compasses were made. From these corrected deviations the deviations on the true magnetic points can be found by simple interpolation. 'Therefore, if we let

$m=$ the true, minus the adopted, magnetic azimuth of the distant object used as an azimuth mark: the azimuths being taken as increasing from the south around by the west.

$\delta^{\prime}=$ the observed deviation of the compass when the ship headed in the direction $A$.

$\delta^{\prime \prime}=$ the observed deviation of the compass when the ship headed in the direction $A \mp 11^{\circ} 15^{\prime}$; the upper sign being taken when $m$ is positive, the lower when $m$ is negative.

$\delta=$ the deviation of the compass when the ship heads to the true magnetic point which lies between $A$ and $A$ F $11^{\circ} 15^{\prime}$; that point being of the same name as $A$ was intended to be when the ship was swung.

Then we shall have with sufficient accuracy

$$
\delta=\delta^{\prime}+m \mp \frac{m\left(\delta^{\prime}-\delta^{\prime \prime}\right)}{11^{\circ} 15^{\prime}}
$$

the upper sign being taken when $m$ is positive, the lower when $m$ is negative. By this formula the deviations of the Forward Alidade, Forward Binnacle, Forward Ritchie, Admiralty Standard, and After Azimuth Compasses, on the true magnetic points, have been computed from the observed deviations.

$2^{\circ}$. In addition to the correction which has just been explained, the observerl deviations of the After Binnacle and After Ritchic Compasses require a further correction on account of the lubber lines of these instruments revolving with the after turret, and thus being frequently out of their true position. This correction, which we will represent by $L$, is constant, and is equal in amount to the clisplacement of the lubber line. Its sign is + if the lubber line is to starboard, - if it is to port, of its true position. 'The deviations of the After Binuacle and After Ritchie Compasses, on the true magnetic points, were therefore computed from the observed deviations by the formula

$$
\delta=\delta^{\prime}+(m+L) \mp \frac{m\left(\delta^{\prime}-\delta^{\prime \prime}\right)}{11^{\circ} 15^{\prime}}
$$

the upper sign being taken when $m$ is positive, the lower when $m$ is negative.

To have computed numerically all the values of $\delta$ for each compass by nieans of the expressions just given, would have involved a great anount of labor; it was therefore done grapluically as follows: 


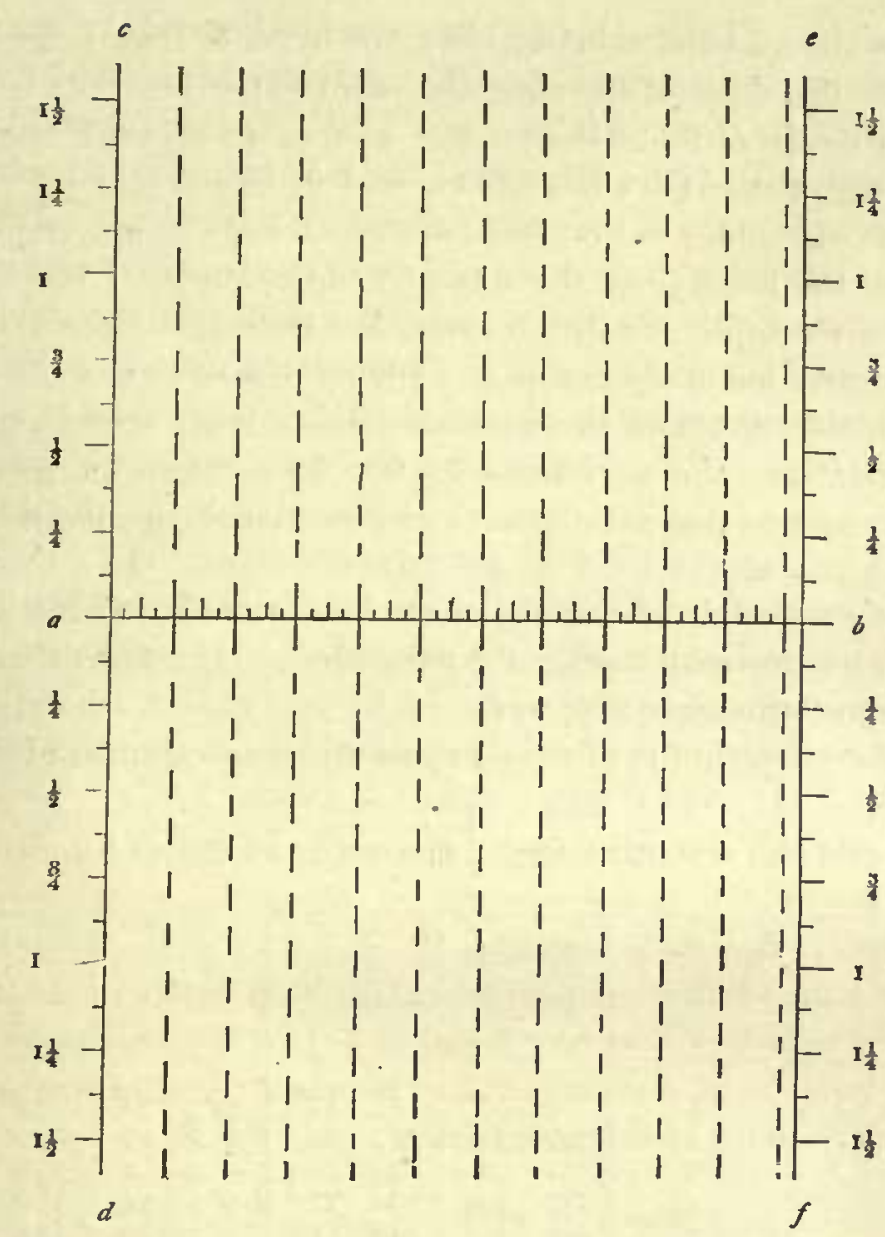

On a piece of cardboard of suitable size a horizontal line $a b, 5 \frac{5}{8}$ inches long, was drawn, and divided into eighths of an inch; each half inch representing one degree, and the whole line representing $11^{\circ} 15^{\prime}$, or one point of the compass. Touching the extremities of the line $a b$, and at right angles to it, were drawn the line $c d$ and $e f$; and each of them was divided, upward and downward from the line $a b$, into points and eights of points; ${ }^{1}$ each point occupying the space of $2 \frac{13}{6}$ of an incl. Finally, a straight slip of drawing paper was divided on its edge into degrees and sixths of a degree, each degree occupying a space of one-quarter of an inch; and the graduation was numbered from the middle towards each extremity.

Then, to compute the values of $\delta$ for any compass at any place, the paper scale was laid down parallel to, and to the right of, $c d$, and at a distance from it (mcasured on the line $a b$ ) equal to $m$; next, without moving the paper scale at all in the direction $a b$, it was slipped up or down, as might be necessary, in the direction parallel to $c d$, till the line $a b$ cut the division on it which was equal to $(m+L)$; the zero of the scale being above the line $a b$ if $(m+L)$ was negative, below it if

1 For computing the deviations of the Admiralty Standard and After Azimuth Compasses the lines $c d$ and $e f$ were dividcd into degrees and sixths of a degree, cach degree occupying the space of one-quarter of an inch. 
$(m+L)$ was positive. Things being thus arranged, a weight was placed on the paper scale to prevent it from moving. 'Then a ruler being laid so that, while it crossed the line $e d$ at a distance from $a$ equal to $\delta^{\prime}$, it also crossed the line $e f$ at a distance from $b$ equal to $\delta^{\prime \prime}$ (the distances $\delta^{\prime}$ and $\delta^{\prime \prime}$ being taken abore the line $a b$ if they were positive, belono it if they were negative), the reading of the point on the paper scale where the ruler crossed its edge was the required value of $\delta$. In that way, without again moving the paper scale, the ralues of the deviations on each of the thirty-two true magnetic points were computed from the observed values.

The following table contains the constants which were used in computing from the observed deviations the deviations on the true magnetic points. 'The first column gives the name of the station. 'The second column, the distance in miles from the ship to the object used as an azimuth mark. The third column, the assumed magnetic azimuth of the object used as an azimuth mark; the azimuth being counted from the south around by the west. The fourth column, the true magnetic azimuth of the same object, found by applying the magnetic declination given in the table on page 61 , section IV, to the true azimuth given in the table on page 36, section III. 'The fifth column, the value of $m$. 'The sixtl column, the value of $L$; and the seventh column, the value of $(m+L)$.

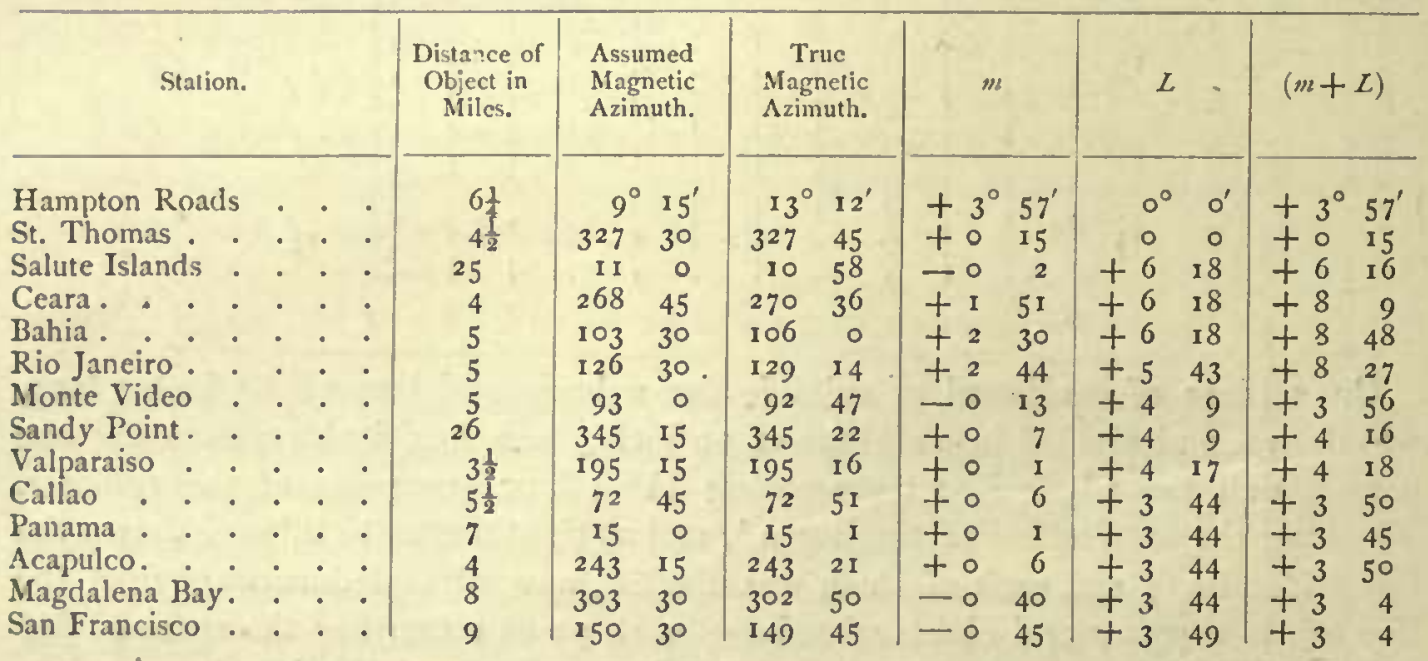

'The following tables contain all the deviations of the compasses which were observed during the cruise. In each table the first column contains the assumed magnetic azimuth of the ship's head at the time the reading of the compass, given on the same line in the second column, was taken. 'The third column contains the observed deviation of the compass for each point, obtained by subtracting the readings in the second column from those in the first coliumn. Hence, a deviation of the nortl point of the compass to the east is designated by the sign + ; a deviation to the west by the sign - The fourth columı contains the deviation of the compass on eacl of the thirty-two true magnetic points. obtained from the observed deviations in the manner already cxplained. 


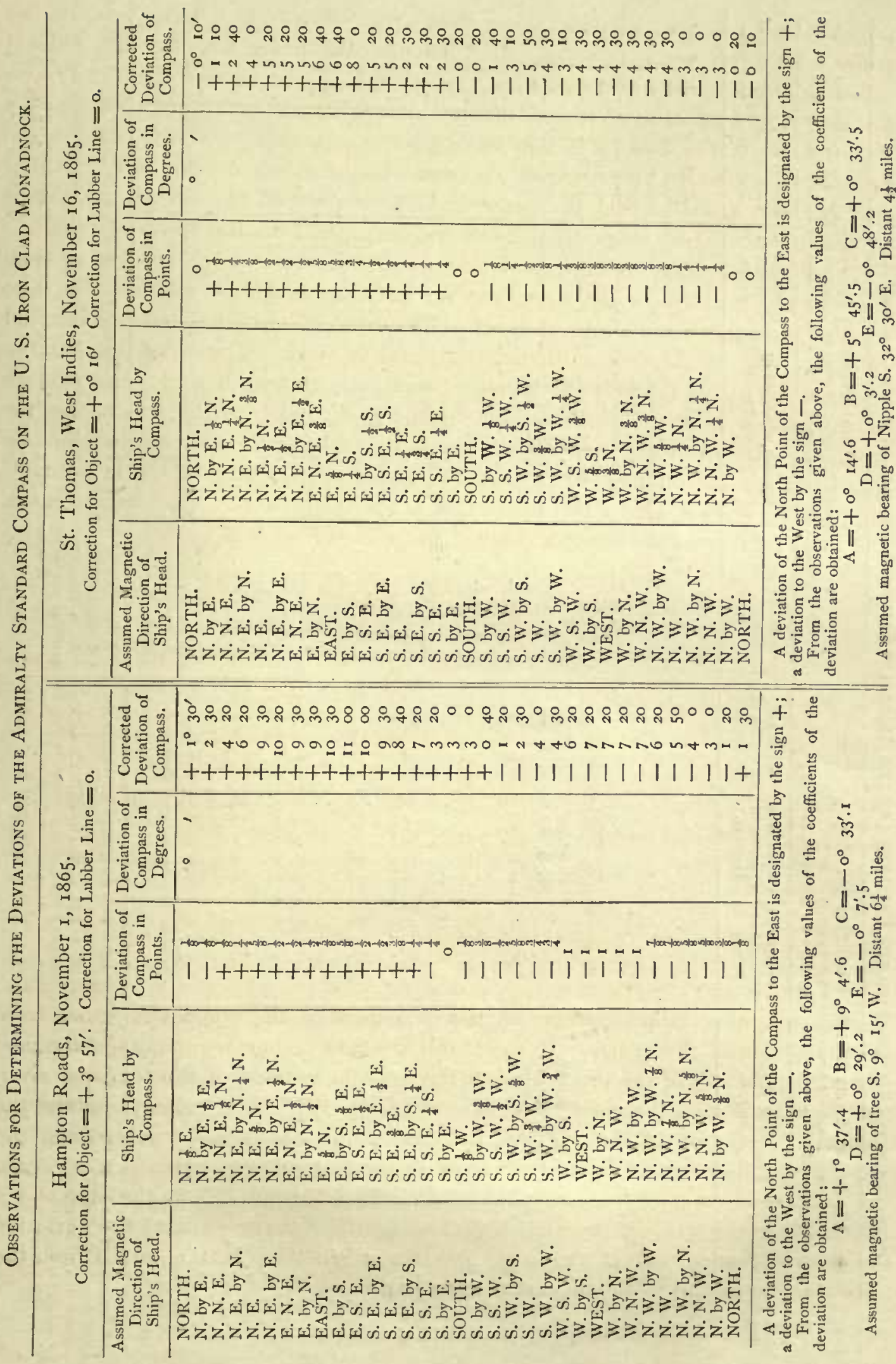




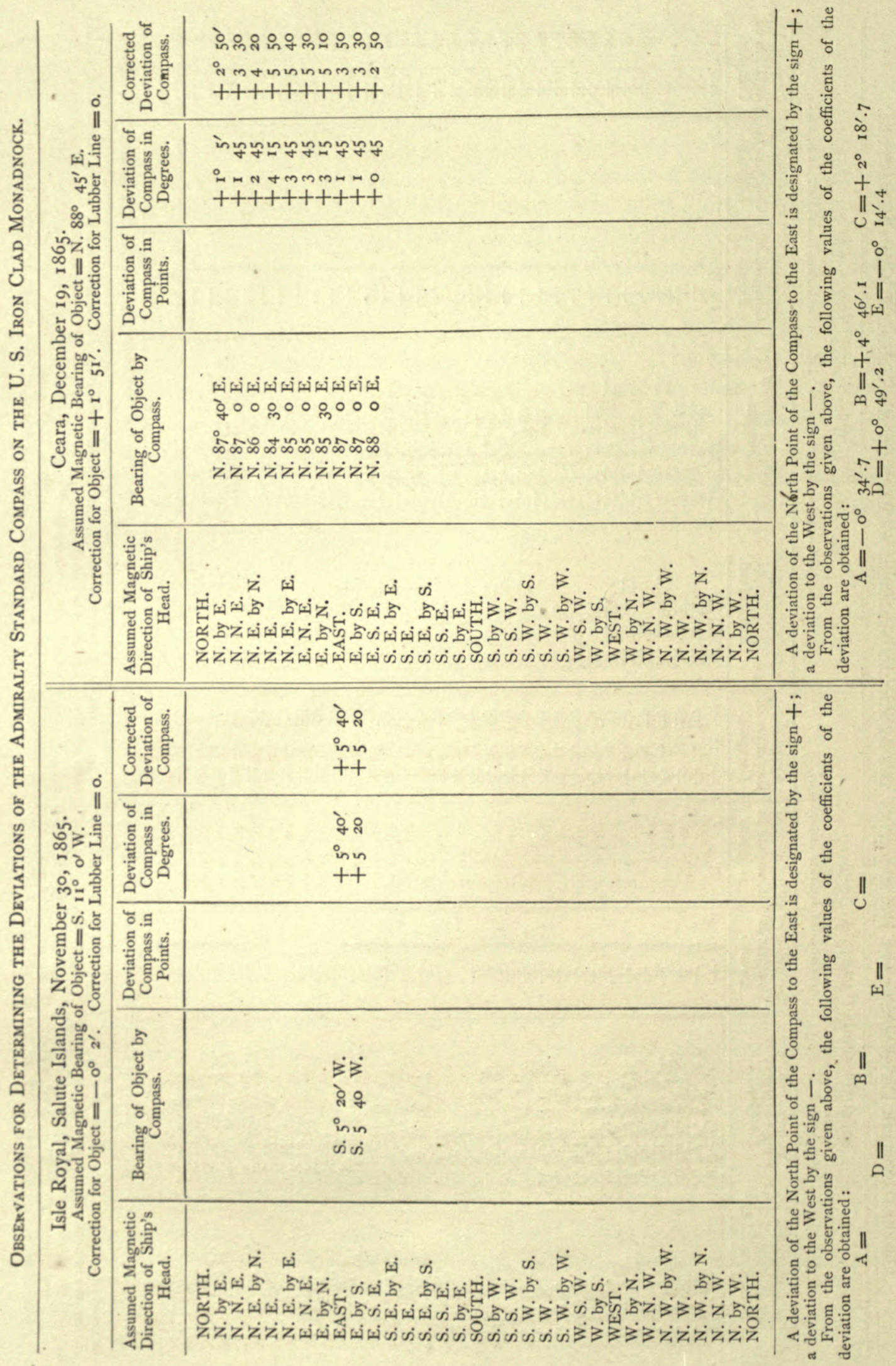




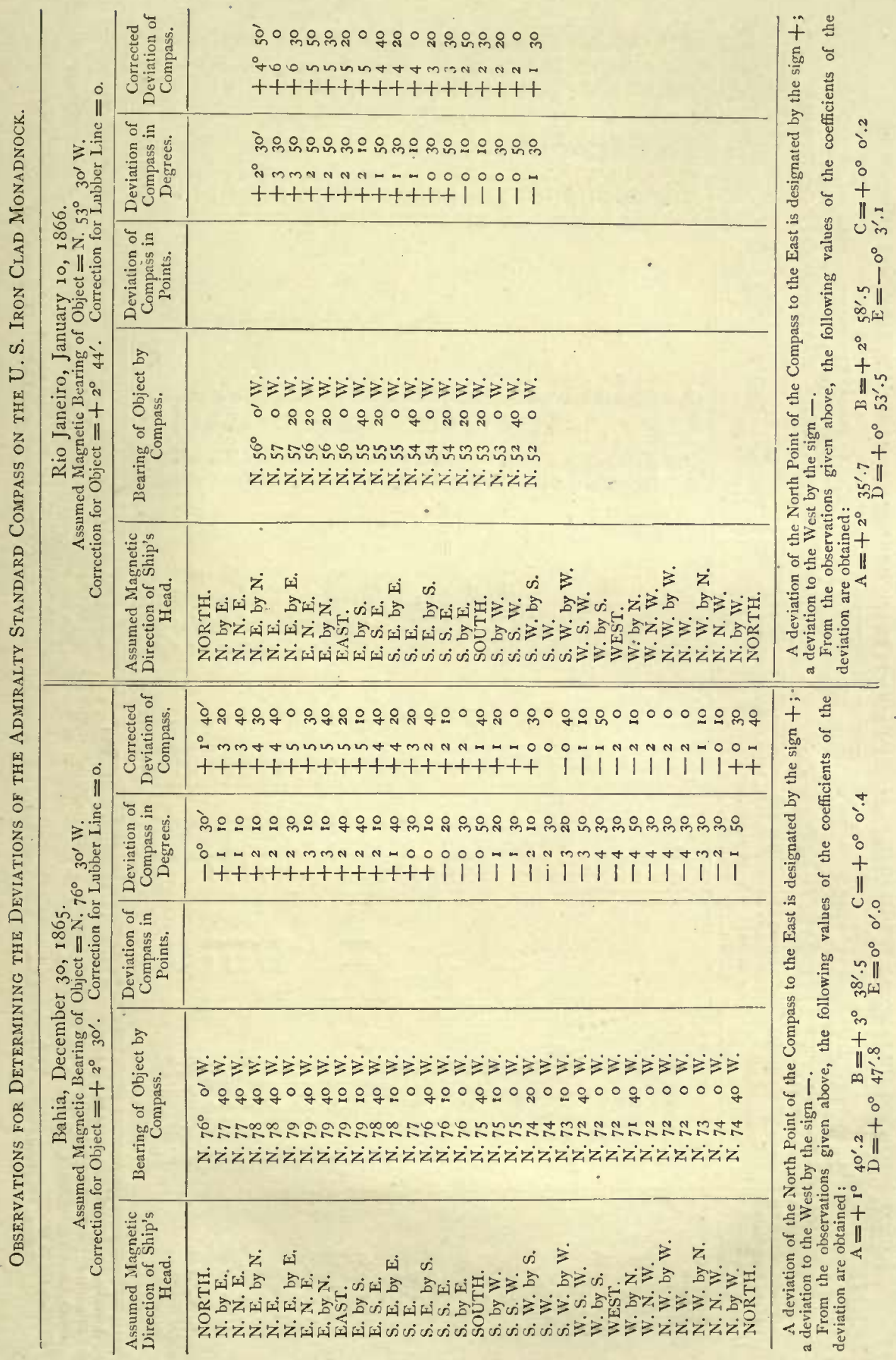







$\begin{array}{lll}2 & 0\end{array}$

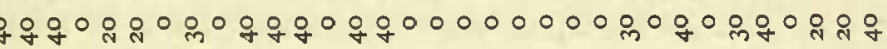

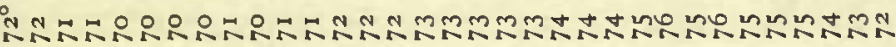

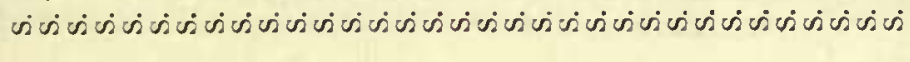

焉

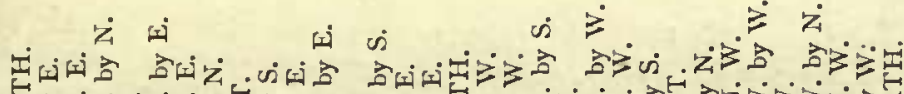

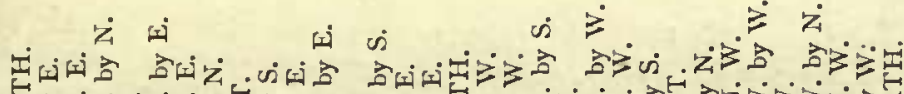

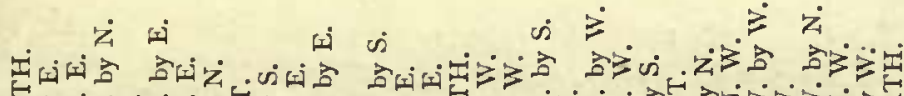

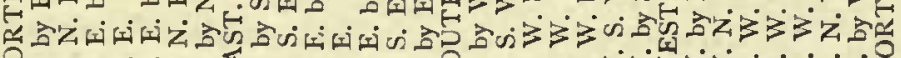

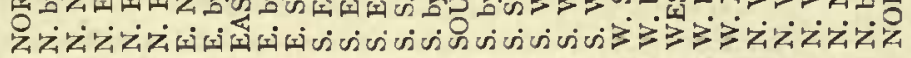

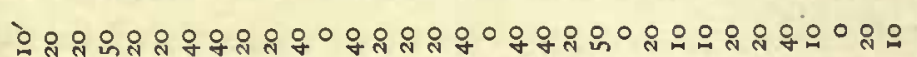

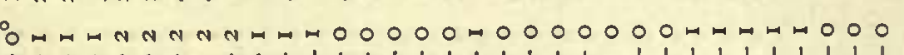
$1+++++++++++++++++++++1111111111$

㷎

.

능.

in

in

லัخ்

空

f.

ने

दे:

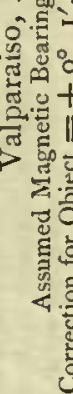

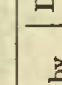

:

苛高

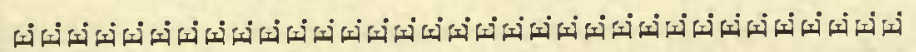

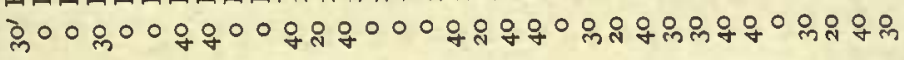
望士

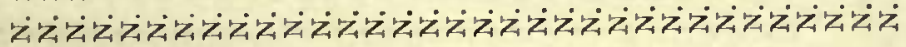

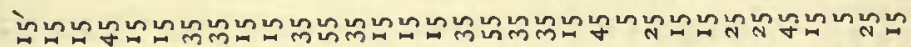

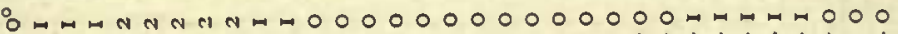
$1+t+t+t+t+t+t+t+t+t+t+1|1| 1|1| 1|1|$

\section{○. $\Xi$}

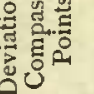

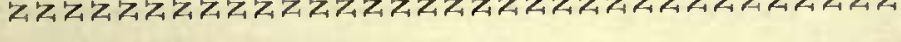

\section{ri}

ai is

$\dot{\infty} \rightleftharpoons$

$\geqslant \dot{z}$

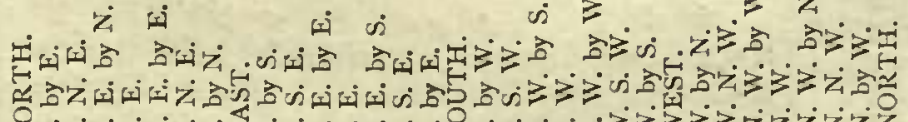

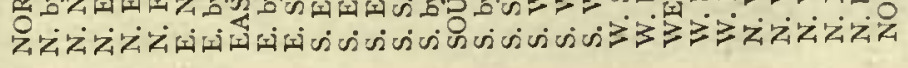




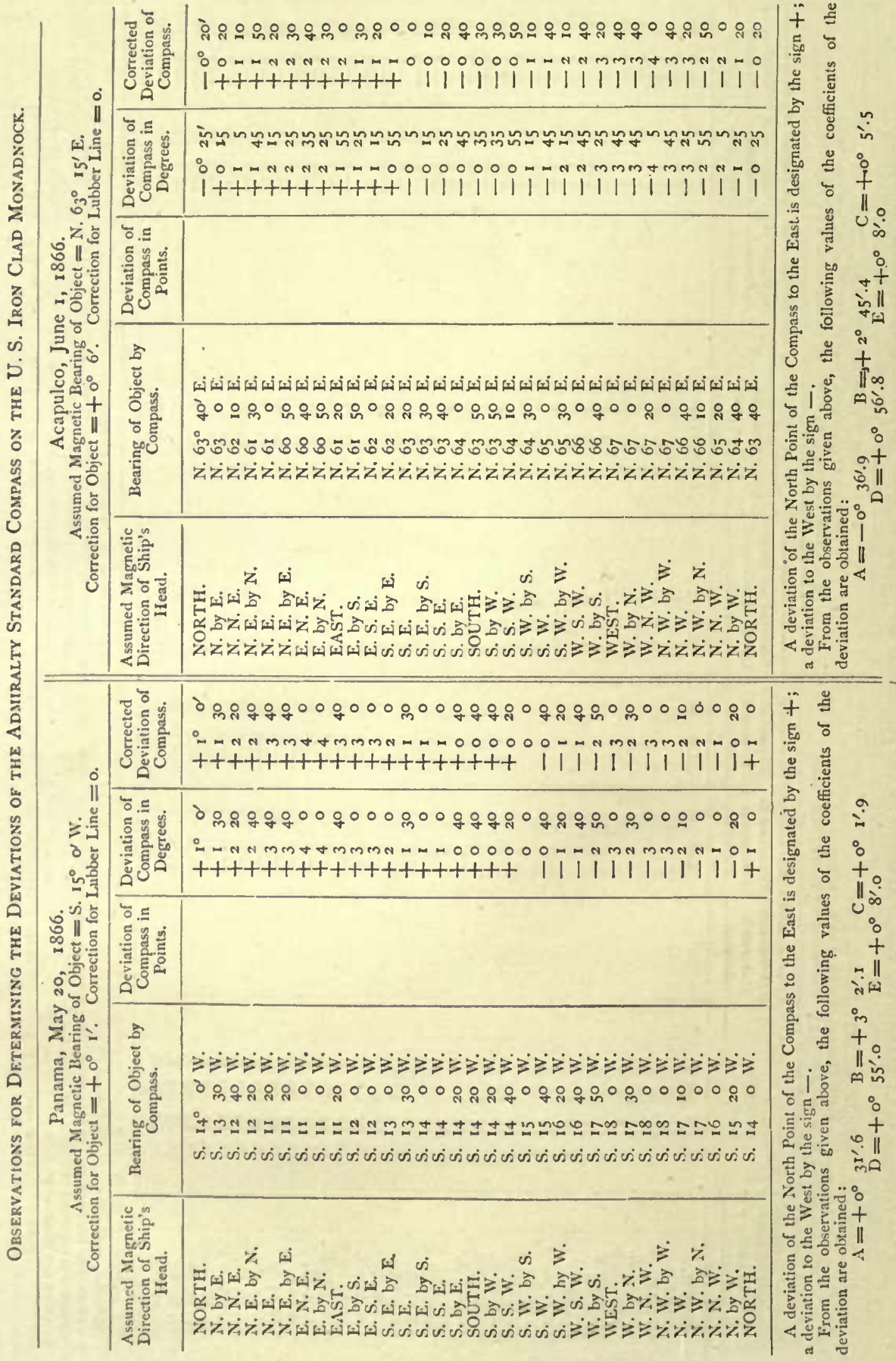




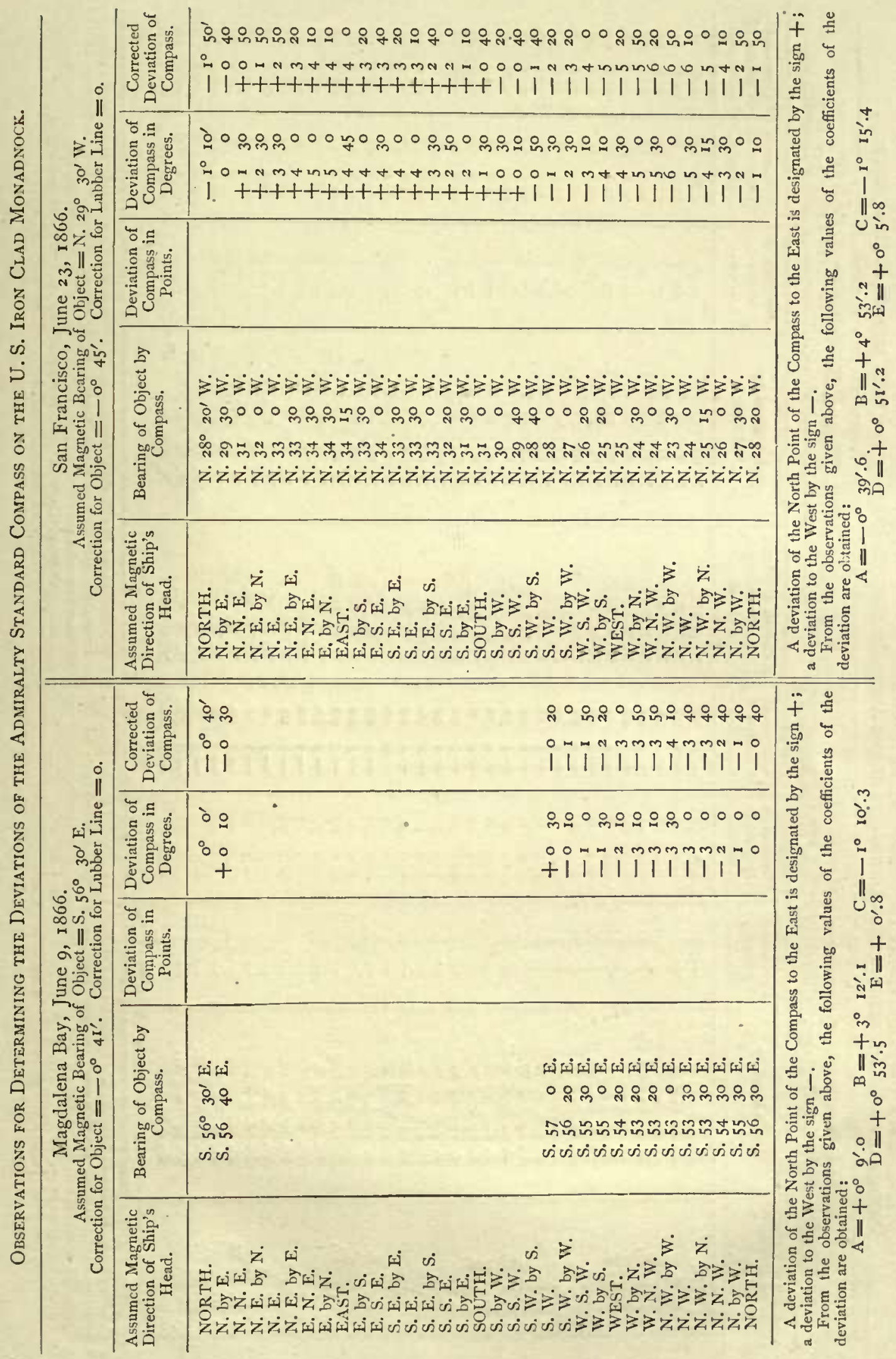




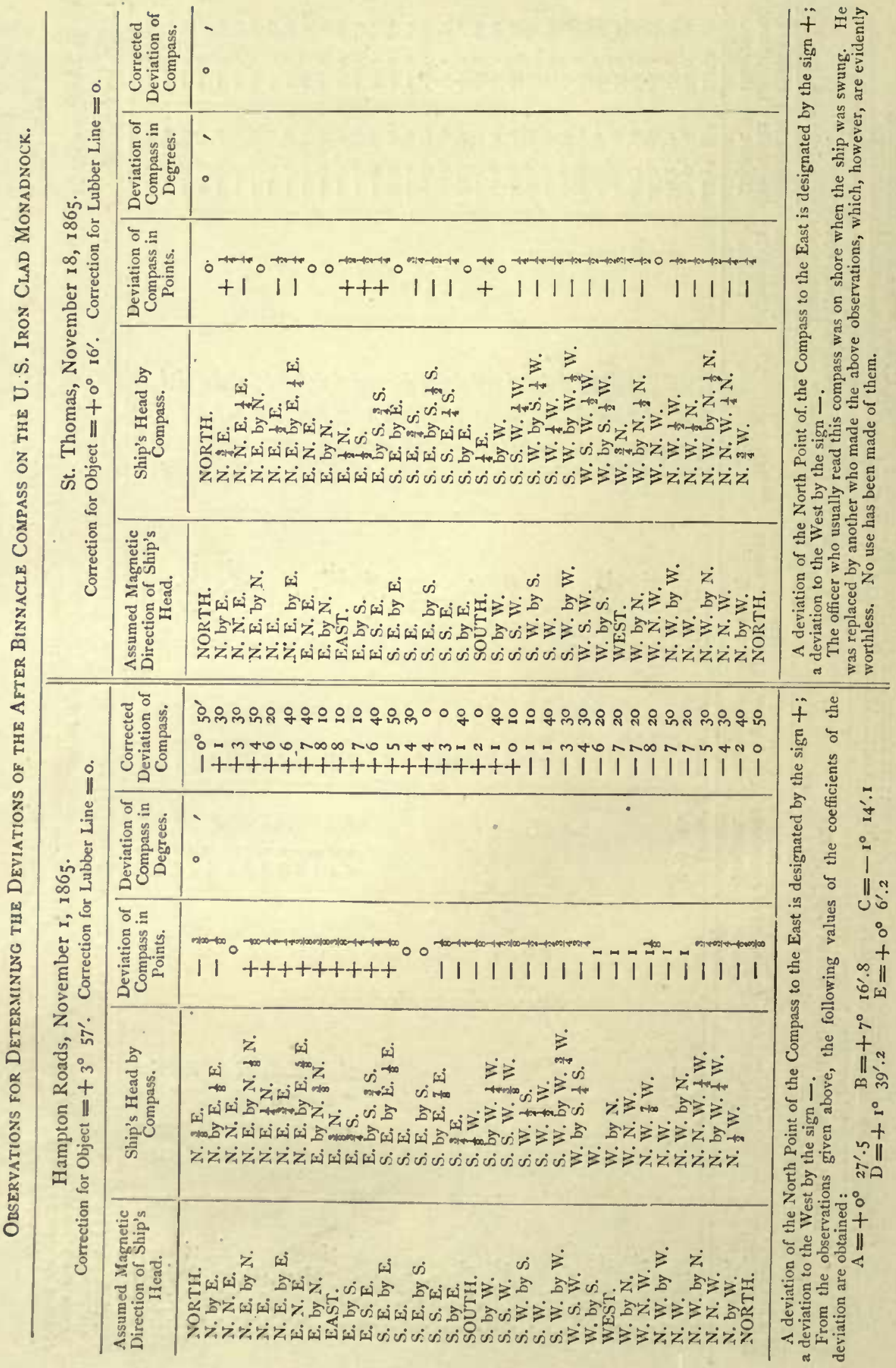




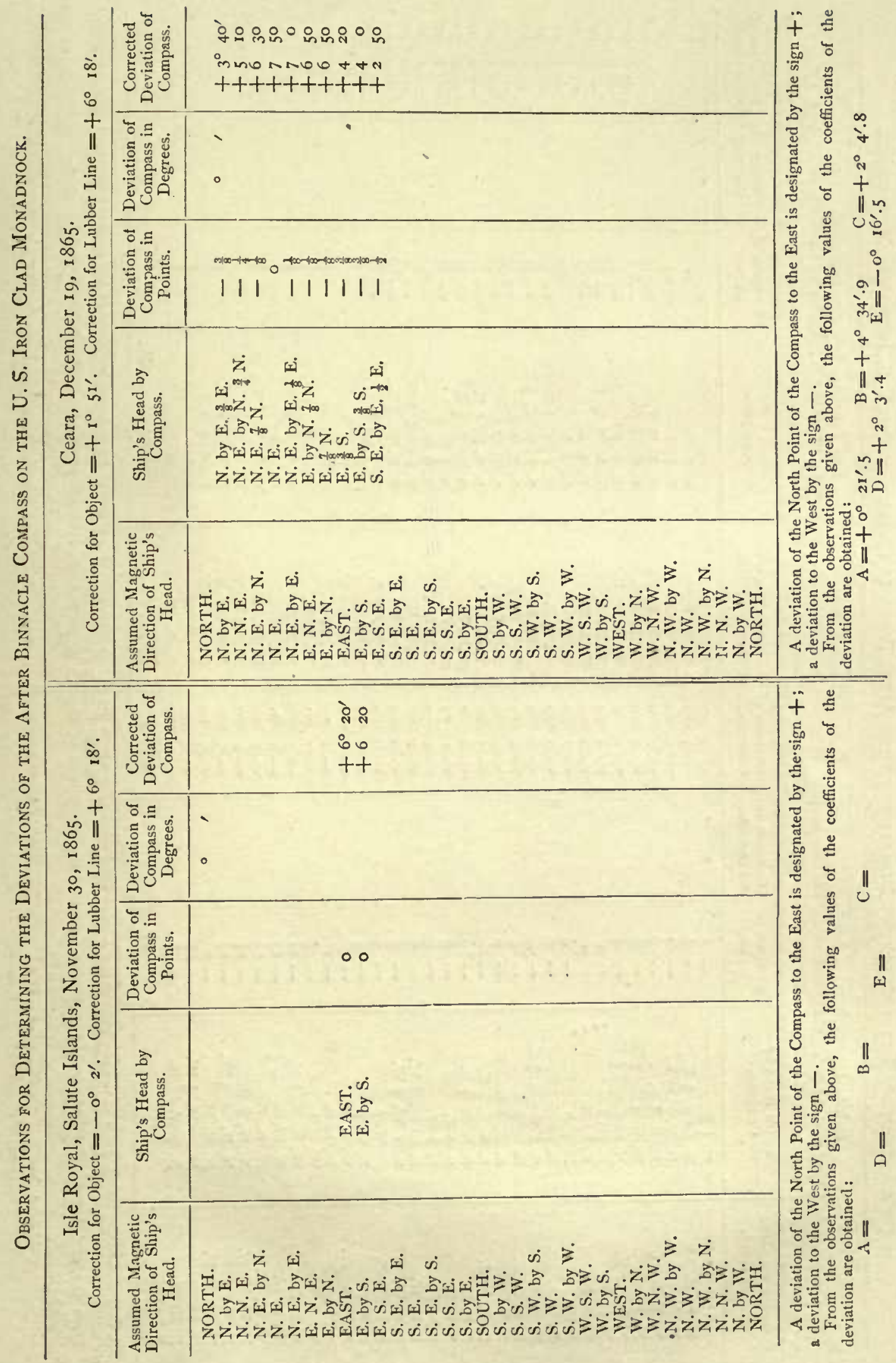




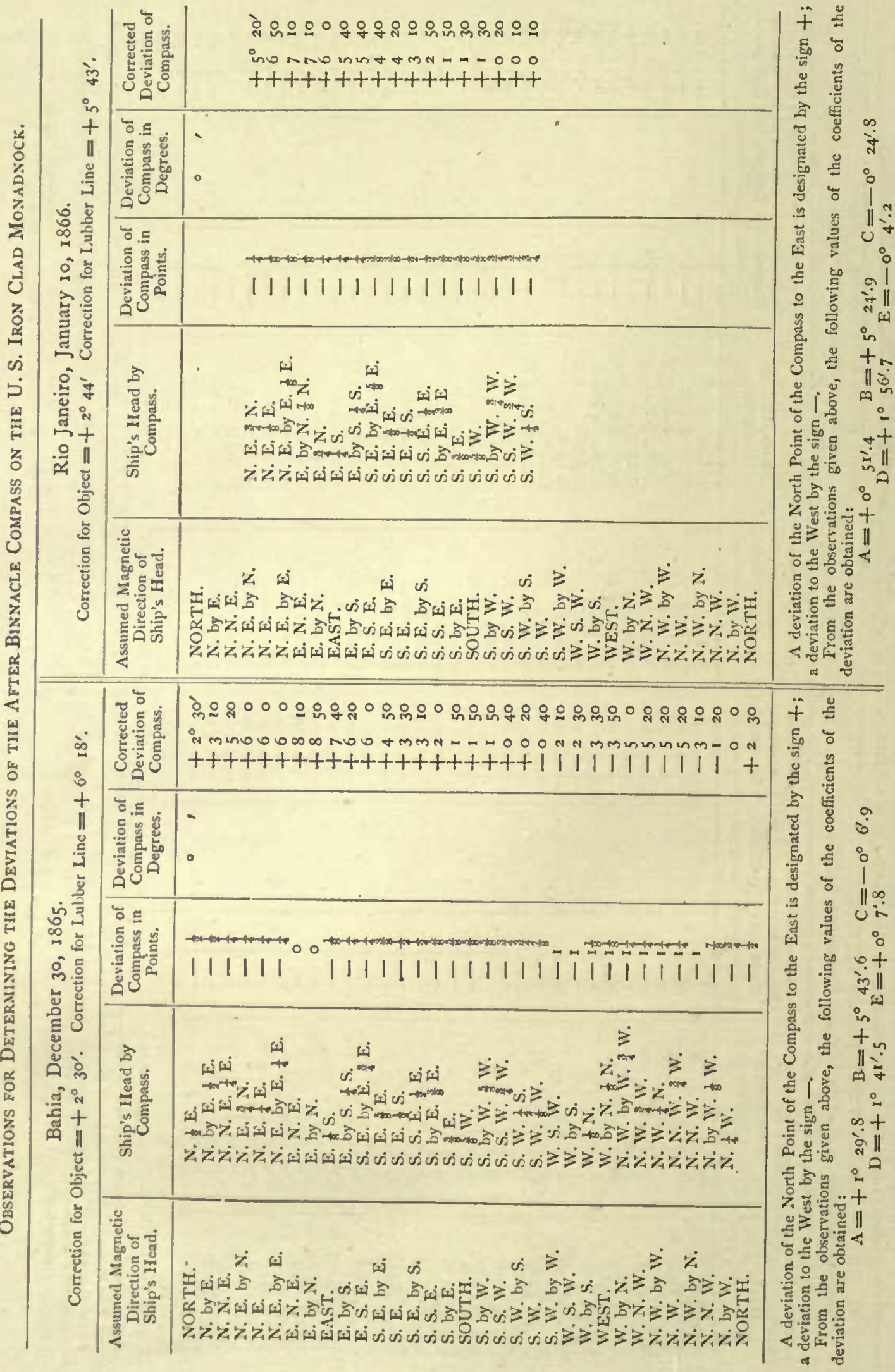




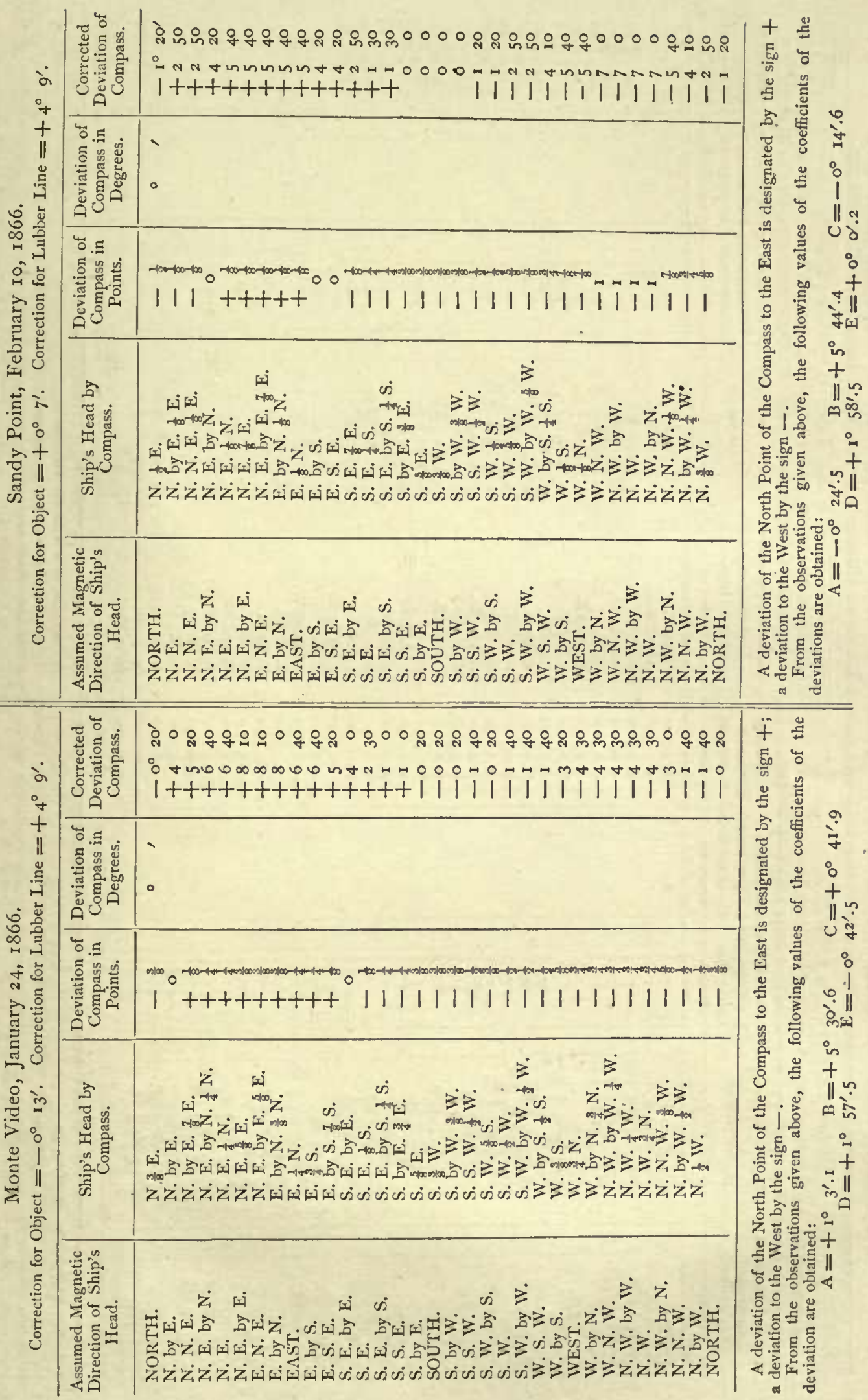




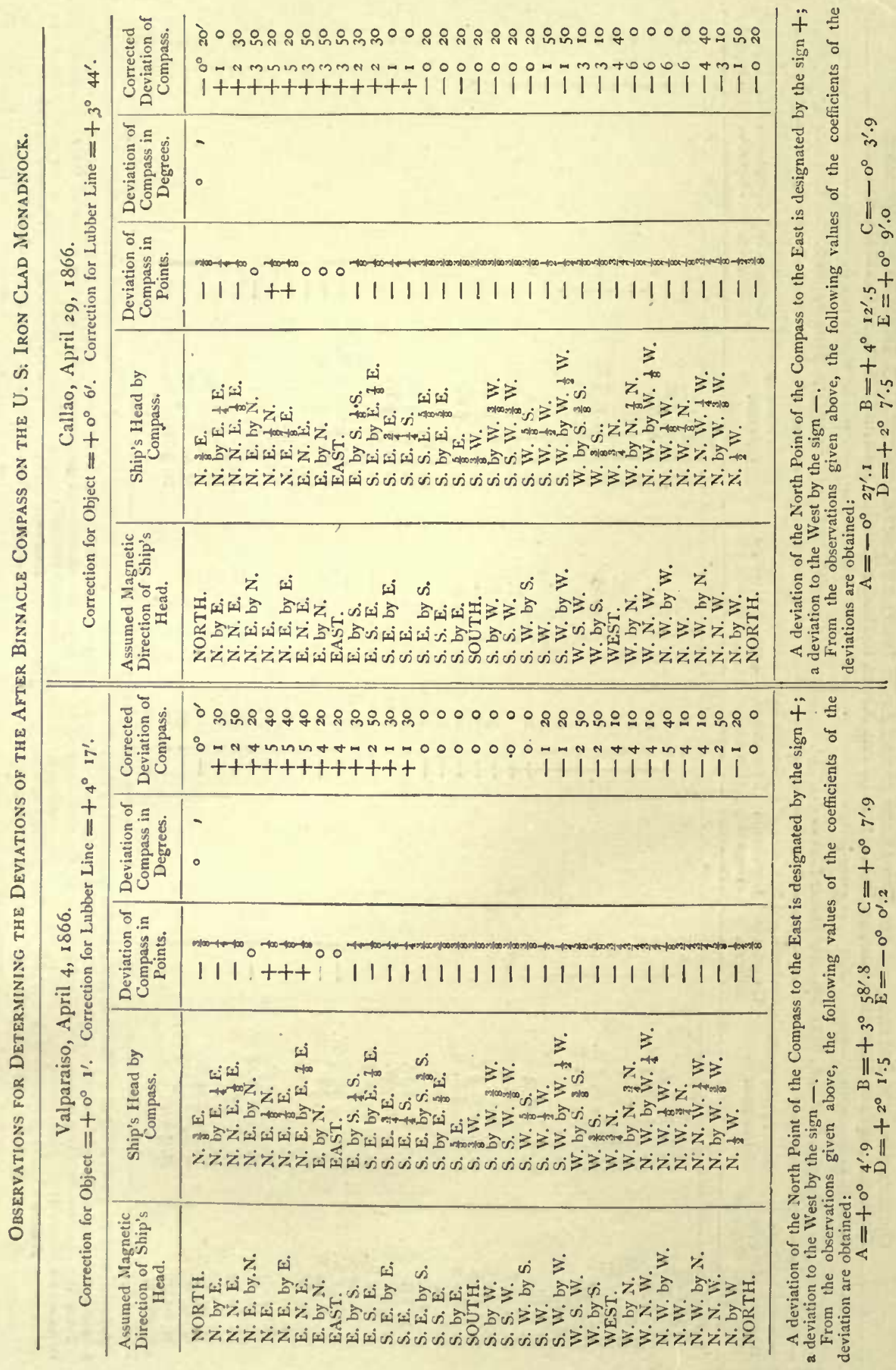




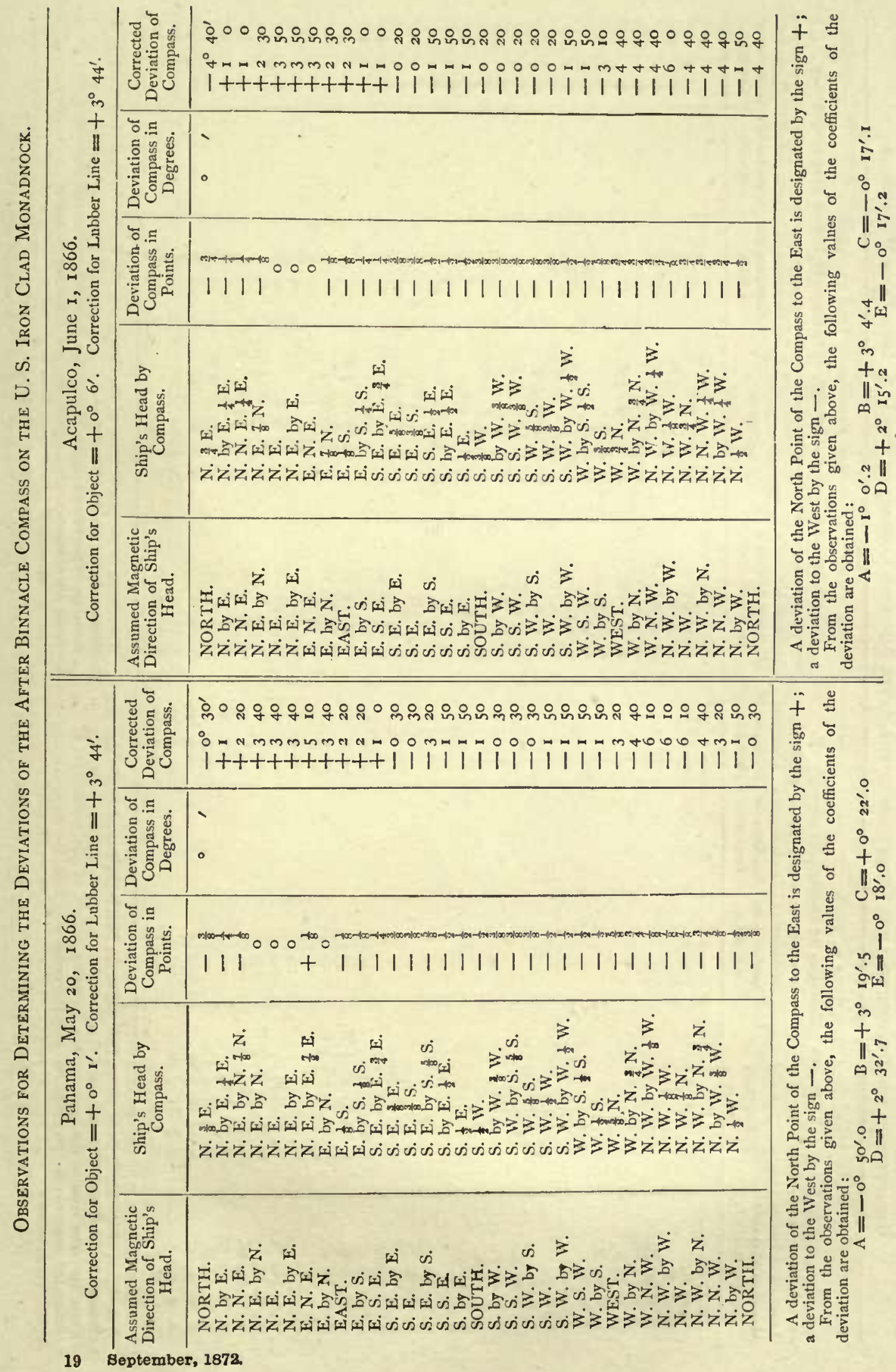




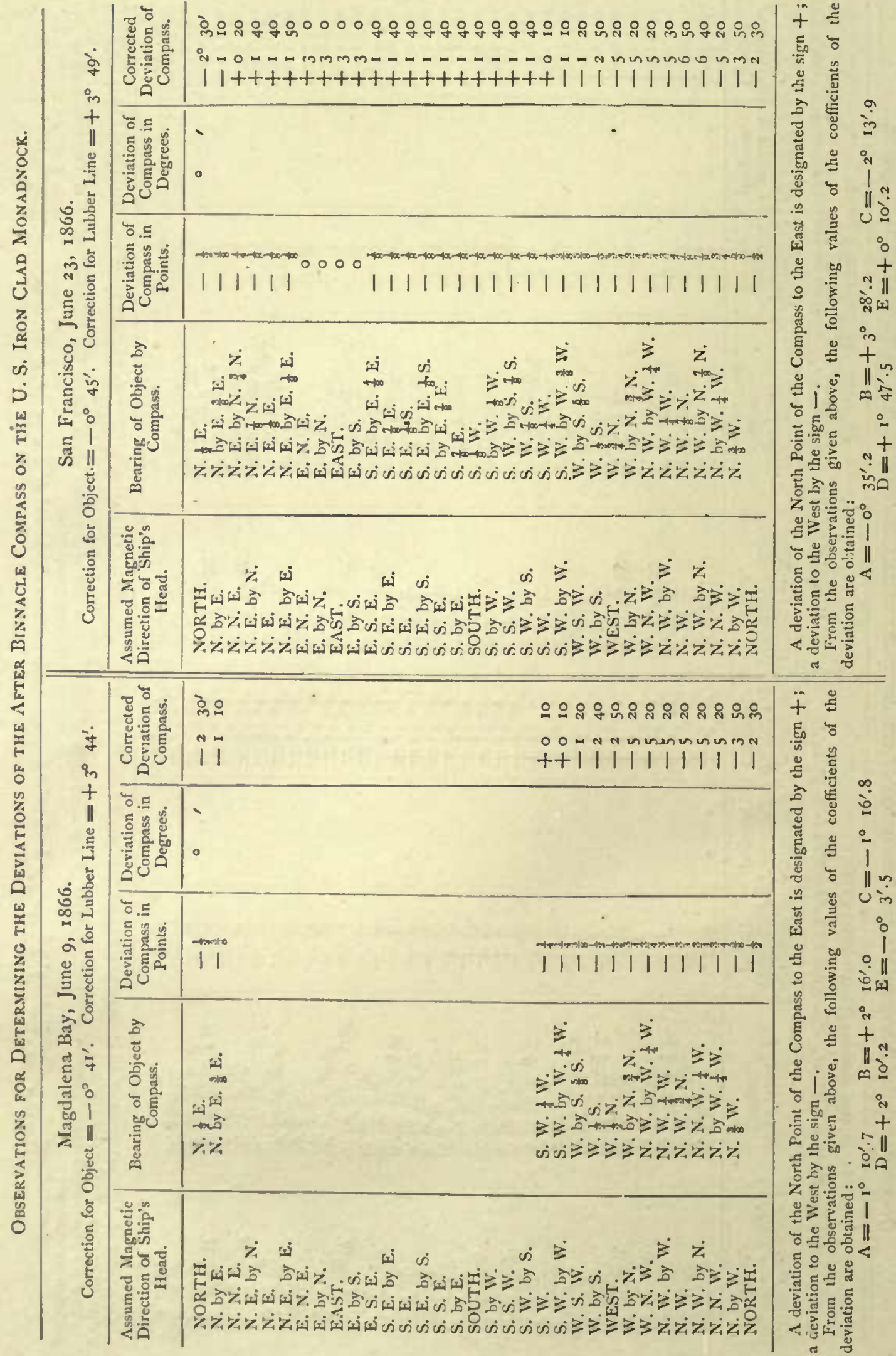




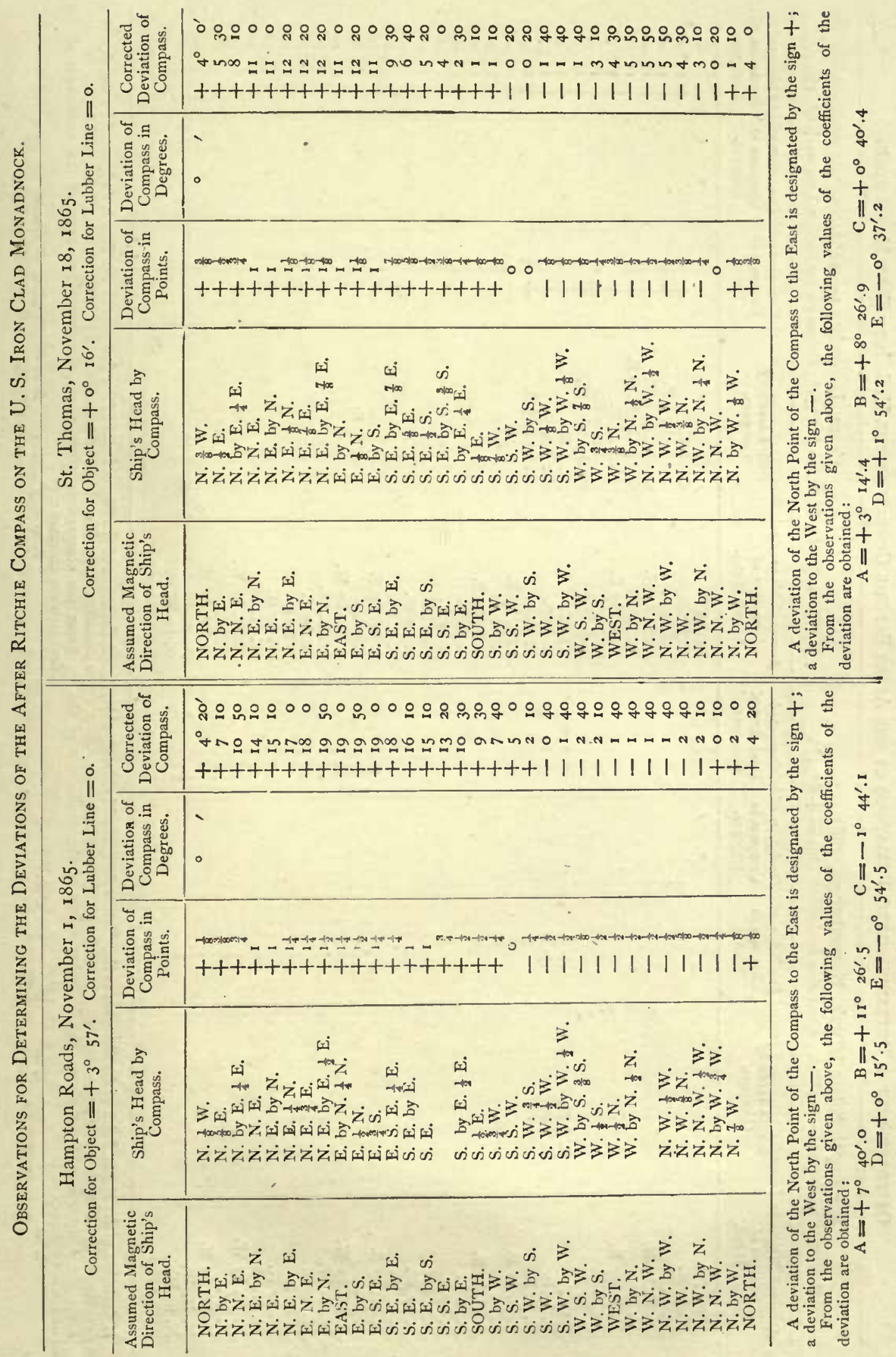




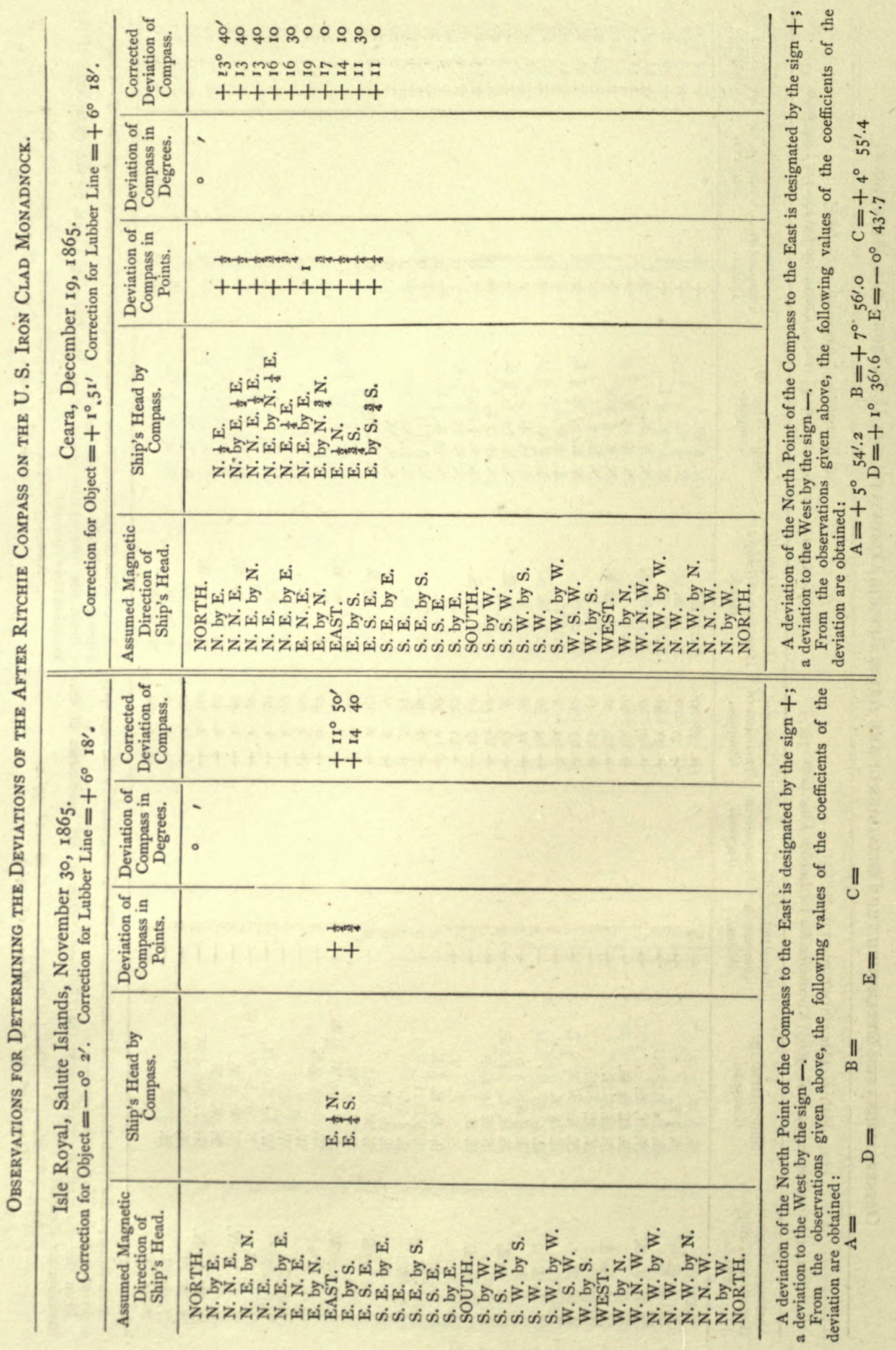




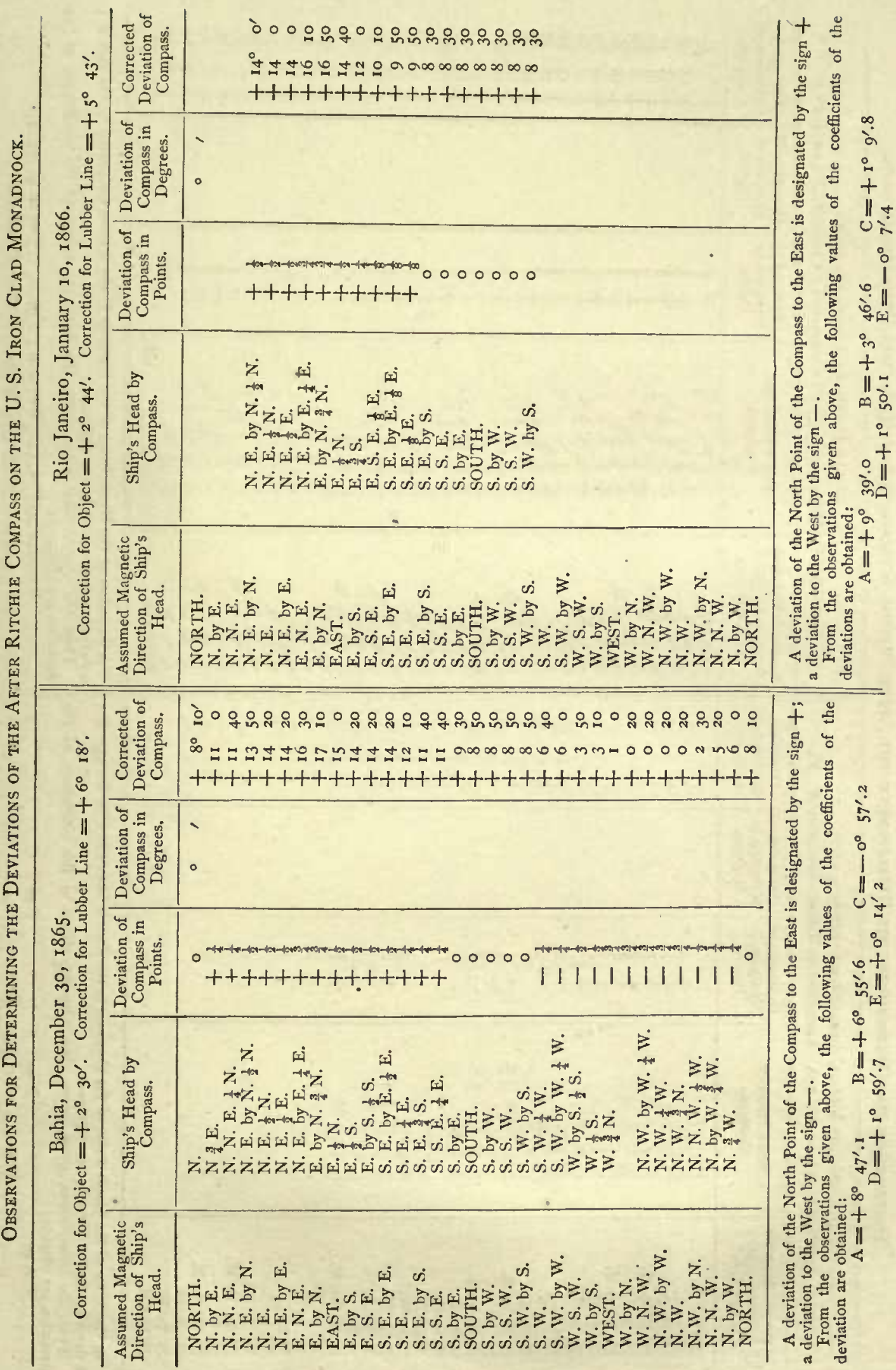




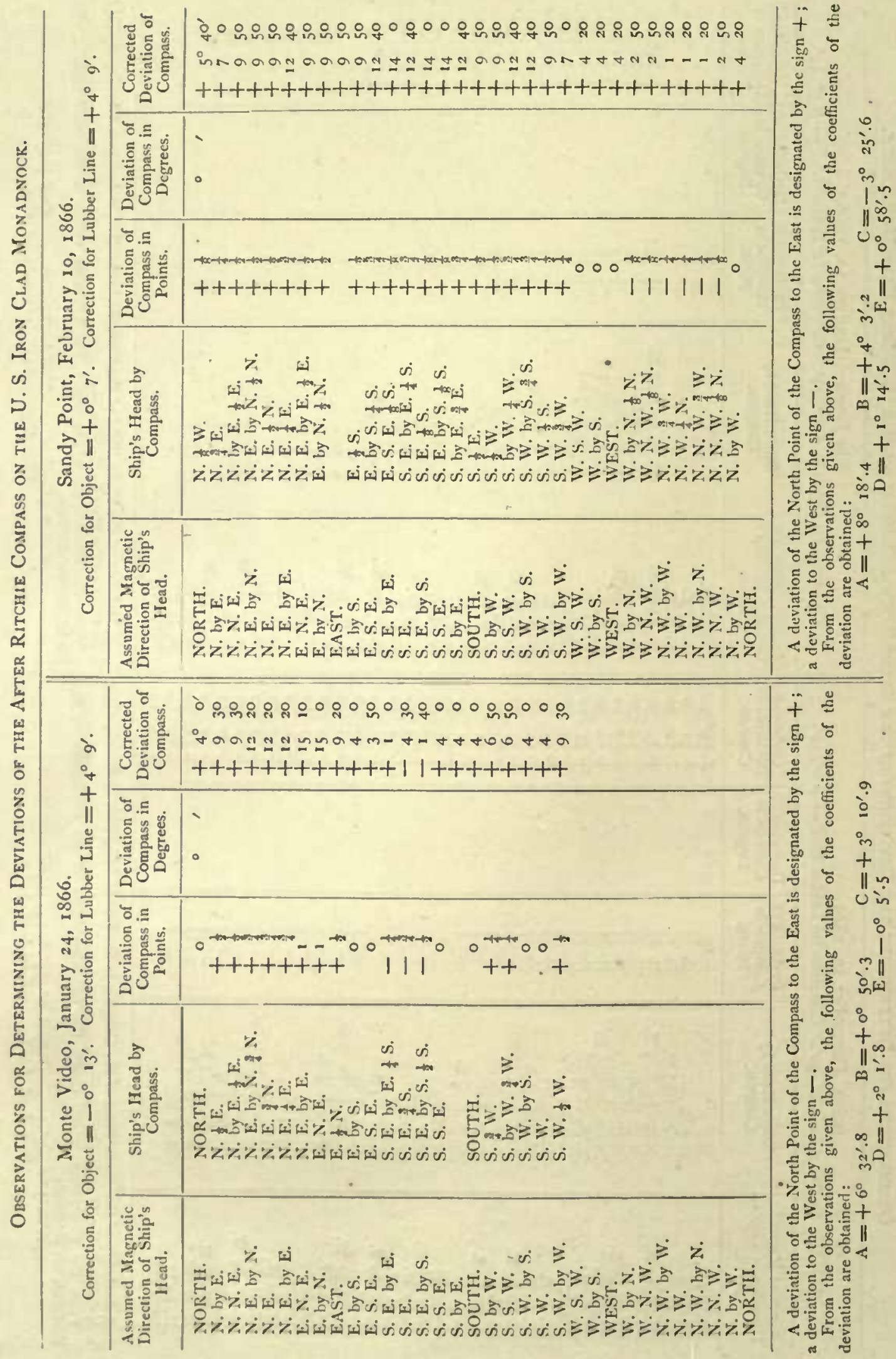




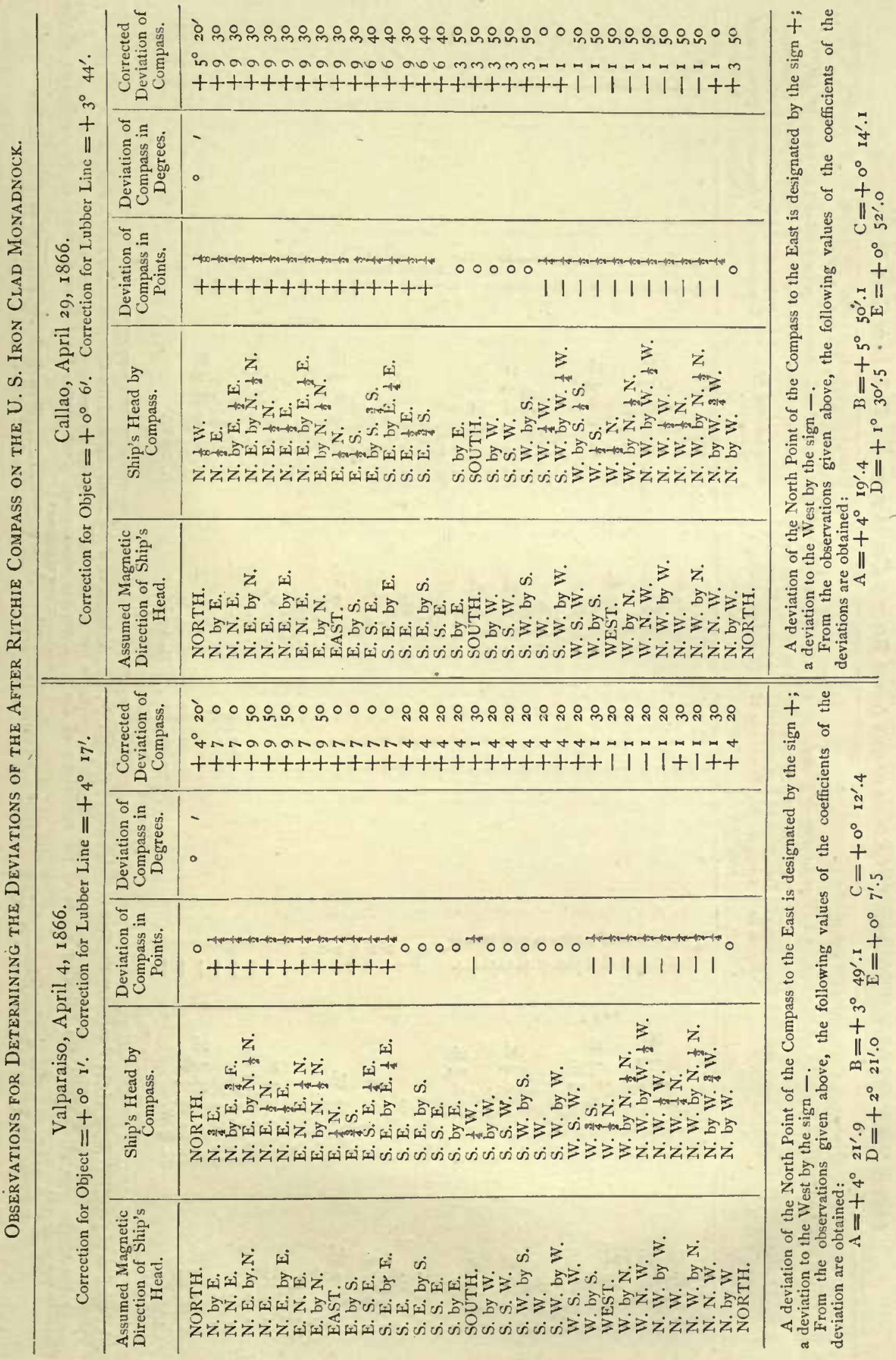




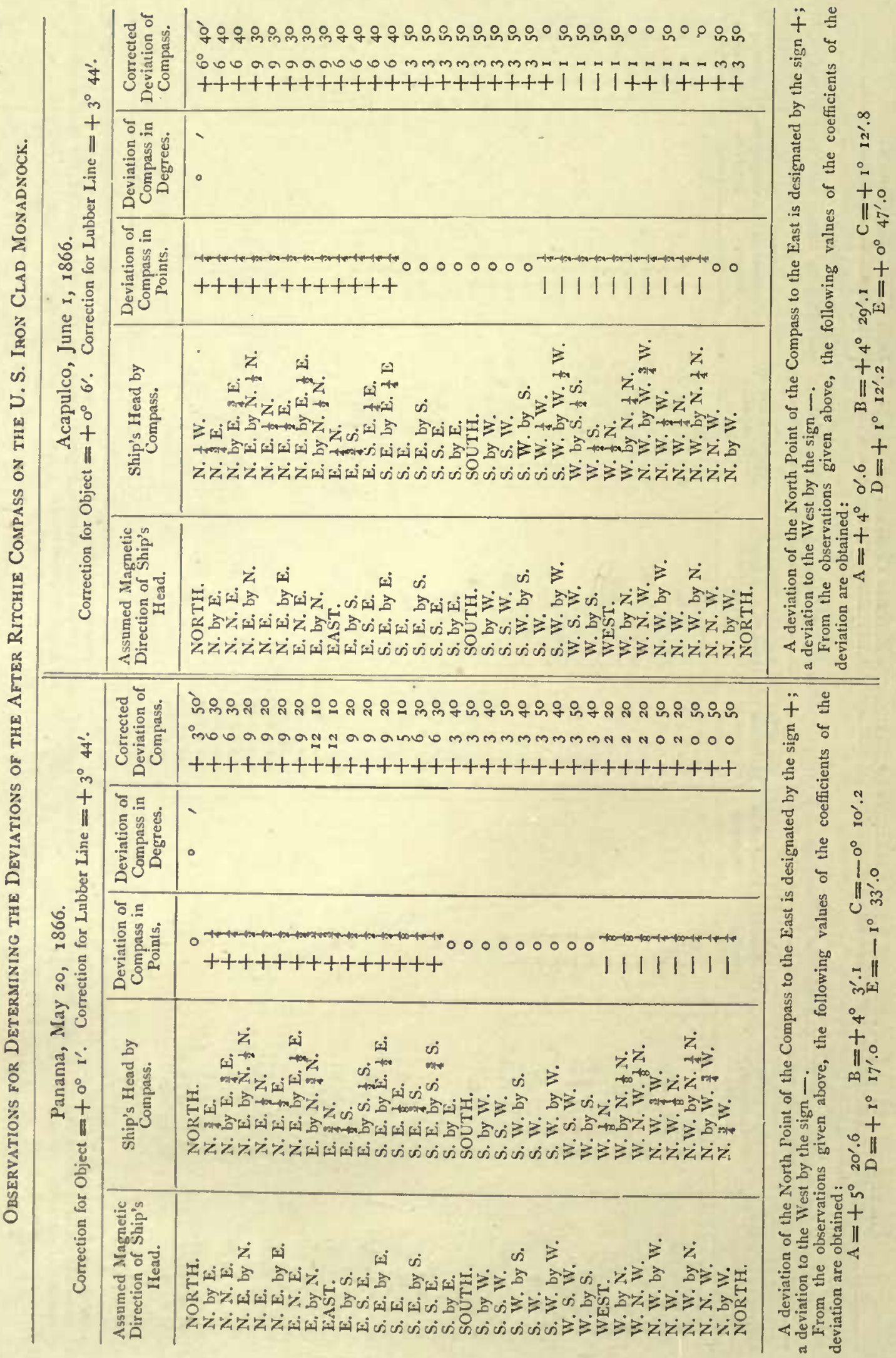




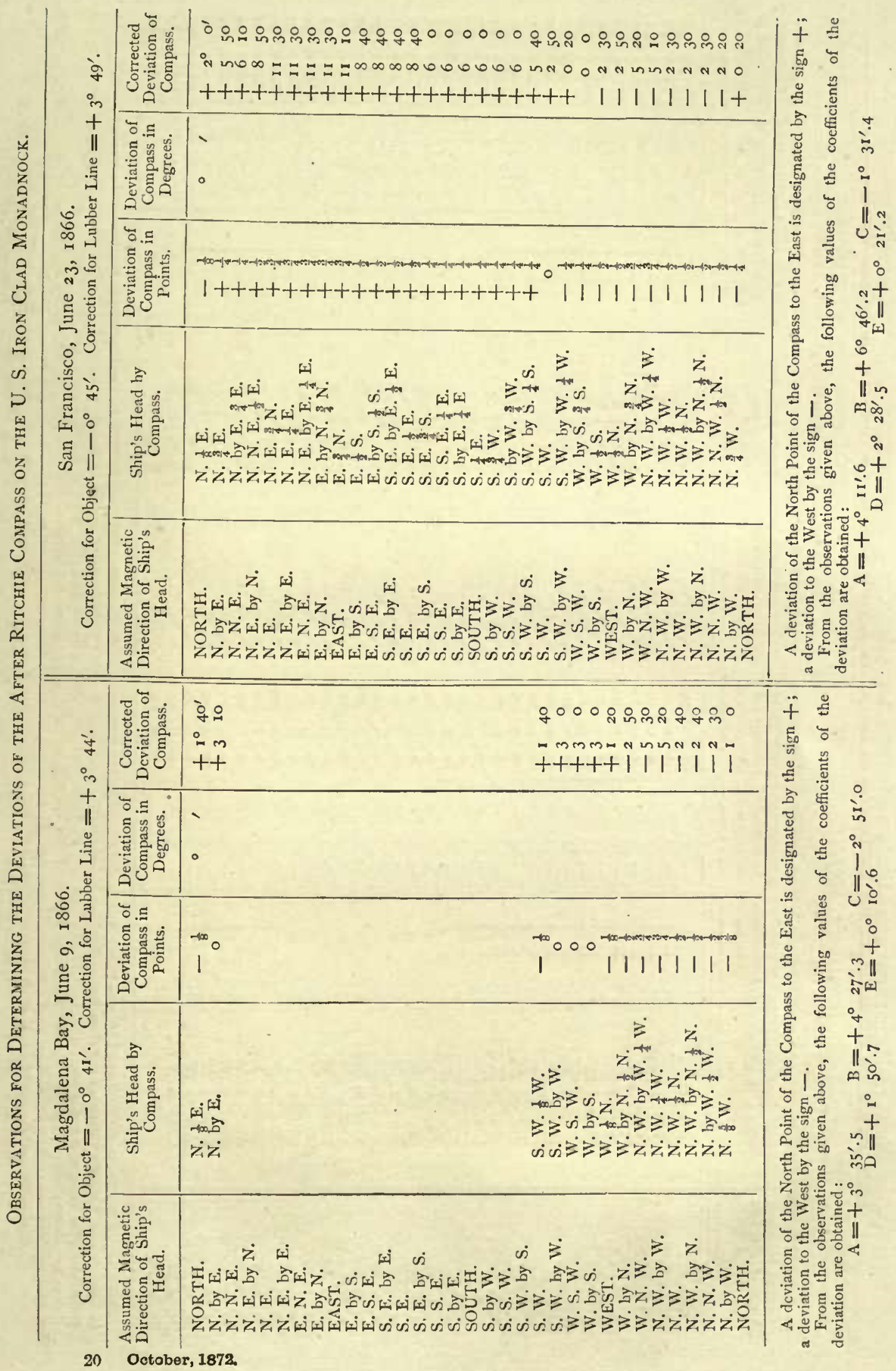




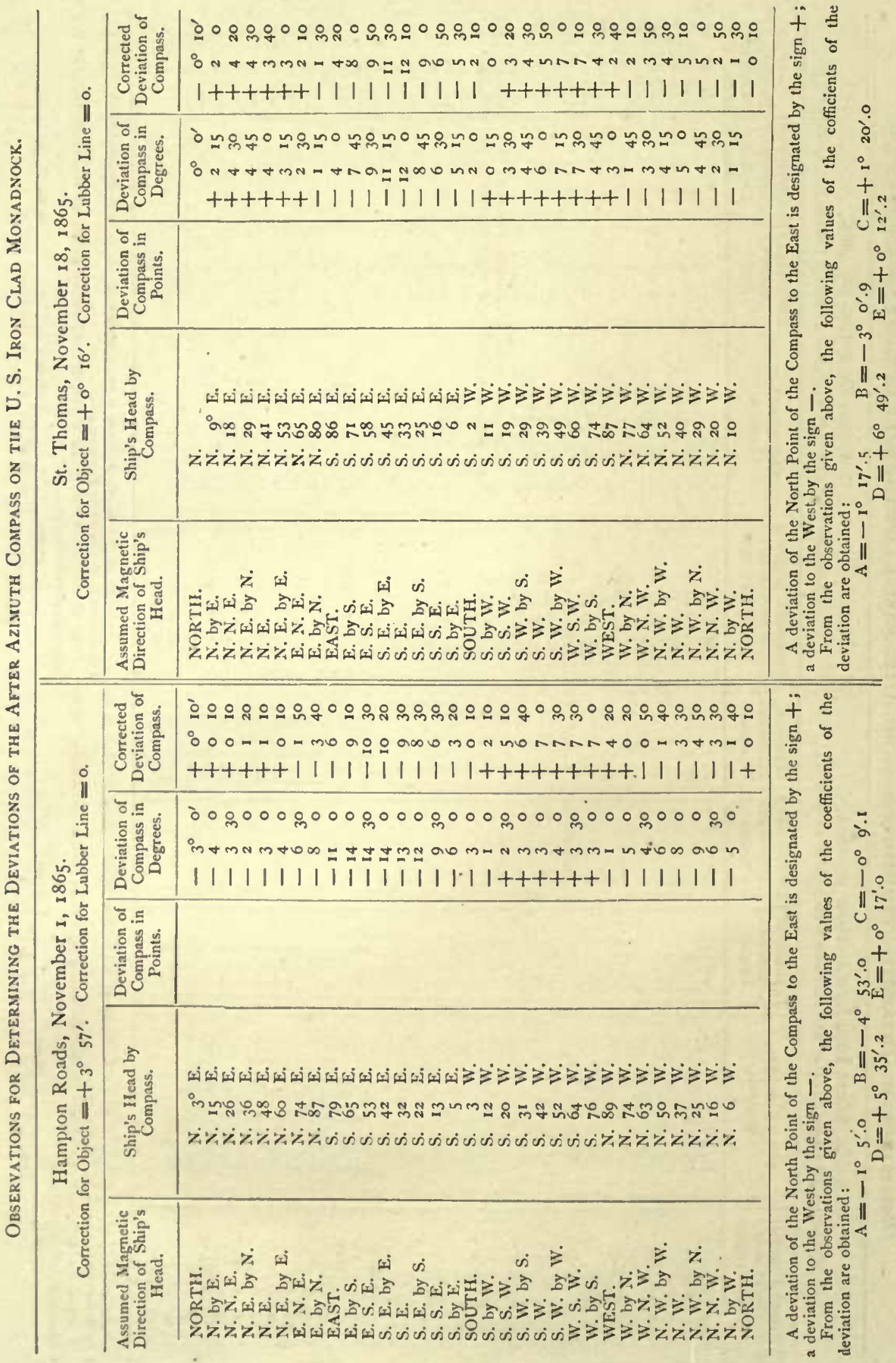




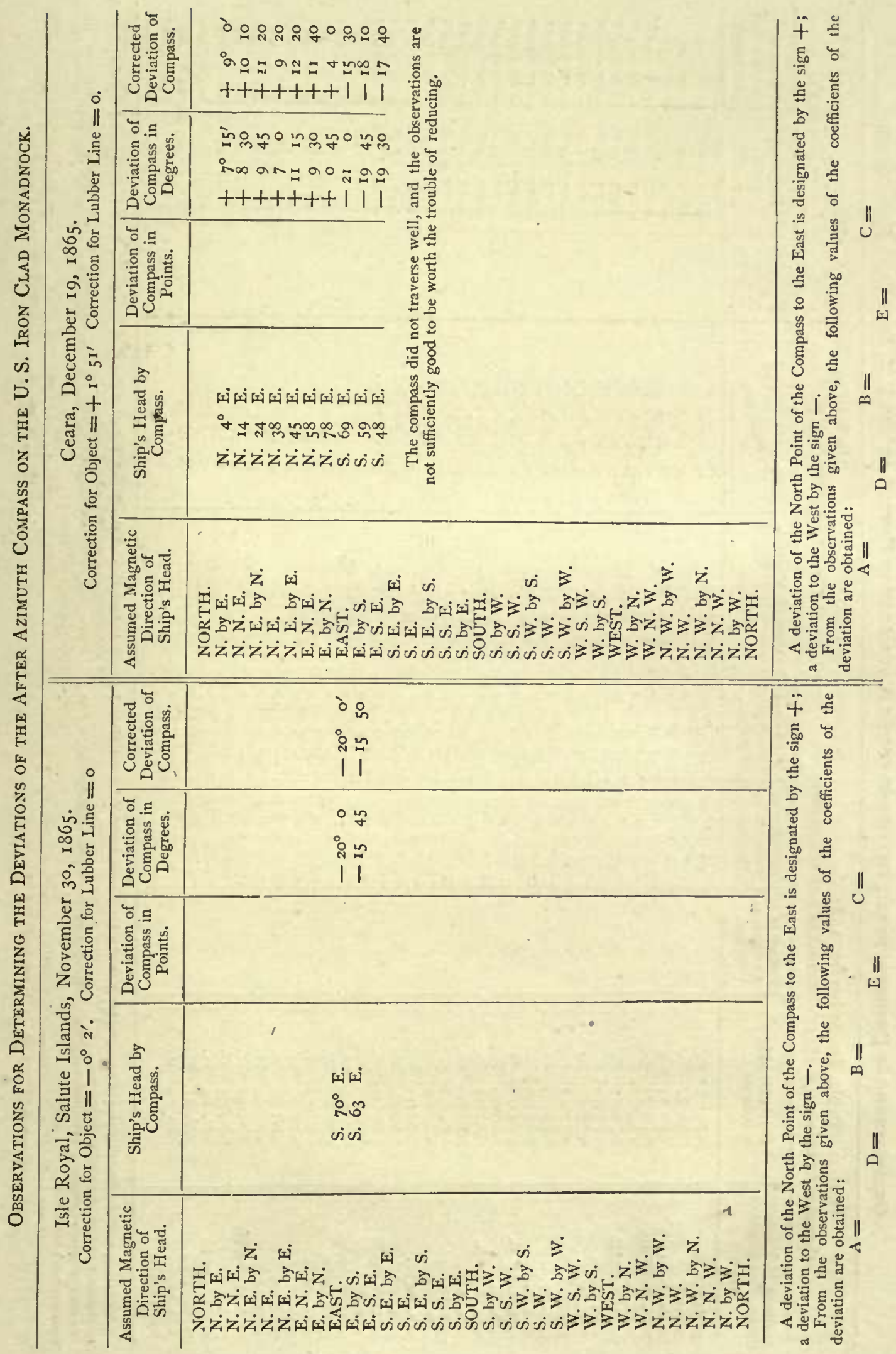




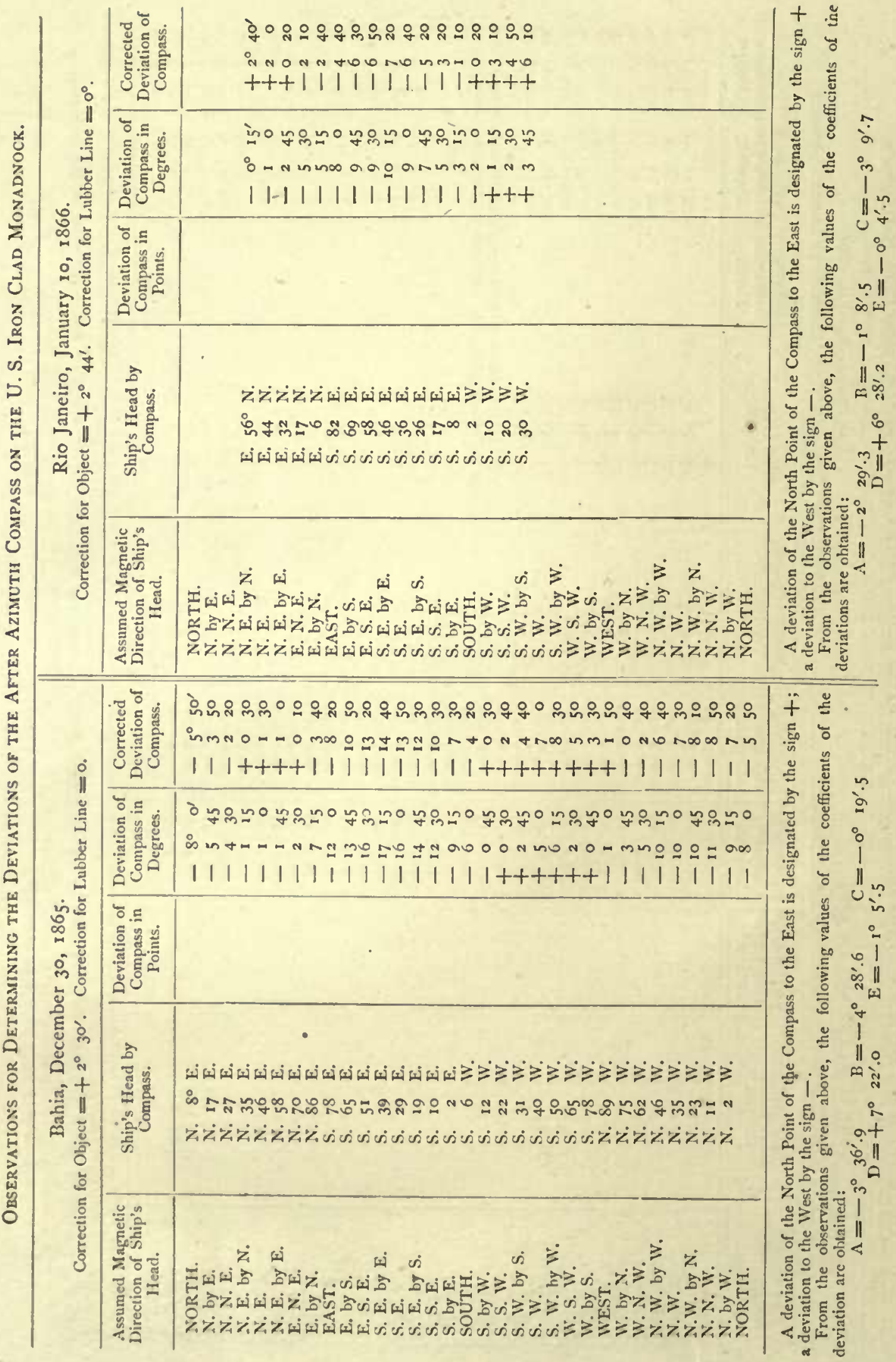




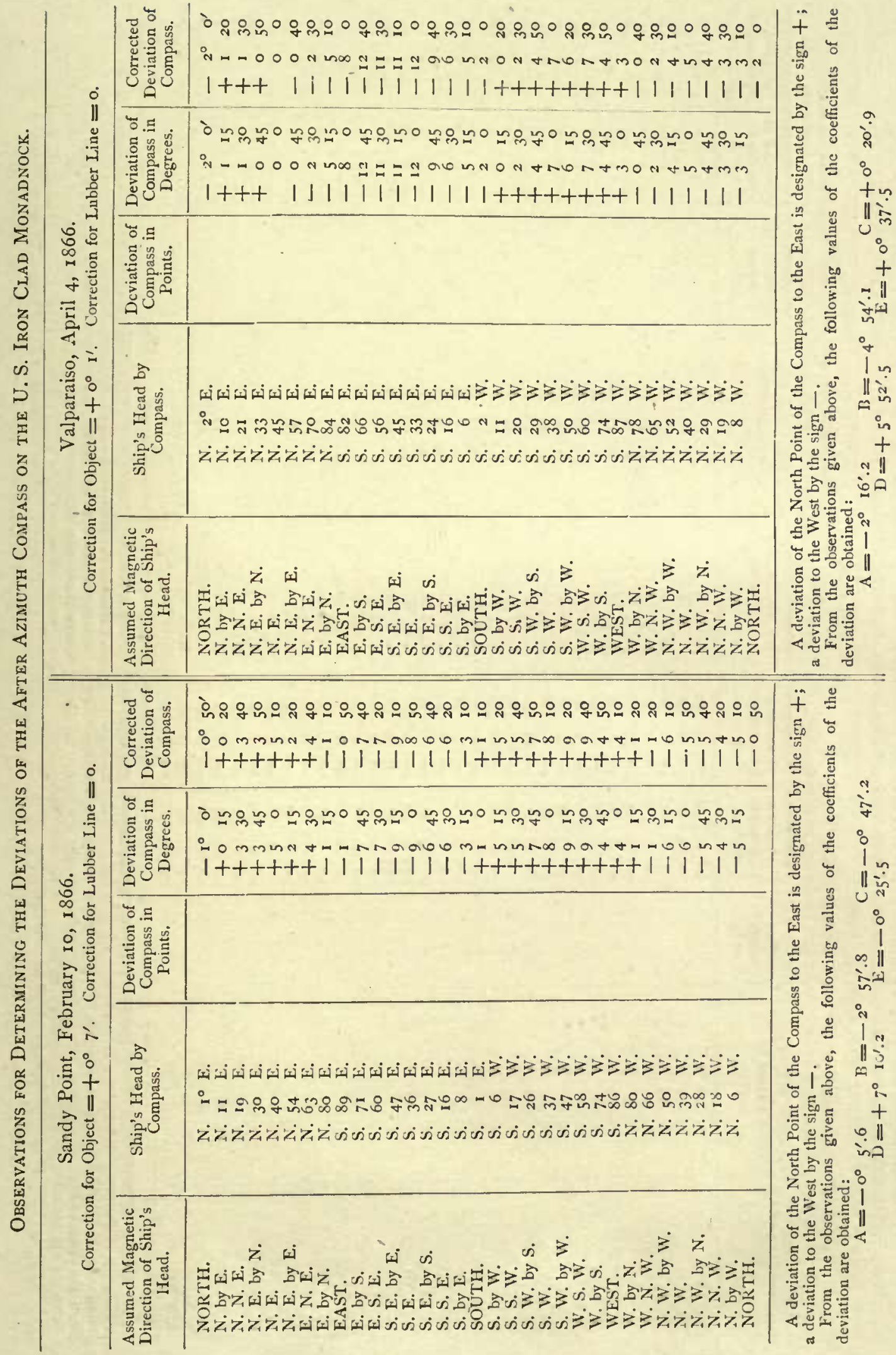




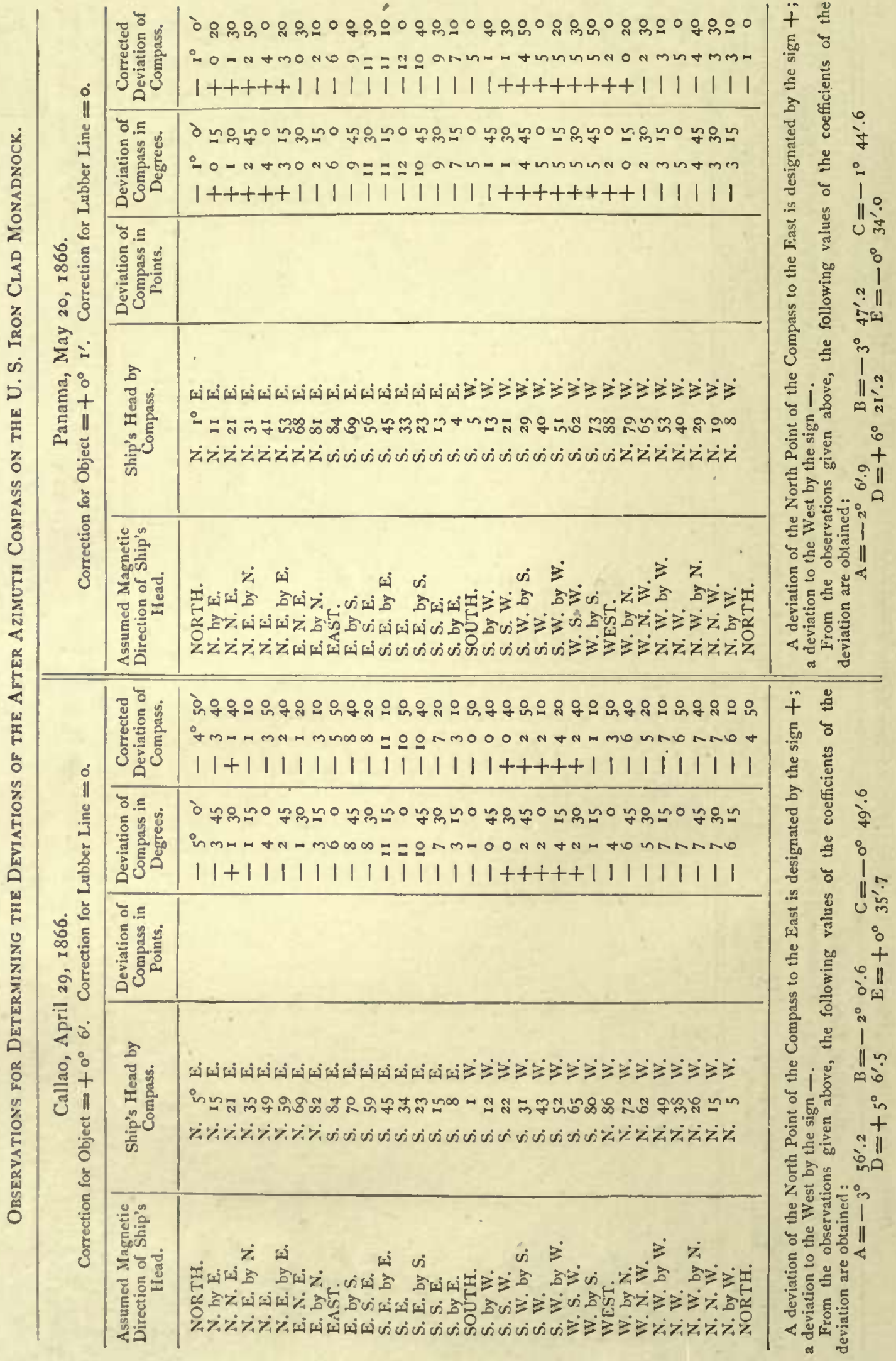




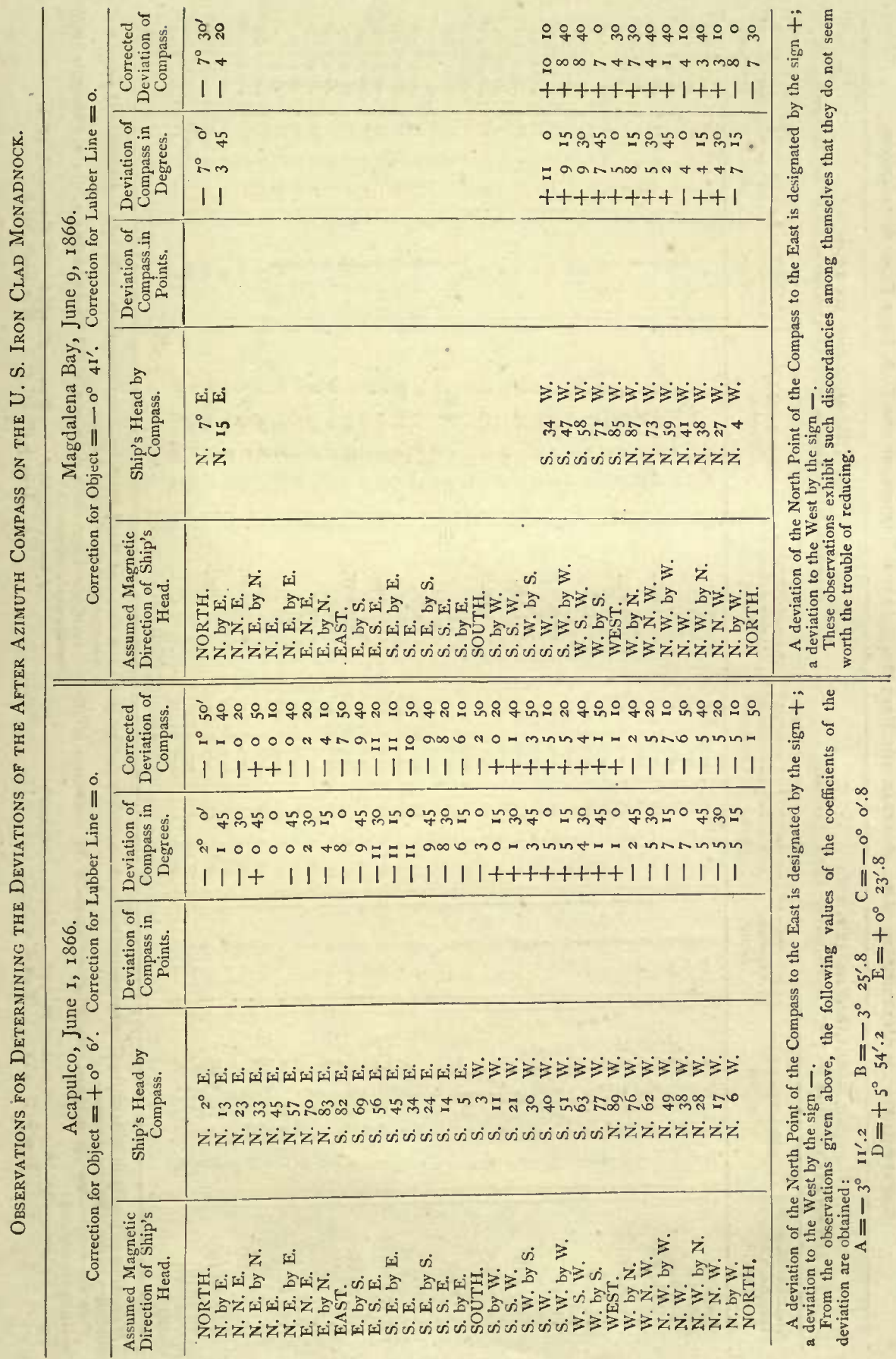




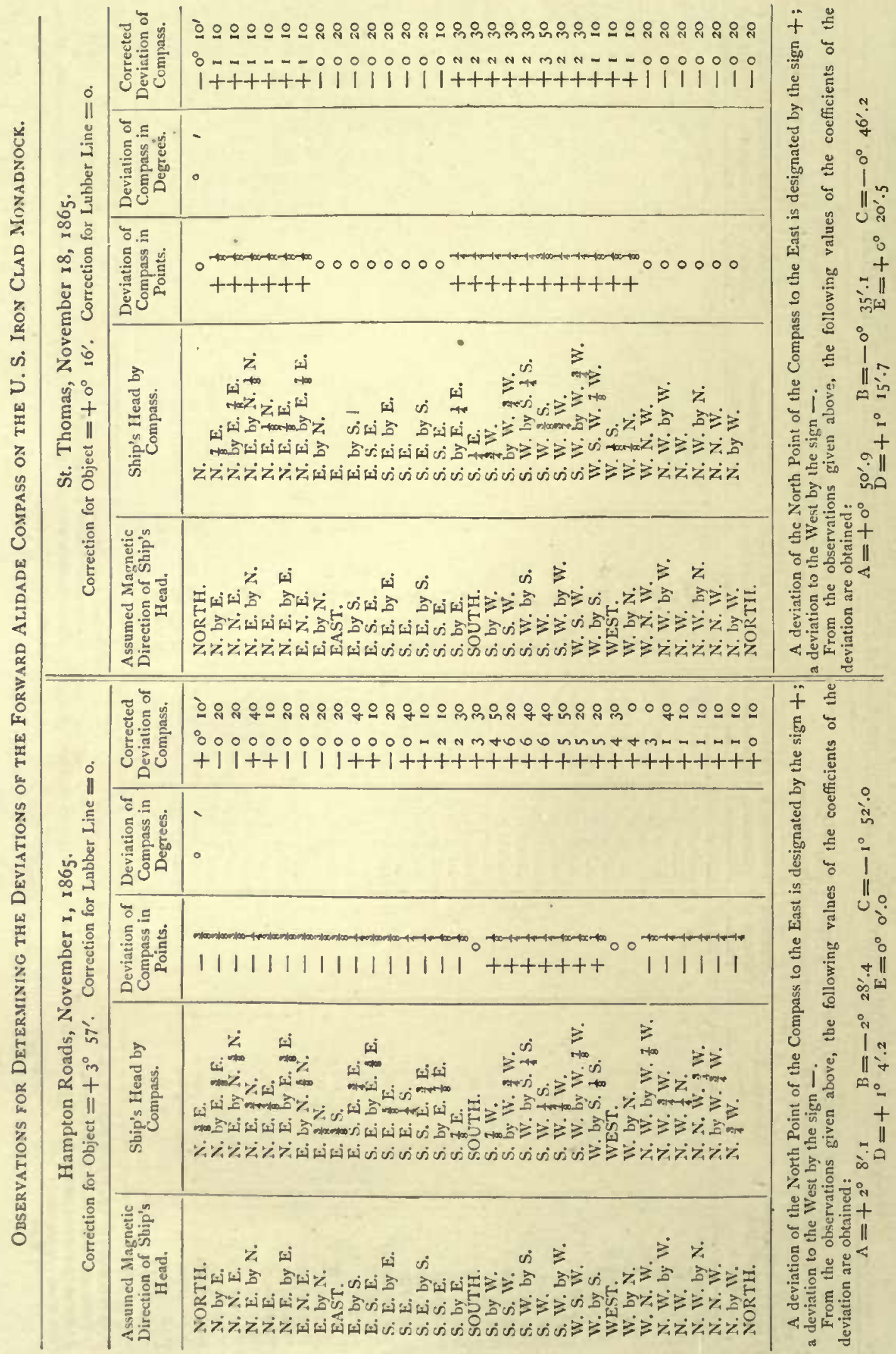




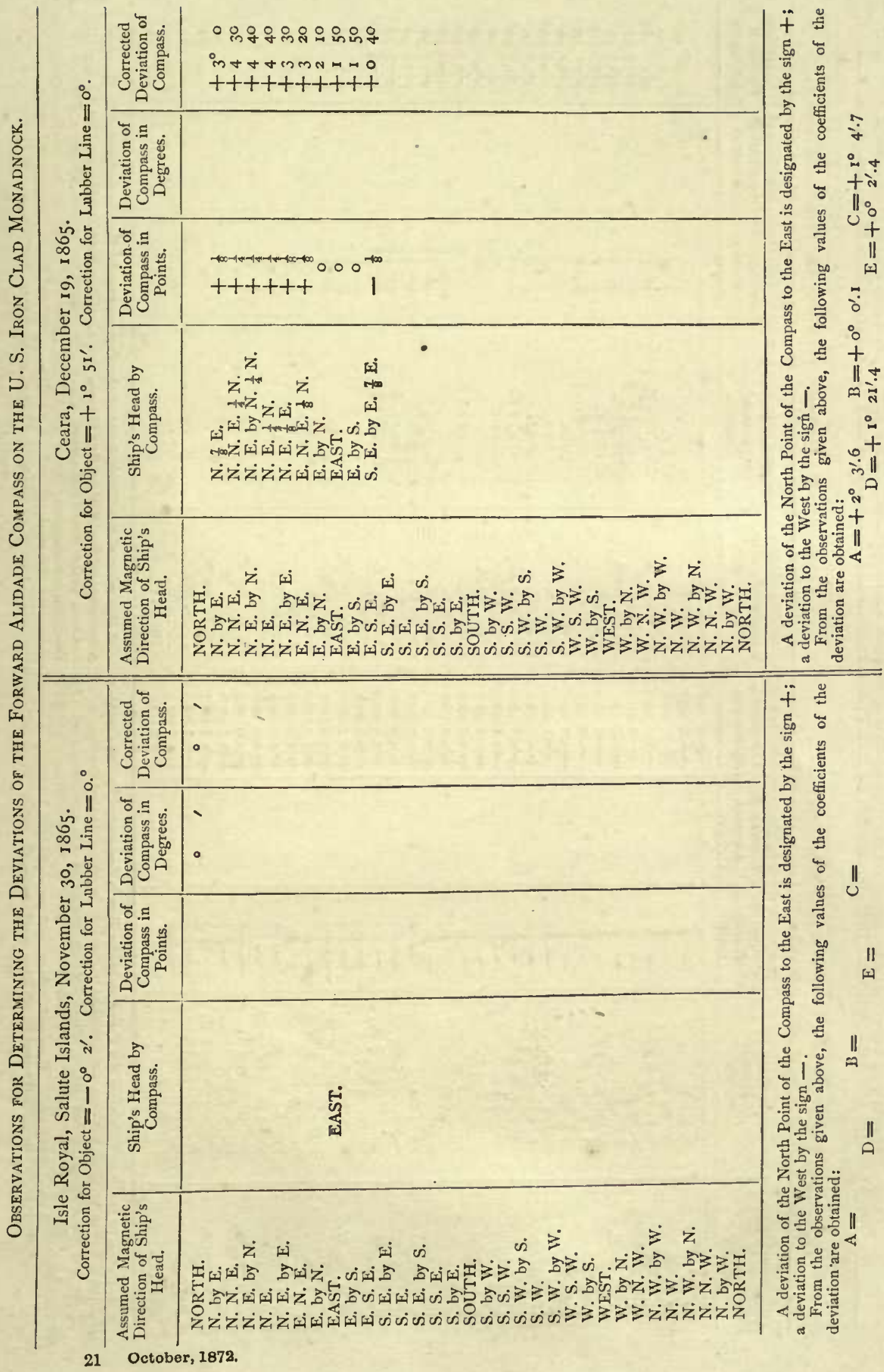




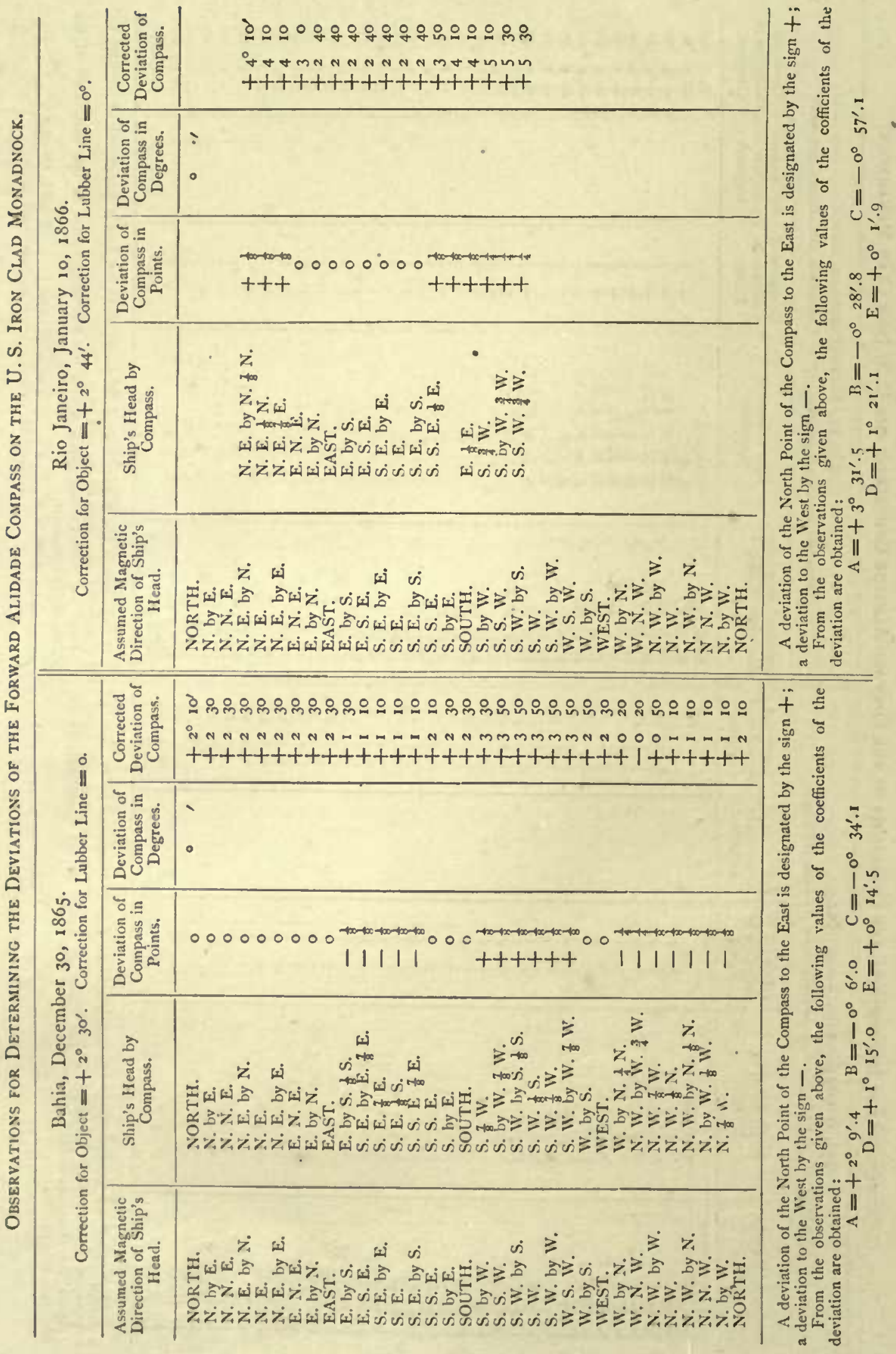




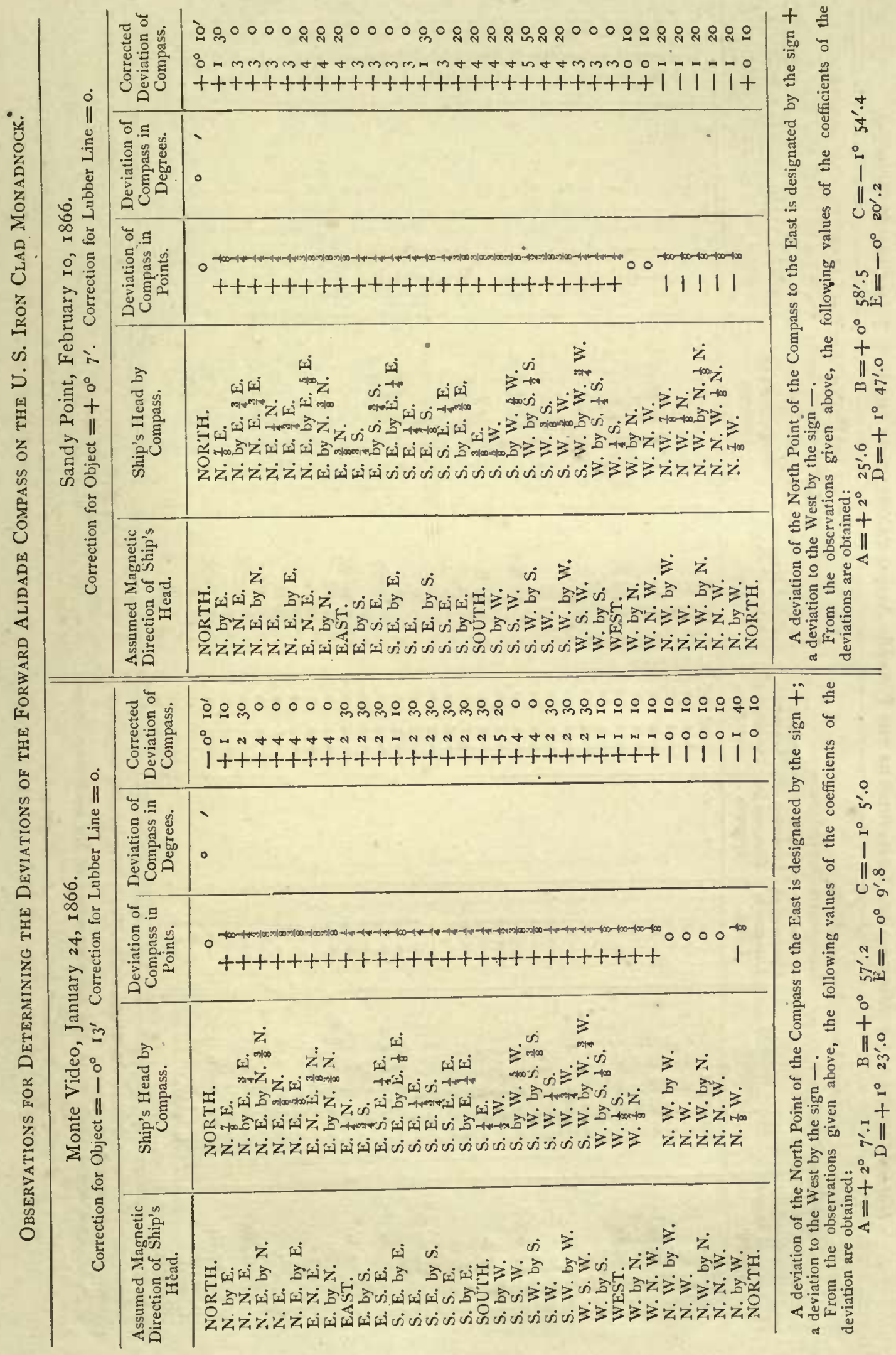




\begin{tabular}{|c|c|}
\hline 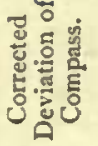 & 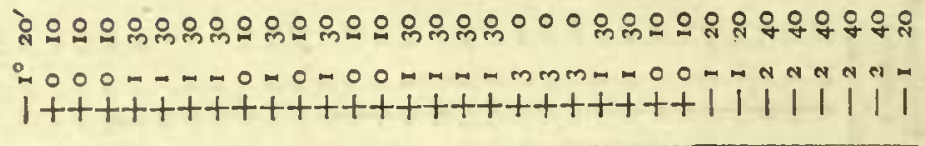 \\
\hline 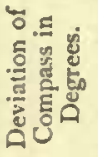 & . \\
\hline
\end{tabular}

落.

: $t+t+t+t+t+t+t+t+1111111$

a

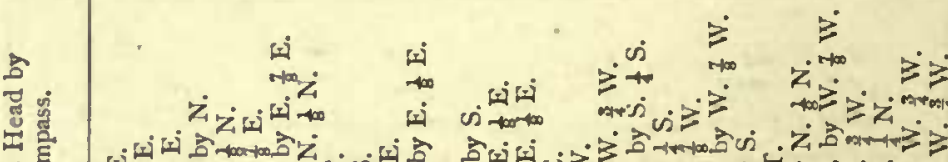

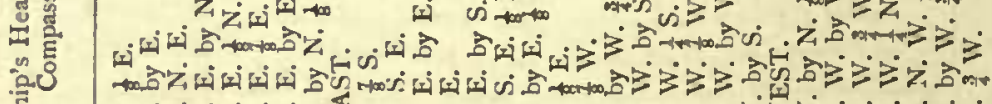

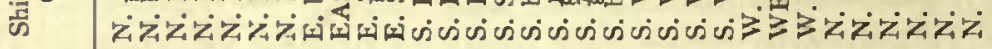

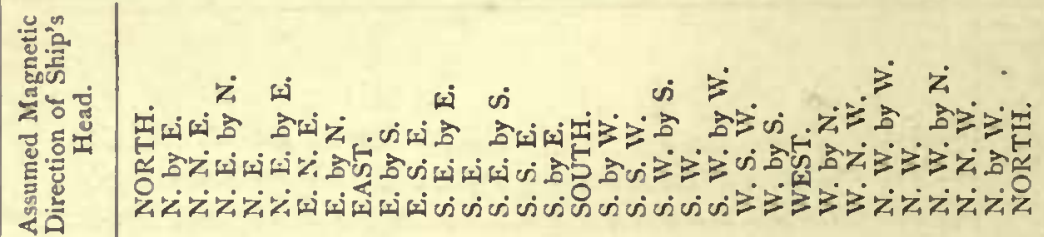

$\ddot{+} \leftrightarrows$

\begin{tabular}{|c|c|}
\hline 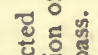 & 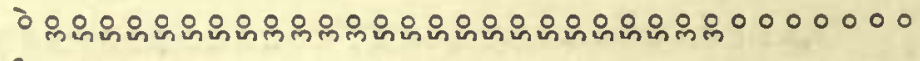 \\
\hline 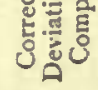 & 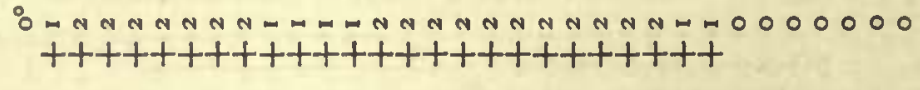 \\
\hline
\end{tabular}

II

.

ธ.

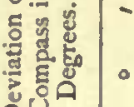

군

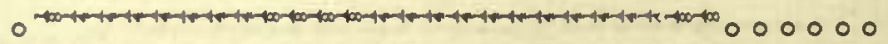

$+t+t+t+t+t+t+t+t+t+t+t+$

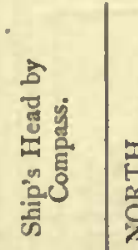

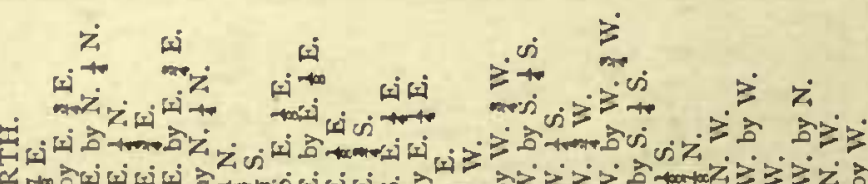

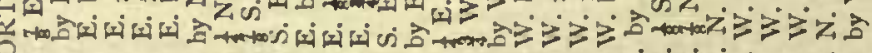

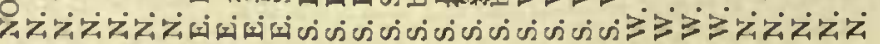

- $\dot{z}$ 近

ค่

vi $\geqslant$

$\geqslant \ddot{z}$

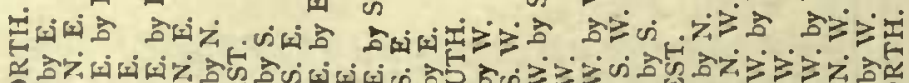

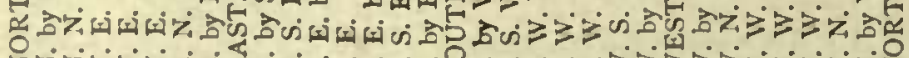

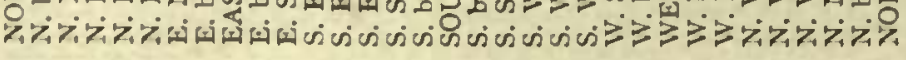

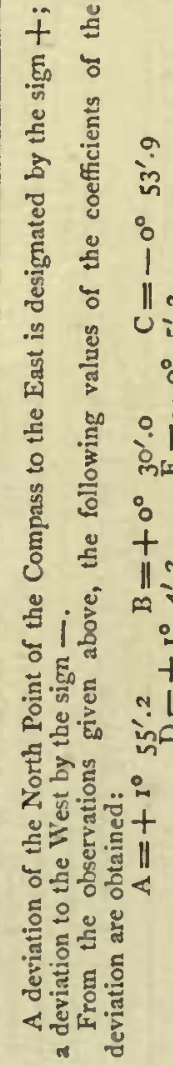




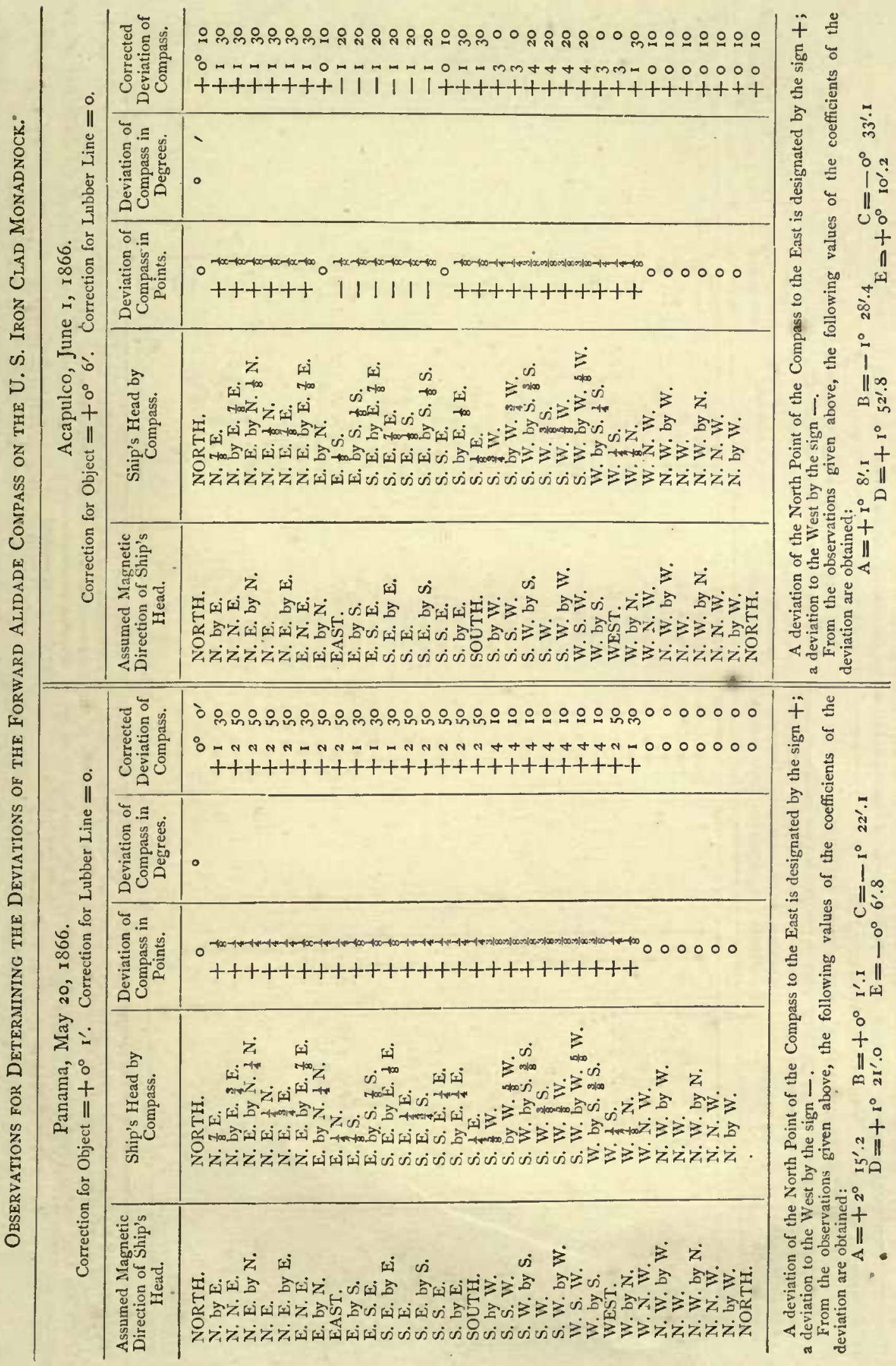




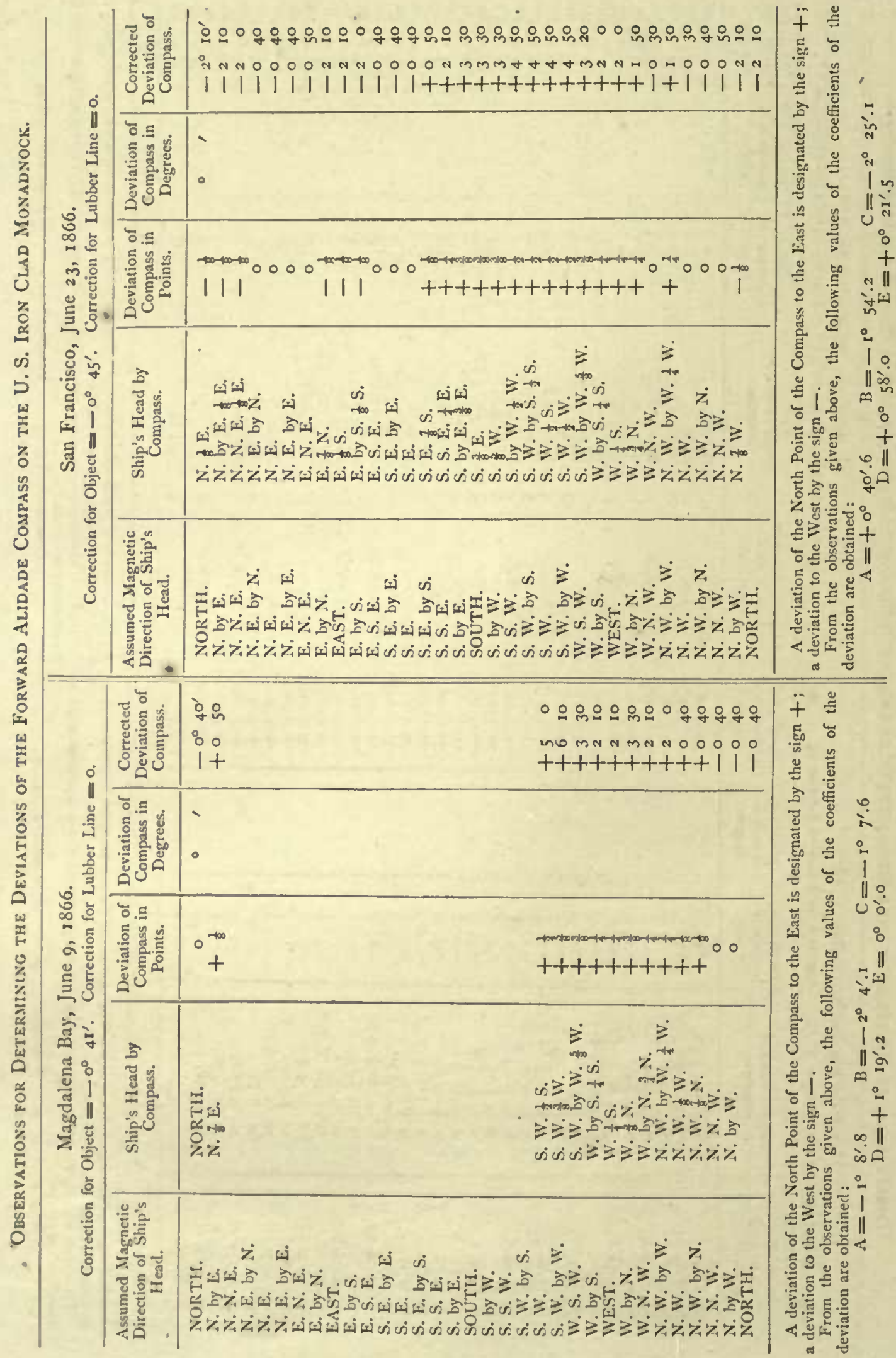




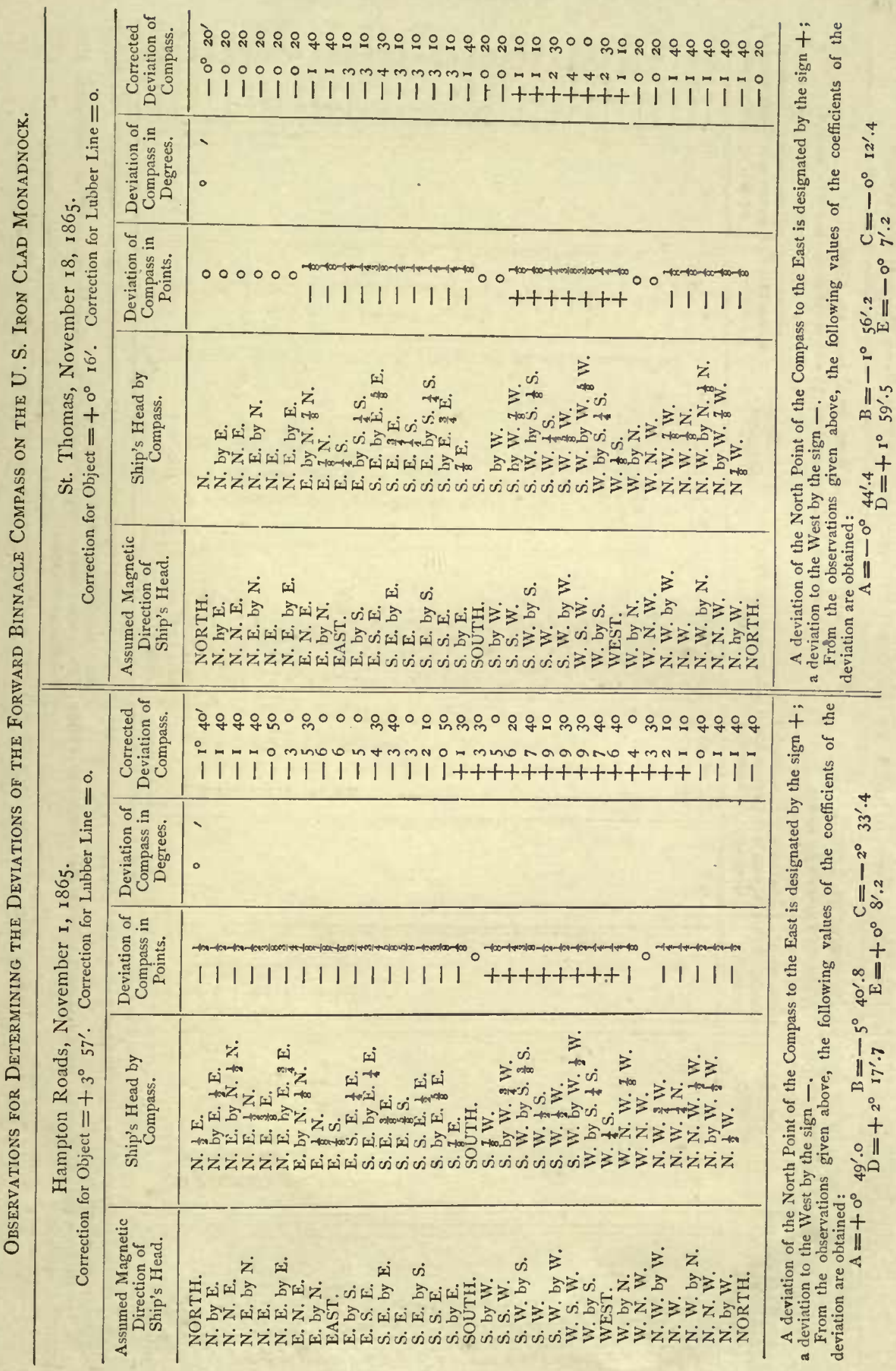




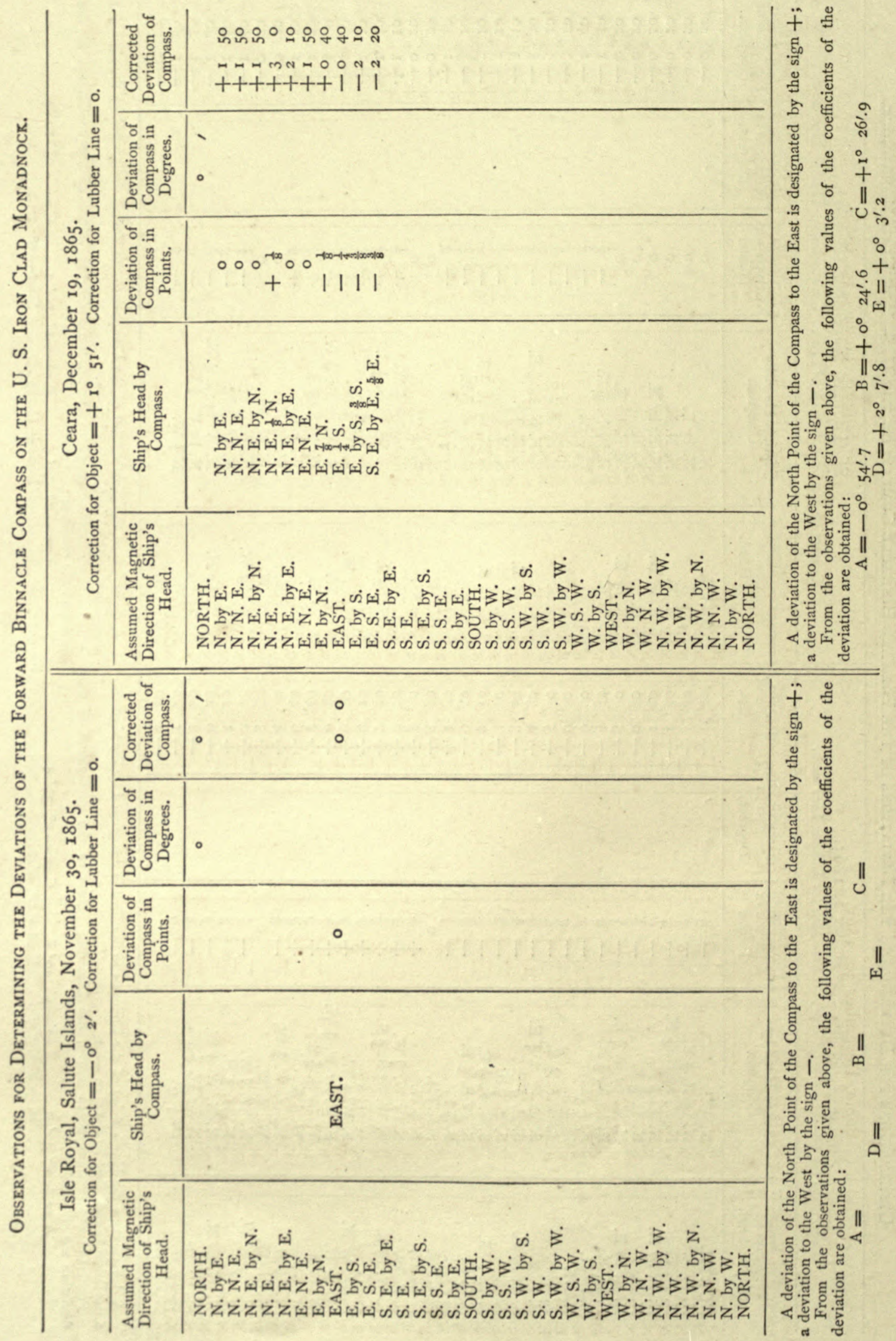




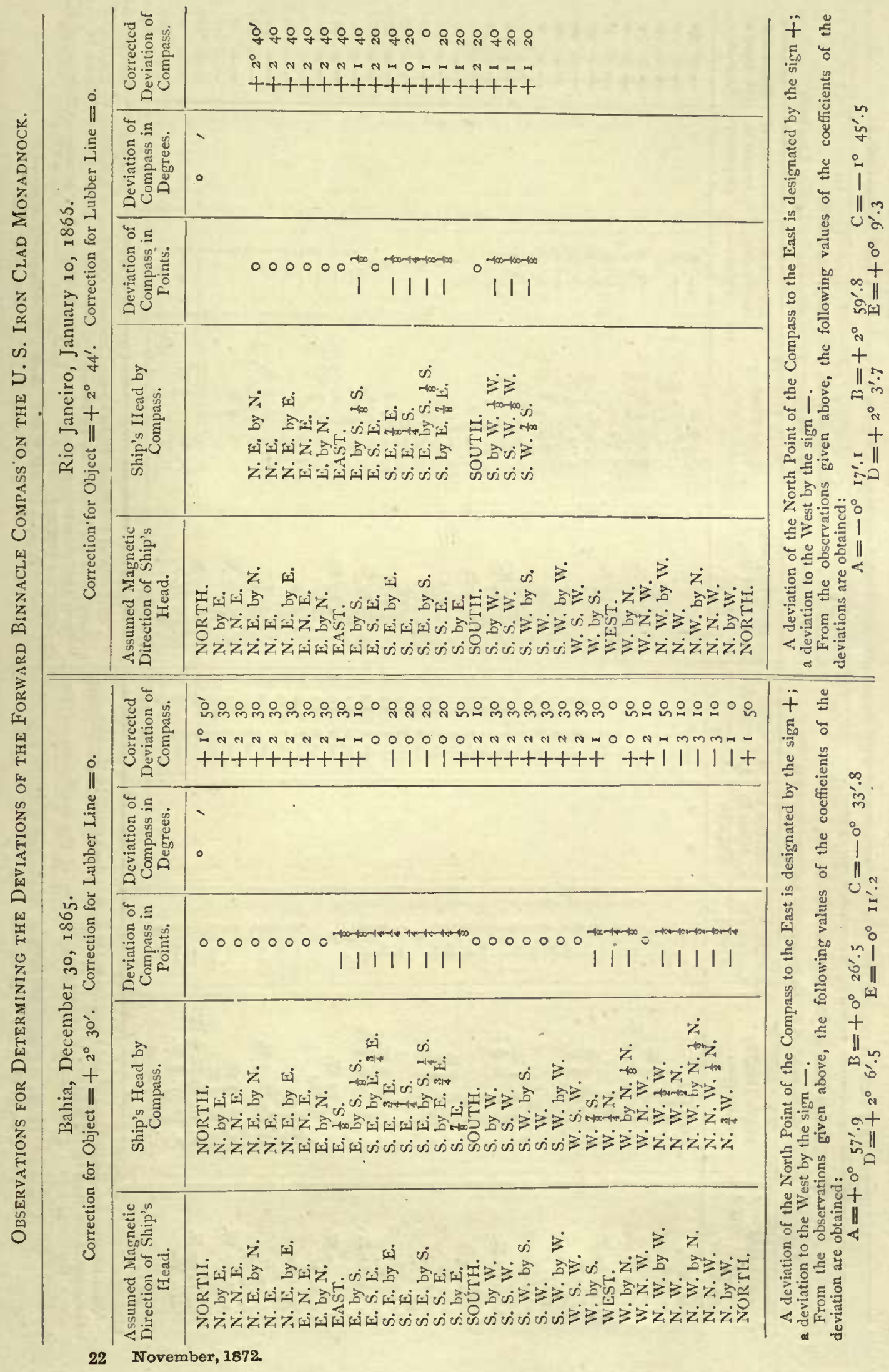




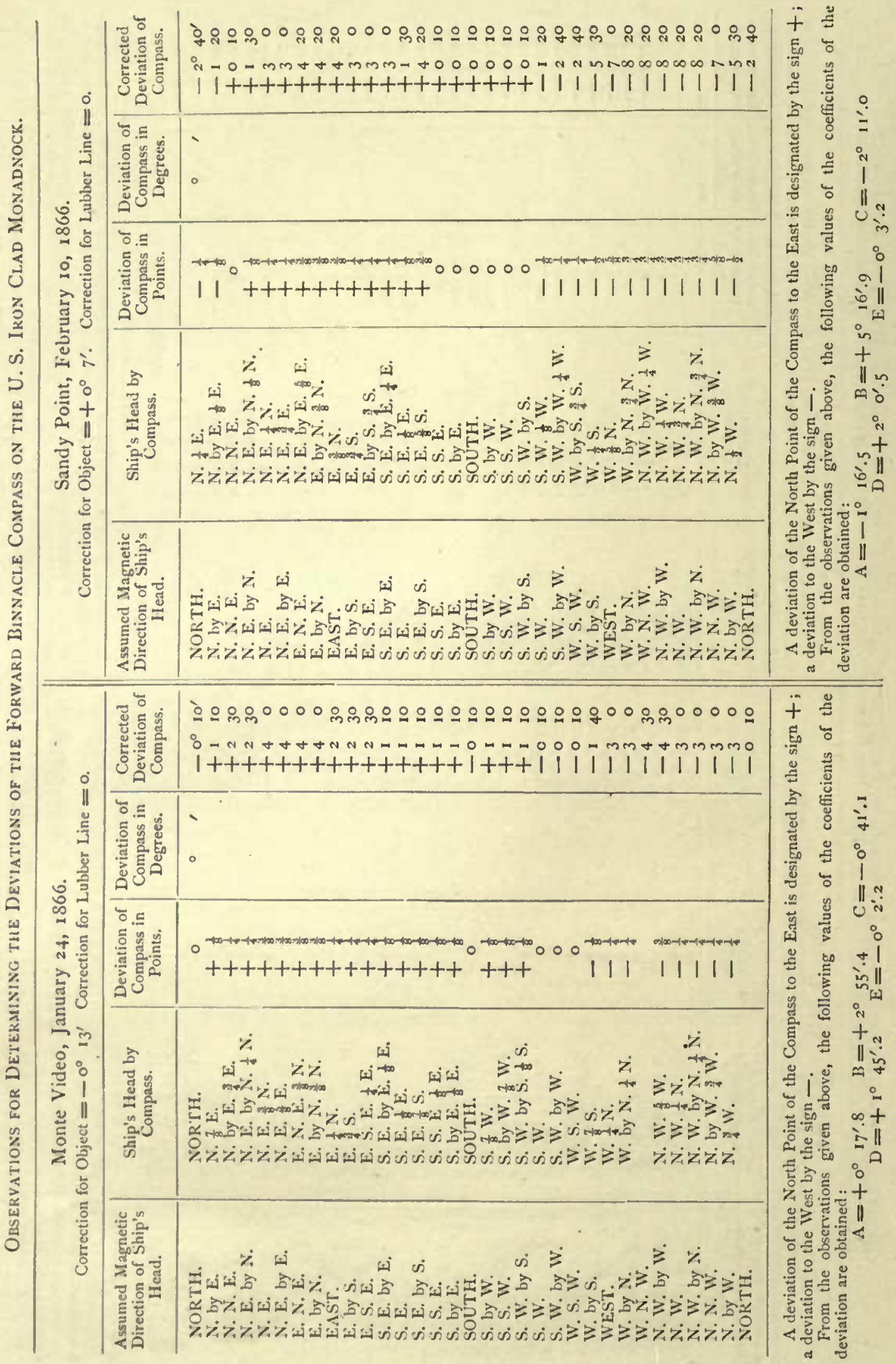









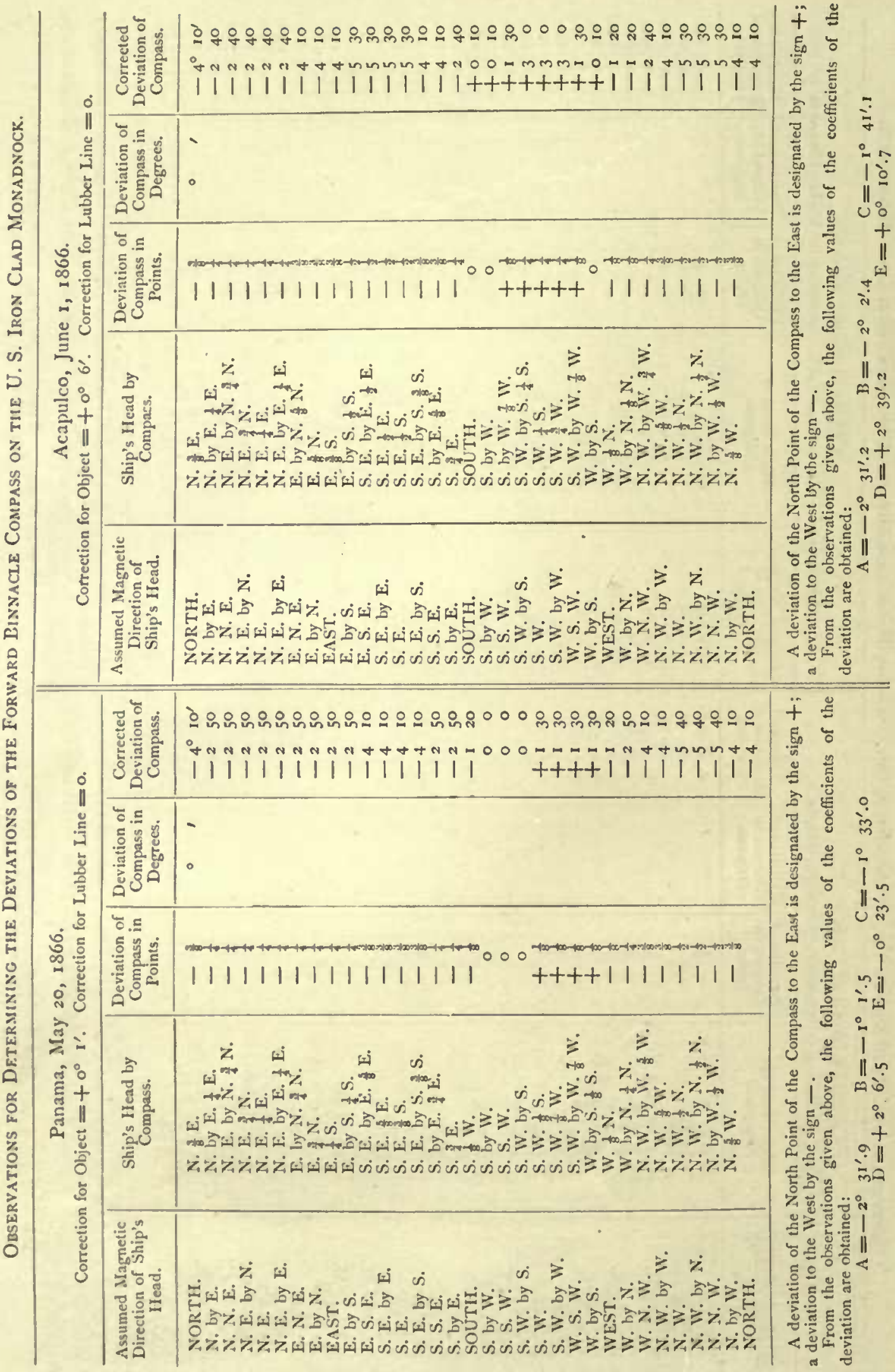




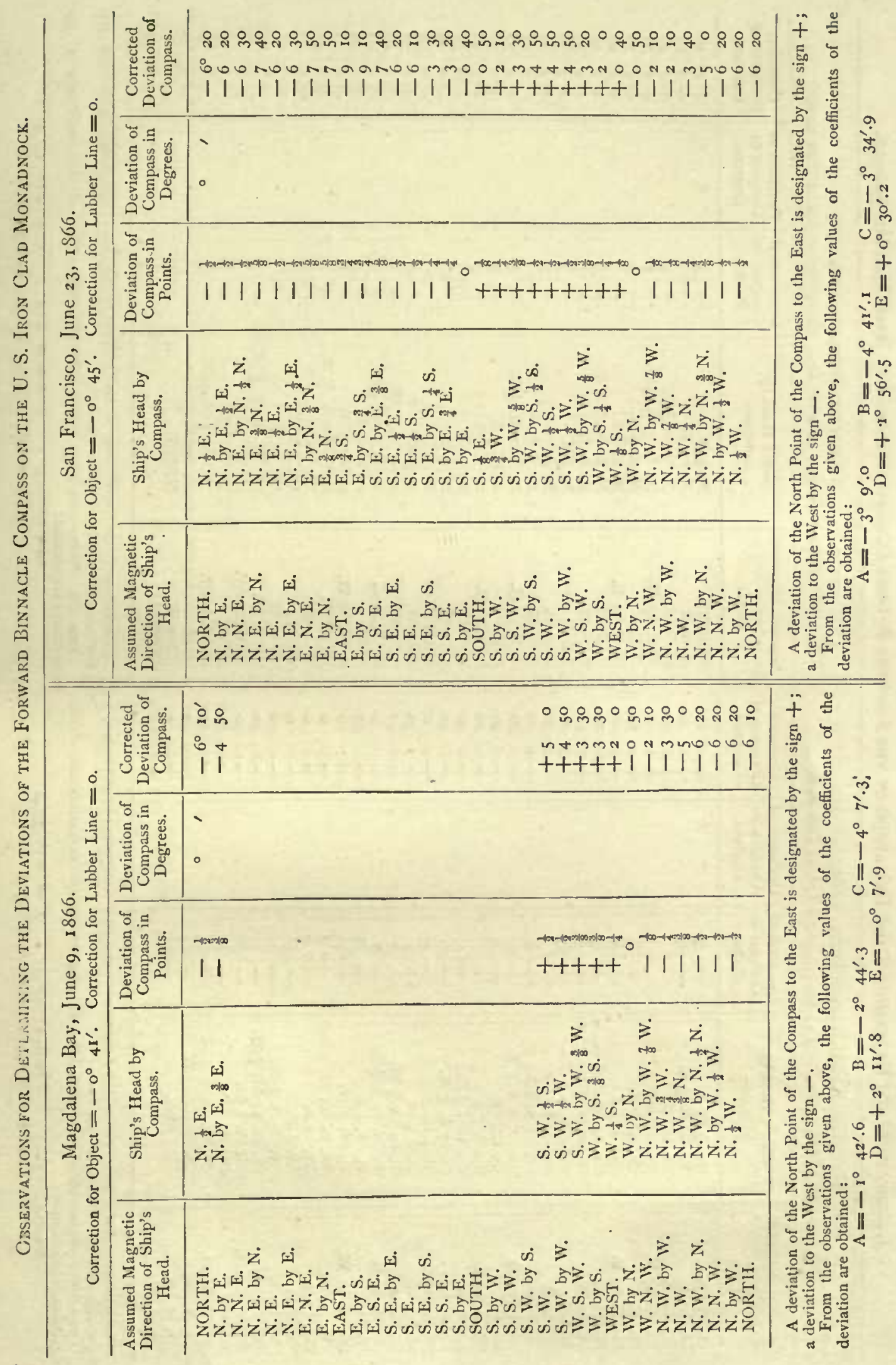




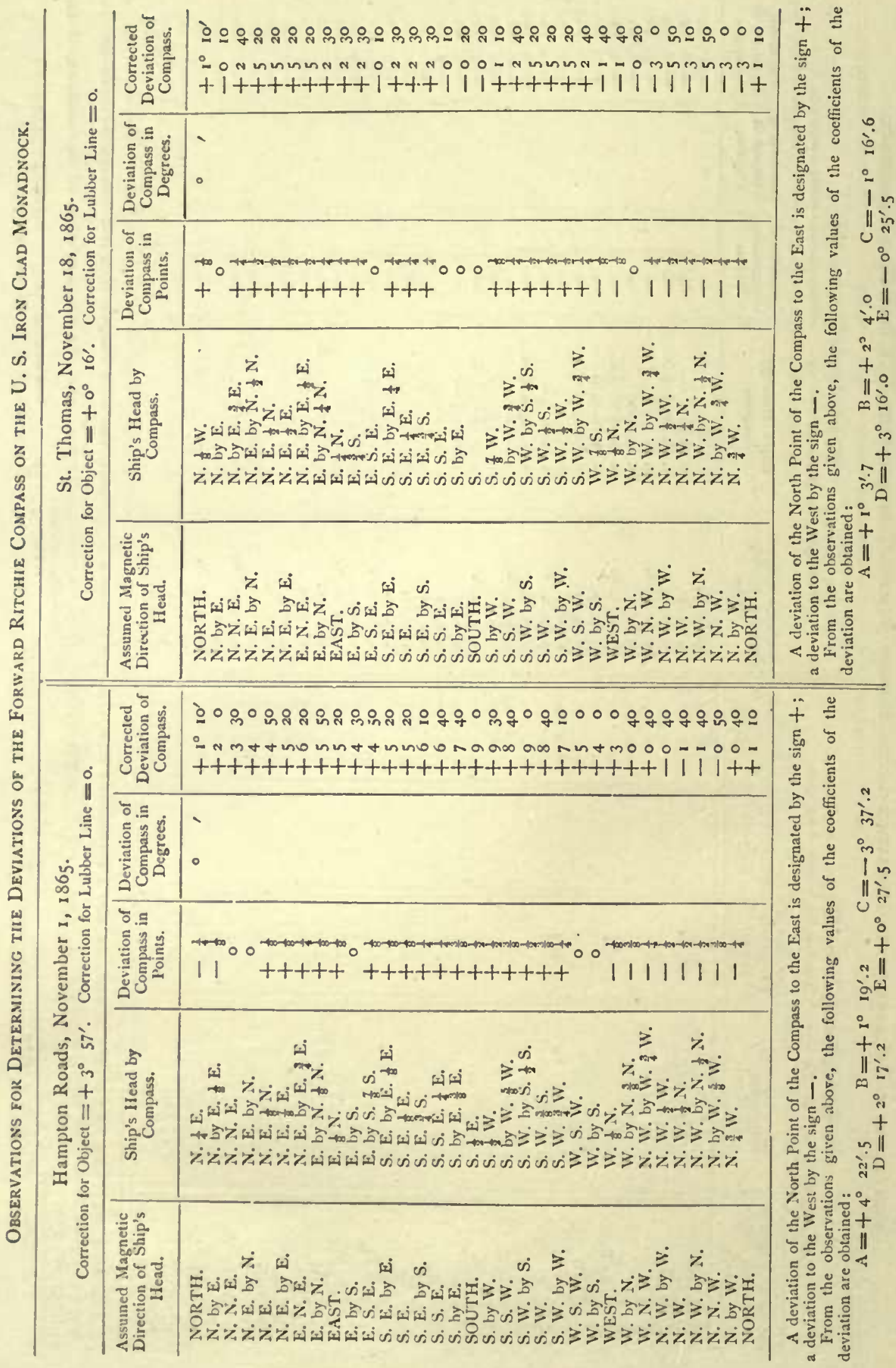




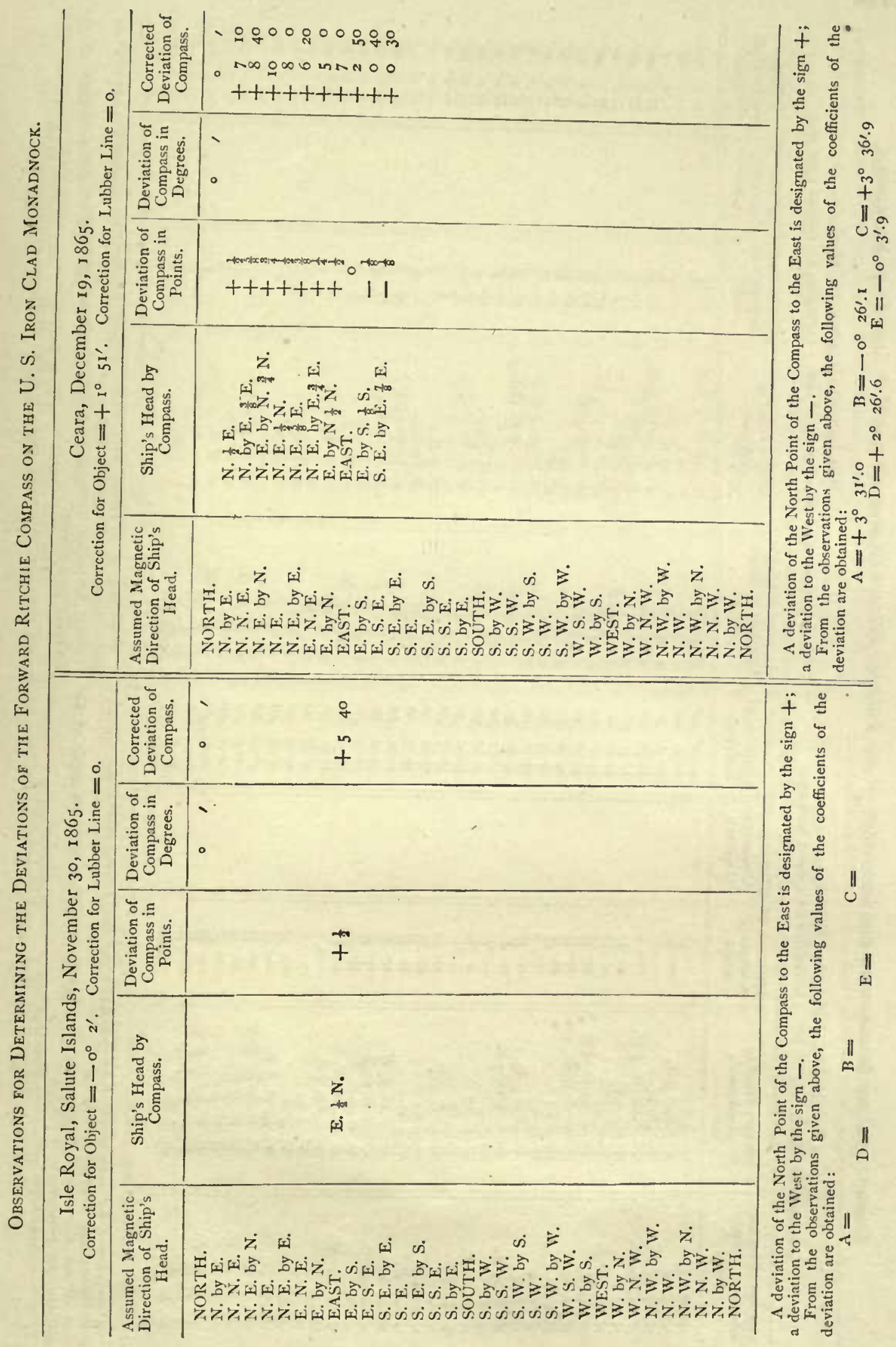









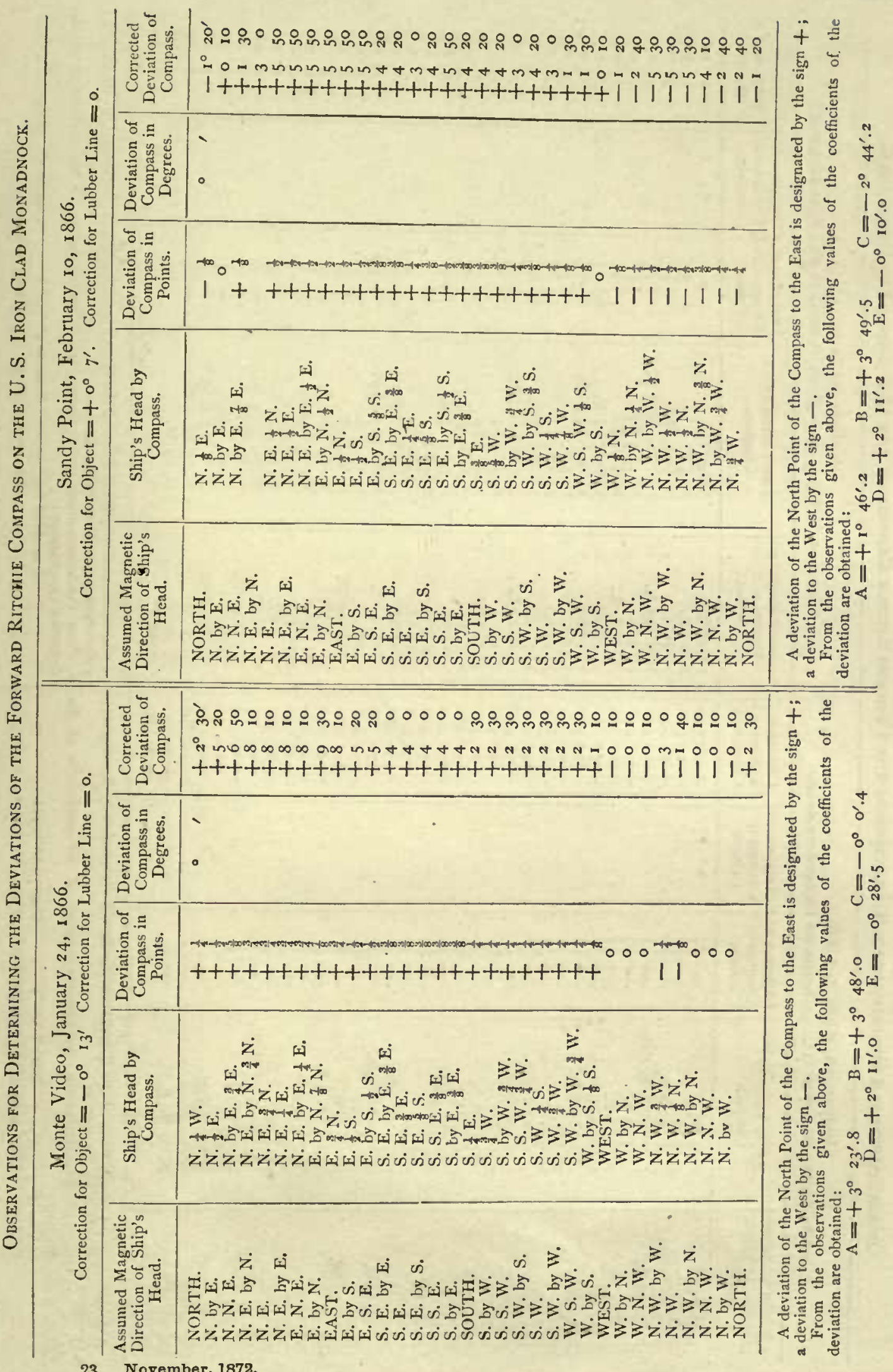




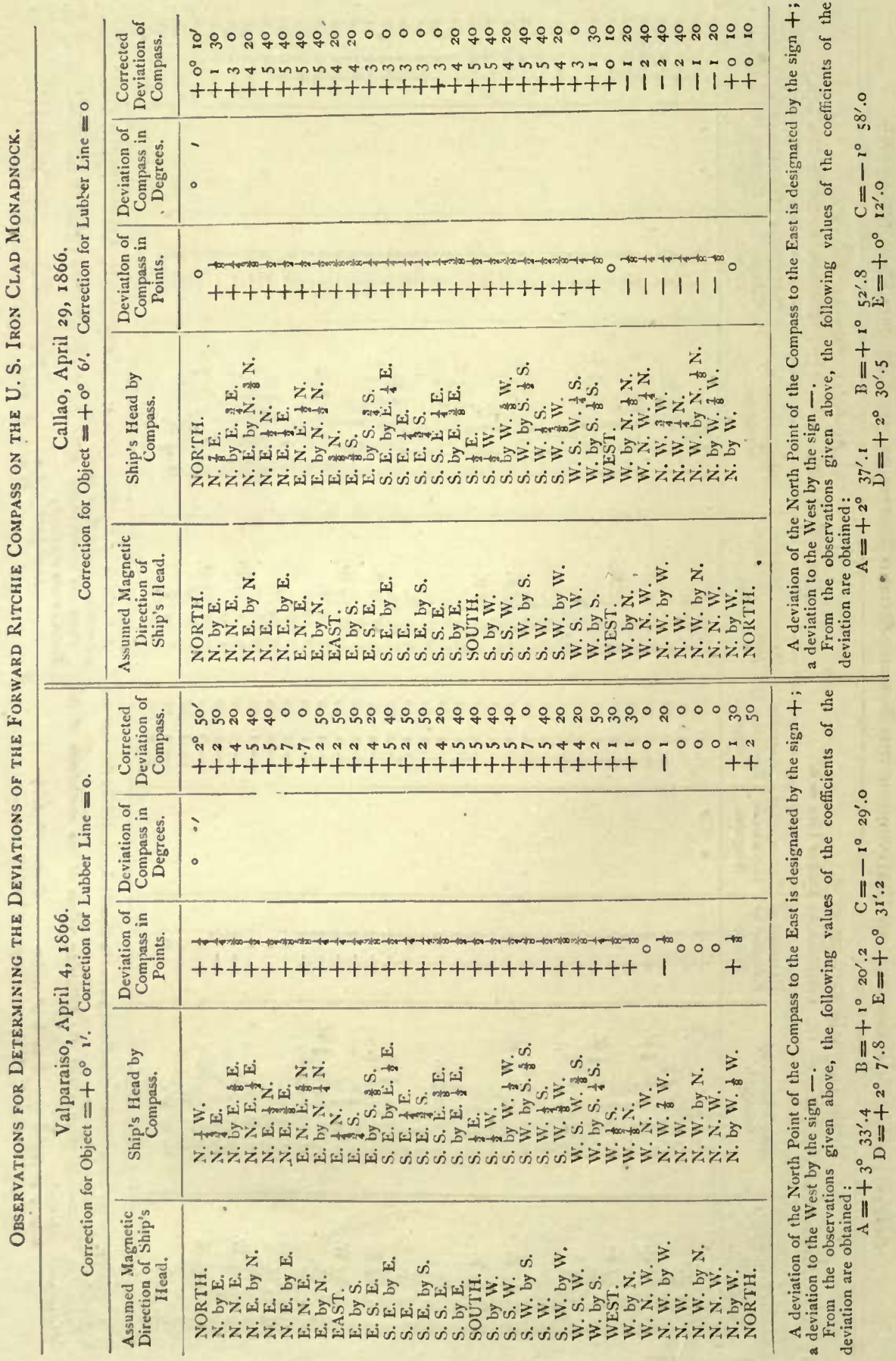




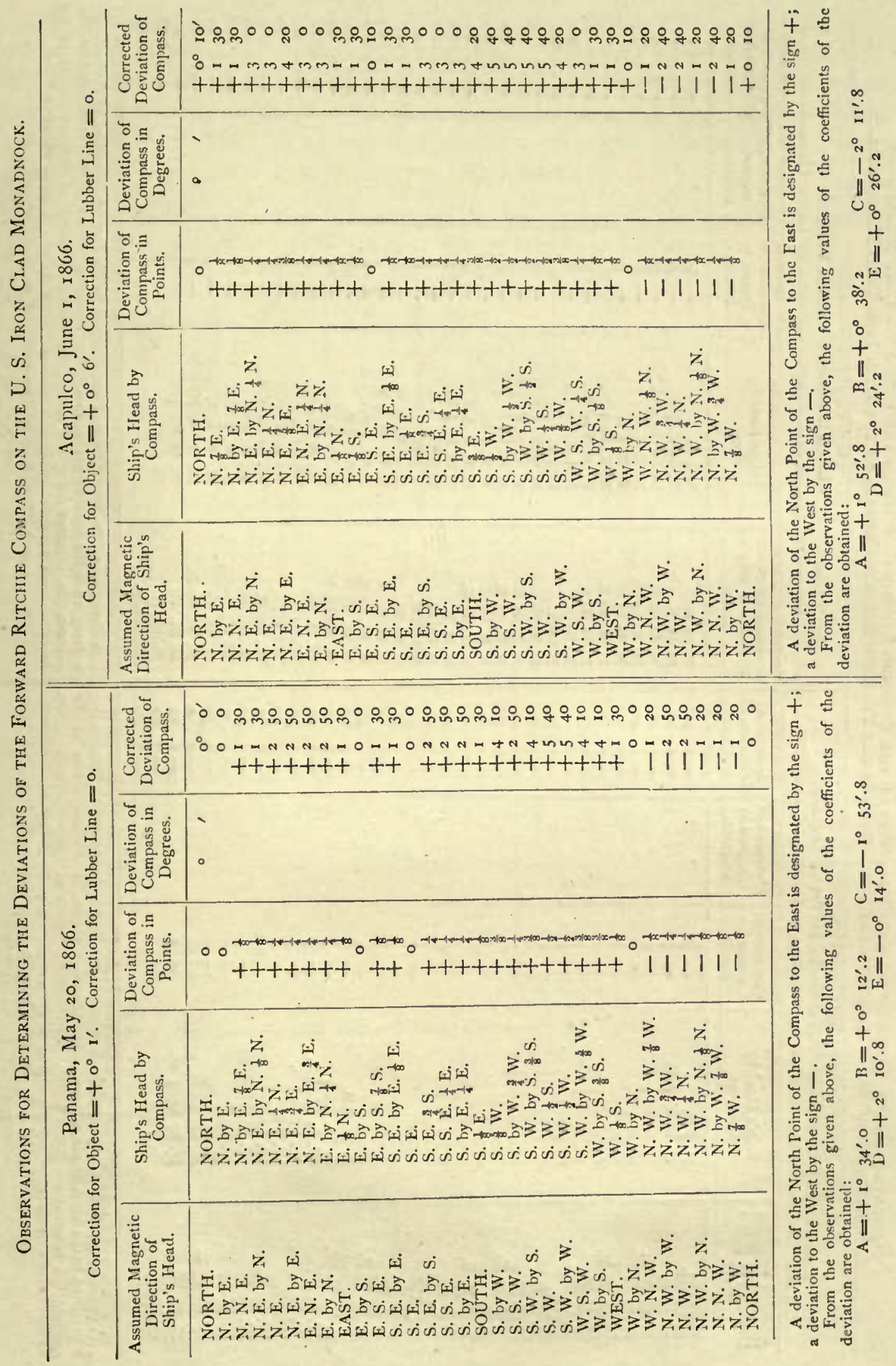




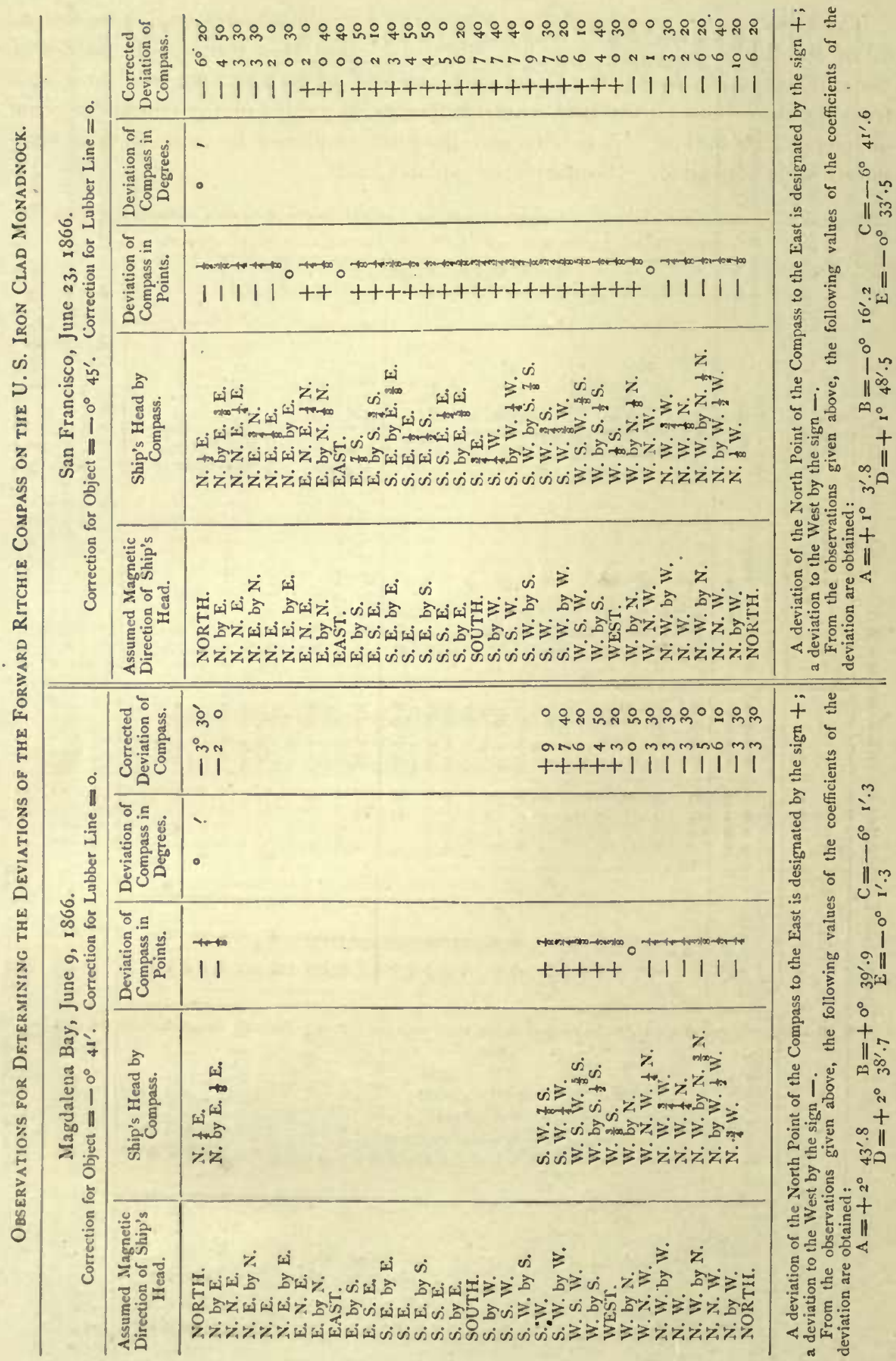


The observations made at stations where the deviations liad been determined on all of the thirty-two points were first discussed. For that purpose the values of the cocfficients $A_{1}, B_{1}, C_{1}, D_{1}, E_{1}$, for each compass, at eacl station, were computed from the deviations on the true magnetic points by means of the equations given on pages 126 to 128. A specimen of the form employed in making these computations is appended. It sufficiently explains itself.

Admiralty Standard Conpass. Computation of Coeficients $B_{1}$ and $C_{1}$, from Deviations observed on 32 Points, on the U. S. Iron Clad Monadnock.

Bahia, December $3^{\circ}, 1865$.

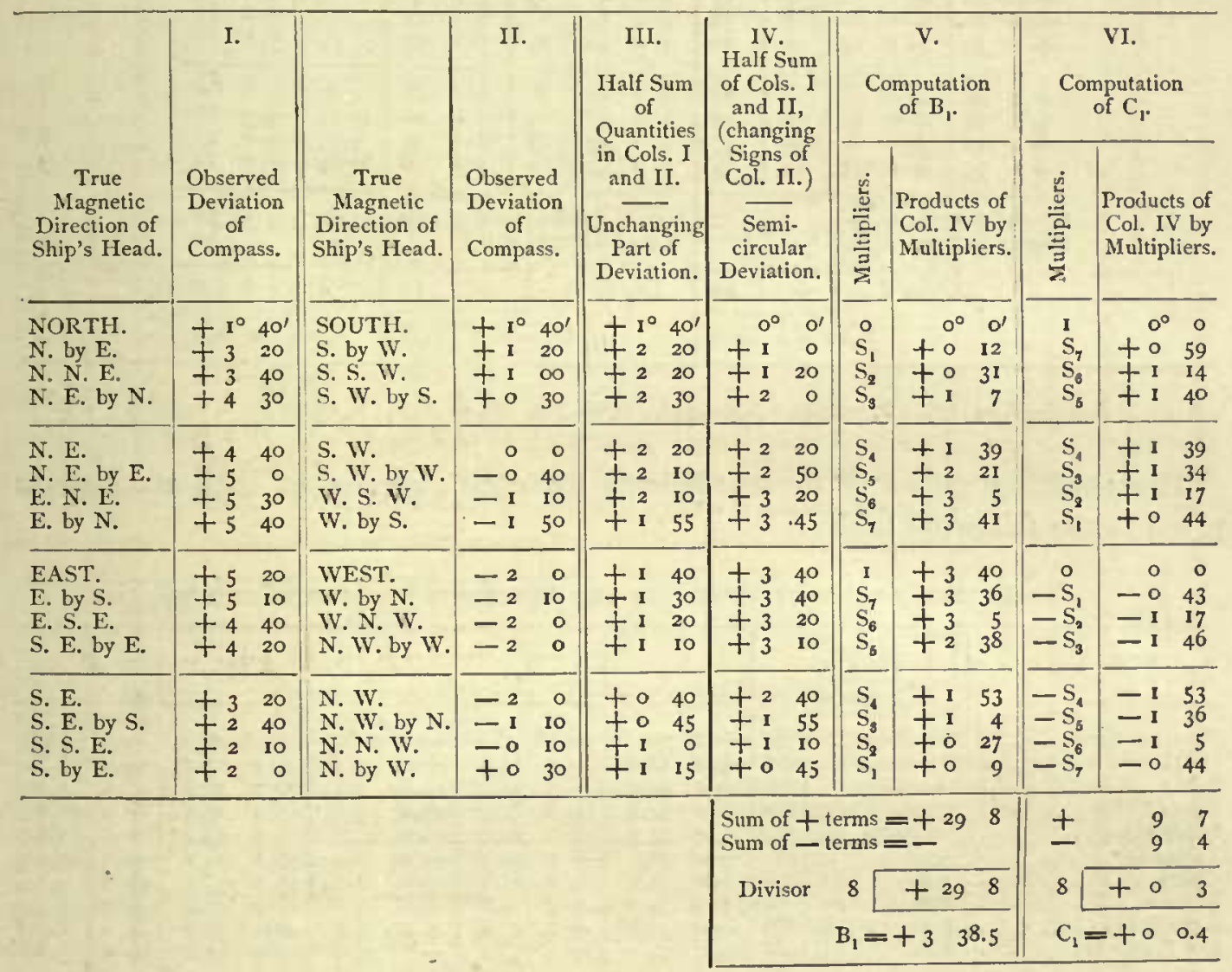

N. B.-Easterly deviations are to be entered in this table with the sign + ; Westerly deviations with the sign - . 
Conputation of Coefficients $A_{1}, D_{1}, E_{1}$, from Deviations observed on 32 Points.

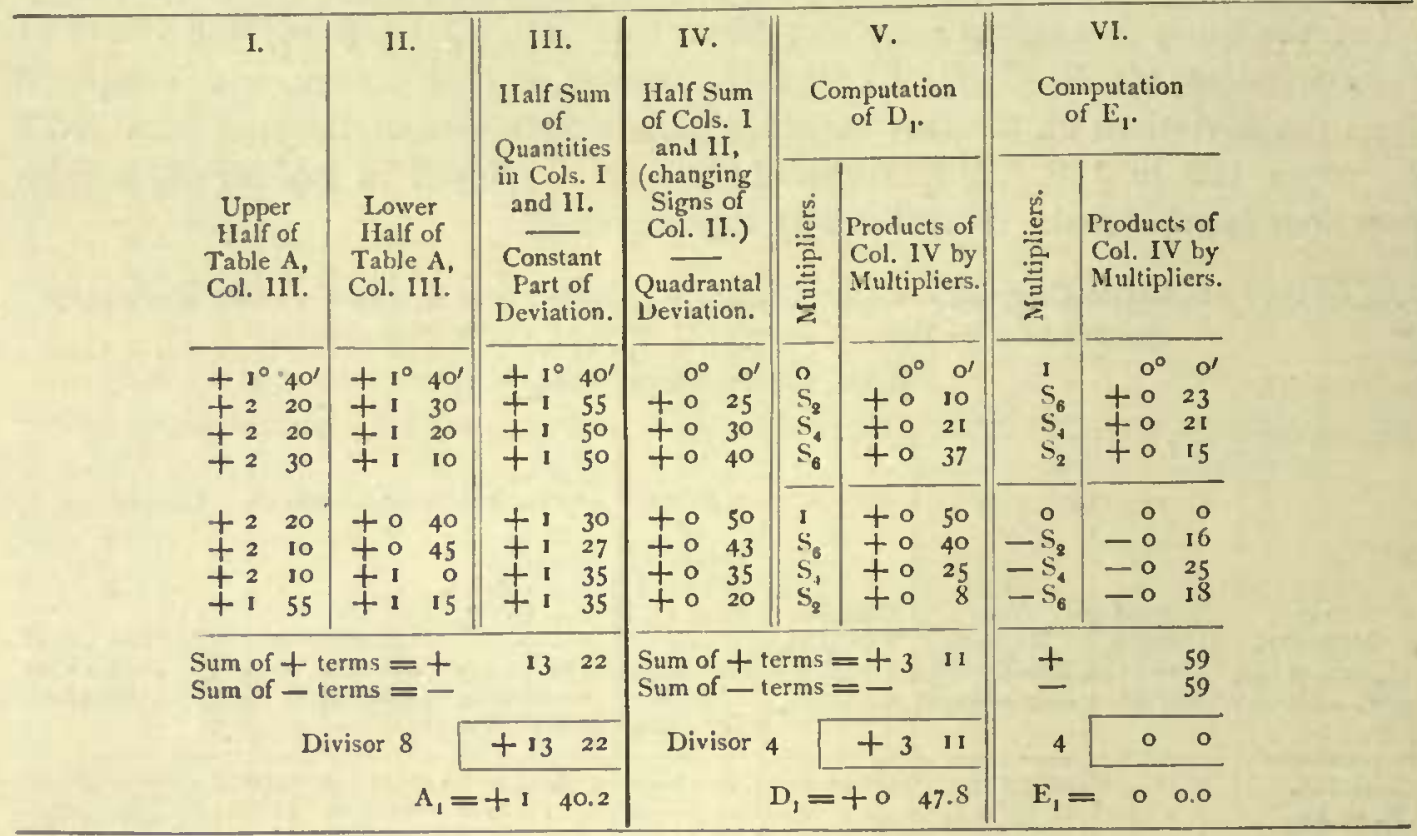

NoTE. $-S_{1}=.195 . \quad S_{8}=.383 . \quad S_{3}=.556 . \quad S_{4}=.707 . \quad S_{8}=.831 . \quad S_{6}=.924 . \quad S_{7}=.98 \mathrm{r}$.

The resulting values of the cocficients for each compass, at cach station, are given in the following tables:

Coefficients of the Deviations of the Admiralty Standard Compass.

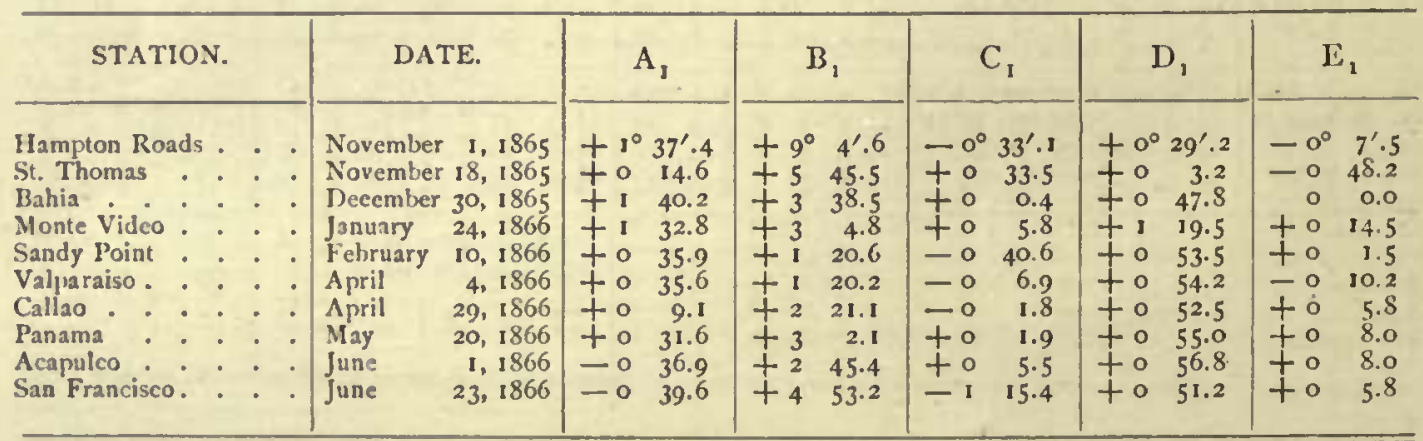

Coefficients of the Deviations of the After Binnacle Compass.

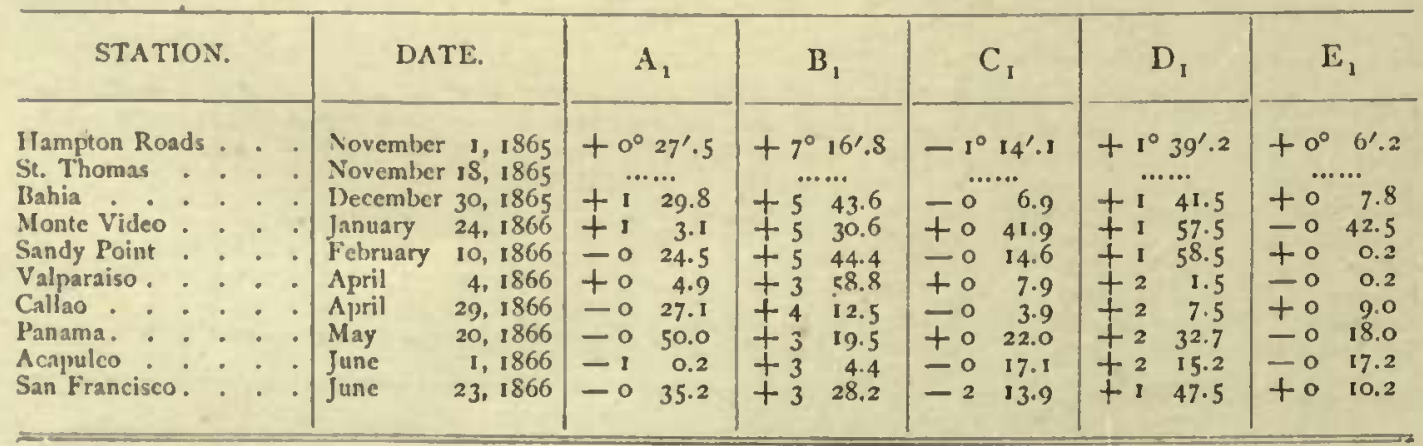


Coefficients of the Deviations of the After Ritchie Compass.

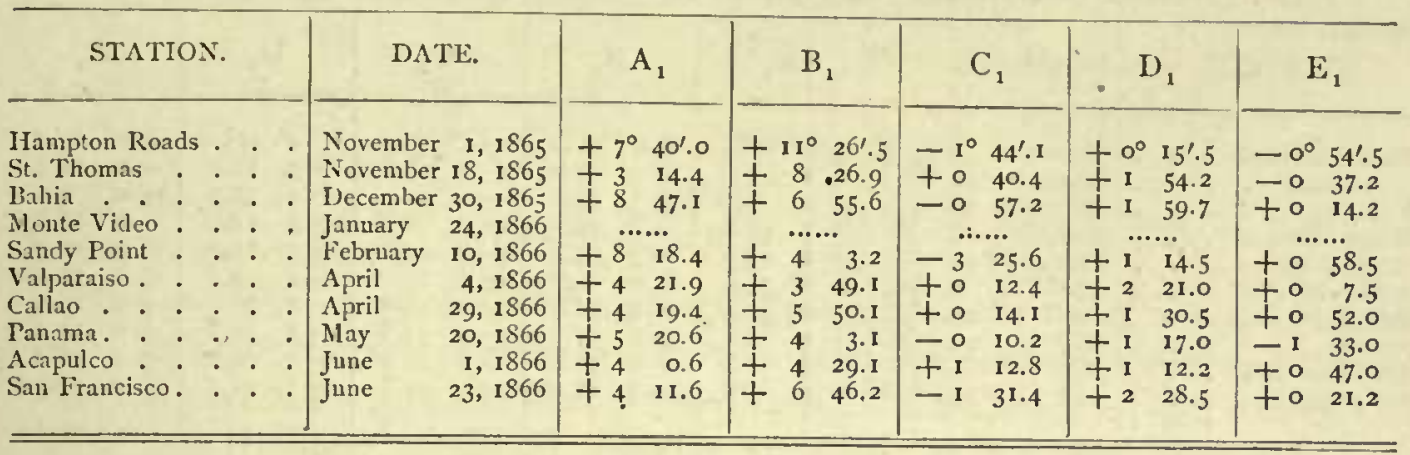

Coefficients of the Deviations of the After Azimuth Compass.

\begin{tabular}{|c|c|c|c|c|c|c|c|c|c|}
\hline STATIOZ & & & & I) ATE. & $A_{1}$ & $B_{i}$ & $\mathrm{C}_{1}$ & $\mathrm{D}_{1}$ & $\mathrm{E}_{\mathrm{I}}$ \\
\hline
\end{tabular}

Coefficients of the Deviations of the Forwird Alidade Compass.

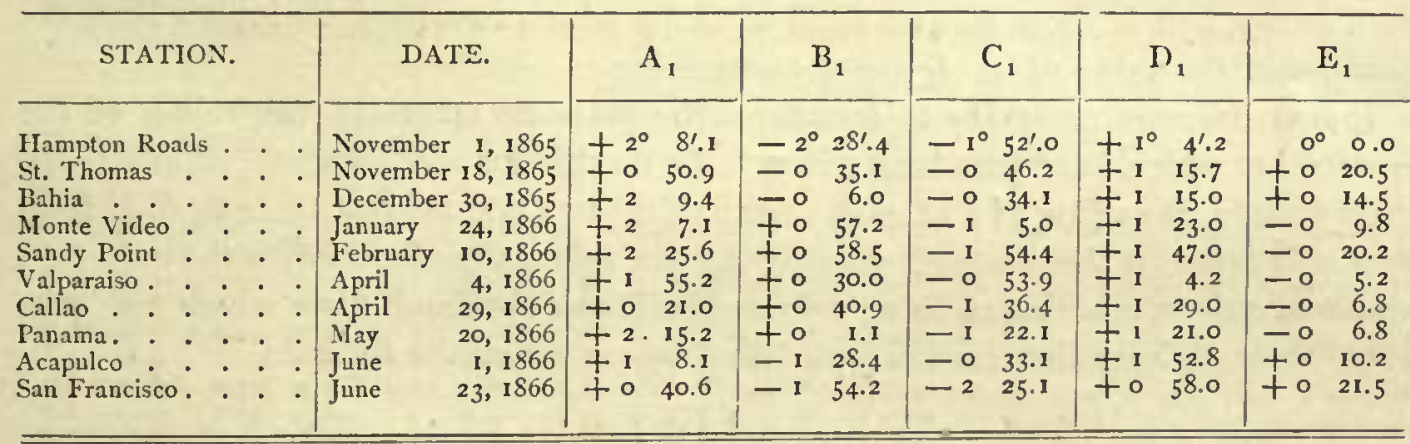

Coefficients of the Deviations of the Forward Binnacle Compass.

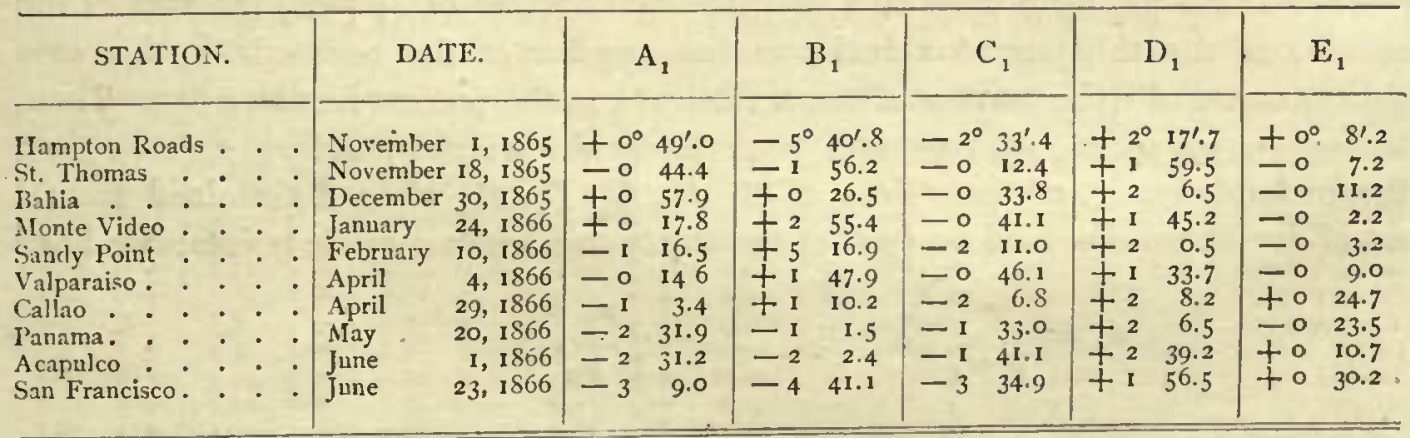


Coefficients of tile Deviations of the Forward Ritchie Compass.

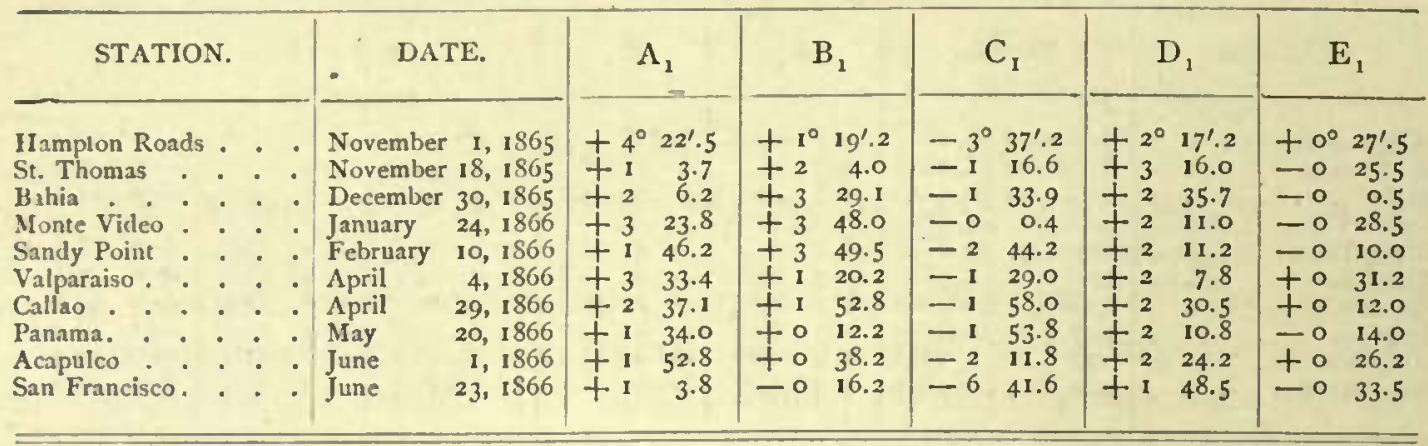

In the case of the Admiralty Standard Compass, for some not very evident reason, the variations in the value of the coefficient. $A_{1}$ are greater than might have been expected. 'The After Binnacle, Forward Alidade, and Forward Bimnacle Compasses were frequently removed from their places, and the fittings were not sufficiently exact to give any certainty of replacing then with their lubber lines always precisely in the same position. This source of error sufficiently accounts for the variations in the values of the $A_{1}$ s belonging to them. 'I'he Forward and After Ritchie Compasses were firmly fixed in their places, and were not removed during the cruise, except at Valparaiso; but the arrangements for reading off their cards were such that an improper position of the eye of the observer might easily introdnce a large parallax, which accounts for the changes in the values of the $A_{1} \mathrm{~s}$ belonging to them. 'The After Azimuth Compass was always taken down after each swing, and as there was, no fixed mark by which to adjust its lubber line, the changes in the value of its $A_{1}$ are not surprising.

It now becomes necessary to determine the probable errors of the values of the coefficients which have just been given. To do this for any compass, at any particular station, the value of $\delta$ at each of the thirty-two points must be computed from the coefficients for that station. Comparing the values thus found with the corrected observel values, a series of thirty-two residuals are obtained, from which the probable error of $\delta$ for that station is deduced by means of the formula

$$
r=0.6745 \sqrt{\frac{[v v]}{m-\mu}}
$$

where $r$ is the probable error of a single observed value of $\delta$; [v ] the sum of the squares of the thirty-two residuals; $m$ the number of the residuals, in this case thirty-two; and $\mu$ the number of the coefficients, in the present instance five. 'Then, letting $p_{A}, p_{B}, p_{C}, p_{D}, p_{E}$, represent respectively the weights, and $r_{A}, r_{B}, r_{C}, r_{D}, r_{E}$, the probable crrors, of the values of $A_{i}, B_{1}, C_{1}, D_{1}, E_{1}$, when determined from a set of deviations observed on each of the thirty-two true magnetic points; we have

$$
r_{A}=\frac{r}{\sqrt{p_{A}}} \quad r_{B}=\frac{r}{\sqrt{p_{B}}}, \quad \text { \&c. }
$$


From the normal equations on page 126, we also have,

$$
\begin{aligned}
& p_{d}=32 \\
& p_{B}=16 \\
& p_{C}=16
\end{aligned}
$$

$$
\begin{aligned}
& p_{D}=16 \\
& p_{E}=16
\end{aligned}
$$

It is therefore evident that the probable errors of $B_{1}, C_{1}, D_{1}$, and $E_{1}$, will all be equal to each other.

The probable error of a single observed value of $\delta$ has been computed in this way, for each compass, at three stations; namely, Bahia, Sandy Point, and l'anama, and the results are given in the following table. The column headed "mean value of $r$ " was obtained by adding together, for each compass, the sum of the squares of the residuals at Bahia, Sandy Point, and Panama; dividing the result by three;

\begin{tabular}{|c|c|c|c|c|c|c|c|}
\hline \multirow{2}{*}{\multicolumn{2}{|c|}{ Compass. }} & \multicolumn{3}{|c|}{ Value of $r$. } & \multirow{2}{*}{$\begin{array}{c}\text { Mean } \\
\text { value of } r \text {. }\end{array}$} & \multirow{2}{*}{$\frac{r}{\sqrt{3^{2}}}$} & \multirow{2}{*}{$\frac{r}{\sqrt{16}}$} \\
\hline & & Bahia. & Sandy Point. & Panama. & & & \\
\hline Admiralty Standard & & $\pm 9^{\prime} .8$ & $\pm \mathrm{r} 2^{\prime} .2$ & $\pm x \mathrm{I}^{\prime} \cdot 3$ & $\pm \mathrm{Ir}^{\prime} . \mathrm{I}$ & $\pm \quad 2^{\prime} .0$ & $\pm \quad 2^{\prime} .8$ \\
\hline After Binnacle. & & \pm 25.8 & \pm 20.1 & \pm 26.2 & \pm 24.2 & $4 \cdot 3$ & \pm 6.1 \\
\hline After Ritchie & 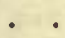 & \pm 30.6 & $\pm 5^{6.6}$ & $\pm 3^{8.8}$ & $\pm 43 \cdot 4$ & 7.7 & \pm 10.8 \\
\hline After Azimuth . & & $\pm 39 \cdot 3$ & \pm 51.1 & \pm 32.6 & \pm 41.7 & $7 \cdot 4$ & \pm 10.4 \\
\hline Forward Alidade . & $\bullet^{\circ}$ & \pm 19.0 & \pm 24.5 & \pm 23.6 & \pm 22.5 & 4.0 & \pm 5.6 \\
\hline Forward Binnacle. & . . & \pm 40.2 & $\pm 3^{1.2}$ & $\pm 25 \cdot 3$ & $\pm 3^{2.8}$ & \pm 5.8 & \pm 8.2 \\
\hline Forward Ritchie . & .. & \pm 59.7 & $\pm 3^{0.2}$ & \pm 37.8 & \pm 44.4 & \pm 7.8 & $\pm 11 . x$ \\
\hline
\end{tabular}
and then computing the value of $r$ from the mean value of $[v v]$ thus found. The column headed " $\frac{r}{\sqrt{32}}$ " gives the probable error of $A_{1}$; and the column headed " $\frac{r}{\sqrt{16}}$ " gives the probable error of $B_{1}, C_{3}, D_{1}$, and $E_{1}$, for each compass, when these coefficients have been computed from a set of deviations observed on thirty-two points.

As an incidental result, this table shows that for ordinary steering compasses (such as the Forward Alidade, Forward Binnacle, and After Binnacle) when read to the nearest eighth of a point, the probable accidental error of a single reading is about half a degree; for Ritchie Monitor Compasses (such as the Forward and After Ritchie) when read to the nearest eighth of a point, the probable accidental error of a single reading is abont three-quarters of a degree; and for Admiralty Standard Compasses, read to the nearest ten minutes, the probable accidental error of a single reading is about eleven minutes.

From the mathematical theory of the deviations of the compass, given in a preceding part of this section, we have

and also

$$
\mathfrak{B}=B_{1}-A_{1} C_{1}
$$

Hence

$$
\mathfrak{B}=\frac{c}{\lambda} \tan \theta+\frac{P}{\lambda} \times \frac{1}{H}
$$

$$
0=-B_{1}+A_{1} C_{1}+\frac{c}{\lambda} \tan \theta+\frac{P}{\lambda} \times \frac{1}{H}
$$


But as $P$ is liable to undergo a slow change, we introduce a term depending upon the time, and the equation becomes

$$
0=-B_{1}+A_{1} C_{1}+\frac{c}{\lambda} \tan \theta+\frac{P}{\lambda} \times \frac{1}{H}+\frac{\Delta P}{\lambda} \times \frac{t}{H}
$$

where $\Delta P$ is the change of the value of $P$ in one day, and $t$ is the elapsed time in days, counted from November 1st, 1865.

We have further

and also

$$
\mathfrak{E}=C_{1}+A_{1} B_{1}
$$

Hence

$$
\Subset=\frac{f}{\lambda} \tan 0+\frac{Q}{\lambda} \times \frac{1}{H}
$$

$$
0=-C_{1}-A_{1} B_{1}+\frac{f}{\lambda} \tan \theta+\frac{Q}{\lambda} \times \frac{1}{H}
$$

But as $Q$ is liable to undergo a slow change, we introduce a term depending upon the time, in the same manner as above, and the equation becomes

$$
0=-C_{1}-A_{1} B_{1}+\frac{f}{\lambda} \tan \theta+\frac{Q}{\lambda} \times \frac{1}{H}+\frac{\Delta Q}{\lambda} \times \frac{t}{H}
$$

Each observed value of $B_{1}$ and $C_{1}$ gives two equations of condition; one of the same form as (17), the other of the same form as (18); and from all the equations of condition thus obtained for any compass, the values of $A_{1}, \frac{c}{\lambda}, \frac{P}{\lambda}, \frac{\Delta P}{\lambda}, \frac{f}{\lambda}, \frac{Q}{\lambda}$, and $\frac{\Delta Q}{\lambda}$, for that compass, have been computed by the method of least squares.

The value of $A_{1}$ thus found we will designate as the "true $A_{1}$ " in order to distinguish it from the "apparent $A_{1}$ " obtained directly from the corrected observed values of the deviations. The value of the true $A_{1}$ depends only upon the value of the constants $a, b, d$, and $e$, in equations (1) and (2); but the apparent $A_{1}$ is made up of the true $A_{1}$, together with any errors that may exist in the placing of the lubber line of the compass, or in the determination of the true magnetic bearing of the distant object used as an azimuth mark in swinging the ship.

The equations of condition, formed in the manner just explained; the normal equations derived from them by the method of least squares; and the resulting values of the constants, $A_{1}, \frac{c}{\lambda}, \frac{P}{\lambda}, \frac{\Delta P}{\lambda}, \frac{f}{\lambda}, \frac{Q}{\lambda}$, and $\frac{\Delta Q}{\lambda}$, for each compass are as follows: the values of $B_{1}$ and $C_{1}$ being expressed in parts of radius. 
Admiralty Standard Compass.

Equations of Condition.

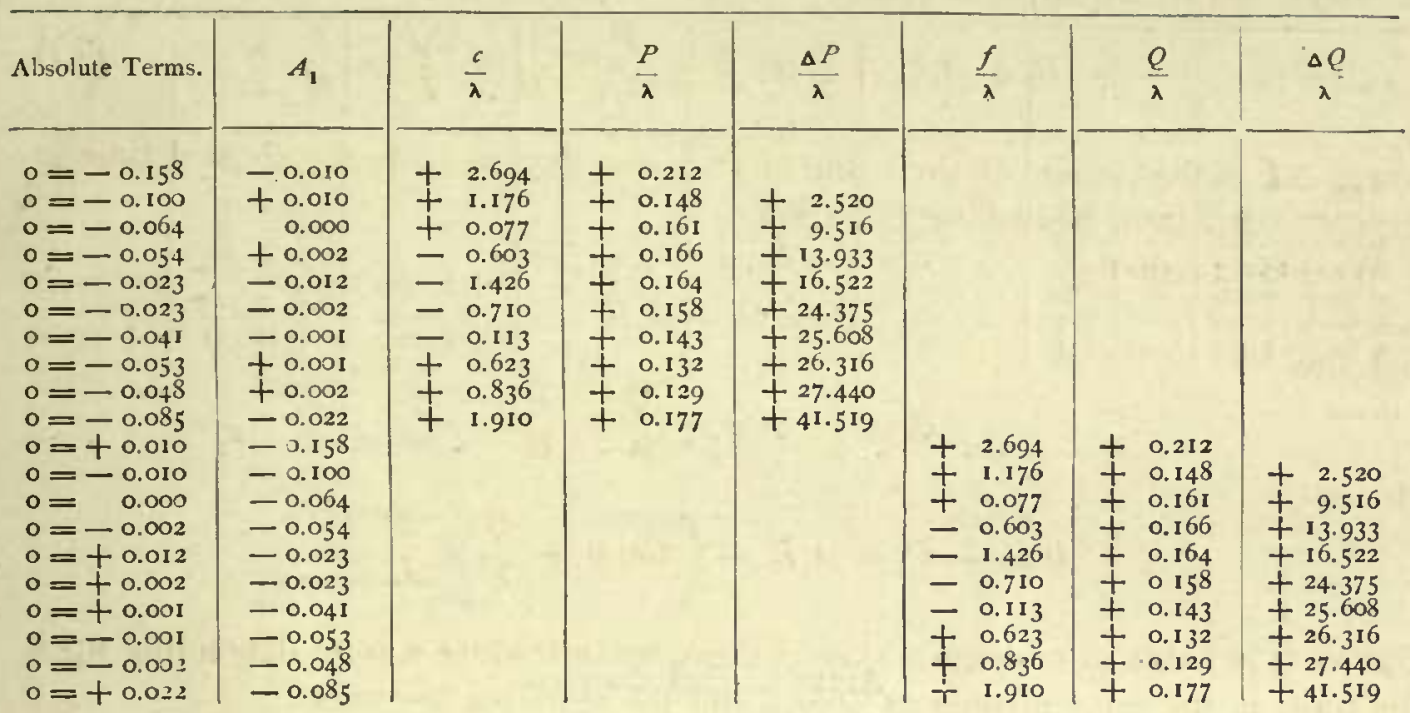

Normal Equations.

\begin{tabular}{|c|c|c|c|c|c|c|}
\hline $\begin{array}{l}0=0.000 \\
0=-0.699 \\
0=-0.109 \\
0=-9.869 \\
0=+0.037 \\
0=+0.006 \\
0=+1.057\end{array}$ & $\begin{array}{l}+0.058 \\
-0.037 \\
-0.006 \\
=1.057 \\
=0.699 \\
-0.109 \\
-9.869\end{array}$ & $\begin{array}{r}+16.294 \\
+\quad 0.826 \\
+70.177\end{array}$ & $\begin{array}{r}0.258 \\
+\quad 28.825\end{array}$ & $+49^{8} 3.3$ & $\begin{array}{r}+\quad 6.294 \\
+\quad 0.826 \\
+70.177\end{array}$ & $\begin{array}{r}0.258 \\
+28.825\end{array}$ \\
\hline
\end{tabular}

Hence

$$
\begin{array}{lll}
A_{1}=0.000 & \frac{P}{\lambda}=+0.460 & \frac{f}{\lambda}=-0.0016 \\
\frac{c}{\lambda}=+0.0240 & \frac{\Delta P}{\lambda}=+0.00102 & \frac{Q}{\lambda}=+0.006 \\
& \frac{\Delta Q}{\lambda}=-0.00023
\end{array}
$$

\begin{tabular}{|c|c|c|c|c|c|c|c|}
\hline Absolute Terms. & $A_{1}$ & $\frac{c}{\lambda}$ & $\frac{P}{\lambda}$ & $\frac{\Delta P}{\lambda}$ & $\frac{f}{\lambda}$ & $\frac{Q}{\lambda}$ & $\frac{\Delta Q}{\lambda}$ \\
\hline $0=-0.127$ & -0.022 & +2.694 & +0.212 & & & & \\
\hline $0=-0.100$ & -0.002 & +0.077 & +0.161 & +9.516 & & & \\
\hline $0=-0.096$ & +0.012 & -0.603 & +0.166 & +13.933 & & & \\
\hline $0=-0.100$ & -0.004 & -1.426 & +0.164 & +16.522 & & & \\
\hline $0=-0.070$ & +0.002 & -0.710 & $+0.15^{8}$ & +24.375 & & & \\
\hline $0=-0.073$ & -0.001 & -0.113 & +0.143 & +25.608 & & & \\
\hline $0=-0.05^{8}$ & +0.006 & +0.623 & +0.132 & +26.316 & & & \\
\hline $0=-0.054$ & -0.005 & $+0.83^{6}$ & +0.129 & +27.440 & & & \\
\hline $0=-0.06 \mathrm{I}$ & -0.039 & +1.910 & +0.177 & +41.519 & +2.694 & & \\
\hline $0=+0.022$ & -0.127 & & & & $\begin{array}{r}+0.094 \\
+0.077\end{array}$ & +0.161 & +9.516 \\
\hline $0=+0.002$ & $\begin{array}{l}-0.100 \\
-0.096\end{array}$ & & & t & -0.603 & +0.166 & +13.933 \\
\hline $\begin{array}{l}0=-0.012 \\
0=+0.004\end{array}$ & $\begin{array}{l}\text { - } 0.096 \\
-0.100\end{array}$ & 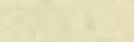 & & & -1.426 & +0.164 & +16.522 \\
\hline $0=-0.002$ & -0.070 & & & & -0.710 & +0158 & +24.375 \\
\hline $0=+0.001$ & -0.073 & & & & -0.113 & +0.143 & +25608 \\
\hline $0=-0.006$ & $-0.05^{8}$ & & & & $\begin{array}{r}+0.623 \\
+0.836\end{array}$ & $\begin{array}{r}+0.132 \\
+0.129\end{array}$ & $\begin{array}{r}+20.310 \\
+27.440\end{array}$ \\
\hline $\begin{array}{l}0=+0.005 \\
0=+0.039\end{array}$ & -0.054 & & & & $\begin{array}{r}+0.30 \\
+1.910\end{array}$ & +0.177 & $\begin{array}{r}+41.519 \\
+\end{array}$ \\
\hline $0=+0.039$ & -0.061 & & & & & & \\
\hline
\end{tabular}

After Binnacle Compass.

Equations of Condition. 
After Binnacle Compass.

Normal Equations.

\begin{tabular}{|c|c|c|c|c|c|c|c|}
\hline Absolute Terms. & $A_{1}$ & $\frac{c}{\lambda}$ & $\frac{P}{\lambda}$ & $\frac{\Delta P}{\lambda}$ & $\frac{f}{\lambda}$ & $\frac{Q}{\lambda}$ & $\frac{\Delta Q}{\lambda}$ \\
\hline $\begin{array}{l}0=0.000 \\
0=-0.288 \\
0=-0.122 \\
0=-13.033 \\
0=+1.136 \\
0=+1.010 \\
0=+18 \\
0=+1.478\end{array}$ & $\begin{array}{ll}+ & 0.068 \\
- & 0.136 \\
- & 0.010 \\
= & 1.478 \\
= & 0.288 \\
- & 0.122 \\
-13.033\end{array}$ & $\begin{array}{r}14.910 \\
+\quad 0.652 \\
+\quad 67.212\end{array}$ & $\begin{array}{l}0.236 \\
+28.451\end{array}$ & +4977.0 & $\begin{array}{r}14.910 \\
+\quad 0.652 \\
+\quad 67.212\end{array}$ & $\begin{array}{r}0.236 \\
+\quad 28.451\end{array}$ & +4977.0 \\
\hline
\end{tabular}

\section{Hence}

$$
\begin{array}{lll}
A_{1}=-0.010 & \frac{P}{\lambda}=+0.664 & \frac{f}{\lambda}=-0.0084 \\
\frac{c}{\lambda}=-0.0048 & \frac{\Delta P}{\lambda}=-0.00112 & \frac{Q}{\lambda}=+0.002 \\
& \frac{\Delta Q}{\lambda}=-0.00022
\end{array}
$$

\begin{tabular}{|c|c|c|c|c|c|c|c|c|c|c|}
\hline Absolute Terms. & & $A_{1}$ & & $\frac{c}{\lambda}$ & $\frac{P}{\lambda}$ & $\frac{\Delta P}{\lambda}$ & & $\frac{f}{\lambda}$ & $\frac{Q}{\lambda}$ & $\frac{\Delta Q}{\lambda}$ \\
\hline $0=-0.200$ & - & 0.030 & + & 2.694 & +0.212 & & & & & \\
\hline $0=-0.148$ & + & 0.012 & + & I. 176 & +0.148 & +2.520 & & & & \\
\hline $0=-0.121$ & - & 0.017 & + & 0.077 & +0.161 & +9.516 & & & & \\
\hline $0=-0.071$ & - & 0.060 & - & 1. 426 & +0.164 & +16.522 & & & & \\
\hline $0=-0.067$ & + & 0.004 & - & 0.710 & $+0.15^{8}$ & +24.375 & & & & \\
\hline $0=-0.102$ & + & 0.004 & - & 0.113 & +0.143 & +25.608 & & & & \\
\hline $0=-0.071$ & $\div$ & 0.003 & + & 0.623 & +0.132 & +26.316 & & & & \\
\hline $0=-0.078$ & + & $0.02 \mathrm{I}$ & + & 0.836 & +0.129 & +27.440 & & & & \\
\hline $0=-0.118$ & - & 0.027 & + & 1.910 & +0.177 & +41.519 & & & & \\
\hline $0=+0.030$ & - & 0.200 & & & & & + & 2.694 & 0.212 & \\
\hline $0=-0.012$ & - & 0.148 & & & & & + & I.176 & $\begin{array}{l}0.148 \\
0.161\end{array}$ & $\begin{array}{r}2.520 \\
+\quad 9.516\end{array}$ \\
\hline $0=+0.017$ & $\overline{-}$ & $\begin{array}{l}0.121 \\
0.071\end{array}$ & & & & & \pm & $\begin{array}{l}0.077 \\
\text { I. } 426\end{array}$ & $\begin{array}{r}1.164 \\
+\quad 0.164\end{array}$ & +16.522 \\
\hline $\begin{array}{l}0=+0.060 \\
0=-0.004\end{array}$ & Z & $\begin{array}{l}0.071 \\
0.067\end{array}$ & & & & & - & $\begin{array}{l}1.420 \\
0.710\end{array}$ & $+0.15^{8}$ & +24.375 \\
\hline $\begin{array}{l}0=-0.004 \\
0=-0.004\end{array}$ & - & 0.102 & & & & & - & 0.113 & 0.143 & +25.608 \\
\hline $0=+0.003$ & - & 0.071 & & & & & + & 0.623 & 0.132 & +26.316 \\
\hline $0=-0.021$ & - & 0.078 & & & & & + & 0.836 & 0.129 & +27.440 \\
\hline $0=+0.027$ & - & 0.118 & & & & & + & 1.910 & +0.177 & +41.519 \\
\hline
\end{tabular}

After Ritchie Compass.

Equations of Condition.

Normal Equations.

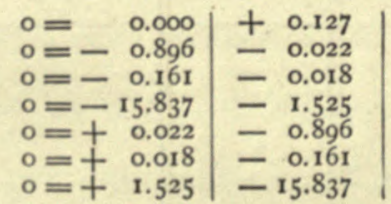

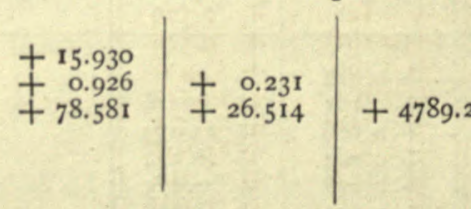

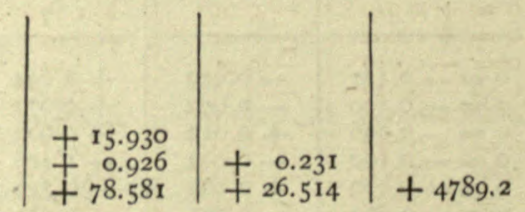

Hence

$$
\begin{array}{lll}
A_{1}=0.000 & \frac{P}{\lambda}=+0.766 & \frac{f}{\lambda}=+0.0052 \\
\frac{c}{\lambda}=+0.0178 & \frac{\Delta P}{\lambda}=-0.00122 & \frac{Q}{\lambda}=-0.149 \\
& \frac{\Delta Q}{\lambda}=+0.00042
\end{array}
$$


After Azmuth Compass.

Equations of Condition.

\begin{tabular}{|c|c|c|c|c|c|c|c|}
\hline Absolute Terms. & $A_{1}$ & $\frac{c}{\lambda}$ & $\frac{P}{\lambda}$ & $\frac{\Delta P}{\lambda}$ & $\frac{f}{\lambda}$ & $\frac{Q}{\lambda}$ & $\frac{\Delta Q}{\lambda}$ \\
\hline $\begin{array}{l}0=0.085 \\
o=+0.053 \\
o=+0.078 \\
0=+0.052 \\
0=+0.086 \\
0=+0.035 \\
0=+0.066 \\
0=+0.060 \\
0= \pm 0.003 \\
0=-0.023 \\
0=+0.006 \\
0=+0.014 \\
0=-0.006 \\
0=+0.014 \\
0=-0.030 \\
0=0.000\end{array}$ & $\begin{array}{l}-0.003 \\
+0.023 \\
+0.006 \\
0.014 \\
+0.006 \\
+0.014 \\
+0.030 \\
0.000 \\
+0.085 \\
+0.053 \\
+0.078 \\
+0.052 \\
+0.086 \\
+0.035 \\
+0.066 \\
+0.060\end{array}$ & $\begin{array}{r}+2.694 \\
+1.176 \\
+0.077 \\
=1.426 \\
-0.710 \\
-0.113 \\
+0.623 \\
+0.836\end{array}$ & $\begin{array}{r}+0.212 \\
+0.148 \\
+0.161 \\
+0.164 \\
+0.158 \\
+0.143 \\
+0.132 \\
+0.129\end{array}$ & $\begin{array}{r}+2.520 \\
+\quad 9.516 \\
+16.522 \\
+24.375 \\
+25.608 \\
+26.316 \\
+\quad 27.440\end{array}$ & $\begin{array}{r}\mathbf{2} .694 \\
+1.176 \\
+0.077 \\
-1.426 \\
=0.710 \\
0.113 \\
+0.623 \\
+0.836\end{array}$ & $\begin{array}{r}+0.212 \\
+0.148 \\
+0.161 \\
+0.164 \\
+0.158 \\
+0.143 \\
+0.132 \\
+0.129\end{array}$ & $\begin{array}{r}+2.520 \\
+\quad 9.516 \\
+16.522 \\
+24.375 \\
+25.608 \\
+26.316 \\
+27.440\end{array}$ \\
\hline
\end{tabular}

Normal Equations.

\begin{tabular}{l|l}
$0=0.000$ & +0.037 \\
$0=+0.250$ & +0.055 \\
$0=+0.082$ & +0.003 \\
$0=+8.100$ & $+0.35^{2}$ \\
$0=-0.055$ & +0.250 \\
$0=-0.003$ & +0.082 \\
$0=-0.35^{2}$ & +8.100
\end{tabular}

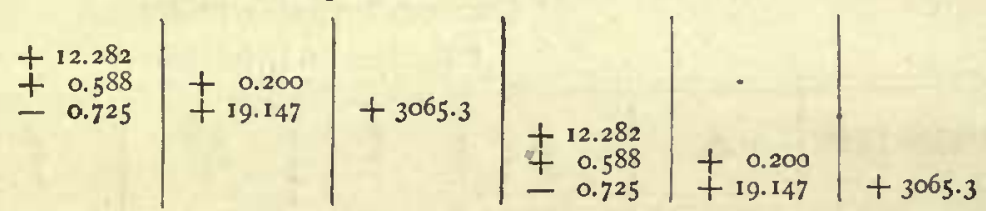

Hence

$$
\begin{array}{lcc}
A_{1}=0.000 & \frac{P}{\lambda}=-0.373 & \frac{f}{\lambda}=+0.0066 \\
\frac{c}{\lambda}=-0.0026 & \frac{\Delta P}{\lambda}=-0.00032 & \frac{Q}{\lambda}=-0.044 \\
& \frac{\Delta Q}{\lambda}=+0.00039
\end{array}
$$

\begin{tabular}{|c|c|c|c|c|c|c|c|}
\hline Absolute Terms. & $A_{1}$ & $\frac{c}{\lambda}$ & $\frac{p}{\lambda}$ & $\frac{\Delta P}{\lambda}$ & $\frac{f}{\lambda}$ & $\frac{Q}{\lambda}$ & $\frac{\Delta Q}{\lambda}$ \\
\hline $\begin{array}{l}0=+0.043 \\
0=+0.010 \\
0= \pm 0.002 \\
0= \pm 0.017 \\
0=-0.017 \\
0=-0.009 \\
0=-0.012 \\
0=0.000 \\
0=+0.026 \\
0=+0.033 \\
0=+0.033 \\
0=+0.013 \\
0=+0.010 \\
0=+0.019 \\
0=+0.033 \\
0=+0.016 \\
0=+0.028 \\
0=+0.024 \\
0=+0.010 \\
0=+0.042\end{array}$ & $\begin{array}{r}-0.033 \\
=0.013 \\
0.010 \\
0.019 \\
=0.033 \\
=0.016 \\
=0.028 \\
=0.024 \\
=0.010 \\
-0.042 \\
+0.043 \\
+0.010 \\
+0.002 \\
=0.017 \\
=0.017 \\
=0.009 \\
-0.012 \\
0.000 \\
+0.026 \\
+0.033\end{array}$ & $\begin{array}{r}+2.694 \\
+1.176 \\
+0.077 \\
-0.603 \\
=1.426 \\
=0.710 \\
0.113 \\
+0.623 \\
+0.836 \\
+1.910\end{array}$ & $\begin{array}{r}+0.212 \\
+0.148 \\
+0.161 \\
+0.166 \\
+0.164 \\
+0.158 \\
+0.143 \\
+0.132 \\
+0.129 \\
+0.177\end{array}$ & $\begin{array}{r}+2.520 \\
+\quad 9.516 \\
+13.933 \\
+16.522 \\
+24.375 \\
+25.608 \\
+26.316 \\
+27.440 \\
+41.519\end{array}$ & $\begin{array}{r}+2.694 \\
+1.176 \\
+0.077 \\
\pm 0.603 \\
=1.426 \\
=0.710 \\
0.113 \\
+0.623 \\
+0.836 \\
+1.910\end{array}$ & $\begin{array}{r}+0.212 \\
+0.148 \\
+0.161 \\
+0.166 \\
+0.164 \\
+0.158 \\
+0.143 \\
+0.132 \\
+0.129 \\
+0.177\end{array}$ & $\begin{array}{r}+\quad 2.520 \\
+\quad 9.516 \\
+13.933 \\
+16.522 \\
+24.375 \\
+25.008 \\
+26.316 \\
+27.440 \\
+41.519\end{array}$ \\
\hline
\end{tabular}

Forward Alidade Compass.

Equations of Condition. 
Forward Alidade Compass.

Normal Equations.

\begin{tabular}{|c|c|c|c|c|c|c|c|}
\hline Absolute Terms. & $A_{1}$ & $\frac{c}{\lambda}$ & $\frac{P}{\lambda}$ & $\frac{\Delta P}{\lambda}$ & $\frac{f}{\lambda}$ & $\frac{Q}{\lambda}$ & $\frac{\Delta Q}{\lambda}$ \\
\hline $\begin{array}{l}0=0.000 \\
0=+0.255 \\
0=+0.012 \\
0= \pm 1.089 \\
0=+0.135 \\
0=+0.037 \\
0=+4.686\end{array}$ & $\begin{array}{l}+0.011 \\
-0.135 \\
-0.037 \\
-4.686 \\
+0.255 \\
+0.012 \\
+1.089\end{array}$ & $\begin{array}{r} \\
+\quad 16.294 \\
+\quad 0.826 \\
+\quad 70.177\end{array}$ & $\begin{array}{r}0.258 \\
+\quad 28.825\end{array}$ & +4983.3 & $\begin{array}{r}16.294 \\
+\quad 0.826 \\
+\quad 70.177\end{array}$ & $\begin{array}{r}0.258 \\
+\quad 28.825\end{array}$ & +4983.3 \\
\hline
\end{tabular}

Hence

$$
\begin{array}{lll}
A_{1}=-0.025 & \frac{P}{\lambda}=+0.014 & \frac{f}{\lambda}=-0.0012 \\
\frac{c}{\lambda}=-0.0162 & \frac{\Delta P}{\lambda}=-0.00010 & \frac{Q}{\lambda}=-0.106 \\
& \frac{\Delta Q}{\lambda}=-0.0003 \mathrm{I}
\end{array}
$$

\begin{tabular}{|c|c|c|c|c|c|c|c|}
\hline Absolute Terms. & $A$ & $\frac{c}{\lambda}$ & $\frac{P}{\lambda}$ & $\frac{\Delta P}{\lambda}$ & $\frac{f}{\lambda}$ & $\frac{Q}{\lambda}$ & $\frac{\Delta Q}{\lambda}$ \\
\hline 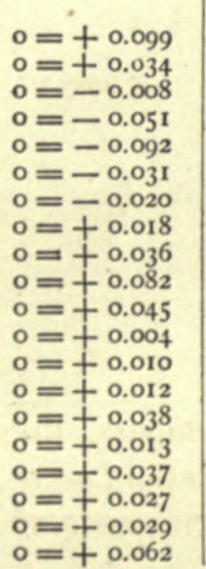 & $\begin{array}{l}-0.045 \\
-0.004 \\
-0.010 \\
-0.012 \\
-0.038 \\
-0.013 \\
-0.037 \\
-0.027 \\
-0.029 \\
-0.062 \\
+0.099 \\
+0.034 \\
-0.008 \\
-0.051 \\
-0.092 \\
-0.031 \\
-0.020 \\
+0.018 \\
+0.036 \\
+0.082\end{array}$ & $\begin{array}{r}+2.694 \\
+1.176 \\
+0.077 \\
+0.603 \\
-1.426 \\
-0.710 \\
-0.113 \\
+0.623 \\
+0836 \\
+1.910\end{array}$ & $\begin{array}{r}+0.212 \\
+0.148 \\
+0.161 \\
+0.166 \\
+0.164 \\
+0.158 \\
+0.143 \\
+0.132 \\
+0.129 \\
+0.177\end{array}$ & $\begin{array}{r}+\quad 2.520 \\
+\quad 9.516 \\
+\quad 13.933 \\
+\quad 16.522 \\
+\quad 24.375 \\
+25.608 \\
+\quad 26.316 \\
+27.440 \\
+\quad 41.519\end{array}$ & $\begin{array}{r} \\
+\quad 2.694 \\
+1.176 \\
+0.077 \\
-0.603 \\
-1.426 \\
-0.710 \\
-0.113 \\
+0.623 \\
+0.836 \\
+1.910\end{array}$ & $\begin{array}{r}+0.212 \\
+0.148 \\
+0.161 \\
+0.166 \\
+0.164 \\
+0.158 \\
+0.143 \\
+0.132 \\
+0.129 \\
+0.177\end{array}$ & $\begin{array}{r} \\
\\
+\quad 2.520 \\
+\quad 9.516 \\
+\quad 13.933 \\
+16.522 \\
+\quad 24.375 \\
+\quad 25.608 \\
+\quad 26.316 \\
+\quad 27.440 \\
+41.519\end{array}$ \\
\hline
\end{tabular}

Forward Binnacle Compass.

Equations of Condition.

$$
\begin{aligned}
& 0=0.000 \\
& 0=+0.690 \\
& 0=+0.015 \\
& 0=+1.334 \\
& 0=+0.211 \\
& 0=+0.046 \\
& 0=+6.283
\end{aligned}
$$

+0.043
-0.211
-0.046
-6.283
+0.690
+0.015
+1.334
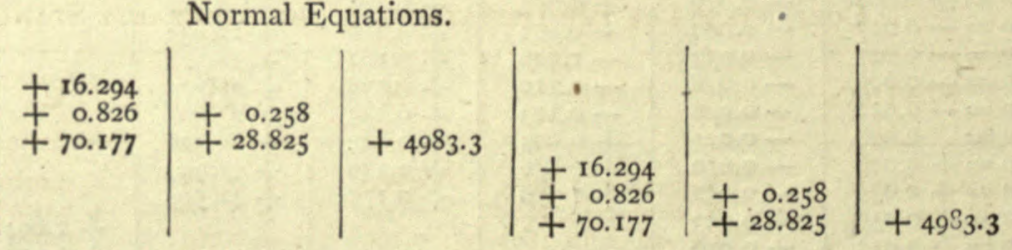

Hence

$$
\begin{aligned}
& A_{\mathrm{t}}=0.000 \\
& \frac{c}{\lambda}=-0.0477
\end{aligned}
$$

$$
\begin{gathered}
\frac{P}{\lambda}=+0.140 \\
\frac{\Delta P}{\lambda}=-0.00041
\end{gathered}
$$

$$
\begin{gathered}
\frac{f}{\lambda}=-0.0059 \\
\frac{Q}{\lambda}=-0.075 \\
\frac{\Delta Q}{\lambda}=-0.00074
\end{gathered}
$$


Foriward Ritchie Compass.

Equations of Condition.

\begin{tabular}{|c|c|c|c|c|c|c|c|}
\hline Absolute Terms. & $A_{1}$ & $\cdot \frac{c}{\lambda}$ & $\frac{P}{\lambda}$ & $\frac{\Delta P}{\lambda}$ & $\frac{f}{\lambda}$ & $\frac{Q}{\lambda}$ & $\frac{\Delta Q}{\lambda}$ \\
\hline $\begin{array}{l}0=-0.023 \\
0=-0.036 \\
0=-0.061 \\
0=-0.066 \\
0=-0.067 \\
0=-0.023 \\
0=-0.033 \\
0=-0.004 \\
0=-0.011 \\
0=0.005 \\
0=+0.063 \\
0=+0.022 \\
0=+0.027 \\
0=0.000 \\
0=+0.048 \\
0=+0.026 \\
0=+0.034 \\
0=+0.033 \\
0=+0.038 \\
0=+0.117\end{array}$ & $\begin{array}{r}-0.063 \\
=0.022 \\
-0.027 \\
0.000 \\
=0.048 \\
=0.026 \\
=0.034 \\
=0.033 \\
=0.038 \\
=0.117 \\
=0.023 \\
=0.036 \\
=0.061 \\
=0.066 \\
=0.067 \\
=0.023 \\
=0.033 \\
=0.004 \\
-0.011 \\
+0.005\end{array}$ & $\begin{array}{r}+2.694 \\
+1.176 \\
+0.077 \\
-0.603 \\
=1.426 \\
-0.710 \\
-0.113 \\
+0.623 \\
+0.836 \\
+1.910\end{array}$ & $\begin{array}{r}+0.212 \\
+0.148 \\
+0.161 \\
+0.166 \\
+0.164 \\
+0.158 \\
+0.143 \\
+0.132 \\
+0.129 \\
+0.177\end{array}$ & $\begin{array}{r}+2.520 \\
+\quad 9.516 \\
+13.933 \\
+16.522 \\
+24.375 \\
+25.608 \\
+26.316 \\
+27.440 \\
+41.519\end{array}$ & $\begin{array}{r}+2.694 \\
+1.176 \\
+0.077 \\
-0.603 \\
=1.426 \\
-0.710 \\
0.113 \\
+0.623 \\
+0.836 \\
+1.910\end{array}$ & $\begin{array}{r}+0.212 \\
+0.148 \\
+0.161 \\
+0.166 \\
+0.164 \\
+0.158 \\
+0.143 \\
+0.132 \\
+0.129 \\
+0.177\end{array}$ & $\begin{array}{r}+\quad 2.520 \\
+\quad 9.516 \\
+\quad 13.933 \\
+16.522 \\
+24.375 \\
+25.608 \\
+26.316 \\
+27.440 \\
+41.519\end{array}$ \\
\hline
\end{tabular}

Normal Equations.

\begin{tabular}{l|r}
$0=$ & $=000$ \\
$0=+0.044$ & +0.042 \\
$0=-0.052$ & -0.384 \\
$0=-4.306$ & -0.068 \\
$0=+0.388$ \\
$0=+0.068$ & +0.044 \\
$0=+9.388$ & -0.052 \\
$0=4.306$
\end{tabular}
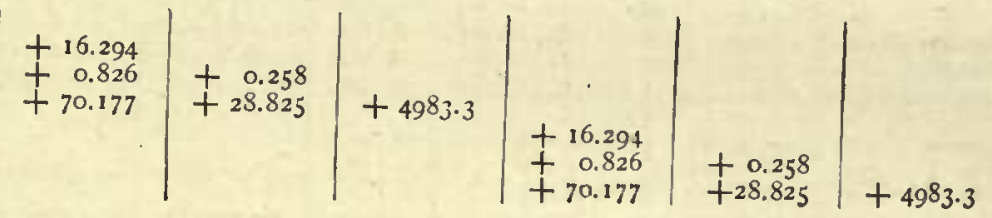

Hence

$$
\begin{array}{lll}
A_{1}=0.000 & \frac{P}{\lambda}=+0.367 & \frac{f}{\lambda}=-0.014^{1} \\
\frac{c}{\lambda}=-0.0169 & \frac{\Delta P}{\lambda}=-0.00102 & Q=-0.083 \\
& \frac{\Delta Q}{\lambda}=-0.00120
\end{array}
$$

The value of the true $A_{1}$ having thus become known for each compass, the

\begin{tabular}{|c|c|c|c|c|c|c|c|}
\hline \multicolumn{2}{|l|}{ STATION. } & DATE. & 91 & $\mathfrak{B}$ & $\mathfrak{C}$ & $D$ & $\mathfrak{E}$ \\
\hline $\begin{array}{l}\text { Iampton Roads. } \\
\text { St. Thomas : } \\
\text { Bahia : } \\
\text { Monte Video : } \\
\text { Sandy Point : } \\
\text { Valparaiso : } \\
\text { Callao : } \\
\text { Panama : : } \\
\text { Acapulco : } \\
\text { San Francisco. }\end{array}$ & 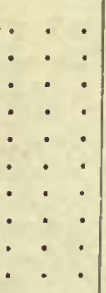 & \begin{tabular}{|lr} 
November & I, I 865 \\
November & I 8,1865 \\
December & 30, I $86 \div$ \\
January & 24,1866 \\
February & 10,1866 \\
April & 4.1866 \\
April & 29.1866 \\
May & 20,1866 \\
June & 1,1866 \\
June & 23,1866
\end{tabular} & $\begin{array}{l}0.000 \\
0.000 \\
0.000 \\
0.000 \\
0.000 \\
0.000 \\
0.000 \\
0.000 \\
0.000 \\
0.000\end{array}$ & $\begin{array}{l}+0.158 \\
+0.100 \\
+0.064 \\
+0.054 \\
+0.023 \\
+0.023 \\
+0.041 \\
+0.053 \\
+0.048 \\
+0.085\end{array}$ & $\begin{array}{r}-0.010 \\
+0.010 \\
0.000 \\
+0.002 \\
-0.012 \\
-0.002 \\
0.000 \\
+0.001 \\
+0.002 \\
-0.022\end{array}$ & $\begin{array}{l}+0.021 \\
+0.006 \\
+0.016 \\
+0.024 \\
+0.016 \\
+0.016 \\
+0.016 \\
+0.017 \\
+0.018 \\
+0.018\end{array}$ & $\begin{array}{r}-0.004 \\
-0.013 \\
0.000 \\
+0.004 \\
0.000 \\
-0.003 \\
+0.002 \\
+0.002 \\
+0.002 \\
0.000\end{array}$ \\
\hline & Means & & & & & +0.017 & -0.001 \\
\hline
\end{tabular}
values of the coefficients $\mathfrak{B}, \mathfrak{E}, \mathfrak{I}$, and $\mathfrak{E}$, for each compass, at each station, were next computed by means of the formulæ (16). 'The results, expressed in parts of radius, are as follows:

Coefficients of the Deviations of the Admiralty Standard Conpass. 
Coefricients of the Deviations of the After Binnacle.

\begin{tabular}{|c|c|c|c|c|c|c|c|}
\hline STATION & & DATE. & 21 & 23 & 5 & $D$ & (i) \\
\hline & & & & & & +0.038 & -0.002 \\
\hline
\end{tabular}

Coefficients of the Deviations of the After Ritchie Compass.

\begin{tabular}{|c|c|c|c|c|c|c|c|}
\hline STATION & & DATE. & 2 & 23 & 5 & 5 & 6 \\
\hline & Means & & & & & +0.034 & -0.001 \\
\hline
\end{tabular}

Coefficients of tile Deviations of the After Azimuth Compass.

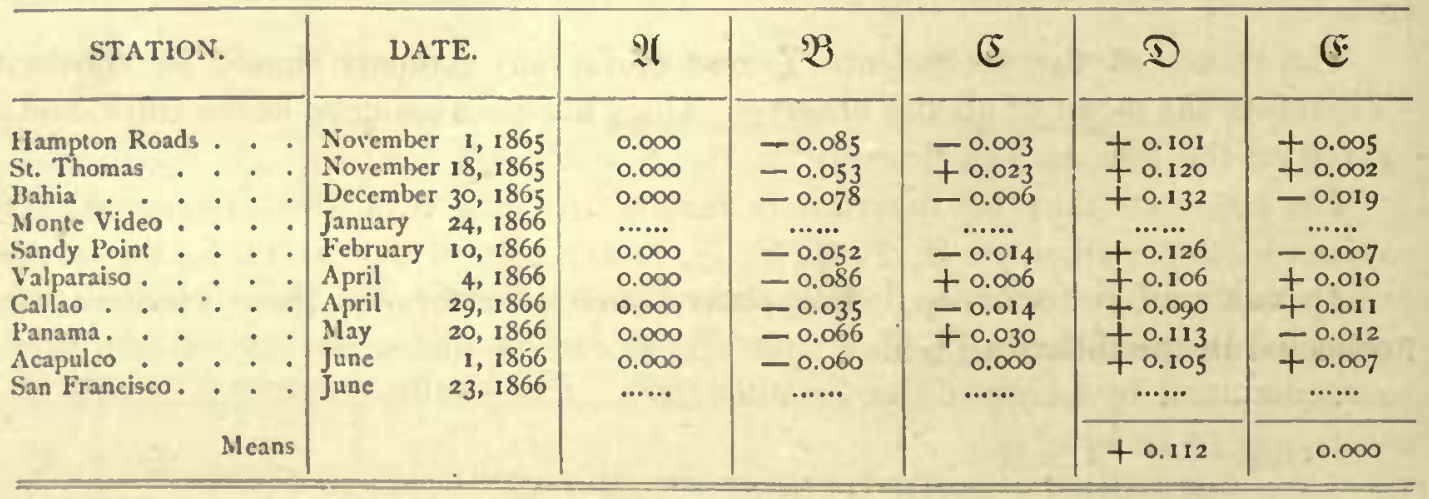

Coefficients of the Deviations of the Forward Alidade Compass.

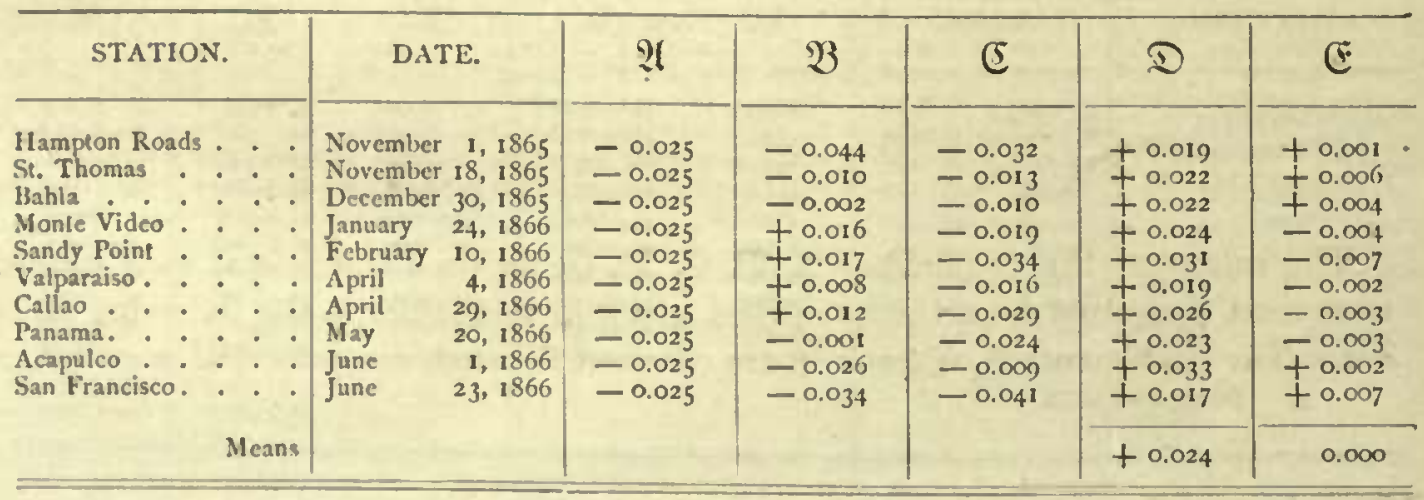


Coefficients of the Deviations of the Forward Binnacle Compass.

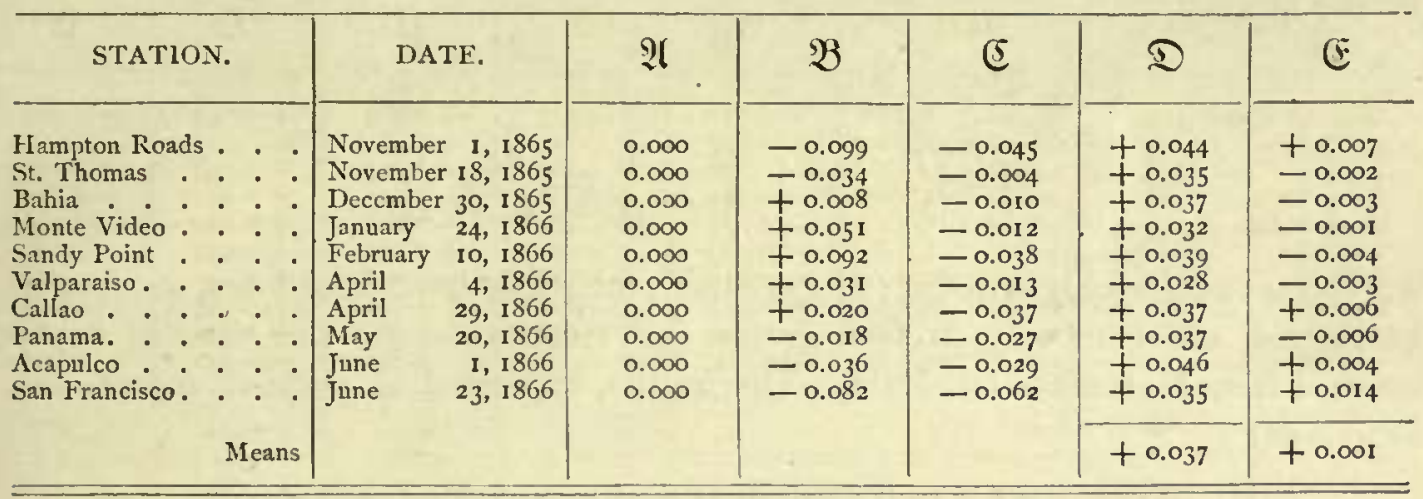

Coefficients of the Deviations of the Forward Ritchie Compass.

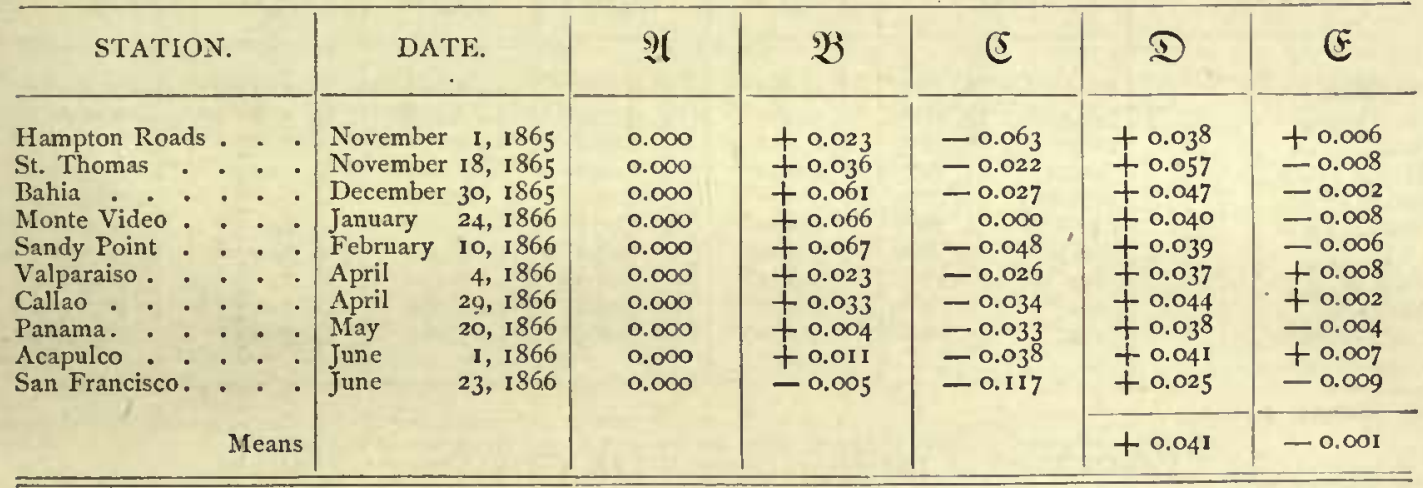

The values of the coefficients $\mathfrak{D}$ and $\mathcal{E}$ for any compass should be constant. Therefore the mean of all the observed values has been assumed as the truth, and is given on the line marked "means" in the case of each compass.

The constants thus far determined furnish the data with which to compute the values of the coefficients $\mathfrak{H}, \mathfrak{B}, \mathfrak{C}, \mathfrak{D}, \mathfrak{F}$, in any part of the world, for any of the compasses nnder discussion. For convenience of reference these constants are collected in the following table:

\begin{tabular}{|c|c|c|c|c|c|c|c|c|c|}
\hline Compass. & $A_{1}=2$ & $\frac{c}{\lambda}$ & $\frac{P}{\lambda}$ & $\frac{P}{\lambda}$ & $\frac{f}{x}$ & $\frac{Q}{\lambda}$ & $\frac{\Delta Q}{\lambda}$ & D & $\mathcal{E}$ \\
\hline Admiralty Standard & 0.000 & +0.0240 & +0.460 & -0.00102 & -0.0016 & +0.006 & -0.00023 & +0.017 & -0.001 \\
\hline After Iinnacle. & -0.010 & -0.0048 & +0.664 & -0.00112 & -0.0084 & +0.002 & -0.00022 & $-0.03^{8}$ & -0.002 \\
\hline After Ritchie . & 0.000 & +0.0178 & +0.766 & -0.00122 & +0.0052 & -0.149 & +0.00042 & -0.034 & -0.001 \\
\hline After A zimuth & 0.000 & -0.0026 & -0.373 & -0.00032 & +0.0066 & -0.044 & +0.00039 & +0.112 & 0.000 \\
\hline Forward Alidade. & -0.025 & -0.0162 & +0.014 & -0.00010 & -0.0012 & -0.106 & -0.00031 & +0.024 & 0.000 \\
\hline Forward Binnacle. & 0.000 & -0.0477 & +0.140 & $-0.0004 \mathrm{I}$ & -0.0059 & -0.075 & -0.00074 & +0.037 & +0.001 \\
\hline Forward Ritchie & 0.000 & -0.0169 & +0.367 & - -0.00102 & -0.0141 & -0.083 & -0.00120 & +0.041 & -0.001 \\
\hline
\end{tabular}

The values of the coefficients $\mathfrak{K}, \mathfrak{Z}, \mathfrak{E}, \mathfrak{D}, \mathfrak{E}$, for each compass at each station, were next computed from the quantities given in this table, in the following manner. The coefficients $\mathfrak{U}, \mathfrak{D}$, and $\mathcal{E}$ are constant for each compass, and were taken 
directly from the table; while the cocfficients $\mathfrak{B}$ and $\mathfrak{S}$ were obtained by means of the formulæ

$$
\begin{aligned}
& \mathfrak{B}=\frac{c}{\lambda} \tan 0+\frac{P}{\lambda} \times \frac{1}{H}+\frac{\Delta P}{\lambda} \times \frac{t}{H} \\
& \mathfrak{C}=\frac{f}{\lambda} \tan 0+\frac{Q}{\lambda} \times \frac{1}{H}+\frac{\Delta Q}{\lambda} \times \frac{t}{H}
\end{aligned}
$$

where 0 is the true magnetic dip; $H$ the cartl's magnetic horizontal force, expressed in English units, namely, in feet, grains, and seconds; and $t$ the time in clays, counted from November 1st, 1865 . 'The results, expressed in parts of radius, are as follows:

Coffficients of the Deviations of the Admiralty Standard Compass.

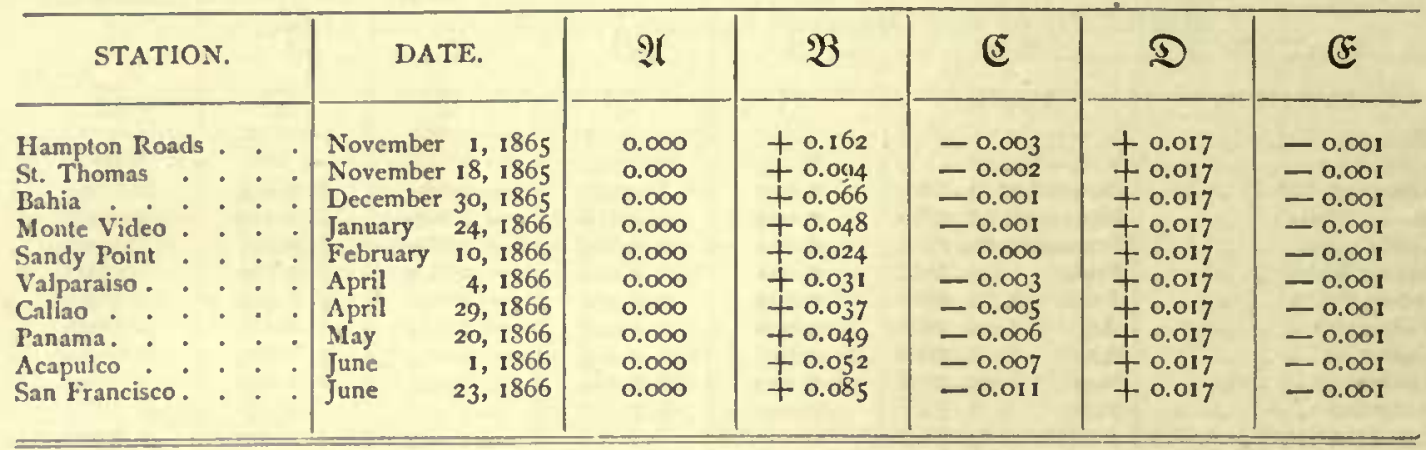

Coefficients of the Deviations of the After Binnacle Compass.

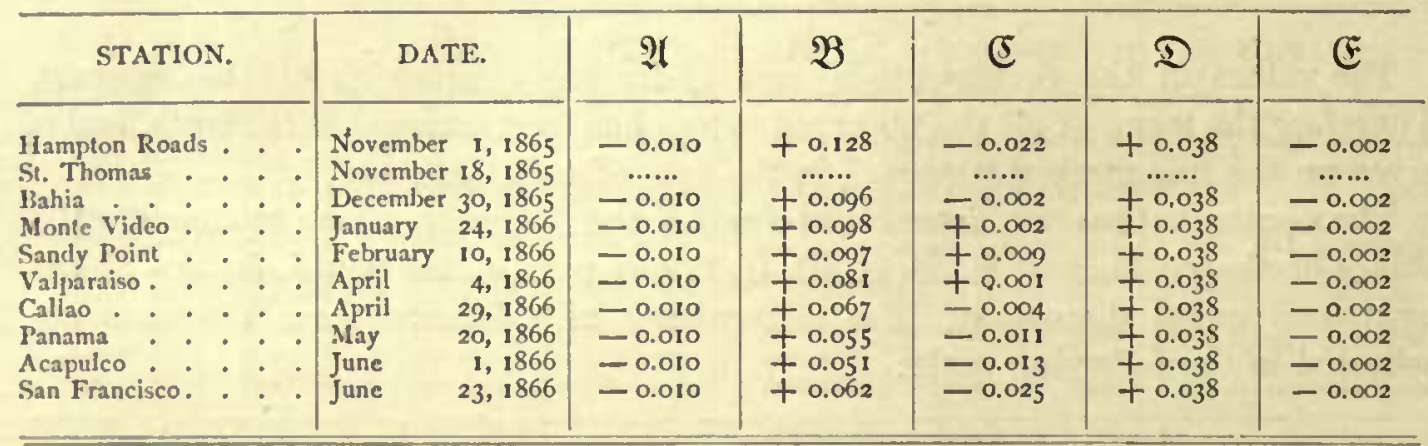

Coefficients of the Deviations of the After Ritchie Compass.

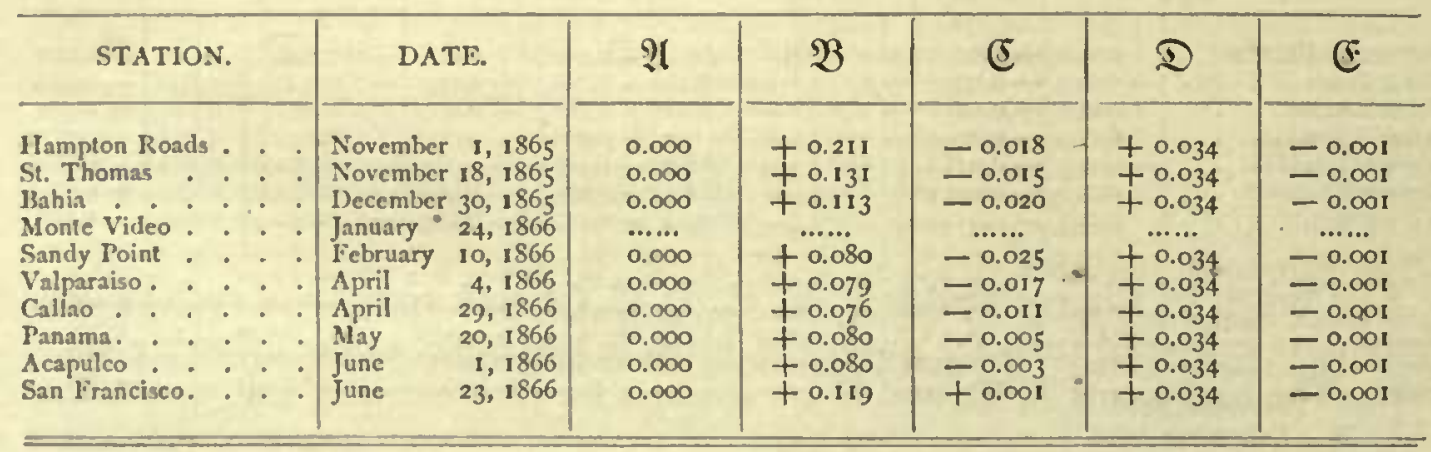


Coefficients of the Deviations of the After Azimuth Compass.

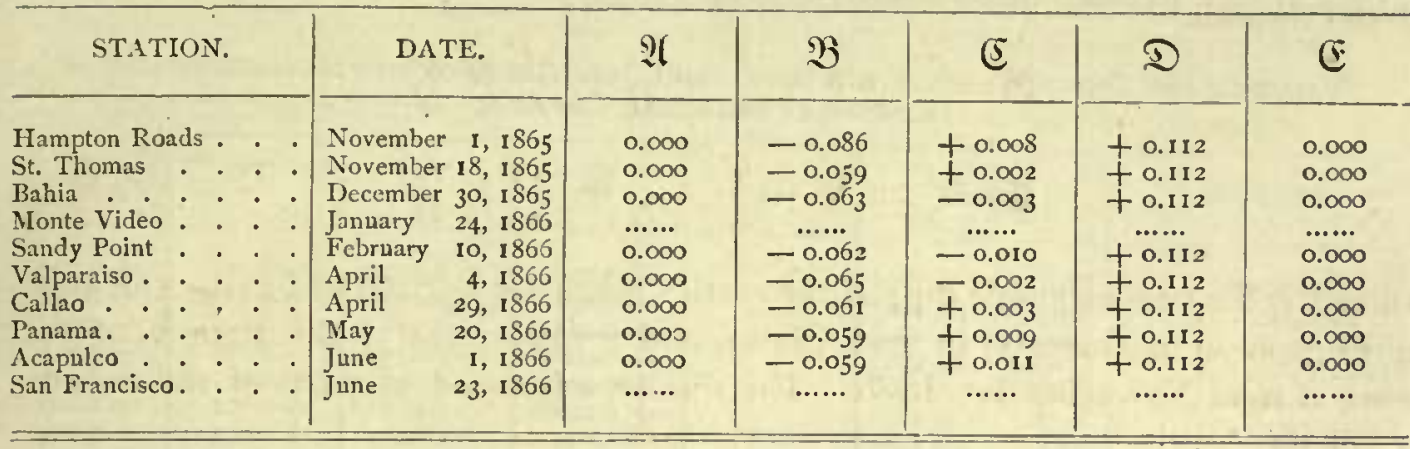

Coefficients of the Deviations of the Forward Alidade Compass.

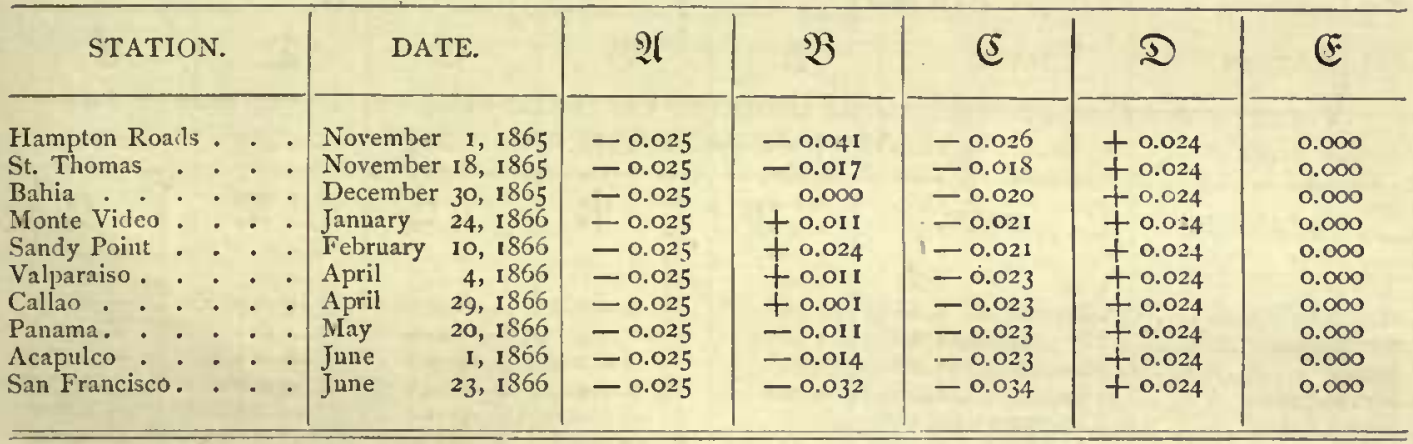

Coefficients of the Deviations of the Forward Binnacle Compass.

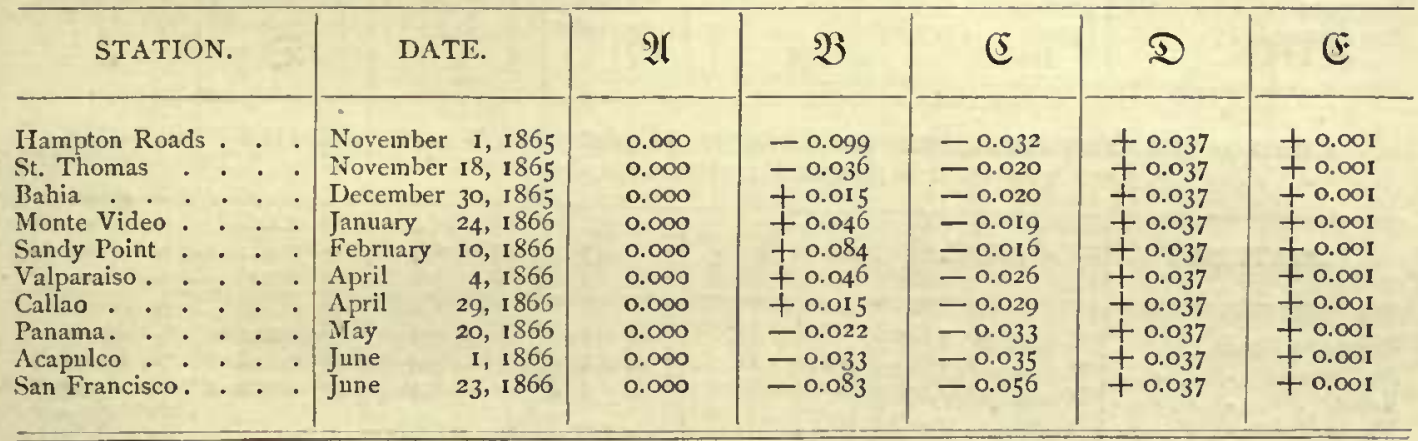

Coefficients of the Deviations of the Forward Ritchie Compass.

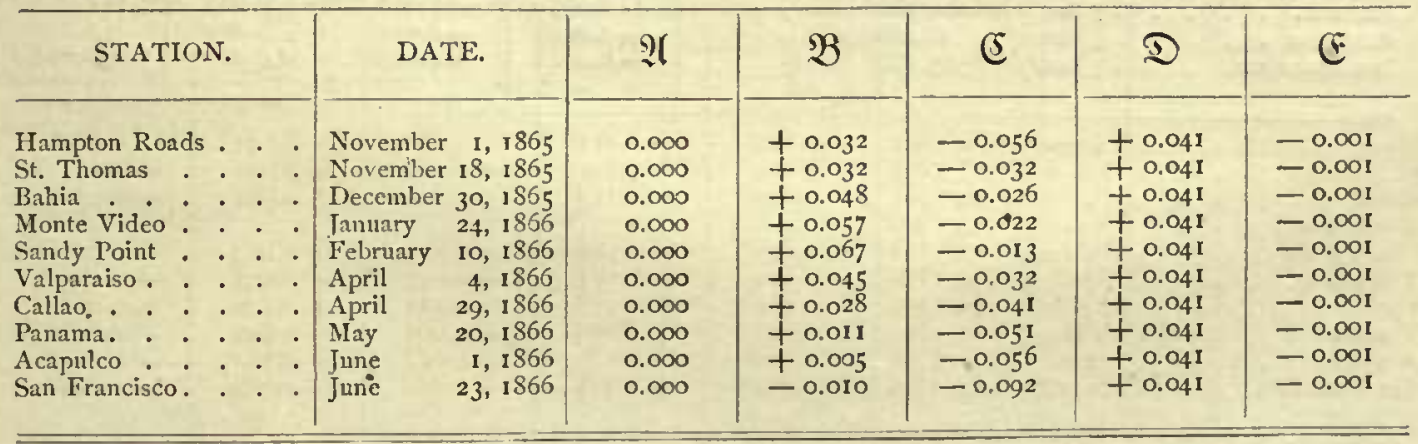


Comparing these computed values with the values before founa direetly from the observations, the following residuals are obtained:

Value of the Computed minus the Observed Coefficients of the Deviations of the Admiralty Standard Compass.

\begin{tabular}{|c|c|c|c|c|c|c|c|}
\hline STATION. & & DATE. & $\mathfrak{2}$ & $\mathfrak{B}$ & (5) & $D$ & C. \\
\hline $\begin{array}{l}\text { Hamplon Roads } \\
\text { St. Thomas : } \\
\text { Bahia : } \\
\text { Monte Video: } \\
\text { Sandy Point: } \\
\text { Valparaiso: : } \\
\text { Callao : : } \\
\text { Panama. : : } \\
\text { Acapulco : } \\
\text { San Francisco. : }\end{array}$ & 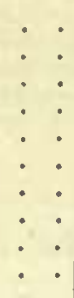 & \begin{tabular}{|lr} 
November 1,1865 \\
November 18,1865 \\
December & 30,1865 \\
January & 24,1866 \\
February & 10,1866 \\
April & 4,1866 \\
April & 29,1866 \\
Mapy & 20,1866 \\
June & 1,1866 \\
June & 23,1866 \\
\end{tabular} & & $\begin{array}{r}+0.004 \\
-0.006 \\
+0.002 \\
-0.006 \\
+0.001 \\
+0.008 \\
-0.004 \\
-0.004 \\
+0.004 \\
0.000\end{array}$ & $\begin{array}{l}+0.007 \\
-0.012 \\
-0.001 \\
-0.003 \\
+0.012 \\
-0.001 \\
-0.005 \\
-0.007 \\
-0.009 \\
+0.011\end{array}$ & $\begin{array}{r}-0.004 \\
+0.011 \\
+0.001 \\
+0.007 \\
+0.001 \\
+0.001 \\
+0.001 \\
0.000 \\
-0.001 \\
-0.001\end{array}$ & $\begin{array}{l}+0.003 \\
+0.012 \\
-0.001 \\
-0.005 \\
-0.001 \\
+0.002 \\
-0.003 \\
-0.003 \\
-0.003 \\
-0.001\end{array}$ \\
\hline
\end{tabular}

Value of the Computed minus the Observed Coefficients of the Deviations of the After Binnacle Compass.

\begin{tabular}{|c|c|c|c|c|c|c|c|c|c|}
\hline STATION & & & $\mathrm{DA}$ & TE. & $\mathfrak{Z}$ & $\mathfrak{B}$ & 5 & $D$ & E \\
\hline $\begin{array}{l}\text { Ilampton Roads } \\
\text { St. Thomas : } \\
\text { Bahia bideo: } \\
\text { Monte Video } \\
\text { Sandy Point : } \\
\text { Valparaiso.: } \\
\text { Callao : : } \\
\text { Panama: : } \\
\text { Acapalco : } \\
\text { San Francisco. }\end{array}$ & : & 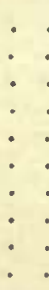 & $\begin{array}{l}\text { November } \\
\text { November } \\
\text { December } \\
\text { January } \\
\text { February } \\
\text { April } \\
\text { April } \\
\text { May } \\
\text { June } \\
\text { June }\end{array}$ & $\begin{array}{r}1,1865 \\
18,1865 \\
30,1865 \\
24,1866 \\
10,1866 \\
4,1866 \\
29,1866 \\
20,1866 \\
1,1866 \\
23,1866\end{array}$ & & $\begin{array}{c}+0.001 \\
\ldots . . . \\
-0.004 \\
+0.002 \\
-0.003 \\
+0.011 \\
-0.006 \\
-0.003 \\
-0.003 \\
+0.002\end{array}$ & $\begin{array}{c}+0.001 \\
\ldots . . . \\
+0.001 \\
0.009 \\
+0.014 \\
-0.001 \\
-0.002 \\
-0.017 \\
-0.007 \\
+0.015\end{array}$ & $\begin{array}{r}+0.001 \\
\ldots \ldots . . . \\
+0.004 \\
-0.001 \\
-0.002 \\
0.000 \\
-0.002 \\
-0.008 \\
-0.003 \\
+0.006\end{array}$ & $\begin{array}{r}-0.001 \\
\ldots . . . \\
-0.004 \\
+0.010 \\
-0.001 \\
-0.002 \\
-0.004 \\
+0.003 \\
+0.004 \\
-0.002\end{array}$ \\
\hline
\end{tabular}

Value of the Computed minus the Observed Coefficients of the Deviations of tife After Ritchie Compass.

\begin{tabular}{|c|c|c|c|c|c|c|c|c|}
\hline STATION. & & & DATE. & $\mathfrak{2}$ & 23 & (5 & $D$ & C: \\
\hline $\begin{array}{l}\text { Hamplon Roads : } \\
\text { St. Thomas : } \\
\text { lalia : } \\
\text { Monte Video : } \\
\text { Sandy Point: } \\
\text { Valparaiso : } \\
\text { Callao : } \\
\text { Janama: : } \\
\text { Acapulco : } \\
\text { San Francisco: }\end{array}$ & : & $:$ & $\begin{array}{lr}\text { November 1, I } 865 \\
\text { November I8, I } 865 \\
\text { December } 30,1865 \\
\text { January } & 24,1866 \\
\text { February } & 10,1866 \\
\text { April } & 4,1866 \\
\text { April } & 29,1866 \\
\text { May } & 20,1866 \\
\text { June } & 1,1866 \\
\text { June } & 23,1866\end{array}$ & & $\begin{array}{l}+0.011 \\
-0.017 \\
-0.008 \\
\quad \ldots .0 \\
+0.009 \\
+0.012 \\
+0.026 \\
+0.009 \\
+0.002 \\
+0.001\end{array}$ & $\begin{array}{l}+0.012 \\
-0.027 \\
-0.003 \\
+0.03 \\
+0.035 \\
=0.011 \\
-0.002 \\
=0.024 \\
+0.028\end{array}$ & $\begin{array}{l}+0.010 \\
-0.010 \\
-0.008 \\
+0.01 \\
+0.012 \\
+0.009 \\
+0.002 \\
+0.010 \\
+0.016\end{array}$ & $\begin{array}{r}+0.021 \\
+0.008 \\
-0.003 \\
\ldots . .0 \\
-0.014 \\
-0.003 \\
-0.017 \\
+0.026 \\
=0.016 \\
-0.004\end{array}$ \\
\hline
\end{tabular}


Value of the Computed minus the Observed Coefficients of the Deviations of the After Azimuth Compass.

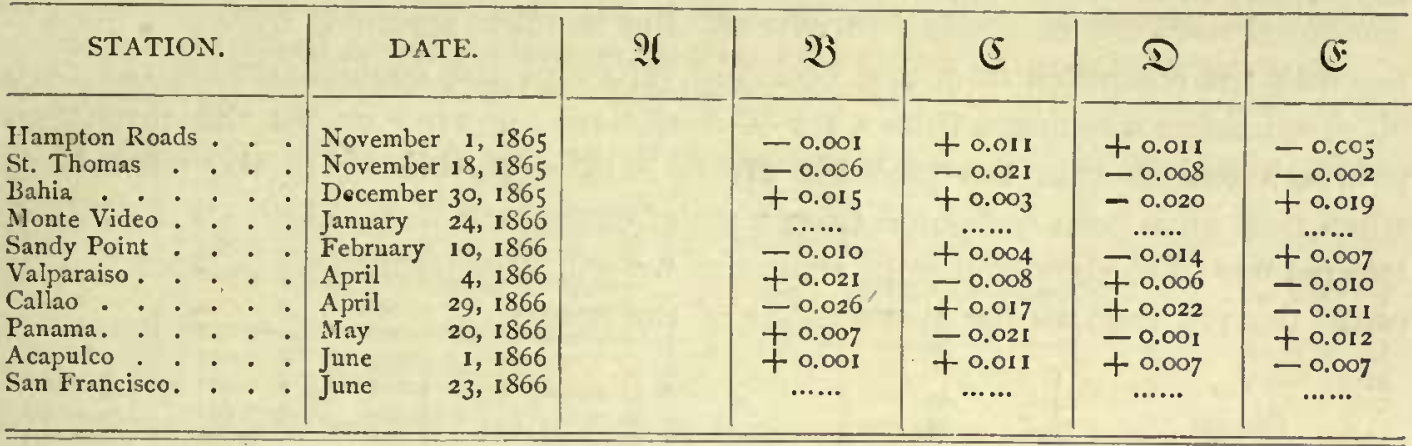

Value of the Computed minus the Observed Coefficients of the Deviations of the Forward Alidade Compass.

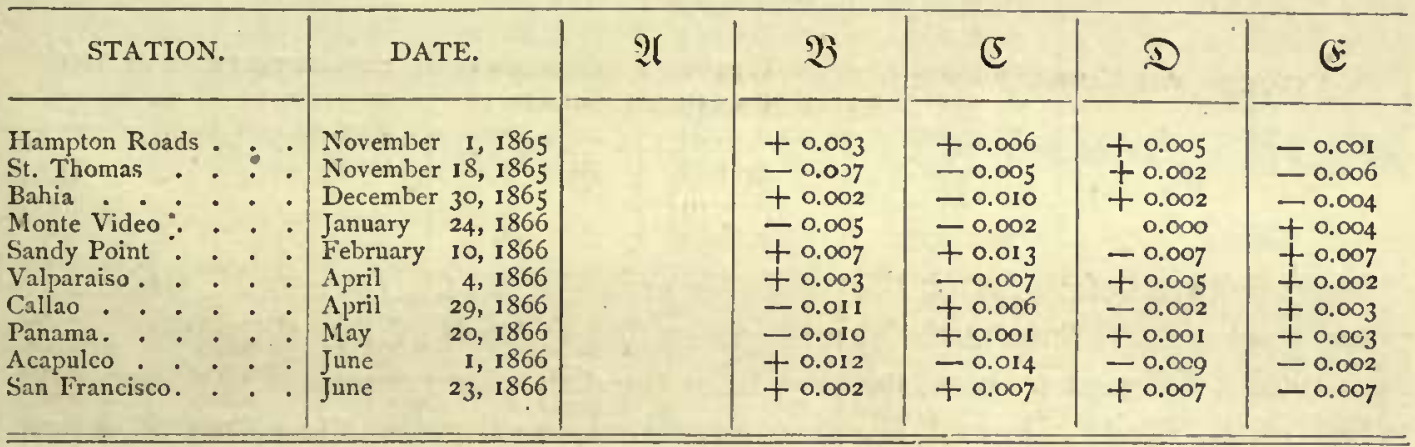

Value of the Computed minus the Observed Coefficients of the Deviations of the Forward Binnacle Compass.

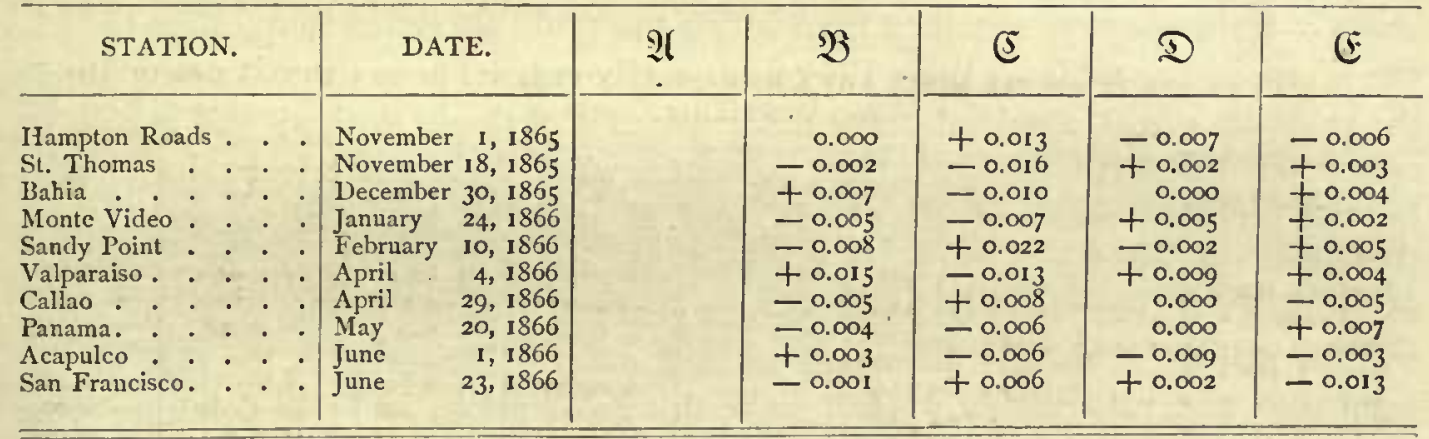

Value of the Computed minus the Observed Coefficients of the Deviations of the Forward Ritchie Compass.

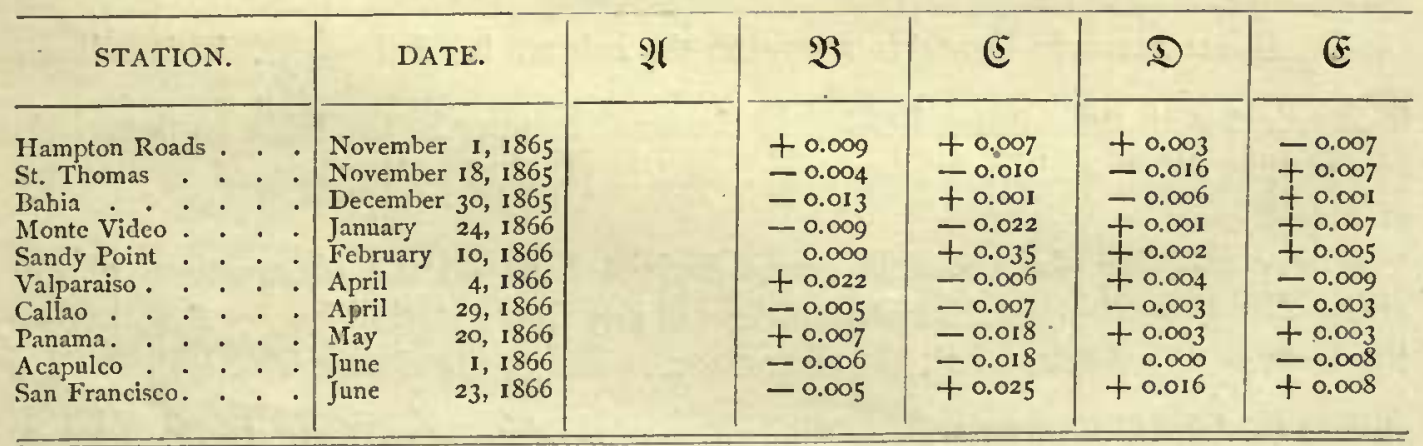


In the following table the columns headed $r_{\mathfrak{F}}, r_{\Xi}, r_{\mathfrak{D}}, r_{\mathbb{E}}$, contain respectively the probable errors of a single observed value of $\mathfrak{B}, \mathfrak{C}, \mathfrak{D}$, and $\mathfrak{E}$, for each compass, computed from the residuals just given. But as these residuals were got by subtracting the computed from the obscrved values of the coefficients, and as each observed value was found from a set of deviations observed on all the thirty-two points, it follows that the probable errors here given belong to the coefficients when they have been computed from a set of deviations observed on all the thirtytwo points. For convenience of reference we will designate these as the probable errors derived from all the observations of the cruise.

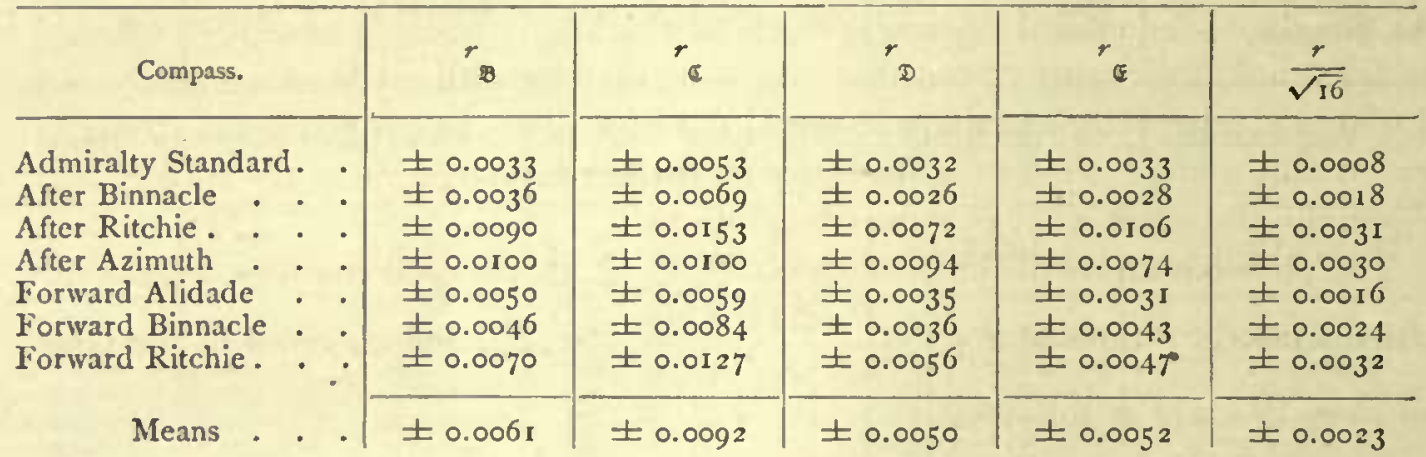

But we have before found the probable errors of $B_{1}, C_{1}, D_{1}$, and $E_{1}$, when computed from observations made at a single station on each of the thirty-two points, by a totally different process, namely, from the thirty-two observed deviations the values of $A_{1}, B_{1}, C_{1}, D_{1}$, and $E_{1}$, were computed; next, with the values of $A_{1}, B_{1}$, $C_{1}, D_{1}$, and $E_{1}$, thus found, the deviations were computed for each point; then, comparing these computed values of the deviation with the observed values, a series of residuals were obtained from which the probable errors in question (which are given in the table on page 185) were easily got. These we will designate as the probable crrors obtained from observations at a single station; and it will be remembered that it was shown that, no matter what their numerical values night be, the probable errors of $B_{1}, C_{1}, D_{1}$, and $E_{1}$ must all be equal to each other. Although the difference between the probable crrors of $B_{1}, C_{1}, D_{1}, E_{1}$, and those of $\mathfrak{B}, \mathfrak{C}, \mathfrak{D}, \mathfrak{E}$, can never be great, yet, in general, it would not be rigorously correct to assume that they are equal to each other. However, in the case of the compasses under discussion we will make this assumption, for by so doing no error greater than the uncertainty of the probable errors themselves will be introduced. In order to facilitate the comparison of the two sets of probable errors, those of $B_{1}$, $C_{1}, D_{1}, E_{1}$ are given in the table above, in the column headed $\frac{r}{\sqrt{16}}$. This column is idlentical with the cohmm headed in the same manner in the table on page 185 , except that the quantities are here expressed in parts of radius instead of minutes of arc.

Now, comparing the probable errors deriverl from all the observations of the cruise with those clerived from observations at any single station, we see that, taking the mean of the results for all the compasses, $r_{D}$ and $r_{\mathbb{E}}$ are almost identical, as they should be, but they are each more than twice as great as $\frac{\sqrt{16}}{16}$. On the other hand, 
$r_{\mathfrak{B}}$ and $r_{\mathscr{C}}$ are neither equal to each other, nor yet to $r_{\mathscr{D}}$ and $r_{\mathscr{E}}$, but are, the one nearly three, and the other four, times as great as $\frac{r}{\sqrt{16}}$. Assuming the theory employed in this discussion to be correct, we should have expected to find $r_{\mathfrak{g}}, r_{\varpi}$, $r_{I}, r_{E}$ sensibly equal to each other, and all sensibly equal to $\frac{r}{\sqrt{16}}$. Such, however, is not the case; and, as the results for each compass all tend in precisely the same direction as the mean result, a doubt naturally arises whether or not the theory really represents the semi-circular deviation as accurately as it does the quadrantal. As this doubt is founded upon observations which may possibly have been affected by some unknown cause of constant error-as they were all made on a single vessel during a single cruise-perhaps it would not be well to insist upon it too strongly; but at all events, it shows the necessity for further investigation of the subject, and especially the great want of more observations.

The probable errors of the coefficients $\mathfrak{B}, \mathfrak{C}, \mathfrak{D}, \mathfrak{E}$, for each compass, when computed from the values of $A_{1}, \frac{c}{\lambda}, \frac{P}{\lambda}, \frac{\Delta P}{\lambda}, \frac{f}{\lambda}, \frac{Q}{\lambda}, \frac{\Delta Q}{\lambda}, \mathfrak{D}$, and $\mathbb{E}$, given in the table on page 193, are as follows:

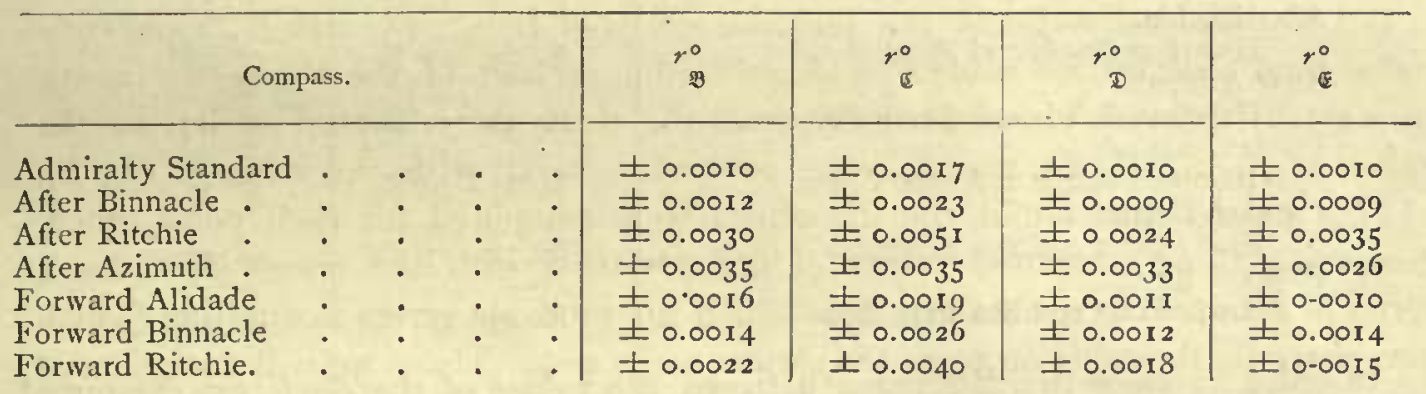

The following table shows, for each compass, the place at which the maximum value of its deviation, $\delta$, was the greatest, together with the point on which that maximum value occurred, and its amount. Also, the place at which the maximum value of its deviation was the least, together with the point on which that maximum occurred, and its amount. These deviations are given on the compass points, and in computing them the true $A$ was used.

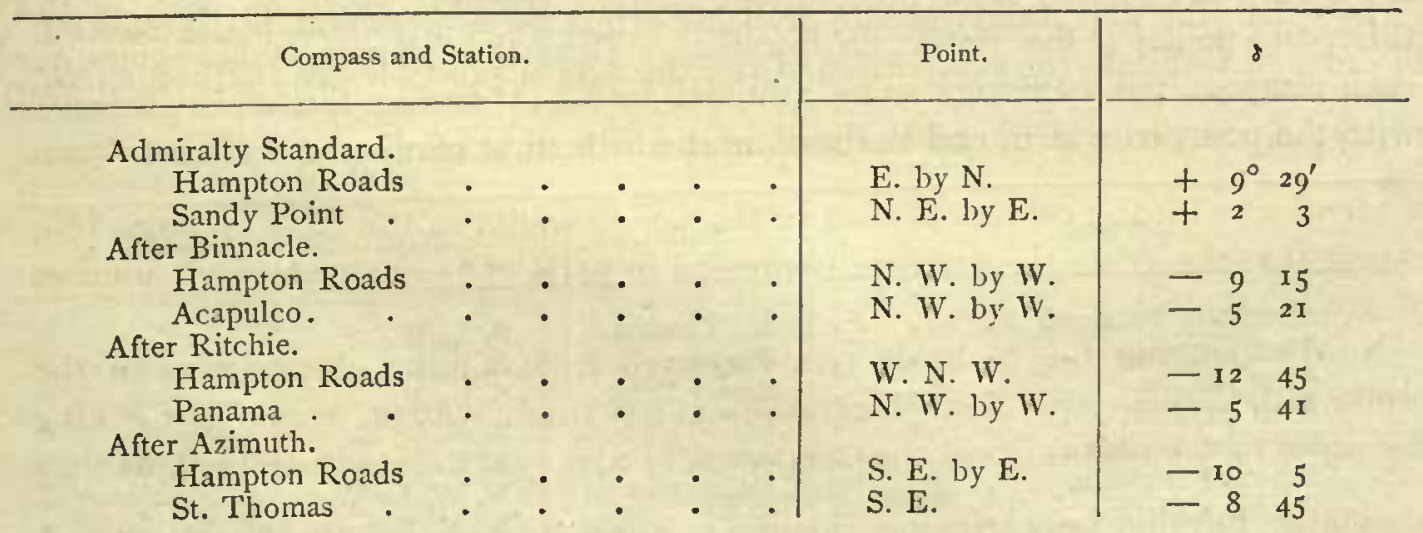




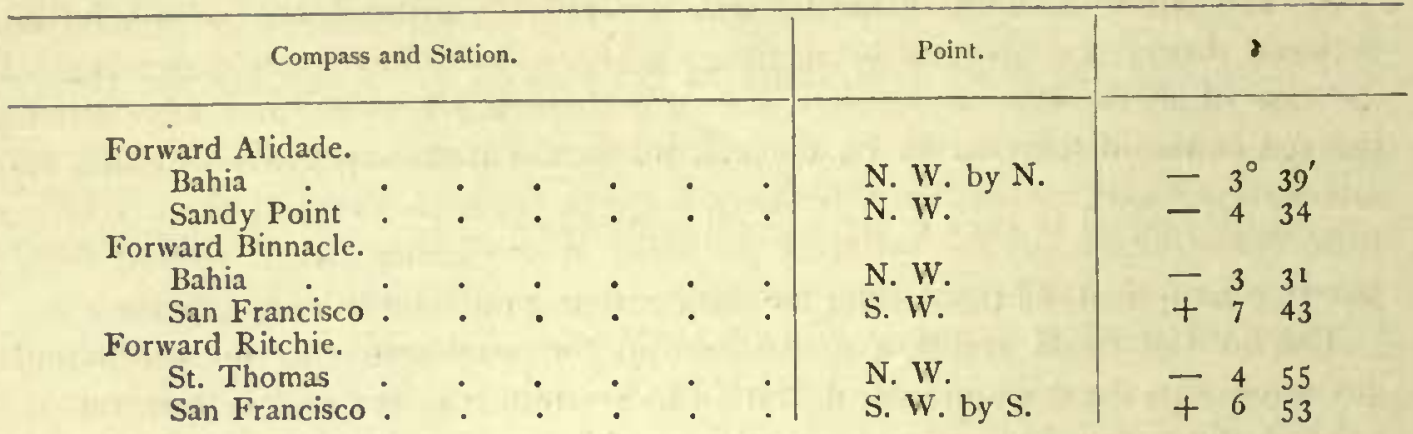

'The following table shows, for each compass, the maximum change, $\Delta s$, in its deviation, which occurred on any single point, together with the azimuth at which, and the places between which that change occurred.

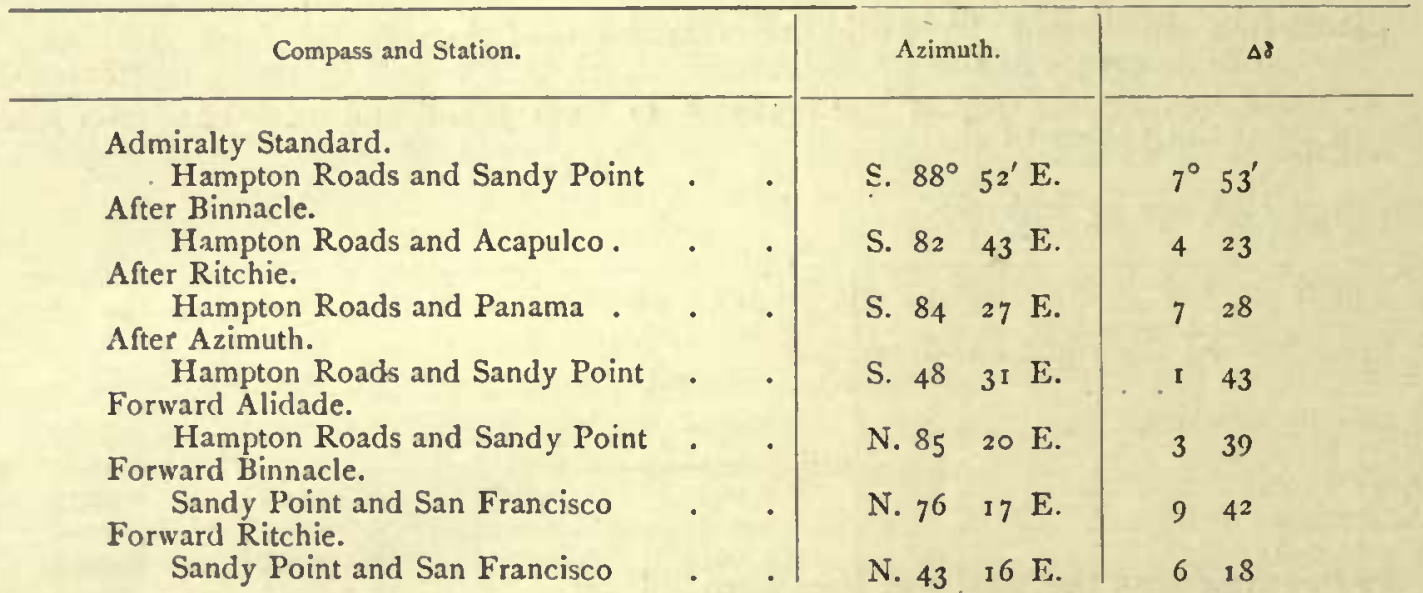

In order to show the difference between the values of the deviation computed from observations made at a single station, and those computed from all the observations of the cruise, or, in other words, the difference between the theory and the observations, let $\delta$ be the deviation of a compass on any point, $\zeta$, at a given station, as computed from values of $A_{1}, B_{1}, C_{1}, D_{1}, E_{1}$, derived from all the observations of that compass made during the cruise; and also let $\delta^{\prime}$ be the deviation of the same compass, on the same point, at the same station, as computed from values of $A_{1}$, $B_{1}, C_{1}, D_{1}, E_{1}$, derived from observations of that compass made on each of the thirty-two points at the station in question. 'Then the following table shows, for each compass, the maximum value attained by $\delta-\delta^{\prime}$ during the cruise, together with the point on which, and the station at which, that maximum occurred.

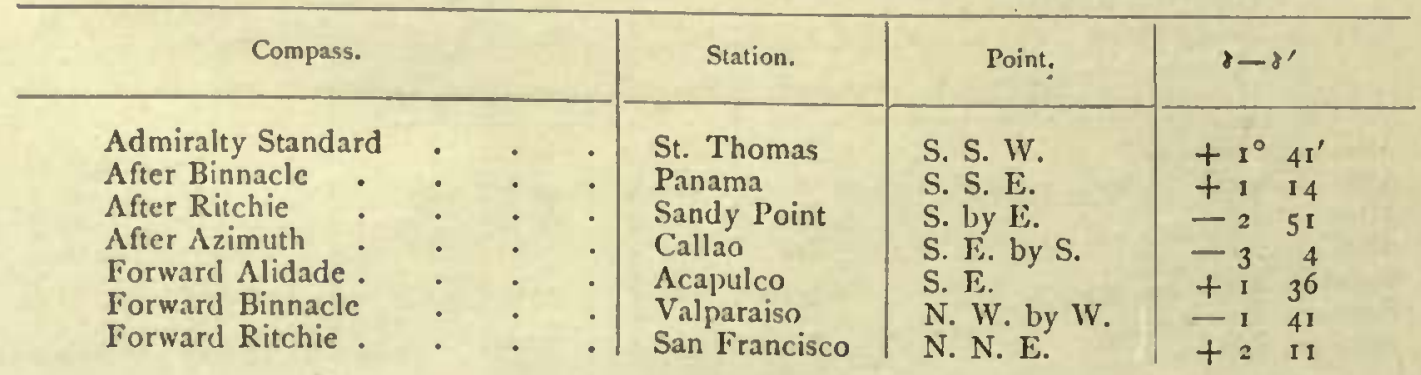


As the After Azimuth Compass was a very poor instrument, the descrepancy between theory and observation in the case of its deviations is not surprising. In the case of all the other compasses, except perhaps the Forward and After Ritchie, the agreement of the observed and computed values of the deviations is much more satisfactory; and indeed the differenees between them are so small as to be of very little consequence for the ordinary purposes of navigation; still, viewed from a purely scientific stand-point, they are larger than might have been expected.

The hard and soft iron forees involved in the production of the semi-circular deviation were next examined in order to ascertain whether or not their relations to each other were such as to render it possible, in the case of a vessel swung for the first time, to predict from the observed deviations of lier standard compass what the deviations would be at any other place. The coefficients of the semi-circular deviation are $\mathfrak{B}$ and $\mathfrak{E}$, and the components of the hard iron force involved in their production are $\frac{P}{\lambda}$ and $\frac{Q}{\lambda}$; while the components of the soft iron force are $\frac{c}{\lambda}$ and $\frac{f}{\lambda}$. As these components act at right angles to each other, the total hard iron force will be

$$
\sqrt{\frac{P^{2}}{\lambda^{2}}+\frac{Q^{2}}{\lambda^{2}}}
$$

and if we let $\alpha$ represent the direction in which it acts, measured from the ship's head toward the right hand, we have

$$
\tan \alpha=\frac{\frac{Q}{\lambda}}{\frac{P}{\lambda}}
$$

In the same way the total soft iron force will be

and to determine its direction we have

$$
\sqrt{\frac{c^{2}}{\lambda^{2}}+\frac{f^{2}}{\lambda^{2}}}
$$

$$
\tan \alpha^{\prime}=\frac{\frac{f}{\lambda}}{\frac{c}{\lambda}}
$$

\begin{tabular}{|c|c|c|c|c|c|c|c|c|}
\hline \multirow{3}{*}{ Compass. } & & & \multicolumn{4}{|c|}{ Hard Iron Force. } & \multirow{2}{*}{\multicolumn{2}{|c|}{ Soft Iron Force. }} \\
\hline & & & \multicolumn{2}{|c|}{ November I, 1865} & \multicolumn{2}{|c|}{ June $23,1866}$. & & \\
\hline & & & Amount. & Direction. & Amount. & Direction. & Amount. & Direction. \\
\hline Admiralty Standard & - & - & 0.460 & $000^{\circ} .8$ & 0.226 & $34^{\circ} .0$ & 0.024 & $35^{6^{\circ} . I}$ \\
\hline After Binnacle & - & - & 0.664 & 000.2 & 0.639 & 353.0 & 0.010 & 240.4 \\
\hline After Ritchie & . & - & 0.780 & 349.0 & $0.43 \mathrm{I}$ & 354.0 & 0.018 & 16.3 \\
\hline After Azimuth . & - & . & 0.375 & I 86.8 & 0.449 & 173.9 & 0.007 & I I I. 2 \\
\hline Forward Alidade. & . & - & 0.107 & 277.6 & 0.178 & $267 \cdot 3$ & 0.016 & I 84.2 \\
\hline Forward Binnacle & - & . & 0.159 & 331.9 & 0.254 & 280.1 & 0.048 & $187 . \mathrm{I}$ \\
\hline Forward Ritchie. & . & . & 0.376 & 347.2 & $0.3^{87}$ & 289.1 & 0.022 & 219.9 \\
\hline
\end{tabular}

By means of these formula the following table was computed. It shows the amount and direction of the hard and soft iron forces acting on each compass on November 1, 1865, and June 23, 1866. 
The following table shows the change, in amount and direction, of the hard iron force between November 1, 1865, and June 23, 1866; the ratio of the liard to the soft iron force on each of these dates; and also the mean ratio of the same forces.

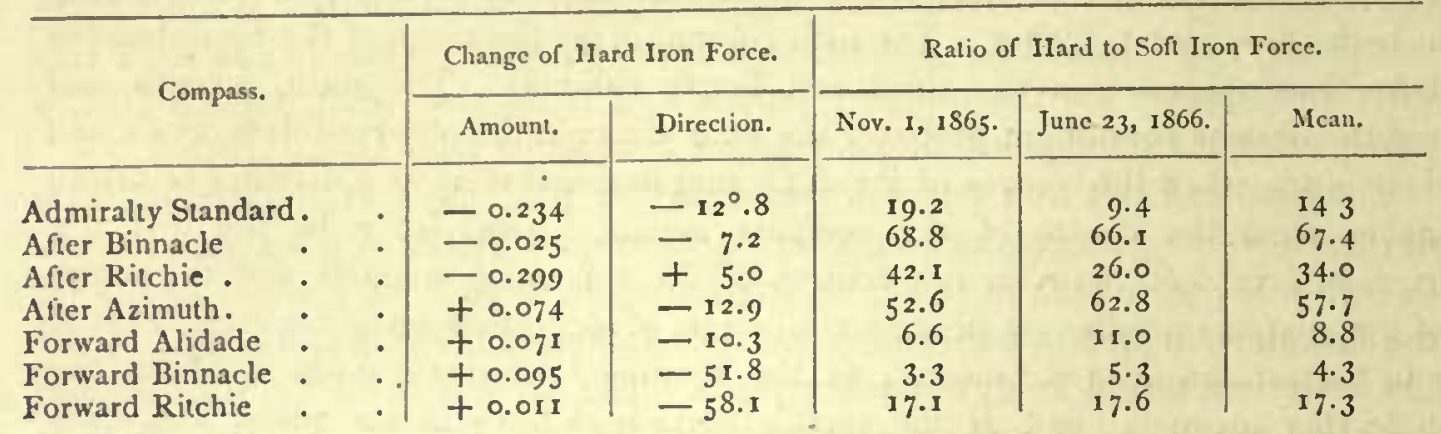

An examination of the last two tables showys that during the whole cruise the hard iron force was changing in a very remarkable manner, both in amount and direction. In the case of the three compasses monnted above the forward turret, the force was increasing: while in the case of those mounted above the after turret, it was lecreasing. In other words, there seems to have been a transfer of hard iron force from aft forward. Now, looking at the change in direction of the force, we sec that in every case, excepting only that of the After Ritchie, it took place in such a manner as to correspond to a rotation from right to left. Further, the ratio of the hard to the soft iron force was slowly varying at each compass; and for the clifferent compasses it ranged between 4.3 and 67.4. Finally, there was not a single compass on board at which the direction of the hard and soft iron force coincided; from which it follows that in no case was the ratio of the hard and soft iron forces the same in the coefficient $\mathfrak{B}$ as it was in the coefficient $\mathfrak{E}$. Under these circumstances we are forced to conclude that, so far as can be judged from the observations here given, in the case of a vessel swung for the first time it is impossible to make any reliable estimate of the ratio of the hard to the soft iron force in the coefficients $\mathfrak{B}$ and $\mathfrak{C}$; and, therefore, it is also impossible to make any reliable estimate as to what changes her deviations will undergo upon a change of magnetic latitude. As a further proof of this, we see that the After Azimuth Compass, with a maximum deviation of $10^{\circ} 5^{\prime}$, changed its deviation during the cruise by only $1^{\circ} 43^{\prime}$, that is, by about one-sixth of its whole amount; while the Forward Binnacle Compass, with a maximum deviation of only $7^{\circ} 43^{\prime}$ changed its deviation during the cruise by $9^{\circ} 4 \mathcal{Z}$, that is, by about one and a quarter times its whole amount.

In the beginning of this section it was stated that, at the positions occupied by the $\Lambda$ dmiralty Standard and $\Delta$ fter Azimuth Compasses, observations of deflection and dip were made in order to determine the absolute magnetic force; and the details of the metlod followerl in taking these observations were explained. We will now proceed to reduce and discuss the observations themselves, and for that purpose the first thing necessary to be known is the magnetic moment of the deflecting magnets. For its determination we have the observations recorded in the following table, which were all made on shore. The first and second columns 
of the table give the place where, and the date when, each observation was made. 'The third and fourth columns give respectively the observed deflections when the north ends of the deflecting magnets were directed towards the west and towards the east; the distance of their centres from the centre of the compass needle being in both cases eleren inches. The fifth column gives the mean of the four observed deflections recorded in the third and fourth columns. The sixth, seventh, and eighth columns contain, in precisely the same manner, the observed deflections, and their mean, when the centres of the deflecting maguets were at a distance of fifteen inches from the centre of the compass needle. Now, let $r$ be the distance, expressed in fect, between the centres of the deflecting magnets and the centre of the compass needle; $u$, the observed angle of deflection given for each value of $r$ in the column hearled "mean"; $m$, the combined magnetic moment of the two deflecting magnets; and $H$, the earth's horizontal foree at the place where the observation was made, taken from the table on page 61 . Then we shall have

$$
\frac{1}{2} r^{3} \tan u=\frac{m}{H}
$$

and the ninth column contains the mean of the two values of $\log \frac{m}{H}$ computed respectively from the angles of deflection observed with $r=11$ inches $=0.917$ foot, and $r=15$ inches $=1.250$ feet. The tenth column contains the value of log. $m$, found by adding to $\log \frac{m}{H}$ the known value of $\log . H$.

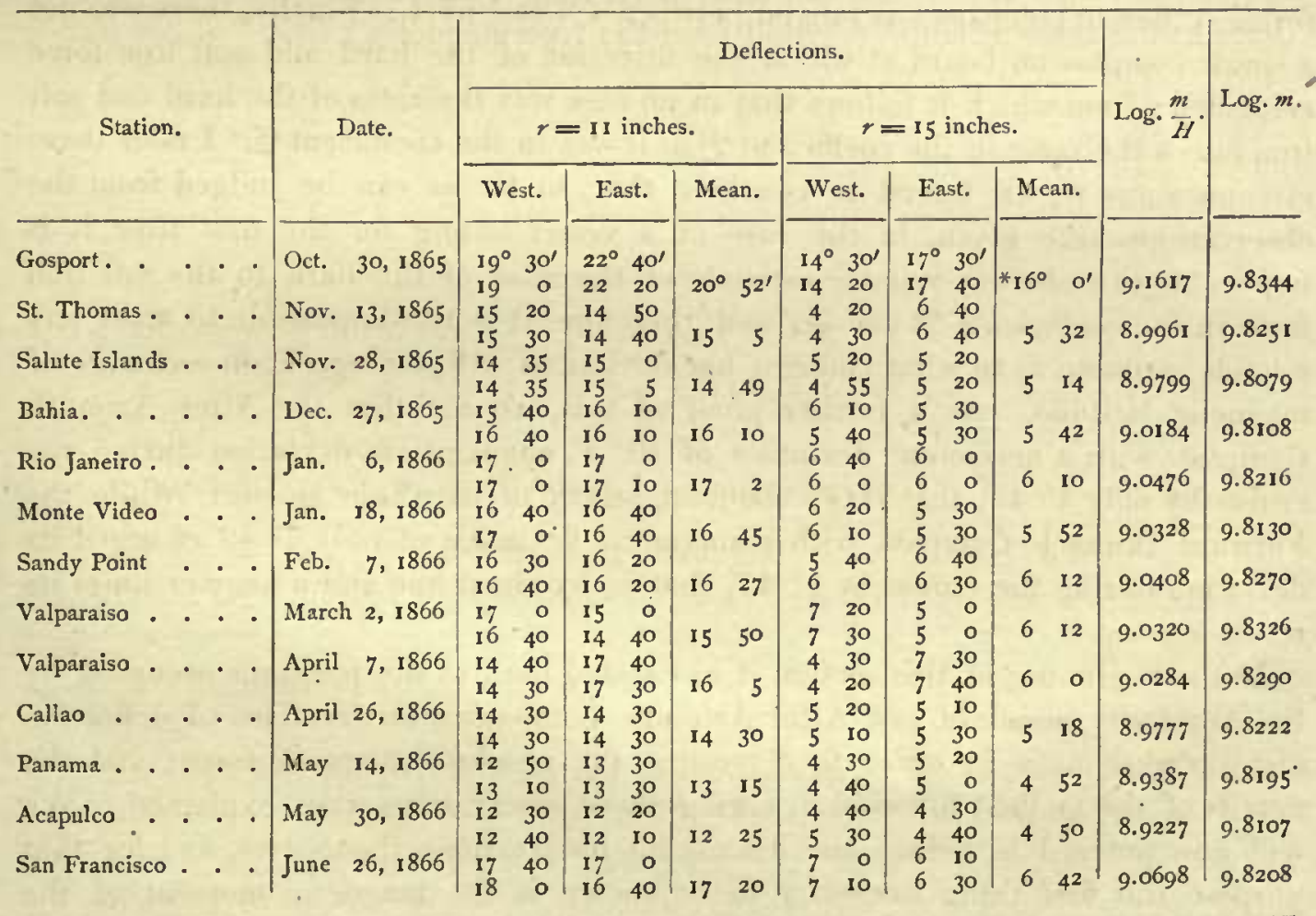


The observed values of $\log$. $m$ show no trace whatever of any change depending upon the time, and therefore the indiscriminate mean of them all has been taken as the truth, and we have

$$
\text { Log. } m=9.8211 \pm 0.0016 \text {. }
$$

The probable error of a single observed value of $\log . m$ is \pm 0.0058 .

The following table contains all the observations which were made at the position occupied by the Admiralty Standard Compass on board the Monadnock, for the determination of absolute force. The first nine columns contain quantities precisely similar to those in the columns headed in the same manner in the table last given. The column headed " $\mathrm{Log}$. $H$ '" gives the logarithm of the combined horizontal force of the earth and ship, obtained by subtracting $\log \frac{m}{H^{\prime}}$ from the value of $\log$. $m$ given above. The column " $\theta$ " contains the dip, which was observed immediately after the deflections. The column "Log. $Z$ " contains the logarithm of the combined vertical force of the earth and ship, computed from the quantities in the tenth and eleventh columns by the formula $Z^{\prime}=H^{\prime} \tan \theta^{\prime}$. The columns " Log. $\frac{H^{\prime}}{H}$,"

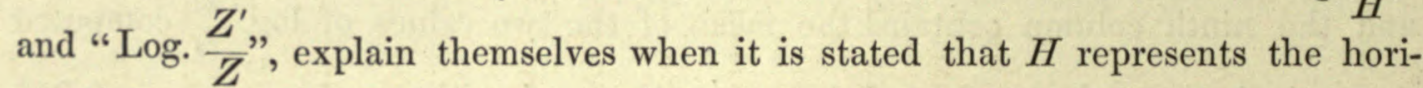
zontal force of the earth; $H^{\prime}$ the combined horizontal force of the earth and ship; $Z$ the earth's vertical force; and $Z^{\prime}$ the combined vertical force of the earth and - ship. The column " $\zeta$ " contains the azimuth of the ship's head as read off from the compass card at the time the deflections were observed; and the column " $\zeta$ " contains the same azimuth, counted from the true magnetic north. 


\begin{tabular}{|c|c|c|c|c|c|c|c|c|c|c|c|c|c|c|c|c|c|}
\hline & * & & & & 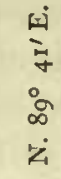 & 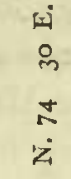 & $\begin{array}{l}\text { Ij } \\
\text { N } \\
\infty \\
\ddot{Z} \\
\dot{Z}\end{array}$ & $\begin{array}{l}3 \\
\text { i } \\
+ \\
z\end{array}$ & in & 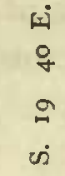 & $\begin{array}{l}3 \\
\dot{m} \\
\dot{m}\end{array}$ & $\begin{array}{l}3 \\
\text { a } \\
\text { i }\end{array}$ & $\begin{array}{l}\vec{Z} \\
\dot{m} \\
\text { in } \\
\dot{z}\end{array}$ & $\begin{array}{l}3 \\
0 \\
0\end{array}$ & $\begin{array}{l}3 \\
6 \\
y \\
z\end{array}$ & $\begin{array}{l}\text { is } \\
\text { i } \\
\text { i } \\
\text { is }\end{array}$ & ส \\
\hline & in & & $\approx$ & & $\begin{array}{l}15 \\
\text { in } \\
\text { co } \\
\text { zi }\end{array}$ & $\begin{array}{l}a \dot{1} \\
\stackrel{R}{2} \\
\dot{z}\end{array}$ & $\begin{array}{l}\dot{15} \\
\dot{m} \\
\dot{z}\end{array}$ & $\begin{array}{l}z \\
+ \\
z\end{array}$ & i & $\begin{array}{l}\text { मे } \\
\text { \& } \\
\text { के }\end{array}$ & $\begin{array}{l}\dot{z} \\
\dot{m} \\
\dot{8}\end{array}$ & $\begin{array}{l}\dot{3} \\
\text { i }\end{array}$ & $\begin{array}{l}\dot{z} \\
\text { in }\end{array}$ & 音 & $\begin{array}{l}\dot{z} \\
y \\
z\end{array}$ & $\begin{array}{l}\dot{1} \\
\dot{m} \\
\dot{m}\end{array}$ & 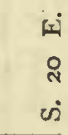 \\
\hline & 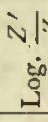 & & & & 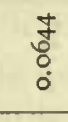 & & 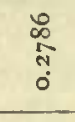 & $\begin{array}{l} \pm \\
\tilde{\infty} \\
\sigma \\
\sigma\end{array}$ & $\begin{array}{l}\text { No } \\
\text { है } \\
\text { Oे }\end{array}$ & $\begin{array}{l}\text { \% } \\
\text { ô } \\
0 \\
0\end{array}$ & $\begin{array}{l}\text { से } \\
\text { کे } \\
0\end{array}$ & 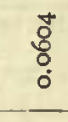 & $\begin{array}{l}0 \\
8 \\
8 \\
0\end{array}$ & $\begin{array}{l}\infty \\
\text { ळ. } \\
0 \\
0 \\
0\end{array}$ & $\begin{array}{l}\text { है } \\
0 \\
0\end{array}$ & $\begin{array}{l}\text { 1 } \\
\text { d } \\
0 \\
0\end{array}$ & $\begin{array}{l}0 \\
0 \\
0 \\
0 \\
0\end{array}$ \\
\hline & 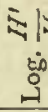 & & $\begin{array}{l}\mathscr{\sigma} \\
\dot{a} \\
\dot{\alpha}\end{array}$ & $\begin{array}{l}\text { ๙్ } \\
\alpha \\
\alpha\end{array}$ & \begin{tabular}{l}
0 \\
\multirow{2}{\alpha}{} \\
$\alpha$ \\
$\alpha$
\end{tabular} & $\begin{array}{l}\stackrel{\circ}{\circ} \\
\text { ू. } \\
\text { a }\end{array}$ & \%ু & $\begin{array}{l}\circ \\
8 \\
8 \\
0\end{array}$ & \begin{tabular}{l}
$\infty$ \\
\multirow{\infty}{0}{} \\
$\dot{\sigma}$ \\
$\dot{\sigma}$
\end{tabular} & $\begin{array}{l}\stackrel{\infty}{4} \\
\text { แू }\end{array}$ & $\begin{array}{l}\text { ๙̃ } \\
\alpha \\
\alpha \\
\alpha\end{array}$ & 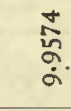 & $\begin{array}{l}1 \\
\text { \% } \\
\alpha \\
\sigma\end{array}$ & 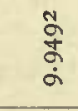 & 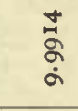 & 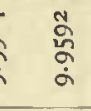 & ले \\
\hline & ì & & & & $\stackrel{\infty}{\tilde{n}}$ & & $\begin{array}{l}\vec{\pi} \\
\text { aू } \\
\alpha\end{array}$ & $\begin{array}{l}\infty \\
\text { â } \\
\alpha \\
\alpha\end{array}$ & $\frac{8}{0}$ & $\begin{array}{l}\text { ปै } \\
\stackrel{0}{0}\end{array}$ & $\begin{array}{l}\text { J్ } \\
\text { oे } \\
0\end{array}$ & $\frac{\pi}{0}$ & $\begin{array}{l}\text { o } \\
\text { o. } \\
0\end{array}$ & $\begin{array}{l}\text { ผ } \\
\text { dू } \\
\alpha\end{array}$ & 志 & {$\left[\begin{array}{l}0 \\
0 \\
0 \\
0 \\
0 \\
0\end{array}\right.$} & 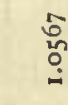 \\
\hline & is & & - & & $\begin{array}{l}\text { oे } \\
\vdots \\
\vdots \\
+\end{array}$ & & $\begin{array}{l}8 \\
\infty \\
+\end{array}$ & $\begin{array}{l}0 \\
\infty \\
1\end{array}$ & $\begin{array}{l}0 \\
1 \\
1\end{array}$ & $\begin{array}{l}\text { i } \\
i \\
i\end{array}$ & $\begin{array}{l}8 \\
8 \\
1\end{array}$ & $\begin{array}{l}0 \\
\text { j }\end{array}$ & $\begin{array}{l}n \\
\text { in } \\
1\end{array}$ & $\begin{array}{l}\stackrel{2}{+} \\
1\end{array}$ & $\begin{array}{l}\text { \& } \\
\dot{m} \\
+\end{array}$ & $\begin{array}{l}\text { ำ } \\
2 \\
+\quad \\
+\end{array}$ & $\begin{array}{l}5 \\
+\end{array}$ \\
\hline & ڤ్ & & $\begin{array}{l}\text { బै } \\
\text { గे } \\
0\end{array}$ & $\begin{array}{l}\infty \\
\infty \\
\\
0\end{array}$ & $\begin{array}{l}\text { 品 } \\
\text { o } \\
\text { í }\end{array}$ & 苋 & 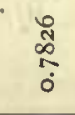 & 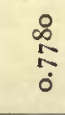 & 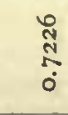 & 웅 & 蒈 & $\begin{array}{l}\stackrel{0}{\infty} \\
\stackrel{0}{\mathfrak{h}} \\
0\end{array}$ & 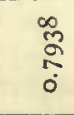 & $\begin{array}{l}\hat{\sigma} \\
\hat{0} \\
0\end{array}$ & $\begin{array}{c}\text { D } \\
\text { Do } \\
0\end{array}$ & \begin{tabular}{c}
0 \\
\multirow{5}{*}{} \\
0 \\
0
\end{tabular} & $\begin{array}{l}\text { 告 } \\
\text { के } \\
0\end{array}$ \\
\hline & $\begin{array}{c}: ! \\
0 \\
0 \\
3\end{array}$ & : & 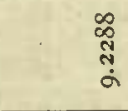 & $\begin{array}{l}\infty \\
\text { ర్ } \\
\dot{\sigma} \\
\dot{\alpha}\end{array}$ & $\begin{array}{l}\vec{b} \\
\dot{0} \\
\dot{\sigma}\end{array}$ & $\begin{array}{l}\hat{\sigma} \\
\dot{0} \\
\dot{\sigma}\end{array}$ & $\begin{array}{l}\infty \\
0 \\
0 \\
\alpha\end{array}$ & $\begin{array}{l}\tilde{m} \\
\dot{\sigma} \\
\dot{\sigma}\end{array}$ & $\begin{array}{l}n \\
0 \\
\delta \\
0\end{array}$ & $\begin{array}{l}\tilde{\Delta} \\
\text { \& } \\
\dot{\alpha}\end{array}$ & 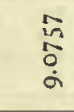 & $\begin{array}{l}\tilde{b} \\
\dot{\sigma} \\
\dot{\sigma}\end{array}$ & 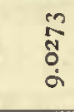 & $\begin{array}{l}\text { to } \\
\text { ồ } \\
\dot{a}\end{array}$ & $\begin{array}{c}\text { के } \\
\text { के } \\
\text { के }\end{array}$ & 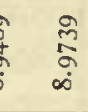 & \begin{tabular}{l}
$: 0$ \\
\hdashline \\
0
\end{tabular} \\
\hline & & 局 & & $\begin{array}{l}\text { iे } \\
\text { io }\end{array}$ & $\begin{array}{l}0 \\
0\end{array}$ & $\begin{array}{l}\text { N } \\
0\end{array}$ & $=$ & N & in & นี & & & $\begin{array}{l}0 \\
0\end{array}$ & & L & $\begin{array}{l}\text { 4 } \\
\text { I }\end{array}$ & $\stackrel{\infty}{7}$ \\
\hline & 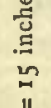 & 惢 & & $\begin{array}{l}0^{\circ} \\
\text { in }\end{array}$ & $g^{\circ}$ & $\begin{array}{l}00 \\
00\end{array}$ & $\begin{array}{l}\circ 0 \\
00 \\
00\end{array}$ & $\begin{array}{l}\circ 0 \\
00\end{array}$ & $\begin{array}{l}\text { 옹 } \\
\text { N }\end{array}$ & 웅 & 요 & & & & o d & 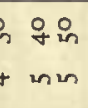 & $\begin{array}{l}00 \\
09\end{array}$ \\
\hline . & " & 范 & & $\begin{array}{l}\text { 항아 } \\
\text { 잉 }\end{array}$ & $\begin{array}{l}\dot{i} q \\
00\end{array}$ & $\begin{array}{l}00 \\
\text { no }\end{array}$ & & $\begin{array}{l}\text { 유요 } \\
00\end{array}$ & & & & & $\begin{array}{l}1 \\
0\end{array}$ & & o : & $\begin{array}{l}00 \\
0\end{array}$ & $\begin{array}{l}80 \\
0 \mathrm{~m}\end{array}$ \\
\hline 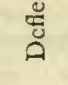 & & 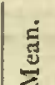 & $\begin{array}{l}\text { j } \\
\text { in }\end{array}$ & 용 & $\cong$ & & & & & & & & $\circ$ & & - & in & . \\
\hline & 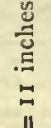 & $\dot{\vec{g}}$ & 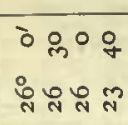 & 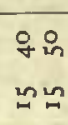 & $\begin{array}{l}00 \\
0 \%\end{array}$ & $\begin{array}{l}\text { 웅 } \\
\text { 윰유 }\end{array}$ & $\begin{array}{l}00 \\
00\end{array}$ & 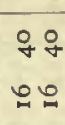 & $\begin{array}{l}q q \\
\infty \\
\infty 2\end{array}$ & $\begin{array}{l}\text { 융 } \\
\infty \infty \\
\infty\end{array}$ & $\begin{array}{l}\text { 용 } \\
\infty \infty \infty\end{array}$ & $\begin{array}{l}\text { 용 } \\
\text { =n }\end{array}$ & $\begin{array}{l}q \circ \\
\pm \pm\end{array}$ & $\begin{array}{l}00 \\
0 \%\end{array}$ & $\begin{array}{l}q \circ \\
\simeq m\end{array}$ & $\begin{array}{l}z+q \\
z \\
z\end{array}$ & 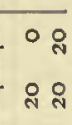 \\
\hline & "I & $\stackrel{\dot{y}}{=}$ & 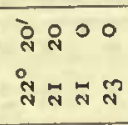 & $\begin{array}{l}20 \\
=5\end{array}$ & 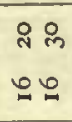 & $\begin{array}{l}00 \\
\infty=\end{array}$ & $\begin{array}{l}8^{\circ} \\
\circ \circ\end{array}$ & 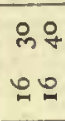 & $\begin{array}{l}\text { 웅 } \\
\text { is }\end{array}$ & $\begin{array}{l}00 \\
\infty \infty \\
\infty\end{array}$ & $\begin{array}{l}\circ g \\
\circ \stackrel{g}{0}\end{array}$ & 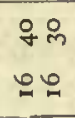 & $\begin{array}{l}80 \\
=\therefore\end{array}$ & 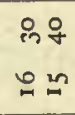 & & $\begin{array}{r}\text { 잉 } \\
+9 m\end{array}$ & $\begin{array}{l}\circ \% \\
\circ 9\end{array}$ \\
\hline & ฮี & & 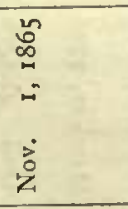 & 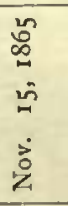 & 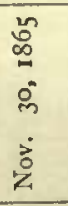 & 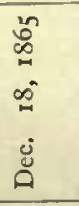 & 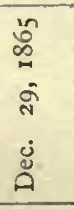 & 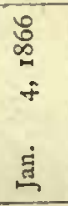 & 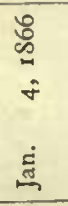 & 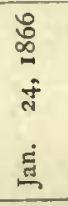 & 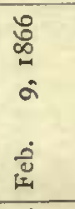 & 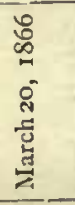 & 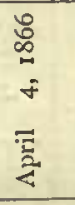 & 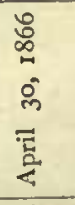 & 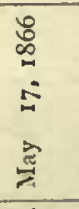 & 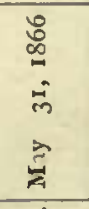 & 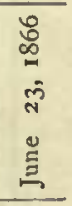 \\
\hline & 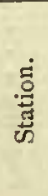 & & 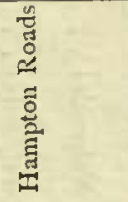 & 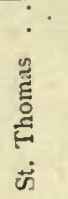 & 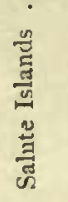 & $\begin{array}{l}\vdots \\
\vdots \\
\text { J }\end{array}$ & $\begin{array}{c}\vdots \\
\vdots \\
\text { 范 }\end{array}$ & & 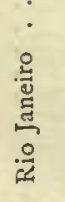 & 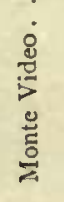 & 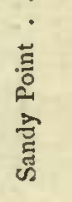 & 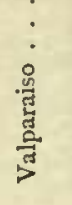 & 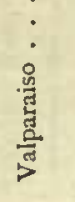 & $\begin{array}{l}\vdots \\
\vdots \\
\text { ڤึ }\end{array}$ & $\begin{array}{l}\vdots \\
\vdots \\
\text { हू } \\
\text { 芴 }\end{array}$ & 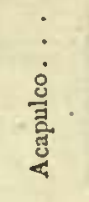 & 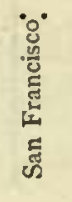 \\
\hline
\end{tabular}


The following table contains, in precisely the same manner, all the observations. which were made for the determination of absolute force at the position occupied by the After Azimuth Compass on board the Monadnock.

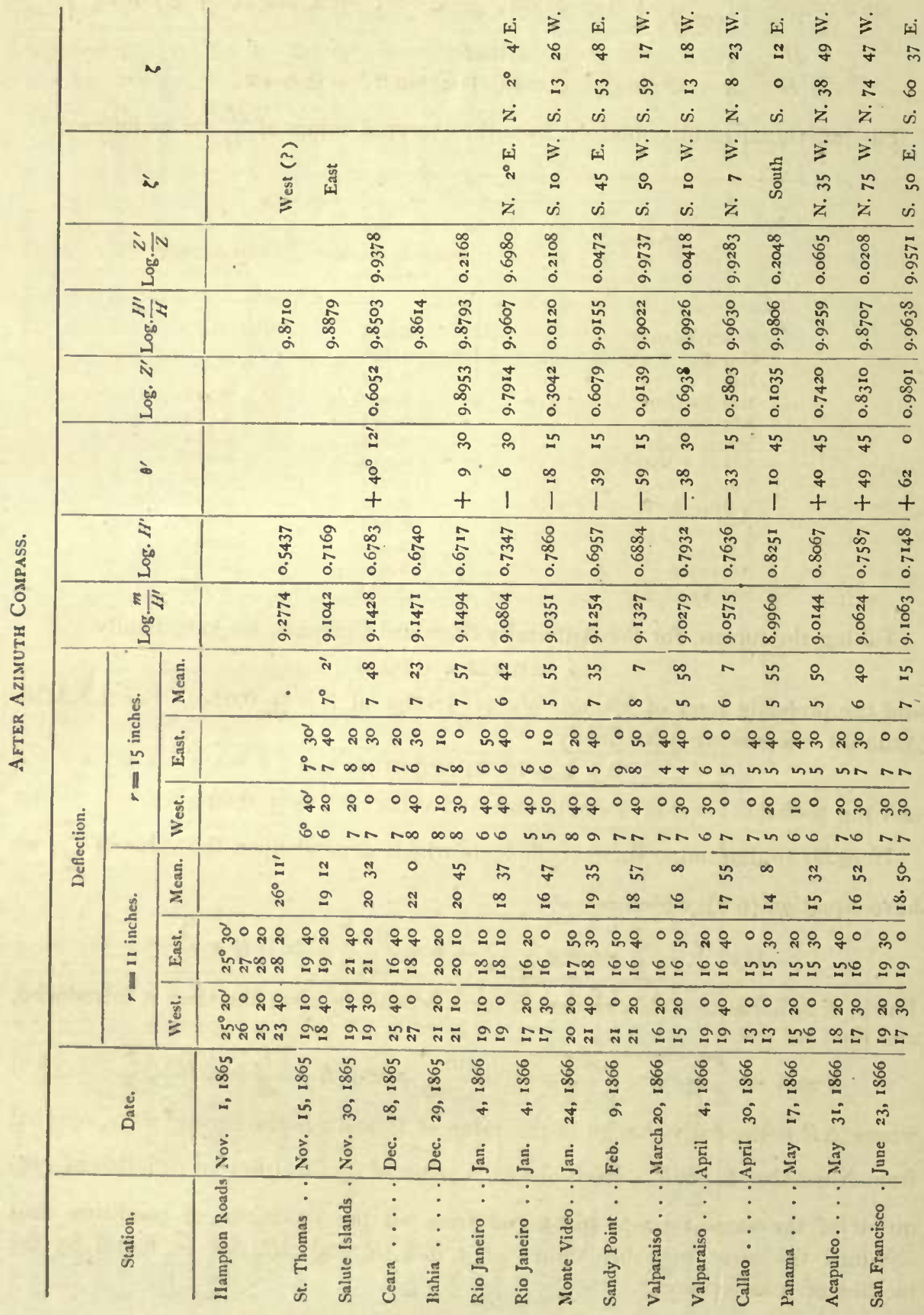


From the data already given, the value of $\lambda$ was next computed by means of the formulæ

$$
\begin{aligned}
\sin \delta & =\frac{1}{1-\mathfrak{D} \cos 2 \zeta^{\prime}}\left[\mathfrak{Q}+\mathfrak{B} \sin \zeta^{\prime}+\mathfrak{C} \cos \zeta^{\prime}+\mathfrak{D} \sin 2 \zeta^{\prime}+\mathfrak{C} \cos 2 \zeta^{\prime}\right] \\
\lambda & =\frac{I^{\prime}}{I I} \times \frac{\sin \delta}{\mathfrak{I}+\mathfrak{B} \sin \zeta+\mathfrak{C} \cos \zeta+\mathfrak{D} \sin 2 \zeta+\mathfrak{C} \cos 2 \zeta}
\end{aligned}
$$

The individual results obtained from the observed values of $\frac{H^{\prime}}{H}$ are as follows:

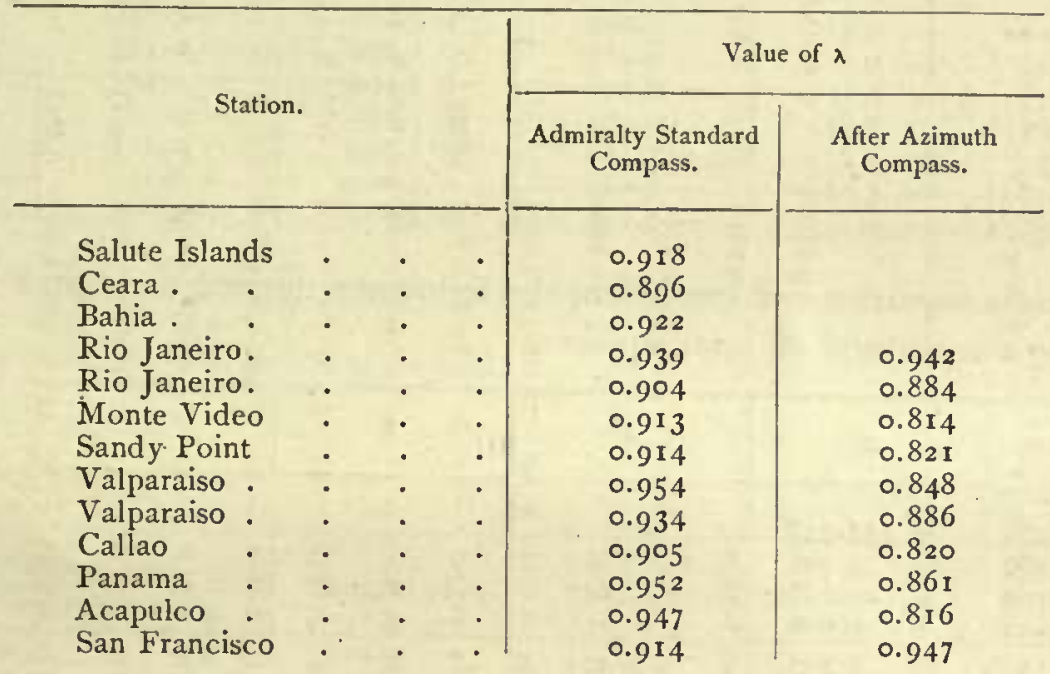

Taking the means, for the Admiralty Standard Compass, we have finally

$$
\lambda=0.924 \pm 0.0036
$$

and the probable error of a single observed value of $\lambda$ is \pm 0.013 . For the After Azimuth compass we have finally

$$
\lambda=0.864 \pm 0.0107
$$

and the probable error of a single observed value of $\lambda$ is \pm 0.034 .

In order to determine these coefficients which depend upon the value of $\frac{Z^{\prime}}{Z}$, we have equation $(6$ a), which is

$$
0=1-\frac{Z^{\prime}}{Z}+g \times \frac{\cos \zeta}{\tan \theta}-h \times \frac{\sin \zeta}{\tan \theta}+\hbar+R \times \frac{1}{Z}
$$

But as $R$ is liable to a slow ehange, a term depending upon the time is introduced, and then we get

$$
0=1-\frac{Z^{\prime}}{Z}+g \times \frac{\cos \zeta}{\tan \theta}-h \times \frac{\sin \zeta}{\tan \theta}+\hbar+R \times \frac{1}{Z}+\Delta R \times \frac{t}{Z}
$$

where $\Delta R$ is the daily change in the value of $R$, and $t$ is the time in days, counted from November 1, 1865. Each observed value of $\frac{Z^{\prime}}{Z}$ furnishes an equation of condition of the same form as $(6 \mathrm{~b})$, and from all the equations of condition thus obtained the most probable values of $g, h, l, R$, and $\Delta R$, can be found by the method of least squares. 
The following are the equations of condition, formed in the manner just explained, for the Admiralty Standard Compass.

\begin{tabular}{|c|c|c|c|c|c|}
\hline Absolute Term. & $g$ & $h$ & $k$ & $R$ & $\Delta R$ \\
\hline $0=-0.160$ & +0.008 & $-\mathrm{I} .448$ & +1.000 & +0.215 & $+\quad 6.24$ \\
\hline $0=-0.899$ & +10.23 & -8.007 & +1.000 & +2.097 & +125.8 \\
\hline $0-+0.320$ & -4.779 & $-0.37^{6}$ & +1.000 & -0.806 & $-5 \mathrm{I} .6 \mathrm{I}$ \\
\hline $0--0.14 \mathrm{I}$ & $4.79 I$ & -0.164 & +1.000 & -0.806 & $5 \mathrm{I} .6 \mathrm{I}$ \\
\hline $0-0.108$ & $1.56 \mathrm{I}$ & $+0.55^{8}$ & +1.000 & -0.275 & 23.10 \\
\hline $0=-0.129$ & 0.545 & -0.442 & +1.000 & -0.115 & I I. 48 \\
\hline $0=-0.149$ & 1.322 & -0.485 & +1.000 & -0.223 & $30.7^{6}$ \\
\hline $0=-0.016$ & I. $40 \mathrm{I}$. & -0.140 & +1.000 & -0.223 & $-34 \cdot 3^{2}$ \\
\hline $0=-0.068$ & 8.822 & -0.033 & +1.000 & -1.263 & $-227 \cdot 3$ \\
\hline $0=-0.175$ & I. 132 & +1.136 & +1.000 & +0.211 & $+4 \mathrm{I} .59$ \\
\hline $0=-0.118$ & 1.046 & -0.580 & +1.000 & +0.155 & 32.66 \\
\hline $0=-0.05^{8}$ & - 0.497 & -0.165 & +1.000 & +0.093 & 21.74 \\
\hline
\end{tabular}

From these equations of condition, the following normal equations have been obtained by the method of least squares.

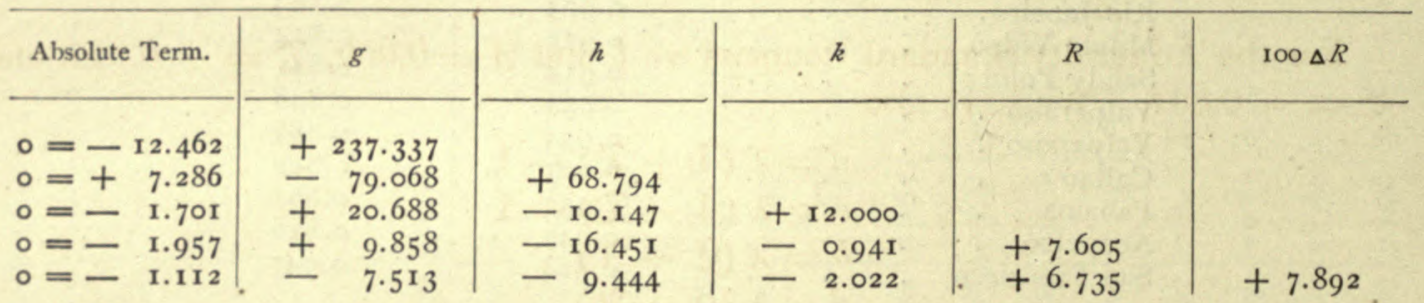

Solving, we find

$$
\begin{array}{rr}
g=+0.04070 & k=+0.1006 \\
h=+0.00504 & R=+0.1665 \\
100 \Delta R=+0.0694
\end{array}
$$

Substituting these results in the equations of condition, we find that the probable error of a single observed value of $\frac{Z^{\prime}}{Z}$ is \pm 0.024 , and the probable error of a computed value of $\frac{Z^{\prime}}{Z}$ is \pm 0.007 .

In a precisely similar manner, from the values of $\frac{Z^{\prime}}{Z}$ observed at the position of the After Azimuth Compass, we obtain the following equations of condition.

\begin{tabular}{l|c|c|c|c|c}
\hline Absolute Term. & \multicolumn{1}{|c|}{$g$} & $h$ & $k$ & $R$ & $\Delta R$ \\
\hline $0=+0.501$ & -4.790 & +0.173 & +1.000 & -0.806 & -51.61 \\
$0=-0.625$ & +4.663 & -1.114 & +1.000 & -0.806 & -51.61 \\
$0=-0.115$ & +0.979 & +1.338 & +1.000 & -0.275 & --23.10. \\
$0=+0.059$ & +0.358 & -0.603 & +1.000 & -0.115 & -11.48 \\
$0=-0.101$ & +1.370 & -0.324 & +1.000 & -0.223 & -30.76 \\
$0=+0.152$ & -1.393 & -0.205 & +1.000 & -0.223 & -34.32 \\
$0=-0.602$ & +8.823 & +0.031 & +1.000 & -1.263 & -227.3 \\
$0=-0.165$ & +1.250 & +1.006 & +1.000 & +0.211 & +41.59 \\
$0=-0.049$ & +0.314 & +1.154 & +1.000 & +0.155 & +32.66 \\
$0=+0.094$ & -0.257 & -0.456 & +1.000 & +0.093 & +21.74
\end{tabular}


And the resulting normal equations are

\begin{tabular}{|c|c|c|c|c|c|}
\hline Absolute Term. & $g$ & $h$ & $k$ & $R$ & $100 \Delta R$ \\
\hline $0=-\mathrm{II} .3 \mathrm{I} 3$ & $+\mathrm{I} 29.164$ & & & & \\
\hline $0=+0.3 \mathrm{II}$ & -3.078 & +6.125 & & & \\
\hline $\begin{array}{l}0=0.851 \\
0=0.840\end{array}$ & $\begin{array}{l}\text { II.3I } 7 \\
\text { Ir.053 }\end{array}$ & $\begin{array}{l}+1.000 \\
+0.888\end{array}$ & $\begin{array}{l}+10.000 \\
\quad 3.253\end{array}$ & +3.161 & \\
\hline $0=+1.367$ & $\begin{array}{l}\mathbf{1} \mathrm{r} .053 \\
-\quad \mathrm{I} 9.634\end{array}$ & $\begin{array}{l}+0.888 \\
+1.042\end{array}$ & $\begin{array}{r}3.253 \\
-\quad 3.342\end{array}$ & $\begin{array}{l}T .108 \\
+4.084\end{array}$ & +6.305 \\
\hline
\end{tabular}

Solving, we find

$$
\begin{array}{rr}
g=+0.11398 & k=-0.0509 \\
h=+0.00981 & R=-0.3918 \\
& 100 \Delta R=+0.3634
\end{array}
$$

Substituting these results in the equations of condition, the probable error of a single observed value of $\frac{Z^{\prime}}{Z}$ comes out \pm 0.030 , and the probable error of a computed value of $\frac{Z^{\prime}}{Z}$ comes out \pm 0.010 .

For the Admiralty Standard Compass we found $\mathfrak{P}=0.000, \mathcal{D}=+0.017$, and E $=-0.001$. We have also

Hence

$$
\begin{aligned}
& a=\lambda(1+\mathfrak{D})-1 \\
& e=\lambda(1-\mathfrak{D})-1 \\
& b=\lambda(\mathfrak{E}-\mathfrak{A}) \\
& d=\lambda(\mathfrak{E}+\mathfrak{A})
\end{aligned}
$$

$$
\begin{aligned}
& a=-0.0605 \\
& b=-0.0008
\end{aligned}
$$$$
\begin{aligned}
& e=-0.0917 \\
& d=-0.0008
\end{aligned}
$$

For the After Azimuth Compass we found $\mathfrak{T}=0.000, \mathfrak{D}=+0.112$, and ङ $=0.000$. Hence, in the same manner,

$$
\begin{array}{ll}
a=-0.0396 & e=-0.2324 \\
b=0.0000 & d=0.0000
\end{array}
$$

Collecting our results, we have the following final values of the coefficients of the Admiralty Standard Compass.

$\mathfrak{H}=0.000$

$\mathfrak{B}=+0.0240 \tan \theta+0.460 \frac{\mathrm{r}}{H}-0.00102 \frac{t}{H} \pm 0.00 \mathrm{r}$

C $=-0.0016 \tan \theta+0.006 \frac{\mathrm{I}}{H}-0.00023 \frac{t}{H} \pm 0.002$

$\mathcal{D}=+0.017 \pm 0.001$

E $=-0.001 \pm 0.001$

$\frac{Z^{\prime}}{Z}=\mathrm{r}+0.0407 \frac{\cos \zeta}{\tan \theta}-0.0050 \frac{\sin \zeta}{\tan \theta}+0.1006+0.1665 \frac{\mathrm{I}}{Z}+0.000694 \frac{t}{Z} \pm 0.007$

27 December, 1872. 
$\lambda=+0.924 \pm 0.004$

$\frac{c}{\lambda}=+0.0240$

$\frac{P}{\lambda}=+0.460$

$\frac{\Delta P}{\lambda}=-0.00102$

$\frac{f}{\lambda}=-0.0016$

$\frac{Q}{\lambda}=+0.006$

$\frac{\Delta Q}{\lambda}=-0.00023$

$$
\begin{gathered}
c=+0.0221 \\
P=+0.425 \\
\Delta P=+0.00094 \\
f=-0.0015 \\
Q=+0.006 \\
\Delta Q=-0.00021 \\
a=-0.0605
\end{gathered}
$$$$
b=-0.0008
$$

$d=-0.0008$

$e=-0.0917$

$g=+0.0407$

$h=+0.0050$

$k=+0.1006$

$R=+0.166$

$\Delta R=+0.00069$

Hence, the general equations for the determination of the deviations of this compass are

$$
\begin{aligned}
& X^{\prime}=X-0.0605 X-0.0008 Y+0.0221 Z+0.425-0.00094 t \\
& Y^{\prime}=Y-0.0008 X-0.0917 Y-0.0015 Z+0.006-0.00021 t \\
& Z^{\prime}=Z+0.0407 X+0.0050 Y+0.1006 Z+0.166+0.00069 t
\end{aligned}
$$

The following are the final values of the coefficients of the

After Azimuth Compass.

$$
\begin{aligned}
& \mathfrak{A}=0.000 \\
& \mathfrak{B}=-0.0026 \tan \theta-0.373 \frac{\mathrm{I}}{H}-0.00032 \frac{t}{H} \pm 0.004 \\
& D=+0.112 \pm 0.003 \\
& \text { E }=0.000 \pm 0.003 \\
& \frac{Z^{\prime}}{Z}=1+0.1140 \frac{\cos \zeta}{\tan \theta}-0.0098 \frac{\sin \zeta}{\tan \theta}-0.0509-0.3918 \frac{1}{Z}+0.00363 \frac{t}{Z} \pm 0.010 \\
& \lambda=+0.864 \pm 0.011 \\
& \frac{c}{\lambda}=-0.0026 \\
& \frac{P}{\lambda}=-0.373 \\
& \frac{\Delta P}{\lambda}=-0.0003^{2} \\
& \frac{f}{\lambda}=+0.0066 \\
& \frac{Q}{\lambda}=-0.044 \\
& \frac{\Delta Q}{\lambda}=+0.00039
\end{aligned}
$$$$
\text { E }=+0.0066 \tan \theta-0.044 \frac{\mathrm{I}}{H}+0.00039 \frac{t}{H} \pm 0.004
$$

$$
\begin{gathered}
c=-0.0022 \\
P=-0.322 \\
\Delta P=-0.00027 \\
f=+0.005^{8} \\
Q=-0.03^{8} \\
\Delta Q=+0.00034 \\
a=-0.039^{6}
\end{gathered}
$$

$$
\begin{gathered}
b=0.0000 \\
d=0.0000 \\
e=-0.2324 \\
g=+0.1140 \\
h=+0.0098 \\
k=-0.0509 \\
R=-0.39^{2} \\
\Delta R=+0.003^{6} 3
\end{gathered}
$$


Hence, the general equations for the determination of the deviations of this compass are

$$
\begin{aligned}
X^{\prime} & =X-0.0396 X-0.0000 Y-0.0022 Z-0.322-0.00027 t \\
Y^{\prime} & =Y-0.0000 X-0.2324 Y-0.0058 Z-0.038+0.00034 t \\
Z^{\prime} & =Z+0.1140 X+0.0098 Y-0.0509 Z-0.39^{2}+0.00363 t
\end{aligned}
$$

The constants $P, Q, R$, are the resolved values of the hard iron magnetism of the slip; and in order to show as clearly as possible how it varied during the cruise, at the positions occupied by the two compasses under discussion, the following table is appended. "The columns headed " $F$ " contain the values of the total hard iron

\begin{tabular}{|c|c|c|c|c|c|c|c|c|}
\hline \multirow{2}{*}{ Date. } & \multicolumn{4}{|c|}{ Admiralty Standard Compass. } & \multicolumn{4}{|c|}{ After Azimuth Compass. } \\
\hline & $P$. & e. & $R$. & $F$. & $P$. & Q. & $R$. & F. \\
\hline November $\mathrm{I}, 186_{5}$ & +0.425 & +0.006 & +0.166 & 0.456 & -0.322 & -0.038 & -0.392 & 0.509 \\
\hline 23,1866 & +0.205 & -0.043 & +0.327 & $0.3^{88}$ & -0.385 & $|+0.042|$ & $|+0.45 \pi|$ & 0.599 \\
\hline
\end{tabular}
force, computed by means of the formula

$$
F=\sqrt{P^{2}+Q^{2}+R^{2}}
$$

Thus it appears that in the interval between November 1, 1865, and June 23, 1866, the total hard iron force had decreased fifteen per centum at the position of the Admiralty Standard Compass, while it liad increased eighteen per centum at the position of the After Azimutli Compass; and in both cases the changes in the direction of the force were very great. On the whole, the so-called permanent and sub-permanent magnetism of the Monadnock seem to have been in a very unstable condition.

There were some places where observations of the deviations of the compasses were obtained on a number of points less than thirty-two, because the ship could not be made to swing completely around. In order to deduce from these observations the corresponding values of the coefficients $A_{1}, B_{1}, C_{1}, D_{1}, E_{1}$, we remark that each observed deviation furnishes an equation of condition of the form

$$
0=-\delta+A_{1}+B_{1} \sin \zeta+C_{1} \cos \zeta+D_{1} \sin 2 \zeta+E_{1} \cos 2 \zeta
$$

and from all the equntions thus obtained the values of the cocfficients must be found by the method of least squares. As all the compasses were observed simultaneously; the deviations at each place are given on the same points in the case of each compass. Hence, although the absolute terms in the equations of condition will be different, the numerical coefficients of the unknown quantities $A_{1}, B_{1}, C_{1}$, $D_{1}, E_{1}$, will be identical for all the compasses at any one station. Advantage has been taken of this circumstance in forming the following table, which gives the cquations of condition for all the compasses at Ceara. The absolute terms of the equations of condition belonging to any compass will be found in the column headed with the name of that compass, while the coefficients of the remaining terms of the equations will be found in the columns headed $A_{1}, B_{1}, C_{1}, D, E_{1}$. For example, the first equation of condition for the Admiralty Standard Compass is

$$
0=-170+A_{1}+0.195 B_{1}+0.981 C_{1}+0.383 D_{1}+0.92+E_{\mathrm{i}} \text {. }
$$


In the same way, the first equation of condition for the After Bmuacle Compass is $0=-220+A_{1}+0.195 B_{1}+0.981 C_{1}+0.383 D_{1}+0.924 E_{1}$

Equations of Condition at Ceara.

\begin{tabular}{|c|c|c|c|c|c|c|c|c|c|c|}
\hline \multicolumn{6}{|c|}{ Absolute Terms. } & \multirow{2}{*}{\multicolumn{5}{|c|}{ Coefficients of the Unknown Quantities. }} \\
\hline \multirow{2}{*}{ 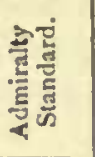 } & \multirow{2}{*}{ 芯芯 } & \multirow{2}{*}{ نِّ } & \multirow{2}{*}{ 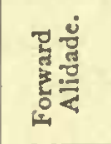 } & \multirow{2}{*}{ 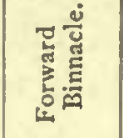 } & \multirow{2}{*}{ 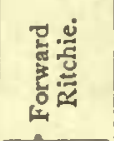 } & & & & & \\
\hline & & & & & & $A_{1}$ & $B_{1}$ & $C_{1}$ & $D_{1}$ & $E_{1}$ \\
\hline-170 & $-22 \alpha^{\prime}$ & -820 & $-180^{\prime}$ & $-110^{\prime}$ & $-430^{\prime}$ & +1.000 & +0.195 & +0.981 & $+0.3^{8} 3$ & +0.924 \\
\hline-210 & -310 & -820 & -270 & - ו & -520 & +1.000 & +0.383 & +0.924 & +0.707 & +0.707 \\
\hline-260 & -390 & $-8 \geq 0$ & -280 & - 110 & -600 & +1.000 & +0.556 & $+0.8_{3 i}$ & +0.924 & $+0.3^{s_{3}}$ \\
\hline-350 & -470 & $-97^{\circ}$ & -280 & -180 & $-4^{80}$ & +1.000 & +0.707 & +0.707 & +1.000 & 0.000 \\
\hline-340 & -420 & - 990 & -211 & -130 & -380 & +1.000 & $+0.83 i$ & +0.556 & +0.924 & $-0.3^{8} 3$ \\
\hline-330 & -410 & -1140 & -200 & -110 & -300 & +1.000 & +0.924 & $+0.3^{8} 3$ & +0.707 & -0.707 \\
\hline-310 & -410 & -1020 & -130 & -40 & -420 & +1.000 & +0.981 & +0.195 & +0.383 & -0.924 \\
\hline-230 & -260 & -850 & -110 & +40 & -170 & +1.000 & +1.000 & 0.000 & 0.000 & -1.000 \\
\hline-210 & -240 & -690 & -110 & +130 & -40 & +1.000 & +0.981 & -0.195 & -0.383 & -0.924 \\
\hline-170 & -170 & -660 & -40 & +140 & -30 & +1.000 & +0.924 & $-0.3^{83}$ & -0.707 & -0.707 \\
\hline
\end{tabular}

From these equations of condition five normal equations were obtained for each compass by the metliod of least squares; but on attempting to solve them the numerical cocfficients of $D_{1}$ and $E_{1}$ came ont so small that no confidence could be placed in the resulting values of these quantities; and moreover, the uncertainty of them vitiated the values of $A_{1}, B_{1}$, and $C_{1}$. It was therefore considered best to reject the normal equations in $D_{1}$ and $E_{1}$, and to employ in their stead the equations

$$
\begin{aligned}
& 0=-\mathfrak{D}+\mathrm{D}_{1}+\frac{1}{2}\left(B_{1}{ }^{2}-C_{1}{ }^{2}\right) \\
& 0=-\mathfrak{C}+\mathrm{E}_{1}+B_{1} C_{1}+A_{1} D_{1}
\end{aligned}
$$

using for $\mathfrak{D}$ and $\mathbb{C}$ the numerical values already found. The following are the normal equations thus formed, and the resulting values of $A_{1}, B_{1}, C_{1} D_{1}$, and $E_{1}$, for each compass. For convenience of computation, the unit of the absolute terms of the normal equations has been changed from minutes of are to radius.

Admiralty Standard Compass.

Hence

$$
\begin{aligned}
& 0=-0.7505+10.000 A_{1}+7.482 B_{1}+3.999 C_{1}+3.938 D_{1}-2.631 E_{1} \\
& 0=-0.5789+7.482 A_{1}+6.317 B_{1}+1.969 C_{1}+2.334 D_{1}-3.774 E_{1} \\
& 0=-0.3183+3.999 A_{1}+1.969 B_{1}+3.685 C_{1}+3.708 D_{1}+1.665 E_{1} \\
& 0=-0.0169+D_{1}+\frac{1}{2}\left(B_{1}^{2}-C_{1}^{2}\right) \\
& 0=+0.0009+E_{1}+B_{1} C_{1}
\end{aligned}
$$

$$
\begin{aligned}
& A_{1}=-0.0102=-0^{\circ} 35^{\prime} \cdot 1 \\
& B_{1}=+0.0833=+446.3 \\
& C_{1}=+0.0405=+2 \quad 19.2 \\
& D_{1}=+0.0142=+048.8 \\
& E_{1}=-0.0043=-0 \quad 14.8
\end{aligned}
$$


After Binnacle Compass.

Hence

$$
\begin{aligned}
& 0=-0.9599+10.000 A_{1}+7.482 B_{1}+3.999 C_{1}+3.938 D_{1}-2.631 E_{1} \\
& 0=-0.7253+7.482 A_{1}+6.317 B_{1}+1.969 C_{1}+2.334 D_{1}-3.774 E_{1} \\
& 0=-0.4413+3.999 A_{1}+1.969 B_{1}+3.685 C_{1}+3.708 D_{1}+1.665 E_{1} \\
& 0=-0.0385+D_{1}+\frac{1}{2}\left(B_{1}{ }^{2}-C_{1}{ }^{2}\right) \\
& 0=+0.0018+E_{1}+B_{1} C_{1}+0.0047\left(B_{1}{ }^{2}-C_{1}{ }^{2}\right)
\end{aligned}
$$

$$
\begin{array}{lr}
A_{1}=+0.0062=+0^{\circ} & 2 x^{\prime} \cdot 3 \\
B_{1}=+0.0801=+4 & 35.2 \\
C_{1}=+0.0362=+2 & 4.6 \\
D_{1}=+0.0360=+2 & 3.6 \\
E_{1}=-0.0048=-0 & 16.3
\end{array}
$$

Hence

\section{After Ritchie Cómpass.}

$$
\begin{aligned}
& 0=-2.5540+10.000 A_{1}+7.482 B_{1}+3.999 C_{1}+3.938 D_{1}-2.631 E_{1} \\
& 0=-1.9282+7.482 A_{1}+6.317 B_{1}+1.969 C_{1}+2.334 D_{1}-3.774 E_{1} \\
& 0=-1.0844+3.999 A_{1}+1.969 B_{1}+3.685 C_{1}+3.708 D_{1}+1.665 E_{1} \\
& 0=-0.0340+D_{1}+\frac{1}{2}\left(B_{1}{ }^{2}-C_{1}{ }^{3}\right) \\
& 0=+0.0008+E_{1}+B_{1} C_{1}
\end{aligned}
$$

$$
\begin{aligned}
& A_{1}=+0.1030=+5^{\circ} 54^{\prime} .2 \\
& B_{1}=+0.13^{85}=+75^{6.0} \\
& C_{1}=+0.0859=+455.4 \\
& D_{1}=+0.0281=+136.6 \\
& E_{1}=-0.0127=-043.7
\end{aligned}
$$

Hence

\section{Forward Alidade Compass.}

$0=-0.5265+10.000 A_{1}+7.482 B_{1}+3: 999 C_{1}+3.93^{8} D_{1}-2.631 E_{1}$ $0=-0.35^{89}+7.482 A_{1}+6.317 B_{1}+1.969 C_{1}+2.334 D_{1}-3.774 E_{1}$ $0=-0.3022+3.999 A_{1}+1.969 B_{1}+3.685 C_{1}+3.708 D_{1}+1.665 E_{1}$ $0=-0.0235+D_{1}+\frac{1}{2}\left(B_{1}^{3}-C_{1}{ }^{3}\right)$

$0=-0.0007+E_{1}+B_{1} C_{1}+0.0125\left(B_{1}^{2}-C_{1}^{3}\right)$

$$
\begin{array}{rr}
A_{1}=+0.0359=+2^{\circ} & 3^{\prime} \cdot 5 \\
B_{1}=+0.0001=+0 & 0.2 \\
C_{1}=+0.0188=+\mathrm{r} & 4.8 \\
D_{1}=+0.0237=+\mathrm{r} & 21.4 \\
E_{1}=+0.0007=+0 & 2.4
\end{array}
$$

Forward Binnacle Compass.

$$
\begin{aligned}
& 0=-0.1396+10.000 A_{1}+7.482 B_{1}+3.999 C_{1}+3.938 D_{1}-2.631 E_{1} \\
& 0=-0.0593+7.482 A_{1}+6.317 B_{1}+1.969 C_{1}+2.334 D_{1}-3.774 E_{1} \\
& 0=-0.1831+3.999 A_{1}+1.969 B_{1}+3.685 C_{1}+3.708 D_{1}+1.665 E_{1} \\
& 0=-0.0369+D_{1}+\frac{1}{2}\left(B_{1}^{2}-C_{1}^{2}\right) \\
& 0=-0.0011+E_{1}+B_{1} C_{1}
\end{aligned}
$$

Hence

$$
\begin{array}{lr}
A_{1}=-0.0159=-0^{\circ} & 54^{\prime} .7 \\
B_{1}=+0.0072=+0 & 24.6 \\
C_{1}=+0.0253=+1 & 26.9 \\
D_{1}=+0.0372=+2 & 7.8 \\
E_{1}=+0.0009=+0 & 3.2
\end{array}
$$


Forward Ritchie Compass.

Hence

$$
\begin{aligned}
& \circ=-0.9803+10.000 A_{1}+7.482 B_{1}+3.999 C_{1}+3.938 D_{1}-2.631 E_{1} \\
& \circ=-0.6394+7.482 A_{1}+6.317 B_{1}+1.969 C_{1}+2.334 D_{1}-3.774 E_{1} \\
& \circ=-0.6193+3.999 A_{1}+1.969 B_{1}+3.685 C_{1}+3.708 D_{1}+1.665 E_{1} \\
& \circ=-0.0407+D_{1}+\frac{1}{2}\left(B_{1}^{2}-C_{1}^{3}\right) \\
& \circ=+0.0013+E_{1}+B_{1} C_{1}
\end{aligned}
$$

$$
\begin{array}{lr}
A_{1}=+0.0614=+3^{0} & 3 \mathrm{I}^{\prime} .0 \\
B_{1}=-0.0076=-0 & 26.1 \\
C_{1}=+0.063 \mathrm{I}=+3 & 3^{6.9} \\
D_{1}=+0.0427=+2 & 26.6 \\
E_{1}=-0.0011=-0 & 3.9
\end{array}
$$

\begin{tabular}{|c|c|c|c|c|c|c|c|c|c|c|c|c|}
\hline \multicolumn{7}{|c|}{ Absolute Terms. } & \multirow{2}{*}{\multicolumn{6}{|c|}{ Coefficients of the Unknown Quantities. }} \\
\hline \multirow{2}{*}{ 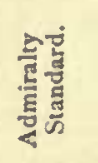 } & \multirow{2}{*}{ 飐总 } & \multirow{2}{*}{ 递 } & \multirow{2}{*}{ 峞 } & \multirow{2}{*}{ 司 } & \multirow{2}{*}{ 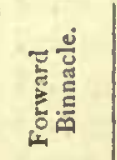 } & \multirow{2}{*}{ 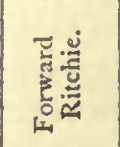 } & & & & & & \\
\hline & & & & & & & P & $A_{1}$ & $B_{1}$ & $C_{1}$ & $D_{1}$ & $E$, \\
\hline$+290^{\prime}$ & $-320^{\prime}$ & $-840^{\prime}$ & $-160^{\prime}$ & $-250^{\prime}$ & $-160^{\prime}$ & $-500^{\prime}$ & t & 1.000 & +0.556 & $+0 . \delta_{3} \mathbf{I}$ & +0.924 & +0.383 \\
\hline+360 & -410 & -840 & -120 & -250 & -160 & -500 & + & 1.000 & +0.707 & +0.707 & +1.000 & \\
\hline+390 & -430 & -840 & -20 & -250 & -160 & -370 & + & 1.000 & $+0.83 i$ & +0.556 & +0.924 & -0.383 \\
\hline+350 & -430 & - 970 & +130 & -180 & -160 & -460 & + & 1.000 & +0.924 & +0.383 & +0.707 & -0.707 \\
\hline+330 & -360 & - I010 & +160 & -160 & -160 & -500 & + & 1.000 & $+0.98 i$ & +0.195 & +0.383 & -0.924 \\
\hline+320 & -340 & -880 & +280 & -160 & -160 & -440 & + & 1.000 & +1.000 & 0.000 & 0.000 & -1.000 \\
\hline+300 & $-34^{\circ}$ & -720 & +390 & -160 & -100 & -420 & + & 1.000 & $+0.98 \mathrm{I}$ & -0.195 & -0.383 & -0.924 \\
\hline+280 & - 280 & - 610 & +410 & -160 & -140 & -350 & + & 1.000 & +0.924 & -0.383 & -0.707 & -0.707 \\
\hline+260 & -260 & -590 & +440 & -160 & -100 & -330 & + & 1.000 & +0.831 & -0.556 & -0.924 & $-0.3^{8} 3$ \\
\hline+240 & -190 & -590 & +400 & -160 & -20 & -330 & + & 1.000 & +0.707 & -0.707 & -1.000 & 0.000 \\
\hline+200 & -170 & -510 & +320 & -160 & -60 & -330 & + & 1.000 & +0.556 & -0.831 & -0.924 & $+0.3^{8} 3$ \\
\hline+210 & -110 & -510 & +200 & -230 & -80 & $-33^{\circ}$ & + & 1.000 & $+0.3^{8} 3$ & -0.924 & -0.707 & +0.707 \\
\hline+170 & -90 & -510 & +70 & -250 & -80 & -270 & $\dot{t}$ & 1.000 & +0.195 & $-0.98 \mathbf{I}$ & -0.383 & +0.924 \\
\hline+150 & - 90 & -510 & -20 & -250 & -140 & -250 & + & 1.000 & 0.000 & -1.000 & 0.000 & +1.000 \\
\hline+140 & - 20 & -510 & -190 & -310 & -100 & -180 & + & 1.000 & -0.195 & $-0.98 I$ & +0.383 & +0.924 \\
\hline+120 & -10 & -510 & -290 & -330 & -80 & -230 & + & 1.000 & -0.383 & -0.924 & +0.707 & +0.707 \\
\hline+90 & -10 & -510 & -310 & -330 & -80 & -250 & + & 1.000 & $|-0.556|$ & $|-0.831|$ & +0.924 & +0.383 \\
\hline
\end{tabular}

The following are the equations of condition, together with the resulting normal equations, and the values of the coefficients $A_{1}, B_{1}, C_{1}, D_{1}, E_{1}$, as determined for each compass from the obscrvations made at Rio Janciro.

Equations of Condition at Rio Janeiro.

\section{Nor'mal Equations.}

Admiralty Stanidard Compass.

$0=-1.2217+17.000 A_{1}+8.442 B_{1}-5.641 C_{1}+0.924 D_{1}+0.3^{8} 3 E_{1}$ $0=-0.7991+8.442 A_{1}+8.310 B_{1}+0.46_{2} C_{1}-1.205 D_{1}-4.543 E_{1}$ $0=+0.1662-5.641 A_{1}+0.462 B_{1}+8.691 C_{1}+3.900 D_{1}-4.438 E_{1}$ $0=-0.0169+D_{1}+\frac{1}{2}\left(B_{1}^{2}-C_{1}^{2}\right)$

Hence $0=+0.0009+E_{1}+B_{1} C_{1}$

$$
\begin{array}{lr}
A_{1}=+0.0453=+2^{\circ} & 35^{\prime} \cdot 7 \\
B_{1}=+0.0519=+2 & 58.5 \\
C_{1}=+0.0001=+0 & 0.2 \\
D_{1}=+0.0156=+0 & 535 \\
E_{1}=-0.0009=-0 & 3.1
\end{array}
$$


After Binnacle Compass.

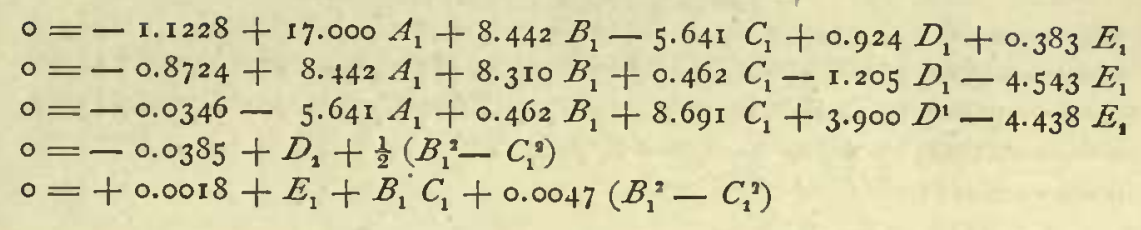

Hence

$$
\begin{array}{lr}
A_{1}=+0.0148=+0^{\circ} & 50^{\prime} .8 \\
B_{1}=+0.0947=+5 & 25.4 \\
C_{1}=-0.0073=-0 & 25.2 \\
D_{1}=+0.0340=+\mathrm{I} & 57 . \mathrm{I} \\
E_{1}=-0.0012=-0 & 4 . \mathrm{I}
\end{array}
$$

\section{After Ritchie Compass.}

$0=-3.3336+17.000 A_{1}+8.442 B_{1}-5.641 C_{1}+0.924 D_{1}+0.383 E_{1}$ $0=-1.9499+8.442 A_{1}+8.310 B_{1}+0.462 C_{1}-1.205 D_{1}-4.543 E_{1}$ $0=+0.6086-5.641 A_{1}+0.462 B_{1}+8.691 C_{1}+3.900 D_{1}-4.43^{8} E_{1}$ $0=-0.0340+D_{1}+\frac{1}{2}\left(B_{1}{ }^{2}-C_{1}{ }^{2}\right)$

Hence $\circ=+0.0008+E_{1}+B_{1} C_{1}$

$$
\begin{array}{lr}
A_{1}=+0.1684=+9^{\circ} & 39^{\prime} .0 \\
B_{1}=+0.0659=+3 & 46.6 \\
C_{1}=+0.0203=+\mathrm{I} & 9.8 \\
D_{1}=+0.0320=+\mathrm{I} & 50 . \mathrm{I} \\
E_{1}=-0.002 \mathrm{I}=-0 & 7.4
\end{array}
$$

\section{After Azimuth Compass.}

$0=+0.4916+17.000 A_{1}+8.442 B_{1}-5.641 C_{1}+0.924 D_{1}+0.38_{3} E_{1}$ $0=+0.6880+8.442 A_{1}+8.310 B_{1}+0.462 C_{1}-\mathrm{r} .205 D_{1}-4.543 E_{1}$ $0=-0.2024-5.641 A_{1}+0.462 B_{1}+8.691 C_{1}+3.900 D_{1}-4.438 E_{1}$ $0=-0.1116+D_{1}+\frac{1}{2}\left(B_{1}^{3}-C_{1}^{3}\right)$

Hence $0=+0.0002+E_{1}+B_{1} C_{1}$

$$
\begin{array}{lr}
A_{1}=-0.0434=-2^{\circ} & 29^{\prime} \cdot 3 \\
B_{1}=-0.0199=-1 & 8.5 \\
C_{1}=-0.055^{2}=-3 & 9.7 \\
D_{1}=+0.1129=+6 & 28.2 \\
E_{1}=-0.0013=-0 & 4.5
\end{array}
$$

\section{Forward Alidade Compass.}

$0=-1.0908+17.000 A_{1}+8.442 B_{1}-5.641 C_{1}+0.924 D_{1}+0.383 E_{1}$ $0=-0.4111+8.442 A_{1}+8.310 B_{1}+0.462 C_{1}-1.205 D_{1}-4.543 E_{1}$ $0=+0.4058-5.641 A_{1}+0.462 B_{1}+8.691 C_{1}+3.900 D_{1}-4.438 E_{1}$ $0=-0.0235+D_{1}+\frac{1}{2}\left(B_{1}{ }^{3}-C_{1}{ }^{3}\right)$

Hence $0=-0.0007+E_{1}+B_{1} C_{1}+0.0125\left(B_{1}^{2}-C_{1}{ }^{2}\right)$

$$
\begin{array}{lr}
A_{1}=+0.06 \mathrm{I} 5=+3^{0} & 3 \mathrm{I}^{\prime} \cdot 5 \\
B_{1}=-0.0084=-0 & 28.8 \\
C_{1}=-0.0166=-0 & 57.2 \\
D_{1}=+0.0236=+\mathrm{I} & 2 \mathrm{I} . \mathrm{I} \\
E_{1}=+0.0006=+0 & \mathrm{I} .9
\end{array}
$$


Forward Binnacle Compass.

$$
\begin{aligned}
& \circ=-0.5643+17.000 A_{1}+8.442 B_{1}-5.641 C_{1}+0.924 D_{1}+0.383 E_{1} \\
& 0=-0.3228+8.442 A_{1}+8.310 B_{1}+0.462 C_{1}-1.205 D_{1}-4.543 E_{1} \\
& \circ=+0.0861-5.641 A_{1}+0.462 B_{1}+8.691 C_{1}+3.900 D_{1}-4.438 E_{1} \\
& \circ=-0.0369+D_{1}+\frac{1}{2}\left(B_{1}{ }^{2}-C_{1}{ }^{2}\right) \\
& \circ=-0.0011+E_{1}+B_{1} C_{1}
\end{aligned}
$$

Hence

$$
\begin{array}{lr}
A_{1}=-0.005^{0}=-0^{\circ} & 17^{\prime} \cdot 1 \\
B_{1}=+0.05^{2} 3=+2 & 59 \cdot 8 \\
C_{1}=-0.0307=-1 & 45 \cdot 5 \\
D_{1}=+0.0360=+2 & 3 \cdot 7 \\
E_{1}=+0.0027=+0 & 9 \cdot 3
\end{array}
$$

Hence

\section{Forward Ritchie CoMpass.}

$$
\begin{aligned}
& \circ=-1.7570+17.000 A_{1}+8.442 B_{1}-5.64 \mathrm{I} C_{1}+0.924 D_{1}+0.383 E_{1} \\
& 0=-1.05^{82}+8.442 A_{1}+8.310 B_{1}+0.462 C_{1}-1.205 D_{1}-4.543 E_{1} \\
& 0=+0.3128-5.641 A_{1}+0.462 B_{1}+8.691 C_{1}+3.900 D_{1}-4.438 E_{1} \\
& \circ=-0.0407+D_{1}+\frac{1}{2}\left(B_{1}{ }^{2}-C_{1}{ }^{2}\right) \\
& \circ=+0.0013+E_{1}+B_{1} C_{1}
\end{aligned}
$$

$$
\begin{array}{lr}
A_{1}=+0.0564=+3^{\circ} & 14.0 \\
B_{1}=+0.0766=+4 & 23.5 \\
C_{1}=-0.0205=-1 & 10.4 \\
D_{1}=+0.0380=+2 & 10.5 \\
E_{1}=0.0000=\quad 0 & 0.0
\end{array}
$$

The following are the equations of condition for the determination of the coefficients of the After Ritchie Compass at Monte Video.

$$
\begin{aligned}
& 0=-240^{\prime}+1.000 A_{1} \quad 0.000 B_{1}+1.000 C_{1} \quad 0.000 D_{1}+1.000 E_{1} \\
& 0=-570+1.000 A_{1}+0.195 B_{1}+0.981 C_{1}+0.383 D_{1}+0.924 E_{1} \\
& 0=-570+1.000 A_{1}+0.383 B_{1}+0.924 C_{1}+0.707 D_{1}+0.707 E_{1} \\
& 0=-740+1.000 A_{1}+0.556 B_{1}+0.831 C_{1}+0.924 D_{1}+0.383 E_{1} \\
& 0=-740+1.000 A_{1}+0.707 B_{1}+0.707 C_{1}+1.000 D_{1} 0.000 E_{1} \\
& 0=-740+1.000 A_{1}+0.831 B_{1}+0.556 C_{1}+0.924 D_{1}-0.383 E_{1} \\
& 0=-910+1.000 A_{1}+0.924 B_{1}+0.383 C_{1}+0.707 D_{1}-0.707 E_{1} \\
& 0=-900+1.000 A_{1}+0.981 B_{1}+0.195 C_{1}+0.383 D_{1}-0.924 E_{1} \\
& 0=-560+1.000 A_{1}+1.000 B_{1} \quad 0.000 C_{1} \quad 0.000 D_{1}-1.000 E_{1} \\
& 0=-240+1.000^{\circ} A_{1}+0.981 B_{1}-0.195 C_{1}-0.383 D_{1}-0.924 E_{1} \\
& 0=-230+1.000 A_{1}+0.924 B_{1}-0.383 C_{1}-0.707 D_{1}-0.707 E_{1} \\
& 0=-60+1.000 A_{1}+0.831 B_{1}-0.55^{6} C_{1}-0.924 D_{1}-0.38_{3} E_{1} \\
& 0=+270+1.000 A_{1}+0.707 B_{1}-0.707 C_{1}-1.000 D_{1} \quad 0.000 E_{1} \\
& 0=+100+1.000 A_{1}+0.55^{6} B_{1}-0.831 C_{1}-0.924 D_{1}+0.383 E_{1} \\
& 0=-240+1.000 A_{1}+0.383 B_{1}-0.924 C_{1}-0.707 D_{1}+0.707 E_{1} \\
& 0=-240+1.000 A_{1}+0.195 B_{1}-0.981 C_{1}-0.383 D_{1}+0.924 E_{1} \\
& 0=-240+1.000 A_{1} \quad 0.000 B_{1}-1.000 C_{1} \quad 0.000 D_{1}+1.000 E_{1} \\
& 0=-4 \mathrm{ro}+\mathrm{r} .000 A_{1}-0.195 B_{1}-0.98 \mathrm{r} C_{1}+0.383 D_{1}+0.924 E_{1} \\
& 0=-410+\mathrm{r} .000 A_{1}-0.383 B_{1}-0.924 C_{1}+0.707 D_{1}+0.707 E_{1} \\
& 0=-240+\mathrm{r} .000 A_{1}-0.55^{6} B_{1}-0.831 C_{1}+0.924 D_{1}+0.383 E_{1} \\
& 0=-240+1.000 A_{1}-0.707 B_{1}-0.707 C_{1}+1.000 D_{1} \quad 0.000 E_{1} \\
& \circ=-570+\mathrm{r} .000 A_{1}-0.831 B_{1}-0.556 C_{1}+0.924 D_{1}-0.383 E_{1}
\end{aligned}
$$


The resulting normal equations are

Hence

$$
\begin{aligned}
& 0=-2.5365+22.000 A_{1}+7.482 B_{1}-3.999 C_{1}+3.938 D_{1}+2.631 E_{1} \\
& 0=-1.0294+7.482 A_{1}+9.685 B_{1}+1.969 C_{1}-2.334 D_{1}-3.774 E_{1} \\
& 0=-0.3901-3.999 A_{1}+1.969 B_{1}+12.316 C_{1}+3.708 D_{1}-1.665 E_{1} \\
& 0=-0.0340+D_{1}+\frac{1}{2}\left(B_{1}{ }^{2}-C_{1}{ }^{2}\right) \\
& 0=+0.0008+E_{1}+B_{1} C_{1}
\end{aligned}
$$

$$
\begin{array}{lr}
A_{1}=+0.1143=+6^{\circ} & 3^{\prime} .8 \\
B_{1}=+0.0146=+0 & 50.3 \\
C_{1}=+0.0555=+3 & 10.9 \\
D_{1}=+0.0354=+2 & \text { r.8 } \\
E_{1}=-0.0016=-0 & 5.5
\end{array}
$$

\begin{tabular}{|c|c|c|c|c|c|c|c|c|c|c|}
\hline & & Absolut & & & & & & & & \\
\hline \multirow{2}{*}{ 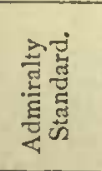 } & \multirow{2}{*}{ 竞 } & \multirow{2}{*}{ 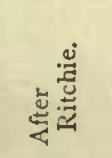 } & \multirow{2}{*}{ 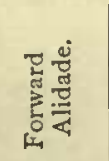 } & \multirow{2}{*}{ 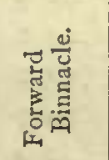 } & \multirow{2}{*}{ 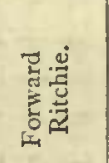 } & \multicolumn{5}{|c|}{ Coefficients of the Unknown Quantities. } \\
\hline & & & & & & $A_{1}$ & $\cdot B_{1}$ & $C_{1}$ & $D_{1}$ & $E_{1}$ \\
\hline$+20^{\prime}$ & - $10^{\prime}$ & $-100^{\prime}$ & $-300^{\prime}$ & -30 & $-540^{\prime}$ & & -0.707 & -0.707 & +1.000 & \\
\hline+60 & - 10 & -180 & -370 & -290 & $=-460$ & +1 & $-0.83 \mathrm{I}$ & -0.556 & +0 & $-0.3^{8}$ \\
\hline+110 & +80 & -180 & -210 & -210 & $-3^{80}$ & +1.000 & -0.924 & $-0.3^{8} 3$ & +0 & $-0.7 c$ \\
\hline+140 & +160 & -180 & -130 & -210 & - 290 & +1.000 & $-0.98 \mathrm{I}$ & -0.195 & $+0.3^{8} 3$ & -0.9 \\
\hline+18 & +170 & -80 & - I30 & - I 20 & -200 & +1.000 & - 1.000 & & & -1.0 \\
\hline+230 & $+3^{20}$ & +170 & $-2 I$ & +50 & +50 & +1.000 & $-0.98 \mathrm{I}$ & +0.195 & -0.383 & -0.92 \\
\hline+23 & +320 & +33 & $-13^{\circ}$ & +130 & +210 & +1.000 & -0.924 & +0.3 & -0.707 & -0.70 \\
\hline+2 & +320 & & -120 & +210 & +210 & +1.000 & -0.831 & +0. & -0.9 & $-0.3^{8}$ \\
\hline+220 & +320 & +16 & -40 & +300 & +210 & +1.000 & -0.707 & +0. & -1.000 & 0.00 \\
\hline+22 & +320 & +160 & -40 & $+3^{80}$ & +300 & & -0.556 & $+0.83 \mathrm{I}$ & -0.924 & $+0.3^{8}$ \\
\hline+160 & +320 & +150 & +40 & +380 & +370 & +1.000 & $-0.3^{8} 3$ & +0.924 & -0.707 & +0.70 \\
\hline+100 & +230 & +60 & +40 & $+3^{80}$ & +210 & +1.000 & -0.195 & +0.981 & $-0.3^{8} 3$ & +0.92 \\
\hline+40 & +150 & 100 & +40 & +370 & +210 & +1.000 & 0.000 & +1.000 & 0.000 & +1.00 \\
\hline+30 & +70 & - 190 & -50 & +290 & +120 & +1.000 & +0.195 & $+0.98 I$ & $+0.3^{8} 3$ & +0.92 \\
\hline
\end{tabular}

The following are the equations of condition, together with the resulting normal equations, and the values of the coefficients $A_{1}, B_{1}, C_{1}, D_{1}, E_{1}$, as determined for each compass from the observations made in Magdalena Bay.

Equations of Condition at Magdalena Bay.

\section{Normal Equations.}

\section{Admiralty Standard Compass.}

$$
\begin{aligned}
& 0=+0.5789+\times 4.000 A_{1}-8.825 B_{1}+4.7 \times 7 C_{1}-1.631 D_{1}-1.090 E_{1} \\
& 0=-0.4310-8.825 A_{1}+7.545 B_{1}-0.816 C_{1}+0.934 D_{1}+4.272 E_{1} \\
& 0=+0.235^{2}+4.717 A_{1}-0.816 B_{1}+6.456 C_{1}-4.554 D_{1}+3.784 E_{1} \\
& 0=-0.0169+D_{1}+\frac{1}{2}\left(B_{1}^{3}-C_{1}^{3}\right) \\
& 0=+0.0009+E_{1}+B_{1} C_{1}
\end{aligned}
$$

Hence

$$
\begin{array}{lr}
A_{1}=+0.0026=+0^{\circ} & 9^{\prime} .1 \\
B_{1}=+0.0559=+3 & 12.1 \\
C_{1}=-0.0204=-1 & 10.3 \\
D_{1}=+0.0156=+0 & 53.5 \\
E_{1}=+0.0002=+0 & 0.8
\end{array}
$$




\section{After Binnacle Compass.}

$0=+0.8029+14.000 A_{1}-8.825 B_{1}+4.717 C_{1}-1.631 D_{1}-1.090 E_{1}$ $0=-0.5291-8.825 A_{1}+7.545 B_{1}-0.816 C_{1}+0.934 D_{1}+4.272 E_{1}$ $0=+0.4497+4.717 A_{1}-0.816 B_{1}+6.456 C_{1}-4.554 D_{1}+3.784 E_{1}$ $0=-0.0385+D_{1}+\frac{1}{2}\left(B_{1}^{2}-C_{1}^{2}\right)$

Hence

$0=+0.0018+E_{1}+B_{1} C_{1}+0.0047\left(B_{1}{ }^{2}-C_{1}{ }^{2}\right)$

$$
\begin{array}{lr}
A_{1}=-0.0208=-\mathrm{I}^{\circ} & \mathrm{II}^{\prime} .4 \\
B_{1}=+0.0393=+2 & 15.0 \\
C_{1}=-0.0222=-1 & 16.2 \\
D_{1}=+0.0380=+2 & 10.5 \\
E_{1}=-0.0010=-0 & 3.3
\end{array}
$$

After Ritchie Compass.

o $=+0.0989+\mathrm{r} 4.000 A_{1}-8.825 B_{1}+4.717 C_{1}-\mathrm{r} .63 \mathrm{r} D_{1}-\mathrm{r} .090 E_{1}$ $0=-0.1171-8.825 A_{1}+7.545 B_{1}-0.816 C_{1}+0.934 D_{1}+4.272 E_{1}$ $0=+0.223^{8}+4.717 A_{1}-0.816 B_{1}+6.456 C_{1}-4.554 D_{1}+3.784 E_{1}$ $0=-0.0340+D_{1}+\frac{1}{2}\left(B_{1}{ }^{2}-C_{1}{ }^{2}\right)$

$\circ=+0.0008+E_{1}+B_{1} C_{1}$

Hence

$$
\begin{array}{ll}
A_{1}=+0.0627=+3^{\circ} & 35^{\prime} \cdot 5 \\
B_{1}=+0.0778=+4 & 27 \cdot 3 \\
C_{1}=-0.0497=-2 & 5^{1} .0 \\
D_{1}=+0.0322=+\mathrm{r} & 50.7 \\
E_{1}=+0.0031=+0 & 10.6
\end{array}
$$

Forward Alidade Compass.

$0=-0.4683+14.000 A_{1}-8.825 B_{1}+4.717 C_{1}-1.631 D_{1}-1.090 E_{1}$ $\circ=+0.4115-8.825 A_{1}+7.545 B_{1}-0.816 C_{1}+0.934 D_{1}+4.272 E_{1}$ $\circ=+0.1082+4.717 A_{1}-0.816 B_{1}+6.456 C_{1}-4.554 D_{1}+3.784 E_{1}$ $0=-0.0235+D_{1}+\frac{1}{2}\left(B_{1}^{2}-C_{1}^{2}\right)$

$0=-0.0007+E_{1}+B_{1} C_{1}+0.0125\left(B_{1}^{2}-C_{1}^{2}\right)$

Hence

$$
\begin{array}{lr}
A_{1}=+0.0200=+\mathrm{I}^{\circ} & 8^{\prime} .8 \\
B_{1}=-0.0361=-2 & 4.1 \\
C_{1}=-0.0197=-1 & 7.6 \\
D_{1}=+0.0230=+\mathrm{I} & 19.2 \\
E_{1}=0.0000=0 & 0.0
\end{array}
$$

\section{Forward Binnacle Compass.}

$0=+0.3956+14.000 A_{1}-8.825 B_{1}+4.717 C_{1}-1.631 D_{1}-1.090 E_{1}$ $\circ=+0.0125-8.825 A_{1}+7.545 B_{1}-0.816 C_{1}+0.934 D_{1}+4.272 E_{1}$ $\circ=+0.7497+4.717 A_{1}-0.816 B_{1}+6.456 C_{1}-4.554 D_{1}+3.784 E_{1}$ $0=-0.0369+D_{1}+\frac{1}{2}\left(B_{1}{ }^{2}-C_{1}{ }^{2}\right)$

Hence $\circ=-0.0011+E_{1}+B_{1} C_{1}$

$$
\begin{array}{lr}
A_{1}=-0.0298=-\mathbf{r}^{0}{ }^{\prime \prime} & 42^{\prime} .6 \\
B_{1}=-0.0478=-2 & 44.3 \\
C_{1}=-0.0719=-4 & 7 \cdot 3 \\
D_{1}=+0.03^{8}=+2 & \mathbf{1 1 . 8} \\
E_{1}=-0.0023=-0 & 7.9
\end{array}
$$


Hence

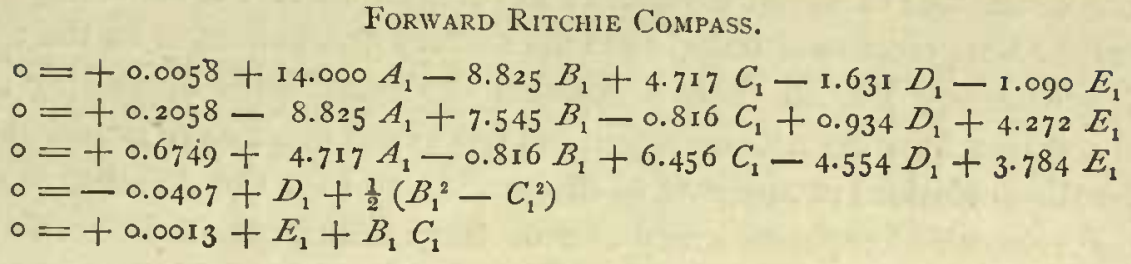

Foriward Ritchie Compass.

$$
\begin{array}{lr}
A_{1}=+0.0477=+2^{\circ} & 43^{\prime} .8 \\
B_{1}=+0.0116=+0 & 39.9 \\
C_{1}=-0.1051=-6 & 1.3 \\
D_{1}=+0.0462=+2 & 3^{8.7} \\
E_{1}=-0.0004=-0 & 1.3
\end{array}
$$

For convenience of reference the values of the cocfficients $A_{1}, B_{1}, C_{1}, D_{1}, E_{1}$, obtained at stations where the compasses were not read on all the thirty-two points, have been collected in the following table. No use has been made of them.

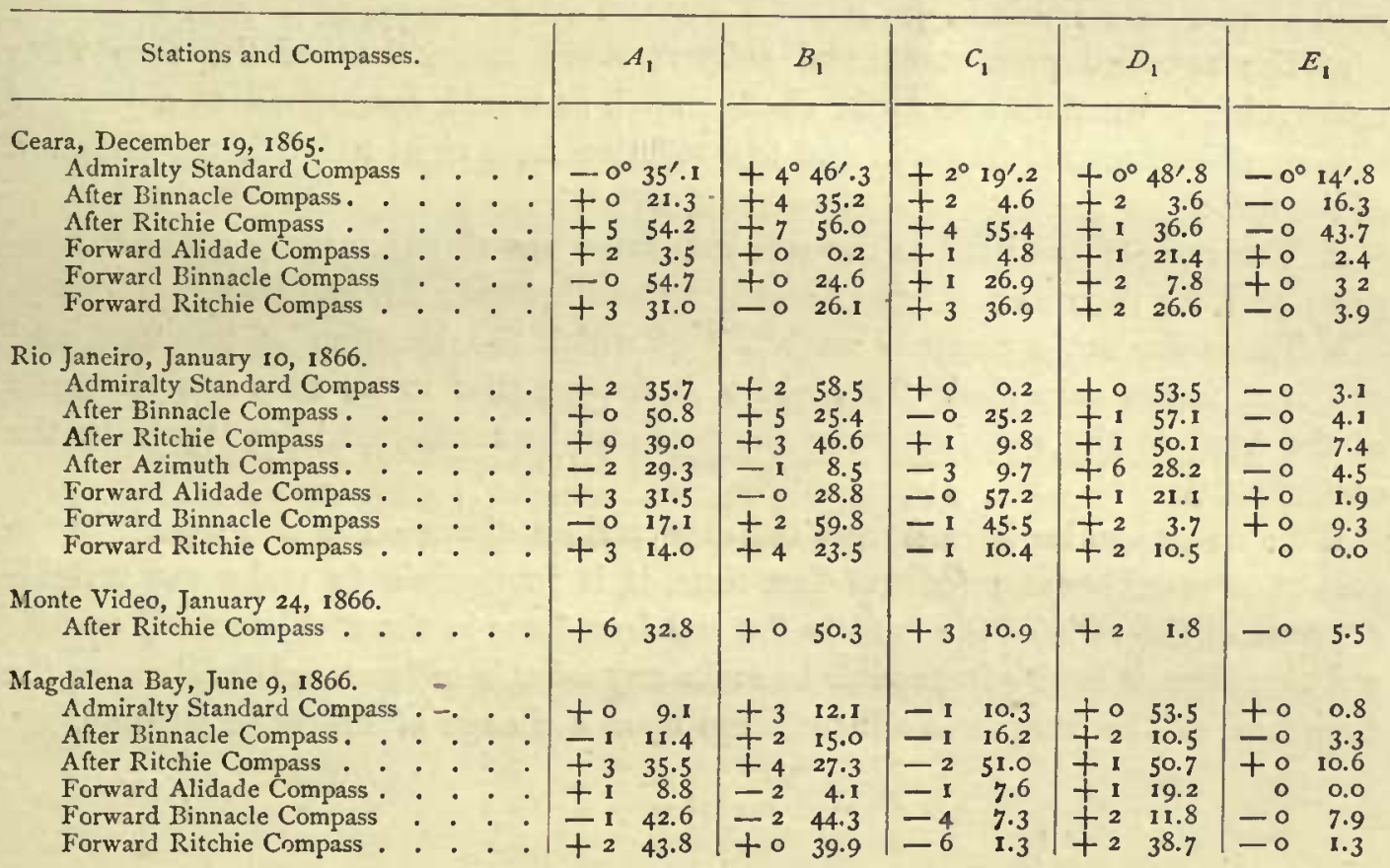

At a number of the ports visited during the cruise, the line dividing the north from the south polarity, on the exterior of the turrets, was traced out; but as the boundary between the two kinds of magnetism was frequently very badly defined, and the observations were otherwise unsatisfactory; and further, as they throw no light whatever on the theory of the deviations of the compasses, and can only be shown by means of drawings on a rather large scale, it has not been deemed worth while to insert them here.

In conclusion, the results of the observations made during the cruise may be briefly recapitulated as follows:

$1^{\circ}$. The latitudes of seven points have been determined.

$2^{\circ}$. The magnetic declination, inclination, and horizontal force, have been determined at eighteen places. 




\section{UNIVERSITY OF CALIFORNIA LIBRARY BERKELEY}

Return to desk from which borrowed.

This book is DUE on the last date stamped below.

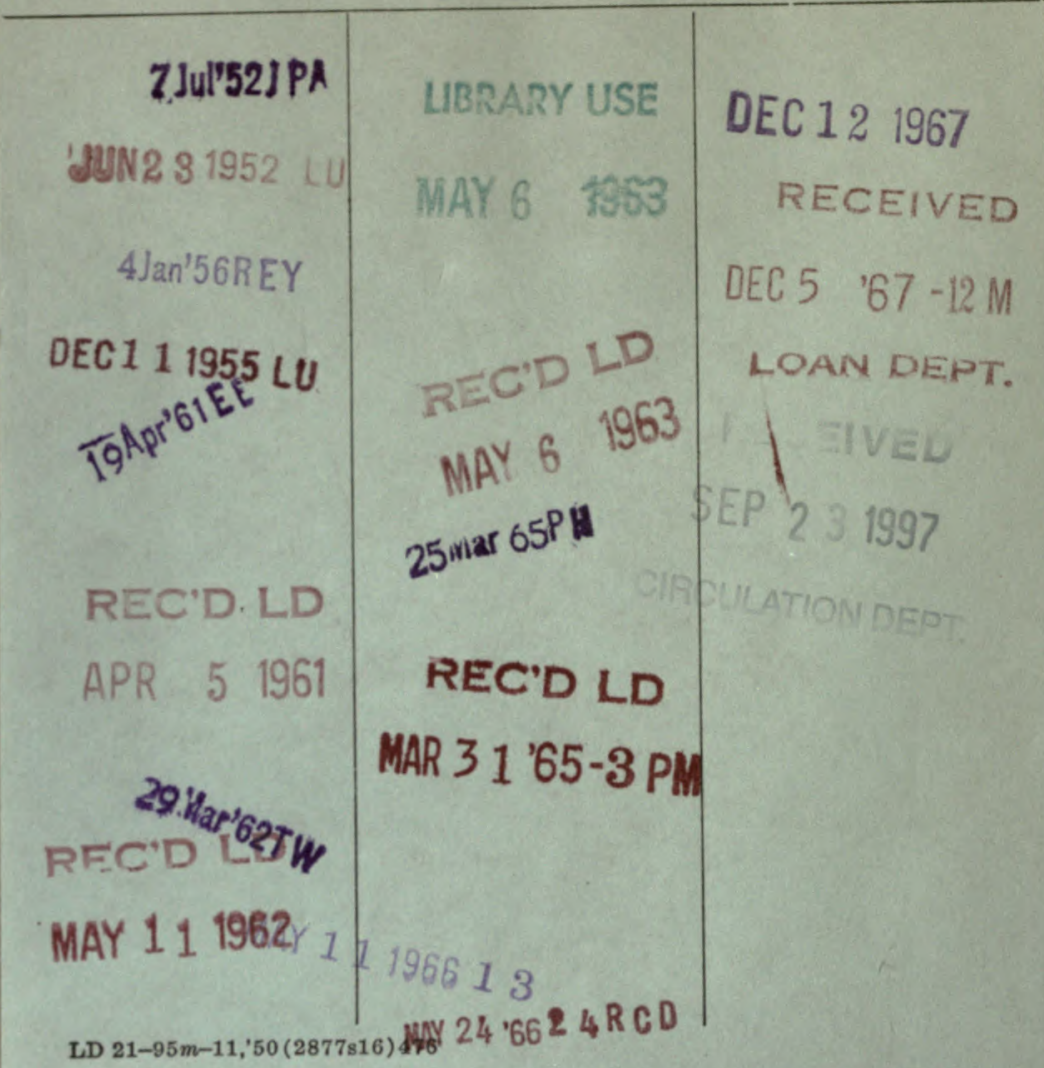




\section{C05489496}
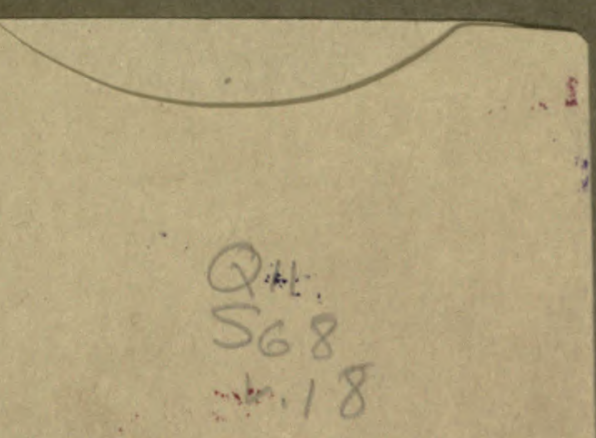

THE UNIVERSITY OF CALIFORNIA LIBRARY

M. 
